\title{
Procesos catalíticos para biorrefinerías: \\ Conversión de glicerol para la producción de biopropilenglicol
}

\author{
Tesis de Doctorado
}

\section{Martín Nicolás Gatti}

Presentada ante la Facultad de Ingeniería de la

Universidad Nacional de La Plata

como requisito para la obtención del grado académico de

\section{DOCTOR EN INGENIERÍA}

\author{
Dirección de tesis: \\ Dra. Nora Nancy Nichio
}

\section{Jurado de tesis:}

Dra. María Alicia Volpe (PLAPIQUI-UNS)

Dra. Sandra Graciela Casuscelli (CITeQ-UTN-FRC)

Dra. Viviana Guadalupe Milt (INCAPE-UNL) 



\section{CAPÍTULO 1}

\section{Introducción}

1.1. Introducción

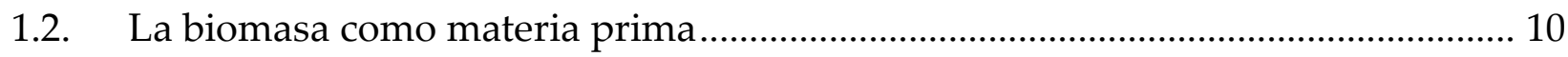

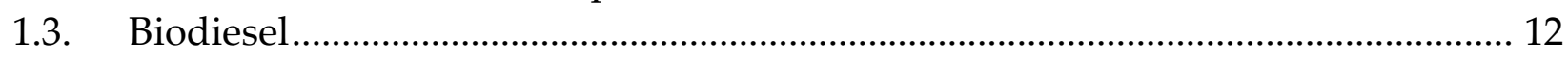

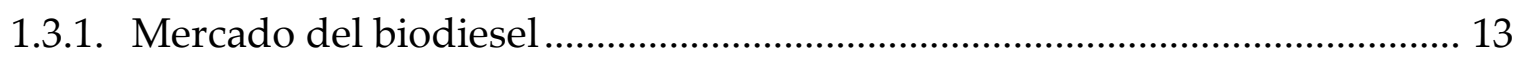

1.4. El glicerol como subproducto del biodiesel ........................................................ 18

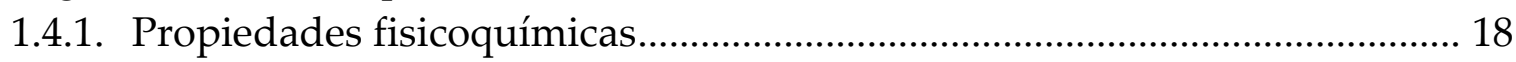

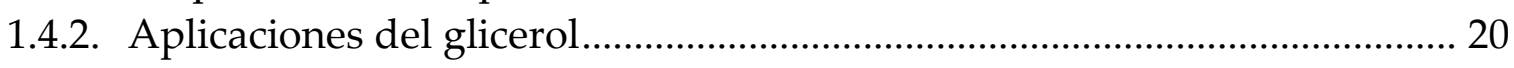

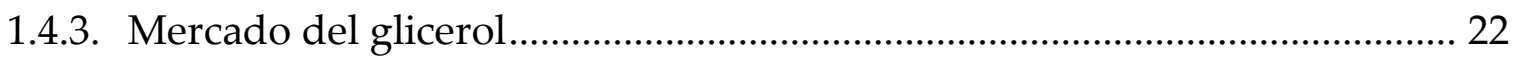

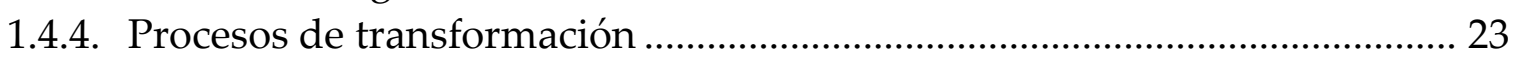

1.5. El biopropilenglicol a partir de glicerol .............................................................. 24

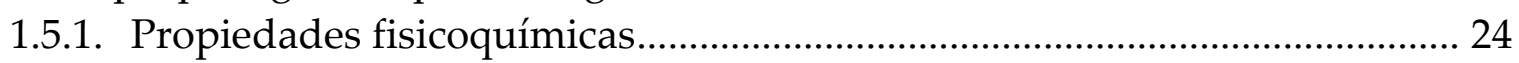

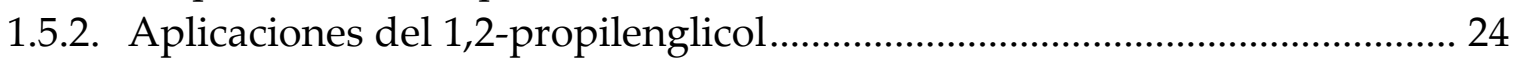

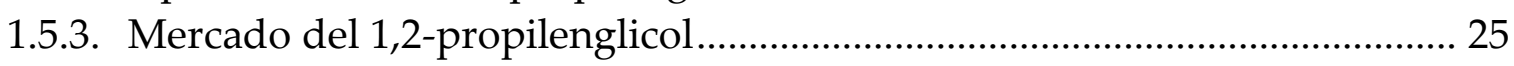

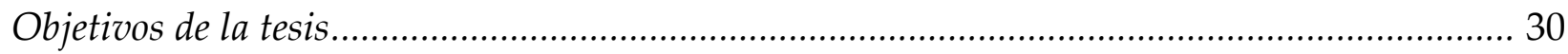

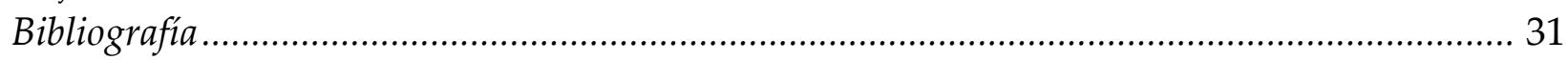

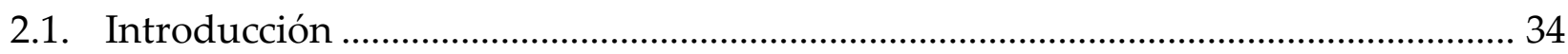

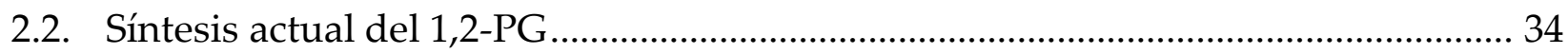

2.3. Bibliografía sobre 1,2-PG a partir de glicerol.......................................................... 36

2.4. Mecanismos de reacción de la hidrogenólisis de glicerol........................................ 38

2.4.1. Mecanismo de deshidrogenación-deshidratación-hidrogenación ................ 40

2.4.2. Mecanismo de deshidratación-hidrogenación ............................................. 43

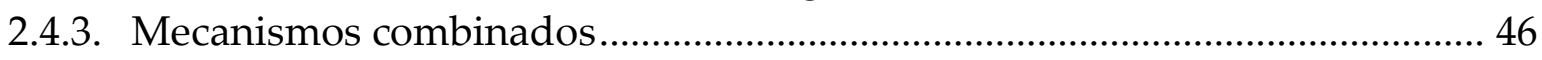

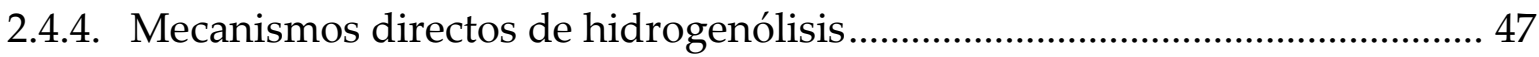

2.4.5. Mecanismo de eterificación-hidrogenación .................................................. 49

2.4.6. Mecanismo de quelación-hidrogenación........................................................ 50

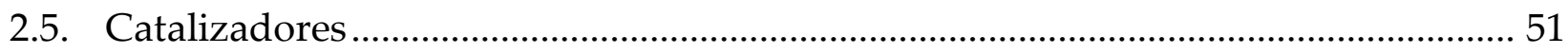

2.5.1. Catalizadores másicos para la producción de 1,2-PG en fase líquida........... 51

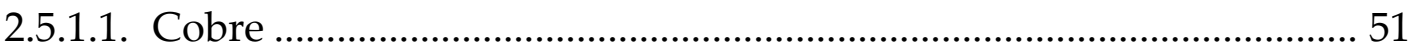

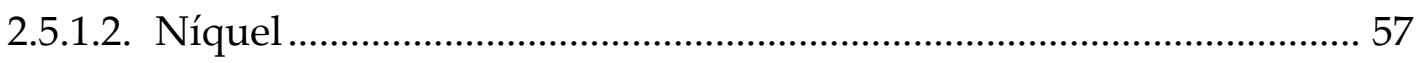

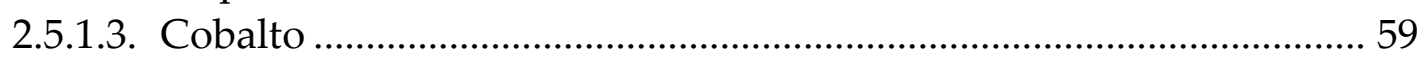

2.5.2. Catalizadores soportados para la producción de 1,2-PG en fase líquida ..... 60

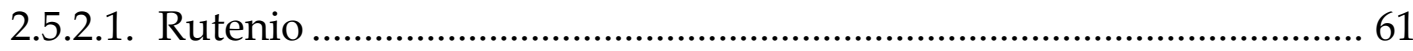

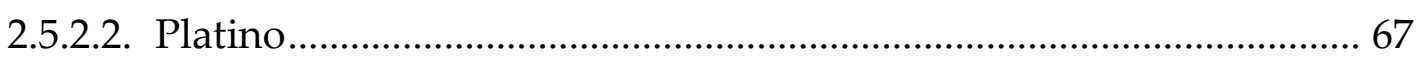

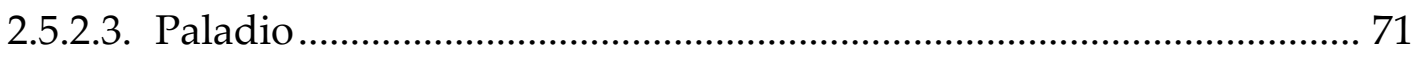




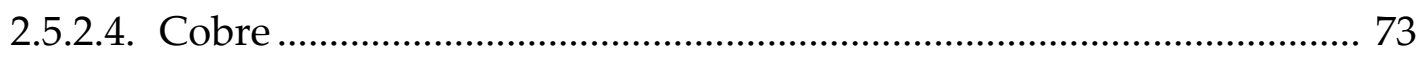

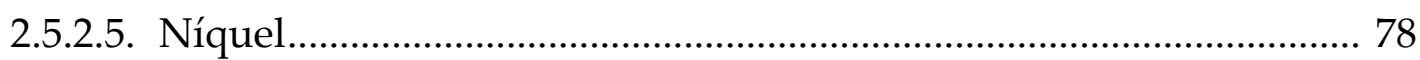

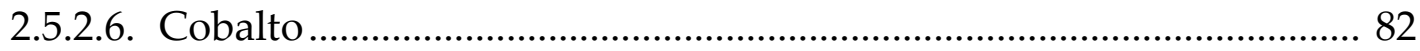

2.5.3. Catalizadores para la producción de 1,2-PG en fase vapor........................... 83

2.6. Efecto de las condiciones de operación en la hidrogenólisis de glicerol.................. 85

2.6.1. Efecto de la concentración inicial de glicerol................................................ 85

2.6.2. Efecto de la concentración inicial de agua ................................................... 86

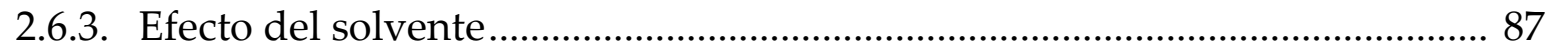

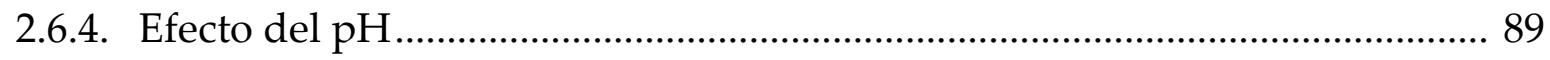

2.6.5. Efecto de la concentración de catalizador ...................................................... 90

2.6.6. Efecto del agregado de co-catalizadores ........................................................ 91

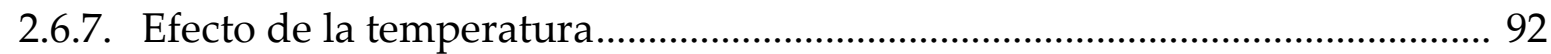

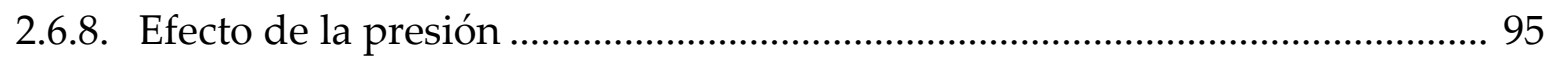

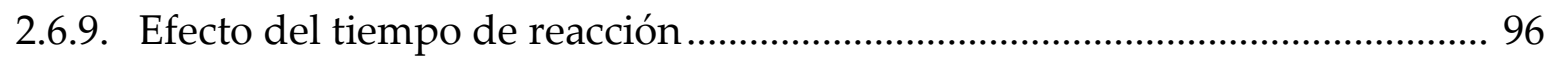

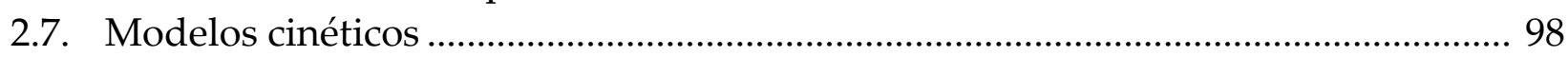

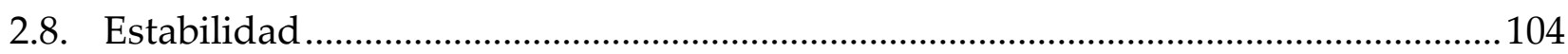

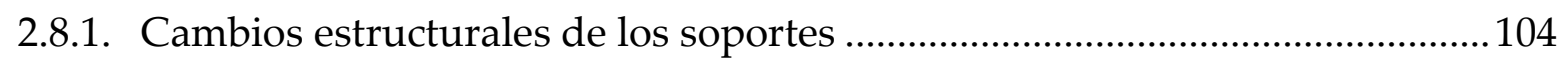

2.8.2. Oxidación y pérdida de la fase activa por lixiviación .................................... 105

2.8.3. Adsorción de especies carbonosas y formación de depósitos de carbón ......106

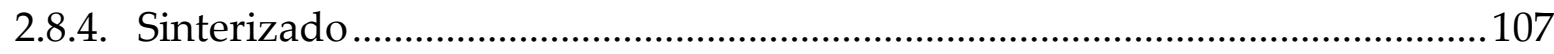

2.8.5. Desactivación por las impurezas del glicerol crudo.....................................109

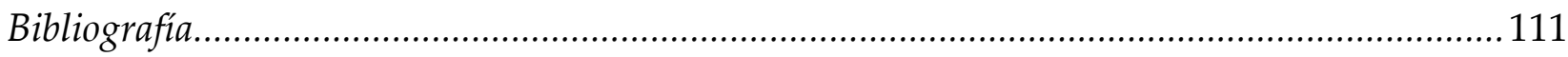

\section{CAPÍTULO 3}

Materiales, equipos y técnicas experimentales

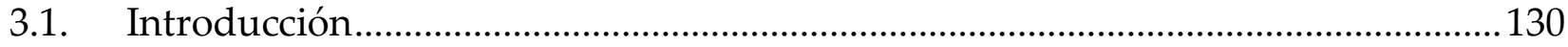

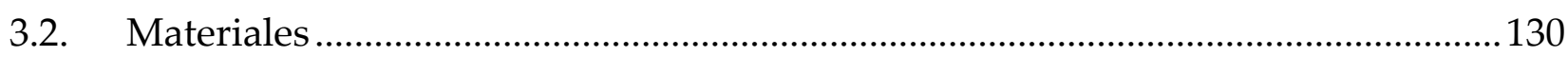

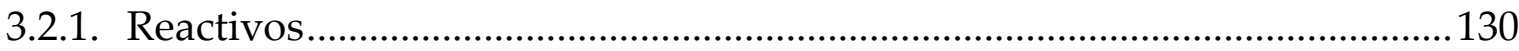

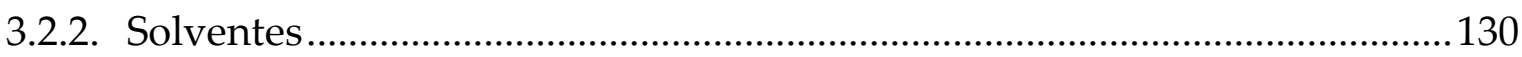

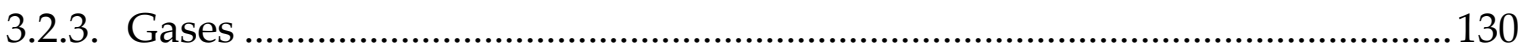

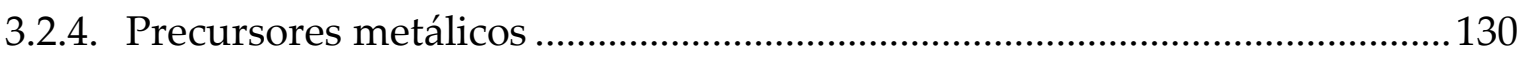

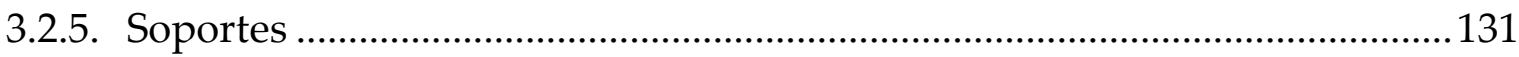

3.2.6. Indicadores, ácidos y bases …..................................................................... 131

3.3. Técnicas experimentales de preparación de soportes y catalizadores ...................131

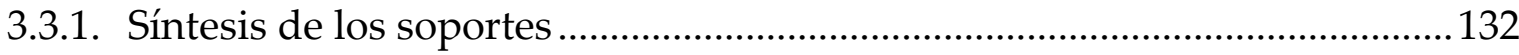

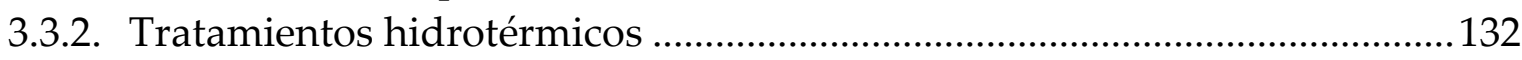

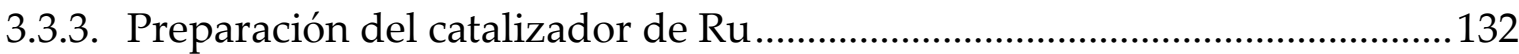

3.3.4. Preparación de los catalizadores de $\mathrm{Cu}$ y Ni .............................................. 133

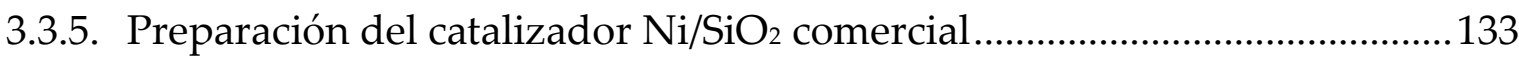

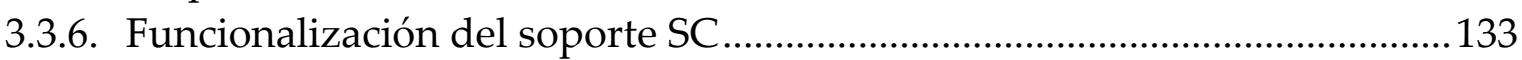

3.3.7. Preparación de los catalizadores bimetálicos NiZn/SC .............................. 134

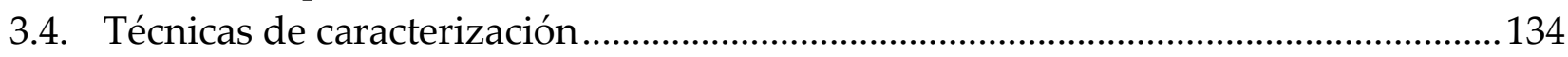

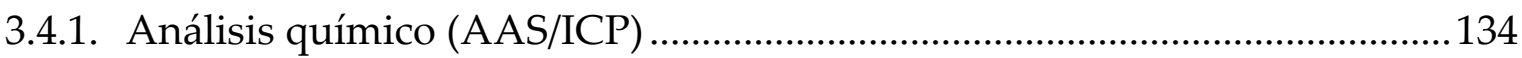


3.4.2. Adsorción-desorción de $\mathrm{N}_{2}(\mathrm{BET})$..................................................................135

3.4.3. Difracción de rayos $X(\mathrm{DRX})$......................................................................135

3.4.4. Reducción a temperatura programada (TPR) ...............................................137

3.4.5. Titulación potenciométrica...............................................................................138

3.4.6. Titulación de Bohem .....................................................................................139

3.4.7. Reacción test de descomposición de isopropanol (IPA) ………………….....140

3.4.8. Espectroscopia de infrarrojo (IR) ................................................................141

3.4.9. Espectroscopía Raman .................................................................................142

3.4.10. Análisis termogravimétricos (TGA-ATD) .......................................................142

3.4.11. Microscopia de barrido electrónico (SEM)................................................142

3.4.12. Microscopía de transmisión electrónica (TEM)................................................143

3.4.13. Espectroscopia de fotoelectrones (XPS) ..........................................................144

3.4.14. Absorción de rayos X (XAS) y absorción de rayos X extendido a estructura fina

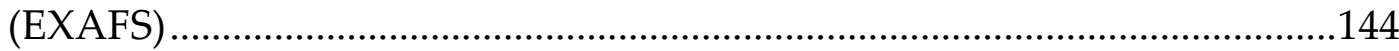

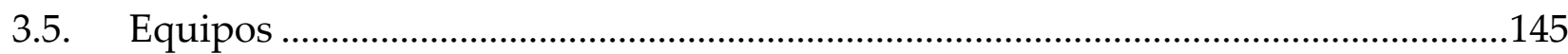

3.5.1. Reactor de flujo continuo................................................................................. 145

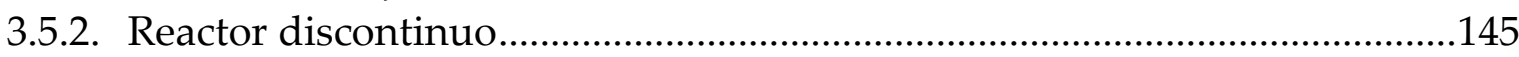

3.5.3. Cromatógrafo de gases con detector de ionización a la llama (FID)............146

3.5.4. Cromatógrafo de gases con detector de conductividad térmica (TCD) .....150

3.5.5. Cálculos de parámetros de actividad .............................................................151

\section{CAPÍTULO 4}

Sintesis, caracterización y estabilidad de los soportes

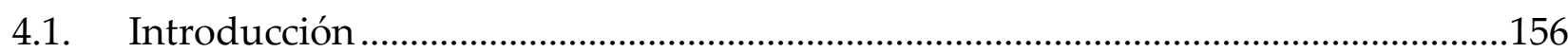

4.2. Antecedentes sobre estabilidad de soportes............................................................156

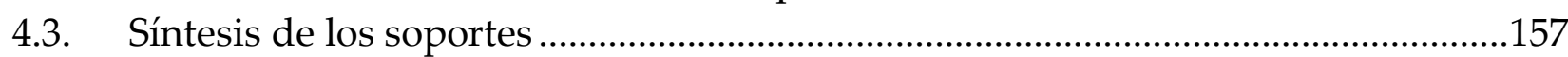

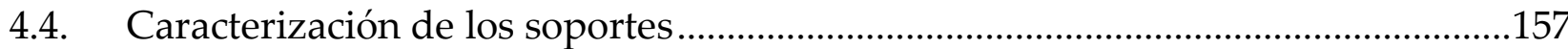

4.4.1. Análisis termogravimétrico (TGA) .........................................................157

4.4.2. Adsorción-desorción de $\mathrm{N}_{2}$ (BET) ……………….....................................158

4.4.3. Difracción de rayos X (DRX) ....................................................................160

4.4.4. Espectroscopía de infrarrojo (IR) ...............................................................160

4.4.5. Titulación potenciométrica...............................................................................161

4.4.6. Reacción test de descomposición de isopropanol (IPA) ...............................162

4.4.7. Titulación de Bohem .................................................................................163

4.4.8. Microscopia de barrido electrónico (SEM) ………………………………......164

4.4.9. Microscopía de transmisión electrónica (TEM)...............................................166

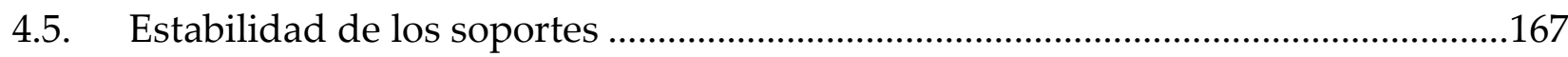

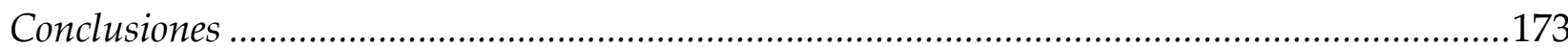

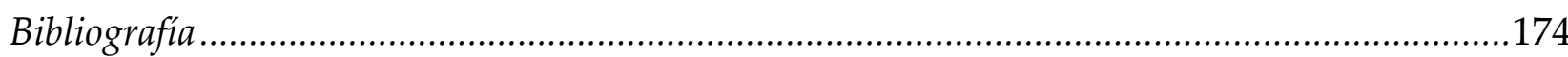




\section{CAPÍTULO 5}

Estudios preliminares de actividad catalítica

5.1. Introducción 178

5.2. Puesta en marcha del reactor discontinuo - consideraciones generales 178

5.2.1. Verificación de la ausencia de resistencias externas a la transferencia de materia 178

5.2.2. Verificación de la ausencia de resistencias internas a la transferencia de materia 179

5.2.3. Verificación de la ausencia de resistencias externas a la transferencia de energía 180

5.2.4. Verificación de la ausencia de resistencias internas a la transferencia de energía

5.3. Estudios de actividad catalítica para la selección de la fase metálica 181

5.3.1. Preparación de catalizadores $\mathrm{Ru} / \mathrm{SC}$ 181

5.3.2. Preparación de catalizadores $\mathrm{Cu} / \mathrm{SC}$ 182

5.3.3. Preparación de catalizadores Ni/SC 182

5.3.4. Ensayos de actividad empleando los catalizadores $\mathrm{Ru} / \mathrm{SC}, \mathrm{Cu} / \mathrm{SC}$ y Ni/SC

Bibliografía 185

\section{CAPÍTULO 6}

\section{Catalizadores Ni/SC}

6.1. Introducción

6.2. Análisis de la descomposición de los precursores de Ni por TGA.........................192

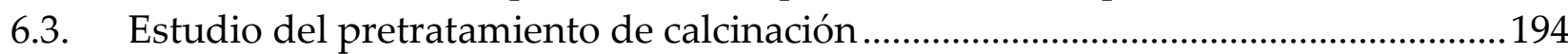

6.4. Estudio del pretratamiento de reducción o activación................................................199

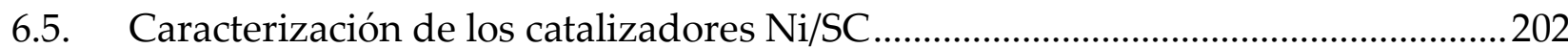

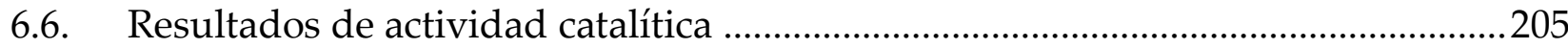

6.7. Efecto del precursor metálico en la reacción de hidrogenólisis de glicerol............206

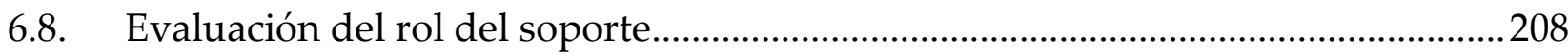

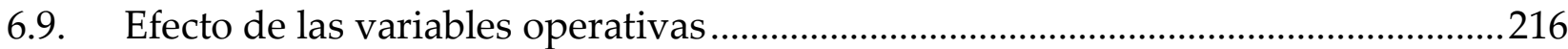

6.9.1. Efecto de la relación masa de glicerol a masa de catalizador $\left(\mathrm{m}_{\mathrm{gli}} / \mathrm{m}_{\mathrm{c}}\right)$......216

6.9.2. Efecto del contenido de agua........................................................................218

6.9.3. Efecto de la presión ........................................................................................220

6.9.4. Efecto de la temperatura ............................................................................221

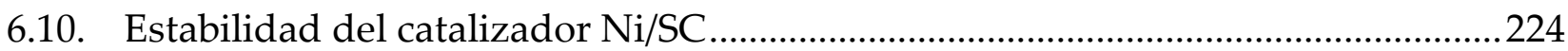

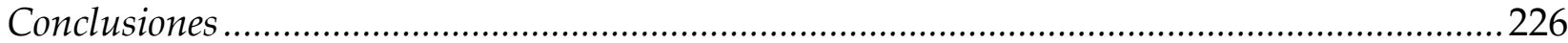

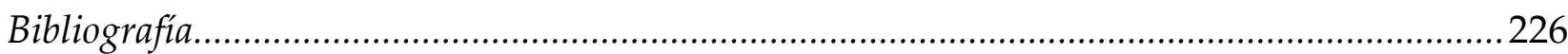




\section{CAPÍTULO 7}

Funcionalización del soporte SC

7.1. Introducción

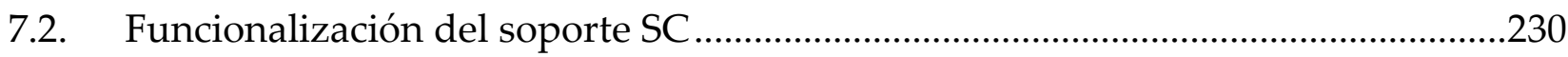

7.3. Caracterización de los soportes SC funcionalizados.............................................231

7.4. Preparación de catalizadores funcionalizados.....................................................237

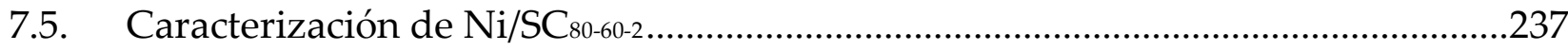

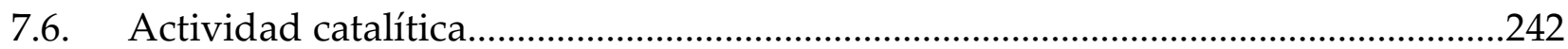

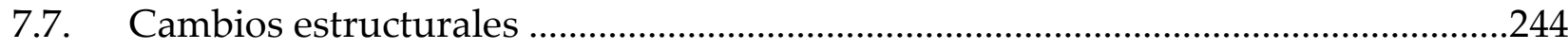

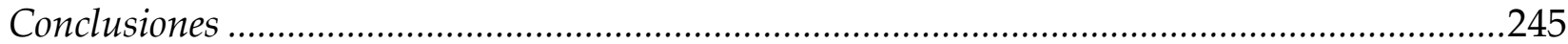

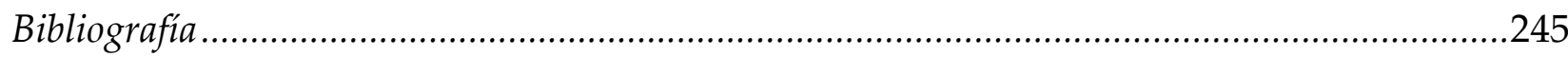

\section{CAPÍTULO 8}

8.1. Introducción

8.2. Antecedentes sobre catalizadores bimetálicos ..................................................248

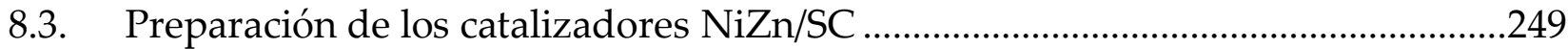

8.4. Caracterización de los catalizadores NiZn/SC ....................................................249

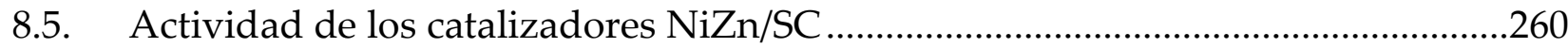

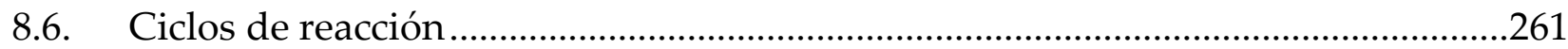

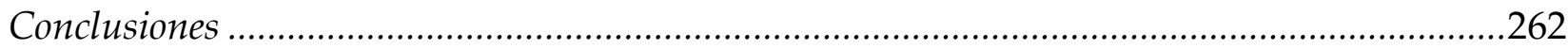

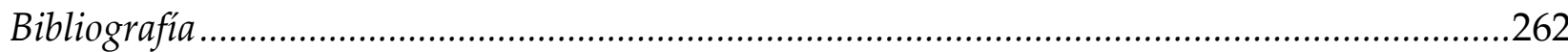

\section{CAPÍTULO 9}

\section{Conclusiones y perspectivas}

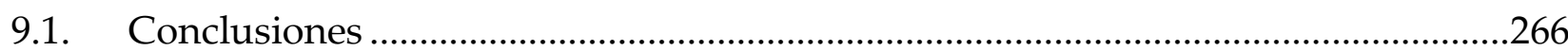

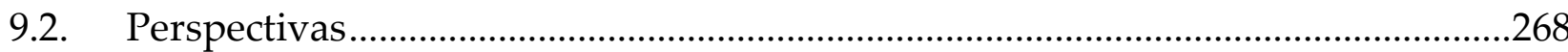

\section{ANEXO I \\ Catalizadores bimetálicos NiZn/SC}

I.1. Verificación de la ausencia de resistencias externas a la transferencia de materia

I.2. Verificación de la ausencia de resistencias internas a la transferencia de materia

I.3. Verificación de la ausencia de resistencias externas a la transferencia de energía

I.4. Verificación de la ausencia de resistencias internas a la transferencia de energía

Bibliografía 
Agradecimientos

Al CONICET, por el otorgamiento de la beca doctoral y la financiación recibida a lo largo de todo el desarrollo de esta tesis.

Al CINDECA, en donde pude desarrollar todas las labores concernientes al desarrollo de la presente tesis.

A la Facultad de Ingeniería de la Universidad Nacional de La Plata.

A mi equipo de trabajo, comenzando por mi directora Nora, por su dirección y seguimiento de mis trabajos experimentales, por haberme brindado su experiencia, dedicación y esfuerzo para realizar esta tesis.

A Francisco Pompeo, quién me enseñó a trabajar en el laboratorio, me brindó su ayuda durante todo momento y me dio la libertad para desarrollar los experimentos según mi criterio.

A Gerardo Santori, por su ayuda en temas vinculados a la reacción en estudio y la preparación de catalizadores bimetálicos.

A los Profesionales de apoyo del CINDECA: Graciela Valle, Lilian Osiglio, Edgardo Soto, Juan Tara y Pablo Fetsis, por su valiosa colaboración.

A mi familia, que apoya todas y cada una de las decisiones que tomo en mi vida. 


\section{Resumen}

Esta tesis plantea la preparación y caracterización de catalizadores para la conversión de glicerol a biopropilenglicol. En el capítulo 1 se presentan conceptos básicos de biomasa, su transformación y la posibilidad, a partir de ella, de sustituir algunos de los productos químicos derivados del petróleo que la sociedad utiliza actualmente.

En este marco, es interesante plantear la utilización del glicerol como recurso proveniente de la biomasa obtenido a partir de la producción de biodiesel.

El 1,2-propilenglicol (1,2-PG) es tradicionalmente obtenido por hidratación del óxido de propileno (OP), compuesto que se obtiene vía petroquímica. El proceso de transformación del glicerol para producir 1,2 PG generaría un reemplazo de procesos de síntesis petroquímicos por procesos que valorizan fuentes renovables.

El precio del 1,2-PG en el mercado es mucho mayor que el precio del glicerol, lo cual estimula el desarrollo de un nuevo proceso químico que permita la producción de 1,2-PG a partir del glicerol. Además, debido a que actualmente Argentina no produce 1,2-PG, sino que debe importarlo en su totalidad, este nuevo proceso permitiría un mayor desarrollo productivo nacional.

En el capítulo 2 se presenta la revisión bibliográfica, que aborda todo lo relativo a la reacción química de hidrogenólisis, los mecanismos de reacción, los catalizadores empleados y sus propiedades; destacando el efecto de las condiciones operativas empleadas, así como también estudios vinculados a la cinética y estabilidad de los catalizadores.

En el capítulo 3 se detallan los materiales empleados (reactivos, solventes, gases, indicadores, ácidos y bases) para llevar a cabo el estudio experimental de la presente tesis. Se describen los equipos de reacción empleados y las técnicas experimentales de preparación y caracterización de los catalizadores (AAS, TPR, BET, DRX, TEM, Titulación potenciométrica, XPS, Raman, EXAFS, etc.), y la metodología empleada para la cuantificación de los resultados experimentales. Además se presentan las ecuaciones empleadas en los cálculos realizados.

En la revisión bibliográfica, capítulo 2, queda demostrada la importancia de la estabilidad del soporte en las condiciones de reacción en fase líquida a temperaturas entre 150-260 ${ }^{\circ} \mathrm{C}$, altas presiones entre 20-80 bar y la presencia de agua líquida. En el capítulo 4 se muestran los resultados de la preparación de soportes del tipo silíceos-carbonosos mediante la técnica sol-gel. Esta técnica permite el diseño de estructuras nano y mesoporosas con características texturales controladas, tales como el tamaño y tipo de poros y la superficie específica.

Las propiedades ácido-base del soporte fueron evaluadas empleando varias técnicas que se complementan entre sí: la titulación potenciométrica, la reacción de descomposición de isopropanol y la titulación de Boehm.

Con el objetivo de evaluar la estabilidad de los soportes en las condiciones hidrotérmicas de la reacción de hidrogenólisis en fase líquida, los materiales SC, $\mathrm{C}$ y $\mathrm{SiO}_{2}$ fueron tratados en agua caliente a diferentes temperaturas. Se caracterizaron las muestras de soportes por análisis termogravimétrico (TPO/TGA), análisis térmico diferencial (ATD), adsorción-desorción de $\mathrm{N}_{2}$ (BET), difracción de rayos $X(\mathrm{DRX})$, espectroscopía de fotoelectrones (XPS) y espectroscopía Raman. 
En el capítulo 5 se presenta el análisis realizado para verificar la ausencia de resistencias externas e internas a la transferencia de materia y energía. En este capítulo también se presentan los resultados de los ensayos de reacción, con catalizadores de $\mathrm{Ru}, \mathrm{Ni}$ y $\mathrm{Cu}$, para seleccionar la fase metálica de los estudios posteriores.

En el capítulo 6 se presenta un estudio de los catalizadores de Ni preparados a partir de tres precursores de $\mathrm{Ni}$; $\mathrm{NiCl}_{2} .6 \mathrm{H}_{2} \mathrm{O}, \mathrm{Ni}\left(\mathrm{CH}_{3} \mathrm{COO}\right)_{2} .4 \mathrm{H}_{2} \mathrm{O}$ y $\mathrm{Ni}\left(\mathrm{NO}_{3}\right)_{2} .6 \mathrm{H}_{2} \mathrm{O}$. En primera instancia se estudian los diferentes pretratamientos, considerando que el precursor empleado, las temperaturas, atmósferas y tiempos de los tratamientos afectan al catalizador final. Posteriormente se estudia el efecto del precursor de níquel, para seleccionar el catalizador que conduce a mayor nivel de conversión y selectividad a 1,2-PG. Luego, para el precursor seleccionado, se procede a evaluar el efecto del soporte, considerando para este análisis los soportes $\mathrm{C}, \mathrm{SiO}_{2}$, además del SC. Finalmente, con el catalizador de Ni/SC, se estudia el efecto de las principales variables operativas de la reacción de hidrogenólisis y se analizan los cambios estructurales que sufre el catalizador luego de la reacción.

En el capítulo 7 se estudia la funcionalización del soporte SC empleando la técnica de oxidación con $\mathrm{HNO}_{3}$, dado que se logran elevados niveles de acidez con bajas pérdidas de masa de carbón. Se caracterizan las propiedades estructurales y ácidas y se correlacionan con las variables operativas de la funcionalización. Finalmente se compara la actividad de los catalizadores preparados con los soportes SC funcionalizados con el catalizador Ni/SC.

En el capítulo 8 se presentan los resultados de la modificación de la fase activa de $\mathrm{Ni}$ por adición de un promotor metálico. En la primera parte de este capítulo se detalla la preparación del catalizador bimetálico mediante la técnica derivada de la química organometálica de superficies (QOMS/M), una técnica de preparación controlada que se caracteriza por la obtención de fases bimetálicas homogéneas y bien dispersas, sobre todo cuando se adicionan pequeñas cantidades de un promotor metálico. Posteriormente se presentan los resultados de caracterización por adsorción-desorción de $\mathrm{N}_{2}$ (BET), microscopía de transmisión electrónica (TEM), titulación potenciométrica, difracción de rayos X (DRX) y absorción de rayos $X$ extendida a estructura fina (EXAFS). Finalmente se presentan los resultados de actividad catalítica y se correlacionan con los resultados de caracterización de los catalizadores.

Por último, se presentan las conclusiones generales y las perspectivas surgidas a partir de este estudio de tesis. 

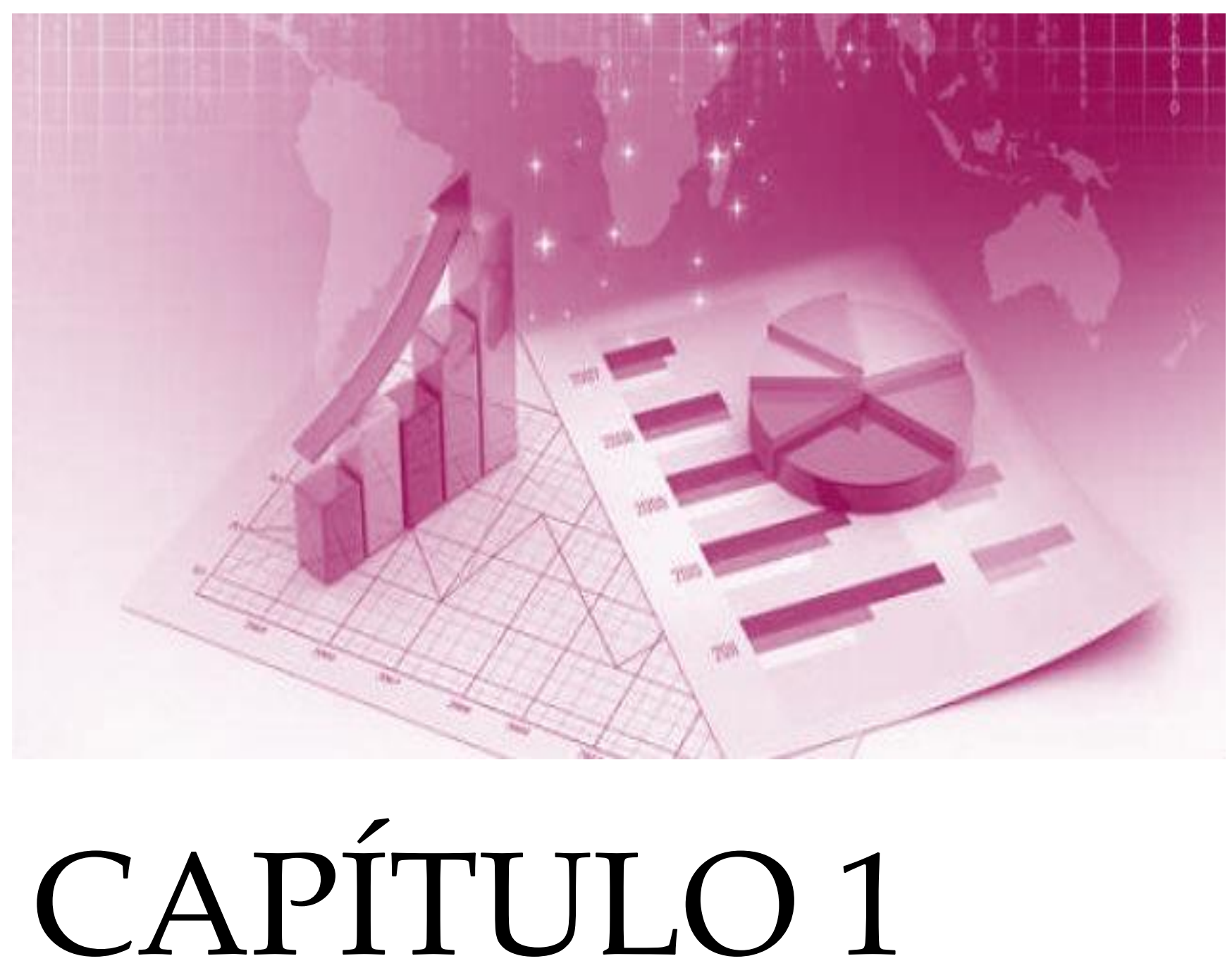

Introducción 


\subsection{Introducción}

En este capítulo introductorio se presenta el concepto de biomasa, su transformación y la posibilidad, a partir de ella, de sustituir algunos de los productos químicos derivados del petróleo que la sociedad utiliza actualmente. Se explica cómo los compuestos derivados de la biomasa pueden ser utilizados como materias primas, muchos de los cuales tienen un bajo valor comercial, y pueden transformarse en compuestos químicos de interés cuando se implementan procesos químicos limpios y sustentables.

En este marco, es interesante plantear la utilización del glicerol como recurso proveniente de la biomasa obtenido a partir de la producción de biodiesel. Al tratarse de un polialcohol, son múltiples las reacciones que pueden transformarlo en compuestos de interés, tales como hidrocarburos, alcoholes de cadena corta, ácidos carboxílicos, aldehídos y cetonas, entre otros. Por otro lado, el 1,2-propilenglicol (1,2-PG) es un compuesto químico de gran atractivo para la industria por sus diferentes aplicaciones.

El 1,2-PG es tradicionalmente obtenido por hidratación del óxido de propileno (OP), compuesto que se obtiene vía petroquímica. El proceso de transformación del glicerol para producir 1,2 PG generaría un reemplazo de procesos de síntesis petroquímicos por procesos que valorizan fuentes renovables.

El precio del 1,2-PG en el mercado es mucho mayor que el precio del glicerol, lo cual estimula a desarrollar un nuevo proceso químico que permita la producción de 1,2-PG a partir del glicerol. Además, debido a que actualmente Argentina no produce 1,2-PG, sino que debe importarlo en su totalidad, este nuevo proceso permitiría un mayor desarrollo productivo nacional.

\subsection{La biomasa como materia prima}

Según la Especificación Técnica Europea CEN/TS 14588, la biomasa se define como todo material de origen biológico exceptuando aquellos que han sufrido un proceso de mineralización dentro del campo de la geología. Según esta definición, el petróleo, el carbón y el gas natural no son parte de la biomasa, ya que su origen es del tipo geológico.

A diferencia de estos tres últimos, la combustión de los compuestos de la biomasa no contribuye al efecto invernadero, ya que el carbón liberado a la atmósfera proviene originalmente de ella. De esta forma, cualquier proceso de transformación química de la biomasa resulta en un balance neutro de carbón.

La biomasa se clasifica en dos grandes categorías, la biomasa húmeda y la biomasa seca [1] (Figura 1-1).

La biomasa húmeda consiste en material orgánico con un contenido de agua superior al 60 \%. Algunos ejemplos de este tipo de biomasa lo constituyen los residuos animales y vegetales acuáticos. Para su transformación se emplean principalmente procesos bioquímicos y en menor medida procesos químicos a alta presión y temperatura. Estos procesos se resumen en la Figura 2-1.

La biomasa seca, por su parte, consiste en materia orgánica con un contenido de agua menor al $60 \%$. Algunos ejemplos de este tipo de biomasa lo constituyen los residuos forestales, como la paja y la leña. Para su transformación se emplean principalmente procesos 
termoquímicos, dentro de los cuales se encuentran la combustión, la gasificación y la pirólisis. Estos procesos se resumen en la Figura 3-1.
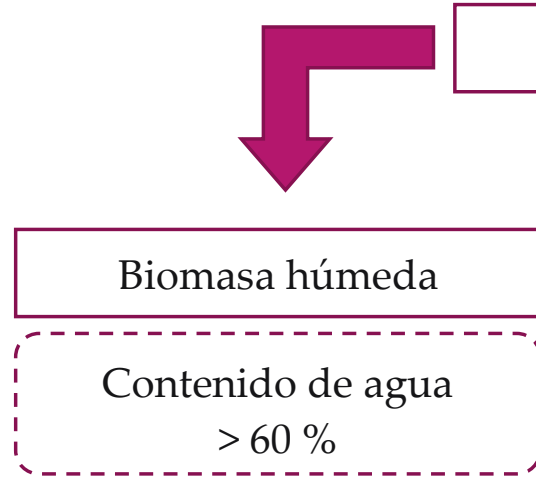

Biomasa
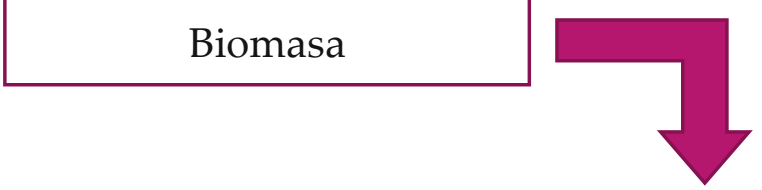

Biomasa seca

Contenido de agua $<60 \%$

Figura 1-1. Clasificación de la biomasa según su contenido de agua.

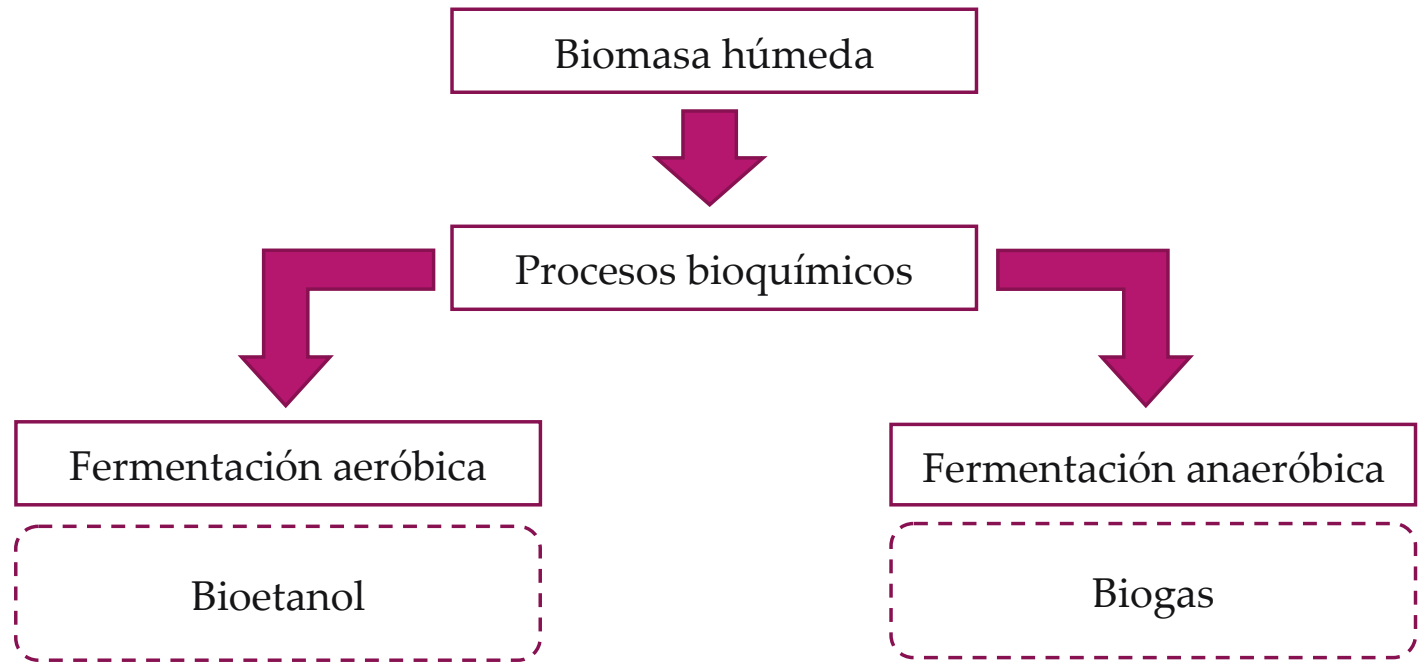

Figura 2-1. Procesos de transformación de la biomasa húmeda.

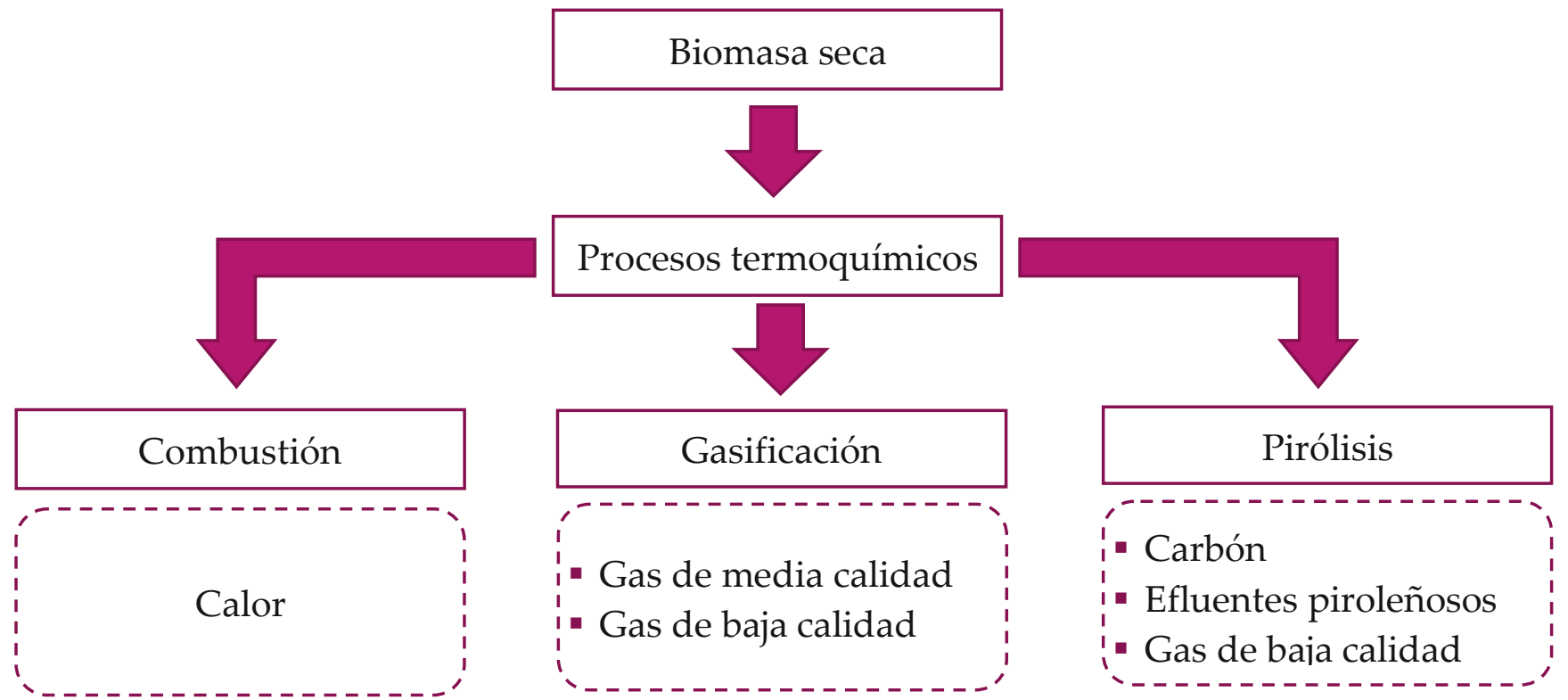

Figura 3-1. Procesos de transformación de la biomasa húmeda. 


\subsection{Biodiesel}

El biodiesel es un ejemplo, al igual que el bioetanol, que puede ser incluido como biocombustible a partir de biomasa de primera, de segunda o de tercera generación.

Es de primera generación cuando se emplean aceites vegetales o grasas animales, y cuando estos aceites o grasas ya han sido usados se convierte en biodiesel de segunda generación [2].

El biodiesel de tercera generación corresponde a aquel que ha sido obtenido a partir de procesos de producción alternativos, como por ejemplo a partir de algas [3].

La obtención del biodiesel consiste en la reacción de transesterificación de los triglicéridos que forman parte de los aceites o grasas, en presencia de alcoholes de bajo peso molecular, como metanol, etanol o 1-propanol, mediante el empleo de catalizadores básicos, másicos o soportados. El resultado de la reacción es una mezcla compleja de ésteres metílicos, etílicos o propílicos según el alcohol empleado, y esta mezcla es la que constituye el biodiesel en sí mismo [4].

Como producto secundario se obtiene glicerol, tal como se muestra en las ecuaciones 1-1, 2-1 y 3-1 para los casos en que el alcohol es metanol (MeOH) (1-1), etanol (EtOH) (2-1) o 1-propanol (1-POH) (3-1) respectivamente.<smiles>[R]C(=O)OCC(COC([R])=O)OC([R])=O</smiles>

Ecuación 1-1. Transesterificación de triglicéridos empleando metanol.<smiles>[R]C(=O)OCC(COC([R])=O)OC([R])=O</smiles>

Ecuación 2-1. Transesterificación de triglicéridos empleando etanol. 


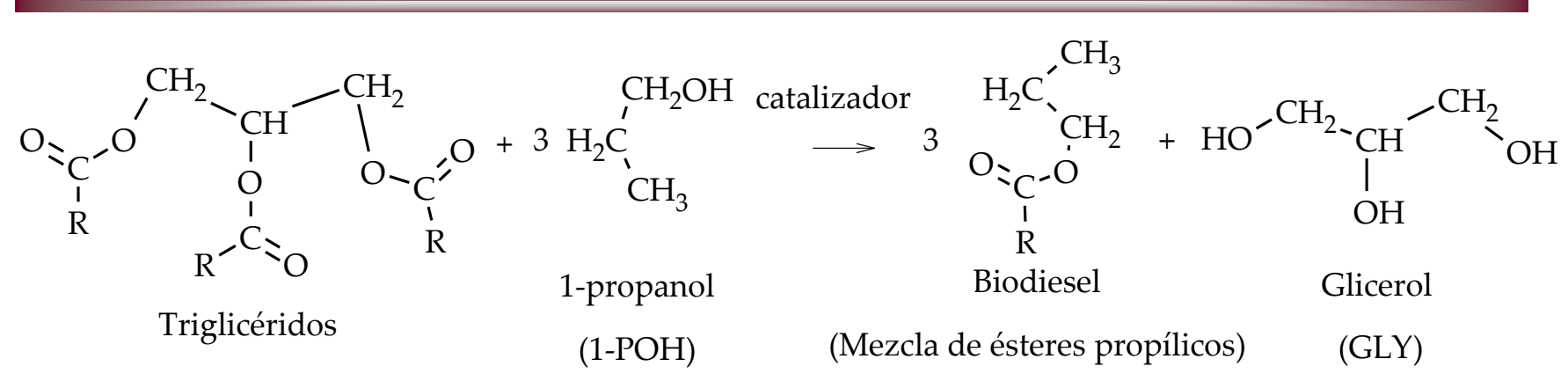

Ecuación 3-1. Transesterificación de triglicéridos empleando 1-propanol.

\subsubsection{Mercado del biodiesel}

Desde hace más de diez años, el biodiesel es el biocombustible que ha experimentado el mayor crecimiento a nivel mundial. La expansión de su producción ha sido observada no solo en países desarrollados como Alemania, Italia, Francia y Estados Unidos, sino también en países en vías de desarrollo, como Brasil, Argentina, Indonesia y Malasia [5].

Del total de biodiesel producido a nivel mundial, el mayor aporte lo realiza Estados Unidos ( 15\%), seguido por Indonesia ( 13\%), Brasil ( 10\%), Alemania ( 9\%) y Argentina $(\sim 7 \%)$. Otros países productores del biodiesel, como Francia, Italia y Malasia, no llegan a tener un porcentaje significativo en la producción y juntos suman una participación del $45 \%$ (Figura 4-1).

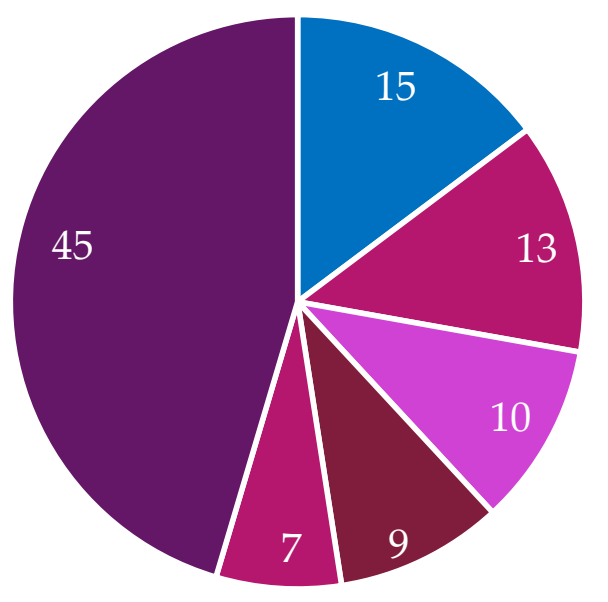

- Estados Unidos

- Indonesia

- Brasil

- Alemania

- Argentina

- Otros

Figura 4-1. Distribución de la producción mundial de biodiesel por países.

La Figura 5-1 muestra la producción mundial de biodiesel (en millones de toneladas anuales) entre los años 2008 y 2014.

A partir de la Figura 5-1, es posible observar que la producción de biodiesel aumentó desde 2008 a 2017. En 2013 la producción mundial de biodiesel fue de 27.060 .000 de toneladas, lo que se traduce en un aumento del $3.000 \%$ respecto del 2001. Estados Unidos es 
el mayor productor de biodiesel con 4.500 .000 toneladas anuales, seguido por Indonesia, Brasil, Alemania y Argentina [7].

Un informe reciente de la FAO prevé que para el 2026 la producción podrá alcanzar los 40 millones de toneladas por año, un 12 \% más respecto de la producción en 2016 [6].

El biodiesel argentino es producido principalmente a partir del aceite de soja. El biodiesel así obtenido corresponde a un biocombustible de primera generación. Desde el año 2008 hasta el 2017, la Argentina pasó de tener 18 plantas productoras de biodiesel a un total de 37 (Tabla 1-1).

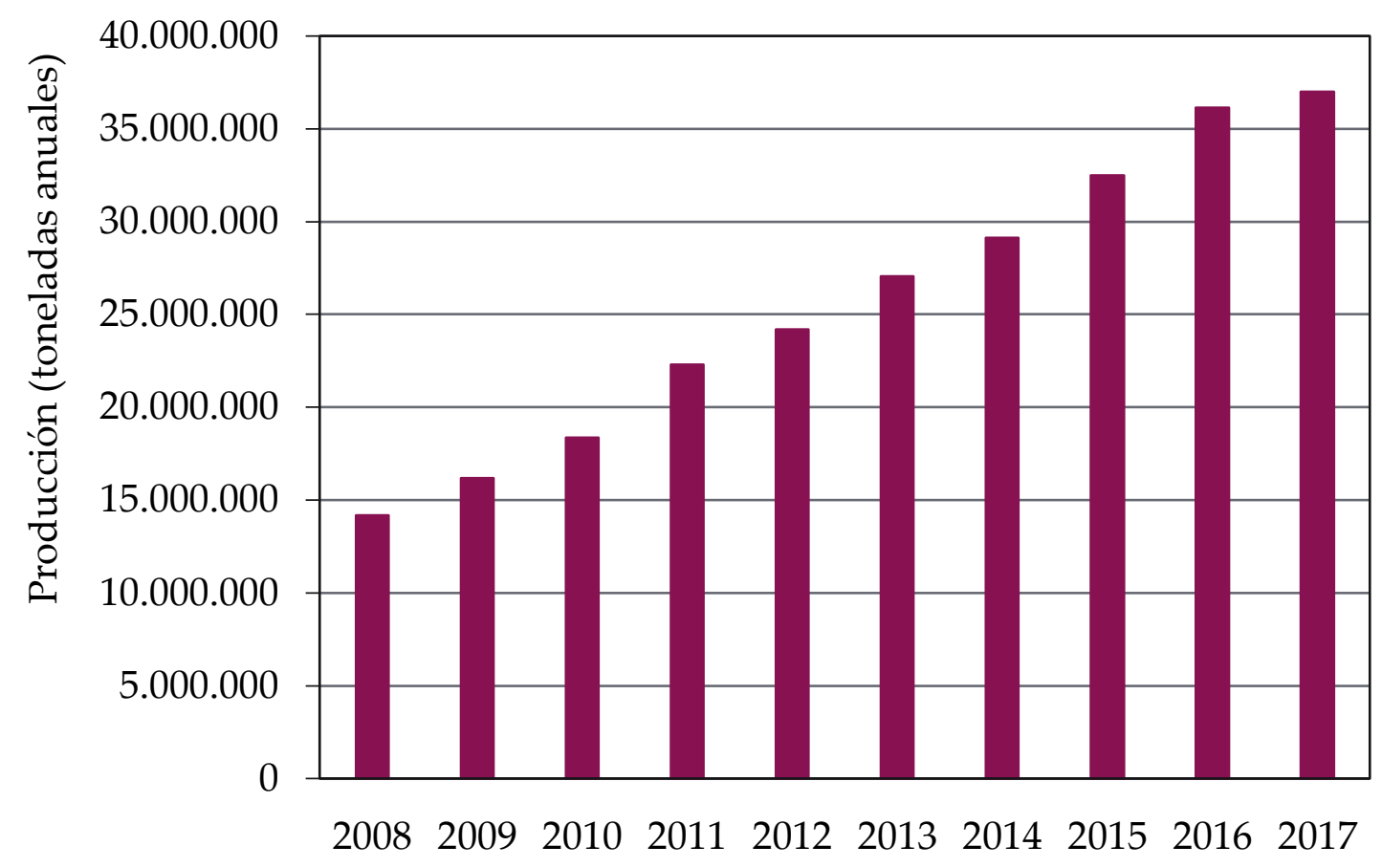

Figura 5-1. Producción mundial de biodiesel (en toneladas anuales) entre 2008 y 2017.

Tabla 1-1. Número de plantas productoras de biodiesel instaladas en Argentina entre 2008 y 2017.

\begin{tabular}{lc}
\hline Año & Número de plantas instaladas \\
\hline 2008 & 18 \\
2009 & 22 \\
2010 & 24 \\
2011 & 27 \\
2012 & 33 \\
2013 & 36 \\
2014 & 37 \\
2015 & 37 \\
2016 & 37 \\
2017 & 37 \\
\hline
\end{tabular}


Dado que los cultivos de soja se ubican principalmente en la zona del sur de Santa Fe, el norte de la provincia de Buenos Aires y al este de Córdoba [8], la mayor parte de las plantas productoras de Biodiesel radican en esa región, tal como se muestra en la Figura 6-1. Existen, no obstante, plantas radicadas en la provincia de San Luis y Neuquén.

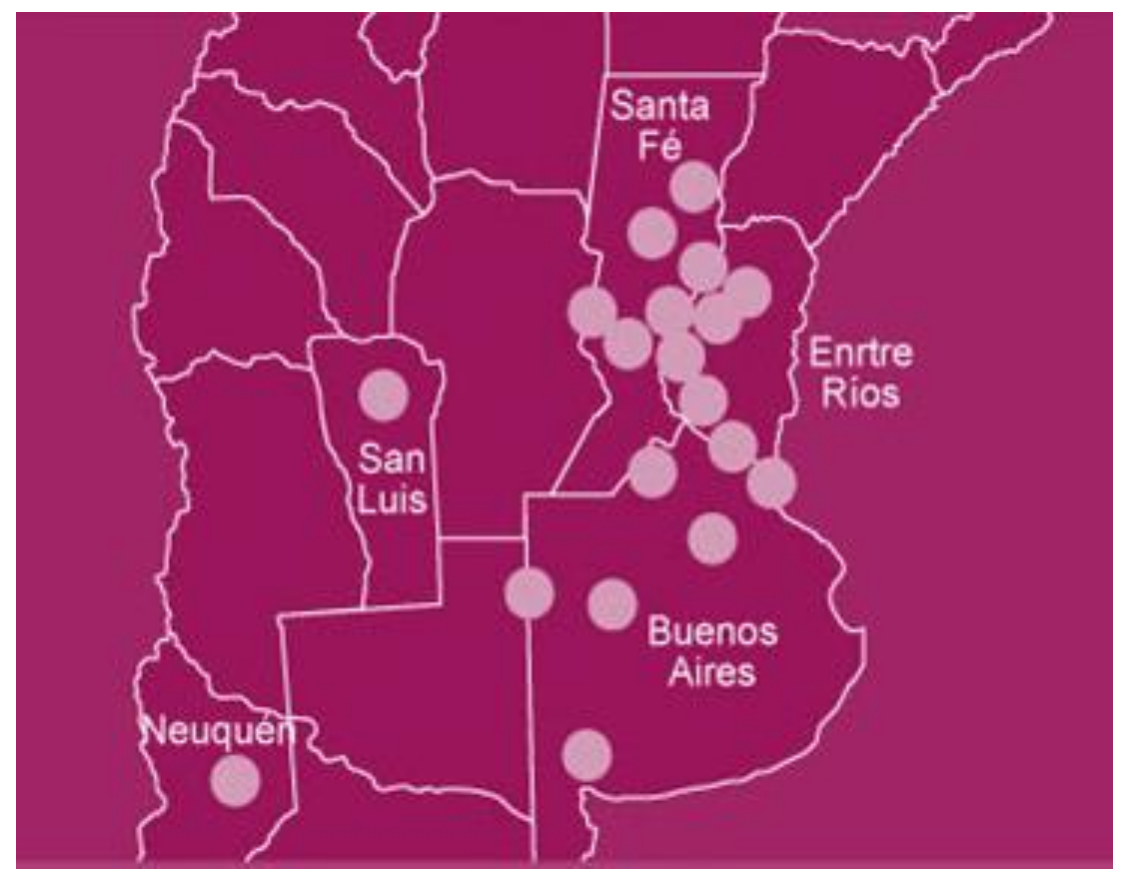

Figura 6-1. Ubicación de las plantas productoras de biodiesel en Argentina.

Las principales empresas productoras de biodiesel son las que figuran en la Tabla 2-1, y se muestra para cada una de ellas, su producción anual en base a la capacidad de planta instalada.

Tabla 2-1. Principales empresas productoras de biodiesel en Argentina.

\begin{tabular}{lc}
\hline Empresas & Producción (toneladas anuales) \\
\hline LDC ARGENTINA S.A. & 610.000 \\
RENOVA S.A. & 480.000 \\
TERMINAL 6 S.A. & 480.000 \\
PATAGONIA BIOENERGÍA & 480.000 \\
COFCO ARGENTINA S.A. & 240.000 \\
CARGILL S.A. & 240.000 \\
UNITEC-BIO S.A. & 240.000 \\
VILUCO S.A. & 200.000 \\
VICENTIN & 120.000 \\
EXPLORA S.A. & 120.000 \\
MOLINOS & 120.000 \\
DIASER & 96.000 \\
ARIPAR & 50.000 \\
\hline
\end{tabular}


Dentro del ámbito nacional, desde sus comienzos en 2007, la producción de biodiesel se sumó como un eslabón más a la cadena de valor agregado del complejo agroindustrial argentino, consolidándose como uno de los mayores polos de producción a nivel mundial, con tecnología a gran escala que lo ubican entre los más eficientes del mundo. Desde entonces, la producción nacional de biodiesel en la Argentina ha mostrado un crecimiento significativo y su capacidad alcanza en la actualidad los 4,1 millones de toneladas anuales [16-18].

La Figura 7-1 muestra la evolución en la producción nacional de biodiesel (en toneladas anuales) entre los años 2008 y 2017.

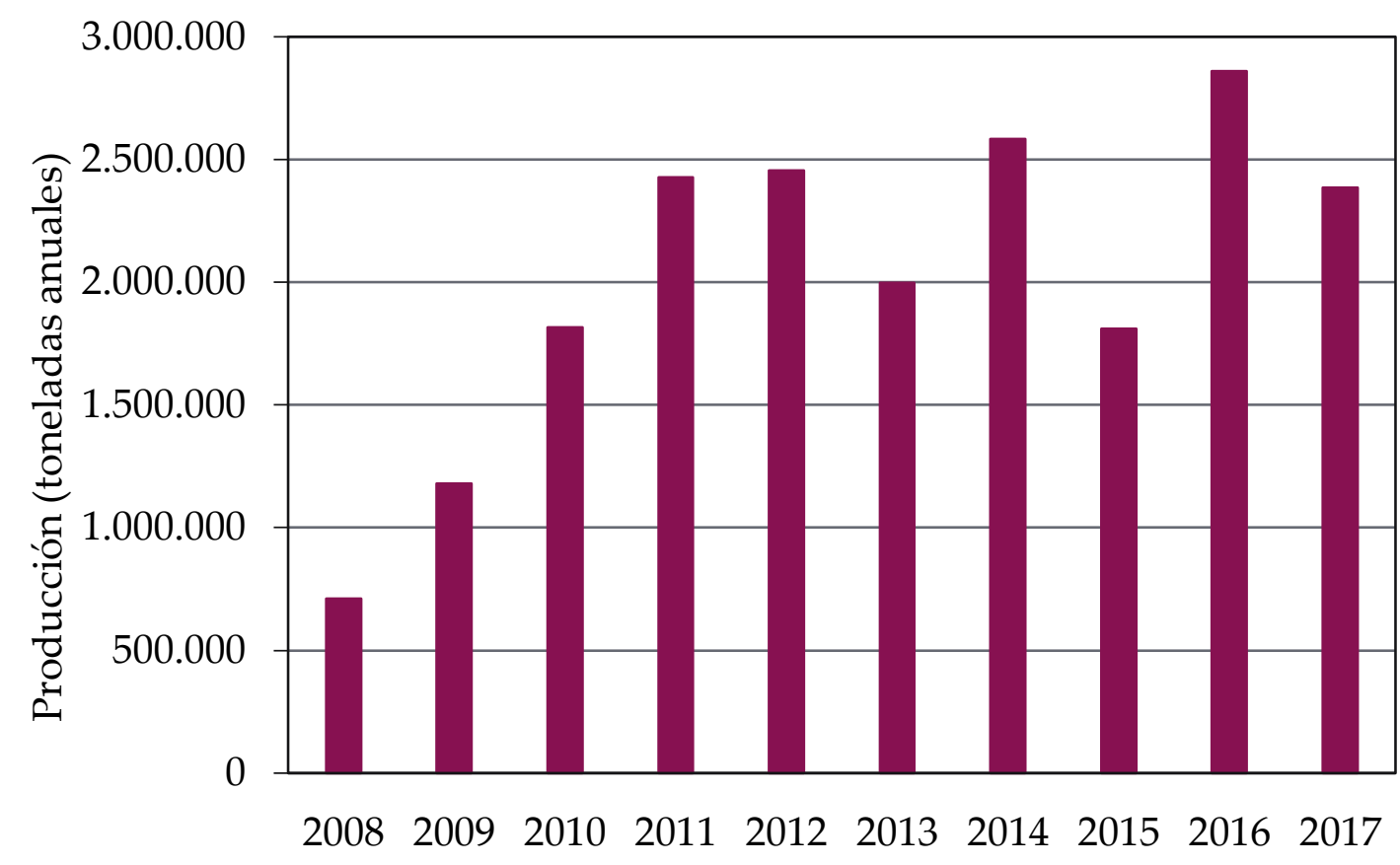

Figura 7-1. Producción nacional de biodiesel (en toneladas anuales) entre 2008 y 2017.

Del total de biodiesel producido en nuestro país, la mayor parte se exporta, siendo Estados Unidos, Perú, Reino Unido, España, Paraguay, Panamá y Chile los principales países consumidores del biodiesel argentino.

La Figura 8-1 muestra las exportaciones de biodiesel (en toneladas anuales) entre los años 2008 y 2017.

El pico máximo de exportaciones tuvo lugar en 2011, con un total de casi 1,7 millones de toneladas de biodiesel.

Pocos años después, las exportaciones cayeron abruptamente. El cambio comenzó en 2012, debido a que España excluyó a las industrias argentinas del listado de plantas autorizadas a venderle biodiesel. Por otro lado, en 2013 la Unión Europea aplicó una medida antidumping al biodiesel argentino, penalizándolo con un arancel de hasta U\$S 250 por tonelada [9]. 


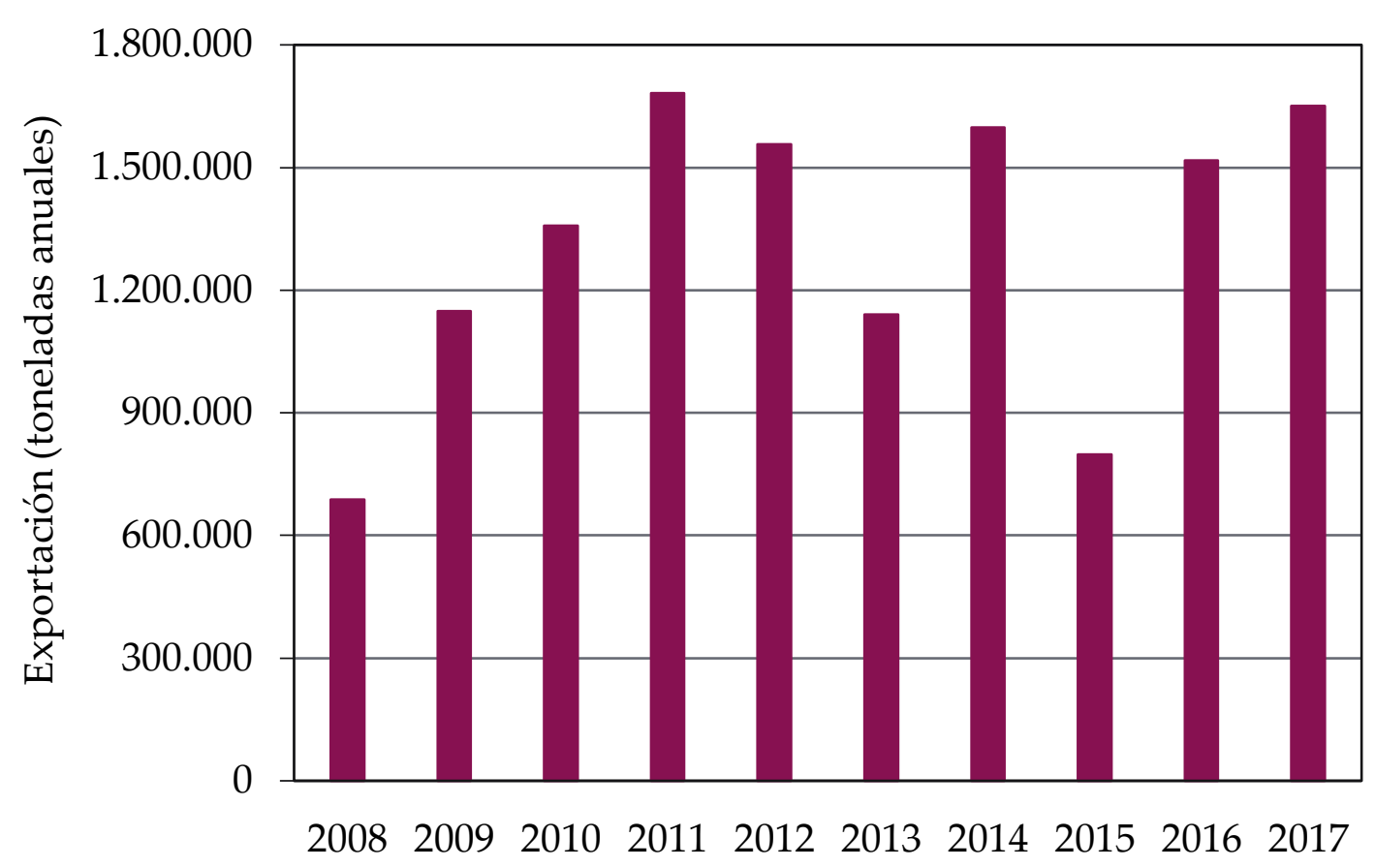

Figura 8-1. Exportación nacional de biodiesel (en toneladas anuales) entre 2008 y 2017.

A diferencia de las cantidades exportadas de biodiesel, en el mercado local el consumo es más bajo (Figura 9-1) [17,18].

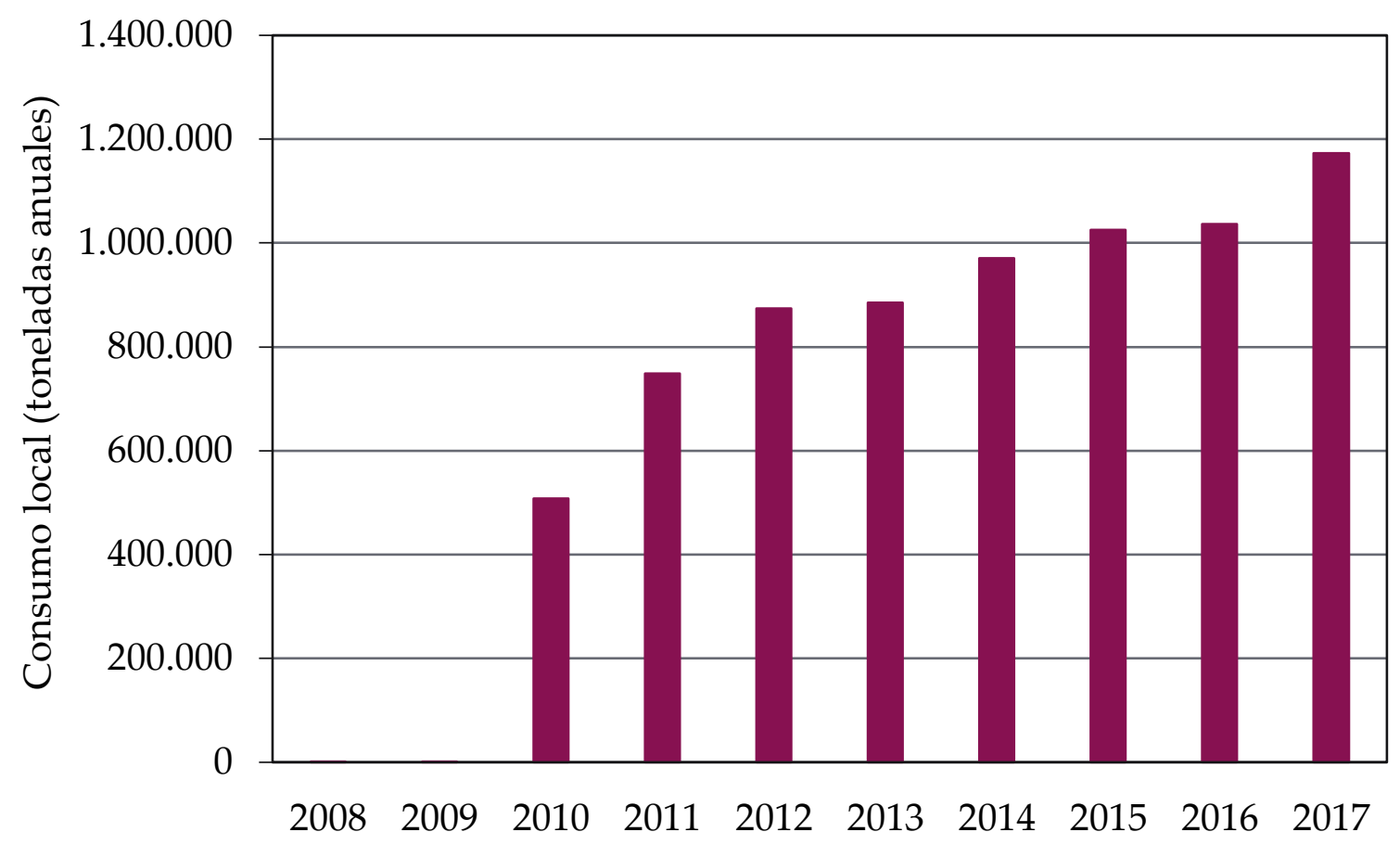

Figura 9-1. Consumo nacional de biodiesel en el mercado local entre 2008 y 2017. 


\subsection{El glicerol como subproducto del biodiesel}

Con la producción de biodiesel se obtienen grandes cantidades de glicerol, que es el principal subproducto de la reacción. Ya sea a través de la transesterificación de aceites o grasas (sin usar o usados) con cualquiera de los alcoholes de cadena corta mencionados (metanol, etanol o 1-propanol), siempre se genera glicerol como producto secundario de la reacción (Ecuaciones 1.1., 1.2 y 1.3).

Desde el punto de vista estequiométrico, para producir $100 \mathrm{~kg}$ de biodiesel son necesarios $100 \mathrm{~kg}$ de aceite vegetal y $10 \mathrm{~kg}$ de metanol. Este proceso genera como subproducto $10 \mathrm{~kg}$ de glicerol. Este glicerol, que acompaña al biodiesel producido, tiene una pureza que varía en el rango de $55-90 \%$ p/p y es denominado glicerol crudo. Entre las impurezas encontradas se hallan restos de triglicéridos y monoalcoholes que no han reaccionado, biodiesel, jabones y otros contaminantes minoritarios [10].

Debido a su bajo nivel de pureza, el glicerol crudo no es adecuado para su aplicación en química fina, farmacia y en el mercado agroalimentario, y requiere ser tratado y purificado [11]. Actualmente, el glicerol crudo se somete a una destilación fraccionada para obtener glicerol de grado técnico. Sin embargo, ni el mercado farmacéutico ni el agroalimentario pueden absorber todo el glicerol producido. Este excedente ha sobresaturado estos mercados, devaluando el glicerol y así, la búsqueda de nuevas alternativas para el glicerol resulta muy atractiva [12].

\subsubsection{Propiedades fisicoquímicas}

El glicerol (1,2,3-propanotriol) es un polialcohol cuya estructura se muestra en la Figura 10-1.

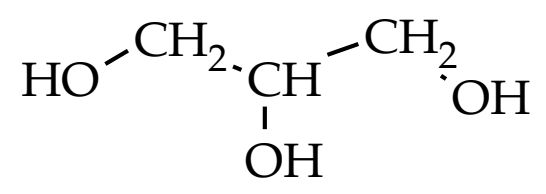

Figura 10-1. Molécula del glicerol (1,2,3-propanotriol).

Cuando se encuentra en estado puro (99.99\%p/p) es un líquido viscoso $(\mu=1.5$ Pa.s). Posee un bajo nivel de toxicidad y no es irritante. Por otro lado, su molécula es tan estable a temperatura ambiente que puede almacenarse por largos períodos de tiempo sin sufrir descomposición alguna.

El glicerol tiene un punto de fusión (p.f.) igual a $18.2^{\circ} \mathrm{C}$ y un punto de ebullición de $290{ }^{\circ} \mathrm{C}$, temperatura a la cual también se descompone.

La Tabla 3-1 resume las principales propiedades físicas y químicas del glicerol puro [13]. 
Tabla 3-1. Propiedades físicas y químicas del glicerol puro.

\begin{tabular}{ll}
\hline Propiedad & Valor \\
\hline Peso molecular $(\mathrm{PM})$ & $92.09 \mathrm{~g} / \mathrm{mol}$ \\
Densidad $(\delta)$ & $1.26 \mathrm{~g} / \mathrm{ml}$ \\
Viscosidad $(\mu)$ & $1.5 \mathrm{~Pa} . \mathrm{s}$ \\
Punto de fusión (p.f.) & $18.2^{\circ} \mathrm{C}$ \\
Punto de ebullición (p.e.) & $290^{\circ} \mathrm{C}$ \\
Presión de vapor $\left(p_{\mathrm{v}}\right)$ & $0.0025 \mathrm{mmHg}$ \\
Tensión superficial $(\gamma)$ & $64 \mathrm{mN} / \mathrm{m}$ \\
Coeficiente de dilatación $(\lambda)$ & $-0.0598 \mathrm{mN} / \mathrm{mK}$ \\
Punto de descomposición $($ p.d.) & $290^{\circ} \mathrm{C}$ \\
\hline
\end{tabular}

Si bien el compuesto se llama glicerol, comercialmente se nombra como glicerina, hallándose a menudo en mezclas acuosas, con distintos porcentajes en peso de glicerol.

La mayor parte del glicerol refinado es fabricado para satisfacer los estrictos requisitos de la Farmacopea de los Estados Unidos (USP) y del Código de los productos químicos alimentarios (FCC).

Por otra parte, el glicerol crudo consiste en una solución de glicerol y agua con un rango de concentración de glicerol que se halla entre el $40 \%$ p/p y el $88 \%$ p/p. Lo más usual es una concentración cercana al $80 \% \mathrm{p} / \mathrm{p}$.

El glicerol grado técnico, se encuentra libre de jabones, sales y alcohol que no haya reaccionado en el proceso de obtención del biodiesel. Puede contener en baja proporción, cloruros, ácidos grasos, ésteres y algunos restos orgánicos de triglicéridos. Su concentración es cercana al $98 \% \mathrm{p} / \mathrm{p}$.

El glicerol refinado es un producto de calidad farmacéutico altamente purificado para ser utilizado en la industria de cosméticos, productos farmacéuticos e industria alimenticia. Este producto debe cumplir las especificaciones de la Farmacopea de los Estados Unidos (USP 30). En el caso de ser empleada en productos alimenticios debe cumplir las normas del Código de productos químicos alimenticios (FCC). La concentración de glicerol en agua es en este caso del $99.7 \% \mathrm{p} / \mathrm{p}$.

La Tabla 4-1 muestra algunas de las propiedades del glicerol crudo, técnico y refinado [14]. 
Tabla 4-1. Calidades de glicerol y algunas de sus propiedades.

\begin{tabular}{|c|c|c|c|}
\hline Propiedad & $\begin{array}{c}\text { Glicerol } \\
\text { crudo }\end{array}$ & $\begin{array}{l}\text { Glicerol } \\
\text { técnico }\end{array}$ & $\begin{array}{l}\text { Glicerol } \\
\text { refinado }\end{array}$ \\
\hline Concentración de glicerol & $40-88 \% \mathrm{p} / \mathrm{p}$ & $98 \% \mathrm{p} / \mathrm{p}$ & $99.7 \% p / p$ \\
\hline Concentración máxima de agua & $12 \% \mathrm{p} / \mathrm{p}$ & $2 \% \mathrm{p} / \mathrm{p}$ & $0.3 \% \mathrm{p} / \mathrm{p}$ \\
\hline Concentración máxima de cenizas & $2 \% \mathrm{p} / \mathrm{p}$ & - & - \\
\hline Concentración máxima de cloruros & - & 10 ppm & 10 ppm \\
\hline Concentración máxima de sulfatos & - & - & 20 ppm \\
\hline Concentración máxima de metales pesados & - & 5 ppm & 5 ppm \\
\hline Concentración máxima de compuestos clorados & - & 30 ppm & 30 ppm \\
\hline Concentración máxima de ácidos grasos y ésteres & - & 1 ppm & 1.000 ppm \\
\hline Concentración máxima de residuos orgánicos & $2 \% \mathrm{p} / \mathrm{p}$ & $2 \% p / p$ & - \\
\hline pH (solución al 10 \%) & 4 a 9 & 4 a 9.1 & - \\
\hline
\end{tabular}

\subsubsection{Aplicaciones del glicerol}

Su principal uso es en la industria farmacéutica para la elaboración de drogas medicinales $(\sim 18 \%)$, seguido por su empleo en la industria cosmética $(\sim 16 \%)$, de polímeros $(\sim 14 \%)$, de alimentos $(\sim 11 \%)$ y en la industria química para la fabricación de triacetina $(\sim 10$ $\%)$, resinas alquídicas $(\sim 8 \%)$, tabaco $(\sim 6 \%)$, detergentes $(\sim 2 \%)$, celofán $(\sim 2 \%)$ y explosivos $(\sim 2 \%)$ [13]. La Figura 11-1 muestra la distribución de aplicaciones del glicerol por sector.

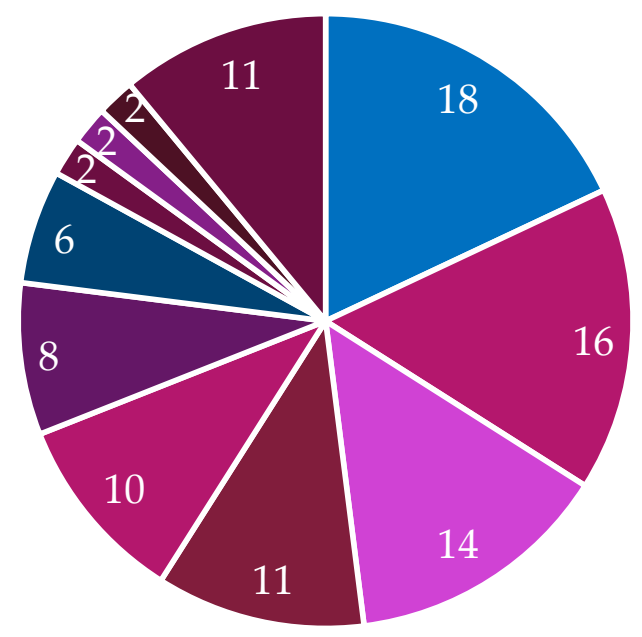

- Farmacéuticos

- Cosméticos

- Polímeros

- Alimentos

- Triacetina

- Resinas alquídicas

- Tabaco

- Detergentes

- Celofán

- Explosivos

- Otros

Figura 11-1. Aplicaciones del glicerol.

Con respecto a su uso farmacéutico, el glicerol bajo la forma de glicerina refinada puede ser usada en preparaciones medicinales debido a su poder lubricante, humectante y suavizante. Debido a su poder higroscópico permite mantener fuera del alcance de la humedad la mayoría de los preparados farmacéuticos, controlando la textura de las muestras y su actividad acuosa. Es usado como aditivo en laxantes, jarabes y expectorantes. 
En la industria cosmética el glicerol se emplea como humectante, solvente, emoliente y lubricante, en la fabricación de cremas, pasta dental, jabones, espuma de afeitar y perfumes.

En la industria de polímeros, el glicerol se emplea como iniciador de las reacciones de polimerización, por ejemplo, para la producción de espuma de poliuretano.

En la industria de alimentos el glicerol se emplea como solvente, endulzante y conservante. Para citar un ejemplo, el glicerol endulza tanto como la sucrosa, pero a diferencia de esta no produce placas ni caries dentales, y tampoco eleva los valores de azúcar en sangre.

En la producción de resinas alquídicas, el glicerol se emplea como suavizante y plastificante, para impartir flexibilidad en revestimientos y pinturas de superficies.

\subsubsection{Mercado del glicerol}

Uno de los mayores obstáculos en la comercialización del biodiesel es la saturación del mercado del glicerol, lo que causa una reducción abrupta del precio del mismo en el mercado y en consecuencia afecta directamente a la economía del biodiesel. Evidencias de esta premisa fueron los cierres en las plantas de Procter \& Gamble Chemicals en Inglaterra (2006) y Dow Chemical en Texas (2007) [13].

Si bien el glicerol se produce principalmente a partir de la reacción de transesterificación de aceites y grasas $(\sim 65 \%)$, también se produce a partir de la fabricación de ácidos grasos $(\sim 23 \%)$, alcoholes $(\sim 7 \%)$ y jabones $(\sim 3 \%)$. La Figura 12-1 muestra la distribución porcentual de los procesos que dan origen al glicerol.

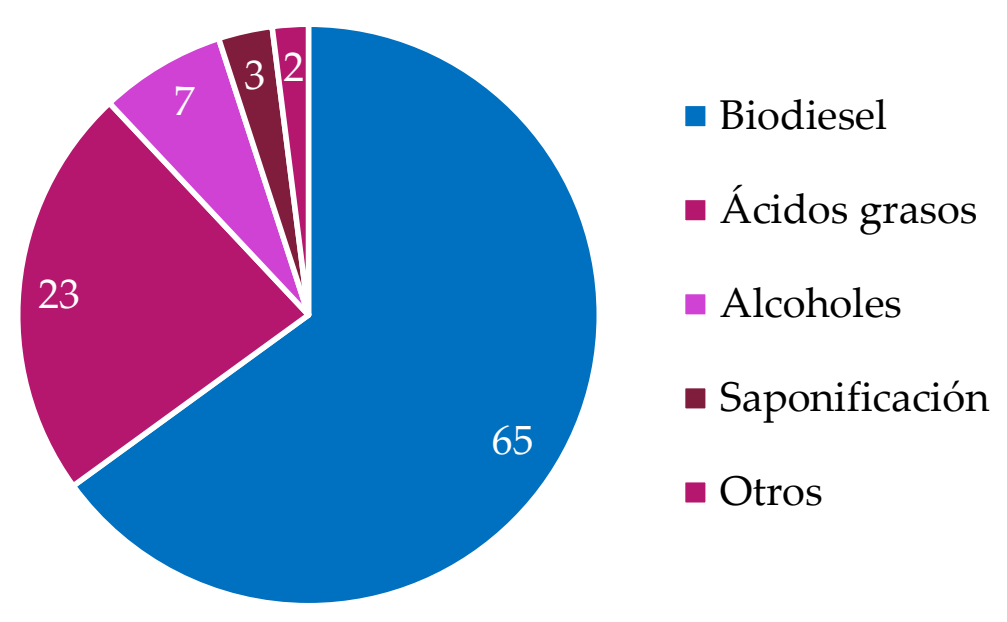

Figura 12-1. Procesos industriales que dan origen al glicerol.

La producción mundial de glicerol sufrió un crecimiento importante en los años posteriores al 2002, debido principalmente al crecimiento en la producción de biodiesel. Después del año 2005, el precio del glicerol crudo disminuyó de 300 U\$S/tonelada a 40 U\$S/tonelada [12,15].

En la actualidad, es posible adquirirlo a un precio entre 100-300 U\$S/tonelada de glicerol crudo. En el caso del glicerol de grado técnico el precio es aproximadamente el doble. 


\subsubsection{Procesos de transformación}

El glicerol constituye entonces una molécula plataforma para la obtención de productos químicos y biocombustibles. A partir del glicerol se podrían obtener otros productos químicos que se muestran en la Figura 13-1 a través de procesos de oxidación [16], esterificación [17], eterificación [19], hidrogenólisis [20], reformado [21], polimerización [13], cloración [22], carbonatación [23], deshidratación [24] y nitración [13].

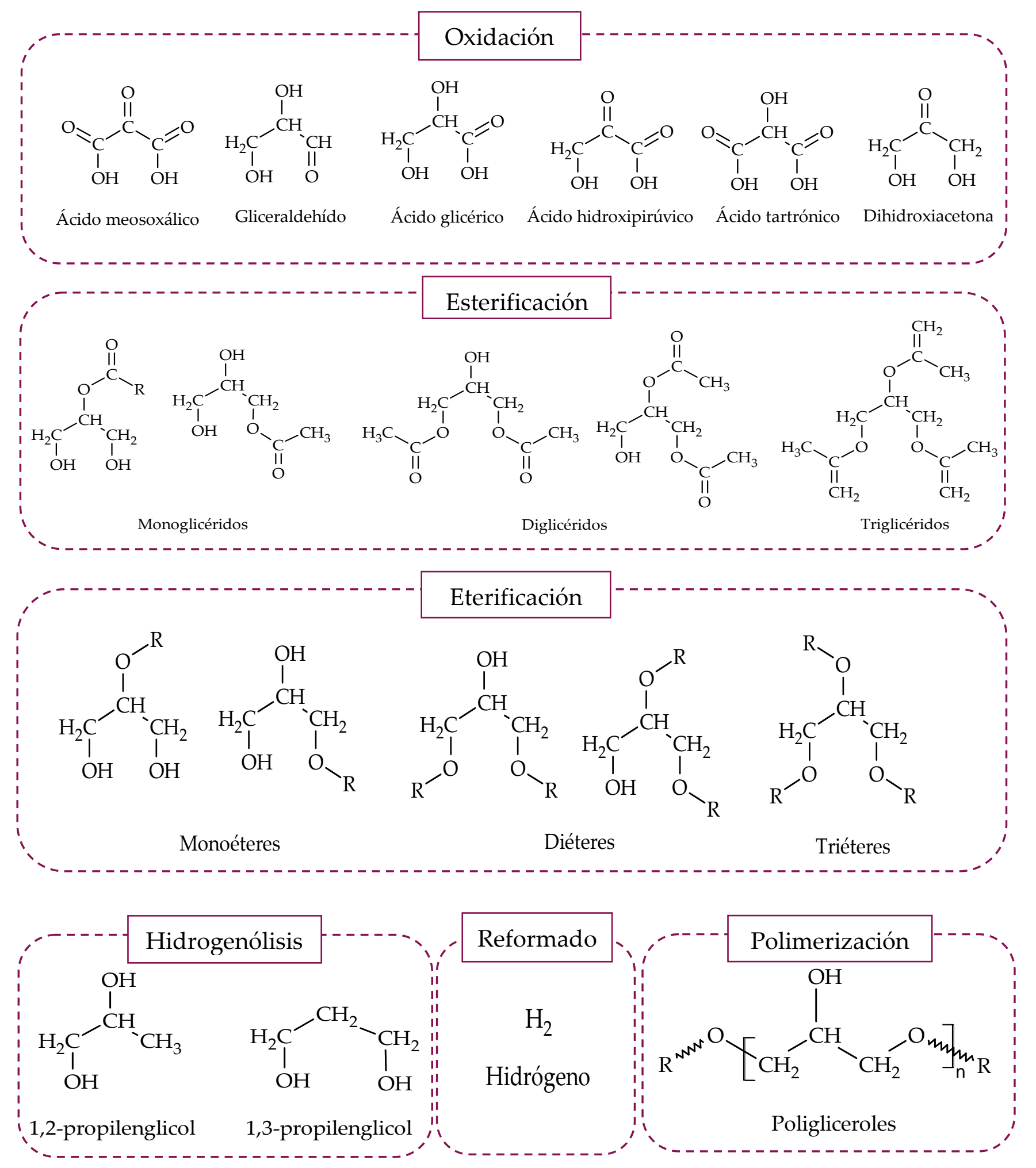




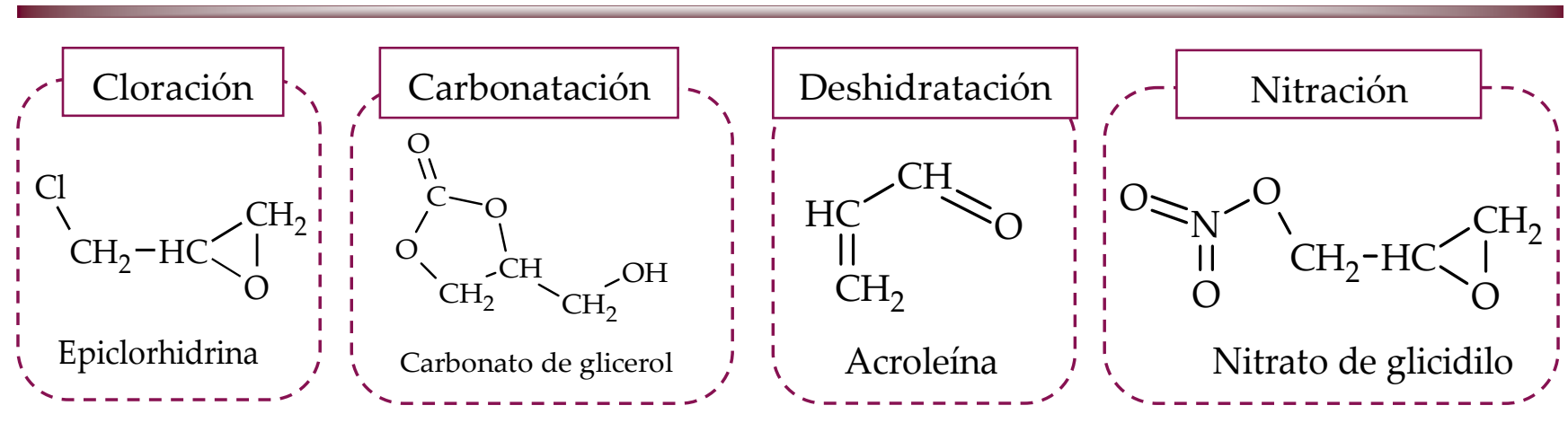

Figura 13-1. Procesos de transformación del glicerol en productos de alto valor agregado.

\subsection{El biopropilenglicol a partir de glicerol}

De los procesos de transformación del glicerol resulta muy interesante la hidrogenólisis de glicerol para producir glicoles, tales como el 1,2-propilenglicol (1,2-PG), el cual procede vía una ruptura de enlace C-O (Ecuación 4-1). Como consecuencia de esta reacción también se genera agua.

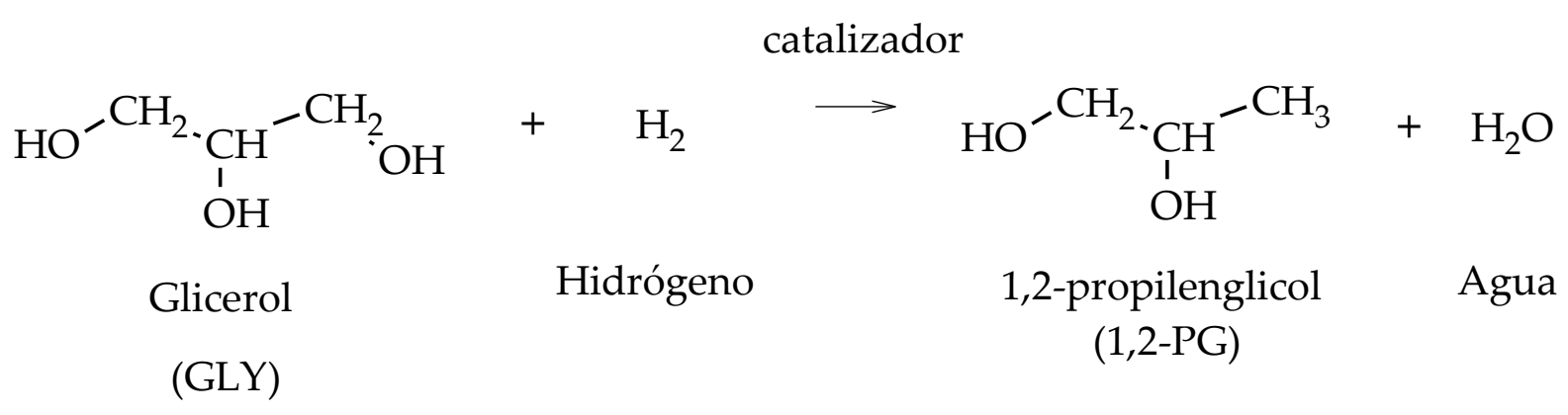

Ecuación 4-1. Hidrogenólisis de glicerol para producir 1,2-PG.

La reacción de hidrogenólisis puede dar lugar, dependiendo de las condiciones de presión, temperatura, concentración de glicerol, $\mathrm{pH}$, catalizador, etc., a otros productos de reacción tales como etilenglicol (EG), etanol (EtOH), 1-propanol (1-POH), 2-propanol (2$\mathrm{POH})$ y acetona (AcO) (Figura 14-1).

La reacción puede llevarse a cabo en fase líquida a altas presiones y moderadas temperaturas, o en fase vapor, a altas temperaturas y bajas presiones. Cada una de estas condiciones se discutirán en el capítulo 2. El empleo de catalizadores, másicos y soportados, abarca un gran número de metales nobles, como $\mathrm{Ru}, \mathrm{Pt}$ y Pd, y no nobles, como Ni, $\mathrm{Cu}$ y Co. Los aspectos relativos a la reacción de hidrogenólisis y los catalizadores se presentan detalladamente en el capítulo 2. 
<smiles>CCCO</smiles>

1-propanol

(1-POH)<smiles>OCCO</smiles>

Etilenglicol (EG)<smiles>CC(C)O</smiles>

2-propanol

(2-POH)

$\mathrm{HO}$<smiles>CCC</smiles>

Etanol (EtOH)<smiles>CC(C)=O</smiles>

Acetona

$(\mathrm{AcO})$

$\mathrm{HO}$<smiles>CC</smiles>

Metanol (MeOH)

Figura 14-1. Productos de reacciones laterales obtenidos en la hidrogenólisis catalítica de glicerol.

\subsubsection{Propiedades fisicoquímicas}

El 1,2-PG en su estado puro (99,99\%p/p) es un líquido viscoso, incoloro e inodoro (Figura 15-1). No es volátil a temperatura ambiente y es completamente soluble en agua, así como también en alcoholes, ésteres, éteres, aldehídos, cetonas, algunos aceites y grasas animales y vegetales.<smiles>CC(O)CO</smiles>

Figura 15-1. Molécula del 1,2-PG (1,2-propanodiol).

Además, su toxicidad es prácticamente nula, a diferencia de otros glicoles como el etilenglicol, y esta característica le permite ser utilizado en productos farmacéuticos, cosméticos y de alimentos. Su capacidad para absorber agua y retenerla en diversos productos alimenticios es mucho mayor que la de otros alcoholes como glicerol, manitol y sorbitol. Comercialmente se obtiene propilenglicol de grado industrial y de alta pureza, llamado de grado USP/EP [25].

\subsubsection{Aplicaciones del 1,2-propilenglicol}

El 1,2-PG se emplea en la industria química, de alimentos, cosmética, farmacéutica y de polímeros [26].

En la industria química se emplea como solvente, anticongelante, refrigerante y fluido calefactor [26]. 
En la industria de alimentos se emplea para ayudar a conservar la calidad original de los productos, preservando sus propiedades organolépticas. En este sentido, se emplea como agente humectante, suavizante, solvente, controlador de viscosidad, modificador de la cristalización, auxiliar en la rehidratación y como aditivo alimenticio [26].

En la industria cosmética, el 1,2-PG es empleado como emoliente, suavizante, modificador de la viscosidad y humectante en más de 4.000 productos cosméticos. Además, su capacidad de solubilizar compuestos orgánicos lo convierte en un excelente solvente en tintas y fragancias, contribuyendo a la dispersión de compuestos en solución. También es un buen emulsificante de aceites esenciales. Su uso en cosméticos fue aprobado por el Comité de Revisión de Ingredientes Cosméticos y puede emplearse en una concentración máxima del 50 \%p/p. Algunos productos cosméticos que contienen 1,2-PG son: desodorantes, antitranspirantes, cremas faciales, filtros solares, champús, acondicionadores y geles de baño [26].

En la industria farmacéutica se emplea en la elaboración de medicamentos de vía oral, tópicos e inyectables, debido a su capacidad de solubilizar compuestos orgánicos e inorgánicos. Además, sus propiedades texturales permiten su uso como emoliente y humectante, propiedades especialmente importantes en el uso de medicamentos tópicos como cremas y lociones [26].

Con respecto a los usos del 1,2-PG a nivel nacional, Argentina emplea este producto principalmente en la fabricación de resinas poliéster $(\sim 36 \%)$, en productos de limpieza y cuidado personal ( $\sim 19 \%)$, en fragancias ( 15\%) y en productos farmacéuticos $(\sim 10 \%)$. Entre otros usos menores se encuentra la industria tabacalera $(\sim 5 \%)$, la industria química en general $(\sim 4 \%)$ y la industria de pinturas ( 3\%) (Figura 16-1) [27].

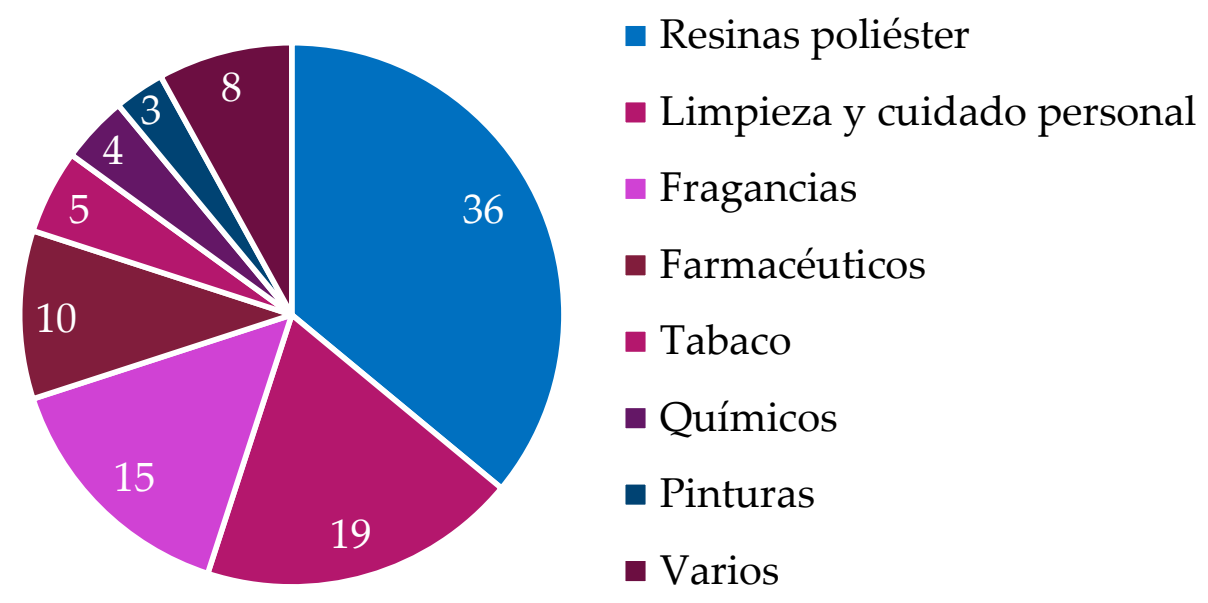

Figura 16-1. Aplicaciones del 1,2-PG a nivel nacional.

\subsubsection{Mercado del 1,2-propilenglicol}

La oferta mundial de 1,2-PG se encuentra liderada por la región de Asia-pacífico ( 40 $\%)$ seguida por América del Norte ( $29 \%)$ y Europa ( $27 \%)$. El resto del 1,2-PG es producido 
en Latinoamérica ( 4\%) [28]. Cabe aclarar que estos datos corresponden al 1,2 PG de origen petroquímico (Figura 17-1).

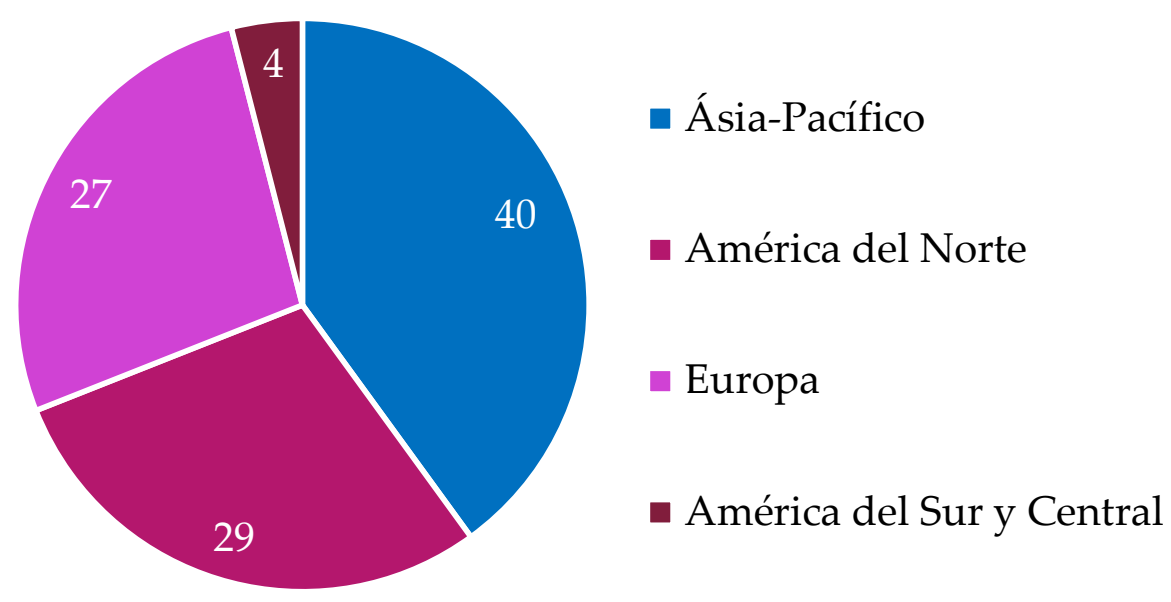

Figura 17-1. Distribución de la producción mundial de 1,2-PG.

A nivel mundial, la capacidad de producción de 1,2-PG sufrió un incremento entre los años 2007 y 2015. En 2007, la producción mundial fue de 1.400 .000 toneladas [29], aumentando hasta las 1.600 .000 toneladas en 2010 [25], luego hasta las 2.180 .000 toneladas en 2013 [28] y finalmente a 2.400.000 toneladas en 2014 [30]. Dado que en 2014 la producción de 1,2-PG creció en un $8 \%$ anual, se estima que la producción de 2015 fue de aproximadamente 2.600.000 toneladas. La Figura 18-1 muestra la evolución en la producción de 1,2-PG (en toneladas anuales) entre los años 2007 y 2015.

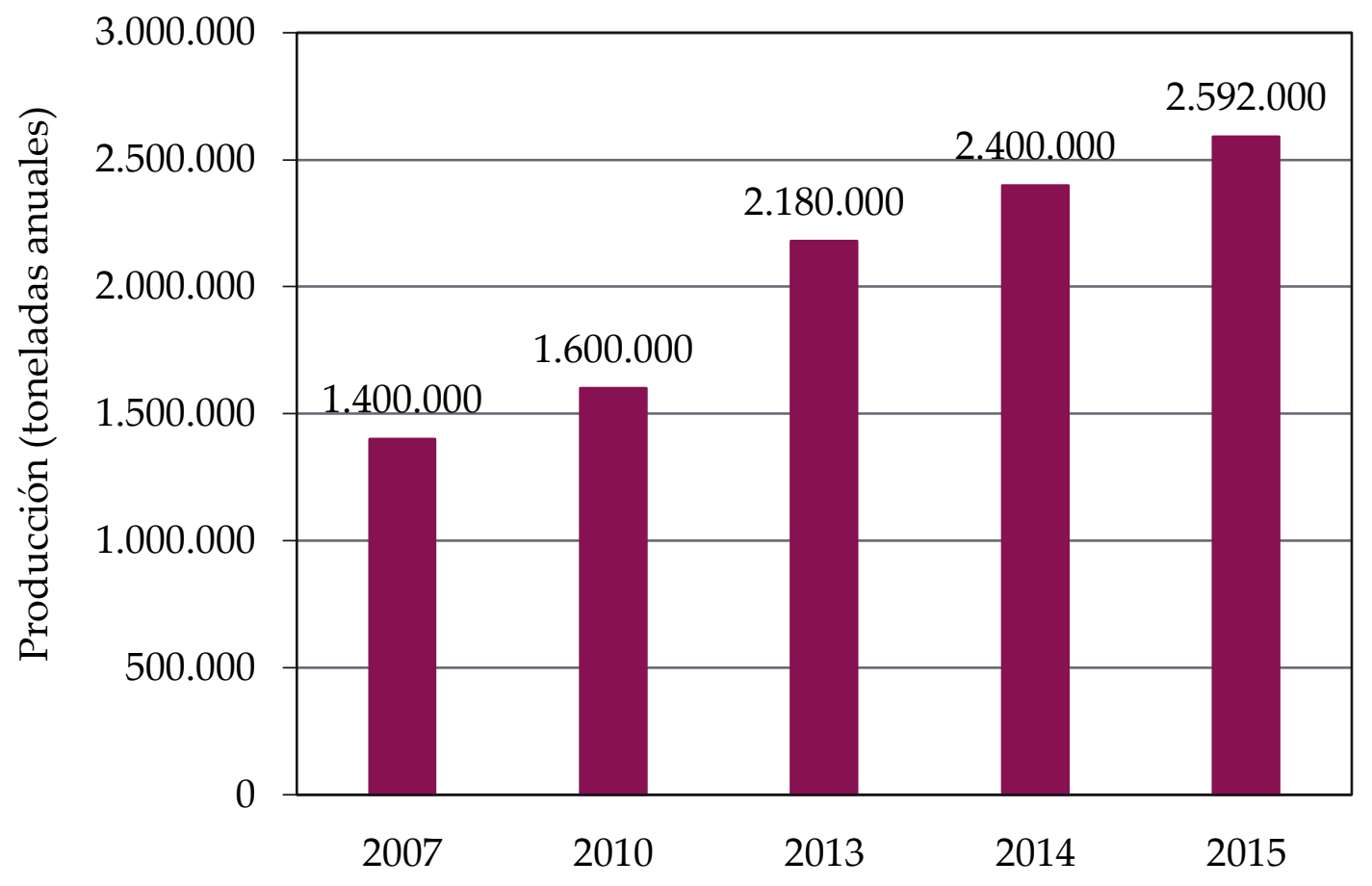

Figura 18-1. Producción mundial (en toneladas anuales) de 1,2-PG. 
La Figura 19-1 muestra la distribución de la producción según los principales países productores: Estados Unidos ( 1.020.000 toneladas anuales), China ( 629.000 toneladas anuales), Corea del Sur ( 600.000 toneladas anuales), Francia ( 410.000 toneladas anuales) y Bélgica ( 20.000 toneladas anuales) [31].

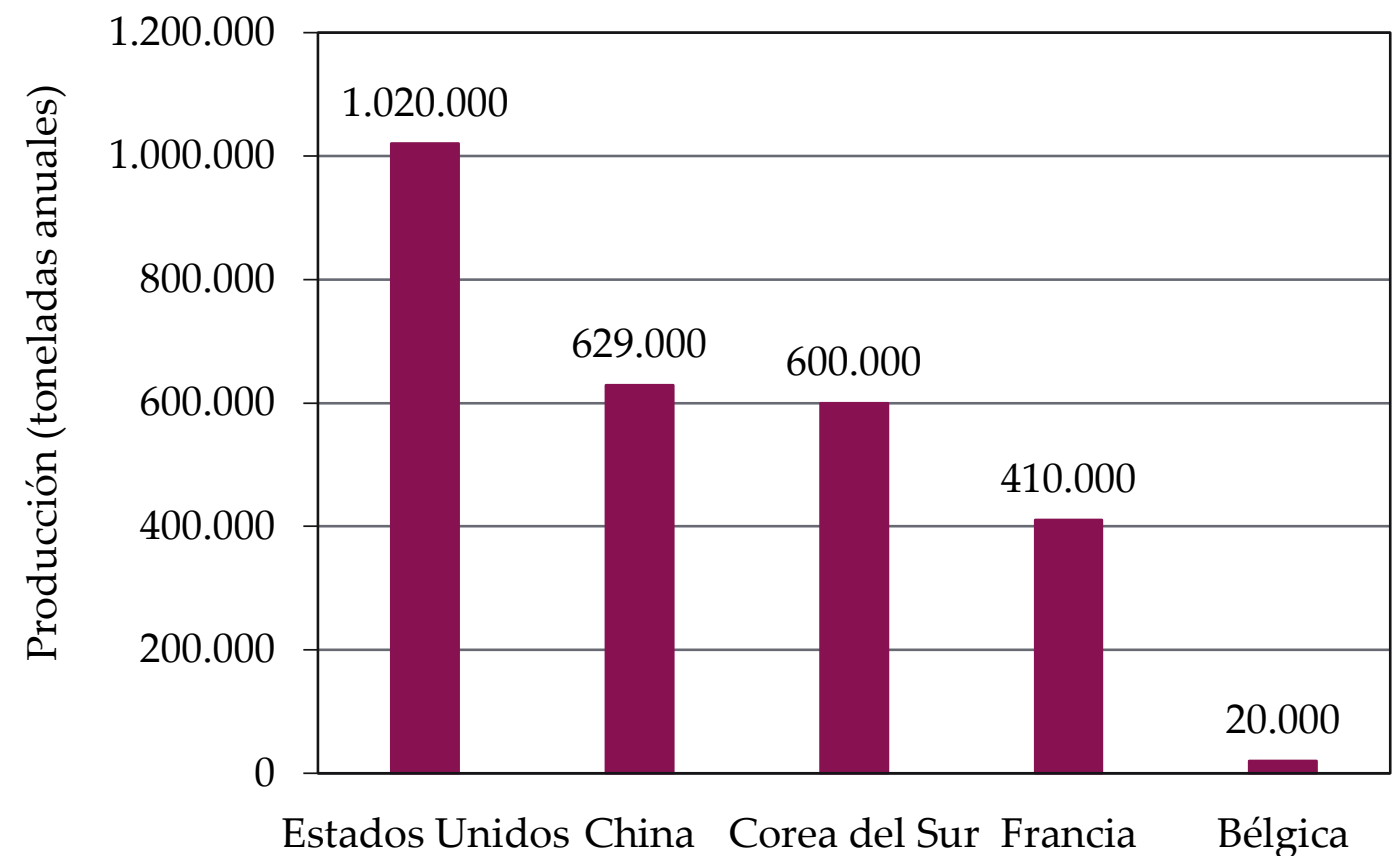

Figura 19-1. Producción mundial (en toneladas anuales) de 1,2-PG por países.

De toda la producción mundial, se estima que solo el $10 \%$ del 1,2-PG es producido a partir de glicerol. El restante $90 \%$ aún sigue produciéndose a partir de la hidratación del óxido de propileno, es decir, por vía petroquímica.

La Tabla 5-1 muestra las principales empresas productoras de 1,2-PG a nivel mundial con su capacidad de producción instalada. Las líderes del mercado son Dow Chemical (Estados Unidos) y SKC Chemical Group (Corea del Sur) [31].

Tabla 5-1. Principales empresas productoras de 1,2-PG a nivel mundial.

\begin{tabular}{llc}
\hline Empresa & País & $\begin{array}{c}\text { Producción } \\
\text { (toneladas anuales) }\end{array}$ \\
\hline Dow Chemical & Estados Unidos & 920.000 \\
SKC Chemical Group & Corea del Sur & 600.000 \\
Lyondell Chemical & Francia & 410.000 \\
Sinopec & China & 249.000 \\
Global Bio-Chem Technology Group & China & 200.000 \\
Tongling Jintai Chemical Industry Company & China & 100.000 \\
Archer Daniels Midland Company & Estados Unidos & 100.000 \\
Arrow Chemical Group Corporation & China & 80.000 \\
Oleon N.V. & Bélgica & 20.000 \\
\hline
\end{tabular}


A nivel nacional, Argentina no posee plantas productoras de 1,2-PG y por lo tanto debe importar todo el propilenglicol que consume. El consumo local tuvo una evolución según se muestra en el gráfico de la Figura 20-1 [4].

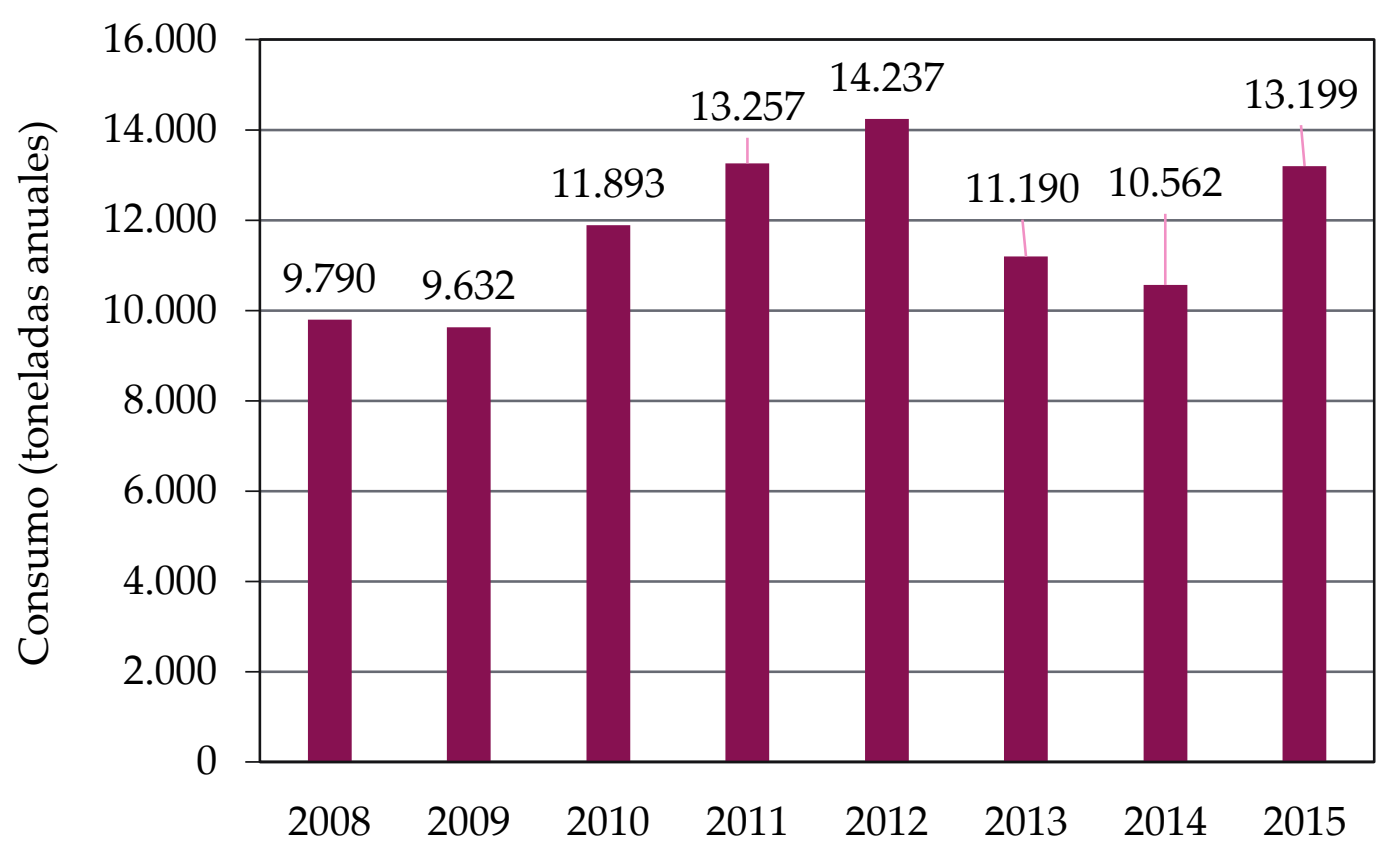

Figura 20-1. Consumo local (en toneladas anuales) de 1,2-PG entre 2008 y 2015.

En 2013 y 2014, debido a restricciones gubernamentales que limitaron las importaciones de bienes de capital, bienes intermedios, piezas y autopartes, hubo un descenso en el consumo de 1,2-PG. A partir de 2015 el consumo local se reactivó.

Las importaciones acompañaron este consumo, como se muestra en la Figura 21-1 [4].

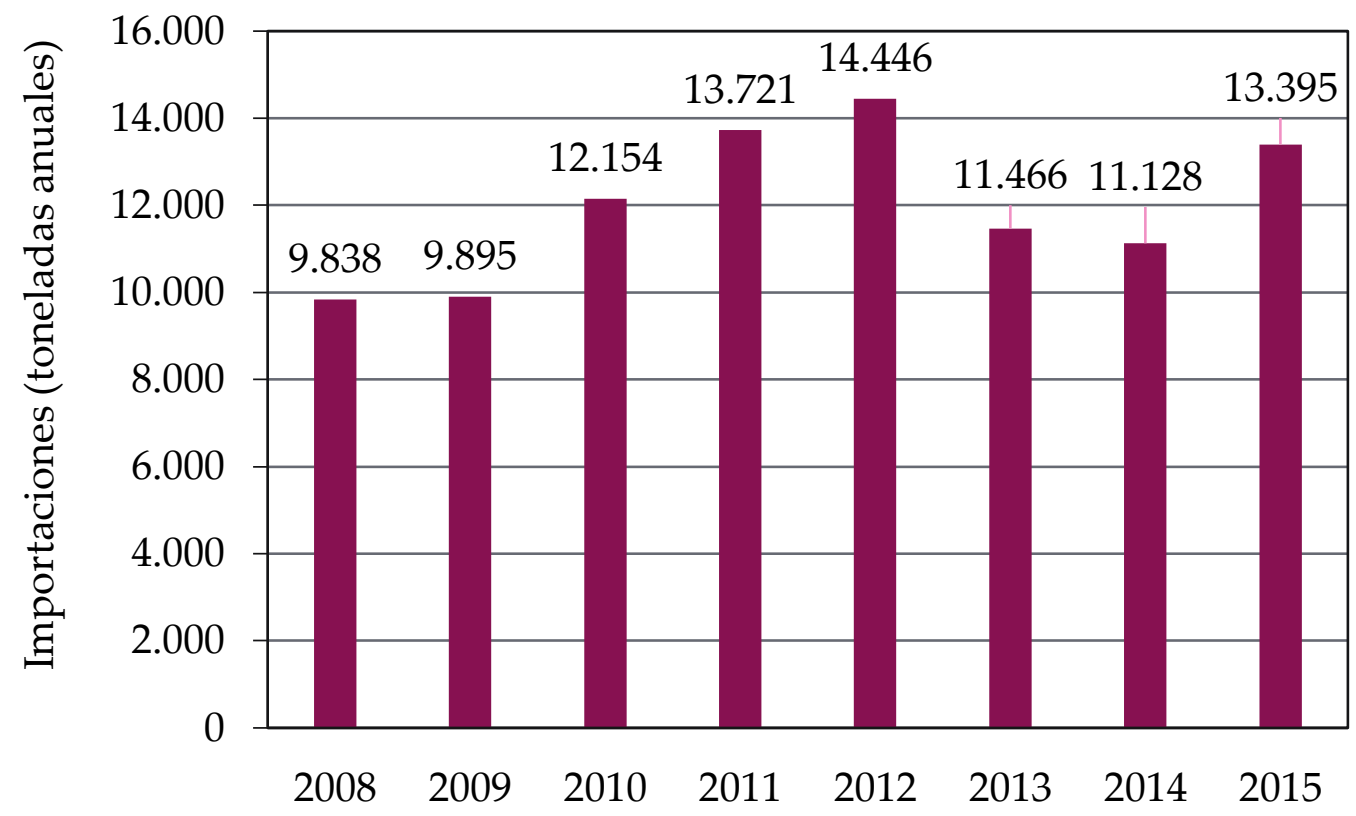

Figura 21-1. Importaciones nacionales (en toneladas anuales) de 1,2-PG. 
Las principales empresas importadoras de 1,2-PG en la Argentina se muestran en la Tabla 6-1, en donde se puede apreciar la cantidad de 1,2-PG importada por cada una de ellas, el país exportador y la aplicación a la cual está destinado el 1,2-PG [32].

Tabla 6-1. Principales empresas importadoras de 1,2-PG a nivel nacional.

\begin{tabular}{|c|c|c|c|}
\hline Empresa & País & Aplicación & Importación (toneladas anuales) \\
\hline Dow Química Argentina S.A. & Brasil & Distribuidora & 7.384 .700 \\
\hline Henry Hirschen y Cía S.A. & China & Distribuidora & 659.400 \\
\hline Massalin Particulares S.R.L. & Alemania & Tabaco & 392.200 \\
\hline Total Química S.A. & China & Distribuidora & 344.000 \\
\hline Inmbal Nutrer S.A. & China & Plastificantes & 324.400 \\
\hline Copsa S.A. & China & Distribuidora & 275.200 \\
\hline Dalgar S.A. & China & Distribuidora & 233.000 \\
\hline Laquimar S.A. & China & Distribuidora & 221.800 \\
\hline Plaquimet Química S.A. & China & Resinas & 220.200 \\
\hline Ester Vinil S.R.L. & China & Resinas & 220.000 \\
\hline Varteco Química Puntana S.A. & China & Plastificantes & 220.000 \\
\hline Tibex S.R.L. & Corea & Cosméticos & 212.500 \\
\hline Milberg y Asociados S.A. & China & Distribuidora & 132.200 \\
\hline Saporiti S.A. & Alemania & Alimentos & 125.600 \\
\hline Aditivos Alimentarios S.R.L. & China & Alimentos & 97.200 \\
\hline Carboclor S.A. & China & Solvente & 86.800 \\
\hline Cordis & China & Alimentos & 86.000 \\
\hline Bayer S. A. & China & Farmacia & 68.800 \\
\hline Proagro S.A. & China & Farmacia & 55.200 \\
\hline Flair S.R.L. & China & Tabaco & 52.400 \\
\hline Gabriel Bouillard y Cía S.R.L. & China & Vinos & 51.600 \\
\hline Cicloquimica & Corea & Distribuidora & 34.400 \\
\hline Fritzsche Saica & Corea & Alimentos & 26.000 \\
\hline Brouwer S.A. & China & Farmacia & 24.000 \\
\hline Cevasa S.A. & China & Distribuidora & 17.200 \\
\hline Deltaquim S.R.L. & Corea & Distribuidora & 17.200 \\
\hline Catalent Argentina & Alemania & Farmacia & 11.600 \\
\hline Basf Argentina S.A. & Alemania & Pinturas & 5.200 \\
\hline
\end{tabular}

Las importaciones nacionales de 1,2-PG provienen principalmente de Brasil, China Alemania y Corea. La distribución total de importaciones se visualiza en el gráfico de la Figura 22-1 [32]. 


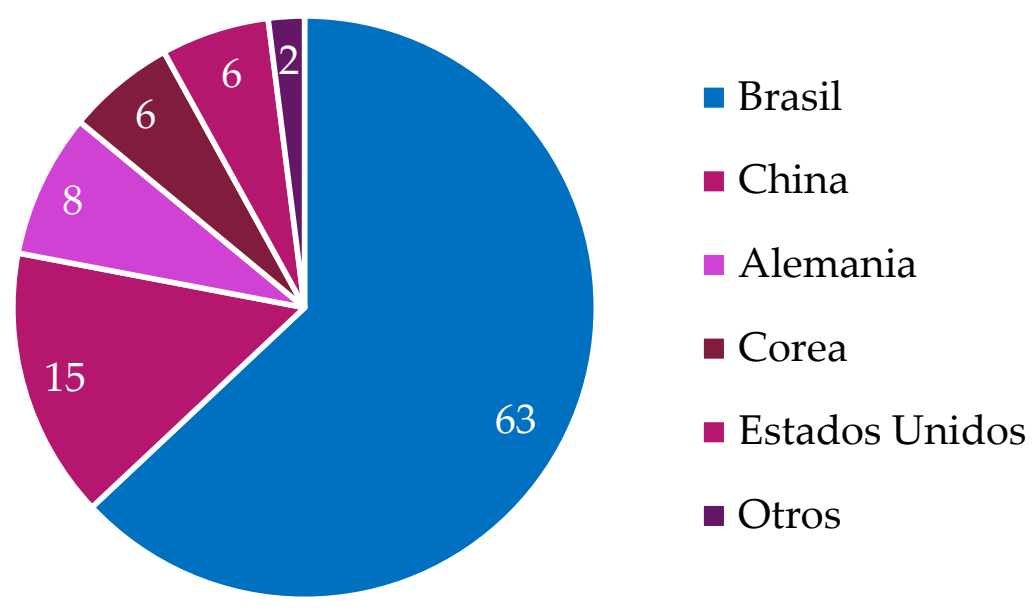

Figura 22-1. Distribución de las importaciones nacionales por países.

\section{Objetivos de la tesis}

Queda claro que la biomasa permite obtener una amplia gama de productos químicos y que Argentina siendo un país de fuerte carácter agrícola-forestal podría generar un desarrollo industrial estratégico a partir del aprovechamiento de la biomasa. La conversión selectiva de compuestos altamente oxigenados, como el glicerol, permitirá transformarlos en una gran cantidad de productos químicos útiles.

El panorama expuesto permite proyectar investigaciones futuras y definir como objetivo general y fundamental para esta tesis, el estudio de tecnologías sustentables que permitan obtener, a partir de materia prima renovable proveniente de la biomasa, productos destinados a la industria química.

El glicerol, que surge como subproducto de la industria del biodiesel, se encuentra disponible y con bajo costo en Argentina. El planteo de la obtención 1,2 PG a partir de la reacción de hidrogenólisis del glicerol permitiría no sólo avanzar hacia el desarrollo de procesos que sustituyen procesos petroquímicos, sino además le permitiría a nuestro país sustituir las actuales importaciones con posibilidades de exportación en la región.

Los objetivos específicos planteados en esta tesis son:

1) Desarrollar catalizadores metálicos soportados (mono o bimetálicos) activos y selectivos en la reacción de hidrogenólisis del glicerol a biopropilenglicol.

2) Estudiar y determinar las condiciones operativas para la obtención de biopropilenglicol (1,2-PG).

3) Comprender los factores que controlan la dinámica de los procesos químicos mediante el uso y aplicación de diferentes técnicas experimentales. Examinar las características estructurales de los soportes y de las fases metálicas activas para determinar su relación con el comportamiento catalítico y modo de acción.

4) Analizar los fenómenos básicos de desactivación asociados a las reacciones bajo estudio. 


\section{Bibliografía}

[1] Energías Renovables, Energía Biomasa, Secretaría de Energía (2008), Argentina.

[2] http://www.emb.cl/electroindustria/articulo.mvc?xid=959

[3] http://www.energiasrenovablesinfo.com/biomasa/tipos-biocombustibles/

[4] F. Ma, M. A. Hann, Bioresource Technology 70 (1999) 1-15

[5] Carriquiry, M. A. A comparative analyisis of the development of the United States and European Union biodiesel industries. Briefing Paper 07-BP 51 (2007).

[6] http://www.fao.org/3/a-BT092s.pdf.

[7] Informe Sectorial 2015, Infinita Renovables, Informe Biodiesel 2015.

[8] http://www.intagro.com/mapas/arg_soja.asp

[9] https://biodiesel.com.ar/8367/biodiesel-y-la-pregunta-incomoda-por-que-el-gobiernobusca-reactivar-una-industria-en-terapia-intensiva

[10] L. C. Meher, D. V. Sagar, S. N. Naik, Renewable \& Sustainable Energy Reviews 10 (2006) 248-268.

[11] P. F. Fonseca Amaral, T. F. Ferreira, G. Cardoso Fontes, M. A. Zarur Coelho, Food and Bioproducts Processing 87 (2009) 179-186.

[12] M. Anitha, S. K. Kamarudin, N. T. Kofli, Chemical Engineering Journal 295 (2016) 119130.

[13] M. Pagliaro y M. Rossi, The Future of Glycerol, RSC Green Chemistry 8 (2010).

[14] http://www.srsbiodiesel.com/technologies/glycerin-purification/glycerin-specifications/ en J. A. Posada-Duque y C. A. Cardona-Alzate, Ing. Univ. Bogotá (Colombia), 14 (1) (2010) 927.

[15] M. Ayoub, A.Z. Abdullah, Renewable \& Sustainable Energy Reviews 16 (2012) 26712686.

[16] C. L. Bianchi, P. Canton, N. Dimitratos, F. Porta, L. Prati, Catalysis Today 102-103 (2005) 203-212. 
[17] F. Jérome, G. Kharchafi, I. Adam, J. Barrault, Green Chemistry 6 (2004) 72-74.

[18]

https://www.bcr.com.ar/Pages/Publicaciones/informativosemanal_noticias.aspx?pIDNoticia= 764

[19] J. A. Melero, G. Vicente, G. Morales, M. Paniagua, J. M. Moreno, R. Roldán, A. Ezquerro, C. Pérez, Applied Catalysis A: General 346 (2008) 44-51.

[20] M. A. Dasari, P. Kiatsimkul, W. R. Sutterlin, G. J. Suppes, Applied Catalysis A: General 281 (2005) 225-231.

[21] F. Pompeo, G. F. Santori, N. N. Nichio, Catalysis Today 172 (2011) 183-188.

[22] A. Almena, M. Martín, Ind. Eng. Chem. Res. 55 (2016) 3226-3238.

[23] J. Li, T. Wang, Journal of Chemical Thermodynamics 43 (2011) 731-736

[24] F. Cavani, S. Guidetti, L. Marinelli, M. Piccinini, E. Ghedini, M. Signoretto, Applied Catalysis B: Environmental 100 (2011) 197-204.

[25]

http://msdssearch.dow.com/PublishedLiteratureDOWCOM/dh_08ea/0901b803808eabba.pdf? filepath=productsafety/pdfs/noreg/233-00248\&fromPage=GetDoc

[26]

http://msdssearch.dow.com/PublishedLiteratureDOWCOM/dh_003b/0901b8038003bfb7.pdf

[27] Información Estadística de la Industria Petroquímica y Química de la Argentina, 36 Edición (2016).

[28] https://mcgroup.co.uk/news/20140418/propylene-glycol-market-reach-supplydemandbalance-2015.html

[29] http://www.interempresas.net/Quimica/Articulos/19235-Ashland-y-Cargill-produciranpropilenglicol-renovable-en-una-nueva-planta-europea.html.

[30] http://www.quiminet.com/noticias/baja-en-el-precio-del-propilenglicol-en-el-20154145765.htm.

[31] https://mcgroup.co.uk/news/20150910/propylene-glycol-production-dominatedcompanies.html

[31] Sistema Maria, AFIP. 


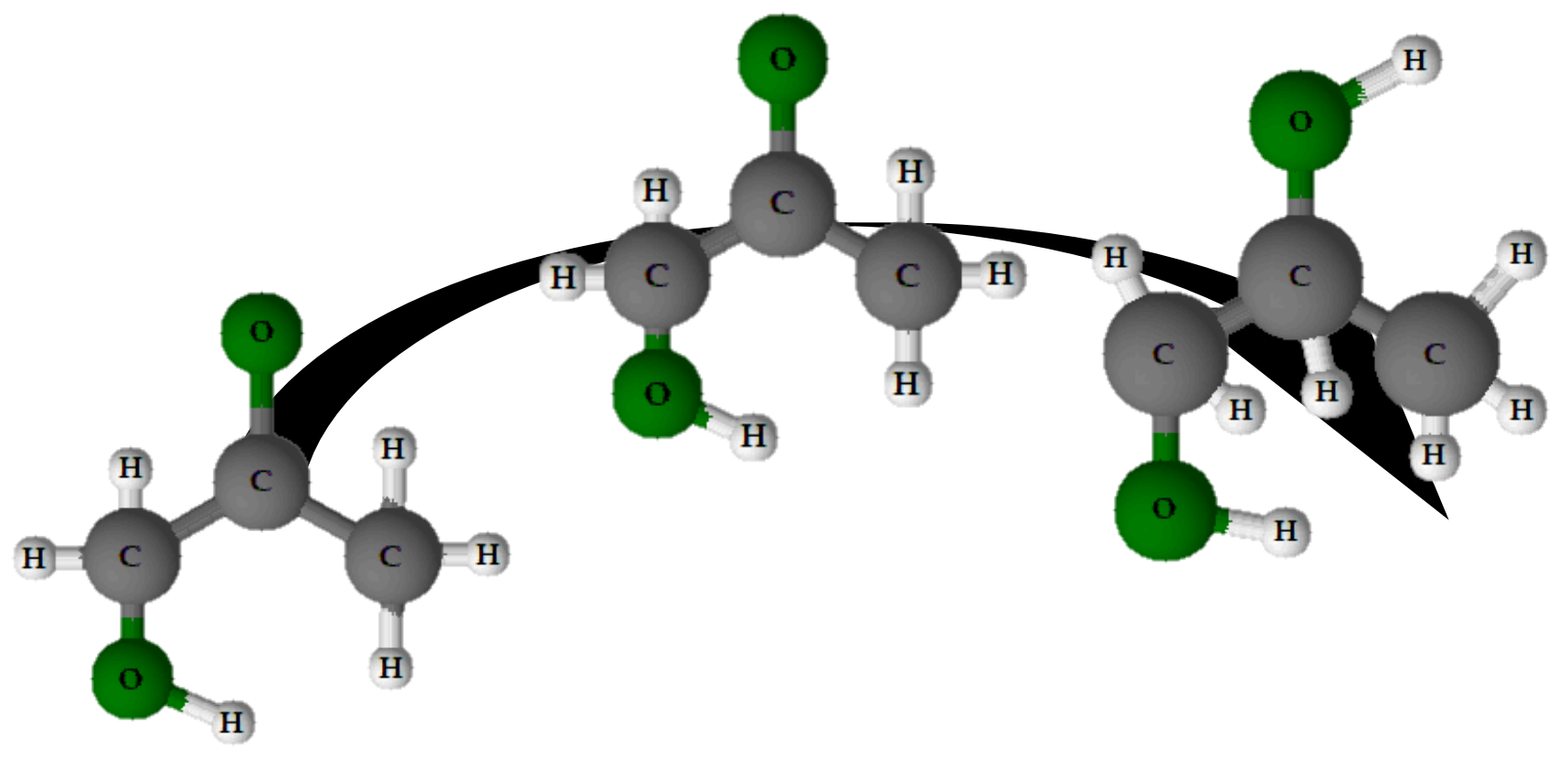

CAPÍTULO 2

Revisión bibliográfica 


\subsection{Introducción}

Del capítulo anterior quedó claro que, entre las transformaciones del glicerol posibles, resulta atractiva la reacción catalítica de hidrogenólisis para producir 1,2-PG debido a que tiene múltiples aplicaciones industriales, un alto valor agregado en el mercado en comparación al glicerol y además porque es un producto proveniente de la vía petroquímica por hidratación del óxido de propileno que actualmente se importa a nivel nacional (Argentina no produce 1,2-PG).

El objetivo de este capítulo es el análisis de una revisión bibliográfica completa, que aborda todo lo relativo a la reacción química de hidrogenólisis, los mecanismos de reacción, los catalizadores empleados y sus propiedades; destacando el efecto de las condiciones operativas empleadas, así como también estudios vinculados a la cinética y estabilidad de los catalizadores.

\subsection{Síntesis actual del 1,2-PG}

La actual síntesis de 1,2-PG a partir de una materia prima proveniente del petróleo, consiste en la hidratación del óxido de propileno (PO), a $125^{\circ} \mathrm{C}$ y 20 bar (Esquema 1-2).<smiles>CC(O)CO</smiles>

Óxido de propileno (PO)

1,2-propilenglicol (1,2-PG)

Esquema 1-2. Obtención de 1,2-PG a partir del óxido de propileno (PO).

Existen cinco tecnologías para la producción de PO [1]:

(1) El proceso de hidroperóxido de cumeno (Sumitomo Chemical Company).

(2) La epoxidación con peróxido de hidrógeno (Dow-BASF).

(3) El proceso de monómero de óxido de propileno/estireno

(LyondellBasel y Shell Company).

(4) El proceso de óxido de propileno/alcohol t-butílico

(LyondellBasel y Hunts-man Corporation).

(5) El proceso de clorhidrina (Dow).

Las reacciones involucradas en los mencionados procesos se presentan en el Esquema $2-2$.

(a)<smiles>CC(C)c1ccccc1</smiles><smiles>C=CC(C)CC1CC1CCCOO</smiles><smiles>CC(C)(O)c1ccccc1</smiles><smiles>CC1CO1</smiles>

Cumeno Óxido de propileno $(\mathrm{PO})$ 
(b)

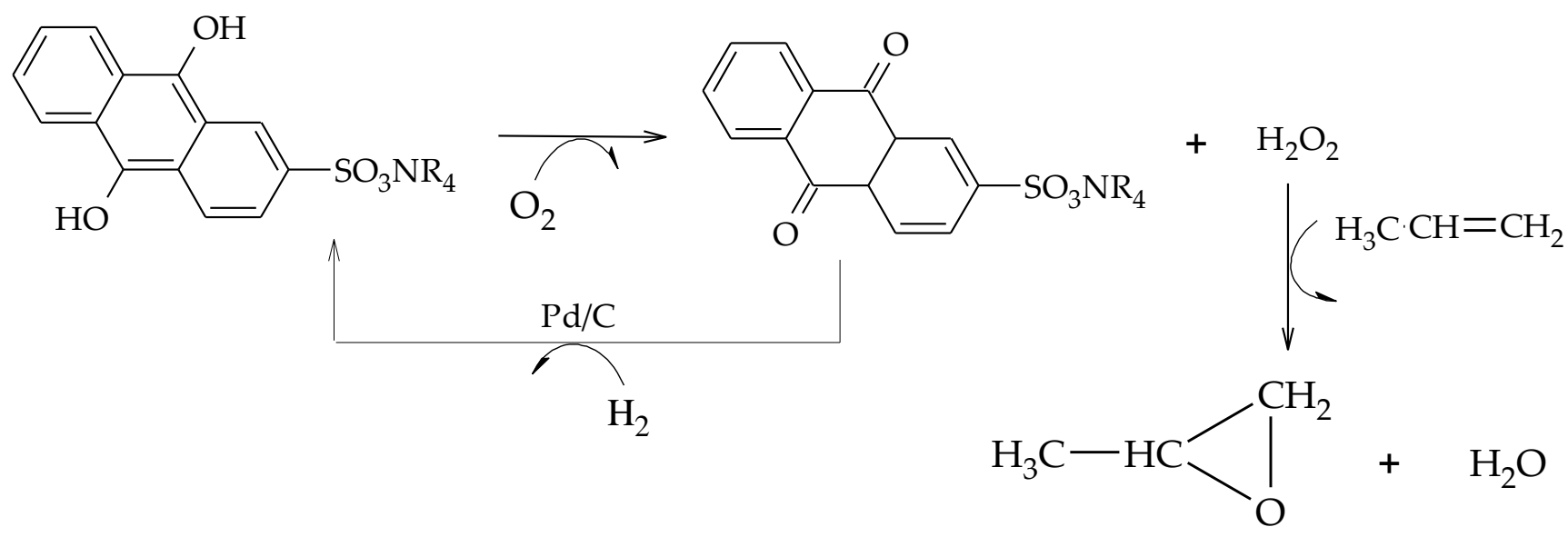

(c)

Óxido de propileno (PO)<smiles>C=CC(C)C(C)C(C)C(C)OO</smiles>

Etilbenceno

Óxido de propileno (PO)

(d)<smiles>C=C(C)C1CC1C(C)(C)OO</smiles>
Isobutano Óxido de propileno (PO)

(e)<smiles>CCC[CH+]Cl</smiles><smiles>CC(C)C1CC1</smiles><smiles>CC1CO1</smiles>
Óxido de propileno (PO)

Esquema 2-2. Tecnologías para la producción de óxido de propileno (PO). 
También se ha estudiado la epoxidación directa de propeno con oxígeno gaseoso en presencia de catalizadores de $\mathrm{Ag}$ y $\mathrm{Au}$, pero esta alternativa aún no es viable porque requiere mejoras en la selectividad y estabilidad de los catalizadores [2].

De los cinco procesos mencionados, los más empleados son el proceso de óxido de propileno/alcohol t-butílico (LyondellBasel y Hunts-man Corporation) y el proceso de clorhidrina (Dow), aunque este último tiene como principal desventaja el uso de gas $\mathrm{Cl}_{2}$, que además de ser tóxico y corrosivo, es caro [1].

\subsection{Bibliografía sobre 1,2-PG a partir del glicerol}

Desde 1988 hasta la actualidad, se han reportado trabajos de investigación que tratan el estudio de la reacción catalítica de hidrogenólisis partiendo de glicerol como materia prima. El número de publicaciones ha crecido exponencialmente desde sus comienzos hasta la actualidad dado el creciente interés por la búsqueda de una alternativa a partir de una fuente renovable (Figura 1-2).

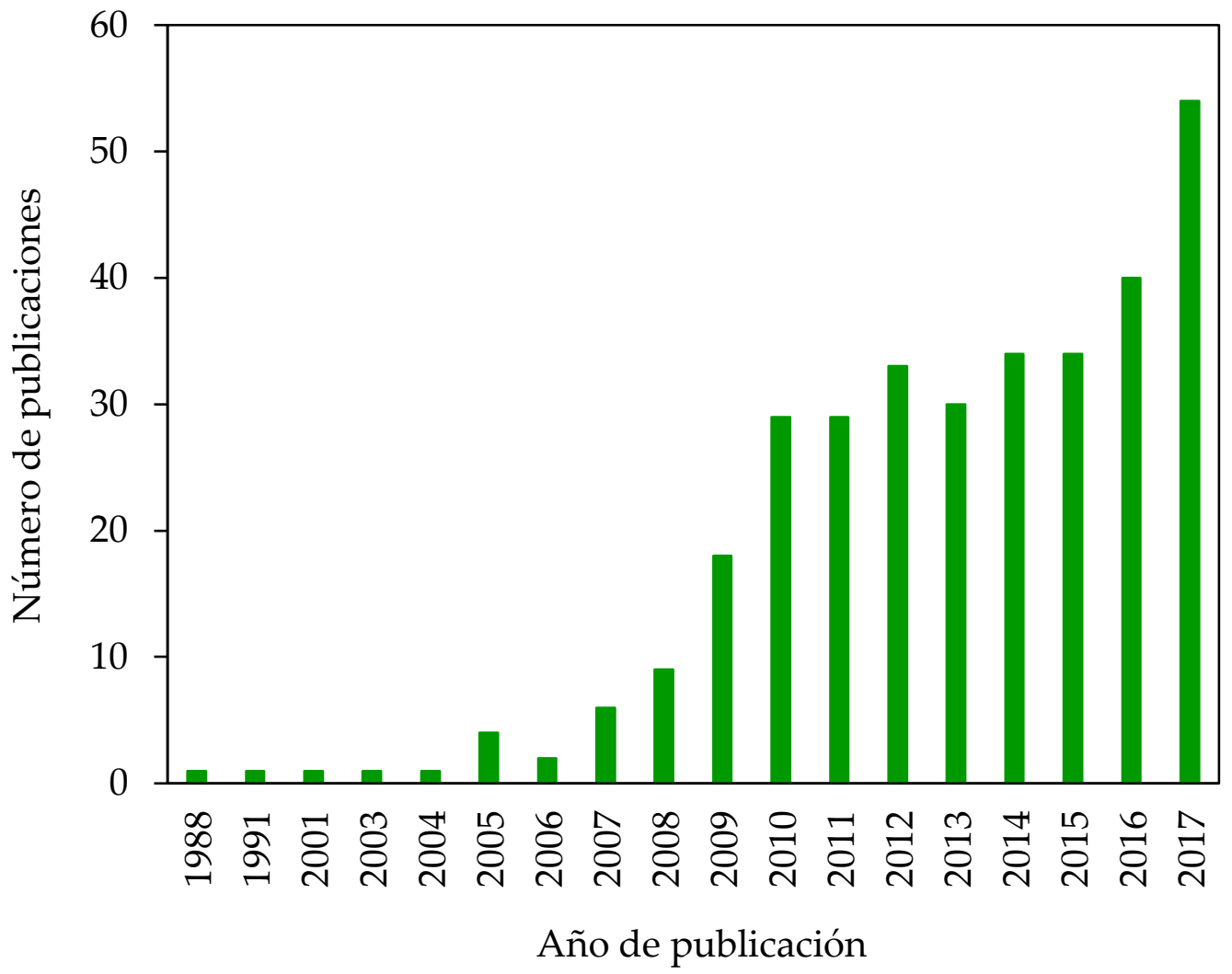

Figura 1-2. Número anual de publicaciones sobre hidrogenólisis de glicerol.

La reacción de hidrogenólisis de glicerol puede llevarse a cabo en fase líquida o vapor. La condición de fase líquida requiere moderadas temperaturas $\left(150-300{ }^{\circ} \mathrm{C}\right)$ y altas presiones (20-100 bar) de $\mathrm{H}_{2}$ o $\mathrm{N}_{2}$ dependiendo del caso. Generalmente se emplea una atmósfera de $\mathrm{H}_{2}$ debido al requerimiento en la etapa de hidrogenación, aunque existen algunos trabajos en donde se utiliza $\mathrm{N}_{2}$ y se incluyen sustancias donadoras de $\mathrm{H}_{2}$ [3-6]. La condición de fase 
líquida supone mayores costos fijos asociados al equipo de reacción debido a las altas presiones utilizadas, pero no requiere vaporizar la mezcla de reacción [7].

Para llevar a cabo la reacción de hidrogenólisis en fase líquida se pueden utilizar reactores batch o discontinuos y reactores de flujo continuos. La mayor parte de la bibliografía reporta el uso de reactores batch para la obtención de datos experimentales, la formulación de modelos cinéticos [8-10], y los estudios de las variables operativas como temperatura, presión, tiempo, concentración de reactivos y catalizador, entre otras. Una de las desventajas de los reactores batch es el aumento de la concentración de productos secundarios a medida que aumenta el tiempo de reacción, lo que afecta el rendimiento a glicoles [11].

Recientemente, Jean et al. recomendaron el uso de reactores de flujo continuo del tipo trickle bed [12]. Este tipo de reactor ofrece varias ventajas, debido principalmente a los bajos tiempos de contacto entre el glicerol y los sitios activos del catalizador [11,13-15], y de este modo los catalizadores muestran mayor estabilidad.

Para llevar a cabo la reacción en la condición de fase vapor, se han empleado reactores de flujo continuo de tipo lecho fijo. Entre las desventajas se puede mencionar la necesidad de vaporizar la solución de glicerol alimentada, lo que requiere altas temperaturas y consumo energético elevado. Debido a que el glicerol crudo se encuentra en una concentración que va del $40-80 \% \mathrm{p} / \mathrm{p}$, las temperaturas requeridas para la vaporización podrían provocar la descomposición del glicerol. Debido a que se emplean menores presiones de $\mathrm{H}_{2}$, se obtienen mayores valores de selectividad a $\mathrm{AcOH}$ [16] y además pueden favorecerse las reacciones de polimerización.

Del total de los trabajos publicados hasta 2018, el 80\% está dirigido a la producción de 1,2-PG a partir de la hidrogenólisis de glicerol, mientras que solo un $16 \%$ investiga la producción de 1,3-PG y el restante 4\% la producción de 1-POH, 2-POH y EG. Además, el 9095\% de las investigaciones se basa en el empleo de reactores batch en fase líquida. Solo entre el 5 y 10\% de las publicaciones estudian la reacción de hidrogenólisis en fase vapor (Figura 22).

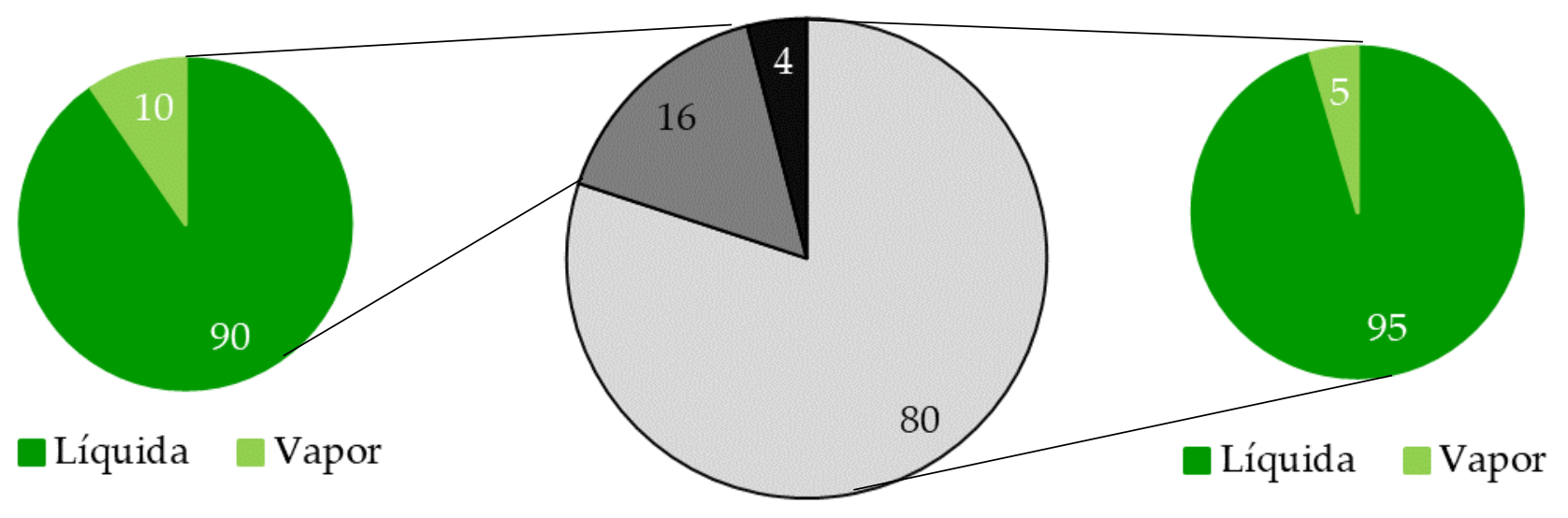

$\square$ 1,2-PG $\square$ 1,3-PG $\quad$ Otros

Figura 2-2. Porcentaje de publicaciones por producto de interés, en fase líquida y vapor. 
También se destacan algunos trabajos de revisión sobre el tema. Nakagawa et al. ha reportado una revisión de trabajos sobre catalizadores heterogéneos (de metales nobles y no nobles) en la reacción de hidrogenólisis en fase líquida y en fase vapor [17]. Feng et al. reportaron una revisión sobre los mecanismos de reacción de hidrogenólisis [18]. Vasiliadou et al. realizaron una revisión sobre mecanismos de reacción, modelos cinéticos y las variables operativas del proceso [19].

\subsection{Mecanismos de reacción de la hidrogenólisis de glicerol}

El término hidrogenólisis describe el proceso mediante el cual, una molécula es fragmentada en moléculas más pequeñas a través de la ruptura de enlaces químicos en su estructura utilizando como agente de ruptura el hidrógeno. En particular, si se toma como molécula de base el glicerol, la ruptura de enlaces químicos $\mathrm{C}-\mathrm{OH}$ da origen a 1,2propilenglicol (1,2-PG) y 1,3-propilenglicol (1,3-PG) (Esquema 3-2) [20].

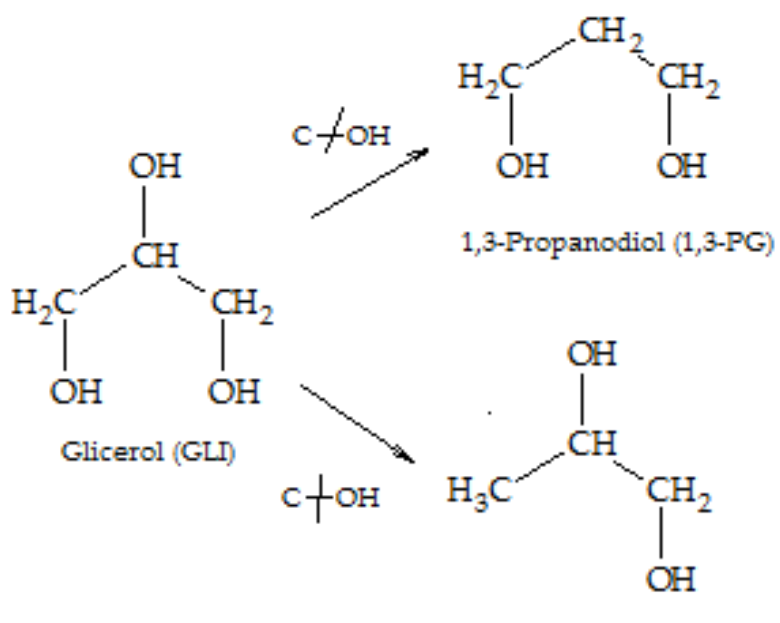

1,2-Propilenglicol (1,2-PG)

Esquema 3-2. Obtención de 1,2-PG y 1,3-PG a partir de la ruptura de enlaces C-OH.

Por otro lado, si la ruptura de enlaces químicos es del tipo C-C se produce etilenglicol (EG) (Esquema 4-2), que posee similares aplicaciones que 1,2-PG, aunque el EG posee un mayor grado de toxicidad para ciertas aplicaciones [20].<smiles>CCC(CC)(CC)OCO</smiles>

Glicerol (GLI)

Esquema 4-2. Esquema de obtención del EG a partir de la ruptura de enlaces C-C. 
Dependiendo del catalizador y el tipo de sitios, así como las condiciones del medio de reacción (temperatura, presión total, presión parcial de hidrógeno, concentración de glicerol, cantidad de catalizador, $\mathrm{pH}$, acidez, etc.), pueden obtenerse otros productos de reacción, tales como metanol $(\mathrm{MeOH})$, etanol $(\mathrm{EtOH})$, 1-propanol (1-POH), 2-propanol (2-POH), acetol $(\mathrm{AcOH})$, acetona $(\mathrm{AcO})$, piruvaldehído $(\mathrm{PAL})$, formaldehído $(\mathrm{FAL})$, ácido láctico $(\mathrm{AL})$, 3hidroxipropionaldehído (3-HPA), gliceraldehído (GLA), glicolaldehído (GAL), 2hidroxiacroleína (2-HA), y gases tales como metano, etano y propano. Estos productos no necesariamente provienen de la molécula de glicerol, sino que pueden generarse como consecuencia de la presencia de productos intermediarios de reacción y posterior modificación de enlaces C-C o C-OH. Si la ruptura de enlaces C-C es excesiva, pueden generarse productos gaseosos, como metano, etano y propano, aun cuando la reacción se lleve a cabo en fase líquida.

Las estructuras de estos compuestos y la nomenclatura utilizada en esta tesis se presentan en la Esquema 5-2.<smiles>CC(=O)COC(=O)CC(C)=O</smiles><smiles>C=O</smiles>

Acetona (AcO)<smiles>CC(=O)CC(=O)O</smiles>

Ácido Láctico (AL)<smiles>O=CCCO</smiles><smiles>O=CC(O)CO</smiles>

Gliceraldehido (GLA)<smiles>O=CCO</smiles>

Glicolaldehido (GAL)<smiles>C=C(O)CC=O</smiles>

2-Hidroxiacroleina (2-HA)<smiles>CCCOC(=O)OCCO</smiles><smiles>CCCOC(=O)OCC</smiles>

Esquema 5-2. Otros productos de la reacción de hidrogenólisis de glicerol. 
Se han reportado cinco mecanismos de reacción, dependiendo de las condiciones del medio en la que se lleva a cabo la hidrogenólisis de glicerol.

\subsubsection{Mecanismo de deshidrogenación-deshidratación-hidrogenación}

Los comienzos del estudio de la reacción de hidrogenólisis surgen a partir de ensayos experimentales destinados a la hidrogenación selectiva de azúcares (glicerol, sorbitol, xilosa) para la producción de monoalcoholes [21-23]. Los primeros ensayos en 1988 corresponden a Montassier et al. sobre la hidrogenación selectiva en fase líquida de soluciones de glicerol en muy bajas concentraciones (1-4 \%p/p), utilizando un catalizador de $\mathrm{Ru} / \mathrm{C}$, temperaturas moderadas (180-260 ${ }^{\circ} \mathrm{C}$ ) y altas presiones (30-40 bar) [21]. Los resultados mostraron la presencia de gliceraldehído (GLA), 2-hidroxiacroleína (2-HA) y 1,2-PG, sugiriendo que la reacción procedía mediante los siguientes pasos:

(1) Deshidrogenación de glicerol para producir GLA en los sitios metálicos del catalizador.

(2) Deshidratación del GLA para producir 2-HA, en presencia de agua o iones $\mathrm{OH}$ adsorbidos sobre el catalizador.

(3) Hidrogenación de 2-HA para producir 1,2-PG en los sitios metálicos del catalizador.

El Esquema 6-2 muestra el mecanismo propuesto por Montassier contemplando estas tres etapas mencionadas.<smiles>CCCCCC(O)CO</smiles>

Glicerol (GLI)<smiles>O=CC(O)CO</smiles>

Gliceraldehído (GLA)

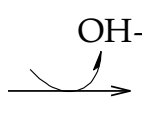<smiles>C=C(O)CC=O</smiles>

2-hidroxiacroleína (2-HA)

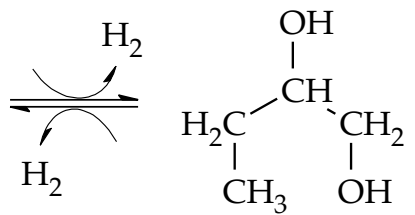

1,2-propilenglicol (1,2-PG)

Esquema 6-2. Esquema de reacción propuesto por Montassier et al. para la formación de 1,2-PG.

La etapa de deshidrogenación de GLI a GLA se encuentra termodinámicamente desfavorecida debido a la presencia de $\mathrm{H}_{2}$, sobre todo cuando la reacción se lleva a cabo a altas presiones de $\mathrm{H}_{2}$. El GLA puede ser hidrogenado rápidamente para volver a formar GLI. Por lo tanto, para favorecer el mecanismo de Montassier, la etapa de deshidratación debe ser muy rápida, y esto puede ocurrir en presencia de bases en el medio de reacción o de catalizadores básicos.

Montassier et al. proponen dos rutas diferentes para la formación de productos secundarios provenientes de reacciones de ruptura de enlaces C-C [22].

Cuando se emplea un catalizador de Ru proponen que la formación de EG y $\mathrm{MeOH}$ provienen de una reacción retro-aldol según lo indicado en el Esquema 7-2 (a). Posteriormente el $\mathrm{MeOH}$ podría seguir hidrogenándose para generar $\mathrm{CH}_{4}$ y $\mathrm{H}_{2} \mathrm{O}$.

Cuando se emplea un catalizador de $\mathrm{Cu}$, los autores proponen que la formación de EG proviene de una reacción retro-Claisen según está indicado en el Esquema 7-2 (b) [22]. 
(a)<smiles>OCC(O)CC1CC1CC1CC1</smiles><smiles>O=CC(O)CO</smiles><smiles>CCCCCCC</smiles><smiles>O=CC=O</smiles>

Glicerol (GLI) Gliceraldehído (GLA)<smiles>CCCCC(C)(C)O</smiles>

Etilenglicol (EG)

(b)<smiles>OCC(O)CC1CC1CC1CC1</smiles><smiles>O=CC(O)CO</smiles><smiles>CCCC</smiles><smiles>O=CC=O</smiles><smiles>O=CO</smiles>

Glicerol (GLI) Gliceraldehído (GLA)

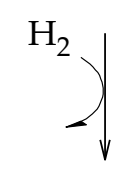<smiles>[O-][O+]([O-])[PH3+]</smiles>

Etilenglicol (EG)

Esquema 7-2. Esquema de reacción propuesto por Montassier et al. para la formación de EG, $\mathrm{MeOH}$, $\mathrm{CO}_{2}$ mediante (a) reacción de retro-aldol (b) reacción de retro-Claisen.

Lahr et al. reportaron el efecto del $\mathrm{pH}$ del medio de reacción sobre la reacción de hidrogenólisis de glicerol con un catalizador de $\mathrm{Ru} / \mathrm{C}$. Demostraron que la adición de bases aumenta la velocidad de reacción para la formación de 1,2-PG y EG en distinta proporción dependiendo del valor del $\mathrm{pH}$ del medio. A niveles de $\mathrm{pH} 8$ se incrementa la producción de EG, mientras que en niveles de $\mathrm{pH}$ 11,7 se desfavorece la formación de EG [24].

Maris et al. [25] estudiaron el efecto del agregado de bases, $\mathrm{NaOH}$ y $\mathrm{CaO}$, empleando soluciones acuosas al $1 \% \mathrm{p} / \mathrm{p}$ de glicerol, a $200{ }^{\circ} \mathrm{C}$ y 40 bar de $\mathrm{H}_{2}$, con catalizadores comerciales de $\mathrm{Ru} / \mathrm{C}$ y Pt/C. A pH neutro, el Ru fue más activo que Pt en la conversión de glicerol a glicoles. Sin embargo, Ru favoreció la producción de EG sobre 1,2-PG y también catalizó la formación de metano. Aunque menos activo, el Pt produce 1,2-PG con alta selectividad. La presencia tanto de $\mathrm{NaOH}$, $8 \mathrm{M}$ como de $\mathrm{CaO}$ mejoró la reactividad de Pt en 
mayor medida que la de $\mathrm{Ru}$, pero la formación de lactato fue significativa a $\mathrm{pH}$ alto en presencia del $\mathrm{Pt}$ o Ru. En base a sus resultados, los autores proponen un esquema de reacciones según se indica en el Esquema 8. En este mecanismo, el primer paso es la deshidrogenación del GLI catalizada por sitios del metal de transición, y puede ser mejorada por la presencia de una base. A partir del GLA se proponen dos rutas distintas para la formación de EG, donde una de ellas procede por la reacción de deshidratación a glicolaldehido (GAL) y la otra por hidrogenación directa y ruptura de enlaces C-C. Observaron la presencia de ácido láctico (AL) a valores de $\mathrm{pH}$ altos. La deshidratación del GLA (gliceraldehído) catalizada por una base conduce al piruvaldehído (PAL), que posteriormente produciría el ácido láctico (AL).

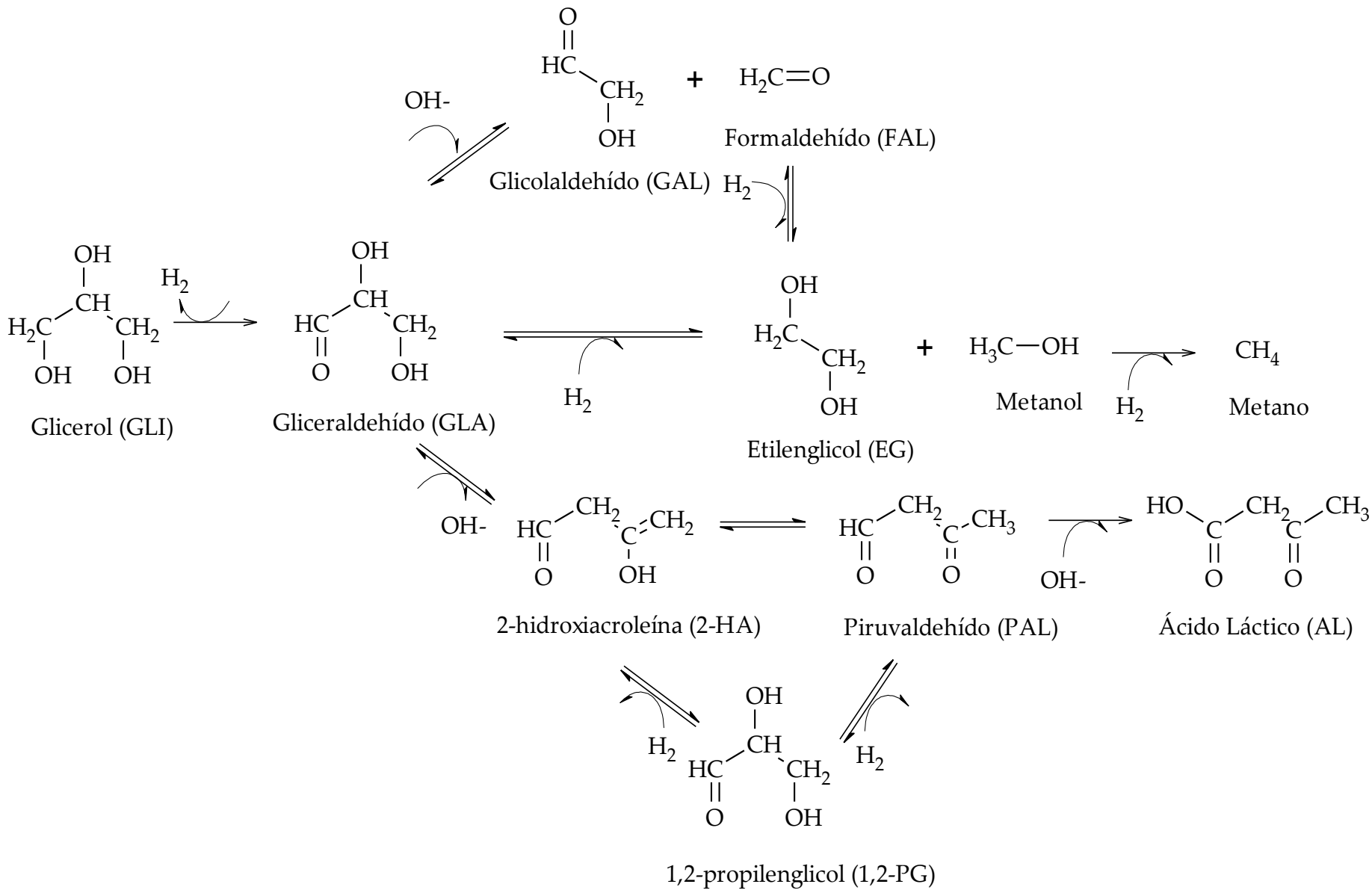

Esquema 8-2. Esquema del mecanismo de reacción propuesto por Maris et al.

Feng et al. estudiaron un catalizador de $\mathrm{Ru} / \mathrm{TiO}_{2}$ y el efecto del agregado de distintas bases inorgánicas como $\mathrm{LiOH}, \mathrm{NaOH}, \mathrm{KOH}, \mathrm{Na}_{2} \mathrm{CO}_{3}, \mathrm{~K}_{2} \mathrm{CO}_{3}, \mathrm{Li}_{2} \mathrm{CO}_{3}$. Determinaron que a 170 ${ }^{\circ} \mathrm{C}$ y 30 bar de $\mathrm{H}_{2}$, con soluciones acuosas de glicerol al $20 \% \mathrm{p} / \mathrm{p}$, el agregado de $\mathrm{LiOH}$ permitió alcanzar los mayores niveles de conversión (90 \%) y selectividad a 1,2-PG de 87 \%. Los autores demostraron que el agregado de bases favorece la deshidrogenación de GLI a GLA y promueve la deshidratación de GLA a 2-hidroxiacroleína (2-HA) [26], lo que se encuentra en concordancia con la propuesta de Maris et al.

Feng et al. también han indicado que se puede formar un producto de oxidación como ácido láctico (AL) aún bajo una atmosfera reductora. Los resultados obtenidos por DFT 
muestran que el AL puede obtenerse fácilmente mediante una reacción de Cannizzaro a partir de piruvaldehído (PAL), donde este último proviene del equilibrio ceto-enólico con la 2-hidroxiacroleína (2-HA) (Esquema 9-2).<smiles>C=CC=CC(O)C=O</smiles><smiles>CC(=O)C=O</smiles>

2-hidroxiacroleína (2-HA) Piruvaldehído (PAL)<smiles>CC(O)C(=O)O</smiles>

Ácido láctico (AL)

Esquema 9-2. Formación del ácido láctico a partir de piruvaldehído.

\subsubsection{Mecanismo de deshidratación-hidrogenación}

Alrededor del 90\% de todos los trabajos publicados en la literatura desde 1988 a 2018, reportan que la ruta de reacción de la hidrogenólisis del glicerol corresponde a este mecanismo. Poco tiempo antes de los trabajos publicados por Montassier et al., los resultados publicados por Cameron et al. en 1986 sobre biocatálisis, demostraron la presencia de acetol $(\mathrm{AcOH})$ entre los productos de reacción de la hidrogenólisis de GLI [27]. Dasari et al. encontraron $\mathrm{AcOH}$ en la reacción en fase líquida a $200{ }^{\circ} \mathrm{C}$ y 14 bar, empleando concentraciones de glicerol del $80 \% \mathrm{p} / \mathrm{p}$ y tiempos de reacción de $24 \mathrm{~h}$ en un reactor discontinuo, con un catalizador de $\mathrm{Cu} / \mathrm{Cr}_{2} \mathrm{O}_{4}$ [7]. Basándose en estos resultados, los autores propusieron un mecanismo que propone dos pasos:

(1) La etapa de deshidratación de GLI a AcOH.

(2) La hidrogenación de AcOH para producir 1,2-PG.

El Esquema 10-2 muestra el mecanismo propuesto por Dasari et al.<smiles>OCC(O)C(O)O</smiles>

Glicerol<smiles>OCCCCCCO</smiles>

Acetol $(\mathrm{AcOH})$<smiles>CCCCCC(C)=O</smiles><smiles>CC(O)CO</smiles>

1,2-propilenglicol (1,2-PG)

Esquema 10-2. Mecanismo de reacción propuesto por Dasari et al. para la formación de 1,2-PG.

Desde el punto de vista termodinámico, se ha reportado que la formación de 1,2-PG a partir de $\mathrm{AcOH}$ es un proceso reversible en el cual la velocidad de reacción directa $(\mathrm{AcOH} \rightarrow$ $1,2-\mathrm{PG})$ resulta mayor que la velocidad de reacción inversa (1,2-PG $\rightarrow \mathrm{AcOH})$, por lo que es 
de esperar que en presencia de $\mathrm{H}_{2}$ la ruta de transformación de $\mathrm{AcOH}$ en 1,2-PG sea la más propicia [28].

Hay que destacar que el mecanismo de reacción propuesto por Dasari et al. no incluye la formación de 1,3-PG ni tampoco de los propanoles, 1-POH y 2-POH [7]. Miyazawa et al. comprobaron que la deshidratación de GLI a AcOH es catalizada mediante el empleo de materiales ácidos $\left(\mathrm{H}_{2} \mathrm{SO}_{4}, \mathrm{HCl}\right.$ y resina Amberlyst), y la hidrogenación posterior del AcOH sobre los sitios metálicos del catalizador $(\mathrm{Ru}, \mathrm{Pt}, \mathrm{Rh}, \mathrm{Pd})$ conduce a la formación de 1,2-PG. Adicionalmente, entre sus resultados se evidencia la presencia de 1,3-PG y se propone una ruta de obtención del mismo a partir de dos etapas por analogía a la formación de 1,2-PG. Según esta ruta el GLI se deshidrata en una primera instancia a 3-hidroxipropionaldehído (3HPA) que luego se hidrogena para generar el 1,3-PG. Desde un punto de vista termodinámico, la formación de 1,2-PG predomina frente a la formación de 1,3-PG [29]. No obstante, la presencia de 3-HPA no ha sido identificada en la mayoría de los trabajos, pero sí la presencia de $\mathrm{AcOH}$, debido a que este último intermediario es más estable que el primero [30].

La hidrogenación puede conducir a productos secundarios tales como 1-POH y 2$\mathrm{POH}$. Los autores también propusieron la formación de EG y $\mathrm{MeOH}$ y la posterior hidrogenación del EG para producir EtOH (Esquema 11-2) [31].

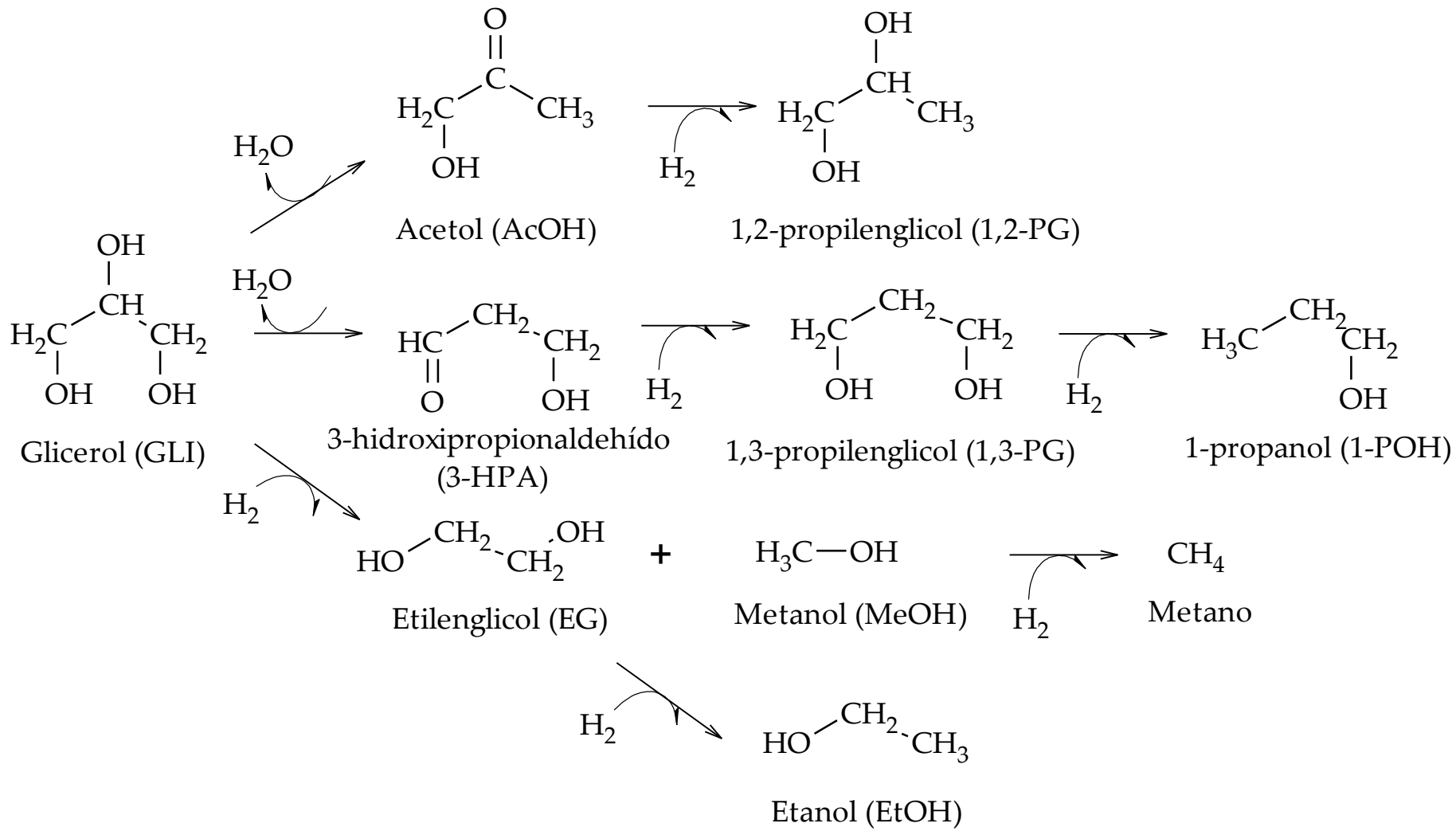

Esquema 11-2. Mecanismo de deshidratación-hidrogenación reportado por Miyazawa et al.

Maglinao et al. calcularon constantes de equilibrio Kp en fase vapor para varias de las reacciones involucradas en este mecanismo de hidrogenólisis. En lo que respecta a la primera etapa de deshidratación, se ha reportado que las reacciones son termodinámicamente 
favorables, tanto la deshidratación de GLI a $\mathrm{AcOH}\left(\mathrm{Kp}\left(190{ }^{\circ} \mathrm{C}\right) \sim 7.3 \times 10^{9}\right)$ como la deshidratación de GLI a 3-hidroxipropionaldehido (3-HPA) (Kp $\left(190{ }^{\circ} \mathrm{C}\right) \sim 8.2$ x 107). Estos valores indican que la formación de $\mathrm{AcOH}$ es más favorable que la formación de 3-HPA.

Con respecto a la segunda etapa, la hidrogenación de los intermediarios formados, se encuentra limitada por el equilibrio termodinámico, tanto la hidrogenación de $\mathrm{AcOH}$ a 1,2PG $\left(\mathrm{Kp}\left(190{ }^{\circ} \mathrm{C}\right) \sim 10^{-1}\right)$ como la hidrogenación de 3-HPA a 1,3-PG $\left(\mathrm{Kp}\left(190{ }^{\circ} \mathrm{C}\right) \sim 2.6 \times 10^{-2}\right)$ [32].

Perosa et al. reportaron la formación de productos secundarios durante el estudio de la hidrogenólisis del glicerol con un catalizador de Ni-Raney. En su esquema de reacción establecen la formación de 1-propanol (1-POH) y 2-propanol (2-POH) a partir del 1,3-PG y del 1,2-PG respectivamente, que a su vez pueden continuar hidrogenándose hasta formar propano (Esquema 12-2) [33].

Furikado et al. comprobaron que la formación de propanoles sigue una ruta de reacción distinta para catalizadores de $\mathrm{Rh} / \mathrm{C}$ con respecto a catalizadores de $\mathrm{Ru} / \mathrm{C}$. En el caso de $\mathrm{Rh} / \mathrm{C}$, el 2-POH se forma a partir de 1,2-PG, mientras que para el $\mathrm{Ru} / \mathrm{C}$ solo existe la presencia de 1-POH que podría provenir del 1,2-PG [34].<smiles>CCCCC(C)O</smiles>

1,2-propilenglicol (1,2-PG) 2-propanol (2-POH)<smiles>CCCCCCCCCCCCCCCCCO</smiles>

1,3-propilenglicol (1,3-PG) 1-propanol (1-POH)

Esquema 12-2. Reacciones de obtención de 1-POH, 2-POH y propano a partir de glicoles.

Kunosoki et al. sugirieron la formación de 1-POH tanto por hidrogenación del 1,2-PG como del 1,3-PG, y adicionalmente propusieron la formación de $\mathrm{MeOH}$ y EtOH a partir de ambos glicoles (Esquema 13-2) [35]. 
<smiles>CC(O)CO</smiles>

1,2-propilenglicol (1,2-PG)<smiles>OCCCO</smiles>

1,3-propilenglicol (1,3-PG)

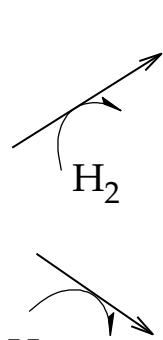

$\mathrm{H}_{2}$<smiles>CCCC</smiles><smiles>CC1CC1</smiles>

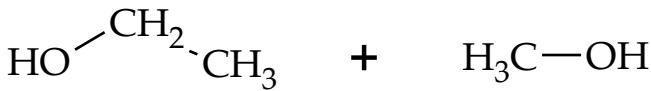

Etanol $(\mathrm{EtOH}) \quad$ Metanol $(\mathrm{MeOH})$<smiles>CCCO</smiles>

1-propanol (1-POH)<smiles>CCO</smiles>

Etanol (EtOH) Metanol (MeOH)<smiles>CCCO</smiles>

1-propanol (1-POH)

Esquema 13-2. Reacciones para la obtención de 1-POH, EtOH y MeOH a partir de glicoles.

Con respecto a la formación de $\mathrm{EtOH}$, Magliano et al. indicaron que si bien puede producirse por hidrogenólisis de 1,2-PG o de $\mathrm{AcOH}$, la primera predomina termodinámicamente sobre la segunda. No obstante, como ambos valores de constante de equilibrio son elevados, el diseño y las propiedades del catalizador determinan cuál de las dos reacciones tiene incidencia en la formación de EtOH [28].

\subsubsection{Mecanismos combinados}

Existen reportes en donde coexiste la presencia de algunos de los mecanismos mencionados. Podrían clasificarse como mecanismos híbridos en donde parte de las reacciones involucradas corresponden a las reacciones del mecanismo de deshidrataciónhidrogenación y parte a reacciones del mecanismo de deshidrogenación-deshidrataciónhidrogenación.

$\mathrm{Wu}$ et al. propusieron dos vías posibles para la formación de acetol $(\mathrm{AcOH})$, la tradicional a partir de la deshidratación de GLI sobre los sitios del soporte y otra a partir de la deshidrogenación de GLI a gliceraldehido (GLA) sobre sitios metálicos, la deshidratación de GLA a piruvaldehido (PAL) y la hidrogenación de PAL para formar AcOH (Esquema 142) [36]. En este estudio trabajaron con catalizadores de $\mathrm{Cu} /$ Bohemita. Los autores proponen además la formación de una especie tipo enol, 2-propen-1,2-diol, previa a la formación de $\mathrm{AcOH}$. Otros trabajos $[29,30,37,38]$ también reportan este tipo de intermediario en la formación de $\mathrm{AcOH}$. 


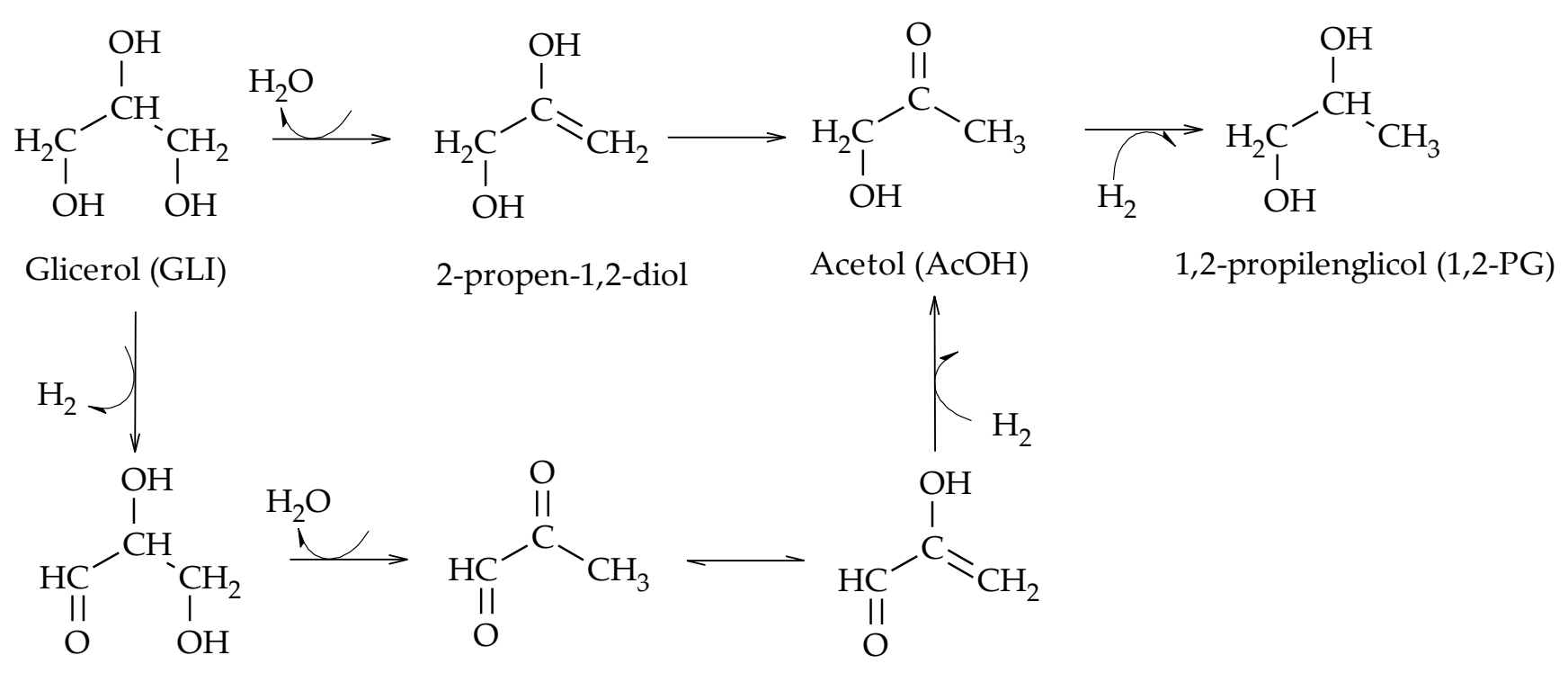

Gliceraldehído (GLA) Piruvaldehído (PAL) 2-hidroxiacetona (2-HA)

Esquema 14-2. Mecanismo de reacción combinado.

Limtrakul et al. realizaron cálculos DFT para una zeolita del tipo H-ZSM-5 y encontraron que la formación de $\mathrm{AcOH}$ procede mediante dos etapas, una primera deshidratación de GLI a 2-propen-1,2-diol y luego una tautomerización de la forma enólica para formar $\mathrm{AcOH}$ [37]. Esta especie fue también identificada por Auneau et al. con un catalizador de $\mathrm{Rh} / \mathrm{C}$ [38]. Guan et al. concluyeron que la formación de $\mathrm{AcOH}$ procede vía 2propen-1,2-diol con catalizadores de $\mathrm{Cu} / \mathrm{MgO}$ y $\mathrm{Cu} / \mathrm{ZrO}_{2}$ [29].

Vila et al. investigaron la hidrogenólisis del glicerol utilizando glicerol deuterado y agua deuterada en presencia de catalizadores de $\mathrm{Cu} / \mathrm{Al}_{2} \mathrm{O}_{3}$. Por DRIFT identificaron la formación de especies isoméricas, 1,2-enediol, 2,3-enediol y 2-hidroxipropanal, que se encuentran en equilibrio tautomérico con $\mathrm{AcOH}$. Las especies identificadas fueron seguidas durante el proceso de reducción empleando la técnica de resonancia magnética nuclear $\left({ }^{1} \mathrm{H}-\right.$ NMR) y los resultados mostraron que la formación de 1,2-PG procede principalmente vía 2,3enediol (50 \%), seguido por 2-hidroxipropanal (40\%) y finalmente por AcOH (10\%) [39].

\subsubsection{Mecanismos directos de hidrogenólisis}

Algunos trabajos han reportado la hidrogenólisis de GLI a través de un mecanismo directo. Tomishige et al. reportaron catalizadores de $\mathrm{Ir}-\mathrm{MO}_{\times} / \mathrm{SiO}_{2}$ y $\mathrm{Rh} /-\mathrm{MO}_{\times} / \mathrm{SiO}_{2}(\mathrm{M}=\mathrm{Re}$, $\mathrm{Mo}, \mathrm{V})$ que fueron estudiados en la reacción en fase líquida, en el rango de $100-180{ }^{\circ} \mathrm{C}$ y presiones entre 20-80 bar de $\mathrm{H}_{2}$, empleando soluciones acuosas de glicerol con concentraciones entre 20-100 \% p/p. Tomando como referencia los catalizadores de Ir$\mathrm{ReO} \times / \mathrm{SiO}_{2}$ y $\mathrm{Rh}-\mathrm{ReO}_{x} / \mathrm{SiO}_{2}$, formularon un mecanismo directo de hidrogenólisis basado en la formación de hidroxipropóxidos sobre la superficie catalítica que conducen a la formación de 1,2-PG o de 1,3-PG dependiendo del intermediario formado. Según este mecanismo, representado en el Esquema 15-2, el glicerol se adsorbe sobre los sitios superficiales de las especies de $\mathrm{ReO}_{x}$ formando el 1,3-dihidroxipropóxido o el 2,3-dihidroxipropóxido ( ${ }^{\circ}$ paso). 
Luego, el $\mathrm{H}_{2}$ adsorbido disociativamente sobre la superficie del metal ( $\mathrm{Ir}$ o $\mathrm{Rh}$ ) ataca el carbono terciario o secundario de las especies intermediarias formando el 1hidroxipropóxido o el 3-hidroxipropóxido respectivamente $\left(2^{\circ}\right.$ paso). Finalmente, estas especies son hidrolizadas para dar lugar a la formación de 1,2-PG o 1,3-PG respectivamente ( $3^{\circ}$ paso) $[40-42]$.

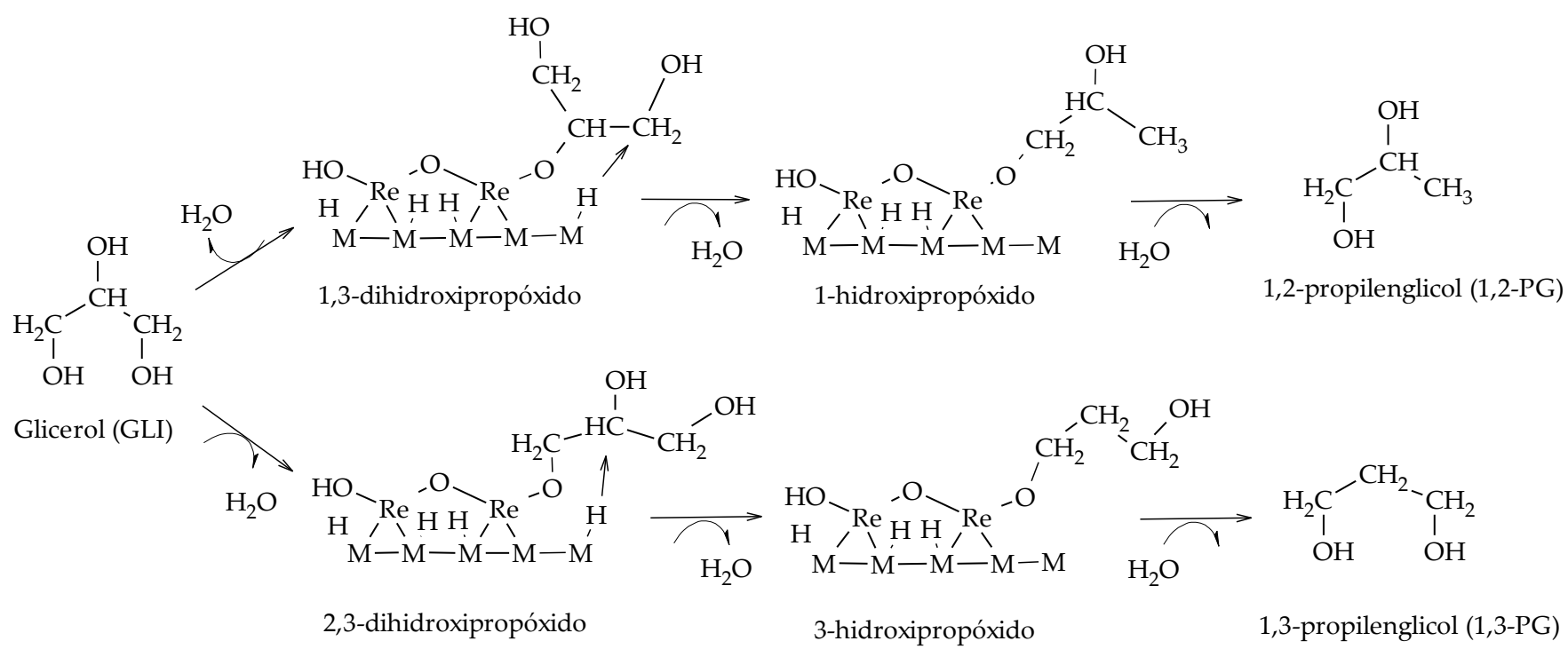

Esquema 15-2. Mecanismo directo de hidrogenólisis sobre catalizadores de $M-\operatorname{ReO} x(M=I r, R h)$.

Guan et al. emplearon catalizadores de $\mathrm{Ir}-\mathrm{ReO} \times / \mathrm{ZrO}_{2}$ y cálculos de DFT que le permitieron concluir que la formación de 1,3-PG procede mediante un mecanismo de reacción directo vía especies alcóxidos que se forman sobre las partículas de $\mathrm{ReO}$. En este sentido, los resultados mostraron que la formación de especies alcóxido terminales (2,3dihidroxipropóxido) prevalece sobre la formación de especies alcóxido secundarias (1,3dihidroxipropóxido), con lo cual la formación de 1,3-PG se ve más favorecida que la formación de 1,2-PG [43]. Estos resultados coinciden con la performance catalítica del Ir$\mathrm{Re} / \mathrm{SiO}_{2}$ reportada por el grupo de Tomishige [40-42].

Otro mecanismo directo de la hidrogenólisis de glicerol fue propuesto para sistemas de $\mathrm{Pt} / \mathrm{WO}_{x}-\mathrm{ZrO}_{2}$ [43bis], $\mathrm{Pt} / \mathrm{WO}_{x}$ [44], $\mathrm{Pt} / \mathrm{WO}_{x}-\mathrm{AlOOH}$ [45-47], $\mathrm{Pt} / \mathrm{WO}_{\mathbf{x}}-\mathrm{Al}_{2} \mathrm{O}_{3}, \mathrm{Pt} / \mathrm{WO}-\mathrm{SBA}-15$ [48]. Sobre estos catalizadores se ha propuesto que la formación de glicoles ocurre mediante un mecanismo iónico, que involucra los pasos de transferencia de protones e hidruros en la superficie catalítica [43bis]. Si bien el mecanismo presenta variaciones según el soporte empleado, la formación de glicoles (1,2-PG o 1,3-PG) comienza con la adsorción del glicerol en el soporte y la adsorción del $\mathrm{H}_{2}$ a través de una ruptura heterolítica en $\mathrm{H}^{+}$y $\mathrm{H}^{-}$sobre los sitios metálicos de la fase activa ( $1^{\circ}$ paso). Seguidamente, se produce una protonación y deshidratación del glicerol adsorbido para formar un intermediario del tipo oxocarbenio primario (I) o segundario (II), dependiendo del ataque de los $\mathrm{H}+$ sobre el grupo $-\mathrm{OH}$ primario o secundario del glicerol adsorbido ( $2^{\circ}$ paso). Finalmente, los iones $\mathrm{H}$ - son transferidos a los iones oxocarbenio (I) o (II) para formar el 1,2-PG o 1,3-PG respectivamente ( $3^{\circ}$ paso) (Esquema 16-2). 
Se ha reportado que la elección del soporte (S) en catalizadores de Pt/WOx-S, juega un rol fundamental en el mecanismo de reacción puesto que dispersa y estabiliza las partículas metálicas de $\mathrm{Pt}$ y las especies de $\mathrm{WO}_{x}$ [44]. La presencia de especies $\mathrm{WO}_{\mathrm{x}}$ es fundamental porque permiten una mejor dispersión del Pt lo que facilita la ruptura heterolítica de las moléculas de $\mathrm{H}_{2}$ en $\mathrm{H}^{+}$y $\mathrm{H}^{-}[44,46]$, y por otro lado proveen sitios para la adsorción del glicerol y estabilización de los carbocationes intermediarios [47]. Según reportes recientes, las especies $\mathrm{WO}_{x}$ tienen carácter de ácidos de Brønsted y favorecen la formación de 1,3-PG [48].

Estudios teóricos basados en cálculos de DFT han demostrado que los intermediarios del tipo oxocarbenio son relativamente estables y que por lo tanto es poco probable la formación de otros intermediarios tipo enoles a partir de oxocarbenios [49].

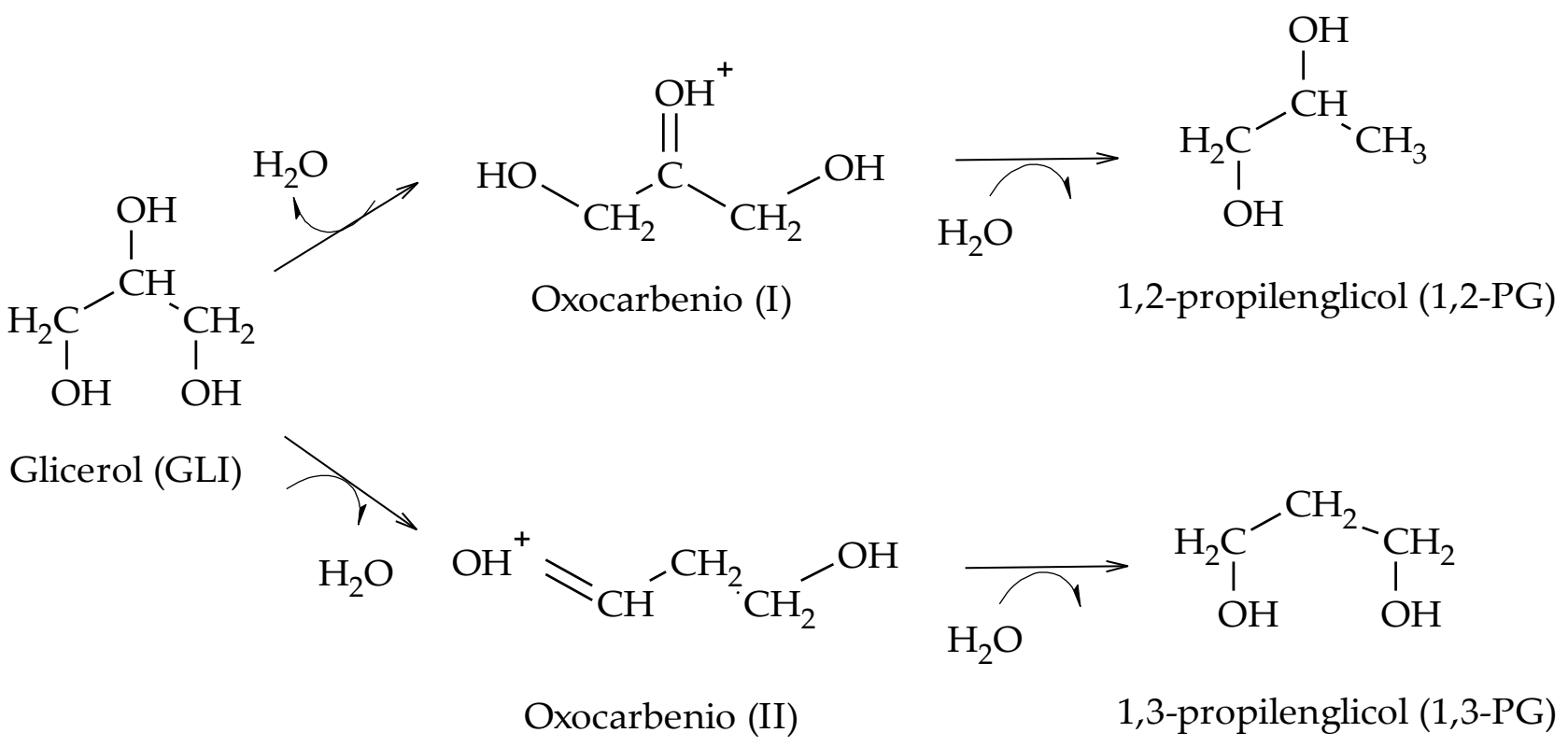

Esquema 16-2. Mecanismo directo de hidrogenólisis sobre catalizadores de Pt-WOx/soporte.

\subsubsection{Mecanismo de eterificación-hidrogenación}

Wang et al. propusieron la formación de glicidol como intermediario de reacción para la formación de 1,2-PG, aunque no hay otros autores que mencionen la presencia de este intermediario. Emplearon catalizadores de $\mathrm{Cu}-\mathrm{ZnO}$, preparados mediante el método de coprecipitación, a $180-240{ }^{\circ} \mathrm{C}$ y 42 bar de $\mathrm{H}_{2}$. Los resultados mostraron que la hidrogenólisis de glicerol ocurre mediante un mecanismo bifuncional que incluye la deshidratación de glicerol a $\mathrm{AcOH}$ y a glicidol sobre la superficie de las partículas de ZnO y la hidrogenación de estos intermediarios sobre las partículas de $\mathrm{Cu}$. Tanto la conversión de glicerol como la selectividad a 1,2-PG dependen de los tamaños de las partículas de $\mathrm{ZnO}$ y $\mathrm{Cu}$.

Los autores proponen una nueva vía para la formación de 1,2-PG que se presenta en el Esquema 17-2 [50]. 
<smiles>OCC(O)CO</smiles>

Glicerol (GLI)<smiles>OCC1CC1</smiles><smiles>CCCC(C)O</smiles>

1,2-propilenglicol (1,2-PG)

Esquema 17-2. Mecanismo de reacción de obtención de 1,2-PG vía glicidol.

Recientemente, Gebretsadik et al. reportaron la hidrogenólisis de glicidol que permiten completar el mecanismo de reacción de eterificación-hidrogenación. Emplearon catalizadores soportados en una saponita y como fase activa $\mathrm{Ni}$, $\mathrm{Cu}$ y $\mathrm{Ni}-\mathrm{Cu}$ modificados con óxidos de metales de transición $(\mathrm{V}, \mathrm{Mo}, \mathrm{W}, \mathrm{Re})$. El $\mathrm{ReO}_{x}$ resultó el mejor promotor. $\mathrm{Cu}-\mathrm{ReO} \times$ permitió la obtención de 1-POH vía reacciones de deoxigenación-hidrogenación, mientras que $\mathrm{Ni}-\mathrm{ReO}_{x}$ favoreció principalmente la formación de 1,3-PG. El soporte de saponita modificada con $\mathrm{ReO}_{x}$ favoreció la formación de productos de condensación (Esquema 18-2) [51].

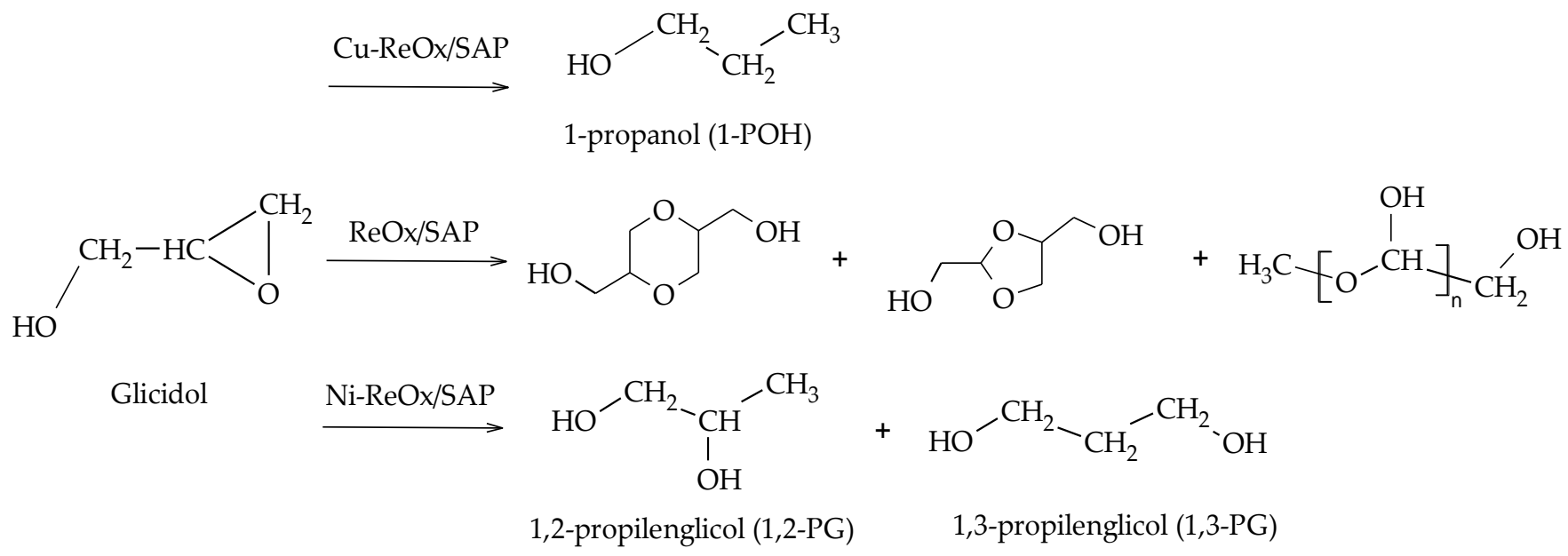

Esquema 18-2. Reacciones de transformación del glicidol.

\subsubsection{Mecanismo de quelación-hidrogenación}

Este mecanismo de reacción solo ha sido reportado por Chaminand et al., quienes emplearon catalizadores de $\mathrm{Cu}, \mathrm{Pd}$ y $\mathrm{Rh}$ soportados en $\mathrm{C}, \mathrm{ZnO}$ y $\mathrm{Al}_{2} \mathrm{O}_{3}$ para llevar a cabo la reacción de hidrogenólisis a $180{ }^{\circ} \mathrm{C}$ y 80 bar de $\mathrm{H}_{2}$. De los catalizadores estudiados, $\mathrm{Rh} / \mathrm{C}$ promovido por $\mathrm{H}_{2} \mathrm{WO}_{4}$ permitió la obtención de 1,2-PG y 1,3-PG. Mediante el reemplazo de agua por distintos solventes (sulfolane y dioxano) lograron aumentar la conversión de glicerol y hacer la reacción más selectiva a cada uno de estos glicoles. En base a sus resultados, los autores propusieron un mecanismo con tres probables rutas para la formación de glicoles. Dos de ellas, son las ya expuestas en los mecanismos mencionados en 2.4.1 y 2.4.2. La tercera ruta propuesta consiste en una etapa de quelación sobre los sitios metálicos y posterior hidrogenación en presencia de $\mathrm{H}_{2}$ (Esquema 19-2) [52]. 
<smiles>OCC(O)CO</smiles>

Glicerol (GLI)

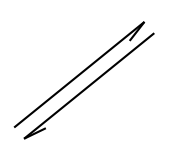<smiles>[M]OC(CO)CO</smiles>

$\mathrm{H}_{2}$<smiles>CCCCCCO</smiles>

1,3-propilenglicol (1,3-PG)<smiles>[M]OCC(O)CO[M]</smiles><smiles>CCCC(C)O</smiles>

1,2-propilenglicol (1,2-PG)

Esquema 19-2. Mecanismo de quelación-hidrogenación reportado por Chaminand et al.

La quelación del glicerol sobre los sitios metálicos del catalizador $(\mathrm{M})$ y su posterior hidrogenación hacen suponer que la formación del 1,3-PG está favorecida por sobre la formación del 1,2-PG debido a la estabilidad del intermediario formado.

\subsection{Catalizadores}

Los catalizadores que se han reportado en la bibliografía se presentan separadamente según la reacción es conducida en fase líquida o en fase vapor.

\subsubsection{Catalizadores másicos para la producción de 1,2-PG en fase líquida}

Dentro de los catalizadores másicos han sido estudiados metales como $\mathrm{Cu}, \mathrm{Ni}$, y Co.

A continuación, se presenta en primer lugar la revisión de los trabajos que estudian los catalizadores másicos de $\mathrm{Cu}$ debido a que representan la gran mayoría de las contribuciones científicas del tema.

\subsubsection{Cobre}

Las Tablas 1-2 y 1-3 resumen las condiciones operativas y los resultados de actividad de los catalizadores másicos de $\mathrm{Cu}$ para reactores batch y de flujo continuo respectivamente. Como puede observarse en la mayoría de los trabajos de investigación, los ensayos de evaluación catalítica son realizados en reactores batch a temperaturas en el rango de $180{ }^{\circ} \mathrm{C}$ a $230{ }^{\circ} \mathrm{C}$ y presiones entre 14 bar y 40 bar de $\mathrm{H}_{2}$. Excepcionalmente se pueden encontrar algunas publicaciones en las que trabajan con presiones superiores a los 50 bar de $\mathrm{H}_{2}$. También se puede observar que son muy variados la masa de catalizador y los tiempos de reacción empleados, ya que se reportan tiempos de reacción entre 3 h y 24 h y una relación masa de glicerol a masa de catalizador $\left(\mathrm{m}_{\mathrm{gli}} / \mathrm{m}_{\mathrm{c}}\right)$ entre 1 y 59 . 
Tabla 1-2. Hidrogenólisis 1,2-PG en reactores batch empleando catalizadores másicos de Cu.

\begin{tabular}{|c|c|c|c|c|c|c|c|c|}
\hline Catalizador & $\mathrm{T}\left({ }^{\circ} \mathrm{C}\right)$ & $\mathrm{P}$ (bar) & $\mathrm{m}_{\mathrm{gli}} / \mathrm{mc}_{\mathrm{c}}(\mathrm{g} / \mathrm{g})$ & $\mathrm{t}(\mathrm{h})$ & $\mathrm{X}_{\mathrm{GLI}}(\%)$ & $\mathrm{S}_{1,2-\mathrm{PG}}(\%)$ & $\mathrm{R}_{1,2-\mathrm{PG}}(\%)$ & Ref. \\
\hline \multirow{2}{*}{ Cu-Raney } & 240 & $30\left(\mathrm{H}_{2}\right)$ & 3.0 & 7 & 93 & 86 & 79 & [21] \\
\hline & 200 & $14\left(\mathrm{H}_{2}\right)$ & 20.0 & 24 & 48.9 & 69.1 & 33.7 & [80] \\
\hline Cu-Raney-MgO & 180 & $10\left(\mathrm{H}_{2}\right)$ & 47.0 & 24 & 75.0 & 85.0 & 63.7 & {$[53,54]$} \\
\hline \multirow{4}{*}{$\mathrm{Cu}-\mathrm{Cr}_{2} \mathrm{O}_{4}$} & 200 & $14\left(\mathrm{H}_{2}\right)$ & 20.0 & 24 & 54.8 & 85.0 & 46.5 & [7] \\
\hline & 220 & $80\left(\mathrm{H}_{2}\right)$ & 45.0 & 12 & 80.3 & 83.9 & 67.4 & [56] \\
\hline & 200 & $30\left(\mathrm{H}_{2}\right)$ & 16.7 & 24 & 30.3 & 67.3 & 20.3 & [55] \\
\hline & 130 & $20\left(\mathrm{H}_{2}\right)$ & 20.0 & 4 & 52.4 & 99.6 & 52.2 & [60] \\
\hline $\mathrm{Cu}-\mathrm{Ba}-\mathrm{Cr}_{2} \mathrm{O}_{4}$ & 220 & $52\left(\mathrm{H}_{2}\right)$ & 20.0 & 5 & 34.0 & 85.0 & 28.9 & {$[58]$} \\
\hline \multirow{3}{*}{$\mathrm{Cu}-\mathrm{Al}_{2} \mathrm{O}_{3}$} & 200 & $30\left(\mathrm{H}_{2}\right)$ & 16.7 & 24 & 59.0 & 79.4 & 46.8 & [55] \\
\hline & 200 & $40\left(\mathrm{H}_{2}\right)$ & 20.0 & 24 & 75.7 & 95.8 & 72.5 & [73] \\
\hline & 200 & $20\left(\mathrm{H}_{2}\right)$ & 16.0 & 18 & 39.2 & 97.6 & 38.2 & [79] \\
\hline $\mathrm{Cu}-\mathrm{Cr}$ & 200 & $41\left(\mathrm{H}_{2}\right)$ & 20.0 & 5 & 32.0 & 93.0 & 29.7 & [59] \\
\hline \multirow{3}{*}{$\mathrm{Cu}-\mathrm{ZnO}$} & 200 & $42\left(\mathrm{H}_{2}\right)$ & 14.0 & 12 & 22.5 & 83.6 & 18.8 & [50] \\
\hline & 200 & $20\left(\mathrm{H}_{2}\right)$ & 16.7 & 16 & 37.0 & 92.0 & 34.0 & [61] \\
\hline & 200 & $60\left(\mathrm{H}_{2}\right)$ & 4.5 & 6 & 75.0 & 93.0 & 69.8 & [62] \\
\hline $\mathrm{CuO}-\mathrm{ZnO}$ & 200 & $50\left(\mathrm{H}_{2}\right)$ & 58.8 & 7 & 46.0 & 90.0 & 41.4 & [63] \\
\hline $\mathrm{Cu}-\mathrm{ZnO}-\mathrm{Ga}_{2} \mathrm{O}_{3}$ & 220 & $50\left(\mathrm{H}_{2}\right)$ & 25.3 & 5.5 & 99.0 & 80.0 & 79.2 & [64] \\
\hline \multirow{4}{*}{$\mathrm{Cu}-\mathrm{MgO}$} & 200 & $35\left(\mathrm{H}_{2}\right)$ & 16.7 & 10 & 57.0 & 29.1 & 16.5 & [68] \\
\hline & 180 & $30\left(\mathrm{H}_{2}\right)$ & 7.1 & 20 & 72.0 & 97.6 & 70.2 & [69] \\
\hline & 200 & $40\left(\mathrm{H}_{2}\right)$ & 17.5 & 8 & 49.3 & 92.3 & 45.5 & [70] \\
\hline & 200 & $0\left(\mathrm{H}_{2}\right)$ & 25.0 & 6 & 55.0 & 68.0 & 37.4 & [6] \\
\hline \multirow{4}{*}{$\mathrm{Cu}-\mathrm{ZnO}-\mathrm{Al}_{2} \mathrm{O}_{3}$} & 200 & $50\left(\mathrm{H}_{2}\right)$ & 20.0 & 10 & 20.4 & 80.1 & 16.3 & [80] \\
\hline & 200 & $27\left(\mathrm{H}_{2}\right)$ & 20.0 & 24 & 92.3 & 94.5 & 87.2 & [81] \\
\hline & 200 & $27\left(\mathrm{H}_{2}\right)$ & 20.0 & 20 & 72.6 & 76.4 & 55.4 & [82] \\
\hline & 230 & $70\left(\mathrm{H}_{2}\right)$ & 20.0 & 4 & 96.1 & 81.4 & 78.2 & [83] \\
\hline $\mathrm{CuAl}_{2} \mathrm{O}_{4}$ & 220 & $50\left(\mathrm{H}_{2}\right)$ & 50.0 & 12 & 91.0 & 91.0 & 82.9 & [71] \\
\hline \multirow{2}{*}{$\mathrm{Cu}-\mathrm{Al}$} & 220 & $20\left(\mathrm{~N}_{2}\right)$ & 20.0 & 3 & 51.0 & 24.0 & 12.2 & [72] \\
\hline & 220 & $70\left(\mathrm{H}_{2}\right)$ & 19.3 & 24 & 74.2 & 78.8 & 58.4 & [77] \\
\hline $\mathrm{Cu}-\mathrm{Al}_{2} \mathrm{O}_{\mathrm{x}}$ & 180 & $10\left(\mathrm{H}_{2}\right)$ & 1.3 & 6 & 100.0 & 99.0 & 99.0 & [74] \\
\hline $\mathrm{Cu}-\mathrm{Fe}$ & 190 & $41\left(\mathrm{H}_{2}\right)$ & 20.0 & 10 & 47.0 & 92.0 & 43.2 & [78] \\
\hline \multirow{3}{*}{$\mathrm{Cu}-\mathrm{ZnO}-\mathrm{MgO}-\mathrm{Al}_{2} \mathrm{O}_{3}$} & 200 & $20\left(\mathrm{H}_{2}\right)$ & 15.0 & 10 & 85.5 & 98.6 & 84.3 & [84] \\
\hline & 200 & $14\left(\mathrm{H}_{2}\right)$ & 20.0 & 24 & 47.9 & 93.8 & 44.9 & [85] \\
\hline & 210 & $45\left(\mathrm{H}_{2}\right)$ & 13.3 & 12 & 98.3 & 91.5 & 89.9 & [86] \\
\hline $\mathrm{Cu}-\mathrm{ZnO}-\mathrm{Cr}_{2} \mathrm{O}_{3}-\mathrm{ZrO}_{2}$ & 240 & $40\left(\mathrm{H}_{2}\right)$ & 26.7 & 10 & 100.0 & 97.0 & 97.0 & [8] \\
\hline $\mathrm{Cu}-\mathrm{SiO}_{2}$ & 200 & $90\left(\mathrm{H}_{2}\right)$ & 16.0 & 12 & 73.4 & 94.0 & 69.0 & {$[66,67]$} \\
\hline $\mathrm{Cu}-\mathrm{ZrO}_{2}$ & 200 & $40\left(\mathrm{H}_{2}\right)$ & 16.7 & 8 & 10.0 & 90.0 & 9.0 & [88] \\
\hline $\mathrm{Cu}-\mathrm{ZrO}_{2}-\mathrm{MgO}$ & 180 & $40\left(\mathrm{H}_{2}\right)$ & 16.7 & 8 & 61.7 & 96.5 & 59.5 & [89] \\
\hline $\mathrm{Cu}-\mathrm{Ca}-\mathrm{Al}$ & 200 & $35\left(\mathrm{H}_{2}\right)$ & 16.7 & 8 & 73.2 & 42.6 & 31.1 & [75] \\
\hline $\mathrm{Cu}_{1.5-} \mathrm{Ca}_{2} \mathrm{AlO}_{3.5}$ & 180 & $20\left(\mathrm{H}_{2}\right)$ & 8.0 & 21 & 75.3 & 98.1 & 73.8 & [76] \\
\hline
\end{tabular}

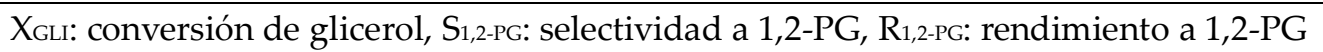


Tabla 2-2. Hidrogenólisis 1,2-PG en reactores de flujo continuo en fase líquida empleando catalizadores másicos de Cu.

\begin{tabular}{lccccccc}
\hline Catalizador & $\mathrm{T}\left({ }^{\circ} \mathrm{C}\right)$ & $\mathrm{P}($ bar $)$ & LHSV/WHSV $\left(\mathrm{h}^{-1}\right)$ & $\mathrm{X}_{\mathrm{GLI}}(\%)$ & $\mathrm{S}_{1,2-\mathrm{PG}}(\%)$ & $\mathrm{R}_{1,2-\mathrm{PG}}(\%)$ & Ref. \\
\hline $\mathrm{Cu}-\mathrm{ZnO}-\mathrm{Al}_{2} \mathrm{O}_{3}$ & 220 & $40\left(\mathrm{H}_{2}\right)$ & $4.6(\mathrm{LHSV})$ & 81.5 & 93.4 & 76.1 & {$[87]$} \\
\hline $\mathrm{Cu}-\mathrm{ZnO}$ & 250 & $20\left(\mathrm{H}_{2}\right)$ & $7.6(\mathrm{WHSV})$ & 96.0 & 83.0 & 79.7 & {$[65]$} \\
\hline
\end{tabular}

XGLI: conversión de glicerol, $\mathrm{S}_{1,2-\mathrm{PG}}$ selectividad a 1,2-PG, $\mathrm{R}_{1,2-\mathrm{PG}}$ rendimiento a 1,2-PG

Montassier et al. estudiaron la reacción de hidrogenólisis, en presencia de Cu-Raney obtenido por leaching de una aleación cobre-aluminio tratada con hidróxido de sodio. Los resultados obtenidos a 30 bar de $\mathrm{H}_{2}$ y $240{ }^{\circ} \mathrm{C}$, mostraron que el $\mathrm{Cu}$ tiene buena capacidad para la ruptura de enlaces C-O y baja capacidad de ruptura C-C, lo que conduce a una alta selectividad a 1,2-PG (86 \%) y baja selectividad a productos secundarios como EG y CO2 (14 \%) [21].

Yue et al. modificaron el catalizador de Cu-Raney con distintos óxidos mediante la mezcla húmeda de óxidos y posterior calcinación. El MgO resultó ser el mejor porque se pudo alcanzar, luego de $24 \mathrm{~h}$ de reacción, una conversión de glicerol del $75 \%$ con una selectividad a 1,2-PG del $85 \%$. Los resultados de caracterización del catalizador mostraron que la dispersión del $\mathrm{MgO}$ en los poros del Cu-Raney conjuntamente con la formación de una fase de Cu-MgO podrían explicar el alto rendimiento a 1,2-PG [53,54].

Dasari et al. también estudiaron $\mathrm{Cu}$-Raney, pero seleccionaron $\mathrm{Cu}-\mathrm{Cr}_{2} \mathrm{O}_{4}$ como uno de los catalizadores más prometedores para esta reacción. Estudiaron la reducción de $\mathrm{Cu}-\mathrm{Cr}_{2} \mathrm{O}_{4}$ en presencia de flujo de hidrógeno en el rango $150-400{ }^{\circ} \mathrm{C}$ y encontraron que cuando la reducción se realiza a $300{ }^{\circ} \mathrm{C}$ durante $4 \mathrm{~h}$ se alcanza el mayor rendimiento a 1,2-PG. Estos autores obtuvieron luego de $24 \mathrm{~h}$ de reacción, una conversión de glicerol del 55\% y una selectividad del 85\% a 1,2-PG [7]. Wolosiak-Hnat et al., reportaron años más tarde que el tiempo de reducción es fundamental para lograr la formación de especies $\mathrm{Cu}^{0} \mathrm{y} \mathrm{C \textrm {Cu } ^ { + }}$ en la matriz de $\mathrm{Cr}_{2} \mathrm{O}_{4}$. Reduciendo el catalizador de $\mathrm{Cu}-\mathrm{Cr}_{2} \mathrm{O}_{4}$ a $300{ }^{\circ} \mathrm{C}$ durante $8 \mathrm{~h}$ encontraron la máxima selectividad a 1,2-PG. Los valores de selectividad no son comparables con los de Dasari et al. ya que las condiciones de reacción son muy distintas. Un posterior aumento del tiempo de reducción genera el sinterizado de las partículas de $\mathrm{Cu}$ y produce una disminución en la actividad. El catalizador de $\mathrm{Cu}-\mathrm{Cr}_{2} \mathrm{O}_{4}$ preparado por el método de coprecipitación tiene mejor performance que un catalizador comercial [55].

Kim et al. estudiaron la síntesis de $\mathrm{Cu}-\mathrm{Cr}_{2} \mathrm{O}_{4}$ por coprecipitación. Para una relación molar $\mathrm{Cu}: \mathrm{Cr}=1: 2$ obtuvieron una conversión de glicerol del $80 \%$ con una selectividad del $84 \%$ a 1,2-PG. Los resultados fueron atribuidos a la formación de la especie espinela de $\mathrm{CuCr}_{2} \mathrm{O}_{4}$ que favorece el paso de hidrogenación debido a la capacidad para acumular tanto $\mathrm{H}_{2}$ como $\mathrm{H}$ bulk [56].

Recientemente, Yun et al. reportaron un estudio teórico con cálculos de DFT. Revelaron que la formación de $\mathrm{AcOH}$ está favorecida tanto termodinámicamente como cinéticamente en la superficie del $\mathrm{Cu}$ y de la espinela de $\mathrm{CuCr}_{2} \mathrm{O}_{4}$. La baja energía de activación encontrada para la formación de 1,2-PG sobre la superficie de la espinela $\mathrm{CuCr}_{2} \mathrm{O}_{4}$ 
se debe exclusivamente a su estructura, otorgando los sitios adecuados para la adsorción del glicerol, su deshidratación y la posterior hidrogenación del $\mathrm{AcOH}$ [57].

Para mejorar los niveles de actividad de $\mathrm{Cu}-\mathrm{Cr}_{2} \mathrm{O}_{4}$, Rode et al. estudiaron la adición de $\mathrm{Ba}, \mathrm{Al}$ y $\mathrm{Zn}$ mediante el método de coprecipitación conjunta con $\mathrm{Cu}$ y $\mathrm{Cr}$. La incorporación de Ba resultó la mejor alternativa, porque incrementa la conversión de glicerol de $16 \%$ a $24 \%$ manteniendo una selectividad del $85 \%$ a 1,2-PG. Los resultados fueron atribuidos a la estabilización de las partículas de $\mathrm{Cu}^{0}$ por parte del Ba bajo la forma de la fase $\mathrm{BaCrO}_{4}$. Esta fase evitó además el sinterizado de las partículas metálicas de Cu [58].

Una variante del catalizador de $\mathrm{Cu}-\mathrm{Cr}_{2} \mathrm{O}_{4}$ lo constituye el catalizador sintetizado por Xiao et al., que fue denominado $\mathrm{Cu}-\mathrm{Cr}$, y sintetizado a partir de la técnica sol-gel empleando soluciones de $\mathrm{Cu}\left(\mathrm{NO}_{3}\right)_{2} .3 \mathrm{H}_{2} \mathrm{O}$ y $\mathrm{Cr}\left(\mathrm{NO}_{3}\right)_{3} .9 \mathrm{H}_{2} \mathrm{O}$ en etanol y gelificando en presencia de óxido de propileno. Las etapas de calcinación y reducción fueron optimizadas para lograr el mayor rendimiento a 1,2-PG. Los resultados de la reacción mostraron una conversión de glicerol del $32 \%$ con una selectividad del $90 \%$ a 1,2-PG, luego de 5 h de reacción. [59]. En otro de sus trabajos, los autores probaron distintas relaciones molares $\mathrm{Cu}: \mathrm{Cr}$ en el rango 0.25-4 y concluyeron que para una relación $\mathrm{Cu}: \mathrm{Cr}=4$, fue detectada la presencia de las fases $\mathrm{CuCr}_{2} \mathrm{O}_{4}$, $\mathrm{CuO}_{\text {y }} \mathrm{Cr}_{2} \mathrm{O}_{3}$, y los resultados fueron muy buenos, con un $100 \%$ de selectividad a 1,2-PG [60].

Otro de los catalizadores másicos de $\mathrm{Cu}$ es $\mathrm{Cu}-\mathrm{ZnO}$. Wang et al. prepararon este catalizador por el método de coprecipitación empleando soluciones acuosas de $\mathrm{Cu}\left(\mathrm{NO}_{3}\right)_{2} .3 \mathrm{H}_{2} \mathrm{O}$ y $\mathrm{Zn}\left(\mathrm{NO}_{3}\right)_{2} .6 \mathrm{H}_{2} \mathrm{O}$ y precipitando los óxidos en presencia de urea a $90{ }^{\circ} \mathrm{C}$ durante $2 \mathrm{~h}$. Los autores probaron este catalizador reducido en la reacción de hidrogenólisis y luego de $12 \mathrm{~h}$ de reacción obtuvieron una conversión de glicerol del $22 \%$ con una selectividad del 84\% a 1,2-PG. Con estos resultados demostraron la capacidad del ZnO para deshidratar combinada con la capacidad del $\mathrm{Cu}$ para hidrogenar. Pequeños tamaños de partícula de $\mathrm{Cu}$ mejoran la actividad y selectividad a 1,2-PG y esto puede lograrse mediante el proceso de reducción del catalizador $\mathrm{Cu}-\mathrm{ZnO}$ [50]. En otros de sus trabajos, los autores estudiaron distintas relaciones atómicas $\mathrm{Cu} / \mathrm{Zn}$ y encontraron que, si bien en todas las relaciones se mantiene una alta selectividad a 1,2-PG (93\%), la conversión es función exclusiva de la relación $\mathrm{Cu} / \mathrm{Zn}$. Para una relación atómica $\mathrm{Cu}: \mathrm{Zn}=1: 1$ se obtiene la máxima velocidad de reacción del glicerol. Esta diferencia en actividad es atribuida a la formación de precursores del tipo hidroxicarbonatos de $\mathrm{Cu}$ y $\mathrm{Zn}$ con distintas fases cristalinas, en particular la aurichalsita monofásica que favorece la formación de partículas de $\mathrm{Cu}$ de alta interacción con el $\mathrm{ZnO}$. Estas partículas promueven la deshidrogenación de glicerol a gliceraldehído que a su vez se deshidrata a piruvaldehído. El piruvaldehído finalmente es hidrogenado para formar 1,2-PG [61].

Siguiendo el mismo método, Balaraju et al. prepararon un catalizador de $\mathrm{Cu}-\mathrm{ZnO}$ que alcanza una conversión del 37\% con selectividad del 92\% a 1,2-PG luego de 16 h de reacción [62].

Para evitar el proceso de reducción, Bienholz et al. prepararon un catalizador de CuO$\mathrm{ZnO}$ empleando una solución en etanol de ácido oxálico como agente de precipitación en lugar de urea. Los resultados mostraron que este catalizador fue más activo que el preparado por el método de coprecipitación estándar debido fundamentalmente a la mayor área superficial del CuO. La selectividad obtenida fue del $90 \%$ a 1,2-PG con un $46 \%$ de conversión luego de $7 \mathrm{~h}$ de reacción empleando glicerol puro [63]. En otro trabajo, estos 
autores mostraron que la reducción previa del catalizador de $\mathrm{CuO}-\mathrm{ZnO}$ afecta positivamente la performance catalítica [64].

Gao et al. emplearon el catalizador de $\mathrm{Cu}-\mathrm{ZnO}$ previamente reducido, en un reactor de flujo continuo a $250{ }^{\circ} \mathrm{C}$ y 20 bar de $\mathrm{H}_{2}$. El catalizador resultó estable por 200 h de reacción, con conversiones del 93-96 \% y selectividad a 1,2-PG del 79-83 \% empleando glicerol crudo y glicerol grado analítico respectivamente. Para una relación molar Cu:Zn $=1.86$ se alcanza el máximo rendimiento a 1,2-PG debido a que alcanza la máxima superficie expuesta de $\mathrm{Cu}$ [65].

Huang et al. sinterizaron un catalizador másico de $\mathrm{Cu}-\mathrm{SiO}_{2}$ empleando la técnica de coprecipitación. Utilizaron una solución acuosa de $\mathrm{Cu}\left(\mathrm{NO}_{3}\right)_{2} \cdot 3 \mathrm{H}_{2} \mathrm{O}$ en presencia de $\mathrm{NaOH}, y$ lograron formar un precipitado que fue mezclado posteriormente con una solución acuosa de $\mathrm{SiO}_{2}$ coloidal. Los resultados mostraron que luego del secado, la superficie catalítica contiene $\mathrm{Cu}(\mathrm{OH})_{2}$ y $\mathrm{Cu}(\mathrm{OH})_{3} \mathrm{NO}_{3}$. La calcinación del catalizador genera $\mathrm{CuO}$ y iones de $\mathrm{Cu}^{+2}$ y la reducción genera $\mathrm{Cu}^{0}$ y $\mathrm{Cu}^{+}$. Los resultados luego de $12 \mathrm{~h}$ de reacción, mostraron una conversión del 75\% con una selectividad del 95\% a 1,2-PG. El menor tamaño de partícula de $\mathrm{Cu}^{0}$ conjuntamente con la presencia de $\mathrm{Cu}^{+}$en la matriz de sílice conduce a una mayor interacción metal-soporte y evita el sinterizado, permitiendo que el catalizador sea estable durante 200 h en un reactor continuo [66,67].

También se ha estudiado el reemplazo de $\mathrm{ZnO}$ por $\mathrm{MgO}$. Niu et al. emplearon un catalizador de $\mathrm{Cu}-\mathrm{MgO}$ sintetizado mediante el método de coprecipitación empleando $\mathrm{Cu}\left(\mathrm{NO}_{3}\right)_{2} \cdot 3 \mathrm{H}_{2} \mathrm{O}$ y $\mathrm{Mg}\left(\mathrm{NO}_{3}\right)_{2} \cdot 6 \mathrm{H}_{2} \mathrm{O}$ como precursores. Los resultados de actividad luego de 10 $\mathrm{h}$ de reacción, y empleando soluciones de glicerol en etanol, mostraron una conversión de glicerol del 57\% y una selectividad del 29\% a 1,2-PG [68]. Yuan et al., también prepararon catalizadores de $\mathrm{Cu}-\mathrm{MgO}$ por coprecipitación, pero emplearon otros precursores: $\mathrm{CuCl}_{2} \cdot 2 \mathrm{H}_{2} \mathrm{O}$ y $\mathrm{MgCl}_{2} \cdot 6 \mathrm{H}_{2} \mathrm{O}$ en medio básico de $\mathrm{Na}_{2} \mathrm{CO}_{3}$ a $\mathrm{pH}=10,5$. Los autores probaron distintas formulaciones del catalizador variando el contenido de $\mathrm{Cu}$. Para un contenido del 15 \%p/p de $\mathrm{Cu}$ obtuvieron muy buenos resultados de actividad luego de 20 h en reacción, una conversión del 72 \% y selectividad del 97 \% a 1,2-PG. Esto fue atribuido al menor tamaño de partículas de $\mathrm{Cu}$ y de $\mathrm{MgO}$ formadas durante la preparación [69]. M. Balaraju et al prepararon catalizadores de $\mathrm{Cu}-\mathrm{MgO}$ también mediante el método de coprecipitación sin paso de reducción previo. Los resultados mostraron que con $20 \%$ p/p de $\mathrm{Cu}$, es posible alcanzar luego de 8 h en reacción, una conversión del 49 \% con una selectividad a 1,2-PG del $92 \%$. La buena performance de estos catalizadores fue atribuida a la basicidad del soporte en combinación con la alta dispersión de las partículas de $\mathrm{Cu}$ [70].

La técnica de coprecipitación también ha sido utilizada para preparar catalizadores de $\mathrm{Cu}-\mathrm{Al}[55,71,72,73,74,75,76,77]$ y $\mathrm{Cu}-\mathrm{Fe}$ [78]. Mane et al. prepararon catalizadores de $\mathrm{Cu}-\mathrm{Al}$ encontrando que la presencia de la fase $\mathrm{CuAl}_{2} \mathrm{O}_{4}$ y las especies $\mathrm{Cu}^{+}$y $\mathrm{Cu}^{0}$ determina el éxito en la performance de los catalizadores [72]. Valencia et al. prepararon de forma similar catalizadores de $\mathrm{Cu}-\mathrm{Al}$ y encontraron que para una relación atómica $\mathrm{Cu}: \mathrm{Al}=3: 1$ el rendimiento a 1,2-PG resulta máximo [77].

Wolosiak-Hnat et al. prepararon catalizadores de $\mathrm{Cu}-\mathrm{Al}_{2} \mathrm{O}_{3}$ que mostraron una mejor performance que los catalizadores de $\mathrm{Cu}-\mathrm{Cr}_{2} \mathrm{O}_{4}$ [55]. En otro de sus trabajos indicaron que la presencia de $\mathrm{Cu}^{0}$ y de las fases $\mathrm{CuAlO}_{2}$ y $\mathrm{CuAl}_{4} \mathrm{O}_{7}$ permitieron alcanzar altos niveles de 
actividad [73]. Nikolaev et al. prepararon catalizadores de $\mathrm{Cu}-\mathrm{Al}_{2} \mathrm{O}_{3}$ empleando como agentes de precipitación alternativamente $\mathrm{NaOH}$ y $\mathrm{NH}_{4} \mathrm{OH}$. Los resultados mostraron la presencia de las fases $\mathrm{CuO}$ y $\mathrm{Cu}_{2} \mathrm{O}$, siendo esta última la fase que provee al catalizador una mayor actividad. El mayor rendimiento a 1,2-PG se obtuvo empleando $\mathrm{NaOH}$ como agente de precipitación y calcinando el catalizador a $450{ }^{\circ} \mathrm{C}[79]$.

Otros autores sintetizaron de forma directa la fase de $\mathrm{CuAl}_{2} \mathrm{O}_{4}$, y relacionaron directamente la buena performance catalítica con la reducibilidad y la capacidad de la fase activa de adsorber y desorber fácilmente el $\mathrm{H}_{2}$ [71]. Mizugaki et al. prepararon catalizadores basados en nanopartículas de $\mathrm{Cu}$ en una matriz de óxido de aluminio amorfo, $\mathrm{Cu}-\mathrm{Al}_{2} \mathrm{O}_{x}$ a partir de la reducción de hidrotalcitas de $\mathrm{Cu}$. Sus resultados mostraron muy altos rendimientos, conversiones de glicerol del $100 \%$ con selectividades del $98 \%$ a 1,2-P empleando soluciones muy diluidas de glicerol en 1,4-dioxano [74].

Hidrotalcitas de Cu-Ca-Al también han sido evaluadas en la hidrogenólisis de glicerol. Para una relación molar $\mathrm{Cu}: \mathrm{Ca}: \mathrm{Al}=1: 3: 5$, se obtuvo una conversión del $73 \%$ con una selectividad a 1,2-PG de casi el $42 \%$, luego de 8 h de reacción. La incorporación de Ca, en este tipo de hidrotalcitas, conduce a mejorar las propiedades ácido-básicas del catalizador y así mejoran la performance catalítica [75]. Zheng et al. prepararon hidrotalcitas de Cu-Ca-Al mediante el método de coprecipitación y encontraron que la hidrotalcita del tipo Cu1.5$\mathrm{Ca}_{2} \mathrm{AlO}_{3.5}$ presenta el mayor rendimiento a 1,2-PG debido al mayor número de sitios básicos presentes en el material y a la buena dispersión del Cu [76].

Xiao et al. prepararon catalizadores de $\mathrm{Cu}-\mathrm{Fe}$ y encontraron que una etapa de calcinación a $500{ }^{\circ} \mathrm{C}$ y una relación $\mathrm{Cu}: \mathrm{Fe}=0.5$, permite la formación de una espinela del tipo $\mathrm{CuFe}_{2} \mathrm{O}_{4}$ que sería la responsable de la actividad para la formación de 1,2-PG [78].

Recientemente se ha reportado la hidrogenólisis de glicerol sin presión de $\mathrm{H}_{2}$ y con catalizadores de $\mathrm{Cu}$ preparados por coprecipitación. Los resultados mostraron el siguiente de orden de actividad:

$$
\mathrm{Cu}-\mathrm{MgO}>\mathrm{Cu}-\mathrm{ZnO}>\mathrm{Cu}-\mathrm{SiO}_{2}>\mathrm{Cu}-\mathrm{Al}_{2} \mathrm{O}_{3}
$$

Este orden indica el rol del óxido para estabilizar las partículas de $\mathrm{Cu}$ sobre la superficie catalítica. Los resultados mostraron que son mejores las superficies básicas. El máximo rendimiento a 1,2-PG fue obtenido, sin adición de $\mathrm{H}_{2}$, empleando el catalizador de $\mathrm{Cu}-\mathrm{MgO}$, con relación molar $\mathrm{Cu}: \mathrm{MgO}=0.5$, debido a la generación de $\mathrm{H}_{2}$ por el reformado del glicerol [6].

Sistemas más complejos basados en $\mathrm{Cu}-\mathrm{ZnO}-\mathrm{Al}_{2} \mathrm{O}_{3}$ [80-83] y $\mathrm{Cu}-\mathrm{ZnO}-\mathrm{MgO}-\mathrm{Al}_{2} \mathrm{O}_{3}$ [8486] también han sido mencionados en la literatura.

Huang et al. prepararon un catalizador de $\mathrm{Cu}-\mathrm{ZnO}-\mathrm{Al}_{2} \mathrm{O}_{3}$ empleando el método de coprecipitación utilizando las sales de $\mathrm{Cu}\left(\mathrm{NO}_{3}\right)_{2} .3 \mathrm{H}_{2} \mathrm{O}, \mathrm{Zn}\left(\mathrm{NO}_{3}\right)_{2} .6 \mathrm{H}_{2} \mathrm{O}$ y $\mathrm{Al}\left(\mathrm{NO}_{3}\right)_{3} .9 \mathrm{H}_{2} \mathrm{O}$. Luego de 10 h de reacción obtuvieron conversiones del $20 \%$ de glicerol con selectividades del $80 \%$ a $1,2-\mathrm{PG}[80]$.

Liu et al. compararon la preparación del catalizador de $\mathrm{Cu}-\mathrm{ZnO}-\mathrm{Al}_{2} \mathrm{O}_{3}$ mediante el método de coprecipitación tradicional con el método de coprecipitación vía formación de gel de oxalato. Sus resultados mostraron que, empleando el método vía formación gel se obtiene una mayor actividad y selectividad a 1,2-PG debido a una mayor dispersión de las partículas de $\mathrm{Cu}$ formadas sobre la matriz de alúmina [81]. 
Kim et al. prepararon el catalizador de $\mathrm{Cu}-\mathrm{ZnO}-\mathrm{Al}_{2} \mathrm{O}_{3}$ mediante la técnica asistida de microondas. Sus resultados mostraron que, sin etapa de reducción, el tratamiento con microondas genera menor conversión y menor selectividad que el catalizador preparado mediante el método de coprecipitación. Esto lo explican por el menor número de sitios ácidos generados con la técnica de microondas [82].

Kolena et al. prepararon una serie de hidrotalcitas basadas en metales de la serie de transición ( $\mathrm{Ni}, \mathrm{Fe}, \mathrm{Co}, \mathrm{Zn}$ ), siendo la hidrotalcita de $\mathrm{Cu}-\mathrm{ZnO}-\mathrm{Al}_{2} \mathrm{O}_{3}$ la que mostró mejor performance en la hidrogenólisis de glicerol. Los resultados fueron explicados por la distribución específica de volumen de poros y a la mayor fracción de macroporos (de 1 a 10 $\mu \mathrm{m})$ [83].

Xia et al. prepararon catalizadores de $\mathrm{Cu}-\mathrm{ZnO}-\mathrm{MgO}-\mathrm{Al}_{2} \mathrm{O}_{3}$ empleando el método de coprecipitación utilizando las sales de $\mathrm{Cu}\left(\mathrm{NO}_{3}\right)_{2} .3 \mathrm{H}_{2} \mathrm{O}, \mathrm{Zn}\left(\mathrm{NO}_{3}\right)_{2} .6 \mathrm{H}_{2} \mathrm{O}, \mathrm{Al}\left(\mathrm{NO}_{3}\right)_{3} .9 \mathrm{H}_{2} \mathrm{O}$ y $\mathrm{Mg}\left(\mathrm{NO}_{3}\right)_{2} \cdot 6 \mathrm{H}_{2} \mathrm{O}$. A la solución acuosa formada con esas sales se le añadió una solución de $\mathrm{NaOH}$ y $\mathrm{Na}_{2} \mathrm{CO}_{3}$ para lograr una mezcla alcalina $(\mathrm{pH}=9.5)$. Se obtuvieron conversiones del $85 \%$ con selectividad del $98 \%$ a 1,2-PG, luego de 10 h de reacción. Además, el catalizador resultó estable luego de 5 ciclos de reacción de 10 h cada uno. La buena actividad del catalizador fue explicada por las propiedades básicas del soporte, así como la presencia de sitios metálicos de $\mathrm{Cu}$ en contacto directo con el $\mathrm{ZnO}$ que favorecen la hidrogenación [84].

Meher et al. prepararon catalizadores de $\mathrm{Cu}-\mathrm{ZnO}-\mathrm{MgO}-\mathrm{Al}_{2} \mathrm{O}_{3}$ por el método de coprecipitación. Luego de 24 h de reacción obtuvieron conversiones de glicerol del 48 \% con selectividad a 1,2-PG del $94 \%$ [85].

Mondal et al. compararon la performance del catalizador de $\mathrm{Cu}-\mathrm{ZnO}-\mathrm{MgO}-\mathrm{Al}_{2} \mathrm{O}_{3}$ con el catalizador $\mathrm{Cu}-\mathrm{MgO}-\mathrm{Al}_{2} \mathrm{O}_{3}$, este último sin presencia del $\mathrm{Zn}$. Los resultados mostraron que la presencia de $\mathrm{ZnO}$ genera una fuerte interacción con el $\mathrm{Cu}$, generando pequeñas partículas de $\mathrm{Cu}$ con alta dispersión y buena reducibilidad, y esto permite obtener mejor actividad catalítica [86]. Zhou et al. [87] estudiaron un catalizador Cu:Zn:Al (1:1:0,5), y lograron obtener conversiones del $81 \%$ con una selectividad del $93 \%$ a 1,2-PG.

Durán-Martín et al. prepararon catalizadores de $\mathrm{Cu}-\mathrm{ZrO}_{2}$ a partir del método de coprecipitación empleando $\mathrm{Cu}\left(\mathrm{NO}_{3}\right)_{2} \cdot 2 \mathrm{H}_{2} \mathrm{O}$ y $\mathrm{ZrO}\left(\mathrm{NO}_{3}\right)_{2} \cdot \mathrm{xH}_{2} \mathrm{O}$ como precursores. La precipitación la llevaron a cabo manteniendo un $\mathrm{pH}=7$ empleando $\mathrm{Na}_{2} \mathrm{CO}_{3}$. Los catalizadores de $\mathrm{Cu}-\mathrm{ZrO}_{2}$ con las mayores relaciones de $\mathrm{Cu}: \mathrm{Zr}$ (2.5:1 y 6:1) mostraron las mayores conversiones de glicerol y selectividad a 1,2-PG [88].

Rekha et al. prepararon catalizadores de $\mathrm{Cu}-\mathrm{ZrO}_{2}-\mathrm{MgO}$ empleando el método de coprecipitación variando los contenidos de $\mathrm{Cu}$ y $\mathrm{ZrO}_{2}$. La actividad es proporcional al número de sitios activos de $\mathrm{Cu}$ y a la moderada basicidad del material de $\mathrm{ZrO}_{2}-\mathrm{MgO}$. Los mejores resultados fueron obtenidos para un contenido del $20 \%$ p/p de $\mathrm{Cu}$ y 10 \%p/p de $\mathrm{ZrO}_{2}$ [89].

\subsubsection{Níquel}

A diferencia de los catalizadores basados en $\mathrm{Cu}$, los catalizadores basados en Ni han sido menos estudiados en la literatura. En particular hay aún un número menor de trabajos 
que reportan catalizadores másicos de $\mathrm{Ni}$. La mayoría de estos son hidrotalcitas y compuestos de Ni preparados por coprecipitación.

La Tabla 3-2 resume las condiciones operativas y los resultados de actividad de los catalizadores másicos de $\mathrm{Ni}$ en reactores batch. Como puede observarse en la mayoría de esos trabajos, los ensayos de evaluación catalítica se realizan en el rango de temperaturas de $190{ }^{\circ} \mathrm{C}$ a $230{ }^{\circ} \mathrm{C}$ y presiones entre 14 bar y 55 bar de $\mathrm{H}_{2}$. También puede observarse que la cantidad de catalizador y los tiempos de reacción empleados son muy diferentes, pero generalmente se reportan tiempos de reacción superior a las 10 h y una relación de masa de glicerol a masa de catalizador $\left(\mathrm{m}_{\mathrm{gli}} / \mathrm{m}_{\mathrm{c}}\right)$ que fluctúa entre 4 y 100.

Tabla 3-2. Hidrogenólisis 1,2-PG en reactores batch en fase líquida empleando catalizadores másicos basados en $\mathrm{Ni}$.

\begin{tabular}{lcccccccc}
\hline Catalizador & $\mathrm{T}\left({ }^{\circ} \mathrm{C}\right)$ & $\mathrm{P}(\mathrm{bar})$ & $\mathrm{m}_{\mathrm{gli}} / \mathrm{m}_{\mathrm{c}}(\mathrm{g} / \mathrm{g})$ & $\mathrm{t}(\mathrm{h})$ & $\mathrm{X}_{\mathrm{GLI}}(\%)$ & $\mathrm{S}_{1,2-\mathrm{PG}}(\%)$ & $\mathrm{R}_{1,2-\mathrm{PG}}(\%)$ & Ref. \\
\hline \multirow{2}{*}{$\mathrm{Ni}-\mathrm{Raney}$} & 200 & $14\left(\mathrm{H}_{2}\right)$ & 20.0 & 24 & 49.5 & 52.7 & 26.1 & {$[7]$} \\
\cline { 2 - 9 } & 190 & $10\left(\mathrm{H}_{2}\right)$ & 4.0 & 44 & 97.0 & 71.0 & 68.8 & {$[33]$} \\
\cline { 2 - 9 } & 230 & $40\left(\mathrm{H}_{2}\right)$ & 6.7 & 9 & 80.0 & 23.0 & 18.4 & {$[90]$} \\
\hline $\mathrm{Ni}-\mathrm{Raney}-\mathrm{Ag}$ & 210 & $40\left(\mathrm{H}_{2}\right)$ & 8.0 & 6 & 78.0 & 65.9 & 51.4 & {$[91]$} \\
\hline $\mathrm{Ni}-\mathrm{MgO}-\mathrm{Al}_{2} \mathrm{O}_{3}$ & 200 & $14\left(\mathrm{H}_{2}\right)$ & 20.0 & 24 & 8.7 & 24.4 & 2.1 & {$[85]$} \\
\hline $\mathrm{Ni}-\mathrm{Co}-\mathrm{MgO}_{2} \mathrm{Al}_{2} \mathrm{O}_{3}$ & 200 & $14\left(\mathrm{H}_{2}\right)$ & 20.0 & 24 & 9.2 & 36.2 & 3.3 & {$[85]$} \\
\hline $\mathrm{Ni} 3 \mathrm{P}$ & 190 & $55\left(\mathrm{H}_{2}\right)$ & 100.0 & 4 & 5.0 & 86.4 & 4.3 & {$[42]$} \\
\hline $\mathrm{Ni}-\mathrm{ZnO}-\mathrm{Al}_{2} \mathrm{O}_{3}$ & 230 & $30\left(\mathrm{H}_{2}\right)$ & 10.5 & 5 & 100.0 & 54.2 & 54.2 & {$[203]$} \\
\hline
\end{tabular}

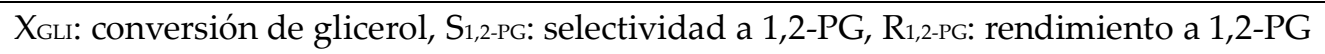

Los trabajos que emplearon Ni-Raney en condiciones moderadas de temperatura y presión, obtuvieron bajos rendimientos a 1,2-PG aún a altos tiempos de reacción [7,33]. Condiciones operativas más severas promueven reacciones de ruptura de enlaces $\mathrm{C}-\mathrm{C}$ y la formación de productos secundarios [90].

Chen et al. estudiaron catalizadores másicos de Ni-Raney modificados por la adición de Ag. Para una relación atómica Ni:Ag = 6:1, encontraron el máximo rendimiento a 1,2-PG. Los resultados demostraron que la adición de Ag genera nuevos sitios activos del tipo Ni-Ag que promueven las reacciones de ruptura de enlaces $\mathrm{C}-\mathrm{O}$ en lugar de las reacciones de ruptura de enlaces C-C [91].

Shi et al. sinterizaron un catalizador de $\mathrm{Ni}_{3} \mathrm{P}$ mediante un método hidrotermal a $150{ }^{\circ} \mathrm{C}$ en presencia de una solución amoniacal de $\mathrm{NiH}_{2} \mathrm{PO}_{2}$ y $\mathrm{NH}_{4} \mathrm{H}_{2} \mathrm{PO}_{2}$. Los catalizadores obtenidos mostraron conversiones del 5\% con selectividades del 94\% a 1,2-PG, empleando soluciones al $10 \%$ p/p de glicerol [92].

Hidrotalcitas del tipo $\mathrm{Ni}-\mathrm{ZnO}-\mathrm{Al}_{2} \mathrm{O}_{3}$ fueron empleadas para investigar el rol del $\mathrm{Zn}$ como promotor del Ni. Los autores explican que la formación de una aleación Ni-Zn es la responsable de la mejora en los niveles de actividad y selectividad a 1,2-PG, debido a la inhibición de las reacciones de ruptura de enlaces C-C y a la mejora en la adsorción del grupo hidroxilo terminal del glicerol promoviendo la ruptura del enlace C-O [93]. 
Otros catalizadores de $\mathrm{Ni}-\mathrm{MgO}-\mathrm{Al}_{2} \mathrm{O}_{3}$ fueron preparados por el método de coprecipitación, pero los rendimientos obtenidos a 1,2-PG fueron bajos, aún con la incorporación de Co al catalizador [85].

\subsubsection{Cobalto}

La Tabla 4-2 resume las condiciones operativas y los resultados de actividad de los catalizadores másicos de Co en reactores batch. Como puede observarse en la mayoría de los trabajos de investigación, los ensayos de evaluación catalítica se realizan a temperaturas entre $180{ }^{\circ} \mathrm{C}$ y $220{ }^{\circ} \mathrm{C}$ y presiones entre 30 bar y 60 bar de $\mathrm{H}_{2}$. La masa de catalizador y los tiempos de reacción son muy diferentes, pero generalmente se reportan tiempos de reacción entre 7 h y 15 h, y una relación de masa de glicerol a masa de catalizador $\left(\mathrm{m}_{\mathrm{gli}} / \mathrm{m}_{\mathrm{c}}\right)$ que fluctúa entre 3 y 80. La Tabla 5-2 resume las condiciones operativas y los resultados de actividad de los catalizadores másicos de Co en reactores de flujo continuo en fase líquida.

Tabla 4-2. Hidrogenólisis 1,2-PG en reactores batch en fase líquida empleando catalizadores másicos basados en Co.

\begin{tabular}{lcccccccc}
\hline Catalizador & $\mathrm{T}\left({ }^{\circ} \mathrm{C}\right)$ & $\mathrm{P}(\mathrm{bar})$ & $\mathrm{m}_{\mathrm{gli}} / \mathrm{m}_{\mathrm{c}}(\mathrm{g} / \mathrm{g})$ & $\mathrm{t}(\mathrm{h})$ & $\mathrm{X}_{\mathrm{GLI}}(\%)$ & $\mathrm{S}_{1,2-\mathrm{PG}}(\%)$ & $\mathrm{R}_{1,2-\mathrm{PG}}(\%)$ & Ref. \\
\hline Co-Al & 200 & $40\left(\mathrm{H}_{2}\right)$ & 3.0 & 15 & 100.0 & 70.1 & 70.1 & {$[94]$} \\
\hline \multirow{3}{*}{ Co } & 220 & $52\left(\mathrm{H}_{2}\right)$ & 80.0 & 7 & 35.0 & 72.0 & 25.2 & {$[95]$} \\
\cline { 2 - 8 } & 220 & $30\left(\mathrm{H}_{2}\right)$ & 80.0 & 7 & 44.0 & 60.0 & 26.4 & {$[96]$} \\
\hline \multirow{2}{*}{ Co-Ni } & 220 & $60\left(\mathrm{H}_{2}\right)$ & 40.0 & 8 & 33.5 & 47.6 & 15.9 & {$[99]$} \\
\hline Co-Cu & 220 & $30\left(\mathrm{H}_{2}\right)$ & 80.0 & 7 & 61.0 & 63.0 & 38.4 & {$[96]$} \\
\hline Co-ZnO & 220 & $30\left(\mathrm{H}_{2}\right)$ & 80.0 & 7 & 71.1 & 48.2 & 34.2 & {$[97]$} \\
\hline
\end{tabular}

XGL: conversión de glicerol, $\mathrm{S}_{1,2-\mathrm{PG}}$ selectividad a 1,2-PG, $\mathrm{R}_{1,2-\mathrm{PG}}$ rendimiento a 1,2-PG

Tabla 5-2. Hidrogenólisis 1,2-PG en reactores de flujo continuo en fase líquida empleando catalizadores másicos de Co.

\begin{tabular}{lccccccc}
\hline Catalizador & $\mathrm{T}\left({ }^{\circ} \mathrm{C}\right)$ & $\mathrm{P}($ bar $)$ & WHSV $\left(\mathrm{h}^{-1}\right)$ & $\mathrm{X}_{\mathrm{GLI}}(\%)$ & $\mathrm{S}_{1,2-\mathrm{PG}}(\%)$ & $\mathrm{R}_{1,2-\mathrm{PG}}(\%)$ & Ref. \\
\hline $\mathrm{Co}-\mathrm{Al}$ & 230 & $35\left(\mathrm{H}_{2}\right)$ & 2.6 & 48.7 & 77.2 & 37.6 & {$[15]$} \\
\hline $\mathrm{Co}-\mathrm{Al}-\mathrm{H}_{4}\left[\mathrm{Si}\left(\mathrm{W}_{3} \mathrm{O}_{10}\right)_{4}\right.$ & 230 & $35\left(\mathrm{H}_{2}\right)$ & 2.6 & 76.3 & 60.2 & 45.9 & {$[15]$} \\
\hline
\end{tabular}

XGL: conversión de glicerol, $\mathrm{S}_{1,2-\mathrm{PG}}$ selectividad a 1,2-PG, R R,2-PG: rendimiento a 1,2-PG

Guo et al. reportaron el uso de un catalizador comercial de Co-Al que resultó similar en la actividad a un catalizador de Ni-Raney. Sus resultados mostraron conversión completa de glicerol con selectividad del $70 \%$ a 1,2-PG en condiciones moderadas de presión y temperatura. Estos resultados fueron atribuidos a la capacidad del Al para deshidratar [94]. Cai et al. prepararon un catalizador de Co-Al por coprecipitación, que presentó baja 
conversión (48 \%) fue muy selectivo a 1,2-PG (77 \%). Posteriormente fue modificado por un heteropoliácido del tipo $\mathrm{H}_{4}\left[\mathrm{Si}\left(\mathrm{W}_{3} \mathrm{O}_{10}\right)_{4}\right.$ que permitió incrementar el nivel de conversión (76 $\%)$, con una ligera disminución de la selectividad a 1,2-PG (60\%). Los resultados en la mejora de actividad fueron atribuidos a la mejor dispersión de las partículas de Co mientras que la caída en la selectividad a 1,2-PG por el aumento en la selectividad a 1,3-PG debido a la generación de sitios ácidos de BrØnsted [15]. En otro de sus trabajos, sintetizaron una serie de nanoestructuras de $\mathrm{Co}$, entre 4 y $10 \mu \mathrm{m}$, mediante un método hidrotermal empleando $\mathrm{Co}\left(\mathrm{CH}_{3} \mathrm{COO}\right)_{2} .4 \mathrm{H}_{2} \mathrm{O}$ como precursor y ácido esteárico como surfactante. Los autores explican la influencia de la morfología de los materiales de Co sobre la actividad y selectividad. Reportan estructuras de Co que resulta activas ( $35 \%$ de conversión) y selectivas para la formación de 1,2-PG ( 72 \%) [95]. Con el objetivo de mejorar estos resultados, sintetizaron nanoestructuras dobles de $\mathrm{Co}$ y $\mathrm{Ni}$ mediante el método hidrotermal con nucleación heterogénea en presencia de un poliol. Para una relación $\mathrm{Co}: \mathrm{Ni}=4$, estos catalizadores mostraron una mayor conversión y selectividad a 1,2-PG que las estructuras monometálicas de Co [96]. Para disminuir el tiempo empleado en la síntesis de estos catalizadores, estos autores propusieron una modificación en el método de preparación mediante el empleo de microondas, pero obtuvieron resultados similares [97]. Posteriormente, sintetizaron nanoestructuras de $\mathrm{Co}-\mathrm{Cu}$, empleando el mismo método de nucleación heterogénea en presencia de un poliol. Para una relación $\mathrm{Co}: \mathrm{Cu}=9$, las nanoestructuras resultaron selectivas a 1,2-PG, atribuido al efecto sinérgico de la unión Co-Cu en la superficie catalítica [98].

Cao et al, sintetizaron nanocompositos de $\mathrm{Co}$, con formas de plato hexagonal y otros poliedros con tamaños a microescala, empleando el método de reducción en presencia de EG como agente reductor y $\mathrm{CoCl}_{2}$ como precursor del metal. Tanto las estructuras de Co hexagonales como los poliedros mostraron buenos rendimientos hacia 1,2-PG [99].

Catalizadores de Co-ZnO preparados mediante el método de coprecipitación también resultaron activos y selectivos hacia la formación de 1,2-PG. Para una relación másica Co:Zn $=1$ se obtuvo el máximo rendimiento a 1,2-PG. Los autores mostraron una correlación lineal entre la conversión de glicerol y la superficie metálica expuesta del Co [100].

\subsubsection{Catalizadores soportados para la producción de 1,2-PG en fase líquida}

Se han empleado catalizadores soportados basados en metales nobles $(\mathrm{Ru}, \mathrm{Pt}, \mathrm{Pd}, \mathrm{Rh})$ y no nobles $(\mathrm{Cu}, \mathrm{Ni}, \mathrm{Co})$ como fases activas, así como soportes tradicionales de óxidos metálicos, no metálicos $\left(\mathrm{Al}_{2} \mathrm{O}_{3}, \mathrm{SiO}_{2}, \mathrm{TiO}_{2}, \mathrm{ZnO}, \mathrm{CuO}\right)$ y soportes carbonosos $(\mathrm{C})$.

Entre los metales nobles se han empleado principalmente $\mathrm{Ru}, \mathrm{Pt}, \mathrm{Pd}$ y $\mathrm{Rh}$. Si bien el costo de estos precursores es mayor que el de los precursores basados en metales no nobles, su contenido porcentual en el catalizador es más bajo (1-5\%p/p).

La performance catalítica depende del metal $(\mathrm{Ru}, \mathrm{Pt}, \mathrm{Pd}$ o $\mathrm{Rh})$ y de su dispersión metálica. El orden de actividad encontrado por tipo de metal es: $\mathrm{Ru}>\mathrm{Pt}>\mathrm{Rh}>\mathrm{Pd}$.

En la preparación de catalizadores soportados con fases activas basadas en metales no nobles, se han empleado principalmente $\mathrm{Cu}$, Ni y Co. Los costos de los precursores son menores pero se requiere un mayor contenido de estos metales (5-30 \%p/p) para alcanzar niveles de actividad comparables a los metales nobles. El orden de actividad por tipo de metal es el siguiente: $\mathrm{Cu}>\mathrm{Ni}>\mathrm{Co}$ 
A continuación, se describen los aspectos más relevantes en el estudio de catalizadores soportados empleados en la reacción de hidrogenólisis de glicerol diferenciando las distintas fases activas y los diversos soportes.

\subsubsection{Rutenio}

La Tabla 8-2 resume las condiciones operativas y los resultados de actividad de los catalizadores de Ru soportados en reactores batch. Puede observarse que en la mayoría de los ensayos de evaluación catalítica se emplearon temperaturas entre $120^{\circ} \mathrm{C}$ y $220{ }^{\circ} \mathrm{C}$ y presiones entre 14 bar y 80 bar de $\mathrm{H}_{2}$. Los tiempos de reacción reportados están entre 3 h y 24 h, y una relación de masa de glicerol a masa de catalizador $\left(\mathrm{m}_{\mathrm{gli}} / \mathrm{m}_{\mathrm{c}}\right)$ que fluctúa entre 2 y 35 , excepcionalmente hasta 168.

Los primeros trabajos reportan el empleo de catalizadores soportados de $\mathrm{Ru}$ comerciales [7,25,101,102], que mostraron niveles de conversión aceptables pero bajas selectividades a 1,2-PG. Dasari et al. evaluaron catalizadores comerciales de $\mathrm{Ru} / \mathrm{C}$ y $\mathrm{Ru} / \mathrm{Al}_{2} \mathrm{O}_{3}$ empleando soluciones acuosas de glicerol al 80\%. Los resultados mostraron que ambos catalizadores resultaron activos, pero no tan selectivos a 1,2-PG como los catalizadores de $\mathrm{Cu}$ ( $\sim 40 \%$ para $\mathrm{Ru} / \mathrm{C}$ y $\sim 60 \%$ para $\mathrm{Ru} / \mathrm{Al}_{2} \mathrm{O}_{3}$ ). Los autores asignaron estos resultados a la menor capacidad del $\mathrm{Ru}$ para hidrogenar los enlaces C-O comparado a la fase metálica de $\mathrm{Cu}$ [7]. Maris et al. estudiaron catalizadores comerciales de $\mathrm{Ru} / \mathrm{C}$ y concluyeron que el $\mathrm{Ru}$ promueve reacciones de ruptura de enlaces $\mathrm{C}-\mathrm{C}$ favoreciendo la formación de productos secundarios tales como EG y EtOH [25].

Maris et al. compararon la actividad del $\mathrm{Ru} / \mathrm{C}$ con la actividad del $\mathrm{Pt} / \mathrm{C}$ y concluyeron que la actividad del primero es mayor que la del segundo en las mismas condiciones operativas [25]. Alhanash et al. evaluaron catalizadores de $\mathrm{Ru}$ y Rh soportados en una sal de heteropoliácido (CsPW). Ru/CsPW condujo a alta selectividad a 1,2-PG (96\%) con conversiones del $20 \%$, empleando baja presión de hidrógeno (5 bar). Este catalizador resultó ser más activo que uno de Rh/CsPW, que por su parte presentó mayor selectividad a 1,3-PG (7\%) [103].

Wang et al. demostraron que el catalizador de $\mathrm{Ru} / \mathrm{ZrO}_{2}$ fue el más activo comparado con los catalizadores de $\mathrm{Rh}, \mathrm{Pt}$ y $\mathrm{Pd}$. El orden de actividad intrínseco, para tamaños de partícula del orden de $2 \mathrm{~nm}$, fue el siguiente: $\mathrm{Ru} \gg \mathrm{Rh}>\mathrm{Pt}>\mathrm{Pd}$. Además, reportaron que el aumento en el tamaño de partícula en $\mathrm{Ru} / \mathrm{ZrO}_{2}$ genera una mayor selectividad hacia las reacciones de ruptura de enlaces $C-C$, disminuyendo la selectividad a 1,2-PG [104].

Los trabajos han reportado que la actividad de los catalizadores soportados de Ru en la reacción de hidrogenólisis se ve afectada por el tamaño de partícula del Ru y la acidez del catalizador.

Con respecto al tamaño de partícula, se ha reportado que tamaños de partícula pequeños dan lugar a altas dispersiones que aumentan los niveles de conversión. Se ha reportado que el tamaño de partícula depende del tipo de precursor de Ru empleado, el método de preparación y soporte utilizado. 
Tabla 8-2. Hidrogenólisis a 1,2-PG en reactores batch en fase líquida empleando catalizadores soportados de Ru.

\begin{tabular}{|c|c|c|c|c|c|c|c|c|}
\hline Catalizador & $\mathrm{T}\left({ }^{\circ} \mathrm{C}\right)$ & $\mathrm{P}$ (bar) & $\mathrm{m}_{\mathrm{gli}} / \mathrm{m}_{\mathrm{c}}(\mathrm{g} / \mathrm{g})$ & $t(h)$ & $\mathrm{X}_{\mathrm{GLI}}(\%)$ & $\mathrm{S}_{1,2-\mathrm{PG}}(\%)$ & $\mathrm{R}_{1,2-\mathrm{PG}}(\%)$ & Ref. \\
\hline \multirow{2}{*}{$\mathrm{Ru} / \mathrm{SiO}_{2}$} & 240 & $80\left(\mathrm{H}_{2}\right)$ & 168.0 & 5 & 21.7 & 60.5 & 13.1 & [107] \\
\hline & 160 & $80\left(\mathrm{H}_{2}\right)$ & 29.4 & 8 & 16.8 & 39.0 & 6.5 & [109] \\
\hline \multirow{5}{*}{$\mathrm{Ru} / \mathrm{C}$} & 200 & $14\left(\mathrm{H}_{2}\right)$ & 20.0 & 24 & 43.7 & 40.0 & 17.4 & [7] \\
\hline & 120 & $80\left(\mathrm{H}_{2}\right)$ & 2.6 & 10 & 20.8 & 12.7 & 2.6 & [34] \\
\hline & 120 & $80\left(\mathrm{H}_{2}\right)$ & 28.0 & 10 & 21.3 & 76.7 & 16.3 & [101] \\
\hline & 200 & $40\left(\mathrm{H}_{2}\right)$ & $\mathrm{NI}$ & 5 & 40.0 & 26.0 & 10.4 & [25] \\
\hline & 160 & $80\left(\mathrm{H}_{2}\right)$ & 29.4 & 8 & 29.7 & 50.9 & 15.1 & [105] \\
\hline \multirow{4}{*}{$\mathrm{Ru} / \mathrm{AC}$} & 220 & $52\left(\mathrm{H}_{2}\right)$ & 12.5 & 5 & 58.0 & 55.0 & 31.9 & [118] \\
\hline & 180 & $80\left(\mathrm{H}_{2}\right)$ & 22.8 & 24 & 36.0 & 10.0 & 3.6 & [112] \\
\hline & 180 & $80\left(\mathrm{H}_{2}\right)$ & 22.8 & 24 & 11.0 & 14.0 & 1.5 & [113] \\
\hline & 240 & $52\left(\mathrm{H}_{2}\right)$ & NI & 5 & 92.5 & 70.0 & 64.8 & [117] \\
\hline $\mathrm{Ru} / \mathrm{HSAG}$ & 180 & $80\left(\mathrm{H}_{2}\right)$ & 22.8 & 24 & 26.0 & 16.0 & 4.1 & [113] \\
\hline \multirow{2}{*}{$\mathrm{Ru} / \mathrm{CNT}$} & 180 & $80\left(\mathrm{H}_{2}\right)$ & 22.8 & 24 & 28.0 & 22.0 & 6.1 & [113] \\
\hline & 200 & $40\left(\mathrm{H}_{2}\right)$ & 16.8 & 12 & 75.0 & 48.3 & 36.2 & [121] \\
\hline $\mathrm{Ru} / \mathrm{CsPW}$ & 150 & $5\left(\mathrm{H}_{2}\right)$ & 3.3 & 10 & 31.0 & 87.6 & 27.1 & [103] \\
\hline \multirow{2}{*}{$\mathrm{Ru} / \gamma-\mathrm{Al}_{2} \mathrm{O}_{3}$} & 200 & $14\left(\mathrm{H}_{2}\right)$ & 20.0 & 24 & 23.1 & 59.7 & 13.7 & [7] \\
\hline & 160 & $80\left(\mathrm{H}_{2}\right)$ & 29.4 & 8 & 18.7 & 34.5 & 6.4 & [105] \\
\hline $\mathrm{Ru} / \mathrm{AlF}_{3}-\mathrm{Al}_{2} \mathrm{O}_{3}$ & 200 & $40\left(\mathrm{H}_{2}\right)$ & 25.3 & 4 & 48.3 & 23.7 & 11.4 & [114] \\
\hline $\mathrm{Ru} / \mathrm{HY}$ & 220 & $30\left(\mathrm{H}_{2}\right)$ & 6.0 & 10 & 81.3 & 60.1 & 48.8 & [24] \\
\hline Ru/H-ZSM5 & 160 & $80\left(\mathrm{H}_{2}\right)$ & 29.4 & 8 & 20.5 & 42.2 & 8.6 & [109] \\
\hline $\mathrm{Ru} / \mathrm{KL}$ & 180 & $80\left(\mathrm{H}_{2}\right)$ & 22.8 & 24 & 7.5 & 32.0 & 2.4 & [113] \\
\hline \multirow{3}{*}{$\mathrm{Ru} / \mathrm{ZrO}_{2}$} & 160 & $80\left(\mathrm{H}_{2}\right)$ & 29.4 & 8 & 19.5 & 36.3 & 7.0 & [105] \\
\hline & 200 & $60\left(\mathrm{H}_{2}\right)$ & 14.2 & 3 & 22.9 & 45.7 & 10.4 & [104] \\
\hline & 180 & $80\left(\mathrm{H}_{2}\right)$ & 4.0 & 18 & 100.0 & 19.5 & 19.5 & [119] \\
\hline $\mathrm{Ru} / \mathrm{WO}_{3}-\mathrm{ZrO}_{2}$ & 180 & $80\left(\mathrm{H}_{2}\right)$ & 4.0 & 18 & 12.0 & 68.5 & 8.2 & [119] \\
\hline $\mathrm{Ru} / \mathrm{La}_{2} \mathrm{O}_{3}$ & 190 & $60\left(\mathrm{H}_{2}\right)$ & 10.0 & 8 & 69.2 & 77.0 & 53.2 & [115] \\
\hline $\mathrm{Ru} / \mathrm{La}-\mathrm{ZrO}_{2}$ & 190 & $60\left(\mathrm{H}_{2}\right)$ & 10.0 & 8 & 57.8 & 22.0 & 12.7 & [115] \\
\hline $\mathrm{Ru} / \mathrm{LaCO}_{3} \mathrm{OH}$ & 200 & $30\left(\mathrm{H}_{2}\right)$ & 4.0 & 3 & 62.0 & 46.0 & 28.5 & [116] \\
\hline \multirow{3}{*}{$\mathrm{Ru} / \mathrm{TiO}_{2}$} & 170 & $30\left(\mathrm{H}_{2}\right)$ & 10.3 & 12 & 66.3 & 47.7 & 31.6 & [106] \\
\hline & 160 & $80\left(\mathrm{H}_{2}\right)$ & 29.4 & 8 & 6.0 & 44.9 & 2.6 & [109] \\
\hline & 180 & $60\left(\mathrm{H}_{2}\right)$ & 16.7 & 8 & 46.0 & 63.0 & 28.9 & [110] \\
\hline $\mathrm{Ru} / \mathrm{H} \beta$ & 160 & $80\left(\mathrm{H}_{2}\right)$ & 29.4 & 8 & 32.0 & 43.6 & 13.9 & [109] \\
\hline $\mathrm{Ru} /$ Bentonita- $\mathrm{TiO}_{2}$ & 150 & $20\left(\mathrm{H}_{2}\right)$ & 20.0 & 7 & 69.8 & 80.6 & 56.2 & [123] \\
\hline $\mathrm{Ru} /$ Bentonita & 150 & $20\left(\mathrm{H}_{2}\right)$ & 20.0 & 7 & 72.5 & 66.9 & 48.5 & [111] \\
\hline Ru/CaMgZn-Al & 180 & $25\left(\mathrm{H}_{2}\right)$ & 35.0 & 18 & 58.5 & 85.5 & 50.0 & [120] \\
\hline
\end{tabular}

NI: no informado

XGL: conversión de glicerol, $\mathrm{S}_{1,2-\mathrm{PG}}$ selectividad a 1,2-PG, $\mathrm{R}_{1,2-\mathrm{PG}}$ rendimiento a 1,2-PG 
Los precursores más empleados para preparar catalizadores soportados basados en $\mathrm{Ru}$ han sido $\mathrm{RuCl}_{3}[26,80,101,103-119], \mathrm{Ru}(\mathrm{NO})\left(\mathrm{NO}_{3}\right)_{3}$ [101,107,112,117,120], $\mathrm{Ru}$ (AcAc)3 [101,111] y $\mathrm{Ru}_{3}(\mathrm{CO})_{12}[111]$.

Los trabajos han reportado que de todos los precursores, el $\mathrm{Ru}(\mathrm{NO})\left(\mathrm{NO}_{3}\right)_{3}$ conduce a obtener los mayores niveles de conversión de glicerol y selectividad a 1,2-PG [101,107, $112,117,118,121]$ debido a que su descomposición genera partículas de $\mathrm{Ru}$ de tamaño pequeño menores a $2 \mathrm{~nm}$ [101].

Un efecto similar fue reportado empleando el precursor de $\mathrm{RuCl}_{3}$, que ha sido el precursor más empleado [121]. Algunos trabajos han destacado que la presencia de iones Clgeneran sitios ácidos de BrØnsted en la superficie de los soportes [113] que promueven las reacciones laterales de formación de productos secundarios, tales como 1-POH y 2-POH [107] y promueven reacciones de ruptura de enlaces C-C que conducen a la formación de EG y $\mathrm{MeOH}$ [117].

Otros precursores como $\mathrm{Ru}(\mathrm{AcAc})_{3}$ y $\mathrm{Ru}_{3}(\mathrm{CO})_{12}$ han sido menos empleados y en comparación a los otros precursores han mostrado menores niveles de actividad [101,111]. En base a estos resultados podría establecerse el siguiente orden de actividad por tipo de precursor: $\mathrm{Ru}(\mathrm{NO})\left(\mathrm{NO}_{3}\right)_{3}>\mathrm{RuCl}_{3}>\mathrm{Ru}_{3}(\mathrm{CO})_{12}>\mathrm{Ru}(\mathrm{AcAc})_{3}$.

Con respecto al método de preparación, los más empleados han sido la impregnación a humedad incipiente [25,101,103-107,109-111,113,114,116-123] y la deposición-precipitación $[110,115]$. Se ha reportado que el método de deposición-precipitación permite alcanzar mayores niveles de actividad que el método de impregnación a humedad incipiente. Balaraju et al. prepararon catalizadores de $\mathrm{Ru} / \mathrm{TiO}_{2}$ empleando ambos métodos. Sus resultados mostraron que el método de deposición-precipitación permitió alcanzar mayor dispersión metálica (29-53 \%) debido a la reducción de especies $\mathrm{Ru}(\mathrm{OH})_{3}$ generadas durante el proceso de preparación del catalizador, lo que condujo a obtener partículas metálicas de tamaño pequeño $\left(\mathrm{d}_{\mathrm{va}} \sim 1-3 \mathrm{~nm}\right)$. Con el empleo del método de impregnación a humedad incipiente, la formación de partículas de $\mathrm{Ru}$ de mayor tamaño $\left(\mathrm{d}_{\mathrm{va}} \sim 10 \mathrm{~nm}\right)$ dio lugar a menores niveles de actividad [110].

La temperatura de reducción y la forma de llevarla a cabo también impactan sobre el tamaño de partícula. Para catalizadores de $\mathrm{Ru} / \mathrm{C}$ [101] y $\mathrm{Ru} / \mathrm{TiO}_{2}$ [106], se ha reportado que altas temperaturas conducen a una aglomeración de las partículas de $\mathrm{Ru}$ y esto provoca una caída en los niveles de conversión. Además, el método empleado para llevar a cabo la reducción impacta en el tamaño de la partícula de $\mathrm{Ru}$ y la acidez del catalizador. Para catalizadores de $\mathrm{Ru} / \mathrm{AC}$, la reducción en atmósfera de $\mathrm{H}_{2}$ resultó ser menos efectiva que la reducción en presencia de $\mathrm{NaBH}_{4}$ en fase líquida, debido a la menor acidez presente en el catalizador y los mayores tamaños de partícula obtenidos para el Ru (3-5 nm) [117].

Las propiedades del soporte también impactan en los niveles de actividad, no solo debido a su efecto sobre el tamaño de partícula de Ru sino también por su acidez.

Se ha reportado el uso de soportes carbonosos bajo la forma de carbono grafito (C), carbonos activados (AC), nanotubos de carbono (CNT) y grafito de alta superficie específica (HSAG), además de óxidos como $\mathrm{Al}_{2} \mathrm{O}_{3}, \mathrm{SiO}_{2}, \mathrm{ZrO}_{2}, \mathrm{TiO}_{2}$ y zeolitas del tipo $\mathrm{H} \beta$ y HZSM-5. 
Dentro de este conjunto, los soportes carbonosos han sido los más estudiados, debido a que proveen la superficie específica necesaria para la formación de partículas de Ru con alta dispersión $[113,118]$ y se pueden funcionalizar para incrementar su acidez [112].

Con respecto al efecto sobre el tamaño de partícula, los carbones activados (AC) han resultado ser mejores soportes que los carbonos grafito con distinto grado de cristalinidad (C) debido a que logran una mayor dispersión del $\mathrm{Ru}$. Mane et al. indicaron que Ru/AC resultó el más activo y selectivo a 1,2-PG debido a la formación de partículas esféricas de Ru de tamaños entre 1.1 y $1.7 \mathrm{~nm}$. El empleo de catalizadores de $\mathrm{Ru} / \mathrm{C}$ condujo a obtener partículas de $\mathrm{Ru}$ de mayor tamaño, entre 4 y $5 \mathrm{~nm}$, con la presencia de óxidos de $\mathrm{Ru}$ con distintos estados de oxidación obteniéndose menores niveles de actividad [118]. Por otro lado, catalizadores de $\mathrm{Ru}$ soportados sobre nanotubos de carbono (CNT) y carbono grafito de alta superficie específica (HSAG) resultaron ser más activos que catalizadores de Ru/AC, debido a la formación de una mayor cantidad de especies de $\mathrm{Ru}^{\mathrm{\delta}-}$ ricas en electrones que favorecen la ruptura del enlace C-O terminal del glicerol para formar 1,2-PG [113].

De acuerdo a estos resultados, puede establecerse el siguiente orden de actividad general:

$$
\mathrm{Ru} / \mathrm{CNT}>\mathrm{Ru} / \mathrm{HSAG}>\mathrm{Ru} / \mathrm{AC}>\mathrm{Ru} / \mathrm{C} \text {. }
$$

Por otro lado, el empleo de soportes carbonos permite aumentar los niveles de acidez necesaria para la reacción de hidrogenólisis. No obstante, no cualquier tipo de acidez es requerida y el aumento debe ser justo para evitar pérdidas en la selectividad a 1,2-PG. Gallegos-Suarez et al. estudiaron catalizadores de Ru/AC modificados por funcionalización con ácido nítrico. Los resultados mostraron que la presencia de grupos - $\mathrm{COOH}$, generados durante la oxidación del carbón, favorece la ruptura de enlaces C-O. Además, el estudio mostró que, si bien la actividad fue promovida, la selectividad a 1,2-PG disminuyó comparada a los catalizadores soportados en AC sin funcionalizar. Los resultados fueron atribuidos a la presencia de productos secundarios tales como 1-POH, 2-POH, MeOH y otros gases como metano, etano y propano, debido al elevado nivel de acidez proporcionado por el proceso de funcionalización [112].

Con respecto a otros óxidos tradicionales como $\mathrm{Al}_{2} \mathrm{O}_{3}, \mathrm{SiO}_{2}, \mathrm{ZrO}_{2}, \mathrm{TiO}_{2}$ y zeolitas del tipo $\mathrm{H} \beta$ y HZSM-5 también fueron empleados como soportes, pero la actividad de los catalizadores de $\mathrm{Ru}$ resultó menor que empleando soportes carbonosos. Ma et al. reportaron el uso de $\mathrm{Al}_{2} \mathrm{O}_{3}$ y $\mathrm{ZrO}_{2}$ como soportes [105], así como también $\mathrm{SiO}_{2}, \mathrm{TiO}_{2}$ y las del tipo $\mathrm{H} \beta$ y HZSM-5 [109]. El orden de actividad (en base al rendimiento a 1,2-PG) fue el siguiente:

$$
\mathrm{Ru} / \mathrm{C}>\mathrm{Ru} / \mathrm{H} \beta>\mathrm{Ru} / \mathrm{H}-\mathrm{ZSM} 5>\mathrm{Ru} / \mathrm{ZrO}_{2}>>\mathrm{Ru} / \mathrm{SiO}_{2} \sim \mathrm{Ru} / \mathrm{Al}_{2} \mathrm{O}_{3}>\mathrm{Ru} / \mathrm{TiO}_{2}
$$

Los autores encontraron que el tamaño de partícula de $\mathrm{Ru}$ es menor para el catalizador de $\mathrm{Ru} / \mathrm{C}$, seguido por los catalizadores de $\mathrm{Ru} / \mathrm{ZrO}_{2}$ y $\mathrm{Ru} / \mathrm{SiO}_{2}$, sugiriendo que la actividad encontrada se debe a la mayor dispersión obtenida sobre los soportes [105]. No obstante, debe notarse que la actividad para los catalizadores basados en las zeolitas ha resultado muy superior al resto de los soportes, lo cual requiere un estudio específico de acidez sobre el cual los autores no han indagado.

Con el objetivo de mejorar las propiedades texturales y la acidez de algunos de los óxidos tradicionales empleados como soportes, se ha reportado la adición de modificadores.

Para el soporte de $\mathrm{ZrO}_{2}$, la adición de $\mathrm{WO}_{3}$ produjo un descenso en la actividad de catalizadores de $\mathrm{Ru} / \mathrm{ZrO}_{2}-\mathrm{WO}_{3}$, pero una mejora en la selectividad a 1,2-PG, debido a la 
supresión de las reacciones de ruptura de enlaces C-C [119]. La adición de La a catalizadores de $\mathrm{Ru} / \mathrm{ZrO}_{2}$, por otro lado, provocó una disminución de la selectividad a 1,2-PG debido a la promoción de reacciones de ruptura de enlaces $C-C$ que aumentaron la selectividad a EG [115].

Para el soporte de $\mathrm{TiO}_{2}$ se ha demostrado que es posible obtener buenas dispersiones metálicas por modificación del mismo con arcillas. Hamzah et al. emplearon un soporte de $\mathrm{TiO}_{2}$-bentonita en una relación másica 1:2 y obtuvieron partículas de $\mathrm{Ru}$ del orden de 1,5 nm que permitieron alcanzar alta conversión de glicerol $(\sim 70 \%)$ con una alta selectividad a 1,2PG ( 80\%) [123].

Con respecto a catalizadores de $\mathrm{Ru} / \mathrm{Al}_{2} \mathrm{O}_{3}$, la modificación del soporte con $\mathrm{AlF}_{3}$ para contenidos entre 17-58 \% p/p permite alcanzar las máximas conversiones de glicerol, debido a una mayor dispersión de las partículas de $\mathrm{Ru}$, aunque también promueve la formación de EG y gases como metano [114].

Otros soportes menos estudiados fueron las hidrotalcitas. Lee et al. prepararon catalizadores de $\mathrm{Ru} / \mathrm{CaMgZn}-\mathrm{Al}$ basados en un soporte de hidrotalcita. Los resultados mostraron altos niveles de conversión y selectividad a 1,2-PG luego de 18 h de reacción, debido a la mayor acidez presente en la hidrotalcita con respecto a otros soportes como $\gamma$ $\mathrm{Al}_{2} \mathrm{O}_{3}$ y al menor tamaño de partícula metálica $\left(\mathrm{d}_{\mathrm{va}} \sim 13,7 \mathrm{~nm}\right)$ [120].

Otros sistemas basados en $\mathrm{Ru} / \mathrm{LaCO}_{3} \mathrm{OH}$ fueron preparados empleando el método de impregnación a humedad incipiente con $\mathrm{RuCl}_{3}$. Durante la impregnación, el precursor de $\mathrm{RuCl}_{3}$ reacciona con el soporte $\mathrm{LaCO}_{3} \mathrm{OH}$ para formar un complejo de $\mathrm{LaRu}\left(\mathrm{CO}_{3}\right)_{2} \mathrm{Cl}_{2}$ y $\mathrm{LaOCl}$. Durante la reducción hidrotermal, tanto el complejo como LaOCl se hidrolizan formando $\mathrm{LaCO}_{3} \mathrm{OH}$ y $\mathrm{Ru}(\mathrm{OH})_{3}$, que posteriormente con la reducción se transforman en nanopartículas de $\mathrm{Ru}^{0}$. Estas partículas de $\mathrm{Ru}^{0}$ son encapsuladas mediante una capa protectora de $\mathrm{LaCO}_{3} \mathrm{OH}$. Este catalizador $\mathrm{Ru} / \mathrm{LaCO}_{3} \mathrm{OH}$ fue más activo, selectivo y estable que $\mathrm{Ru} / \mathrm{SiO}_{2}$ y $\mathrm{Ru} / \mathrm{ZrO}_{2}$ [116].

Se han estudiado catalizadores bimetálicos empleando varios metales, tales como $\mathrm{Pt}$ [102,124], Au [102], Cu [125-128], Fe, Co [128,129] y Ni [128]. La Tabla 9-2 resume las condiciones operativas y los resultados de actividad de los catalizadores bimetálicos de $\mathrm{Ru}$ en reactores batch. Los ensayos de evaluación catalítica se realizan a temperaturas entre $125 \mathrm{y}$ $230{ }^{\circ} \mathrm{C}$, presiones entre 25 y 100 bar de $\mathrm{H}_{2}$, tiempos de reacción entre 5 y 24 horas y una relación de masa de glicerol a masa de catalizador $\left(\mathrm{m}_{\mathrm{gli}} / \mathrm{m}_{\mathrm{c}}\right)$ que fluctúa entre 5 y 63 .

Los trabajos han reportado que las combinaciones $\mathrm{Ru}-\mathrm{Pt}$ y $\mathrm{Ru}-\mathrm{Au}$ no produjeron mejoras en la actividad de los catalizadores monometálicos de Ru. La combinación Ru-Pt/C por ejemplo, no generó un aumento en los niveles de conversión y selectividad a 1,2-PG con respecto a un catalizador de $\mathrm{Ru} / \mathrm{C}$, mientras que la combinación $\mathrm{Ru}-\mathrm{Au}$ produjo una mayor selectividad a EG y lactato disminuyendo los valores de selectividad a 1,2-PG. Además, la incorporación de Au favoreció la desactivación del catalizador debido al sinterizado de las partículas de $\mathrm{Ru}$ [102].

Por otro lado, la adición de Re y formulación de catalizadores bimetálicos Ru-Re fue favorable en todos los casos mejorando tanto la conversión como la selectividad a 1,2-PG $[105,109,130,131]$. Los primeros estudios reportan que la adición de un precursor de $\operatorname{Re}_{2}(C O)_{10}$ al medio de reacción mejoró notablemente la actividad y la selectividad a 1,2-PG del 
catalizador de $\mathrm{Ru} / \mathrm{Al}_{2} \mathrm{O}_{3}$ [105]. Estudios posteriores mostraron que la formulación de catalizadores de $\mathrm{Ru}$-Re soportados en $\mathrm{SiO}_{2}, \mathrm{Al}_{2} \mathrm{O}_{3}, \mathrm{ZrO}_{2}, \mathrm{TiO}_{2}$ y zeolitas del tipo HZSM-5 y H$\beta$ resultaron en una mejora en los niveles de actividad que fue asignada a la dispersión de las partículas de Ru por la adición de Re, sugiriendo un efecto sinérgico entre ambas especies. El aumento en la selectividad a 1,2-PG con respecto a los catalizadores monometálicos de Ru fue atribuido a un efecto inhibitorio del Re en la formación de productos secundarios, tales como 1-POH y 2-POH [109]. Se ha determinado que la existencia de partículas de $\mathrm{ReO}_{x}$ que interactúen con las partículas de $\mathrm{Ru}^{0}$ son las responsables en la mejora de la dispersión metálica [130]. Dichas partículas otorgan mayor acidez al catalizador [131]. Algunos reportes han indicado que la mejora en la actividad por parte del Re también depende del método de preparación. $\mathrm{Li}$ et al. reportaron la preparación de catalizadores bimetálicos de $\mathrm{Ru}-\mathrm{Re}$ empleando la deposición de un coloide de Ru-polivinilpirrolidona seguido por la impregnación con el precursor de Re. Los resultados mostraron que, frente al método de impregnación convencional, este catalizador presentó una mejor performance debido al menor tamaño de partícula y al alto contenido metálico que es posible alcanzar con este método de preparación [132].

La adición de otros metales como $\mathrm{Cu}, \mathrm{Fe}$, $\mathrm{Co}$ y $\mathrm{Ni}$ ha tenido un impacto positivo en los niveles de actividad del Ru. Feng et al. estudiaron la adición de esos metales a catalizadores de $\mathrm{Ru} / \mathrm{TiO}_{2}$, mostrando que, si bien la conversión disminuye, se produce un aumento en la selectividad a 1,2-PG. La formulación de un catalizador de Ru-Co resultó ser la mejor, aun empleando otros soportes como $\mathrm{SiO}_{2}, \mathrm{ZrO}_{2}$ y $\mathrm{Al}_{2} \mathrm{O}_{3}[128,129,133]$.

La adición de Fe a un catalizador de $\mathrm{Ru} / \mathrm{CNT}$, promovió una mejora en la actividad y estabilidad del catalizador, que pudo ser empleado durante 5 ciclos de reacción de $12 \mathrm{~h}$ cada uno. Los resultados fueron atribuidos a la formación de óxidos de hierro en la periferia de las partículas de $\mathrm{Ru}$ bajo la forma de $\mathrm{FeO}$ y $\mathrm{FeO}_{1+\mathrm{x}}(0<\mathrm{x}<0.5)$. Estas especies interactúan de forma sinérgica con las partículas de $\mathrm{Ru}$ hasta una relación molar $\mathrm{Ru}: \mathrm{Fe}=2$. La adición de mayores cantidades de Fe provoca una caída en los niveles de actividad debido a un bloqueo superficial del Ru [134].

La preparación de catalizadores bimetálicos de $\mathrm{Ru}-\mathrm{Cu}$ también ha sido reportada en la literatura. Liu et al. prepararon catalizadores soportados sobre soportes de $\mathrm{SiO}_{2}, \mathrm{TiO}_{2}, \mathrm{ZrO}_{2}$, $\mathrm{Al}_{2} \mathrm{O}_{3}$ y zeolitas $\mathrm{HY}$ y NaY. De todos los catalizadores preparados, el $\mathrm{Ru}-\mathrm{Cu} / \mathrm{ZrO}_{2}$ con una relación molar $\mathrm{Cu}: \mathrm{Ru}=1: 10$, mostró la mejor performance, debido no sólo a la acidez del soporte sino además al efecto sinérgico entre el $\mathrm{Ru}$ y $\mathrm{Cu}$ por la transferencia de electrones del $\mathrm{Ru}$ al $\mathrm{Cu}$ [127]. Salazar et al estudiaron catalizadores de $\mathrm{Ru}-\mathrm{Cu} / \mathrm{TiO}_{2}$ y encontraron el máximo rendimiento a 1,2-PG para una relación másica $\mathrm{Cu}: \mathrm{Ru}=1: 1$, lo que fue atribuido a la interacción entre el $\mathrm{Cu}$ y el $\mathrm{Ru}$. La fase metálica de $\mathrm{Cu}$ diluye las partículas de Ru que son las responsables de promover las reacciones que favorecen la formación de EG [135]. 
Tabla 9-2. Hidrogenólisis 1,2-PG en reactores batch en fase líquida empleando catalizadores bimetálicos de Ru.

\begin{tabular}{|c|c|c|c|c|c|c|c|c|}
\hline Catalizador & $\mathrm{T}\left({ }^{\circ} \mathrm{C}\right)$ & $\mathrm{P}$ (bar) & $\mathrm{m}_{\mathrm{gli}} / \mathrm{m}_{\mathrm{c}}(\mathrm{g} / \mathrm{g})$ & $t(h)$ & $\mathrm{X}_{\mathrm{GLI}}(\%)$ & $\mathrm{S}_{1,2-\mathrm{PG}}(\%)$ & $\mathrm{R}_{1,2-\mathrm{PG}}(\%)$ & Ref. \\
\hline $\mathrm{Ru}-\mathrm{Pt} / \mathrm{C}$ & 200 & $40\left(\mathrm{H}_{2}\right)$ & $\mathrm{NI}$ & 5 & 42.0 & 24.0 & 10.0 & [102] \\
\hline $\mathrm{Ru}-\mathrm{Cu} /$ Bentonita & 230 & $100\left(\mathrm{H}_{2}\right)$ & 5.4 & 18 & 100.0 & 86.4 & 86.4 & [125] \\
\hline $\mathrm{Ru}-\mathrm{Cu} / \mathrm{Al}_{2} \mathrm{O}_{3}$ & 200 & $25\left(\mathrm{H}_{2}\right)$ & 17.5 & 24 & 45.0 & 94.0 & 42.3 & [126] \\
\hline $\mathrm{Ru}-\mathrm{Cu} / \mathrm{ZrO}_{2}$ & 180 & $80\left(\mathrm{H}_{2}\right)$ & 6.9 & 24 & 100.0 & 84.0 & 84.0 & [127] \\
\hline $\mathrm{Ru}-\mathrm{Cu} / \mathrm{TiO}_{2}$ & 200 & $25\left(\mathrm{H}_{2}\right)$ & 17.5 & 12 & 53.9 & 93.2 & 50.2 & [135] \\
\hline \multirow{2}{*}{$\mathrm{Ru}-\mathrm{Co} / \mathrm{ZrO}_{2}$} & 180 & $50\left(\mathrm{H}_{2}\right)$ & 12.6 & 12 & 65.7 & 57.5 & 37.7 & [129] \\
\hline & 180 & $50\left(\mathrm{H}_{2}\right)$ & 12.6 & 10 & 56.2 & 70.3 & 39.5 & [133] \\
\hline $\mathrm{Ru}-\mathrm{Co} / \mathrm{TiO}_{2}$ & 180 & $50\left(\mathrm{H}_{2}\right)$ & 63.1 & 12 & 72.8 & 41.7 & 30.3 & [128] \\
\hline $\mathrm{Ru}-\mathrm{Au} / \mathrm{C}$ & 200 & $40\left(\mathrm{H}_{2}\right)$ & NI & 5 & 25.0 & 30.0 & 7.5 & [102] \\
\hline $\mathrm{Ru}-\mathrm{Re} / \mathrm{ZrO}_{2}$ & 160 & $80\left(\mathrm{H}_{2}\right)$ & 29.4 & 8 & 56.9 & 47.2 & 26.8 & [109] \\
\hline \multirow{2}{*}{$\mathrm{Ru}-\mathrm{Re} / \mathrm{SiO}_{2}$} & 160 & $80\left(\mathrm{H}_{2}\right)$ & 29.4 & 8 & 51.7 & 44.8 & 23.1 & {$[109,130,131]$} \\
\hline & 125 & $75\left(\mathrm{H}_{2}\right)$ & 29.4 & 8 & 45.0 & 64.7 & 29.2 & [132] \\
\hline $\mathrm{Ru}-\mathrm{Re} / \mathrm{TiO}_{2}$ & 160 & $80\left(\mathrm{H}_{2}\right)$ & 29.4 & 8 & 36.3 & 46.4 & 16.8 & [109] \\
\hline $\mathrm{Ru}-\mathrm{Re} / \mathrm{H} \beta$ & 160 & $80\left(\mathrm{H}_{2}\right)$ & 29.4 & 8 & 52.8 & 42.8 & 22.5 & [109] \\
\hline Ru-Re/HSZM-5 & 160 & $80\left(\mathrm{H}_{2}\right)$ & 29.4 & 8 & 54.2 & 41.5 & 22.4 & [109] \\
\hline $\mathrm{Ru}-\mathrm{Fe} / \mathrm{CNT}$ & 200 & $40\left(\mathrm{H}_{2}\right)$ & 16.8 & 24 & 100.0 & 50.0 & 50.0 & [134] \\
\hline
\end{tabular}

$\mathrm{X}_{\mathrm{GLI}}$ : conversión de glicerol, $\mathrm{S}_{1,2-\mathrm{PG}}$ selectividad a 1,2-PG, $\mathrm{R}_{1,2-\mathrm{PG}}$ rendimiento a 1,2-PG

\subsubsection{Platino}

La Tabla 10-2 resume las condiciones operativas y los resultados de actividad de los catalizadores de Pt en reactores batch. Los ensayos de evaluación catalítica se realizaron a temperaturas entre $160{ }^{\circ} \mathrm{C}$ y $230{ }^{\circ} \mathrm{C}$, presiones entre 6 bar y 60 bar de $\mathrm{H}_{2}$, tiempos de reacción entre $5 \mathrm{~h}$ y $24 \mathrm{~h}$, y una relación de masa de glicerol a masa de catalizador $\left(\mathrm{m}_{\mathrm{gli}} / \mathrm{m}_{\mathrm{c}}\right.$ ) entre 0.4 y 30 .

Desde el punto de vista de la fase activa, los catalizadores de Pt han resultado menos activos que catalizadores de $\mathrm{Ru}$, pero más activos que catalizadores de $\mathrm{Pd}, \mathrm{Cu}$ y Ni. Dasari et al. realizaron un screening de catalizadores y determinaron que, comparativamente, el catalizador de $\mathrm{Pt} / \mathrm{C}$ resulta menos activo que el catalizador de $\mathrm{Ru} / \mathrm{C}$, no obstante, la selectividad a 1,2-PG es mayor que con Pt/C [7]. La mayor selectividad a 1,2-PG ha sido atribuida a la menor capacidad para la ruptura de enlaces C-C para el catalizador de $\mathrm{Pt} / \mathrm{C}$ en comparación con catalizadores de $\mathrm{Ru} / \mathrm{C}$ [102].

Von Held Soares et al. prepararon catalizadores de Pt, Pd y Ni soportados en $\mathrm{Fe}_{3} \mathrm{O}_{4}$. El orden de actividad encontrado fue: $\mathrm{Pt}>\mathrm{Pd}>\mathrm{Ni}$. Los resultados mostraron que, en el caso del $\mathrm{Pt}$, un efecto de spillover también contribuye a mejorar la performance catalítica [136]. Recientemente, Wei et al. prepararon catalizadores de $\mathrm{Pt}, \mathrm{Cu}, \mathrm{Ru}$ y otras combinaciones bimetálicas soportados en carburos de tungsteno, $\mathrm{WC}_{\mathrm{x}}$. Los resultados mostraron que Pt/WC permitió alcanzar los mayores rendimientos a 1,2-PG [137]. 
Tabla 10-2. Hidrogenólisis 1,2-PG en reactores batch en fase líquida empleando catalizadores soportados de Pt.

\begin{tabular}{|c|c|c|c|c|c|c|c|c|}
\hline Catalizador & $\mathrm{T}\left({ }^{\circ} \mathrm{C}\right)$ & P (bar) & $\mathrm{m}_{\mathrm{gli}} / \mathrm{m}_{\mathrm{c}}(\mathrm{g} / \mathrm{g})$ & $\mathrm{t}(\mathrm{h})$ & $X_{\text {GLI }}(\%)$ & $\mathrm{S}_{1,2-\mathrm{PG}}(\%)$ & $\mathrm{R}_{1,2-\mathrm{PG}}(\%)$ & Ref. \\
\hline \multirow{4}{*}{$\mathrm{Pt} / \mathrm{C}$} & 200 & $14\left(\mathrm{H}_{2}\right)$ & 20.0 & 24 & 34.6 & 82.7 & 28.6 & [7] \\
\hline & 200 & $40\left(\mathrm{H}_{2}\right)$ & * & 5 & 13.0 & 79.0 & 10.2 & {$[102]$} \\
\hline & 220 & $30\left(\mathrm{H}_{2}\right)$ & 8.0 & 20 & 1.8 & 43.6 & 0.7 & {$[146]$} \\
\hline & 160 & $40\left(\mathrm{H}_{2}\right)$ & 15.6 & 4 & 57.0 & 73.0 & 41.6 & [148] \\
\hline $\mathrm{Pt} / \mathrm{WC} \mathrm{x}_{\mathrm{x}}$ & 220 & $40\left(\mathrm{H}_{2}\right)$ & 28.0 & 8 & 79.2 & 39.3 & 31.1 & [137] \\
\hline $\mathrm{Pt} / \mathrm{MgO}$ & 220 & $30\left(\mathrm{H}_{2}\right)$ & 8.0 & 20 & 50.0 & 81.2 & 40.6 & [146] \\
\hline $\mathrm{Pt} / \mathrm{HLT}$ & 220 & $30\left(\mathrm{H}_{2}\right)$ & 8.0 & 20 & 92.1 & 93.0 & 85.6 & [146] \\
\hline \multirow{3}{*}{$\mathrm{Pt} / \mathrm{Al}_{2} \mathrm{O}_{3}$} & 220 & $30\left(\mathrm{H}_{2}\right)$ & 8.0 & 20 & 39.0 & 81.2 & 31.6 & [146] \\
\hline & 180 & $6\left(\mathrm{H}_{2}\right)$ & 12.5 & 15 & 16.0 & 44.0 & 7.0 & [142] \\
\hline & 220 & $80\left(\mathrm{H}_{2}\right)$ & 17.7 & 120 & 60.0 & 45.0 & 27.0 & [145] \\
\hline $\mathrm{Al} / \mathrm{Pt} / \mathrm{Al}_{2} \mathrm{O}_{3}$ & 220 & $80\left(\mathrm{H}_{2}\right)$ & 17.7 & 120 & 90.0 & 64.0 & 57.6 & [145] \\
\hline $\mathrm{Pt} / \mathrm{CeO}_{2}$ & 180 & $6\left(\mathrm{H}_{2}\right)$ & 12.5 & 15 & 33.0 & 35.0 & 11.5 & [142] \\
\hline $\mathrm{Pt} / \mathrm{La}_{2} \mathrm{O}_{3}$ & 180 & $6\left(\mathrm{H}_{2}\right)$ & 12.5 & 15 & 33.0 & 38.0 & 12.5 & [142] \\
\hline $\mathrm{Pt} / \mathrm{ZnO}$ & 180 & $6\left(\mathrm{H}_{2}\right)$ & 12.5 & 15 & 28.0 & 32.0 & 8.9 & [142] \\
\hline $\mathrm{Pt} / \mathrm{Fe}_{3} \mathrm{O}_{4}$ & 230 & $20\left(\mathrm{H}_{2}\right)$ & 30.0 & 16 & 81.0 & 79.3 & 64.2 & [136] \\
\hline $\mathrm{Pt} / \mathrm{TiO}_{2}$ & 210 & $60\left(\mathrm{H}_{2}\right)$ & 0.45 & 6 & 23.0 & 49.0 & 11.2 & [141] \\
\hline $\mathrm{Pt} / \mathrm{Al}_{2} \mathrm{O}_{3}-\mathrm{SiO}_{2}$ & 210 & $60\left(\mathrm{H}_{2}\right)$ & 0.45 & 6 & 10.0 & 61.0 & 6.1 & [141] \\
\hline $\mathrm{Pt} / \mathrm{H}-\mathrm{ZSM} 5$ & 220 & $30\left(\mathrm{H}_{2}\right)$ & 8.0 & 20 & 4.0 & 19.5 & 0.7 & [146] \\
\hline $\mathrm{Pt} / \mathrm{H} \beta$ & 220 & $30\left(\mathrm{H}_{2}\right)$ & 8.0 & 20 & 7.0 & 9.5 & 0.6 & [146] \\
\hline $\mathrm{Pt} / \mathrm{SiO}_{2}-\mathrm{Al}_{2} \mathrm{O}_{3}$ & 220 & $45\left(\mathrm{H}_{2}\right)$ & 0.006 & 24 & 90.0 & 11.2 & 10.0 & [138] \\
\hline $\mathrm{Pt} / \mathrm{CaCO}_{3}$ & 200 & $40\left(\mathrm{H}_{2}\right)$ & 20.0 & 18 & 45.0 & 22.5 & 10.1 & [139] \\
\hline $\mathrm{Pt} / \mathrm{Nb}_{2} \mathrm{O}_{5}-\mathrm{Al}_{2} \mathrm{O}_{3}$ & 220 & $50\left(\mathrm{H}_{2}\right)$ & 28.0 & 10 & 78.0 & 95.0 & 74.1 & [147] \\
\hline
\end{tabular}

*Los autores reportan sustrato/superficie metálica $=700$

XGLI: conversión de glicerol, $\mathrm{S}_{1,2-\mathrm{PG}}$ selectividad a 1,2-PG, R1,2-PG: rendimiento a 1,2-PG

Si bien se han empleado catalizadores comerciales de Pt [7,102,138,139], también se ha evaluado la actividad de catalizadores preparados a partir de $\mathrm{H}_{2} \mathrm{PtCl}_{6} \cdot 6 \mathrm{H}_{2} \mathrm{O}$ [102,136,140-145], $\mathrm{Pt}\left(\mathrm{NH}_{3}\right)_{4} \mathrm{Cl}_{2} \mathrm{H}_{2} \mathrm{O}[146,147]$ y $\left(\mathrm{NH}_{4}\right)_{2} \mathrm{PtCl}_{6}$ [137], como precursores. No obstante, a diferencia de los catalizadores de $\mathrm{Ru}$, los trabajos no han reportado estudios sobre el efecto por tipo de precursor empleado o el método de preparación del catalizador. La mayor parte de los estudios se ha focalizado en el rol del soporte y su modificación para lograr buenas dispersiones metálicas y acidez adecuada en los catalizadores, dado que, al igual que con los catalizadores de $\mathrm{Ru}$, la reacción de hidrogenólisis de glicerol resulta sensible a la estructura de los catalizadores de Pt.

En este sentido, se ha reportado se ha reportado el empleo de soportes basados en carbón (C), óxidos de $\mathrm{MgO}, \mathrm{Al}_{2} \mathrm{O}_{3}, \mathrm{SiO}_{2}-\mathrm{Al}_{2} \mathrm{O}_{3}, \mathrm{TiO}_{2}, \mathrm{ZnO}, \mathrm{CeO}_{2}$ y $\mathrm{Fe}_{3} \mathrm{O}_{4}$, zeolitas del tipo HZSM5 y $\mathrm{H} \beta$ e hidrotalcitas (HTL) del tipo $\mathrm{Mg}_{6} \mathrm{Al}_{2}(\mathrm{OH}){ }_{16} \mathrm{CO}_{3} 4 \mathrm{H}_{2} \mathrm{O}$. 
Con respecto al empleo de soportes basados en carbón (C), materiales carbonosos con distintas superficies específicas $\left(\sim 250-1400 \mathrm{~m}^{2} \cdot \mathrm{g}^{-1}\right)$ fueron empleados como soportes de catalizadores preparados por el método de deposición de metal en fase vapor. Los resultados han indicado que se logran buenas dispersiones del Pt con tamaños de partícula entre $1.3 \mathrm{~nm}$ y $2.5 \mathrm{~nm}$ dependiendo de la superficie específica del soporte. Esto permite alcanzar altos niveles de actividad y otorgar a la fase activa una mayor estabilidad frente al sinterizado [148].

Yuan et al. estudiaron catalizadores de $\mathrm{Pt}$ preparados sobre soportes ácidos y alcalinos. Sus resultados mostraron que los soportes más alcalinos conducen a alcanzar altas conversiones y selectividad a 1,2-PG. El orden de actividad encontrado fue el siguiente: HTL $>\mathrm{MgO}>\mathrm{Al}_{2} \mathrm{O}_{3}>\mathrm{H} \beta>\mathrm{H}-\mathrm{Z} 5 \mathrm{M} 5$ [146].

Otros autores han encontrado que los soportes ácidos resultan propicios para obtener altos niveles de actividad. Checa et al. estudiaron catalizadores de Pt soportados en $\mathrm{Al}_{2} \mathrm{O}_{3}$, $\mathrm{CeO}_{2}, \mathrm{La}_{2} \mathrm{O}_{3}$ y $\mathrm{ZnO}$. El orden de actividad de acuerdo al soporte empleado fue el siguiente: $\mathrm{La}_{2} \mathrm{O}_{3}>\mathrm{CeO}_{2}>\mathrm{ZnO}>\mathrm{Al}_{2} \mathrm{O}_{3}$. El aumento de la actividad fue atribuida al orden creciente de acidez de los soportes [142]. Gandarias et al. reportaron que un soporte amorfo de $\mathrm{SiO}_{2}-\mathrm{Al}_{2} \mathrm{O}_{3}$ permite la deshidratación de glicerol a $\mathrm{AcOH}$, debido a sus propiedades ácidas [138]. También se ha reportado que los sitios ácidos presentes en los soportes de $\mathrm{TiO}_{2}$ son los responsables de favorecer las reacciones de deshidratación [141].

Los resultados indican que tanto soportes alcalinos como ácidos permiten preparar catalizadores soportados de Pt. Los soportes alcalinos favorecen la deshidratación de gliceraldehído (GLA) a 2-hidroxiacroleína (2-HA) en el mecanismo de deshidrogenacióndeshidratación-hidrogenación. Los soportes ácidos, por otro lado, favorecen la deshidratación de glicerol a acetol $(\mathrm{AcOH})$ en el mecanismo de deshidrataciónhidrogenación.

Con el objetivo de incrementar la acidez en los soportes, algunos autores han reportado la modificación con promotores ácidos. Rodrigues et al. estudiaron catalizadores de $\mathrm{Pt}$ soportados en $\mathrm{Al}_{2} \mathrm{O}_{3}$ modificada con $\mathrm{Nb}_{2} \mathrm{O}_{5}$. Los resultados mostraron que la adición de $\mathrm{Nb}$ al soporte de $\mathrm{Al}_{2} \mathrm{O}_{3}$ tiene varias ventajas. Por un lado, genera óxidos de $\mathrm{Nb}$ que dotan al soporte de acidez de tipo BrØnsted. Por otra parte, la baja dispersión de los óxidos de $\mathrm{Nb}$ genera una migración de estas partículas hacia el Pt formando sitios activos de alta interacción que favorecen la ruptura del enlace C-O. Además, la presencia de $\mathrm{Nb}$ favorece la reducción de $\mathrm{Pt}$ [147].

También se ha reportado que los sitios ácidos del soporte deben encontrarse lo más próximos posibles a los átomos de Pt. En este sentido, Du et al. modificaron un catalizador de $\mathrm{Pt} / \mathrm{Al}_{2} \mathrm{O}_{3}$ mediante la técnica de deposición atómica en capas. Si bien no hubo un cambio en la acidez total del catalizador, los resultados de la deshidratación de glicerol para dar $\mathrm{AcOH}$ confirmaron la mayor actividad en el catalizador modificado, indicando que la proximidad metal-sitio ácido mejora el mecanismo bifuncional de deshidratación-hidrogenación [145].

La Tabla 11-2 resume las condiciones operativas y los resultados de actividad de los catalizadores bimetálicos de $\mathrm{Pt}$ en reactores batch. Los ensayos de evaluación catalítica se realizan a temperaturas entre $170{ }^{\circ} \mathrm{C}$ y $250{ }^{\circ} \mathrm{C}$, presiones entre 4 bar y 40 bar de $\mathrm{H}_{2}$, tiempos 
de reacción entre 2 h y 17 h, y una relación de masa de glicerol a masa de catalizador $\left(\mathrm{m}_{\mathrm{gli}} / \mathrm{m}_{\mathrm{c}}\right)$ entre 2 y 63.

Tabla 11-2. Hidrogenólisis 1,2-PG en reactores batch en fase líquida empleando catalizadores bimetálicos de Pt.

\begin{tabular}{lcccccccc}
\hline Catalizador & $\mathrm{T}\left({ }^{\circ} \mathrm{C}\right)$ & $\mathrm{P}(\mathrm{bar})$ & $\mathrm{m}_{\mathrm{gli}} / \mathrm{m}_{\mathrm{c}}(\mathrm{g} / \mathrm{g})$ & $\mathrm{t}(\mathrm{h})$ & $\mathrm{X}_{\mathrm{GLI}}(\%)$ & $\mathrm{S}_{1,2-\mathrm{PG}}(\%)$ & $\mathrm{R}_{1,2-\mathrm{PG}}(\%)$ & Ref. \\
\hline $\mathrm{Pt}-\mathrm{Re} / \mathrm{C}$ & 170 & $40\left(\mathrm{H}_{2}\right)$ & $\mathrm{NI}$ & 5 & 50.0 & 36.0 & 18.0 & {$[149]$} \\
\hline $\mathrm{Pt}-\mathrm{Re} / \mathrm{CNT}$ & 170 & $40\left(\mathrm{H}_{2}\right)$ & 3.7 & 8 & 51.2 & 55.0 & 28.2 & {$[150]$} \\
\hline $\mathrm{Pt}-\mathrm{Sn} / \mathrm{SiO}_{2}$ & 200 & $4\left(\mathrm{~N}_{2}\right)$ & 4.1 & 2 & 54.0 & 59.0 & 31.8 & {$[153]$} \\
\hline $\mathrm{Pt}-\mathrm{Fe} / \gamma-\mathrm{Al}_{2} \mathrm{O}_{3}$ & 220 & $26\left(\mathrm{H}_{2}\right)$ & 63.1 & 12 & 33.5 & 61.2 & 20.5 & {$[154]$} \\
\hline $\mathrm{Pt}-\mathrm{Au} / \mathrm{TiO}_{2}$ & 150 & $7\left(\mathrm{H}_{2}\right)$ & 4.7 & 16 & 68.0 & 90.0 & 61.2 & {$[152]$} \\
\hline $\mathrm{Pt}-\mathrm{Ni} / \mathrm{Al}_{2} \mathrm{O}_{3}-\mathrm{CeO}_{2}-\mathrm{ZrO}_{2}$ & 250 & $12\left(\mathrm{~N}_{2}\right)$ & 2.5 & 2 & 61.0 & 70.0 & 42.7 & {$[143]$} \\
\hline $\mathrm{Pt}-\mathrm{Ni} / \gamma-\mathrm{Al}_{2} \mathrm{O}_{3}$ & 240 & $10\left(\mathrm{~N}_{2}\right)$ & 21.0 & 3 & 71.4 & 52.4 & 37.4 & {$[144]$} \\
\hline $\mathrm{Pt}-\mathrm{Ir}-\mathrm{ReO} \times \mathrm{SiO}_{2}$ & 190 & $20(\mathrm{Ar})$ & 20.0 & 17 & 78.0 & 42.0 & 32.7 & {$[151]$} \\
\hline
\end{tabular}

NI: no informado

XGLI: conversión de glicerol, $\mathrm{S}_{1,2-\mathrm{PG}}$ selectividad a 1,2-PG, R1,2-PG: rendimiento a 1,2-PG

Daniel et al. estudiaron catalizadores de $\mathrm{Pt}-\mathrm{Re} / \mathrm{C}$ que resultaron efectivos para la producción de 1,2-PG, debido a la formación de una aleación Pt-Re con tamaños de partícula menor a $2 \mathrm{~nm}$. Estos catalizadores resultaron más activos y selectivos a 1,2-PG que los catalizadores monometálicos de Pt/C y Re/C [149]. También evaluaron catalizadores de Pt$\mathrm{Re} / \mathrm{CNT}$, que resultaron mejores a los catalizadores Pt-Re/C. Los mejores resultados se obtuvieron con el catalizador con $5 \% \mathrm{p} / \mathrm{p}$ de $\mathrm{Pt}$, una relación molar $\mathrm{Pt}: \mathrm{Re}=1: 1$, y partículas del orden de 1,5 nm [150]. Recientemente, Liu et al. reportaron el uso de un catalizador de $\mathrm{Pt} / \mathrm{SiO}_{2}$ modificado con Ir-ReOx. Las especies de Pt-Ir resultaron activas para las reacciones de ruptura de enlaces $\mathrm{C}-\mathrm{C}$ y la formación de $\mathrm{H}_{2}$, mientras que las especies de $\mathrm{ReO}$ × resultaron activas para las reacciones de ruptura de enlaces C-O [151].

A diferencia de los catalizadores de $\mathrm{Ru}$, la adición de Au a catalizadores de Pt mejoró la performance de los catalizadores monometálicos. En este sentido, catalizadores bimetálicos de $\mathrm{Pt}$-Au fueron preparados sobre soportes de $\mathrm{MgO}, \mathrm{SiO}_{2}, \mathrm{ZrO}_{2}$ sulfatada, H-Mordenita, MCM-41 y $\mathrm{TiO}_{2}$. De todos los soportes empleados, el catalizador de $\mathrm{Pt}-\mathrm{Au} / \mathrm{TiO}_{2}$ resultó el catalizador con partículas de Pt-Au más dispersas (3.7 nm) [152].

Otros metales como Sn, Fe y Ni también fueron empleados para la preparación de fases bimetálicas de Pt. Barbelli et a. prepararon catalizadores de Pt-Sn soportados sobre $\mathrm{SiO}_{2}$ mediante la técnica organometálica de superficies sobre metales (QOMS/MS). Para una relación $\mathrm{Sn}: \mathrm{Pt}=0,2: 1$ se obtuvo la mejor performance. Los resultados mostraron la presencia de especies $\mathrm{Sn}^{+n}$ que actúan como sitios ácidos de Lewis sobre las cuales se facilita la adsorción del enlace $\mathrm{C}-\mathrm{OH}$ de la molécula de glicerol y posterior ruptura del enlace C-O [153].

Yan et al. prepararon catalizadores de $\mathrm{Pt}-\mathrm{Ni} / \gamma-\mathrm{Al}_{2} \mathrm{O}_{3}$ y los resultados evidenciaron la presencia de una aleación Pt-Ni que condujo a obtener el máximo rendimiento a 1,2-PG, empleando una relación molar Pt:Ni = 1:1 [144]. Barbelli et al. estudiaron catalizadores de Pt$\mathrm{Ni}$ soportados en $\mathrm{Al}_{2} \mathrm{O}_{3}$ modificada por adición de $\mathrm{CeO}_{2}$ y $\mathrm{ZrO}_{2}$. Los resultados evidenciaron 
la formación de una aleación del tipo $\mathrm{PtNi}$ que condujo a obtener una conversión de glicerol del $61 \%$ con una selectividad a 1,2-PG del $70 \%$ [143].

La adición de Fe a catalizadores de $\mathrm{Pt} / \gamma-\mathrm{Al}_{2} \mathrm{O}_{3}$, en una relación $\mathrm{Pt}: \mathrm{Fe}=1: 2$, también promovió una mayor actividad hacia la formación de 1,2-PG debido a la generación de nuevos sitios activos en los que intervienen tanto átomos de Pt como de Fe [154].

\subsubsection{Paladio}

Los catalizadores soportados basados en Pd como fase activa han sido los menos explorados en la literatura que el $\mathrm{Ru}$ y Pt. La Tabla 12-2 resume las condiciones operativas y los resultados de actividad de los catalizadores de $\mathrm{Pd}$ en reactores batch. Como puede observarse en la mayoría de los trabajos de investigación, los ensayos de evaluación catalítica se realizan a temperaturas entre $150{ }^{\circ} \mathrm{C}$ y $200{ }^{\circ} \mathrm{C}$, presiones entre 5 bar y 60 bar de $\mathrm{H}_{2}$. Los tiempos de reacción son entre $3 \mathrm{~h}$ y $24 \mathrm{~h}$, y una relación de masa de glicerol a masa de catalizador $\left(\mathrm{m}_{\mathrm{gli}} / \mathrm{m}_{\mathrm{c}}\right)$ entre 4 y 20.

Tabla 12-2. Hidrogenólisis 1,2-PG en reactores batch en fase líquida empleando catalizadores soportados de $P d$.

\begin{tabular}{lcccccccc}
\hline Catalizador & $\mathrm{T}\left({ }^{\circ} \mathrm{C}\right)$ & $\mathrm{P}(\mathrm{bar})$ & $\mathrm{m}_{\mathrm{gli}} / \mathrm{m}_{\mathrm{c}}(\mathrm{g} / \mathrm{g})$ & $\mathrm{t}(\mathrm{h})$ & $\mathrm{X}_{\mathrm{GLI}}(\%)$ & $\mathrm{S}_{1,2-\mathrm{PG}}(\%)$ & $\mathrm{R}_{1,2-\mathrm{PG}}(\%)$ & Ref. \\
\hline \multirow{2}{*}{$\mathrm{Pd} / \mathrm{C}$} & 200 & $14\left(\mathrm{H}_{2}\right)$ & 20 & 24 & 11.2 & 57.1 & 6.4 & {$[7]$} \\
\cline { 2 - 8 } & 200 & $50\left(\mathrm{H}_{2}\right)$ & 20 & 10 & 2.1 & 63.2 & 1.3 & {$[80]$} \\
\hline $\mathrm{Pd} / \mathrm{SiO}_{2}$ & 200 & $50\left(\mathrm{H}_{2}\right)$ & 20 & 10 & 2.4 & 65.3 & 1.6 & {$[80]$} \\
\hline $\mathrm{Pd} / \mathrm{ZrO}_{2}$ & 200 & $60\left(\mathrm{H}_{2}\right)$ & 14.2 & 3 & 21.0 & 90.5 & 19.0 & {$[104]$} \\
\hline \multirow{2}{*}{$\mathrm{Pd} / \mathrm{Fe}_{2} \mathrm{O}_{3}$} & 180 & $5\left(\mathrm{~N}_{2}\right)$ & $\mathrm{NI}$ & 24 & 100.0 & 90.0 & 90.0 & {$[156]$} \\
& 180 & $5\left(\mathrm{~N}_{2}\right)$ & 6.0 & 24 & 40.4 & 26.6 & 10.7 & {$[158]$} \\
\hline \multirow{2}{*}{$\mathrm{Pd} / \mathrm{Fe}_{3} \mathrm{O}_{4}$} & 180 & $40\left(\mathrm{H}_{2}\right)$ & 5.1 & 24 & 42.8 & 90.2 & 38.6 & {$[157]$} \\
\hline \multirow{2}{*}{$\mathrm{Pd} / \mathrm{CoO}$} & 200 & $50\left(\mathrm{H}_{2}\right)$ & 1.5 & 12 & 37.5 & 95.0 & 35.6 & {$[159]$} \\
\hline $\mathrm{Pd} /$ Bentonita & 180 & $5\left(\mathrm{~N}_{2}\right)$ & 6.0 & 24 & 100.0 & 55.9 & 55.9 & {$[158]$} \\
\hline & 180 & $5\left(\mathrm{~N}_{2}\right)$ & 6.0 & 24 & 66.5 & 47.7 & 31.7 & {$[158]$} \\
\hline
\end{tabular}

${ }^{*} \mathrm{NI}$ no informado

XGL: conversión de glicerol, $\mathrm{S}_{1,2-\mathrm{PG}}$ selectividad a 1,2-PG, R1,2-PG: rendimiento a 1,2-PG

A diferencia de los catalizadores de $\mathrm{Ru}$ y $\mathrm{Pt}$, los catalizadores de Pd han resultado ser más selectivos hacia la formación de 1,2-PG debido a su capacidad de ruptura del enlace C$\mathrm{O}$, pero han resultado poco activos. Al respecto, se han evaluado catalizadores comerciales de $\mathrm{Pd} / \mathrm{C}$ que mostraron bajos niveles de actividad, pero buena selectividad a 1,2-PG [7,80]. También se ha observado este efecto empleando catalizadores de Pd preparados sobre $\mathrm{SiO}_{2}$ [80] y $\mathrm{ZrO}_{2}$ [104]. Hamzah et al. prepararon catalizadores soportados sobre una bentonita, y 
mostraron una buena selectividad a 1,2-PG, pero con bajos rendimientos globales debido a las bajas conversiones obtenidas [155].

Para la preparación de catalizadores de $\mathrm{Pd}$ se han empleado $\mathrm{Pd}\left(\mathrm{NO}_{3}\right)_{2}$ [80], $\mathrm{PdCl}_{2}$ [104,140,156-158], $\mathrm{Pd}(\mathrm{AcO})_{2}$ y $\mathrm{Na}_{2} \mathrm{PdCl}_{4}$ [159] como precursores, aunque también se ha reportado el uso de catalizadores comerciales $[7,80]$.

Con respecto al precursor empleado, recientemente se ha reportado siguiente orden de actividad: $\mathrm{PdCl}_{2}>\mathrm{Pd}\left(\mathrm{NO}_{3}\right)_{2} \sim \mathrm{Pd}(\mathrm{AcO})_{2}$ para catalizadores de $\mathrm{Pd} / \mathrm{SBA}-15$ [160]. Se ha indicado que la presencia de $\mathrm{Cl}$ - provenientes del precursor $\mathrm{PdCl}_{2}$ permite mejorar las propiedades de reducibilidad del catalizador, generando una mayor dispersión del Pd, y por lo tanto mejorando los niveles de actividad [161].

Con respecto al método de preparación, el método de impregnación ha sido menos eficiente que los métodos de coprecipitación e hidrotermal, debido a que genera menores dispersiones y por lo tanto menores niveles de actividad. Musolino et al. obtuvieron altos rendimientos a 1,2-PG empleando catalizadores de $\mathrm{Pd} / \mathrm{Fe}_{2} \mathrm{O}_{3}$ preparados mediante el método de coprecipitación, utilizando $\mathrm{PdCl}_{2}$ y $\mathrm{Fe}\left(\mathrm{NO}_{3}\right)_{3}$ como precursores en un medio básico de $\mathrm{Na}_{2} \mathrm{CO}_{3}$ y 2-propanol como solvente [156]. En presencia de dioxano como solvente, el catalizador de $\mathrm{Pd} / \mathrm{Fe}_{2} \mathrm{O}_{3}$ también resultó activo y selectivo [157]. En otro de sus trabajos, los autores compararon los catalizadores de $\mathrm{Pd}$ preparados por impregnación a humedad incipiente con los preparados por coprecipitación [158]. Los resultados mostraron la mayor actividad de catalizadores preparados por coprecipitación, siguiendo el orden de actividad:

$\mathrm{Pd} / \mathrm{Fe}_{3} \mathrm{O}_{4}(\mathrm{cop})>\mathrm{Pd} / \mathrm{Fe}_{2} \mathrm{O}_{3}(\mathrm{cop})>\mathrm{Pd} / \mathrm{Fe}_{2} \mathrm{O}_{4}(\mathrm{imp})>\mathrm{Pd} / \mathrm{Fe}_{2} \mathrm{O}_{3}$ (imp)

Catalizadores de $\mathrm{Pd} / \mathrm{CoO}$ fueron preparados mediante el método de coprecipitación, empleando $\mathrm{PdCl}_{2}$ y $\mathrm{Co}\left(\mathrm{NO}_{3}\right)_{2}$ en un medio básico de $\mathrm{Na}_{2} \mathrm{CO}_{3}$. El catalizador de $\mathrm{Pd} / \mathrm{CoO}$ resultó más activo que $\mathrm{Pd} / \mathrm{Fe}_{2} \mathrm{O}_{3}$, debido a la mayor interacción metal-soporte [157]. Se determinó que el catalizador de $\mathrm{Pd} / \mathrm{CoO}$ preparado por impregnación tiene menor nivel de actividad que el catalizador preparado por coprecipitación [158].

Otros trabajos reportan catalizadores de $\mathrm{Pd} / \mathrm{Fe}_{2} \mathrm{O}_{3}$ preparados por deposiciónprecipitación de $\mathrm{Pd}$ empleando una solución de $\mathrm{Na}_{2} \mathrm{PdCl}_{4}$ y dos soportes de $\mathrm{Fe}_{2} \mathrm{O}_{3}$ preparados por precipitación y tratamiento hidrotermal. Los resultados mostraron una mayor actividad y selectividad para el catalizador basado en $\mathrm{Fe}_{2} \mathrm{O}_{3}$ preparado por el método hidrotermal. La mayor dispersión de las partículas metálicas de Pd sobre este soporte y la existencia de vacancias de oxígeno sobre la superficie catalítica serían los factores responsables de los resultados obtenidos [159].

También se han empleado catalizadores bimetálicos de Pd basados en Pd-Re [160,162], Pd-Cu [163,164], Pd-Zn [165,166] y Pd-Ni [167].

La Tabla 13-2 resume las condiciones operativas y los resultados de actividad de los catalizadores bimetálicos de $\mathrm{Pd}$ en reactores batch. Los ensayos de evaluación catalítica se realizan a temperaturas entre $200{ }^{\circ} \mathrm{C}$ y $230{ }^{\circ} \mathrm{C}$, presiones entre 20 bar y 80 bar de $\mathrm{H}_{2}$, tiempos de reacción entre 4 h y 18 h, y una relación de masa de glicerol a masa de catalizador $\left(\mathrm{mgli}_{\mathrm{gli}} / \mathrm{m}_{\mathrm{c}}\right)$ entre 6 y 52. 
Tabla 13-2. Hidrogenólisis 1,2-PG en reactores batch en fase líquida empleando catalizadores bimetálicos de Pd.

\begin{tabular}{lcccccccc}
\hline Catalizador & $\mathrm{T}\left({ }^{\circ} \mathrm{C}\right)$ & $\mathrm{P}(\mathrm{bar})$ & $\mathrm{m}_{\text {gli }} / \mathrm{m}_{\mathrm{c}}(\mathrm{g} / \mathrm{g})$ & $\mathrm{t}(\mathrm{h})$ & $\mathrm{X}_{\mathrm{GLI}}(\%)$ & $\mathrm{S}_{1,2-\mathrm{PG}}(\%)$ & $\mathrm{R}_{1,2-\mathrm{PG}}(\%)$ & Ref. \\
\hline $\mathrm{Pd}-\mathrm{Cu} / \mathrm{Mg}_{5,6-\mathrm{x}} \mathrm{Al}_{2} \mathrm{O}_{8,6-\mathrm{x}}$ & 200 & $20\left(\mathrm{H}_{2}\right)$ & 6.0 & 10 & 95.0 & 96.1 & 91.2 & {$[163]$} \\
\hline $\mathrm{Pd}-\mathrm{CuCr} 2 \mathrm{O}_{4}$ & 220 & $40\left(\mathrm{H}_{2}\right)$ & 50.0 & 18 & 100.0 & 93.9 & 93.9 & {$[164]$} \\
\hline $\mathrm{Pd}-\mathrm{Ni}$ & 220 & $60\left(\mathrm{H}_{2}\right)$ & 21.0 & 12 & 63.5 & 59.4 & 37.7 & {$[167]$} \\
\hline \multirow{2}{*}{$\mathrm{Pd}-\mathrm{Re} / \mathrm{SBA}-15$} & 200 & $80\left(\mathrm{H}_{2}\right)$ & 29.4 & 18 & 45.1 & 60.4 & 27.2 & {$[160]$} \\
\hline & 200 & $80\left(\mathrm{H}_{2}\right)$ & 29.4 & 18 & 72.2 & 41.6 & 30.0 & {$[162]$} \\
\hline $\mathrm{Pd}-\mathrm{Zn} / \mathrm{ZrO} 2$ & 220 & $60\left(\mathrm{H}_{2}\right)$ & 50.0 & 4 & 40.0 & 91.5 & 36.6 & {$[165]$} \\
\hline $\mathrm{Pd}-\mathrm{Zn} / \mathrm{ZnO}-\mathrm{Al}$ & 230 & $30\left(\mathrm{H}_{2}\right)$ & 52.6 & 6 & 70.1 & 92.6 & 64.9 & {$[166]$} \\
\hline
\end{tabular}

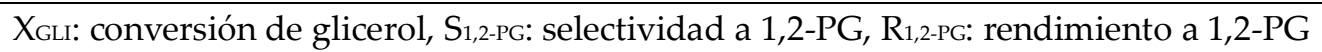

Li et al. estudiaron catalizadores de Pd-Re/SBA-15 y reportaron que la formación de partículas de $\mathrm{ReO}_{x}$ aumentan la acidez del catalizador y mejoran su reducibilidad, produciendo una mejora en los niveles de actividad. Los mejores resultados se obtuvieron con un contenido del $5 \%$ p/p de Pd y $10 \%$ p/p de Re [160]. En otro de sus trabajos, los autores reportaron que la adición de Re disminuye el tamaño promedio del Pd y el estado de oxidación de las partículas de $\mathrm{ReO}_{x}$ es mucho mayor en el catalizador Pd-Re/SBA-15 que en catalizador Re/SBA-15 [162].

Catalizadores de $\mathrm{Pd}-\mathrm{Cu}$ preparados por el método de coprecipitación con los precursores $\mathrm{PdCl}_{2}$ y $\mathrm{Cu}\left(\mathrm{NO}_{3}\right)_{2}$ y sales de $\mathrm{Mg}\left(\mathrm{NO}_{3}\right)_{2}$ y $\mathrm{Al}\left(\mathrm{NO}_{3}\right)_{3}$ permitieron obtener sólidos del tipo $\mathrm{Pd}_{\mathrm{x}}-\mathrm{Cu}_{0,4} / \mathrm{Mg}_{5,6-\mathrm{x}} \mathrm{Al}_{2} \mathrm{O}_{8,6-x}$ que resultaron activos y selectivos para la formación de 1,2PG. Los muy buenos resultados de actividad fueron atribuidos a la mayor capacidad de hidrogenación debido al spillover del $\mathrm{H}_{2}$ del $\mathrm{Pd}$ al $\mathrm{Cu}$ [163]. El mismo efecto fue reportado para catalizadores de $\mathrm{Pd}-\mathrm{CuCr}_{2} \mathrm{O}_{4}$. La presencia de $\mathrm{Pd}$ permitió incrementar la velocidad de reacción cerca de 1.7 veces más que la obtenida para catalizadores de $\mathrm{CuCr}_{2} \mathrm{O}_{4}$. Los átomos de $\mathrm{H}$ almacenados en el $\mathrm{Pd}$ difunden hacia el $\mathrm{CuCr}_{2} \mathrm{O}_{4}$ mejorando su reducibilidad y por lo tanto incrementando el número de sitios activos superficiales formados a partir de $\mathrm{Cu}^{0}$ [164].

Sistemas de $\mathrm{Pd}-\mathrm{Zn} / \mathrm{ZrO}_{2}$ también resultaron activos y selectivos debido a la oxofilicidad del $\mathrm{Zn}$ que promueve la ruptura del enlace $\alpha-\mathrm{C}-\mathrm{H}$ en el intermediario 2,3hidroxipropanoxido sobre la superficie de la aleación de Pd-Zn. Los resultados mostraron que este es el paso determinante en la velocidad de reacción y por eso la performance del catalizador de Pd-Zn es mucho mejor que Pd [165]. El efecto del Zn también fue estudiado por $\mathrm{Li}$ et al, quienes encontraron una mejora en la actividad por la formación de nanopartículas de Pd-Zn [166].

\subsubsection{Cobre}

La Tabla 14-2 resume las condiciones operativas y los resultados de actividad de los catalizadores de $\mathrm{Cu}$ soportado en reactores batch. Los ensayos de evaluación catalítica se 
realizan a temperaturas entre $180{ }^{\circ} \mathrm{C}$ y $240{ }^{\circ} \mathrm{C}$, presiones entre 20 bar y 90 bar de $\mathrm{H}_{2}$, tiempos de reacción reportados están entre 5 h y 24 h, y una relación de masa de glicerol a masa de catalizador $\left(\mathrm{mgli}_{\mathrm{gl}} / \mathrm{m}_{\mathrm{c}}\right)$ entre 2 y 62.

La Tabla 13-2 resume las condiciones operativas y los resultados de actividad de los catalizadores de $\mathrm{Cu}$ soportado en reactores de flujo continuo en fase líquida. Los ensayos de evaluación catalítica se realizan a temperaturas entre $190{ }^{\circ} \mathrm{C}$ y $250{ }^{\circ} \mathrm{C}$, presiones entre 25 bar y 60 bar de $\mathrm{H}_{2}$, y WHSV $\left(\mathrm{h}^{-1}\right)$ entre $0.07 \mathrm{~h}^{-1}$ y $2 \mathrm{~h}^{-1}$.

Tabla 14-2. Hidrogenólisis 1,2-PG en reactores batch en fase líquida empleando catalizadores soportados de Cu.

\begin{tabular}{|c|c|c|c|c|c|c|c|c|}
\hline Catalizador & $\mathrm{T}\left({ }^{\circ} \mathrm{C}\right)$ & $\mathrm{P}$ (bar) & $\mathrm{m}_{\mathrm{gli}} / \mathrm{m}_{\mathrm{c}}(\mathrm{g} / \mathrm{g})$ & $\mathrm{t}(\mathrm{h})$ & $\mathrm{X}_{\mathrm{GLI}}(\%)$ & $\mathrm{S}_{1,2 \mathrm{PG}}(\%)$ & $\mathrm{R}_{1,2-\mathrm{PG}}(\%)$ & Ref. \\
\hline $\mathrm{Cu} / \mathrm{Cr}_{2} \mathrm{O}_{3}$ & 200 & $50\left(\mathrm{H}_{2}\right)$ & 20.0 & 10 & 15.1 & 73.8 & 11.1 & [80] \\
\hline \multirow{4}{*}{$\mathrm{Cu} / \mathrm{SiO}_{2}$} & 200 & $90\left(\mathrm{H}_{2}\right)$ & 16.0 & 12 & 25.6 & 95.2 & 24.3 & [66] \\
\hline & 200 & $90\left(\mathrm{H}_{2}\right)$ & 16.0 & 12 & 65.0 & 92.0 & 59.8 & {$[184]$} \\
\hline & 200 & $34\left(\mathrm{H}_{2}\right)$ & 2.5 & 10 & 98.4 & 98.1 & 96.5 & [191] \\
\hline & 210 & $60\left(\mathrm{H}_{2}\right)$ & 14.7 & 8 & 98.4 & 87.0 & 85.6 & {$[194]$} \\
\hline $\mathrm{Cu} / \mathrm{SBA}-15$ & 240 & $80\left(\mathrm{H}_{2}\right)$ & 16.6 & 5 & 52.0 & 96.2 & 50.0 & {$[176]$} \\
\hline \multirow{4}{*}{$\mathrm{Cu} / \gamma-\mathrm{Al}_{2} \mathrm{O}_{3}$} & 210 & $45\left(\mathrm{H}_{2}\right)$ & 10.5 & 12 & 59.3 & 86.6 & 51.3 & {$[168]$} \\
\hline & 220 & $24\left(\mathrm{H}_{2}\right)$ & 62.5 & 8 & 13.8 & 74.0 & 10.2 & {$[171]$} \\
\hline & 200 & $40\left(\mathrm{H}_{2}\right)$ & 7.5 & 24 & 38.0 & 71.0 & 26.9 & {$[177]$} \\
\hline & 200 & $40\left(\mathrm{H}_{2}\right)$ & 9.4 & 24 & 40.0 & 85.0 & 34.0 & [192] \\
\hline $\mathrm{Cu} / \mathrm{TiO}_{2}$ & 200 & $40\left(\mathrm{H}_{2}\right)$ & 9.4 & 24 & 49.0 & 20.0 & 9.8 & [192] \\
\hline \multirow{2}{*}{$\mathrm{Cu} / \mathrm{ZnO}$} & 200 & $20\left(\mathrm{H}_{2}\right)$ & 16.6 & 16 & 37.0 & 92.0 & 34.0 & {$[62]$} \\
\hline & 220 & $42\left(\mathrm{H}_{2}\right)$ & 17.8 & 12 & 35.0 & 81.4 & 28.5 & [50] \\
\hline $\mathrm{Cu} / \mathrm{MgO}$ & 210 & $45\left(\mathrm{H}_{2}\right)$ & 12.5 & 12 & 96.6 & 92.6 & 89.4 & [185] \\
\hline $\mathrm{Cu} / \mathrm{ZnO}-\mathrm{USY}$ & 220 & $35\left(\mathrm{H}_{2}\right)$ & 16.6 & 5 & 95.1 & 58.4 & 55.5 & {$[183]$} \\
\hline $\mathrm{Cu} / \mathrm{HSM}$ & 240 & $80\left(\mathrm{H}_{2}\right)$ & 16.6 & 5 & 43.0 & 91.1 & 39.1 & {$[175]$} \\
\hline $\mathrm{Cu} / \mathrm{DUSY}$ & 200 & $35\left(\mathrm{H}_{2}\right)$ & 16.6 & 10 & 78.7 & 98.6 & 77.3 & {$[182]$} \\
\hline $\mathrm{Cu}_{0.4} / \mathrm{Mg}_{5.6} \mathrm{Al}_{2} \mathrm{O}_{8.6}$ & 180 & $30\left(\mathrm{H}_{2}\right)$ & 7.1 & 20 & 80.0 & 98.2 & 78.5 & [181] \\
\hline
\end{tabular}

XGLI: conversión de glicerol, S1,2-PG: selectividad a 1,2-PG, R1,2-PG: rendimiento a 1,2-PG

Al igual que con otras fases metálicas, se ha reportado que tanto la acidez del soporte como el tamaño de partícula son dos propiedades igualmente importantes a tener en cuenta en el diseño del catalizador.

La mayor parte de los catalizadores soportados basados en $\mathrm{Cu}$ se han preparado mediante la técnica de impregnación a humedad incipiente, empleando $\mathrm{Cu}\left(\mathrm{NO}_{3}\right)_{2}$ como precursor [62,66,80,168-180]. No obstante, esto, se han utilizado métodos de coprecipitación [66,181-183], deposición-precipitación [184-186] e intercambio iónico [174,187]. 
Tabla 15-2. Hidrogenólisis 1,2-PG en reactores de flujo continuo en fase líquida empleando catalizadores soportados de $\mathrm{Cu}$.

\begin{tabular}{|c|c|c|c|c|c|c|c|}
\hline Catalizador & $\mathrm{T}\left({ }^{\circ} \mathrm{C}\right)$ & P (bar) & WHSV $\left(\mathrm{h}^{-1}\right)$ & $X_{\text {GLI }}(\%)$ & $\mathrm{S}_{1,2-\mathrm{PG}}(\%)$ & $\mathrm{R}_{1,2 \mathrm{PG}}(\%)$ & Ref. \\
\hline $\mathrm{Cu} / \mathrm{SBA}-15$ & 250 & $40\left(\mathrm{H}_{2}\right)$ & 0.8 & 96.0 & 92.4 & 88.7 & [187] \\
\hline \multirow{2}{*}{$\mathrm{Cu} / \mathrm{SiO}_{2}$} & 250 & $40\left(\mathrm{H}_{2}\right)$ & 0.8 & 99.6 & 86.4 & 86.0 & {$[187]$} \\
\hline & 200 & $50\left(\mathrm{H}_{2}\right)$ & 0.07 & 100.0 & 98.3 & 98.3 & {$[190]$} \\
\hline $\mathrm{Cu} / \gamma-\mathrm{Al}_{2} \mathrm{O}_{3}$ & 250 & $40\left(\mathrm{H}_{2}\right)$ & 2.0 & 75.0 & 93.3 & 70.0 & {$[189]$} \\
\hline $\mathrm{Cu} / \mathrm{HZSM}-5$ & 250 & $40\left(\mathrm{H}_{2}\right)$ & 2.0 & 40.0 & 75.0 & 30.0 & {$[189]$} \\
\hline $\mathrm{Cu}-\mathrm{Ni} / \gamma-\mathrm{Al}_{2} \mathrm{O}_{3}$ & 250 & $40\left(\mathrm{~N}_{2}\right)$ & 2.0 & 82.0 & 29.2 & 24.0 & {$[189]$} \\
\hline $\mathrm{Cu}-\mathrm{Ni} / \mathrm{HZSM}-5$ & 250 & $40\left(\mathrm{~N}_{2}\right)$ & 2.0 & 87.0 & 31.0 & 27.0 & {$[189]$} \\
\hline $\mathrm{Cu}-\mathrm{H}_{4} \mathrm{SiW}_{12} \mathrm{O}_{40} / \gamma-\mathrm{Al}_{2} \mathrm{O}_{3}$ & 240 & $60\left(\mathrm{H}_{2}\right)$ & 0.9 & 90.1 & 89.7 & 80.8 & {$[173]$} \\
\hline $\mathrm{Cu} / \mathrm{TALCITA}$ & 190 & $25\left(\mathrm{H}_{2}\right)$ & $\mathrm{NI}$ & 65.0 & 98.3 & 63.8 & [193] \\
\hline $\mathrm{Cu}-\mathrm{B}_{2} \mathrm{O}_{3} / \mathrm{Al}_{2} \mathrm{O}_{3}$ & 250 & $60\left(\mathrm{H}_{2}\right)$ & 0.1 & 98.0 & 98.0 & 96.0 & {$[180]$} \\
\hline
\end{tabular}

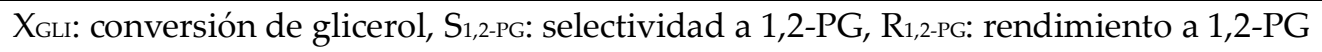

En el estudio de catalizadores de $\mathrm{Cu}$, se han empleado soportes basados en óxidos tales como $\gamma-\mathrm{Al}_{2} \mathrm{O}_{3}[168,171,173,177,180,188,189], \mathrm{SiO}_{2}[66,90,184,190,191], \mathrm{ZnO}[50,62,183]$, $\mathrm{TiO}_{2}$ [177,192], $\mathrm{MgO}$ [185] y $\mathrm{Cr}_{2} \mathrm{O}_{3}$ [80], zeolitas del tipo Y [182] y HZSM-5 [193], sílices mesoporosas (HSM) [175], SBA-15 [176] e hidrotalcitas [181,193].

Para los soportes ácidos, como $\mathrm{ZnO}[50,62,183], \quad \mathrm{Cr}_{2} \mathrm{O}_{3} \quad[80], \quad \gamma-\mathrm{Al}_{2} \mathrm{O}_{3}$ $[168,171,173,177,180,188,189]$, y las zeolitas del tipo Y [182], se ha reportado que los sitios ácidos del soporte favorecen la deshidratación del glicerol a $\mathrm{AcOH}$ que luego se hidrogena sobre los sitios metálicos del $\mathrm{Cu}$, aunque la fase activa de $\mathrm{Cu}$ también genera la ruptura del enlace C-O.

Por otro lado, cuando la acidez del soporte es elevada, como en el caso de la zeolita HZSM-5 [193], la selectividad a 1,2-PG disminuye debido a la deshidratación de glicerol a acroleína. En otros casos, el tipo de sitios ácidos no favorece la formación de 1,2-PG, como es el caso del $\mathrm{TiO}_{2}$ [177,192], en donde el producto principal es 1-propanol (1-POH).

Uno de los soportes más estudiados ha sido la $\gamma-\mathrm{Al}_{2} \mathrm{O}_{3}$ [177]. Si bien se han obtenido bajas conversiones $(\sim 20 \%)$ para altos contenidos de $\mathrm{Cu}$, la selectividad a 1,2-PG ha sido siempre alta $(\sim 90 \%)$ [168], y para bajos contenidos se han logrado altas dispersiones de la fase metálica, obteniéndose buenos resultados catalíticos [189]. El método de preparación del catalizador de $\mathrm{Cu} / \gamma-\mathrm{Al}_{2} \mathrm{O}_{3}$ también ha afectado la performance catalítica. Vila et al. estudiaron los métodos de calcinación y reducción con catalizadores de $\mathrm{Cu} / \gamma-\mathrm{Al}_{2} \mathrm{O}_{3}$ y sus resultados indicaron que la performance catalítica depende fuertemente de los procesos de calcinación, reducción y oxidación. En estos procesos se evidenció la presencia de especies $\mathrm{Cu}^{0}, \mathrm{Cu}^{+} \mathrm{y} \mathrm{Cu}^{+2}$. Los resultados mostraron que la actividad y selectividad a 1,2-PG aumenta en presencia de las especies $\mathrm{Cu}^{0}$ y Cu$^{+}$mientras que las especies $\mathrm{Cu}^{+2}$ resultan las menos activas en la reacción de hidrogenólisis [171]. 
En cuanto a los sitios presentes en $\gamma-\mathrm{Al}_{2} \mathrm{O}_{3}$, un estudio de DFT reveló que la hidrogenólisis de glicerol se ve facilitada por la presencia de los sitios ácidos encontrados en la superficie de la alúmina. La hidroxilación de estos sitios en presencia de agua genera similar actividad en cuanto a la adsorción del glicerol y la formación de acetol que los sitios metálicos del $\mathrm{Cu}$, sin embargo, la energía de activación es menor en el caso de los sitios superficiales de la alúmina, lo cual permite alcanzar altas conversiones empleando este soporte [188].

La modificación de $\gamma-\mathrm{Al}_{2} \mathrm{O}_{3}$ con promotores también ha sido una variable estudiada en la bibliografía. Heteropoliácidos del tipo $\mathrm{H}_{2} \mathrm{SiW}_{12} \mathrm{O}_{40}$ han permitido mejorar la reducibilidad de las partículas de $\mathrm{Cu}$ sobre el soporte y aumentar la acidez del catalizador sin promover reacciones laterales [173]. La modificación con $\mathrm{H}_{3} \mathrm{BO}_{3}$ también resultó benéfica debido a un efecto sobre la dispersión de las partículas de $\mathrm{Cu}$ y la mejora en su capacidad hidrogenante [180].

Para soportes neutros, como la $\mathrm{SiO}_{2}$, SBA-15 y otras sílices mesoporosas (HSM), los reportes han focalizado su estudio en el tamaño de la partícula metálica. Con respecto a catalizadores de $\mathrm{Cu} / \mathrm{SiO}_{2}$, la preparación de los catalizadores por los métodos de impregnación y coprecipitación condujo a mejores resultados de actividad con respecto a catalizadores másicos de $\mathrm{Cu}-\mathrm{SiO}_{2}$. De los dos métodos, el método de coprecipitación permitió una mayor dispersión de las partículas de $\mathrm{Cu}$ y una mejor interacción metal-soporte $[66,184,194]$. Otros métodos de preparación más sofisticados han mostrado aún mejores performances para el catalizador de $\mathrm{Cu} / \mathrm{SiO}_{2}$. La preparación mediante el método hidrotermal de evaporación de amoníaco condujo a obtener especies de $\mathrm{Cu}^{0}$ en forma de nanopartículas dispersas sobre la superficie del soporte y el efecto cooperativo de las especies de $\mathrm{Cu}^{0}$ y $\mathrm{Cu}^{+}$son indicadas como las responsables de la performance catalítica [190]. Otra preparación, mediante el revestimiento de $\mathrm{SiO}_{2}$ con $\mathrm{Cu}$ a partir de un coloide de $\mathrm{Cu}$ polivinilpirrolidona, condujo a obtener altos rendimientos a 1,2-PG [191].

El empleo de sílices mesoporosas, tales como SBA-15 y sílice hexagonal mesoporosa (HSM) condujo a obtener catalizadores más activos que los de $\mathrm{Cu} / \mathrm{SiO}_{2}$ [175] debido a sus propiedades texturales de mesoporosidad y superficie específica, que permitieron alcanzar altas dispersiones de la fase activa $[187,176]$.

Para soportes básicos, como MgO [185] e hidrotalcitas [181,193], los reportes en bibliografía han indicado que una mayor basicidad aumenta los niveles de conversión de glicerol y selectividad a 1,2-PG. Además, en el caso de las hidrotalcitas, se ha observado que las partículas de $\mathrm{Cu}$ se dispersan fácilmente de forma homogénea, lo que contribuye a mejorar la performance del catalizador [181].

Con respecto a los catalizadores bimetálicos basados en $\mathrm{Cu}$, la Tabla 16-2 resume las condiciones operativas y los resultados de actividad en reactores batch. Los ensayos de evaluación catalítica se realizan a temperaturas entre $200{ }^{\circ} \mathrm{C}$ y $250{ }^{\circ} \mathrm{C}$, presiones entre 10 bar y 45 bar de $\mathrm{H}_{2}$, tiempos de reacción están entre 5 h y 24 h, y una relación de masa de glicerol a masa de catalizador $\left(\mathrm{m}_{\mathrm{gli}} / \mathrm{m}_{\mathrm{c}}\right)$ entre 12 y 200. 
Tabla 16-2. Hidrogenólisis 1,2-PG en reactores batch en fase líquida empleando catalizadores bimetálicos de $\mathrm{Cu}$.

\begin{tabular}{lcccccccc}
\hline Catalizador & $\mathrm{T}\left({ }^{\circ} \mathrm{C}\right)$ & $\mathrm{P}(\mathrm{bar})$ & $\mathrm{m}_{\mathrm{gli}} / \mathrm{m}_{\mathrm{c}}(\mathrm{g} / \mathrm{g})$ & $\mathrm{t}(\mathrm{h})$ & $\mathrm{X}_{\mathrm{GLI}}(\%)$ & $\mathrm{S}_{1,2-\mathrm{Pg}}(\%)$ & $\mathrm{R}_{1,2-\mathrm{Pg}}(\%)$ & Ref. \\
\hline \multirow{2}{*}{$\mathrm{Cu}-\mathrm{Ag} / \gamma-\mathrm{Al}_{2} \mathrm{O}_{3}$} & 200 & $36\left(\mathrm{H}_{2}\right)$ & $\mathrm{NI}$ & 10 & 27.0 & 96.0 & 25.9 & {$[172]$} \\
\cline { 2 - 9 } & 200 & $35\left(\mathrm{H}_{2}\right)$ & 30.0 & 8 & 66.4 & 68.2 & 45.2 & {$[196]$} \\
\hline $\mathrm{Cu}-\mathrm{Ru} / \mathrm{CNT}$ & 200 & $40\left(\mathrm{H}_{2}\right)$ & 20.0 & 6 & 99.8 & 86.5 & 86.3 & {$[195]$} \\
\hline \multirow{2}{*}{$\mathrm{Cu}-\mathrm{Ni} / \gamma-\mathrm{Al}_{2} \mathrm{O}_{3}$} & 250 & $10\left(\mathrm{H}_{2}\right)$ & 201.6 & 5 & 27.2 & 96.7 & 26.3 & {$[197]$} \\
\cline { 2 - 8 } & 220 & $40\left(\mathrm{H}_{2}\right)$ & 40.0 & 24 & 92.5 & 62.5 & 57.8 & {$[198]$} \\
\hline \multirow{2}{*}{$\mathrm{Cu}-\mathrm{Zn} / \mathrm{MgO}$} & 210 & $45\left(\mathrm{H}_{2}\right)$ & 12.5 & 12 & 98.7 & 93.4 & 92.2 & {$[186]$} \\
\cline { 2 - 8 } & 212 & $45\left(\mathrm{H}_{2}\right)$ & 14.2 & 12 & 96.9 & 94.2 & 91.2 & {$[199]$} \\
\hline
\end{tabular}

$\mathrm{X}_{\mathrm{GLI}}$ conversión de glicerol, $\mathrm{S}_{1,2-\mathrm{PG}}$ : selectividad a 1,2-PG, $\mathrm{R}_{1,2-\mathrm{PG}}$ rendimiento a 1,2-PG

Dado que el $\mathrm{Cu}$ resulta una fase activa con buena capacidad para la ruptura de enlaces $\mathrm{C}-\mathrm{O}$, la incorporación de otro metal para el diseño del catalizador tiene como objetivo aumentar la conversión del glicerol con respecto a los catalizadores monometálicos.

En este sentido, se ha reportado el estudio de catalizadores de $\mathrm{Cu}-\mathrm{Ru}$ [195], $\mathrm{Cu}-\mathrm{Ag}$ [172,196], Cu-Ni [197,198] y Cu-Zn [186,199].

La incorporación de $\mathrm{Ru}$ a catalizadores de $\mathrm{Cu}$ soportados en nanotubos de carbono (CNT) resultó en un aumento en la actividad debido a que favorece la dispersión de las partículas de $\mathrm{Cu}$ y promueve su capacidad de hidrogenación por un proceso de spillover de $\mathrm{H}$ reactivo del $\mathrm{Ru}$ al $\mathrm{Cu}$ [195].

El mismo efecto de spillover fue encontrado en catalizadores de $\mathrm{Cu}-\mathrm{Zn}$ soportados en $\mathrm{MgO}$ [199]. Los reportes indican que la presencia de Zn mejora la reducibilidad de las especies de $\mathrm{CuO}$ y favorece la dispersión de las partículas de $\mathrm{Cu}^{0}$, a la vez que ofrece los sitios ácidos adecuados para mejorar la etapa de deshidratación del glicerol [186].

Con respecto a la fase bimetálica $\mathrm{Cu}-\mathrm{Ag}$, se ha reportado que la adición de $\mathrm{Ag}$ genera una mayor dispersión de las partículas de $\mathrm{Cu}$ y facilita su reducción, generando especies de $\mathrm{Cu}^{+}$que son activas en la hidrogenólisis de glicerol [172]. Se han empleado varios métodos de preparación empleando diversos soportes, como $\gamma-\mathrm{Al}_{2} \mathrm{O}_{3}, \mathrm{HY}, \mathrm{H} \beta$, y HZSM-5, además de variables en su preparación como la relación molar Cu:Ag. Para una relación Cu:Ag = 7:3, el orden de actividad reportado ha sido el siguiente:

$$
\mathrm{Cu}-\mathrm{Ag} / \gamma-\mathrm{Al}_{2} \mathrm{O}_{3}>\mathrm{Cu}-\mathrm{Ag} / \mathrm{HY} \sim \mathrm{Cu}-\mathrm{Ag} / \mathrm{H}-\beta>\mathrm{Cu}-\mathrm{Ag} / \mathrm{HSZM}-5
$$

Si bien las elevadas áreas superficiales de los soportes tipo zeolitas, HY, H- $\beta$ y HSZM5 permiten una alta dispersión de las partículas de $\mathrm{Cu} \mathrm{y} \mathrm{Ag}$, existe una fuerte interacción entre la fase activa y los sitios superficiales ácidos de los soportes. Esto genera un bajo grado de reducción, lo que ocasiona bajos niveles de actividad si se compara con el soporte $\gamma-\mathrm{Al}_{2} \mathrm{O}_{3}$. Por otro lado, el empleo de estas zeolitas ácidas, como fue mencionado previamente, promueve la formación de acroleína a partir de glicerol [172]. Zhou et al. reportaron un efecto similar para una relación Cu:Ag = 3:1 [196].

$\mathrm{El}$ estudio de catalizadores de $\mathrm{Cu}-\mathrm{Ni}$ fue reportado sobre el soporte de $\gamma-\mathrm{Al}_{2} \mathrm{O}_{3}$. Para una relación másica $\mathrm{Cu}: \mathrm{Ni}=3$, Pudi et al. encontraron el máximo rendimiento a 1,2-PG 
debido a la formación de un óxido mixto del tipo $\mathrm{Cu} 0.75 \mathrm{Ni}_{0.25} \mathrm{Al}_{2} \mathrm{O}_{4}$ [197]. Yun et al., por su parte, prepararon el catalizador de $\mathrm{Cu}-\mathrm{Ni}$ mediante el método de coprecipitación sobre alúmina mesoporosa, que le confiere a la fase metálica una mejor dispersión. Para una relación molar $\mathrm{Cu}: \mathrm{Ni}=9: 1$, el catalizador mostró la mejor actividad y se puso en evidencia que el aumento en las relaciones superficiales de $\mathrm{Ni} /\left(\mathrm{Ni}^{0}+\mathrm{Cu}^{0}\right)$ y $\mathrm{Cu}^{0} /\left(\mathrm{Cu}^{0}+\mathrm{Cu}^{+2}\right)$ son las responsables del aumento en el rendimiento a 1,2-PG [198].

\subsubsection{Níquel}

La Tabla 17-2 resume las condiciones operativas y los resultados de actividad de los catalizadores de $\mathrm{Ni}$ en reactores batch. Los ensayos de evaluación catalítica se realizan a temperaturas entre 180 y $260{ }^{\circ} \mathrm{C}$, presiones entre 14 y 69 bar de $\mathrm{H}_{2}$, tiempos de reacción reportados entre 4 y 24 horas, y una relación de masa de glicerol a masa de catalizador $\left(\mathrm{m}_{\mathrm{gli}} / \mathrm{m}_{\mathrm{c}}\right)$ entre 4 y 20.

Tabla 17-2. Hidrogenólisis 1,2-PG en reactores batch en fase líquida empleando catalizadores soportados de Ni.

\begin{tabular}{|c|c|c|c|c|c|c|c|c|}
\hline Catalizador & $\mathrm{T}\left({ }^{\circ} \mathrm{C}\right)$ & $\mathrm{P}$ (bar) & $\mathrm{m}_{\mathrm{gli}} / \mathrm{m}_{\mathrm{c}}(\mathrm{g} / \mathrm{g})$ & $\mathrm{t}(\mathrm{h})$ & $X_{\text {GLI }}(\%)$ & $\mathrm{S}_{1,2-\mathrm{PG}}(\%)$ & $\mathrm{R}_{1,2-\mathrm{PG}}(\%)$ & Ref. \\
\hline \multirow{2}{*}{$\mathrm{Ni} / \mathrm{C}$} & 200 & $14\left(\mathrm{H}_{2}\right)$ & 20.0 & 24 & 39.8 & 68.6 & 27.3 & [7] \\
\hline & 200 & $50\left(\mathrm{H}_{2}\right)$ & 5.3 & 24 & 63.2 & 77.4 & 48.9 & [201] \\
\hline \multirow{4}{*}{$\mathrm{Ni} / \mathrm{SiO}_{2}-\mathrm{Al}_{2} \mathrm{O}_{3}$} & 200 & $14\left(\mathrm{H}_{2}\right)$ & 20.0 & 24 & 45.1 & 64.5 & 29.1 & [7] \\
\hline & 200 & $25\left(\mathrm{H}_{2}\right)$ & 20.0 & 8 & 30.0 & 98.0 & 29.4 & {$[210]$} \\
\hline & 240 & $33\left(\mathrm{~N}_{2}\right)$ & 4.0 & 4 & 26.8 & 69.0 & 18.4 & {$[202]$} \\
\hline & 240 & $33\left(\mathrm{~N}_{2}\right)$ & 4.0 & 4 & 39.3 & 73.7 & 28.9 & [203] \\
\hline \multirow{2}{*}{$\mathrm{Ni} / \mathrm{SiO}_{2}$} & 200 & $50\left(\mathrm{H}_{2}\right)$ & 20.0 & 10 & 8.5 & 60.5 & 5.1 & [80] \\
\hline & 200 & $60\left(\mathrm{H}_{2}\right)$ & 20.0 & 10 & 56.9 & 44.4 & 25.2 & {$[204]$} \\
\hline \multirow{4}{*}{$\mathrm{Ni} / \gamma-\mathrm{Al}_{2} \mathrm{O}_{3}$} & 200 & $50\left(\mathrm{H}_{2}\right)$ & 20.0 & 10 & 32.3 & 55.1 & 17.7 & [80] \\
\hline & 220 & $45\left(\mathrm{H}_{2}\right)$ & 6.0 & 24 & 69.0 & 61.3 & 42.2 & [3] \\
\hline & 210 & $45\left(\mathrm{H}_{2}\right)$ & 10.5 & 12 & 14.5 & 87.9 & 12.7 & {$[168]$} \\
\hline & 200 & $60\left(\mathrm{H}_{2}\right)$ & 20.0 & 10 & 97.1 & 44.2 & 42.9 & {$[204]$} \\
\hline $\mathrm{Ni} / \mathrm{NaX}$ & 200 & $60\left(\mathrm{H}_{2}\right)$ & 20.0 & 10 & 86.6 & 80.4 & 69.6 & [204] \\
\hline $\mathrm{Ni} / \mathrm{CeO}_{2}$ & 215 & $41\left(\mathrm{H}_{2}\right)$ & 12.0 & 24 & 69.9 & 39.5 & 27.6 & {$[207]$} \\
\hline $\mathrm{Ni} / \mathrm{CeO}_{2}-\mathrm{MgO}$ & 230 & $69\left(\mathrm{H}_{2}\right)$ & 6.0 & 24 & 68.8 & 47.5 & 32.6 & {$[206]$} \\
\hline $\mathrm{Ni} / \mathrm{WO}_{3}-\mathrm{MSAP}$ & 180 & $20\left(\mathrm{H}_{2}\right)$ & 10.0 & 6 & 88.3 & 96.8 & 85.4 & {$[208]$} \\
\hline
\end{tabular}

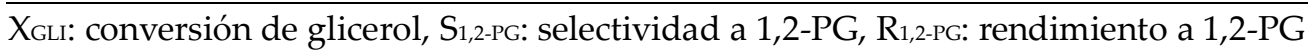

Los catalizadores soportados basados en $\mathrm{Ni}$ como fase activa presentan en general selectividades altas a 1,2-PG, comparables con las obtenidas con catalizadores soportados basados en $\mathrm{Ru}$ y otros metales nobles. Si bien su capacidad para hidrogenar es menor a los 
catalizadores basados en metales nobles, se observa que, en muchos trabajos, esto se compensa con el empleo de mayores temperaturas y presiones de reacción, lo que provoca, por otro lado, una mayor desactivación por sinterizado de la fase activa [200].

La mayor parte de los catalizadores soportados de $\mathrm{Ni}$ se han preparado empleando $\mathrm{Ni}\left(\mathrm{NO}_{3}\right)_{2}$ [3,80,168,201-209] como precursor, siendo el método de impregnación la técnica más empleada para la preparación, aunque también se ha utilizado el método de coprecipitación [3] y deposición-precipitación [206,207]. Algunos autores simplemente han empleado catalizadores comerciales de níquel [7,202,203,210].

Los soportes más utilizados se han basado en $\mathrm{C}[7,201,210]$, óxidos de $\mathrm{SiO}_{2}$ $[80,204,205,210], \gamma-\mathrm{Al}_{2} \mathrm{O}_{3}[3,80,168,204], \mathrm{SiO}_{2}-\mathrm{Al}_{2} \mathrm{O}_{3}[7,202,203,210], \mathrm{CeO}_{2}$ [206,207] y $\mathrm{WO}_{3}$ [208] y zeolitas del tipo NaX, NaA, NaZSM-5 y NaMOR [204].

Catalizadores comerciales de $\mathrm{Ni} / \mathrm{C}$ resultaron activos e igualmente selectivos a 1,2-PG que catalizadores de $\mathrm{Cu}[7,210]$. Para catalizadores de Ni/C preparados a partir de carbones activados también fue posible obtener una buena performance [201].

Catalizadores comerciales de $\mathrm{Ni} / \gamma-\mathrm{Al}_{2} \mathrm{O}_{3}$ también resultaron activos en la hidrogenólisis de glicerol, pero menos selectivos a 1,2-PG debido a una mayor conversión a

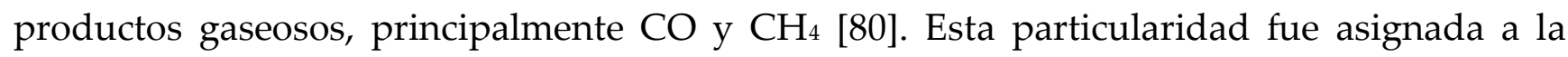
capacidad del níquel para participar en reacciones de metanación. Otros autores también indicaron que estos catalizadores promueven la formación de etanol, propanol, EG, $\mathrm{MeOH}$ y otros productos secundarios [168,204]. Esta capacidad de ruptura de enlaces C-C podría actuar como una fuente generadora de carbón que bloquea parcialmente los sitios activos y la superficie porosa en catalizadores de $\mathrm{Ni} / \gamma-\mathrm{Al}_{2} \mathrm{O}_{3}$. Otros catalizadores de $\mathrm{Ni} / \gamma-\mathrm{Al}_{2} \mathrm{O}_{3}$ preparados mediante la técnica sol-gel, resultaron igualmente activos, obteniéndose valores similares de conversión y selectividad [3].

Sistemas comerciales de $\mathrm{Ni} / \mathrm{SiO}_{2}-\mathrm{Al}_{2} \mathrm{O}_{3}$ resultaron más interesantes desde el punto de vista catalítico [7,202,203,210]. Empleando soluciones acuosas de glicerol al $80 \% \mathrm{p} / \mathrm{p}$, este catalizador presentó valores elevados de conversión y similar selectividad a 1,2-PG a la obtenida con catalizadores de $\mathrm{Cu}_{-} \mathrm{Cr}_{2} \mathrm{O}_{3}$. A diferencia de los catalizadores de $\mathrm{Cu}$, estos sistemas presentan una mayor selectividad a la ruptura de enlaces C-C [7]. Debido a la buena dispersión de las partículas de $\mathrm{Ni}$ algunos autores llevaron a cabo la reacción de hidrogenólisis en atmósfera inerte de $\mathrm{N}_{2}$ para que el $\mathrm{H}_{2}$ sea generado vía reformado acuoso de glicerol (APR) [202,203]. Los resultados obtenidos indicaron una buena performance catalítica a moderadas temperaturas y presiones de $\mathrm{N}_{2}$, tanto para soluciones diluidas como concentradas de glicerol crudo y purificado. Las diferencias más significativas, empleando ambos tipos de glicerol, fue una leve disminución de la selectividad a 1,2-PG debido a la presencia de impurezas en el glicerol crudo [203].

Zhao et al. estudiaron catalizadores de $\mathrm{Ni}$ soportados en diversas zeolitas y compararon la performance con catalizadores $\mathrm{Ni} / \mathrm{SiO}_{2}$ y $\mathrm{Ni} / \mathrm{Al}_{2} \mathrm{O}_{3}$. El orden de actividad encontrado sigue el mismo orden de acidez hallada para los distintos soportes: $\mathrm{Al}_{2} \mathrm{O}_{3}>\mathrm{NaX}_{>}$ $\mathrm{NaA} \sim \mathrm{SiO}_{2}>\mathrm{NaZSM}-5>\mathrm{NaMOR}$.

Sin embargo, la selectividad a 1,2-PG sigue el siguiente orden: $\mathrm{NaX}>\mathrm{NaMOR}>\mathrm{NaA}>$ $\mathrm{Al}_{2} \mathrm{O}_{3} \sim \mathrm{SiO}_{2}>\mathrm{NaZSM}-5$. 
El soporte de $\mathrm{NaX}$ resultó el mejor desde el aspecto de la acidez y de la capacidad del soporte para dispersar la fase metálica. El contenido de $\mathrm{Na}^{+}$en el soporte fue ajustado para obtener el máximo rendimiento a 1,2-PG, encontrando que, a mayor contenido de esta especie, decrece el número de sitios ácidos conjuntamente con la actividad. Mientras que si el contenido de $\mathrm{Na}+$ es muy bajo, los valores de conversión son muy altos pero la selectividad a 1,2-PG decrece debido a la formación de productos secundarios tales como $\mathrm{MeOH}, \mathrm{EtOH}, 1$ $\mathrm{POH}$, entre otros [204].

Catalizadores de $\mathrm{Ni} / \mathrm{CeO}_{2}$ preparados por el método de impregnación también resultaron eficientes para la producción de 1,2-PG, aunque promovieron además la formación de $\mathrm{EtOH}$ [207]. La modificación del soporte de $\mathrm{CeO}_{2}$ por adición de $\mathrm{MgO}$ y el reemplazo del método de impregnación por la deposición-precipitación condujo a obtener mayores rendimientos a 1,2-PG. Los mejores resultados se obtuvieron con un contenido del $25 \%$ p/p Ni y con una relación Ce:Mg = 9:1. Los resultados también mostraron una mejor dispersión del Ni empleando el método de deposición-precipitación [206].

Otros catalizadores de $\mathrm{Ni}$ soportados en una sepiolita modificada (MSEP) con $\mathrm{WO}_{3}$ condujeron a obtener altos rendimientos a 1,2-PG para un $20 \% \mathrm{p} / \mathrm{p}$ Ni y una relación másica $\mathrm{WO}_{3}: \mathrm{MSEP}=7,5: 1$. Los resultados han indicado que la presencia de $\mathrm{WO}_{3}$ permite no solo una dispersión de las partículas de $\mathrm{Ni}$, sino que además inhibe las reacciones de ruptura de enlaces C-C que conducen a la formación de productos secundarios [208].

En ausencia de soportes ácidos, la formación de productos depende exclusivamente de las características estructurales de la fase metálica de Ni. Un ejemplo de sistemas catalíticos en donde ocurre este fenómeno lo constituye el $\mathrm{Ni} / \mathrm{SiO}_{2}[80,204,205,210]$. Si bien se han empleado catalizadores comerciales basados en $\mathrm{Ni} / \mathrm{SiO}_{2}$ [2], los valores de conversión obtenidos con estos catalizadores han sido muy bajos. Otros catalizadores de $\mathrm{Ni} / \mathrm{SiO}_{2}$, preparados por impregnación empleando $\mathrm{Ni}\left(\mathrm{NO}_{3}\right)_{2}$ como precursor, condujeron a obtener bajas conversiones de glicerol pero manteniendo valores de selectividad a 1,2-PG similares a $\mathrm{Ni} / \gamma-\mathrm{Al}_{2} \mathrm{O}_{3}$ y Ni/C ( $\left.65 \%\right)$, lo que podría deberse a una mayor capacidad para las reacciones de ruptura C-C $[80,204,205]$. El Ni es un metal capaz de participar tanto las reacciones de ruptura de enlaces $\mathrm{C}-\mathrm{O}$ como enlaces $\mathrm{C}-\mathrm{C}$ debido a su alta densidad electrónica. En ausencia de propiedades ácidas del soporte, las reacciones de ruptura C-C se ven favorecidas por acción de la fase metálica de Ni [205].

Con el objetivo de mejorar la actividad de los catalizadores de $\mathrm{Ni}$, la preparación de catalizadores bimetálicos también ha sido estudiada en la bibliografía por varios autores. La Tabla 18-2 resume las condiciones operativas y los resultados de actividad de los catalizadores bimetálicos de $\mathrm{Ni}$ en reactores batch. Los ensayos de evaluación catalítica se realizan a temperaturas entre 200 y $260{ }^{\circ} \mathrm{C}$, presiones entre 20 y 50 bar de $\mathrm{H}_{2}$, tiempos de reacción entre 2 y 24 horas, y una relación de masa de glicerol a masa de catalizador ( $\left.\mathrm{mgli}_{\mathrm{gl}} / \mathrm{m}_{\mathrm{c}}\right)$ entre 0,04 y 14 . 
Tesis - Procesos catalíticos para biorefinerías: conversión de glicerol para la producción de bio-propilenglicol-

Tabla 18-2. Hidrogenólisis 1,2-PG en reactores batch en fase líquida empleando catalizadores bimetálicos de Ni.

\begin{tabular}{lcccccccc}
\hline Catalizador & $\mathrm{T}\left({ }^{\circ} \mathrm{C}\right)$ & $\mathrm{p}(\mathrm{bar})$ & $\mathrm{m}_{\mathrm{gli}} / \mathrm{m}_{\mathrm{c}}(\mathrm{g} / \mathrm{g})$ & $\mathrm{t}(\mathrm{h})$ & $\mathrm{X}_{\mathrm{GLI}}(\%)$ & $\mathrm{S}_{1,2-\mathrm{PG}}(\%)$ & $\mathrm{R}_{1,2-\mathrm{PG}}(\%)$ & Ref. \\
\hline \multirow{2}{*}{$\mathrm{Ni}-\mathrm{Cu} / \gamma-\mathrm{Al}_{2} \mathrm{O}_{3}$} & 210 & $45\left(\mathrm{H}_{2}\right)$ & 10.5 & 12 & 71.6 & 93.0 & 66.6 & {$[168]$} \\
\cline { 2 - 8 } & 220 & $45\left(\mathrm{H}_{2}\right)$ & 6.0 & 24 & 70.5 & 66.9 & 47.2 & {$[3]$} \\
\cline { 2 - 9 } & 220 & $45\left(\mathrm{~N}_{2}\right)$ & 10.9 & 24 & 90.0 & 82.0 & 73.8 & {$[211]$} \\
\hline $\mathrm{Ni}-\mathrm{Ir} / \gamma-\mathrm{Al}_{2} \mathrm{O}_{3}$ & 200 & $25\left(\mathrm{H}_{2}\right)$ & 6.6 & 12 & 24.3 & 83.1 & 20.2 & {$[212]$} \\
\hline $\mathrm{Ni}-\mathrm{Ce} / \mathrm{C}$ & 200 & $50\left(\mathrm{H}_{2}\right)$ & 0.04 & 6 & 90.4 & 65.7 & 59.3 & {$[213]$} \\
\hline $\mathrm{Ni}-\mathrm{Ce} / \mathrm{SBA}-15$ & 200 & $24\left(\mathrm{H}_{2}\right)$ & 33.3 & 8 & 51.0 & 29.0 & 14.7 & {$[214]$} \\
\hline $\mathrm{Ni}-\mathrm{P} / \gamma-\mathrm{Al}_{2} \mathrm{O}_{3}$ & 230 & $30\left(\mathrm{H}_{2}\right)$ & 13.9 & 15 & 95.7 & 84.7 & 81.0 & {$[215]$} \\
\hline
\end{tabular}

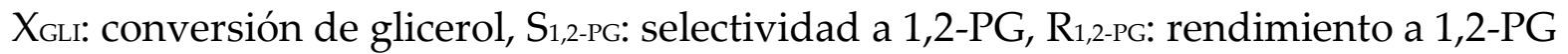

Empleando el método de impregnación a humedad incipiente y precursores de $\mathrm{Ni}\left(\mathrm{NO}_{3}\right)_{2} \cdot 6 \mathrm{H}_{2} \mathrm{O}$ y $\mathrm{Cu}\left(\mathrm{NO}_{3}\right)_{2} \cdot 3 \mathrm{H}_{2} \mathrm{O}$, Pudi et al. prepararon catalizadores de $\mathrm{Ni}-\mathrm{Cu} / \mathrm{Al}_{2} \mathrm{O}_{3}$ con distintas relaciones másicas $\mathrm{Ni}: \mathrm{Cu}=1: 1,3: 1$ y 1:3. Para la relación másica 1:1 obtuvieron el máximo nivel de actividad ( $72 \%$ ) con alta selectividad a 1,2-PG ( $93 \%)$. Los resultados fueron atribuidos a la formación de una aleación $\mathrm{Ni}-\mathrm{Cu}$ de alta superficie y dispersión metálica con un tamaño de partícula pequeño [168]. Gandarias et al. emplearon catalizadores de $\mathrm{Ni}-\mathrm{Cu} / \gamma-\mathrm{Al}_{2} \mathrm{O}_{3}$ preparados mediante el método de sol-gel. Evaluaron estos catalizadores en la reacción de hidrogenólisis empleando una atmósfera inerte de $\mathrm{N}_{2}$ y 2-POH como solvente donador de $\mathrm{H}_{2}$. En todos los casos, el catalizador bimetálico mostró una mejor performance que $\mathrm{Ni} / \gamma-\mathrm{Al}_{2} \mathrm{O}_{3}$ y $\mathrm{Cu} / \gamma-\mathrm{Al}_{2} \mathrm{O}_{3}$. La desactivación del catalizador bimetálico fue más pronunciada debido a la mayor generación de coke que se depositó sobre los sitios activos del catalizador. Los autores encontraron que el $\mathrm{Ni}-\mathrm{Cu} / \gamma-\mathrm{Al}_{2} \mathrm{O}_{3}$ reducido en atmósfera de $\mathrm{H}_{2}$ a $320{ }^{\circ} \mathrm{C}$ tiene mayor actividad que cuando se los reduce a $450{ }^{\circ} \mathrm{C}$, pero con una menor selectividad a 1,2-PG. La pérdida de selectividad fue atribuida a la mayor capacidad de ruptura de enlaces C-C [3]. En otro de sus trabajos, los autores optimizaron la relación Cu:Ni, encontrando que una relación $\mathrm{Cu}: \mathrm{Ni}=0.72$ permite alcanzar el máximo rendimiento a 1,2-PG a 45 bar de $\mathrm{N}_{2}$ y empleando ácido fórmico como sustancia donadora de $\mathrm{H}_{2}$. Explicaron que la mayor capacidad para la ruptura de enlaces C-O se le atribuye a la formación de una aleación $\mathrm{Ni}-\mathrm{Cu}[211]$.

Debido a la alta selectividad a 1,2-PG obtenida con catalizadores monometálicos de Ir, fueron estudiado sistemas de Ni-Ir, con el objetivo de mejorar la actividad de catalizadores de $\mathrm{Ni}$. Se ha reportado que para una relación molar $\mathrm{Ni}: \mathrm{Ir}=2: 1$, el nivel de actividad es mucho mayor los catalizadores monometálicos [212]. Los resultados fueron atribuidos a la presencia de especies $\operatorname{Ir}^{+\delta}(0<\delta<4)$ de morfología y tamaño mayores que las especies de monometálicas de Ni e Ir generadas en el proceso de calcinación (Aire, $400{ }^{\circ} \mathrm{C}, 4 \mathrm{~h}$ ).

$\mathrm{Yu}$ et al. estudiaron la adición de distintos metales, incluyendo $\mathrm{Al}, \mathrm{Sn}, \mathrm{Zn}, \mathrm{Fe}, \mathrm{Cu}, \mathrm{Co}$ y $\mathrm{Ce}$, sobre catalizadores de Ni soportados en carbones activados. Los autores encontraron que la adición de Ce produce las mayores conversiones de glicerol con buena selectividad a 1,2PG. La mejora fue atribuida a una mejora en la dispersión de las partículas de Ni debido a la 
presencia de $\mathrm{Ce}$ en forma de $\mathrm{CeO}_{2}$ [213]. También fue reportado el empleo de Ce para la mejora en la performance catalítica de catalizadores de Ni/SBA-15. Los autores también asignaron esta mejora a la mejor dispersión de las partículas de Ni sobre el soporte y a la mayor acidez proporcionada por el Ce [214].

La adición de $\mathrm{P}$ también fue estudiada en catalizadores de $\mathrm{Ni} / \gamma-\mathrm{Al}_{2} \mathrm{O}_{3}$. La presencia de $\mathrm{P}$ disminuye el grado de reducibilidad del $\mathrm{Ni}$, generando especies de $\mathrm{NiO}$ que aumentan la selectividad a 1,2-PG, pero disminuyen la conversión de glicerol. El rendimiento global a 1,2PG aumenta debido a la presencia de grupos -POx generados por la presencia de P [215].

Tabla 19-2. Hidrogenólisis 1,2-PG en reactores de flujo continuo de fase líquida empleando catalizadores soportados de Ni.

\begin{tabular}{lccccccc}
\hline Catalizador & $\mathrm{T}\left({ }^{\circ} \mathrm{C}\right)$ & $\mathrm{P}($ bar $)$ & WHSV $\left(\mathrm{h}^{-1}\right)$ & $\mathrm{X}_{\mathrm{GLI}}(\%)$ & $\mathrm{S}_{1,2-\mathrm{PG}}(\%)$ & $\mathrm{R}_{1,2-\mathrm{PG}}(\%)$ & Ref. \\
\hline $\mathrm{Ni}_{2} \mathrm{P} / \mathrm{SiO}_{2}$ & 220 & $30\left(\mathrm{H}_{2}\right)$ & 1.13 & 95.1 & 85.9 & 81.7 & {$[205]$} \\
\hline
\end{tabular}

\subsubsection{Cobalto}

La Tabla 20-2 resume las condiciones operativas y los resultados de actividad de los catalizadores de Co en reactores batch. Los ensayos de evaluación catalítica se realizaron a $200{ }^{\circ} \mathrm{C}$ y presiones entre 20 y 50 bar de $\mathrm{H}_{2}$. Los tiempos de reacción reportados son entre 9 y 12 horas y una relación de masa de glicerol a masa de catalizador $\left(\mathrm{m}_{\mathrm{gli}} / \mathrm{m}_{\mathrm{c}}\right)$ entre 13 y 20.

Tabla 20-2. Hidrogenólisis 1,2-PG en reactores batch en fase líquida empleando catalizadores soportados de Co.

\begin{tabular}{lcccccccc}
\hline Catalizador & $\mathrm{T}\left({ }^{\circ} \mathrm{C}\right)$ & $\mathrm{P}(\mathrm{bar})$ & $\mathrm{m}_{\mathrm{gli}} / \mathrm{m}_{\mathrm{c}}(\mathrm{g} / \mathrm{g})$ & $\mathrm{t}(\mathrm{h})$ & $\mathrm{X}_{\mathrm{GLI}}(\%)$ & $\mathrm{S}_{1,2-\mathrm{PG}}(\%)$ & $\mathrm{R}_{1,2-\mathrm{PG}}(\%)$ & Ref. \\
\hline $\mathrm{Co} / \mathrm{SiO}_{2}$ & 200 & $50\left(\mathrm{H}_{2}\right)$ & 20.0 & 10 & 8.3 & 61.7 & 5.1 & {$[80]$} \\
\hline $\mathrm{Co} / \mathrm{MgO}$ & 200 & $20\left(\mathrm{H}_{2}\right)$ & 20.0 & 9 & 44.8 & 42.2 & 18.9 & {$[216]$} \\
\hline $\mathrm{Co} / \mathrm{ZnAl}$ & 200 & $20\left(\mathrm{H}_{2}\right)$ & 13.3 & 12 & 70.6 & 57.8 & 40.8 & {$[217]$} \\
\hline
\end{tabular}

XGL: conversión de glicerol, $\mathrm{S}_{1,2-\mathrm{PG}}$ selectividad a 1,2-PG, R1,2-PG: rendimiento a 1,2-PG

Los catalizadores de Co han sido los menos estudiados en literatura. Los precursores más empleados para la preparación han sido $\mathrm{Co}\left(\mathrm{NO}_{3}\right)_{2}$ [80,217] y $\mathrm{Co}\left(\mathrm{CH}_{3} \mathrm{COO}\right)_{2}$ [216], mientras que la impregnación [80], la coprecipitación [217] y la deposición-precipitación [216] han sido empleados como métodos de preparación.

Los reportes han indicado que los catalizadores de Co resultan menos activos que los catalizadores basados en $\mathrm{Cu}$ y $\mathrm{Ni}$. Huang et al. evaluaron un catalizador de $\mathrm{Co} / \mathrm{SiO}_{2}$, obteniendo bajas conversiones de glicerol ( $~ 8 \%)$ con selectividades a 1,2-PG del orden del $62 \%$ y llegaron a la conclusión de que los catalizadores basados en $\mathrm{Cu}$ y $\mathrm{Ni}$ mostraban mejores performances [80]. Guo et al. estudiaron un catalizador de $\mathrm{Co} / \mathrm{MgO}$ que resultó más activo que el catalizador de $\mathrm{Co} / \mathrm{SiO}_{2}$ debido a la formación de una espinela del tipo $\mathrm{MgCo}_{2} \mathrm{O}_{4}$ y una solución sólida Mg-Co-O. La fuerte interacción entre Co y Mg aumenta la actividad y estabilidad del catalizador de $\mathrm{Co}$, aunque se evidenció la formación de $\mathrm{Mg}(\mathrm{OH})_{2}$ luego de $9 \mathrm{~h}$ 
de reacción con un aumento considerable del tamaño de partícula del Co [216]. En otro de sus trabajos, los mismos autores lograron preparar un catalizador de Co/ZnAl mediante el método de coprecipitación empleando $\mathrm{Co}\left(\mathrm{NO}_{3}\right)_{2}, \mathrm{Zn}\left(\mathrm{NO}_{3}\right)_{2}$ y $\mathrm{Al}\left(\mathrm{NO}_{3}\right)_{3}$ como precursores. La reducción de los mismos a $600{ }^{\circ} \mathrm{C}$ condujo a la obtención de nanopartículas de Co de $16 \mathrm{~nm}$ que resultaron activas y selectivas para la formación de 1,2-PG y con aparente estabilidad luego de dos ciclos de reacción de 12 h cada uno [217].

\subsubsection{Catalizadores para la producción de 1,2-PG en fase vapor}

La Tabla 21-2 resume los principales catalizadores evaluados en reactores de flujo continuo en fase vapor.

Tabla 21-2. Hidrogenólisis 1,2-PG en reactores de flujo continuo en fase vapor.

\begin{tabular}{lccccccc}
\hline Catalizador & $\mathrm{T}\left({ }^{\circ} \mathrm{C}\right)$ & $\mathrm{P}(\mathrm{bar})$ & WHSV $\left(\mathrm{h}^{-1}\right)$ & $\mathrm{X}_{\mathrm{GLI}}(\%)$ & $\mathrm{S}_{1,2-\mathrm{PG}}(\%)$ & $\mathrm{R}_{1,2-\mathrm{PG}}(\%)$ & Ref. \\
\hline $\mathrm{Cu}-\mathrm{Cr}_{2} \mathrm{O}_{4}$ & 200 & $1\left(\mathrm{H}_{2}\right)$ & 1.2 & 100.0 & 77.0 & 77.0 & {$[222]$} \\
\hline $\mathrm{Cu}-\mathrm{ZnO}-\mathrm{Al}_{2} \mathrm{O}_{3}$ & 190 & $6.4\left(\mathrm{H}_{2}\right)$ & 0.08 & 96.2 & 92.2 & 88.6 & {$[80]$} \\
\hline $\mathrm{Cu}-\mathrm{ZnO}-\mathrm{TiO}_{2}$ & 240 & $1\left(\mathrm{H}_{2}\right)$ & $\mathrm{NI}$ & 100.0 & 15.0 & 15.0 & {$[218]$} \\
\hline $\mathrm{Cu}-\mathrm{ZnO}-\mathrm{ZrO}_{2}$ & 240 & $1\left(\mathrm{H}_{2}\right)$ & $\mathrm{NI}$ & 100.0 & 12.0 & 12.0 & {$[218]$} \\
\hline $\mathrm{Cu} / \mathrm{SiO}_{2}$ & 255 & $15\left(\mathrm{H}_{2}\right)$ & 7.1 & 100.0 & 87.0 & 87.0 & {$[174]$} \\
\hline & 250 & $1\left(\mathrm{~N}_{2}\right)$ & 7.6 & 100.0 & 50.0 & 50.0 & {$[169]$} \\
\cline { 2 - 8 } & 200 & $1\left(\mathrm{H}_{2}\right)$ & 30.6 & 100.0 & 60.0 & 60.0 & {$[219]$} \\
\hline $\mathrm{Cu} / \gamma-\mathrm{Al}{ }_{2} \mathrm{O}_{3}$ & 240 & $1\left(\mathrm{H}_{2}\right)$ & 33.0 & 70.0 & 30.0 & 21.0 & {$[179]$} \\
\hline & $200-130$ & $1\left(\mathrm{H}_{2}\right)$ & 0.4 & 100.0 & 94.1 & 94.1 & {$[224]$} \\
\hline $\mathrm{Cu} / \mathrm{SBA}-15$ & 220 & $1\left(\mathrm{H}_{2}\right)$ & 1.0 & 90.0 & 84.0 & 75.6 & {$[178]$} \\
\hline $\mathrm{Cu} / \mathrm{MgO}$ & 220 & $7.5\left(\mathrm{H}_{2}\right)$ & 1.2 & 100.0 & 95.5 & 95.5 & {$[220]$} \\
\hline $\mathrm{Cu}-\mathrm{Ag} / \mathrm{Al}_{2} \mathrm{O}_{3}$ & $200-130$ & $1\left(\mathrm{H}_{2}\right)$ & 0.4 & 100.0 & 96.2 & 96.2 & {$[224]$} \\
\hline $\mathrm{Cu}-\mathrm{Ni} / \gamma-\mathrm{Al}_{2} \mathrm{O}_{3}$ & 220 & $7.5\left(\mathrm{H}_{2}\right)$ & 0.9 & 98.5 & 89.3 & 87.9 & {$[221]$} \\
\hline $\mathrm{Ni} / \mathrm{ZnO}$ & 235 & $31(\mathrm{Ar})$ & 0.8 & 85.0 & 54.0 & 45.9 & {$[223]$} \\
\hline $\mathrm{Ni}-\mathrm{Ag} / \gamma-\mathrm{Al}_{2} \mathrm{O}_{3}$ & 200 & $1\left(\mathrm{H}_{2}\right)$ & 2.0 & 80.0 & 58.0 & 46.4 & {$[209]$} \\
\hline $\mathrm{Ru} / \mathrm{SBA}-15$ & 260 & $1\left(\mathrm{H}_{2}\right)$ & 4.6 & 75.0 & 20.0 & 15.0 & {$[225]$} \\
\hline $\mathrm{Ru} / \gamma-\mathrm{Al}{ }_{2} \mathrm{O}_{3}$ & 230 & $1\left(\mathrm{H}_{2}\right)$ & 2.0 & 42.0 & 40.0 & 16.8 & {$[226]$} \\
\hline $\mathrm{X}$ & 20.0 & & 20.0 & & &
\end{tabular}

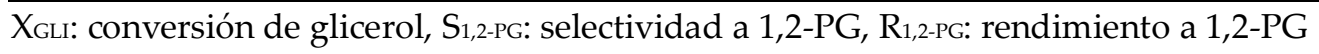

Feng et al. investigaron la reacción de hidrogenólisis en fase vapor a 1 bar y $240{ }^{\circ} \mathrm{C}$ empleando catalizadores másicos de $\mathrm{Cu}-\mathrm{ZnO}_{-} \mathrm{TiO}_{2}$ y $\mathrm{Cu}-\mathrm{ZnO}-\mathrm{ZrO}_{2}$. Si bien la conversión de glicerol fue del 100\%, la selectividad a 1,2-PG fue muy baja, del orden del 15\% para Cu-ZnO$\mathrm{TiO}_{2}$ y $12 \%$ para $\mathrm{Cu}-\mathrm{ZnO}-\mathrm{ZrO}_{2}$. Además, la selectividad a $\mathrm{AcOH}$ fue muy alta, del orden del $60 \%$ para $\mathrm{Cu}-\mathrm{ZnO}-\mathrm{TiO}_{2}$ y $76 \%$ para $\mathrm{Cu}-\mathrm{ZnO}-\mathrm{ZrO}_{2}$. Los resultados indicaron que la acidez de 
los óxidos $\mathrm{TiO}_{2}$ y $\mathrm{ZrO}_{2}$ generan grandes cantidades de $\mathrm{AcOH}$ que no puede hidrogenarse fácilmente a 1,2-PG debido a la baja presión de hidrógeno de la condición de fase vapor [218].

Sato et al. evaluaron catalizadores de $\mathrm{Cu}$ en fase vapor en reacciones de hidrogenación y deshidratación. Los autores indicaron que el glicerol se deshidrata sobre catalizadores de $\mathrm{Cu}$ para formar $\mathrm{AcOH}$ en flujo de $\mathrm{N}_{2}$, en fase vapor. En presencia de flujo de $\mathrm{H}_{2}$ se produce la hidrogenólisis de glicerol para dar EG, 1,2-PG y EtOH. La deshidratación de 1,3-PG produce acroleína, mientras que la deshidrogenación de 1,2-PG produce $\mathrm{AcOH}$ [169]. Dieuzeide et al. evaluaron un catalizador de $\mathrm{Cu} / \gamma-\mathrm{Al}_{2} \mathrm{O}_{3}$ en fase vapor a presión atmosférica en el rango de 200 a $240{ }^{\circ} \mathrm{C}$. Optimizando las condiciones operativas, para un contenido de $\mathrm{Cu}$ del $15 \% \mathrm{p} / \mathrm{p}$, obtuvieron el máximo rendimiento a 1,2-PG a $200{ }^{\circ} \mathrm{C}$ con una fracción molar de $\mathrm{H}_{2}$ del $61 \%$ [219]. En otro de sus trabajos los autores probaron que el rendimiento a 1,2-PG es función de la superficie metálica total de $\mathrm{Cu}$ y alcanza un máximo para un contenido del $15 \%$ p/p Cu [179].

Bienholz et al. evaluaron catalizadores de $\mathrm{Cu} / \mathrm{SiO}_{2}$ preparados por impregnación a humedad incipiente e intercambio iónico, tanto en fase líquida como en fase vapor. Empleando un catalizador de $\mathrm{Cu} / \mathrm{SiO}_{2}$ preparado por intercambio iónico y lograron una conversión completa de glicerol con una selectividad del $87 \%$ a 1,2-PG a $255{ }^{\circ} \mathrm{C}$ y 15 bar de $\mathrm{H}_{2}$ empleando soluciones de glicerol al $40 \% \mathrm{p} / \mathrm{p}$. Los autores encontraron que tanto la velocidad de reacción de la hidrogenólisis en fase líquida como en fase vapor depende linealmente de la superficie específica del $\mathrm{Cu}$, y que en fase vapor la deshidratación de glicerol a $\mathrm{AcOH}$ y la hidrogenación de $\mathrm{AcOH}$ para producir 1,2-PG se favorece a mayores áreas superficiales de $\mathrm{Cu}$ expuesto [174].

Catalizadores de Cu/SBA-15 fueron evaluados y encontraron que para un contenido de $\mathrm{Cu}$ del $5 \%$ p/p se obtuvo el máximo rendimiento a 1,2-PG. Los resultados también fueron atribuidos a la mayor dispersión de la fase activa, bajo la forma de partículas de óxido de cobre $\mathrm{CuO}$ que poseen menor tamaño que aquellas formadas a altos contenidos de $\mathrm{Cu}$ (20 $\% \mathrm{p} / \mathrm{p})[178]$.

Catalizadores de $\mathrm{Cu} / \mathrm{MgO}$ preparados mediante el método de deposiciónprecipitación fueron evaluados en fase vapor empleando soluciones acuosas de glicerol al 10 \%p/p. Para un contenido de $\mathrm{Cu}$ del $10 \%$ p/p el rendimiento a 1,2-PG fue máximo con una conversión completa de glicerol. Los resultados mostraron que el catalizador promueve la ruptura de enlaces C-O limitando la ruptura de enlaces C-C [220].

Catalizadores de $\mathrm{Cu}-\mathrm{Ni} / \gamma-\mathrm{Al}_{2} \mathrm{O}_{3}$ preparados por el método de impregnación a humedad incipiente también fueron evaluados en fase vapor empleando soluciones acuosas de glicerol al $10 \%$ p/p. Los mejores resultados se obtuvieron para un contenido metálico del $20 \%$ p/p con una relación $\mathrm{Cu}: \mathrm{Ni}=1: 1$. La presencia de un sitio bimetálico $\mathrm{Cu}-\mathrm{Ni}$, con alta superficie metálica y dispersión, fue el responsable del alto rendimiento obtenido a 1,2-PG [221].

Akiyama et al. emplearon $\mathrm{Cu}-\mathrm{Cr}_{2} \mathrm{O}_{4}$ en la reacción de hidrogenólisis, con una solución de glicerol al $30 \%$ p/p y obtuvieron una conversión completa de glicerol con una selectividad a 1,2 PG del 77\% [222].

Huang et al. evaluaron un catalizador másico de $\mathrm{Cu}-\mathrm{ZnO}-\mathrm{Al}_{2} \mathrm{O}_{3}$ en fase vapor empleando glicerol puro sin solvente, y obtuvieron una conversión completa del glicerol con selectividad a 1,2-PG del 77\%. Los autores explican estos resultados por la capacidad para 
deshidratar del $\mathrm{ZnO}$ y $\mathrm{Al}_{2} \mathrm{O}_{3}$ y por la capacidad para hidrogenar de los sitios metálicos del $\mathrm{Cu}[80]$.

$\mathrm{Hu}$ et al. emplearon catalizadores de $\mathrm{Ni} / \mathrm{ZnO}$ preparados mediante las técnicas de impregnación a humedad incipiente, coprecipitación, tratamiento hidrotérmico y templado sobre microesferas de carbón. Sus resultados mostraron que el catalizador de $\mathrm{Ni} / \mathrm{ZnO}$ preparado en base al templado sobre microesferas de carbón resultó el más activo y selectivo a 1,2-PG debido a la mayor dispersión de las partículas de Ni. Los autores encontraron que a bajas velocidades espaciales el 1,2-PG se convierte en otros productos laterales tales como etanol y productos gaseosos mientras que a altas velocidades espaciales la hidrogenación de $\mathrm{AcOH}$ a 1,2-PG se convierte en el paso limitante de la reacción [223].

Catalizadores comerciales de $\mathrm{Cu} / \mathrm{Al}_{2} \mathrm{O}_{3}$ y su modificación mediante la adición de $\mathrm{Ag}$ por el método de impregnación a humedad incipiente, fueron evaluados en la condición de hidrogenólisis en fase vapor. Empleando un gradiente de temperaturas en el reactor, para un contenido de $\mathrm{Ag}$ del $1 \% \mathrm{p} / \mathrm{p}$, los catalizadores de $\mathrm{Cu}-\mathrm{Ag} / \mathrm{Al}_{2} \mathrm{O}_{3}$ resultaron más activos y selectivos a 1,2-PG debido al rol de Ag para inhibir las reacciones laterales que conducen a la formación de EG [224].

Catalizadores de Ru/SBA-15 preparados por distintos métodos fueron evaluados en fase vapor, empleando soluciones acuosas de glicerol al 40 \%p/p. Los resultados mostraron que la preparación de un catalizador al $3 \% \mathrm{p} / \mathrm{p}$ de $\mathrm{Ru}$ en presencia de EG como poliol reductor conduce a alcanzar los mayores rendimientos a 1,2-PG debido a la mayor dispersión del $\mathrm{Ru}$ [225]. Estudios de catalizadores de $\mathrm{Ru}$ soportados sobre $\gamma-\mathrm{Al}_{2} \mathrm{O}_{3}$ también mostraron que el máximo rendimiento a 1,2-PG se obtiene para un contenido del $3 \% \mathrm{p} / \mathrm{p}$ de Ru, debido a la mayor dispersión de las partículas de $\mathrm{Ru}$ y la fuerte interacción-metal soporte [226].

$\mathrm{La}$ adición de $\mathrm{Ag}$ a catalizadores de $\mathrm{Ni} / \gamma-\mathrm{Al}_{2} \mathrm{O}_{3}$ también favoreció la dispersión de las partículas de $\mathrm{Ni}$ incrementando la superficie metálica expuesta y por lo tanto la actividad hacia la formación de 1,2-PG. Para contenidos de Ni y Ag del $10 \%$ p/p y 5 \%p/p respectivamente se obtuvo el máximo rendimiento a 1,2-PG [209].

\subsection{Efecto de las condiciones de operación en la hidrogenólisis de glicerol}

\subsubsection{Efecto de la concentración inicial de glicerol}

El glicerol crudo se obtiene de la síntesis del biodiesel con una concentración aproximada del $80 \%$ p/p de glicerol en agua y sus impurezas (triglicéridos, sales, restos de metanol, etanol $\mathrm{u}$ otros alcoholes, $\mathrm{NaOH}$ y $\mathrm{KOH}$ ) pueden afectar la performance de los catalizadores.

En la literatura, el efecto de la concentración de glicerol se ha reportado tanto en estudios de la reacción en fase líquida (Tabla 22-2), como en fase vapor (Tabla 23-2).

Los resultados indican que el aumento en la concentración de glicerol produce una disminución en la conversión del mismo, independientemente del sistema catalítico considerado y la condición operativa de fase líquida [34,70,89,100,122,185,213,227] o fase vapor $[178,209,225,228,229]$. Este efecto se debe a la menor disponibilidad de sitios activos a altas concentraciones de glicerol, ya que la masa de catalizador no se modifica, pero si lo hace 
el contenido de glicerol [70,110,122,185]. La selectividad a glicoles, depende de la concentración de glicerol, y disminuye con el aumento de la concentración en presencia de catalizadores basados en $\mathrm{Ru}[34,227], \mathrm{Pt}[228,229]$ y Ni [209], mientras que para catalizadores de $\mathrm{Cu}[70,185]$ y Co [100] permanece prácticamente invariable debido a su alta capacidad para las reacciones de ruptura de enlaces $\mathrm{C}-\mathrm{O}$.

Tabla 22-2. Efecto de la concentración de glicerol en fase líquida empleando reactores batch.

\begin{tabular}{lccccc}
\hline Catalizador & Rango $(\% \mathrm{p} / \mathrm{p})$ & $\mathrm{T}\left({ }^{\circ} \mathrm{C}\right)$ & $\mathrm{P}(\mathrm{bar})$ & $\mathrm{t}(\mathrm{h})$ & Ref. \\
\hline $\mathrm{Ru} / \mathrm{C}$ & $20-40$ & 120 & $80\left(\mathrm{H}_{2}\right)$ & 10 & {$[34]$} \\
\hline $\mathrm{Rh} / \mathrm{SiO}_{2}$ & $20-40$ & 120 & $80\left(\mathrm{H}_{2}\right)$ & 10 & {$[34]$} \\
\hline $\mathrm{Ru} / \mathrm{C}+\mathrm{Nb}_{2} \mathrm{O}_{5}$ & $20-80$ & 180 & $60\left(\mathrm{H}_{2}\right)$ & 8 & {$[122]$} \\
\hline $\mathrm{Ru} / \mathrm{C}+\mathrm{Amberlyst}^{15}$ & $20-80$ & 130 & $80\left(\mathrm{H}_{2}\right)$ & 24 & {$[227]$} \\
\hline $\mathrm{Cu}-\mathrm{MgO}$ & $10-80$ & 200 & $40\left(\mathrm{H}_{2}\right)$ & 8 & {$[70]$} \\
\hline $\mathrm{Cu} / \mathrm{MgO}$ & $10-80$ & 210 & $45\left(\mathrm{H}_{2}\right)$ & 12 & {$[185]$} \\
\hline $\mathrm{Cu}-\mathrm{ZrO}-\mathrm{MgO}$ & $10-40$ & 180 & $40\left(\mathrm{H}_{2}\right)$ & 8 & {$[89]$} \\
\hline $\mathrm{Ni}-\mathrm{Ce} / \mathrm{AC}$ & $25-75$ & 200 & $50\left(\mathrm{H}_{2}\right)$ & 6 & {$[213]$} \\
\hline $\mathrm{Co}-\mathrm{ZnO}$ & $10-40$ & 180 & $40\left(\mathrm{H}_{2}\right)$ & 8 & {$[100]$} \\
\hline
\end{tabular}

Tabla 23-2. Efecto de la concentración de glicerol en fase líquida empleando reactores de flujo continuo.

\begin{tabular}{lccccc}
\hline Catalizador & Rango $(\% \mathrm{p} / \mathrm{p})$ & $\mathrm{T}\left({ }^{\circ} \mathrm{C}\right)$ & $\mathrm{P}(\mathrm{bar})$ & $\mathrm{WHSV}\left(\mathrm{h}^{-1}\right)$ & Ref. \\
\hline $\mathrm{Ru} / \mathrm{SBA}-15$ & $40-60$ & 260 & $1\left(\mathrm{H}_{2}\right)$ & 4.6 & {$[225]$} \\
\hline $\mathrm{Pt} / \mathrm{AlPO}_{4}$ & $5-20$ & 260 & $1\left(\mathrm{H}_{2}\right)$ & 1.0 & {$[228]$} \\
\hline $\mathrm{Pt} / \mathrm{WO}_{3} / \mathrm{SBA}-15$ & $5-20$ & 210 & $1\left(\mathrm{H}_{2}\right)$ & 1.0 & {$[229]$} \\
\hline $\mathrm{Cu} / \mathrm{SBA}-15$ & $20-60$ & 220 & $1\left(\mathrm{H}_{2}\right)$ & $\mathrm{NI}$ & {$[178]$} \\
\hline $\mathrm{Ni}-\mathrm{Ag} / \gamma-\mathrm{Al}_{2} \mathrm{O}_{3}$ & $10-40$ & 200 & $1\left(\mathrm{H}_{2}\right)$ & 2.0 & {$[209]$} \\
\hline
\end{tabular}

NI: no informado

\subsubsection{Efecto de la concentración inicial de agua}

El glicerol crudo tiene una concentración en agua en el rango de 40-80 \%p/p.

Cuando el contenido de agua es muy alto, la hidrogenólisis de glicerol puede conducir a la formación de productos de ruptura de enlaces C-C, tales como EtOH [76].

Dado que el agua es generada durante la hidrogenólisis, resulta mejor trabajar con bajos contenidos de agua en la solución de partida, de modo de desplazar el equilibrio hacia la formación de 1,2-PG.

Dasari et al. reportaron una mejora en los niveles de conversión cuando la concentración inicial de agua fue reducida progresivamente empleando un catalizador 
másico de $\mathrm{Cu}-\mathrm{Cr}_{2} \mathrm{O}_{4}$ [7]. El mismo efecto fue encontrado para catalizadores de $\mathrm{Ru} / \mathrm{C}$ que fueron testeados en presencia de una resina Amberlyst 15 [227].

Xia et al. reportaron una caída en los valores de conversión del $91 \%$ al 69 \% cuando el contenido de agua aumentó de $0 \%$ a $40 \%$ en un medio de etanol empleado como solvente, en presencia de catalizadores de tipo hidrotalcita, $\mathrm{Rh}_{0.02} \mathrm{Cu}_{0.4} / \mathrm{Mg}_{5.6} \mathrm{Al}_{1.98} \mathrm{O}_{8.57}$ a $180{ }^{\circ} \mathrm{C}$ y 20 bar de $\mathrm{H}_{2}$ [230]. Menchavez et al. también reportaron una caída en la conversión del $80 \%$ al $43 \%$ con un mantenimiento de la selectividad a 1,2-PG entre 56-58\%, cuando el contenido de agua aumentó del del $0 \%$ al $40 \%$ en presencia de catalizadores de $\mathrm{Ni} / \mathrm{CeO}_{2}-\mathrm{MgO}$ [206].

Por otro lado, es necesario un contenido mínimo de agua en la mezcla de reacción inicial, puesto que su presencia inhibe reacciones laterales de deshidratación de glicerol a productos no deseados en la producción de 1,2-PG [76], así como también las reacciones de condensación entre el glicerol y productos secundarios, tales como EG, EtOH y MeOH [227].

Otro aspecto a tener en cuenta es que la presencia de agua afecta la estabilidad de los catalizadores en fase líquida. Hou et al. estudiaron el efecto de la concentración inicial de agua en el medio de reacción en presencia de catalizadores de $\mathrm{Cu} / \mathrm{ZnO}$ y vincularon dicho efecto con las propiedades texturales y fisicoquímicas del catalizador. La presencia de una mayor concentración de agua genera un aumento en el tamaño de las partículas de $\mathrm{Cu}$ y $\mathrm{ZnO}$, lo que conduce a una menor área metálica y menor acidez en el catalizador. Además, la presencia de agua transforma las partículas de $\mathrm{Cu}^{0}$ a $\mathrm{Cu}^{+2}$, promoviendo la formación de EG y disminuyendo la selectividad a 1,2-PG. Estos procesos traen como resultado una caída en el rendimiento obtenido a 1,2-PG [231].

En reactores de flujo continuo en fase vapor, es conveniente minimizar el contenido de agua para producir un ahorro energético en la vaporización [232], pero a su vez el agua permite lograr la vaporización de las soluciones de glicerol a menor temperatura.

Recientemente, se ha reportado un estudio técnico-económico para llevar a cabo la purificación del 1,2-PG mediante destilación en etapas. La primera etapa consiste en la separación del agua de los productos líquidos, para luego separar el glicerol que no ha reaccionado y finalmente el 1,2-PG del resto de los productos, en especial EG. El estudio económico determinó que la separación del agua en la primera etapa de destilación es el paso de mayor costo de toda la purificación [233].

\subsubsection{Efecto del solvente}

Dado que el contenido de agua en la solución de glicerol de partida afecta los niveles de conversión y selectividad a 1,2-PG, el reemplazo de la misma por otros solventes tiene un impacto sobre el desarrollo de la reacción. Dentro de los solventes empleados en la reacción de hidrogenólisis, se han utilizado solventes próticos y apróticos.

De los solventes apróticos, el sulfolane y el dioxano se han empleado en el medio de reacción en presencia de catalizadores de $\mathrm{Rh} / \mathrm{C}$. Mientras que el uso del sulfolane incrementó los valores de conversión de glicerol, pero disminuyó la selectividad a 1,2-PG, el empleo alternativo de dioxano disminuyó los niveles de actividad acompañados de una caída en la selectividad a 1,2-PG debido a una promoción en la ruptura de enlaces $C-C$, indicando que tanto uno como otro no resultan adecuados para ser empleados en la reacción de 
hidrogenólisis [52]. Catalizadores de Co-Al mostraron similares resultados en presencia de sulfolane, siendo la actividad hacia la formación de 1,2-PG la más baja alcanzada empleando este solvente [15].

El empleo de solventes próticos tiene la ventaja de que muchos de ellos son sustancias donadoras de $\mathrm{H}_{2}$ que permiten generar $\mathrm{H}_{2}$ in situ y de esta forma mejorar la performance de los catalizadores. Entre los solventes próticos se destacan $\mathrm{MeOH}, \mathrm{EtOH}, 2-\mathrm{POH}$ y el ácido fórmico [3,4,5,6,233], aunque también se han empleado EG y 1,2-butanodiol [196,234].

Gandarias et al. estudiaron ácido fórmico, 2-POH y MeOH como sustancias donadoras de $\mathrm{H}_{2}$ en presencia de catalizadores de $\mathrm{Ni}-\mathrm{Cu} / \gamma-\mathrm{Al}_{2} \mathrm{O}_{3}$ [4]. La máxima conversión de glicerol y selectividad a 1,2-PG la obtuvieron en presencia de ácido fórmico siendo la mejora en la actividad de hidrogenólisis correspondiente al siguiente orden: Ácido fórmico > 2-POH > $\mathrm{MeOH}$.

Por otro lado, Zhou et al. [6] reportaron que en presencia de catalizadores de $\mathrm{Cu}-\mathrm{MgO}$ preparados mediante el método de coprecipitación, la mejora en la actividad y selectividad a 1,2-PG se produjo siguiendo el orden: 2-POH $>\mathrm{EtOH}>\mathrm{MeOH}>$ Ácido fórmico.

Dada estas diferencias, los resultados sugieren que la mejora en la actividad depende de la capacidad del catalizador para producir $\mathrm{H}_{2}$ a partir del solvente en cuestión. Al respecto, Yuan et al. emplearon un catalizador de $\mathrm{Cu}-\mathrm{ZrO}_{2}$, en presencia de ácido fórmico como solvente donador de $\mathrm{H}_{2}$. Sus resultados mostraron que el carácter anfótero del soporte de $\mathrm{ZrO}_{2}$ son características esenciales para producir la descomposición del ácido fórmico y generar in situ el $\mathrm{H}_{2}$ necesario para la formación de 1,2-PG [5].

Existen algunos inconvenientes en el uso de solventes próticos donadores de $\mathrm{H}_{2}$. Dado que el glicerol y las sustancias donadoras de hidrógeno compiten por los mismos sitios activos en el proceso de hidrogenólisis, debería haber un balance entre la cantidad de glicerol y la cantidad de sustancia donadora de hidrógeno para alcanzar alta conversión y selectividad a 1,2-PG [4]. Se ha reportado que en presencia de 2-POH, se produce en fase líquida una desactivación más rápida que utilizando agua como solvente debido a la ocupación de los sitios activos por el solvente y a la deposición de productos carbonosos en la superficie del catalizador [3]. Por otro lado, un estudio de factibilidad económica ha reportado recientemente que el uso de ácido fórmico comparado con $\mathrm{H}_{2}$, es económicamente viable si su precio en el mercado es menor a $0.14 \mathrm{US} \$ / \mathrm{kg}$ [233].

Otra de las razones por las cuales los solventes próticos permiten una mejora ha sido atribuida a la mayor solubilidad del $\mathrm{H}_{2}$ molecular en estas sustancias. Se ha reportado que en presencia de alcoholes como $\mathrm{MeOH}$ y EtOH la solubilidad el $\mathrm{H}_{2}$ es mucho mayor que en agua [9].

En presencia de catalizadores de $\mathrm{Cu}-\mathrm{Ag} / \gamma-\mathrm{Al}_{2} \mathrm{O}_{3}$, se estudió el efecto del solvente en el medio de reacción empleando EtOH, $\mathrm{MeOH}, 1-\mathrm{POH}$ y EG como solventes. De todos ellos, el EtOH permitió alcanzar la máxima conversión y selectividad a 1,2-PG, atribuido a la mayor solubilidad del $\mathrm{H}_{2}$ en $\mathrm{EtOH}$ [196].

En presencia de catalizadores de $\mathrm{Cu}-\mathrm{MgO}$, el uso de 2-POH permitió mejorar notablemente la performance catalítica debido a su efecto como molécula donadora de $\mathrm{H}_{2}$, mientras que el $\mathrm{EtOH}$ y $\mathrm{MeOH}$ permitieron no solo la mejor disolución del $\mathrm{H}_{2}$, sino además a la acción reformadora del catalizador sobre estos alcoholes y por lo tanto a la generación de $\mathrm{H}_{2}$ in situ [6]. 
Como desventaja al empleo de alcoholes como solventes se ha reportado que, en presencia de catalizadores de Co-Al, la selectividad a glicoles fue baja, empleando EtOH y $\mathrm{MeOH}$, debido a la formación de productos de condensación, como éteres de glicerilo [15].

Con el objetivo de disminuir la desactivación de catalizadores, se han empleado otros solventes en el medio de reacción como MeOH y 1,2-butanodiol.

Catalizadores de $\mathrm{Cu} / \mathrm{SiO}_{2}$ preparados por el método hidrotermal de evaporación de amoníaco resultaron altamente estables cuando fueron testeados en un reactor de flujo continuo en fase líquida durante 300 h de reacción a $200{ }^{\circ} \mathrm{C}$ y 50 bar de $\mathrm{H}_{2}$, empleando $\mathrm{MeOH}$ como solvente [190]. Bienholz et al. reportaron un aumento en la conversión de glicerol del 5 $\%$ al $55 \%$ cuando el agua fue reemplaza por 1,2-butanodiol como solvente de reacción, a 200 ${ }^{\circ} \mathrm{C}$ y 50 bar de $\mathrm{H}_{2}$ empleando soluciones de glicerol al $50 \%$ p/p en presencia de un catalizador másico de CuO-ZnO. Los resultados mostraron que el empleo de 1,2-butanodiol evita el fenómeno de desactivación porque no favorece un aumento del tamaño de cristal en fase líquida como ocurre con el agua [63]. También se encontró que la alta polaridad del solvente influye positivamente en la formación del 1,2-PG debido a la fácil remoción del mismo sobre la superficie catalítica con respecto a solventes apróticos [234].

\subsubsection{Efecto del $\mathrm{pH}$}

Las soluciones acuosas empleadas para la hidrogenólisis de glicerol en fase líquida tienen un $\mathrm{pH}$ ligeramente ácido $(\mathrm{pH} \sim 5-6)$, ya sea en soluciones de glicerol muy diluidas (10$40 \% \mathrm{p} / \mathrm{p})$ o en las más concentradas (50-80\%p/p).

El pH inicial de estas soluciones puede variar con la adición de ácidos o bases, que tienen una incidencia particular en los parámetros catalíticos, dependiendo de la especie química incorporada al medio de reacción. El mecanismo por el cual ocurre la reacción de hidrogenólisis también puede verse influenciado por el $\mathrm{pH}$.

El pH, como variable operativa, no ha sido muy estudiada. Lahr et al. [235] estudiaron el efecto del pH mediante la modificación del medio de reacción con $\mathrm{CaO}$ y $\mathrm{CaCO}_{3}$. Para catalizadores comerciales de $\mathrm{Ru} / \mathrm{C}$ encontraron que la velocidad de reacción del glicerol, 1,2PG y EG resultan mayor cuanto más básico es el medio. Además, probaron que la selectividad a 1,2-PG no varía con el pH del medio, pero sí lo es la selectividad a EG [235].

Siguiendo con el estudio anterior, Feng et al. [26] estudiaron el agregado de distintas bases al medio de reacción en presencia de un catalizador de $\mathrm{Ru} / \mathrm{TiO}_{2}$. Sus resultados indicaron que $\mathrm{LiOH}, \mathrm{NaOH}, \mathrm{Na}_{2} \mathrm{CO}_{3}, \mathrm{Li}_{2} \mathrm{CO}_{3}$ aumentan la conversión del glicerol manteniendo la selectividad a 1,2-PG invariable para todas las bases estudiadas. En todos los casos se observó un incremento más pronunciado en la conversión siguiendo el orden $\mathrm{Li}^{+}>$ $\mathrm{Na}^{+}>\mathrm{K}^{+}$, que fue atribuido al tamaño de los iones metálicos que forman parte de cada una de las bases testeadas. La razón de porqué las bases aumentan la conversión estaría dada porque la presencia de $\mathrm{OH}^{-}$cataliza el primer paso de la deshidrogenación de glicerol a GLA. Los mismos resultados fueron obtenidos por Marinoiu et al. años más tarde empleando el catalizador de $\mathrm{CuCr}_{2} \mathrm{O}_{4}[236]$. 
Maris et al. comprobaron también que la adición de base disminuye la actividad del $\mathrm{Ru} / \mathrm{C}$ y aumenta la del $\mathrm{Pt} / \mathrm{C}$, promoviendo la máxima deshidrogenación cuando se adiciona $\mathrm{NaOH}$ y $\mathrm{CaOH}$ al 0,8 $\mathrm{M}[25]$.

Chaminand et al. estudiaron el agregado de $\mathrm{H}_{2} \mathrm{WO}_{4}$ a soluciones acuosas de $18 \% \mathrm{p} / \mathrm{p}$ glicerol, empleando catalizadores de $\mathrm{CuO} / \mathrm{ZnO}, \mathrm{Pd} / \mathrm{C}$ y $\mathrm{Rh} / \mathrm{C}$, encontrando que aumenta la conversión de glicerol con poco cambio en la selectividad a 1,2-PG [52].

Dam et al. estudiaron la presencia de $\mathrm{NaOH}$ en el medio de reacción. Para un incremento en el pH de 5.6 a 12 obtuvieron un aumento en la conversión del $25 \%$ al $45 \%$, acompañada de un aumento en la selectividad a ácido láctico (LA). Esto provocó una caída en los valores de selectividad a 1,2-PG, a diferencia de los resultados obtenidos por otros autores [139].

Yuan et al. estudiaron la adición de $\mathrm{NaOH}$ al medio de reacción y catalizadores basados en hidrotalcitas de $\mathrm{Cu}$. La adición de la base mejoró la performance del catalizador. Los resultados fueron atribuidos a la mayor deshidrogenación de glicerol a gliceraldehído GLA seguida de una deshidratación a 2-HA y posteriormente la hidrogenación de la misma para formar el 1,2-PG [181].

Ahmed et al. estudiaron el efecto del $\mathrm{pH}$ empleando un catalizador de $\mathrm{Ru} / \mathrm{AlF}_{3}-\mathrm{Al}_{2} \mathrm{O}_{3}$ en presencia de una solución de $\mathrm{NaOH}$. Los resultados mostraron un incremento en la conversión y selectividad a 1,2-PG, conjuntamente con una caída en la selectividad a EG debido a la reacción entre EG y GLA para formar otros productos secundarios [114].

$\mathrm{Zhu}$ et al. evaluaron un catalizador de $\mathrm{Cu}-\mathrm{Ag} / \gamma-\mathrm{Al}_{2} \mathrm{O}_{3}$ para valores de $\mathrm{pH}$ de 4,7 y 10 . La mayor conversión y selectividad a 1,2-PG se obtuvo en condiciones neutras, debido a que la acidez y basicidad modificaron las propiedades texturales del catalizador. Condiciones ácidas promovieron el aumento de superficie específica y la dispersión de la fase activa, dando lugar a la formación de ésteres. Condiciones básicas condujeron a menores valores de área superficial y un aumento en el tamaño de las partículas de $\mathrm{Cu}$, disminuyendo la actividad global [196].

\subsubsection{Efecto de la concentración de catalizador}

Varios autores han estudiado el efecto de la concentración de catalizador en fase líquida, empleando reactores batch, y en fase vapor [221]. La mayor parte de los reportes han estudiado el efecto en presencia de catalizadores de $\mathrm{Cu}[7,70,73,89,182,185]$ y $\mathrm{Ni}[76,208]$, y han coincidido en que el aumento en la concentración del catalizador aumenta los niveles de conversión, independientemente del sistema catalítico en estudio.

Con respecto a la selectividad, se ha reportado que un aumento en la concentración de catalizador produce una disminución en la selectividad a glicoles, debido a la formación de productos secundarios, tales como EG, $\mathrm{MeOH}, \mathrm{EtOH}$ y gases [7,76,89,182]. En algunos casos, debido a la naturaleza selectiva del catalizador, la selectividad a 1,2-PG se mantuvo prácticamente constante frente a cambios en la concentración del catalizador $[185,208]$. Por otro lado, concentraciones muy bajas de catalizador han producido una acumulación de $\mathrm{AcOH}$ en el medio de reacción debido a la falta de sitios activos necesarios para la hidrogenación [76]. 


\subsubsection{Efecto del agregado de co-catalizadores}

Además de modificar el $\mathrm{pH}$, es posible añadir al medio de reacción sólidos que ayuden a mejorar la actividad catalítica de los catalizadores empleados. Uno de los materiales más empleados como co-catalizadores han sido las resinas de intercambio iónico $[35,101,227,237,238]$.

Se ha reportado que el empleo de resinas de intercambio iónico del tipo Amberlyst 15 permite mejorar la selectividad a 1,2-PG y aumentar la conversión debido a que la resina cataliza la primera etapa de deshidratación del glicerol a $\mathrm{AcOH}[35,101,227]$. Esta resina es muy selectiva puesto que no se evidencia la formación de otros glicoles, como EG y 1,3-PG, ni tampoco la formación de propanoles, como 1-POH y 2-POH.

El empleo de otras resinas de intercambio iónico puede modificar significativamente la selectividad a los productos de reacción. Se ha probado que la resina de intercambio Amberlyst 70, si bien mejora la conversión (de un $43 \%$ a un $56 \%$ ) produce una mayor selectividad a 1-POH, EtOH y EG. Otras resinas, como la Amberlyst DT no aumentan la conversión de glicerol y generan productos de condensación [227].

La desventaja de las resinas de intercambio radica en su baja estabilidad térmica. La resina Amberlyst 15, una de las más usadas, comienza a descomponerse a $120{ }^{\circ} \mathrm{C}$. La resina Amberlyst 70, tiene una estabilidad térmica superior, pero no puede superar $180{ }^{\circ} \mathrm{C}-190{ }^{\circ} \mathrm{C}$ debido a que comienza su descomposición [237,238].

Otras resinas del tipo alquino sulfónicas han sido empleadas dada su mayor estabilidad térmica para ser utilizadas a temperaturas superiores a $180{ }^{\circ} \mathrm{C}$. Preparadas a partir de la co-polimerización del ácido 2-acrilamido-2-metil-propanosulfónico con N,Ndimetilacrilamida y dimetilacrilato de etileno, estas resinas resultaron más selectivas hacia la formación de 1,2-PG que la resina Amberlyst 70. Los resultados, empleando un catalizador de $\mathrm{Ru} / \mathrm{C}$ en presencia de las resinas, mostraron conversiones del $23 \%$ con selectividad a 1,2PG del 33 \% luego de 4 h de reacción [238].

Otras sustancias, como sales [33,239], líquidos iónicos [240] y sólidos ácidos [13,122,227,241,242] han sido también empleados como co-catalizadores en la reacción de hidrogenólisis. El agregado de una sal de cloruro de fosfonio al medio de reacción en presencia de Ni-Raney mostró una mejora en la selectividad a 1,2-PG, pero posteriormente dificulta la separación del catalizador del medio de reacción [33].

El empleo de $\mathrm{Na}_{2} \mathrm{~S}$ conjuntamente con catalizadores de $\mathrm{Ru} / \mathrm{C}$ ha permitido suprimir reacciones laterales evitando por ejemplo la formación de EG, mientras que la selectividad a 1,2-PG se ha visto favorecida dada la mayor capacidad del sistema catalítico para deshidratar el glicerol a $\mathrm{AcOH}[239]$.

La adición de líquidos iónicos como cloruro de colina conjuntamente con sales ácidas de $\mathrm{ZnCl}_{2}$ y FeCl 2 ha mostrado ser eficiente con catalizadores $\mathrm{Ru} / \mathrm{C}$ y $\mathrm{Ru} / \mathrm{TiO}_{2}$, pero el efecto intrínseco del líquido iónico con respecto a la sal ácida no ha sido discutido en profundidad ni tampoco la razón por la cual ocurre la mejora en la actividad [240].

Balaraju et al. probaron diversos catalizadores de $\mathrm{Ru} / \mathrm{C}$ con el agregado de sólidos ácidos co-catalíticos. De todos los sólidos ácidos co-catalíticos estudiados, el $\mathrm{Nb}_{2} \mathrm{O}_{5}$ y el $\mathrm{ZrO}_{2}$ muestran una mayor actividad [122]. 
Otros sólidos ácidos como $\mathrm{SiO}_{2}$ impregnada con $\mathrm{H}_{3} \mathrm{PO}_{4}$ y $\mathrm{SiO}_{2}-\mathrm{Al}_{2} \mathrm{O}_{3}$ han sido evaluados obteniéndose mejoras en los niveles de actividad y selectividad a 1,2-PG siguiendo el orden de acidez $\mathrm{SiO}_{2}-\mathrm{H}_{3} \mathrm{PO}_{4}>\mathrm{SiO}_{2}-\mathrm{Al}_{2} \mathrm{O}_{3}$ [227].

Otros sólidos como $\mathrm{SiO}_{2}, \mathrm{MgO}, \mathrm{Al}_{2} \mathrm{O}_{3}, \mathrm{H}-\mathrm{ZSM} 5, \mathrm{TiO}_{2}, \mathrm{ZrO}_{2}, \mathrm{CeO}_{2}$ y $\mathrm{ZnO}$ fueron empleados como co-catalizadores en presencia de catalizadores de Ni-Mo. Los resultados mostraron la siguiente tendencia basada en el rendimiento obtenido a 1,2-PG:

$$
\mathrm{MgO}<\mathrm{TiO}_{2}<\mathrm{Al}_{2} \mathrm{O}_{3} \sim \mathrm{SiO}_{2} \sim \mathrm{ZrO}_{2}<\mathrm{CeO}_{2}<\mathrm{H}-\mathrm{ZSM} 5<\mathrm{ZnO}
$$

De todos los sólidos evaluados, el $\mathrm{ZnO}$ en una relación másica $\mathrm{ZnO}$ :Ni-Mo $=2$, resultó ser el co-catalizador óptimo. Los resultados fueron atribuidos a la mayor acidez superficial de tipo Lewis presente en el sólido de $\mathrm{ZnO}$ [13]. En otros de sus trabajos, estos autores sintetizaron cristales hexagonales de $\mathrm{ZnO}$ formando estructuras de discos y varillas y los emplearon como co-catalizadores en presencia del mismo catalizador de Ni-Mo. La síntesis de las estructuras de $\mathrm{ZnO}$ fue controlada variando la concentración de acetato de cinc. Los resultados mostraron una correlación lineal entre la velocidad de producción de 1,2-PG con la superficie específica de los cristales de $\mathrm{ZnO}$ [241].

Li et al. probaron la adición de la zeolita H-ZSM5 como co-catalizador en presencia de catalizadores de $\mathrm{Ru} / \mathrm{SiO}_{2}$ y $\mathrm{Ru} / \mathrm{Al}_{2} \mathrm{O}_{3}$. Si bien se produce un aumento significativo de la conversión, que es mayor cuando disminuye la relación $\mathrm{SiO}_{2} / \mathrm{Al}_{2} \mathrm{O}_{3}$ en la zeolita, la selectividad a 1,2-PG disminuye debido a la formación de productos tales como $\mathrm{CH}_{4}$, debido a la promoción de las reacciones de ruptura C-C [242].

\subsubsection{Efecto de la temperatura}

La cinética del conjunto de reacciones en la hidrogenólisis es función de la temperatura, y, por lo tanto, la formación de 1,2-PG o de los productos laterales de reacción como $\mathrm{MeOH}$, EtOH y EG depende de esta variable operativa.

Dasari et al fueron los primeros en presentar una sección destinada al estudio del efecto térmico [7]. En el rango $150-260{ }^{\circ} \mathrm{C}$, a una presión de 14 bar de $\mathrm{H}_{2}$, estudiaron el aumento de la conversión y disminución de la selectividad a 1,2-PG por aumento de la temperatura en presencia de un catalizador de $\mathrm{Cu}-\mathrm{Cr}_{2} \mathrm{O}_{3}$. Los resultados mostraron que un aumento de la temperatura genera menores rendimientos a 1,2-PG por la formación de compuestos laterales como $\mathrm{EG}, \mathrm{MeOH}$ y $\mathrm{EtOH}$, los que pueden seguir reaccionando hasta obtener productos gaseosos como metano, etano, propano y $\mathrm{CO}_{2}$.

El efecto térmico reportado inicialmente por Dasari et al. fue posteriormente reportado

por otros autores que evaluaron catalizadores de $\mathrm{Cu}$ $[16,50,62,66,70,72,73,75,84,89,126,168,182,185,191,196,218,220,243,244]$, Ni $[210,206,208,209]$, Co [98,216], Ru [24,34,103-105,123-126,133,132,227], Pt [104,124,136,144], Pd [104,167,245], Rh $[34,40,52,104]$ lo cual indica que estos resultados son independientes del catalizador utilizado.

Las Tablas 24-2 y 25-2 muestran los trabajos que reportan el estudio del efecto de la temperatura. Para cada uno de ellos se muestra el rango térmico estudiado y la temperatura óptima para el máximo rendimiento a 1,2-PG ( $\mathrm{R}_{1,2-\mathrm{PG})}$. 
Tabla 24-2. Efecto térmico estudiado en fase líquida sobre diferentes catalizadores.

\begin{tabular}{|c|c|c|c|c|c|c|c|}
\hline Catalizador & Rango $\left({ }^{\circ} \mathrm{C}\right)$ & Tóptima $\left({ }^{\circ} \mathrm{C}\right)$ & $\mathrm{P}$ (bar) & $\mathrm{m}_{\mathrm{gli}} / \mathrm{m}_{\mathrm{c}}(\mathrm{g} / \mathrm{g})$ & $\mathrm{t}(\mathrm{h})$ & $\mathrm{R}_{1,2-\mathrm{PG}}(\%)$ & Ref. \\
\hline \multirow{2}{*}{$\mathrm{Cu}-\mathrm{ZnO}$} & $180-240$ & 220 & $42\left(\mathrm{H}_{2}\right)$ & 13.8 & 12 & 33.0 & [50] \\
\hline & $120-220$ & 200 & $20\left(\mathrm{H}_{2}\right)$ & 16.6 & 16 & 34.0 & [62] \\
\hline $\mathrm{Cu}-\mathrm{ZnO}-\mathrm{MgO}-\mathrm{Al}_{2} \mathrm{O}_{3}$ & $160-200$ & 200 & $20\left(\mathrm{H}_{2}\right)$ & 15.0 & 10 & 84.3 & [84] \\
\hline $\mathrm{Cu}-\mathrm{SiO}_{2}$ & $160-220$ & 200 & $90\left(\mathrm{H}_{2}\right)$ & 16.0 & 12 & 69.0 & [66] \\
\hline $\mathrm{Cu}-\mathrm{MgO}$ & $160-220$ & 200 & $40\left(\mathrm{H}_{2}\right)$ & 17.5 & 8 & 45.5 & [70] \\
\hline $\mathrm{Cu}-\mathrm{Ca}-\mathrm{Al}$ & $160-230$ & 200 & $35\left(\mathrm{H}_{2}\right)$ & 16.6 & 8 & 31.1 & [75] \\
\hline $\mathrm{Cu}-\mathrm{ZrO}_{2}-\mathrm{MgO}$ & $160-220$ & 180 & $40\left(\mathrm{H}_{2}\right)$ & 16.6 & 8 & 59.5 & [89] \\
\hline \multirow{2}{*}{$\mathrm{Cu} / \gamma-\mathrm{Al}_{2} \mathrm{O}_{3}$} & $180-240$ & 220 & $36\left(\mathrm{H}_{2}\right)$ & 8.5 & 10 & 47.5 & [243] \\
\hline & $150-230$ & 200 & $40\left(\mathrm{H}_{2}\right)$ & 20.0 & 24 & 72.5 & [73] \\
\hline $\mathrm{Cu} / \mathrm{SiO}_{2}$ & $180-220$ & 200 & $34\left(\mathrm{H}_{2}\right)$ & 2.5 & 10 & 96.5 & [191] \\
\hline $\mathrm{Cu} / \mathrm{DUSY}$ & $160-240$ & 200 & $35\left(\mathrm{H}_{2}\right)$ & 16.6 & 10 & 77.6 & {$[182]$} \\
\hline $\mathrm{Cu} / \mathrm{MgO}$ & $190-230$ & 210 & $45\left(\mathrm{H}_{2}\right)$ & 12.5 & 12 & 89.4 & {$[185]$} \\
\hline $\mathrm{Cu}-\mathrm{Ni} / \gamma-\mathrm{Al}_{2} \mathrm{O}_{3}$ & $190-230$ & 210 & $45\left(\mathrm{H}_{2}\right)$ & 10.5 & 12 & 51.3 & [168] \\
\hline $\mathrm{Cu}-\mathrm{Ag} / \gamma-\mathrm{Al}_{2} \mathrm{O}_{3}$ & $180-240$ & 200 & $35\left(\mathrm{H}_{2}\right)$ & 30.0 & 8 & 45.2 & [196] \\
\hline $\mathrm{Cu}-\mathrm{CeO}_{2}-\mathrm{MgO}$ & $160-220$ & 200 & $60\left(\mathrm{H}_{2}\right)$ & 10.0 & 10 & 54.9 & {$[244]$} \\
\hline $\mathrm{Ni} / \mathrm{SiO}_{2}-\mathrm{Al}_{2} \mathrm{O}_{3}$ & $170-250$ & 200 & $25\left(\mathrm{H}_{2}\right)$ & 20.0 & 8 & 29.4 & [210] \\
\hline $\mathrm{Ni} / \mathrm{CeO}_{2}-\mathrm{MgO}$ & $200-230$ & 230 & $69\left(\mathrm{H}_{2}\right)$ & 6.0 & 24 & 32.7 & [206] \\
\hline $\mathrm{Ni} / \mathrm{WO}_{3}-\mathrm{MSAP}$ & $120-220$ & 180 & $20\left(\mathrm{H}_{2}\right)$ & 10.5 & 6 & 83.9 & [208] \\
\hline $\mathrm{Co} / \mathrm{MgO}$ & $180-250$ & 200 & $20\left(\mathrm{H}_{2}\right)$ & 20.0 & 9 & 18.9 & [216] \\
\hline $\mathrm{CoCu}$ & $190-250$ & 220 & $30\left(\mathrm{H}_{2}\right)$ & 80.0 & 7 & 24.5 & [98] \\
\hline $\mathrm{Ru} / \mathrm{C}$ & $120-160$ & 160 & $80\left(\mathrm{H}_{2}\right)$ & 28.0 & 10 & 11.0 & [34] \\
\hline $\mathrm{Ru} / \mathrm{Al}_{2} \mathrm{O}_{3}$ & $120-180$ & 180 & $80\left(\mathrm{H}_{2}\right)$ & 29.4 & 8 & 28.0 & [105] \\
\hline $\mathrm{Ru}-\mathrm{Cu}$ /Bentonita & $190-240$ & 230 & $100\left(\mathrm{H}_{2}\right)$ & 5.4 & 18 & 86.4 & [125] \\
\hline $\mathrm{Ru} / \mathrm{Al}_{2} \mathrm{O}_{3}+\mathrm{Pt} / \mathrm{Al}_{2} \mathrm{O}_{3}$ & $200-250$ & 220 & $14\left(\mathrm{~N}_{2}\right)$ & 12.0 & 6 & 23.6 & [124] \\
\hline $\mathrm{Ru}-\mathrm{Co} / \mathrm{ZrO}_{2}$ & $140-200$ & 180 & $50\left(\mathrm{H}_{2}\right)$ & 12.6 & 10 & 39.5 & [133] \\
\hline $\mathrm{Ru}-\mathrm{Re} / \mathrm{SiO}_{2}$ & $110-160$ & 125 & $75\left(\mathrm{H}_{2}\right)$ & 29.4 & 8 & 29.2 & [132] \\
\hline $\mathrm{Ru} /$ Bentonita- $\mathrm{TiO}_{2}$ & $110-170$ & 150 & $20\left(\mathrm{H}_{2}\right)$ & 20.0 & 7 & 56.2 & [123] \\
\hline $\mathrm{Ru} / \mathrm{HY}$ & $190-220$ & 220 & $40\left(\mathrm{H}_{2}\right)$ & 6.0 & 10 & 48.8 & [24] \\
\hline $\mathrm{Ru}-\mathrm{Cu} / \mathrm{Al}_{2} \mathrm{O}_{3}$ & $180-220$ & 200 & $25\left(\mathrm{H}_{2}\right)$ & 17.5 & 24 & 42.3 & [126] \\
\hline $\mathrm{Ru} / \mathrm{ZrO}_{2}$ & $180-240$ & 210 & $60\left(\mathrm{H}_{2}\right)$ & 1.4 & 3 & 11.3 & {$[104]$} \\
\hline $\mathrm{Ru} / \mathrm{CsPW}$ & $120-200$ & 150 & $5\left(\mathrm{H}_{2}\right)$ & 3.5 & 10 & 27.1 & [103] \\
\hline $\mathrm{Pt} / \mathrm{ZrO}_{2}$ & $180-240$ & 180 & $60\left(\mathrm{H}_{2}\right)$ & 1.4 & 3 & 18.9 & [104] \\
\hline $\mathrm{Pt} / \mathrm{Fe}_{3} \mathrm{O}_{4}$ & $190-240$ & 230 & $20\left(\mathrm{H}_{2}\right)$ & 30.0 & 16 & 64.2 & [136] \\
\hline $\mathrm{Pt}-\mathrm{Ni} / \gamma-\mathrm{Al}_{2} \mathrm{O}_{3}$ & $220-260$ & 240 & $10\left(\mathrm{~N}_{2}\right)$ & 21.0 & 3 & 37.4 & [144] \\
\hline $\mathrm{Pd}-\mathrm{Cu} / \mathrm{KF}-\gamma-\mathrm{Al}_{2} \mathrm{O}_{3}$ & $150-220$ & 200 & $25\left(\mathrm{H}_{2}\right)$ & 11.1 & 20 & 95.5 & [245] \\
\hline $\mathrm{Pd}-\mathrm{Cu} / \mathrm{Mg}_{5,6-x} \mathrm{Al}_{2} \mathrm{O}_{8,6-\mathrm{x}}$ & $120-200$ & 200 & $20\left(\mathrm{H}_{2}\right)$ & 6.0 & 10 & 91.2 & [163] \\
\hline $\mathrm{Pd}-\mathrm{Ni}$ & $160-260$ & 220 & $20\left(\mathrm{H}_{2}\right)$ & 21.0 & 12 & 25.6 & [167] \\
\hline $\mathrm{Rh} / \mathrm{SiO}_{2}$ & $120-160$ & 160 & $80\left(\mathrm{H}_{2}\right)$ & 28.0 & 10 & 7.0 & [34] \\
\hline $\mathrm{Rh}-\mathrm{ReO} \times / \mathrm{SiO}_{2}$ & $100-180$ & 160 & $80\left(\mathrm{H}_{2}\right)$ & 28.0 & 2 & 39.0 & [40] \\
\hline
\end{tabular}


Tabla 25-2. Efecto térmico estudiado en fase vapor sobre diferentes catalizadores.

\begin{tabular}{lcccccc}
\hline Catalizador & Rango $\left({ }^{\circ} \mathrm{C}\right)$ & Tóptima $^{\prime}\left({ }^{\circ} \mathrm{C}\right)$ & $\mathrm{P}($ bar $)$ & WHSV $\left(\mathrm{h}^{-1}\right)$ & $\mathrm{R}_{1,2-\mathrm{PG}}(\%)$ & Ref. \\
\hline $\mathrm{Cu}-\mathrm{ZnO}-\mathrm{TiO}_{2}$ & $240-300$ & 240 & $1\left(\mathrm{H}_{2}\right)$ & $\mathrm{NC}$ & 15.0 & {$[218]$} \\
\hline $\mathrm{Cu}-\mathrm{ZnO}-\mathrm{ZrO}_{2}$ & $240-300$ & 240 & $1\left(\mathrm{H}_{2}\right)$ & $\mathrm{NC}$ & 12.0 & {$[218]$} \\
\hline $\mathrm{Cu}-\mathrm{Cr}_{2} \mathrm{O}_{3}$ & $200-240$ & 220 & $1\left(\mathrm{H}_{2}\right)$ & 0.1 & 42.4 & {$[16]$} \\
\hline $\mathrm{Cu} / \mathrm{MgO}$ & $180-280$ & 220 & $7.5\left(\mathrm{H}_{2}\right)$ & 1.2 & 95.5 & {$[220]$} \\
\hline $\mathrm{Ni}-\mathrm{Ag} / \gamma-\mathrm{Al}_{2} \mathrm{O}_{3}$ & $180-260$ & 200 & $1\left(\mathrm{H}_{2}\right)$ & 2.0 & 46.4 & {$[209]$} \\
\hline $\mathrm{C}$
\end{tabular}

NC: no claro

$\mathrm{X}_{\mathrm{GLI}}$ : conversión de glicerol, $\mathrm{S}_{1,2-\mathrm{PG}}$ selectividad a 1,2-PG, $\mathrm{R}_{1,2-\mathrm{PG}}$ rendimiento a 1,2-PG

El estudio del efecto de la temperatura permite estimar una energía de activación global para la reacción de hidrogenólisis, empleando una ecuación logarítmica basada en la ley de Arrhenius sobre el valor de la velocidad de reacción observada para el consumo de glicerol (robs):

$$
\ln \left(\mathrm{robs}_{\mathrm{os}}\right)=\ln \left(\mathrm{k}_{\mathrm{o}}\right)+\left(-\mathrm{E}_{\mathrm{a}} / \mathrm{R}\right) \cdot(1 / \mathrm{T})
$$

En la ecuación anterior, Ea es la energía de activación aparente y global de la reacción de hidrogenólisis $(\mathrm{kJ} / \mathrm{mol})$ y ko es el factor pre-exponencial encontrado en la velocidad de reacción observada para cinética de las reacciones heterogéneas.

La Tabla 26-2 muestra los catalizadores, las energías de activación encontradas y las condiciones operativas en las que se llevaron a cabo los ensayos.

Tabla 26-2. Energías de activación en fase líquida empleando diferentes catalizadores.

\begin{tabular}{lccc}
\hline Catalizador & Rango $\left({ }^{\circ} \mathrm{C}\right)$ & $\mathrm{Ea}_{\mathrm{a}}(\mathrm{kJ} / \mathrm{mol})$ & Ref. \\
\hline $\mathrm{Cu}-\mathrm{SiO}_{2}$ & $160-220$ & 48.0 & {$[66]$} \\
\hline $\mathrm{Cu} / \mathrm{SiO}_{2}$ & $180-240$ & 96.8 & {$[9]$} \\
\hline $\mathrm{Cu} / \mathrm{MgO}$ & $160-220$ & 58.3 & {$[244]$} \\
\cline { 2 - 4 } & $190-230$ & 78.5 & {$[185]$} \\
\hline $\mathrm{Cu} / \mathrm{CeO}_{2} / \mathrm{MgO}$ & $160-220$ & 26.6 & {$[244]$} \\
\hline $\mathrm{Cu}-\mathrm{ZrO} 2-\mathrm{MgO}$ & $160-220$ & 22.7 & {$[133]$} \\
\hline $\mathrm{Cu}-\mathrm{ZnO}-\mathrm{Cr}_{2} \mathrm{O}_{3}-\mathrm{ZrO}_{2}$ & $220-250$ & 132.7 & {$[8]$} \\
\hline $\mathrm{Co}-\mathrm{ZnO}$ & $160-220$ & 31.0 & {$[100]$} \\
\hline $\mathrm{Pt} / \mathrm{C}$ & $130-160$ & 63.7 & {$[246]$} \\
\hline $\mathrm{Pt} / \mathrm{Fe} 3 \mathrm{O}_{4}$ & $190-240$ & 61.1 & {$[136]$} \\
\hline $\mathrm{Ru}-\mathrm{Re} / \mathrm{SiO}_{2}$ & $110-130$ & 107.8 & {$[132]$} \\
\hline $\mathrm{Ru}-\mathrm{Re} / \mathrm{C}$ & $220-240$ & 54.2 & {$[247]$} \\
\hline $\mathrm{Pd}-\mathrm{Cu} / \mathrm{Mg}_{5,6-\mathrm{x}} \mathrm{Al}_{2} \mathrm{O}_{8,6-\mathrm{x}}$ & $150-180$ & 77.1 & {$[163]$} \\
\hline $\mathrm{Rh} / \mathrm{C}$ & $180-240$ & 98.0 & {$[52]$} \\
\hline
\end{tabular}


2.6.8. Efecto de la presión

El efecto de la presión se ha estudiado tanto en fase líquida, empleando reactores batch (Tabla 27-2), como en fase vapor, empleando reactores de flujo continuo (Tabla 28-2).

Tabla 27-2. Estudio del efecto de la presión en fase líquida empleando reactores batch.

\begin{tabular}{|c|c|c|c|c|c|}
\hline Catalizador & Rango (bar) & $\mathrm{T}\left({ }^{\circ} \mathrm{C}\right)$ & $\mathrm{m}_{\mathrm{gli}} / \mathrm{m}_{\mathrm{c}}(\mathrm{g} / \mathrm{g})$ & $t(h)$ & Ref. \\
\hline $\mathrm{Cu}-\mathrm{Cr}_{2} \mathrm{O}_{4}$ & 3-20 $\left(\mathrm{H}_{2}\right)$ & 200 & 20.0 & 24 & [7] \\
\hline $\mathrm{Ru} / \mathrm{C}$ & $20-80\left(\mathrm{H}_{2}\right)$ & 180 & 16.7 & 8 & {$[122]$} \\
\hline $\mathrm{Ru} / \mathrm{TiO}_{2}$ & $20-80\left(\mathrm{H}_{2}\right)$ & 180 & 16.7 & 8 & {$[110]$} \\
\hline $\mathrm{Ru}-\mathrm{Co} / \mathrm{ZrO}_{2}$ & $20-60\left(\mathrm{H}_{2}\right)$ & 180 & 12.6 & 10 & {$[133]$} \\
\hline $\mathrm{Pt} / \mathrm{Fe}_{3} \mathrm{O}_{4}$ & $25-50\left(\mathrm{H}_{2}\right)$ & 230 & 30.0 & 16 & {$[136]$} \\
\hline $\mathrm{Pd}-\mathrm{Ni}$ & $20-100\left(\mathrm{H}_{2}\right)$ & 220 & 21.0 & 12 & [167] \\
\hline $\mathrm{Cu} / \mathrm{Al}_{2} \mathrm{O}_{3}$ & $35-87\left(\mathrm{H}_{2}\right)$ & 200 & 16.7 & 24 & [73] \\
\hline $\mathrm{Cu} / \mathrm{MgO}$ & $15-60\left(\mathrm{H}_{2}\right)$ & 210 & 12.5 & 12 & {$[185]$} \\
\hline $\mathrm{Cu}-\mathrm{MgO}$ & $20-80\left(\mathrm{H}_{2}\right)$ & 200 & 16.7 & 8 & [70] \\
\hline $\mathrm{Cu}-\mathrm{ZnO}-\mathrm{Al}_{2} \mathrm{O}_{3}$ & $13-27\left(\mathrm{H}_{2}\right)$ & 200 & 20.0 & 24 & [81] \\
\hline $\mathrm{Cu}-\mathrm{ZrO}_{2}-\mathrm{MgO}$ & $20-50\left(\mathrm{H}_{2}\right)$ & 180 & 16.7 & 8 & [89] \\
\hline $\mathrm{Cu}-\mathrm{CaO}-\mathrm{Al}_{2} \mathrm{O}_{3}$ & $20-40\left(\mathrm{H}_{2}\right)$ & 200 & 16.7 & 8 & [75] \\
\hline $\mathrm{Cu}-\mathrm{Ag} / \gamma-\mathrm{Al}_{2} \mathrm{O}_{3}$ & $25-45\left(\mathrm{H}_{2}\right)$ & 200 & 30.0 & 8 & {$[196]$} \\
\hline $\mathrm{Ni} / \mathrm{NaX}$ & $30-70\left(\mathrm{H}_{2}\right)$ & 200 & 20.0 & 10 & {$[204]$} \\
\hline Ni-Raney & $60-100\left(\mathrm{H}_{2}\right)$ & 200 & 20.0 & 4 & [249] \\
\hline $\mathrm{Ni} / \mathrm{CeO}_{2}-\mathrm{MgO}$ & $69-86\left(\mathrm{H}_{2}\right)$ & 215 & 4.0 & 24 & {$[206]$} \\
\hline $\mathrm{Ni} / \mathrm{WO}_{3}-\mathrm{MSAP}$ & $10-40\left(\mathrm{H}_{2}\right)$ & 180 & 14.0 & 6 & {$[208]$} \\
\hline
\end{tabular}

Tabla 28-2. Estudio del efecto de la presión en fase vapor empleando reactores de flujo continuo.

\begin{tabular}{lcccc}
\hline Catalizador & Rango (bar) & T $\left({ }^{\circ} \mathrm{C}\right)$ & WHSV $\left(\mathrm{h}^{-1}\right)$ & Ref. \\
\hline $\mathrm{Cu}-\mathrm{H}_{4} \mathrm{SiW}_{12} \mathrm{O}_{40} / \mathrm{SiO}_{2}$ & $1-5.4\left(\mathrm{H}_{2}\right)$ & 210 & 0.1 & {$[232]$} \\
\hline $\mathrm{Cu}-\mathrm{Ni} / \gamma-\mathrm{Al}_{2} \mathrm{O}_{3}$ & $1-10\left(\mathrm{H}_{2}\right)$ & 220 & 0.9 & {$[221]$} \\
\hline $\mathrm{Cu} / \mathrm{MgO}$ & $1-10\left(\mathrm{H}_{2}\right)$ & 220 & 1.2 & {$[220]$} \\
\hline
\end{tabular}

En fase líquida empleando reactores batch, se ha reportado que un aumento en la presión de $\mathrm{H}_{2}$ genera un aumento en la conversión de glicerol, así como también un aumento en la selectividad a 1,2-PG, empleando catalizadores basados en metales nobles como Ru $[110,122]$ y no nobles, como $\mathrm{Cu}[7,73,81,185]$. En algunos catalizadores, no obstante, no se observaron cambios en la selectividad a 1,2-PG, lo que sugiere que la naturaleza del catalizador es altamente selectiva a este producto [133,185,167]. El efecto de la presión sobre la conversión y selectividad a glicoles también fue probado en fase líquida empleando 
reactores de flujo continuo del tipo trickle bed y los resultados obtenidos fueron similares a los reportados en reactores batch [11]. De forma general, los resultados obtenidos han sido atribuidos a una mayor solubilidad del $\mathrm{H}_{2}$ en fase líquida, lo que permite hidrogenar el $\mathrm{AcOH}[11,73,81,110,122,133,185,216]$.

El empleo de bajas presiones de $\mathrm{H}_{2}$ en condiciones de altas concentraciones de glicerol puede conducir a la generación de productos de condensación, debido a la reacción entre el glicerol y $\mathrm{AcOH}$, que suele producirse por una menor actividad hidrogenante por falta de $\mathrm{H}_{2}$ $[81,248]$.

Aumentar la presión genera dos beneficios, por un lado, permite mantener la condición de fase líquida, y por el otro aumenta la solubilidad del $\mathrm{H}_{2}$ mejorando la selectividad a 1,2-PG. Sin embargo, reactores que operan a mayores presiones presuponen no sólo un mayor costo fijo asociado al equipo, sino también un mayor costo operativo [7].

Se ha reportado también que un aumento excesivo de la presión puede conducir a una caída en la conversión e incluso a una pérdida en la selectividad a glicoles. Por un lado, la caída en los valores de conversión ha sido atribuida en algunos sistemas catalíticos a la competencia entre la adsorción de los átomos de $\mathrm{H}$ sobre el catalizador con la adsorción de intermediarios de reacción [70]. A altas presiones, el $\mathrm{H}_{2}$ se adsorbe sobre los sitios activos bloqueando parte de los mismos para la adsorción del glicerol [136]. En casos donde prima el mecanismo de deshidrogenación-deshidratación-hidrogenación, la caída en la conversión puede ser atribuida a que la etapa de deshidrogenación se encuentra termodinámicamente desfavorecida en presencia de altas presiones de $\mathrm{H}_{2}$ [89].

Por otro lado, varios reportes coinciden en que una excesiva presión de $\mathrm{H}_{2}$ promueve la formación de 1-POH o 2-POH, o la ruptura de enlaces C-C. Con respecto a catalizadores basados en metales nobles, como $\mathrm{Ru}$ [122] la selectividad a 1,2-PG disminuye a expensas de la formación de EG. Sistemas basados en $\mathrm{Cu}$ mostraron similares resultados con una caída en la selectividad a 1,2-PG debido a la formación de productos secundarios [75,196]. Otros catalizadores basados en Ni mostraron la formación de EG [204,208,249] y propanoles [206] debido a la misma razón.

Hay muy pocos trabajos en donde se ha estudiado el efecto de la presión cuando la reacción se conduce en fase vapor, y en ellos se ha reportado un aumento en la conversión y selectividad a 1,2-PG [220,221,232] por efecto de la presión.

\subsubsection{Efecto del tiempo de reacción}

Varios autores han estudiado el efecto del tiempo de reacción, en la condición de fase líquida empleando reactores batch (Tabla 29-2).

Naturalmente, la conversión de glicerol en reactores batch aumenta conforme aumenta el tiempo de reacción. Este efecto fue reportado por varios autores empleando catalizadores basados en metales nobles como Ru [110,122], Pt [144] y Pd [163,167], y en metales no nobles como Cu [70,73,75,89,182,196], Ni [204,206,213,249], Co [100].

A medida que aumenta la conversión se produce una disminución en la selectividad a 1,2-PG debido a la generación de productos laterales, tales como EG, EtOH, $\mathrm{MeOH}$ y en algunos casos, gases, como $\mathrm{CH}_{4}$, etano y propano. Dado que la conversión aumenta conforme aumenta el tiempo de reacción, pero la selectividad a 1,2-PG, disminuye a altos tiempos, se 
alcanza un máximo para el rendimiento a este producto, y por lo tanto se establece un tiempo de reacción óptimo. Este fenómeno ha sido reportado por varios autores, aun en presencia de catalizadores de distinta naturaleza, pero principalmente para sistemas basados en Ru [110,122], Pt [144], Pd [167] y Ni [204,206,213,249], que tienen mayor tendencia a participar en reacciones de ruptura de enlaces $\mathrm{C}-\mathrm{C}$.

Si bien el efecto también fue reportado para catalizadores de $\mathrm{Cu}[73,75,196]$, algunos autores han reportado que, en algunos sistemas basados en $\mathrm{Cu}$, la disminución con el transcurso del tiempo de la selectividad a 1,2-PG no ha sido tan marcada debido a la mayor selectividad de estos catalizadores para las reacciones de ruptura de enlaces C-O [70,89,182]. Este efecto también fue reportado en presencia de catalizadores de Co [100].

Tabla 29-2. Estudio del efecto del tiempo de reacción en fase líquida empleando reactores batch.

\begin{tabular}{|c|c|c|c|c|c|c|c|}
\hline Catalizador & Rango (h) & tóptimo (h) & $\mathrm{T}\left({ }^{\circ} \mathrm{C}\right)$ & $\mathrm{P}$ (bar) & $\mathrm{m}_{\mathrm{gli}} / \mathrm{mc}_{\mathrm{c}}(\mathrm{g} / \mathrm{g})$ & $\mathrm{R}_{1,2-\mathrm{PG}}(\%)$ & Ref. \\
\hline $\mathrm{Ru} / \mathrm{C}$ & $4-16$ & 12 & 180 & $20\left(\mathrm{H}_{2}\right)$ & 16.7 & 32.6 & {$[122]$} \\
\hline $\mathrm{Ru} / \mathrm{TiO}_{2}$ & $4-16$ & 16 & 180 & $60\left(\mathrm{H}_{2}\right)$ & 16.7 & 36.9 & [110] \\
\hline $\mathrm{Pt}-\mathrm{Ni} / \gamma-\mathrm{Al}_{2} \mathrm{O}_{3}$ & $1-10$ & 7 & 240 & $10\left(\mathrm{~N}_{2}\right)$ & 21.0 & 50.0 & {$[144]$} \\
\hline $\mathrm{Pd}-\mathrm{Ni}$ & $6-30$ & 24 & 220 & $60\left(\mathrm{H}_{2}\right)$ & 21.0 & 48.9 & {$[167]$} \\
\hline $\mathrm{Pd}-\mathrm{Cu} / \mathrm{Mg}-\mathrm{Al}_{2} \mathrm{O}_{3}$ & $1-20$ & 20 & 180 & $60\left(\mathrm{H}_{2}\right)$ & 6.0 & 87.1 & {$[163]$} \\
\hline $\mathrm{Cu} / \mathrm{Al}_{2} \mathrm{O}_{3}$ & $16-48$ & 24 & 200 & $20\left(\mathrm{H}_{2}\right)$ & 20.0 & 68.9 & [73] \\
\hline $\mathrm{Cu} / \mathrm{MgO}$ & $4-10$ & 8 & 200 & $40\left(\mathrm{H}_{2}\right)$ & 16.7 & 45.5 & [70] \\
\hline $\mathrm{Cu} / \mathrm{DUSY}$ & $2-10$ & 10 & 200 & $35\left(\mathrm{H}_{2}\right)$ & 16.7 & 79.9 & {$[182]$} \\
\hline $\mathrm{Cu}-\mathrm{CaO}-\mathrm{Al}_{2} \mathrm{O}_{3}$ & $2-10$ & 8 & 200 & $35\left(\mathrm{H}_{2}\right)$ & 16.7 & 31.2 & [75] \\
\hline $\mathrm{Cu}-\mathrm{ZrO}_{2}-\mathrm{MgO}$ & $2-10$ & 10 & 180 & $40\left(\mathrm{H}_{2}\right)$ & 16.7 & 63.9 & [89] \\
\hline $\mathrm{Cu}-\mathrm{Ag} / \gamma-\mathrm{Al}_{2} \mathrm{O}_{3}$ & $4-10$ & 8 & 200 & $35\left(\mathrm{H}_{2}\right)$ & 30.0 & 47.3 & {$[196]$} \\
\hline $\mathrm{Ni} / \mathrm{NaX}$ & $2-10$ & 10 & 200 & $60\left(\mathrm{H}_{2}\right)$ & 20.0 & 68.1 & {$[204]$} \\
\hline $\mathrm{Ni}-\mathrm{Ce} / \mathrm{AC}$ & $2-8$ & 8 & 200 & $50\left(\mathrm{H}_{2}\right)$ & 22.9 & 58.9 & {$[213]$} \\
\hline Ni-Raney & $1-12$ & 12 & 200 & $80\left(\mathrm{H}_{2}\right)$ & 21.0 & 59.8 & [249] \\
\hline $\mathrm{Ni} / \mathrm{CeO}_{2}-\mathrm{MgO}$ & $24-48$ & 48 & 215 & $86\left(\mathrm{H}_{2}\right)$ & 4.0 & 46.0 & {$[206]$} \\
\hline $\mathrm{Ni} / \mathrm{WO}_{3}-\mathrm{MSAP}$ & $2-12$ & 12 & 180 & $20\left(\mathrm{H}_{2}\right)$ & 6.6 & 84.7 & [208] \\
\hline $\mathrm{Co}-\mathrm{ZnO}$ & $4-8$ & 8 & 180 & $40\left(\mathrm{H}_{2}\right)$ & 6.7 & 56.0 & {$[100]$} \\
\hline
\end{tabular}

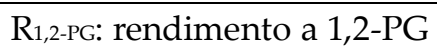

Para reactores de flujo continuo, tanto en la condición de fase líquida [223] como en fase vapor [178,209,220,221,229,232], se ha estudiado la velocidad especial (WHSV), empleando distintos sistemas catalíticos (Tabla 30-2).

En la bibliografía se ha reportado que altos valores de WHSV conducen a obtener menores conversiones debido a los bajos tiempos de contacto [178,209,220,221,229,232]. En algunos casos, altos valores de WHSV condujeron a obtener alta selectividad a glicoles [232], mientras que en otros casos los valores de selectividad fueron bajos [178,209,220,221,229]. En la mayor parte de los trabajos, se ha indicado que existe un valor óptimo de WHSV para el 
cual el rendimiento a glicoles es máximo [209,223]. Por otro lado, bajos valores de WHSV conducen a obtener mayores niveles de conversión, pero baja selectividad a glicoles debido a la formación de productos secundarios debido a los altos tiempos de contacto [232].

Tabla 30-2. Estudio del efecto de la velocidad espacial en fase líquida y vapor empleando reactores de flujo continuo.

\begin{tabular}{lcccccc}
\hline Catalizador & Rango $\left(\mathrm{h}^{-1}\right)$ & WHSV $_{\text {óptimo }}\left(\mathrm{h}^{-1}\right)$ & $\mathrm{p}(\mathrm{bar})$ & $\mathrm{T}\left({ }^{\circ} \mathrm{C}\right)$ & $\mathrm{R}_{1,2 / 1,3-\mathrm{PG}}(\%)$ & Ref. \\
\hline $\mathrm{Ni} / \mathrm{ZnO}$ & $0.48-1.08$ & 0.84 & $31(\mathrm{Ar})$ & 235 & $46.9(1,2-\mathrm{PG})$ & {$[223]$} \\
\hline $\mathrm{Pt} / \mathrm{WO}_{3} / \mathrm{SBA}-15$ & $1.02-4.08$ & 1.02 & $1\left(\mathrm{H}_{2}\right)$ & 210 & $36.1(1,3-\mathrm{PG})$ & {$[229]$} \\
\hline $\mathrm{Cu} / \mathrm{SBA}-15$ & $1.03-5.20$ & 1.03 & $1\left(\mathrm{H}_{2}\right)$ & 220 & $75.6(1,2-\mathrm{PG})$ & {$[178]$} \\
\hline $\mathrm{Cu} / \mathrm{MgO}$ & $1.03-1.80$ & 1.20 & $7.5\left(\mathrm{H}_{2}\right)$ & 220 & $95.5(1,2-\mathrm{PG})$ & {$[220]$} \\
\hline $\mathrm{Cu}-\mathrm{Ni} / \gamma-\mathrm{Al}_{2} \mathrm{O}_{3}$ & $0.97-1.11$ & 0.97 & $7.5\left(\mathrm{H}_{2}\right)$ & 220 & $88.0(1,2-\mathrm{PG})$ & {$[221]$} \\
\hline $\mathrm{Cu}-\mathrm{H}_{4} \mathrm{SiW}_{12} \mathrm{O}_{40} / \mathrm{SiO}_{2}$ & $0.025-0.12$ & 0.065 & $3.6\left(\mathrm{H}_{2}\right)$ & 190 & $17.8(1,3-\mathrm{PG})$ & {$[232]$} \\
\hline $\mathrm{Ni}-\mathrm{Ag} / \gamma-\mathrm{Al}_{2} \mathrm{O}_{3}$ & $1.51-2.52$ & 2.01 & $1\left(\mathrm{H}_{2}\right)$ & 200 & $46.4(1,2-\mathrm{PG})$ & {$[209]$} \\
\hline $\mathrm{R}$
\end{tabular}

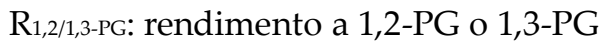

\subsection{Modelos cinéticos}

La mayor parte de los trabajos se han focalizado en estudios cinéticos en la condición de fase líquida y reactores batch. Sólo en algunos trabajos se muestran los resultados de estabilidad del catalizador estudiado en las condiciones de reacción seleccionadas $[8,9,100,250]$ y los resultados previos para asegurar el control cinético en ausencia de gradientes externos e internos a la transferencia de materia $[8,9,89,100,235,239,246,247,249,250]$.

Se han desarrollado modelos cinéticos basados en la ley de la potencia [9,89,100,132,164,247] y del tipo Langmuir-Hinshelwood, considerando uno [235,239,251] o dos tipos de sitios activos $[8,246,248,249,250]$ y en algunos casos el fenómeno de competencia por los sitios activos [235,239,246,248-251]. Se han calculado valores de energías de activación de la velocidad global de reacción [9,251], energías de activación para los pasos de deshidratación e hidrogenación [250], y en algún caso, en presencia de venenos como el azufre [239].

El primero de los trabajos ha sido reportado en 2003 por Lahr et al., quienes emplearon un catalizador comercial de $\mathrm{Ru} / \mathrm{C}$ en presencia de bases $\left(\mathrm{CaO}\right.$ y $\mathrm{CaCO}_{3}$ ) realizaron ensayos cinéticos a 70 bar de $\mathrm{H}_{2}$ con una concentración del catalizador del $5 \% \mathrm{p} / \mathrm{p}$, considerando valores de pH de 8 y 11.7, concentraciones de glicerol, 1,2-PG y EG del 10 \%p/p, y tiempos de reacción de hasta $75 \mathrm{~min}$. $\mathrm{El} \mathrm{H}_{2}$, por las altas presiones empleadas, no fue considerado como especie adsorbida en la superficie catalítica debido a su disponibilidad en el medio de reacción. Los datos cinéticos fueron ajustados con un modelo de Langmuir-Hinshelwood considerando la competencia por los sitios activos por parte del glicerol, del 1,2-PG y del EG. Los resultados mostraron que el glicerol se adsorbe más fuertemente que el 1,2-PG y el EG, 
que compiten entre ellos, siendo el EG preferido por los sitios activos. El modelado permitió obtener una expresión cinética para el consumo de glicerol con un orden parcial de 1.5 [235]:

$$
\left(-\mathrm{r}_{\mathrm{gli}}\right)=\frac{\mathrm{k}_{\mathrm{gli}} \mathrm{C}_{\mathrm{gli}}{ }^{1.5}}{1+\mathrm{K}_{\mathrm{gli}} \mathrm{C}_{\mathrm{gli}}+\mathrm{K}_{\mathrm{EG}} \mathrm{C}_{\mathrm{EG}}+\mathrm{K}_{1,2-\mathrm{PG}} \mathrm{C}_{1,2-\mathrm{PG}}}
$$

En otro de sus trabajos, los autores incorporaron la influencia de azufre como veneno del catalizador incorporando $\mathrm{Na}_{2} \mathrm{~S}$ en el medio de reacción. Las expresiones cinéticas de Langmuir-Hinshelwood fueron mantenidas, pero incorporando el efecto térmico. Los resultados mostraron que la presencia del sulfuro tiene un fuerte efecto sobre la energía de activación de la reacción global de hidrogenólisis de glicerol, cuyo rango de variación fue 44$96 \mathrm{~kJ} / \mathrm{mol}$, tendiendo a incrementarse con el contenido de sulfuro [239].

Empleando un catalizador de Co-Pd-Re/C en presencia de $\mathrm{NaOH}$, Xi et al desarrollaron un modelo cinético a partir de los resultados obtenidos en un reactor tricklebed. Los ensayos fueron llevados a cabo en el rango térmico de $180-202{ }^{\circ} \mathrm{C}$, presiones entre 33-133 bar de $\mathrm{H}_{2}$ empleando soluciones de glicerol al $40 \% \mathrm{p} / \mathrm{p}$ en presencia de $\mathrm{NaOH}$ con concentraciones entre 0.1-0.6 M. Las expresiones cinéticas del modelo fueron desarrolladas considerando tres pasos del mecanismo de reacción: (1) la deshidrogenación de glicerol a gliceraldehído sobre los sitios activos del catalizador, (2) la deshidratación de gliceraldehído a piruvaldehído sobre el mismo sitio catalítico, (3) la hidrogenación del piruvaldehído a 1,2PG. La expresión cinética queda en función de la concentración de glicerol, del $\mathrm{H}_{2}$ en fase líquida y de los $\mathrm{OH}$ - presentes en el medio de reacción (por la presencia de $\mathrm{NaOH}$ ). Los resultados permitieron estimar una energía de activación global de la reacción de aproximadamente $86 \mathrm{~kJ} / \mathrm{mol}$ [251]:

$$
\left(-\mathrm{r}_{\mathrm{gli}}\right)=\frac{\mathrm{k}_{\mathrm{f}} \mathrm{C}_{\mathrm{gli}} \mathrm{C}_{\mathrm{OH}} \mathrm{C}_{\mathrm{H} 2}^{2}}{\mathrm{C}_{\mathrm{gli}} \mathrm{C}_{\mathrm{OH}^{+}}+\mathrm{K}_{\mathrm{H}} \mathrm{C}_{\mathrm{H} 2}{ }^{3}}
$$

Modelos del tipo Langmuir-Hinshelwood fueron implementados para describir la conversión directa de glicerol en 1,2-PG y luego del 1,2-PG en 1-POH, empleando catalizadores de $\mathrm{Ni}-\mathrm{Cu} / \mathrm{Al}_{2} \mathrm{O}_{3}$ y ácido fórmico como solvente donador de $\mathrm{H}_{2}$. Este modelo incluye la adsorción competitiva por los sitios activos entre glicerol y 1,2-PG. Las ecuaciones para la velocidad del consumo de glicerol y de 1,2-PG vienen dadas por las expresiones siguientes, con $\mathrm{K}_{\text {gli }}$ y $\mathrm{K}_{1,2-\mathrm{PG}}$ que representan las constantes de adsorción del glicerol y del 1,2PG respectivamente [248]:

$$
\begin{aligned}
& \left(-\mathrm{r}_{\mathrm{gli}}\right)=\frac{\mathrm{k}_{\mathrm{gli}} \mathrm{C}_{\mathrm{gli}}}{1+\mathrm{K}_{\mathrm{gli}} \mathrm{C}_{\mathrm{gli}}+\mathrm{K}_{1,2-\mathrm{PG}} \mathrm{C}_{1,2-\mathrm{PG}}} \\
& \mathrm{r}_{1,2-\mathrm{PG}}=\frac{\mathrm{k}_{1,2-\mathrm{PG}} \mathrm{C}_{1,2-\mathrm{PG}}}{1+\mathrm{K}_{\mathrm{gli}} \mathrm{C}_{\mathrm{gli}}+\mathrm{K}_{1,2-\mathrm{PG}} \mathrm{C}_{1,2-\mathrm{PG}}}
\end{aligned}
$$


Tao et al. emplearon un catalizador de Ni-Raney para estudiar la cinética de hidrogenólisis y propusieron modelos del tipo Langmuir-Hinshelwood para describir la formación del 1,2-PG, EG y $\mathrm{MeOH}$, considerando un tipo de sitio activo para la adsorción disociativa de moléculas de $\mathrm{H}_{2}$ y otro tipo de sitio para la adsorción del glicerol y de los productos de reacción. Los ensayos, llevados a cabo a una presión de 80 bar de $\mathrm{H}_{2}$ en el rango térmico de $180-220{ }^{\circ} \mathrm{C}$ con soluciones acuosas con $20 \% \mathrm{p} / \mathrm{p}$ de glicerol y $5 \% \mathrm{p} / \mathrm{p}$ de catalizador. La velocidad de consumo del glicerol quedó expresada de la siguiente forma [249]:

$$
\left(-r_{\mathrm{gli}}\right)=\frac{\left(\mathrm{k}_{1,2-\mathrm{PG}}+\mathrm{k}_{\mathrm{EG}}\right) \mathrm{K}_{\mathrm{gli}} \mathrm{C}_{\mathrm{gli}}}{1+\mathrm{K}_{\mathrm{gli}} \mathrm{C}_{\mathrm{gli}}+\mathrm{K}_{1,2-\mathrm{PG}} \mathrm{C}_{1,2-\mathrm{PG}}+\mathrm{K}_{\mathrm{EG}} \mathrm{C}_{\mathrm{EG}}+\mathrm{K}_{\mathrm{MeOH}} \mathrm{C}_{\mathrm{MeOH}}}
$$

Para un catalizador comercial de $\mathrm{Pt} / \mathrm{C}$, un modelo detallado de la cinética de hidrogenólisis considerando la formación de productos en fase líquida y en fase gaseosa fue realizado por Jin et al. Los ensayos experimentales emplearon un reactor tipo batch en el rango térmico de $130-160{ }^{\circ} \mathrm{C}$, concentraciones entre $2-40 \% \mathrm{p} / \mathrm{p}$ de glicerol y entre $0.4-10 \% \mathrm{p} / \mathrm{p}$ de $\mathrm{NaOH}$. El modelo implementado considera reacciones de deshidrogenación, hidrogenólisis, deshidratación y ruptura de enlaces $C-C$ que se producen en forma paralela y compiten entre sí mediante los mismos sitios activos. Los resultados obtenidos muestran que una energía de activación mucho menor $(\mathrm{Ea}=53 \mathrm{~kJ} / \mathrm{mol})$ a la conversión hidrotérmica del glicerol no catalítica $(\mathrm{Ea}=128 \mathrm{~kJ} / \mathrm{mol})$. Para la hidrogenólisis de glicerol empleando $\mathrm{Pt} / \mathrm{C}$, sin adición de $\mathrm{H}_{2}$ externo (en atmósfera de $\mathrm{N}_{2}$ ), los resultados permitieron estimar una energía de activación de $64 \mathrm{~kJ} / \mathrm{mol}$, que resulta baja si se la compara con catalizadores de $\mathrm{Pt} / \mathrm{C}$ en atmósferas de $\mathrm{H}_{2}$. También se encontró que la hidrogenólisis de los glicoles y alcoholes formados en fase líquida para producir gases tales como metano, etano y propano se encuentra restringida en ausencia de la base $\mathrm{NaOH}$ en el medio de reacción debido a su alta energía de activación [246].

$$
\begin{gathered}
\mathrm{r}_{1}=\frac{\left(-\mathrm{r}_{\mathrm{gli}}\right)=\mathrm{w}_{\mathrm{cat}}\left(\mathrm{r}_{1}+\mathrm{r}_{2}+\mathrm{r}_{4}+\mathrm{r}_{5}\right)}{\left(1+\mathrm{K}_{\mathrm{gli}} \mathrm{C}_{\mathrm{gli}}+\mathrm{K}_{\mathrm{EG}} \mathrm{C}_{\mathrm{EG}}+\mathrm{K}_{\mathrm{OH}} \mathrm{C}_{\mathrm{OH}}\right)^{2}} \\
\mathrm{r}_{2}=\frac{\mathrm{k}_{\mathrm{s} 2} \mathrm{~K}_{\mathrm{gli}} \mathrm{C}_{\mathrm{gli}} \mathrm{C}_{\mathrm{OH}}}{\left(1+\mathrm{K}_{\mathrm{gli}} \mathrm{C}_{\mathrm{gli}}+\mathrm{K}_{\mathrm{EG}} \mathrm{C}_{\mathrm{EG}}+\mathrm{K}_{\mathrm{OH}} \mathrm{C}_{\mathrm{OH}}\right)^{2}} \\
\mathrm{r}_{2}=\frac{\mathrm{k}_{\mathrm{s} 4} \mathrm{~K}_{\mathrm{gli}} \mathrm{C}_{\mathrm{gli}} \mathrm{C}_{\mathrm{OH}}}{\left(1+\mathrm{K}_{\mathrm{gli}} \mathrm{C}_{\mathrm{gli}}+\mathrm{K}_{\mathrm{EG}} \mathrm{C}_{\mathrm{EG}}+\mathrm{K}_{\mathrm{OH}} \mathrm{C}_{\mathrm{OH}}\right)^{2}} \\
\mathrm{r}_{2}=\frac{\mathrm{k}_{\mathrm{s} 5} \mathrm{~K}_{\mathrm{gli}} \mathrm{C}_{\mathrm{gli}} \mathrm{C}_{\mathrm{OH}}}{\left(1+\mathrm{K}_{\mathrm{gli}} \mathrm{C}_{\mathrm{gli}}+\mathrm{K}_{\mathrm{EG}} \mathrm{C}_{\mathrm{EG}}+\mathrm{K}_{\mathrm{OH}} \mathrm{C}_{\mathrm{OH}}\right)^{2}}
\end{gathered}
$$


Empleando un catalizador de $\mathrm{Cu}-\mathrm{ZnO}-\mathrm{Al}_{2} \mathrm{O}_{3}$ preparado mediante el método de coprecipitación con una relación $\mathrm{Cu}: \mathrm{Zn}: \mathrm{Al}=1: 1: 0,5$; Zhou et al. llevaron a cabo experimentos cinéticos en un reactor de lecho fijo isotérmico en el rango de 30-50 bar de $\mathrm{H}_{2}$ y temperaturas entre $220-240{ }^{\circ} \mathrm{C}$. Los datos cinéticos fueron ajustados con un modelo basado en una cinética de Langmuir-Hinshelwood considerando dos tipos de sitios activos, uno para la adsorción del $\mathrm{H}_{2}$ en forma disociativa y otro para la adsorción de glicerol en competencia con $\mathrm{AcOH}$ y 1,2-PG. Con errores relativos entre 6 y $7 \%$, el modelo permitió estimar las energías de activación asociadas al paso de deshidratación $(86.56 \mathrm{~kJ} / \mathrm{mol})$ y de hidrogenación (57.80 $\mathrm{kJ} / \mathrm{mol}$ ), resultando el primero el paso determinante en la velocidad de reacción. Las ecuaciones propuestas para la deshidratación de glicerol y la hidrogenación del AcOH fueron las siguientes [250]:

$$
\begin{gathered}
\left(-\mathrm{r}_{\mathrm{gli}}\right)=\frac{\mathrm{k}_{1} \mathrm{~K}_{\mathrm{gli}} \mathrm{C}_{\mathrm{gli}}}{1+\mathrm{K}_{\mathrm{gli}} \mathrm{C}_{\mathrm{gli}}+\mathrm{K}_{\mathrm{AcOH}} \mathrm{C}_{\mathrm{AcOH}}+\mathrm{K}_{1,2-\mathrm{PG}} \mathrm{C}_{1,2-\mathrm{PG}}} \\
\mathrm{r}_{\mathrm{AcOH}}=\frac{\mathrm{k}_{2} \mathrm{~K}_{\mathrm{AcOH}} \mathrm{C}_{\mathrm{AcOH}} \mathrm{K}_{\mathrm{H} 2} \mathrm{P}_{\mathrm{H} 2}}{\left(1+\mathrm{K}_{\mathrm{gli}} \mathrm{C}_{\mathrm{gli}}+\mathrm{K}_{\mathrm{AcOH}} \mathrm{C}_{\mathrm{AcOH}}+\mathrm{K}_{1,2-\mathrm{PG}} \mathrm{C}_{1,2-\mathrm{PG}}\right)\left(1+\sqrt{\mathrm{K}_{\mathrm{H} 2} \mathrm{P}_{\mathrm{H} 2}}\right)^{2}}
\end{gathered}
$$

Catalizadores de $\mathrm{Pd}-\mathrm{CuCr}_{2} \mathrm{O}_{4}$ fueron empleados con el objetivo de obtener una cinética de formación de 1,2-PG a partir de glicerol y $\mathrm{H}_{2}$ empleando modelos del tipo ley de la potencia. Los ensayos se llevaron a cabo variando la concentración inicial de glicerol en el rango 4.5-9.1 \%p/p y la presión de $\mathrm{H}_{2}$ entre 30-70 bar, y encontraron una dependencia lineal entre el logaritmo natural de la velocidad de reacción del glicerol con respecto a los logaritmos naturales de la concentración inicial de glicerol y presión de $\mathrm{H}_{2}$ respectivamente. Esto permitió estimar la velocidad de consumo de glicerol [164]:

$$
\left(-\mathrm{r}_{\mathrm{gli}}\right)=\mathrm{k} \mathrm{C}_{\mathrm{gli}}^{2.28} \mathrm{C}_{\mathrm{H} 2}^{1.09}
$$

Torres et al. emplearon un catalizador de $\mathrm{Ru}-\mathrm{Re} / \mathrm{C}$ en un reactor batch tipo slurry que fue operado en el rango de $220-240{ }^{\circ} \mathrm{C}$ y $24-96$ bar de $\mathrm{H}_{2}$ y lograron obtener un modelo cinético. Los productos involucrados incluyen 1,2-PG, EG, 1-POH, 2-POH, EtOH, MeOH y productos gaseosos, como metano, etano, propano y $\mathrm{CO}_{2}$. El modelado se realizó considerando una ley de la potencia involucrando tanto las reacciones de hidrogenólisis como las de reformado, teniendo en cuenta la concentración de $\mathrm{H}_{2}$ en fase vapor, $\mathrm{CH}_{2} \mathrm{~g}$, y su correspondiente constante de Henry, $\mathrm{H}_{\mathrm{H} 2}$ [247].

$$
\left(-r_{g l i}\right)=\frac{w k_{1} C_{g l i} C_{H 2}{ }^{g}}{H_{H 2}}-\frac{w k_{2} C_{g l i} C_{H 2}{ }^{g}}{H_{H 2}}-w k_{5} C_{g l i}
$$

Para catalizadores másicos de $\mathrm{Co}-\mathrm{ZnO}$ se determinó la cinética a partir de experiencias realizadas en el rango de $160-220{ }^{\circ} \mathrm{C}$ y presiones de $20-40$ bar de $\mathrm{H}_{2}$, empleando concentraciones de $10-40 \% \mathrm{p} / \mathrm{p}$ de glicerol. Determinaron que la velocidad de reacción depende mucho más de la concentración de glicerol que de la concentración del $\mathrm{H}_{2}$ [100]. 


$$
\left(-\mathrm{r}_{\mathrm{gli}}\right)=\mathrm{kC}_{\mathrm{gli}}{ }^{0.73} \mathrm{C}_{\mathrm{H} 2}{ }^{0.53}
$$

Rekha et al. emplearon un catalizador de $\mathrm{Cu}-\mathrm{ZrO}_{2}-\mathrm{MgO}$ para estudiar la cinética de con un modelo de tipo ley de la potencia. Los ensayos se realizaron en el rango térmico de $160-220{ }^{\circ} \mathrm{C}$ y presiones de $\mathrm{H}_{2}$ entre $20-50$ bar, empleando concentraciones de glicerol entre 10$40 \% \mathrm{p} / \mathrm{p}$. Los resultados experimentales validaron el modelo desarrollado con un error de +/$10 \%$ y la expresión es la siguiente [89]:

$$
\left(-\mathrm{r}_{\mathrm{gli}}\right)=\mathrm{k} \mathrm{C}_{\mathrm{gli}}^{0.6069} \mathrm{C}_{\mathrm{H} 2}^{0.6955}
$$

Li et al. emplearon un modelo sencillo basado en la ley de la potencia para estudiar cinéticamente un catalizador de $\mathrm{Ru}-\mathrm{Re} / \mathrm{SiO}_{2}$ a $130{ }^{\circ} \mathrm{C}$ y 75 bar de $\mathrm{H}_{2}$ durante $2-12$ h de reacción. Los autores indican que la velocidad de reacción es de primer orden con respecto al glicerol [132]:

$$
\left(-\mathrm{r}_{\mathrm{gli}}\right)=\mathrm{k} \mathrm{C}_{\mathrm{gli}}
$$

Vasiliadou et al. realizaron ensayos en el rango de $180-240{ }^{\circ} \mathrm{C}, 20-80$ bar de $\mathrm{H}_{2}$, concentraciones de glicerol entre $20-40 \% \mathrm{v} / \mathrm{v}$ y masas de catalizador entre $0.05-0.35 \mathrm{~g}$ empleando un catalizador de $\mathrm{Cu} / \mathrm{SiO}_{2}$. Los datos cinéticos fueron ajustados con un modelo tipo ley de la potencia, y las expresiones son [9]:

$$
\begin{aligned}
& \left(-\mathrm{r}_{\mathrm{gli}}\right)=\mathrm{k} \mathrm{C}_{\mathrm{gli}}{ }^{0.27} \mathrm{C}_{\mathrm{H} 2}{ }^{0.95} \\
& \mathrm{r}_{1,2-\mathrm{PG}}=\mathrm{k}_{1} \mathrm{C}_{\mathrm{gli}}{ }^{0.17} \mathrm{C}_{\mathrm{H} 2}{ }^{1.06}
\end{aligned}
$$

Sharma et al. estudiaron la cinética de hidrogenólisis empleando un catalizador de $\mathrm{Cu}$ $\mathrm{ZnO}-\mathrm{Cr}_{2} \mathrm{O}_{3}-\mathrm{ZrO}_{2}$ en el rango de $10-40$ bar de $\mathrm{H}_{2}$, temperaturas entre $220-250{ }^{\circ} \mathrm{C}$, concentración de glicerol entre $60-100 \% \mathrm{p} / \mathrm{p}$ y concentración de catalizador entre 1-4 \%p/p. Los datos cinéticos fueron ajustados considerando dos tipos de sitios activos, uno para la adsorción del $\mathrm{H}_{2}$ en forma disociativa y otro para la adsorción de glicerol. El modelo permitió estimar las energías de activación de la reacción $(137.2 \mathrm{~kJ} / \mathrm{mol})$ siendo la velocidad de reacción global de pseudo primer orden con respecto al glicerol [8]:

$$
\left(-\mathrm{r}_{\mathrm{gli}}\right)=\mathrm{k} \mathrm{C}_{\mathrm{gli}} \mathrm{P}_{\mathrm{H} 2}
$$

La Tabla 31-2 resume las expresiones cinéticas encontradas para el consumo de glicerol empleando distintos modelos, basados en la ley de la potencia y en el mecanismo de Langmuir-Hinshelwood. 
Tabla 31-2. Resumen de las expresiones cinéticas empleando distintos modelos.

\begin{tabular}{|c|c|c|}
\hline Catalizador & Expresión cinética del modelo para el consumo de glicerol & Ref. \\
\hline $\mathrm{Ru} / \mathrm{C}$ & $\left(-\mathrm{r}_{\mathrm{gli}}\right)=\frac{\mathrm{k}_{\mathrm{gli}} \mathrm{C}_{\mathrm{gli}} 1.5}{1+\mathrm{K}_{\mathrm{gli}} \mathrm{C}_{\mathrm{gli}}+\mathrm{K}_{\mathrm{EG}} \mathrm{C}_{\mathrm{EG}}+\mathrm{K}_{1,2-\mathrm{PG}} \mathrm{C}_{1,2-\mathrm{PG}}}$ & [235] \\
\hline Co-Pd-Re/C & $\left(-r_{g l i}\right)=\frac{k_{f} C_{g l i} C_{\mathrm{OH}} C_{\mathrm{H} 2}^{2}}{\mathrm{C}_{\mathrm{gli}} \mathrm{C}_{\mathrm{OH}^{+}}+\mathrm{K}_{\mathrm{H}} \mathrm{C}_{\mathrm{H} 2}{ }^{3}}$ & [251] \\
\hline Ni-Raney & $\left(-\mathrm{r}_{\mathrm{gli}}\right)=\frac{\left(\mathrm{k}_{1}+\mathrm{k}_{2}\right) \mathrm{K}_{\mathrm{gli}} \mathrm{C}_{\mathrm{gli}}}{1+\mathrm{K}_{\mathrm{gli}} \mathrm{C}_{\mathrm{gli}}+\mathrm{K}_{1,2-\mathrm{PG}} \mathrm{C}_{1,2-\mathrm{PG}}+\mathrm{K}_{\mathrm{EG}} \mathrm{C}_{\mathrm{EG}}+\mathrm{K}_{\mathrm{MeOH}} \mathrm{C}_{\mathrm{MeOH}}}$ & [249] \\
\hline $\mathrm{Ru}-\mathrm{Re} / \mathrm{C}$ & $\left(-r_{\mathrm{gli}}\right)=\frac{w k_{1} \mathrm{C}_{\mathrm{gli}} \mathrm{C}_{\mathrm{H} 2} \mathrm{~g}}{\mathrm{H}_{\mathrm{H} 2}}-\frac{w k_{2} \mathrm{C}_{\mathrm{gli}} \mathrm{C}_{\mathrm{H} 2}{ }^{\mathrm{g}}}{\mathrm{H}_{\mathrm{H} 2}}-\mathrm{wk}_{5} \mathrm{C}_{\mathrm{gli}}$ & [247] \\
\hline $\mathrm{Pt} / \mathrm{C}$ & $\begin{array}{c}\mathrm{r}_{1}=\frac{\left(-\mathrm{r}_{\mathrm{gli}}\right)=\mathrm{w}_{\mathrm{cat}}\left(\mathrm{r}_{1}+\mathrm{r}_{2}+\mathrm{r}_{4}+\mathrm{r}_{5}\right)}{\left(1+\mathrm{K}_{\mathrm{gli}} \mathrm{C}_{\mathrm{gli}}+\mathrm{K}_{\mathrm{EG}} \mathrm{C}_{\mathrm{EG}}+\mathrm{K}_{\mathrm{OH}} \mathrm{C}_{\mathrm{OH}}\right)^{2}} \\
\mathrm{r}_{2}=\frac{\mathrm{k}_{\mathrm{s} 2} \mathrm{~K}_{\mathrm{gli}} \mathrm{C}_{\mathrm{gli}} \mathrm{C}_{\mathrm{OH}}}{\left(1+\mathrm{K}_{\mathrm{gli}} \mathrm{C}_{\mathrm{gli}}+\mathrm{K}_{\mathrm{EG}} \mathrm{C}_{\mathrm{EG}}+\mathrm{K}_{\mathrm{OH}} \mathrm{C}_{\mathrm{OH}}\right)^{2}} \\
\mathrm{r}_{2}=\frac{\mathrm{k}_{\mathrm{s} 4} \mathrm{~K}_{\mathrm{gli}} \mathrm{C}_{\mathrm{gli}} \mathrm{C}_{\mathrm{OH}}}{\left(1+\mathrm{K}_{\mathrm{gli}} \mathrm{C}_{\mathrm{gli}}+\mathrm{K}_{\mathrm{EG}} \mathrm{C}_{\mathrm{EG}}+\mathrm{K}_{\mathrm{OH}} \mathrm{C}_{\mathrm{OH}}\right)^{2}} \\
\mathrm{r}_{2}=\frac{\mathrm{k}_{\mathrm{s} 5} \mathrm{~K}_{\mathrm{gli}} \mathrm{C}_{\mathrm{gli}} \mathrm{C}_{\mathrm{OH}}}{\left(1+\mathrm{K}_{\mathrm{gli}} \mathrm{C}_{\mathrm{gli}}+\mathrm{K}_{\mathrm{EG}} \mathrm{C}_{\mathrm{EG}}+\mathrm{K}_{\mathrm{OH}} \mathrm{C}_{\mathrm{OH}}\right)^{2}}\end{array}$ & [246] \\
\hline $\mathrm{Cu}-\mathrm{ZnO}-\mathrm{Cr}_{2} \mathrm{O}_{3}-\mathrm{ZrO}_{2}$ & $\left(-\mathrm{r}_{\mathrm{gli}}\right)=\mathrm{kC}_{\mathrm{gli}} \mathrm{P}_{\mathrm{H} 2}$ & [8] \\
\hline $\mathrm{Cu}-\mathrm{ZnO}-\mathrm{Al}_{2} \mathrm{O}_{3}$ & $\left(-\mathrm{r}_{\mathrm{gli}}\right)=\frac{\mathrm{k}_{1} \mathrm{~K}_{\mathrm{gli}} \mathrm{C}_{\mathrm{gli}}}{1+\mathrm{K}_{\mathrm{gli}} \mathrm{C}_{\mathrm{gli}}+\mathrm{K}_{\mathrm{AcOH}} \mathrm{C}_{\mathrm{AcOH}}+\mathrm{K}_{1,2-\mathrm{PG}} \mathrm{C}_{1,2-\mathrm{PG}}}$ & [250] \\
\hline $\mathrm{Cu} / \mathrm{SiO}_{2}$ & $\left(-\mathrm{r}_{\mathrm{gli}}\right)=\mathrm{kC}_{\mathrm{gli}}{ }^{0.27} \mathrm{C}_{\mathrm{H} 2}{ }^{0.95}$ & [9] \\
\hline $\mathrm{Cu}-\mathrm{ZrO}_{2}-\mathrm{MgO}$ & $\left(-\mathrm{r}_{\mathrm{gli}}\right)=\mathrm{kC}_{\mathrm{gli}}{ }^{0.6069} \mathrm{C}_{\mathrm{H} 2}{ }^{0.6955}$ & [89] \\
\hline $\mathrm{Cu}-\mathrm{ZnO}$ & $\left(-\mathrm{r}_{\mathrm{gli}}\right)=\mathrm{kC}_{\mathrm{gli}}{ }^{0.73} \mathrm{C}_{\mathrm{H} 2}{ }^{0.53}$ & {$[100]$} \\
\hline $\mathrm{Ru}-\mathrm{Re} / \mathrm{SiO}_{2}$ & $\left(-\mathrm{r}_{\mathrm{gli}}\right)=\mathrm{k} \mathrm{C}_{\mathrm{gli}}$ & [132] \\
\hline $\mathrm{Pd}-\mathrm{CuCr}_{2} \mathrm{O}_{4}$ & $\left(-\mathrm{r}_{\mathrm{gli}}\right)=\mathrm{k} \mathrm{C}_{\mathrm{gli}}^{2.28} \mathrm{C}_{\mathrm{H} 2}{ }^{1.09}$ & [164] \\
\hline
\end{tabular}




\subsection{Estabilidad}

La desactivación de los catalizadores durante la reacción de hidrogenólisis de glicerol, tanto en fase líquida como en fase vapor, puede deberse a varios factores: los cambios estructurales del soporte en el caso de catalizadores metálicos soportados, la oxidación y pérdida de la fase activa por lixiviación, la adsorción de especies carbonosas y el sinterizado de la fase activa.

\subsubsection{Cambios estructurales de los soportes}

Cuando la hidrogenólisis de glicerol se lleva a cabo en fase líquida, la estructura de los sistemas catalíticos puede modificarse irreversiblemente debido a la condición hidrotérmica de la reacción [116]. La condición operativa de fase líquida es perjudicial para la mayor parte de los sistemas catalíticos tradicionales. La estabilidad de los materiales se ve afectada debido a la combinación de tres factores: temperatura, presión y presencia de agua caliente [175]. Se ha reportado, por ejemplo, que la elevada tensión superficial del agua genera la aglomeración de nanopartículas de $\mathrm{Cu}$ sobre la superficie de $\mathrm{ZnO}$ generando la disminución de la cantidad de sitios activos [234]. En otros casos, se ha reemplazado el agua por solventes para evitar este efecto desactivante (ver sección 2.6.3.).

En el caso de catalizadores metálicos soportados, la estructura del soporte puede sufrir un colapso de poros, dando lugar a una caída de la superficie específica y del volumen total de poros, y eventualmente hasta una pérdida de la fase activa por lixiviación. También se han reportado modificaciones en la estructura de catalizadores másicos con similares efectos sobre las propiedades texturales. Meher et al. emplearon un catalizador másico de $\mathrm{Cu}-\mathrm{ZnO}-$ $\mathrm{MgO}-\mathrm{Al}_{2} \mathrm{O}_{3}$ en dos usos consecutivos y observaron una caída significativa en el valor de la conversión. Esta desactivación fue asignada al bloqueo de poros y a la pérdida de superficie específica [85].

Entre los soportes tradicionales, $\gamma-\mathrm{Al}_{2} \mathrm{O}_{3}$ sufre hidratación en un medio acuoso y se transforma a bohemita entre $200-250{ }^{\circ} \mathrm{C}$, lo que genera cambios en las propiedades ácidas superficiales $[252,253]$. Cuando $\delta-\mathrm{Al}_{2} \mathrm{O}_{3}$ y $\theta-\mathrm{Al}_{2} \mathrm{O}_{3}$ son empleadas como soportes, similares resultados han sido obtenidos y se ha observado un sinterizado de la fase metálica debido a cambios en la estructura de los soportes [254,255].

El soporte de $\mathrm{MgO}$, muy empleado en la preparación de catalizadores de $\mathrm{Cu}$, resultó inestable en fase líquida debido su transformación a $\mathrm{Mg}(\mathrm{OH})_{2}$ por interacción con moléculas de $\mathrm{H}_{2} \mathrm{O}$ y posterior lixiviación [53].

La presencia de agua caliente también puede causar la disociación de las uniones Si-O$\mathrm{Si}$ en el soporte de $\mathrm{SiO}_{2}$ [256]. Otras sílices ordenadas del tipo mesoporosas también mostraron cambios en su estructura en la condición de fase líquida. SBA-15 evidenció una caída en la superficie específica del 97 \% luego de un tratamiento hidrotérmico en agua caliente a $200{ }^{\circ} \mathrm{C}$ durante $12 \mathrm{~h}$ debido a un colapso de poros [257,258].

Soportes más complejos de $\mathrm{SiO}_{2}-\mathrm{Al}_{2} \mathrm{O}_{3}$ (SIRALOX 30, Sasol) mostraron también una pérdida en la superficie específica debido a un colapso de poros en agua caliente a $225^{\circ} \mathrm{C}$ y 25 bar [259]. 
Por otro lado, los soportes basados en carbón, tales como carbones activados, carbono grafito de distinta naturaleza y soportes tradicionales modificados con carbón $\left(\mathrm{TiO}_{2}-\mathrm{C}\right)$ han mostrado mejores comportamientos en fase líquida debido a las características hidrofóbicas del carbón que protege los sitios activos del ataque hidrolítico del agua y mantienen la actividad catalítica [260].

Otros soportes como $\mathrm{Fe}_{3} \mathrm{O}_{4}$ no se modifican estructuralmente y pueden ser empleados como materiales soportes [136].

En fase vapor, los soportes tradicionales sufren menos modificaciones en su estructura, ya que las temperaturas son moderadas $\left(250-350{ }^{\circ} \mathrm{C}\right)$ y las presiones son bajas. Se ha reportado, por ejemplo, que un catalizador de $\mathrm{Ni}-\mathrm{Ag} / \gamma-\mathrm{Al}_{2} \mathrm{O}_{3}$ resultó estable a $200{ }^{\circ} \mathrm{C}$ y 1 bar de $\mathrm{H}_{2}$, con niveles de conversión del 72-79\% y selectividad a 1,2-PG del 58 \% por 420 h de reacción [209].

\subsubsection{Oxidación y pérdida de la fase activa por lixiviación}

En lo que se refiere a la fase activa, la oxidación de los metales empleados en la preparación de catalizadores y su lixiviación constituyen dos fenómenos frecuentes de desactivación, sobre todo en la condición de fase líquida.

La lixiviación de la fase activa se ha reportado para varios sistemas catalíticos, siendo los catalizadores de $\mathrm{Cu}$ los más estudiados. Huang et al. prepararon un catalizador de $\mathrm{Cu}$ $\mathrm{SiO}_{2}$ que resultó estable en la condición de fase líquida a $200{ }^{\circ} \mathrm{C}$ y 60 bar de $\mathrm{H}_{2}$ por $200 \mathrm{~h}$, desactivándose luego principalmente por lixiviación y sinterizado de la fase activa [66,67]. El leaching o lixiviado de $\mathrm{Cu}$ también fue observado en catalizadores másicos de $\mathrm{Cu}$-Fe. Luego de tres ciclos de reacción de 10 h cada uno, a $190{ }^{\circ} \mathrm{C}$ y 41 bar de $\mathrm{H}_{2}$, la conversión disminuyó de $47 \%$ a $40 \%$ con un mantenimiento de la selectividad a 1,2-PG del $92 \%$ [78]. Catalizadores de $\mathrm{Cu} / \mathrm{Al}_{2} \mathrm{O}_{3}$ preparados fueron empleados en cuatro ciclos de reacción de $24 \mathrm{~h}$ a $200{ }^{\circ} \mathrm{C}$ y 40 bar de $\mathrm{H}_{2}$, y se reportó una caída en la conversión del $75 \%$ al $70 \%$ entre el primer y el cuarto ciclo de reacción, con una pérdida de selectividad a 1,2-PG del $95 \%$ al 88\%, asignada la pérdida de la acidez superficial debido a un menor contenido de las fases de $\mathrm{CuAl}_{2} \mathrm{O}_{4}$ y $\mathrm{CuAl}_{4} \mathrm{O}_{7}$, así como la pérdida de la fase $\mathrm{CuAlO}_{2}$ [73]. Durán-Martin et al. estudiaron el fenómeno de desactivación en catalizadores de $\mathrm{Cu}-\mathrm{ZnO}$. Luego de 5 ciclos de reacción de $8 \mathrm{~h}$ cada uno a $200{ }^{\circ} \mathrm{C}$ y 24 bar de $\mathrm{H}_{2}$, la conversión disminuyó del $16 \%$ al $5 \%$ con un aumento en la selectividad a 1,2-PG del $44 \%$ al $73 \%$. El rendimiento a 1,2-PG disminuyó drásticamente debido a la fuerte caída de la conversión. Los resultados de caracterización revelaron un fuerte lixiviado del $\mathrm{Zn}$ debido al ataque ácido del medio de reacción, a la formación de complejos de Zn con intermediarios de reacción, y además a la oxidación del $\mathrm{Cu}$ [261]. Catalizadores de $\mathrm{Cu}-\mathrm{Cr}$ en presencia de óxido de propileno como reductor mostraron una leve desactivación luego de 3 ciclos de reacción de $4 \mathrm{~h}$ a $130{ }^{\circ} \mathrm{C}$ y 20 bar de $\mathrm{H}_{2}$. Los resultados de caracterización del catalizador usado mostraron un incremento en la cristalinidad y aumento del tamaño de partículas, así como también el lixiviado del Cu [60]. Luego de 3 ciclos de reacción, de $8 \mathrm{~h}$ cada uno a $200{ }^{\circ} \mathrm{C}$ y 35 bar de $\mathrm{H}_{2}$, catalizadores de $\mathrm{Cu}$ $\mathrm{Ag} / \gamma-\mathrm{Al}_{2} \mathrm{O}_{3}$ sufrieron una caída en la conversión del $66 \%$ al $27 \%$ conjuntamente con una 
disminución en la selectividad a 1,2-PG. Los resultados indicaron la pérdida de la fase activa de Cu y Ag además de una disminución en la acidez superficial [196].

También se ha observado que catalizadores másicos comerciales de CoAl han modificado muy poco sus niveles de actividad al cabo de 5 ciclos de reacción de $15 \mathrm{~h}$ cada uno y por lo tanto no fue importante la pérdida de metal en el medio de reacción [94].

La desactivación por leaching también fue observada en catalizadores basados en metales nobles $\left(\mathrm{Pt}, \mathrm{Pd}, \mathrm{Ru}\right.$ ). Se ha reportado en catalizadores de $\mathrm{Pt} / \mathrm{CeO}_{2}$ y $\mathrm{Pt} / \mathrm{La}_{2} \mathrm{O}_{3}$ [142]. Catalizadores de $\mathrm{Pd} / \mathrm{CoO}$ mostraron una fuerte caída en la conversión del $70 \%$ al 45 \% luego de 5 ciclos de reacción de $24 \mathrm{~h}$ cada uno a $180{ }^{\circ} \mathrm{C}$ y 40 bar de $\mathrm{H}_{2}$ empleando soluciones de glicerol al $12 \% \mathrm{p} / \mathrm{p}$ en 2-POH. Fue atribuida al posible lixiviado de $\mathrm{Pd}$, aunque no fue demostrado [157]. Recientemente, fue reportada la desactivación de catalizadores Pd$\mathrm{Zn} / \mathrm{ZrO}_{2}$, con una caída en la velocidad de reacción del 70 \% luego de 7 ciclos de reacción de 4 h cada uno a $220^{\circ} \mathrm{C}$ y 60 bar de $\mathrm{H}_{2}$, debido a la oxidación y lixiviación del Zn. Para mantener la actividad, los autores adicionan al medio de reacción $\mathrm{ZnO}$ en exceso para que los iones de $\mathrm{Zn}^{+2}$ se reduzcan in situ y generen nuevamente la aleación de Pd-Zn en la superficie catalítica [165].

\subsubsection{Adsorción de especies carbonosas y formación de depósitos de carbón}

Con respecto a la formación de carbón, ha sido reportada principalmente en fase vapor, debido a las altas temperaturas requeridas. Los catalizadores más afectados han sido los basados en metales nobles $(\mathrm{Pt}, \mathrm{Ru}, \mathrm{Pd})$ debido a su capacidad para la ruptura de enlaces $\mathrm{C}-\mathrm{C}$, y en menor medida en catalizadores basados en metales no nobles ( $\mathrm{Ni}, \mathrm{Cu}$ ).

Deng et al. detectaron el fenómeno de desactivación en fase líquida por formación de coque con catalizadores de Pt-Re/CNT's [150]. Pt/CeO y Pt/ $\mathrm{La}_{2} \mathrm{O}_{3}$ han sido reportados por su desactivación por depósitos carbonosos [142].

Catalizadores de $\mathrm{Ni} / \gamma-\mathrm{Al}_{2} \mathrm{O}_{3}$ mostraron desactivación en fase vapor debido a la formación de coque sobre las especies de $\mathrm{Ni}$ y la formación de carburo de níquel, $\mathrm{Ni}_{3} \mathrm{C}$, además de la oxidación de la fase metálica de $\mathrm{Ni}$, durante los ensayos de reacción a $200{ }^{\circ} \mathrm{C}$ y 1 bar de $\mathrm{H}_{2} /$ Ar empleando soluciones acuosas de glicerol al $3 \% \mathrm{v} / \mathrm{v}$ luego de $6 \mathrm{~h}$ de reacción $[262,263]$.

Durán-Martín et al. prepararon catalizadores de $\mathrm{Cu}-\mathrm{ZrO}_{2}$ y observaron una desactivación reversible generada por el depósito de compuestos carbonosos y por la oxidación y sinterización de las partículas de $\mathrm{Cu}$ [88]. Catalizadores de $\mathrm{Cu}$ soportados en sílice hexagonal mesoporosa (HMS) han mostrado ser inestables. Entre todos los factores que contribuyeron a una caída del 50 \% en la conversión del segundo ciclo, se halla la formación de especies carbonosas [175]. Sepúlveda et al. por su parte, no detectaron la presencia de especies carbonosas en catalizadores de $\mathrm{Cu}-\mathrm{Cr}_{2} \mathrm{O}_{4}$ en el rango de $190-245{ }^{\circ} \mathrm{C}$ y $1-18$ bar, pero sí de oligómeros de poligliceroles. Los autores explicaron que la presencia de estas especies fue la causa de desactivación de los catalizadores [264].

En la mayoría de los casos, la desactivación por formación de carbón y de especies carbonosas resulta un fenómeno reversible, pudiéndose regenerar total o parcialmente los catalizadores por un proceso de oxidación y posterior reducción. En el caso de los catalizadores de $\mathrm{Ni} / \gamma-\mathrm{Al}_{2} \mathrm{O}_{3}$, un proceso de oxidación-reducción a $500{ }^{\circ} \mathrm{C}$ permitió regenerar 
el catalizador exitosamente [262,263], mientras que en el caso del catalizador de $\mathrm{Cu}-\mathrm{ZrO}_{2}$ un tratamiento en $\mathrm{H}_{2} / \mathrm{Ar}$ a $300{ }^{\circ} \mathrm{C}$ durante $1 \mathrm{~h}$ logró regenerar el catalizador y alcanzar parcialmente el nivel de actividad del catalizador fresco [88].

La presencia de una fase bimetálica ha mejorado la estabilidad de algunos catalizadores monometálicos. En catalizadores $\mathrm{Ru}-\mathrm{Cu} / \mathrm{TiO}_{2}$, por ejemplo, la adición de $\mathrm{Cu}$ a la fase de $\mathrm{Ru}$ demostró ser efectiva para inhibir la desactivación que se produce en los catalizadores monometálicos de $\mathrm{Ru} / \mathrm{TiO}_{2}$, debido a que se inhiben las reacciones de rupturas de enlaces C-C que generan la fuerte adsorción de intermediarios sobre la superficie catalítica [135].

\subsubsection{Sinterizado}

El sinterizado es el principal mecanismo de desactivación reportado para esta reacción. La mayor parte de los trabajos han indicado el efecto de sinterizado en catalizadores basados en metales no nobles, principalmente $\mathrm{Cu}$.

Se ha reportado que catalizadores de $\mathrm{Cu} / \mathrm{SiO}_{2}$ sufren desactivación en la condición de fase líquida debido a la pérdida de superficie metálica de $\mathrm{Cu}$ [176]. Huang et al. prepararon catalizadores de $\mathrm{Cu} / \mathrm{SiO}_{2}$ empleando $\mathrm{SiO}_{2}$ coloidal y $\mathrm{SiO}_{2}$ comercial y los evaluaron en 3 ciclos sucesivos de reacción de $12 \mathrm{~h}$ cada uno. Si bien ambos catalizadores resultaron activos y selectivos a 1,2-PG, el catalizador de $\mathrm{Cu} / \mathrm{SiO}_{2}$ comercial tuvo mayor estabilidad. La desactivación del catalizador de $\mathrm{Cu} / \mathrm{SiO}_{2}$ coloidal fue atribuida a la aglomeración y sinterizado de las partículas de $\mathrm{Cu}$ [184]. Zhu et al. prepararon el mismo catalizador de $\mathrm{Cu} / \mathrm{SiO}_{2}$ comercial y encontraron similares resultados con una rápida desactivación debido a la aglomeración y sinterizado de las partículas de $\mathrm{Cu}$ de $17 \mathrm{~nm}$ a $34 \mathrm{~nm}$ [265]. Cu/SBA-15 también mostraron desactivación debido a un aumento de tamaño de partícula del $\mathrm{Cu}$, con una caída en la conversión del $90 \%$ al 80 \% conjuntamente con una disminución en la selectividad a 1,2-PG del $84 \%$ al $60 \%$ luego de 10 h de reacción a $220^{\circ} \mathrm{C}$ y 1 bar de $\mathrm{H}_{2}$ [178].

El sistema catalítico de $\mathrm{Cu} / \mathrm{MgO}$ también mostró incremento del tamaño de las partículas de $\mathrm{Cu}$ con el tiempo de reacción [185].

Para $\mathrm{Cu} \mathrm{y} \mathrm{ZnO}$, el fenómeno más común de desactivación fue el sinterizado $[64,183,266]$. Bienholz et al. determinaron que el catalizador de $\mathrm{Cu}-\mathrm{ZnO}$ se desactiva luego del primer uso en reacción a $200{ }^{\circ} \mathrm{C}$ y 50 bar de $\mathrm{H}_{2}$ luego de 7 h de reacción, produciéndose una caída en la conversión del $55 \%$ al $38 \%$ en el segundo uso debido al sinterizado de las partículas de $\mathrm{Cu}$ [64]. Similares resultados fueron reportados por $\mathrm{Du}$ et al. [266]. En catalizadores de $\mathrm{Cu}$ soportados sobre $\mathrm{ZnO}$ modificado con una zeolita del tipo USY, también se observó una caída en la conversión del $95 \%$ al $87 \%$ con un mantenimiento en la selectividad a 1,2-PG del 58 \% luego de 3 ciclos de reacción de $5 \mathrm{~h}$ cada uno a $220^{\circ} \mathrm{C}$ y 35 bar de $\mathrm{H}_{2}$ debido a la agregación de las partículas de $\mathrm{Cu}$ y posterior crecimiento de tamaño, disminuyendo la dispersión metálica [183].

Sistemas más complejos de $\mathrm{Cu}-\mathrm{ZnO}-\mathrm{MgO}-\mathrm{Al}_{2} \mathrm{O}_{3}$, también mostraron una caída en la conversión desde el $98 \%$ al $30 \%$ luego de 3 ciclos de reacción de 12 h cada uno a $210{ }^{\circ} \mathrm{C}$ y 45 bar de $\mathrm{H}_{2}$ con un mantenimiento en la selectividad a 1,2-PG, debido fundamentalmente a la aglomeración y sinterizado de las partículas de $\mathrm{Cu}[86]$. 
Nanocompositos de Co-Cu mostraron una caída en la conversión del 40 \% a menos del $20 \%$ con un mantenimiento en la selectividad a 1,2-PG del 60-65\% luego de 3 ciclos de reacción de $7 \mathrm{~h}$ cada uno a $220^{\circ} \mathrm{C}$ y 30 bar de $\mathrm{H}_{2}$ empleando. La aglomeración y sinterizado de las partículas fue la principal causa de desactivación [98].

Con respecto a catalizadores basados en metales nobles, no se han reportado muchos trabajos en donde el principal mecanismo de desactivación sea el sinterizado. Probablemente debido a que los contenidos metálicos son bajos y existe una mayor interacción metal-soporte que evita o disminuye este fenómeno de desactivación.

Zhou et al. reportaron el fenómeno de desactivación por sinterizado en catalizadores de $\mathrm{Ag} / \mathrm{Al}_{2} \mathrm{O}_{3}$, luego de ser usados en un ciclo de reacción a $220^{\circ} \mathrm{C}$ y 15 bar de $\mathrm{H}_{2}$ durante $10 \mathrm{~h}$. La actividad que inicialmente mostró una conversión del $46 \%$, cayó al $25 \%$ con un mantenimiento de la selectividad a 1,2-PG del $93 \%$. El tamaño de partícula de la fase activa pasó de ser $10 \mathrm{~nm}$ a $30 \mathrm{~nm}$. La calcinación del catalizador en aire a $400{ }^{\circ} \mathrm{C}$ durante $3 \mathrm{~h}$ permitió recuperar los niveles de actividad, provocando una re-dispersión de la fase activa [267]. Por otro lado, catalizadores de $\mathrm{Pt} / \mathrm{TiO}_{2}$ y $\mathrm{Pt} / \mathrm{Al}_{2} \mathrm{O}_{3}-\mathrm{SiO}_{2}$ mostraron un incremento en los tamaños de partícula del Pt debido a un proceso de sinterizado a $210{ }^{\circ} \mathrm{C}$ y 60 bar de $\mathrm{H}_{2}$, siendo menor el efecto para el soporte de $\mathrm{TiO}_{2}$, probablemente debido a una mayor interacción metal-soporte [141].

En fase vapor, catalizadores de $\mathrm{Ru} / \gamma-\mathrm{Al}_{2} \mathrm{O}_{3}$ sufrieron severa desactivación al cabo de 7 h de reacción en fase vapor a $230{ }^{\circ} \mathrm{C}$ y 1 bar de $\mathrm{H}_{2}$ debido a la agregación de las partículas de $\mathrm{Ru}$ [226].

Yan et al. testearon catalizadores de $\mathrm{Pt}-\mathrm{Ni} / \gamma-\mathrm{Al}_{2} \mathrm{O}_{3}$ en 5 ciclos de reacción de $3 \mathrm{~h}$ cada uno a $240{ }^{\circ} \mathrm{C}$ y 10 bar de $\mathrm{N}_{2}$, mostrando una leve caída en la conversión y selectividad a 1,2PG [144]. Otros sistemas bimetálicos de Pd-Ni mostraron ligeros cambios en la conversión con un mantenimiento en la selectividad a 1,2-PG luego de 4 ciclos de reacción de 12 h cada uno a $220{ }^{\circ} \mathrm{C}$ y 60 bar de $\mathrm{H}_{2}$ [167]. La adición de sustancias inhibidoras del agregado y posterior crecimiento de las partículas también fue implementada como estrategia para evitar el fenómeno de sinterizado. Sistemas catalíticos basados en Pd-Zn soportados sobre $\mathrm{ZnO}$ $\mathrm{Al}_{2} \mathrm{O}_{3}$ mostraron alta estabilidad en el tiempo en la condición de fase líquida. Luego de 5 ciclos de reacción de $3 \mathrm{~h}$ cada uno a $230{ }^{\circ} \mathrm{C}$ y 30 bar de $\mathrm{H}_{2}$ la conversión de glicerol (53 \%) y la selectividad a 1,2-PG (92\%) permanecieron invariantes. Los resultados fueron atribuidos al rol de la $\mathrm{Al}_{2} \mathrm{O}_{3}$ que suprime la agregación de las partículas bimetálicas de $\mathrm{Pd}-\mathrm{Zn}$ y protege la superficie del ZnO de la erosión por parte del agua [268].

Catalizadores de $\mathrm{Cu}-\mathrm{Ru} / \mathrm{CNT}$ fueron modificados mediante un coating de $\mathrm{SiO}_{2}$ mesoporosa con el objetivo de mejorar su estabilidad. El catalizador preparado mostró que mantiene su actividad catalítica durante 4 ciclos de reacción a $210{ }^{\circ} \mathrm{C}$ y 75 bar de $\mathrm{H}_{2}$, con conversiones del $45 \%$ y selectividad del $90 \%$ a 1,2-PG. Los resultados fueron atribuidos a la capacidad por parte de la $\mathrm{SiO}_{2}$ mesoporosa de evitar un sinterizado de las partículas de $\mathrm{Cu}$ y $\mathrm{Ru}(\sim 1.8 \mathrm{~nm})$ [269]. Por otro lado, la adición de $\mathrm{Ga}_{2} \mathrm{O}_{3}$ en la preparación de catalizadores de $\mathrm{Cu}-\mathrm{ZnO}$ se ha reportado que previene el sinterizado de las partículas de $\mathrm{Cu}$ en el seno de la fase de $\mathrm{ZnO}$ [64]. Con respecto al catalizador de $\mathrm{Cu} / \mathrm{SiO}_{2}$, la adición de $\mathrm{H}_{3} \mathrm{BO}_{3}$ logró disminuir el efecto del sinterizado mejorando su estabilidad hasta las 72 h de reacción [265]. El efecto de la adición de $\mathrm{H}_{2} \mathrm{BO}_{3}$ también fue estudiado en catalizadores de $\mathrm{Cu} / \mathrm{Al}_{2} \mathrm{O}_{3}$ que resultaron activos y selectivos a 1,2-PG por $60 \mathrm{~h}$ de reacción a $250{ }^{\circ} \mathrm{C}$ y 60 bar de $\mathrm{H}_{2}$ en un reactor de 
flujo continuo en fase líquida [180]. La incorporación de elementos de tierras raras comoY y La mejoraron la estabilidad en el tiempo de un catalizador de $\mathrm{Cu}-\mathrm{SiO}_{2}$, inhibiendo el leaching y el sinterizado de la fase activa, haciendo que sea estable por $600 \mathrm{~h}$ de reacción a $200{ }^{\circ} \mathrm{C}$ y 60 bar de $\mathrm{H}_{2}$ [270]. La adición de La a catalizadores de $\mathrm{Ru} / \mathrm{ZrO}_{2}$ mejoró la estabilidad del catalizador. Para un contenido de Ru del $2 \%$ p/p y un contenido de La del $1 \%$ p/p, el catalizador pudo ser empleado en 7 ciclos de $8 \mathrm{~h}$ cada uno a $190{ }^{\circ} \mathrm{C}$ y 60 bar de $\mathrm{H}_{2}$, no mostrando aparente desactivación ni cambios en la selectividad [115].

\subsubsection{Desactivación por las impurezas del glicerol crudo}

La Tabla 32-2 muestra la composición aproximada de la glicerina cruda, técnica y refinada [271].

Tabla 32-2. Composición de las distintas formas de comercialización de la glicerina.

\begin{tabular}{|c|c|c|c|}
\hline & $\begin{array}{c}\text { Glicerina } \\
\text { cruda }\end{array}$ & $\begin{array}{c}\text { Glicerina } \\
\text { técnica }\end{array}$ & $\begin{array}{c}\text { Glicerina } \\
\text { refinada }\end{array}$ \\
\hline Concentración de glicerol & $40-88 \% \mathrm{p} / \mathrm{p}$ & $98 \% \mathrm{p} / \mathrm{p}$ & $99.7 \% \mathrm{p} / \mathrm{p}$ \\
\hline Concentración máxima de agua & $12 \% \mathrm{p} / \mathrm{p}$ & $2 \% p / p$ & $0.3 \% \mathrm{p} / \mathrm{p}$ \\
\hline Concentración máxima de cenizas & $2 \% \mathrm{p} / \mathrm{p}$ & - & - \\
\hline Concentración máxima de cloruros & - & 10 ppm & 10 ppm \\
\hline Concentración máxima de sulfatos & - & - & 20 ppm \\
\hline Concentración máxima de metales pesados & - & 5 ppm & 5 ppm \\
\hline Concentración máxima de compuestos clorados & - & 30 ppm & 30 ppm \\
\hline Concentración máxima de ácidos grasos y ésteres & - & 1 ppm & 1000 ppm \\
\hline Concentración máxima de residuos orgánicos & $2 \% \mathrm{p} / \mathrm{p}$ & $2 \% \mathrm{p} / \mathrm{p}$ & - \\
\hline pH (solución al 10\%) & 4 a 9 & 4 a 9.1 & - \\
\hline
\end{tabular}

El glicerol crudo contiene una gran cantidad de impurezas, entre las que se encuentran los jabones, sales de sodio o potasio, principalmente cloruros y sulfatos, materia orgánica como glicéridos, compuestos azufrados provenientes de los aceites y grasas transesterificadas, y restos de alcohol, generalmente metanol, que no llegó a reaccionar en el proceso de transesterificación $[86,110,272]$. Por lo general consiste en una solución de glicerol y agua con un rango de concentración de glicerol que se halla entre el 40\%p/p y el 88\% p/p.

Catalizadores de $\mathrm{Cu} / \mathrm{Al}_{2} \mathrm{O}_{3}$ modificados por impregnación con $\mathrm{H}_{3} \mathrm{BO}_{3}$ fueron evaluados utilizando glicerol de grado farmacéutico, técnico y crudo, obteniendo el siguiente orden de actividad y selectividad a 1,2-PG: glicerol farmacéutico > glicerol técnico > glicerol crudo. Los resultados sugieren que si bien la presencia de agua podría ser una barrera termodinámica para disminuir el rendimiento a 1,2-PG, las impurezas pueden adsorberse en la superficie catalítica y competir por los mismos sitios activos que el glicerol [180]. Catalizadores de $\mathrm{Cu}$-Al fueron activos y selectivos a 1,2-PG durante $400 \mathrm{~h}$ de reacción en un reactor de flujo continuo en fase líquida operando con soluciones acuosas de glicerol refinado 
del $20 \%$ p/p a $220{ }^{\circ} \mathrm{C}$ y 20 bar de $\mathrm{N}_{2}$. La conversión de glicerol obtenida fue del $90 \%$ con selectividad a 1,2-PG del 22-25\%. Cuando los ensayos se realizaron con glicerol crudo, se obtuvieron conversiones del $50 \%$ con una selectividad a 1,2-PG del $75 \%$ [72].

Las sales de sodio o potasio, principalmente cloruros y sulfatos, son generadas como consecuencia de la neutralización con $\mathrm{HCl}$ o $\mathrm{H}_{2} \mathrm{SO}_{4}$ luego de los procesos de transesterificación de grasas y aceites en la producción de biodiesel [86,110,272]. La presencia de estas sales podría producir un bloqueo de poros en los catalizadores o incluso desactivar los sitios activos por incorporación de los mismos a la fase activa. Balaraju et al. emplearon catalizadores de $\mathrm{Ru} / \mathrm{TiO}_{2}$ y los evaluaron en la condición de fase líquida en presencia de glicerol crudo y glicerol refinado conteniendo $\mathrm{Na}_{2} \mathrm{SO}_{4}$ como impureza. Los resultados mostraron ligeros cambios en la conversión (46-42 \%) y selectividad a 1,2-PG (63-59\%) indicando que el catalizador es resistente a la presencia de esta impureza en el glicerol crudo [110]. Catalizadores de $\mathrm{Cu}-\mathrm{MgO}$ fueron activos y selectivos a 1,2-PG aún con glicerol crudo y glicerol sintético modificado con $\mathrm{Na}_{2} \mathrm{SO}_{4}$. En ambos casos, el catalizador mostró una conversión que fue entre el $85-90 \%$ de la conversión obtenida empleando glicerol sintético, manteniendo una selectividad a 1,2-PG del $92 \%$ en todos los casos [70]. Recientemente, Rajkhowa et al. estudiaron los fenómenos de desactivación de un catalizador comercial de $\mathrm{Cu}$ testeado en un reactor trickle bed. La presencia de $\mathrm{Cl}^{-}$en el medio de reacción simulando la presencia de cloruro de sodio del glicerol crudo produjo una desactivación del catalizador debido al sinterizado por incorporación del $\mathrm{Cl}$ en las partículas de $\mathrm{Cu}$ [86].

La presencia de compuestos azufrados provenientes de ésteres metílicos de ácidos grasos que forman parte de los aceites y grasas, constituyen un veneno para los catalizadores, principalmente para $\mathrm{Cu}$ y $\mathrm{Ru}$ [239]. Los resultados obtenidos por Rajkhowa et al. empleando un catalizador comercial de $\mathrm{Cu}$ mostraron que la conversión disminuye por el contenido de azufre y que la desactivación es más pronunciada cuanto mayor es la temperatura, debido a la mayor adsorción del azufre sobre los sitios activos [86].

Con respecto a los glicéridos, pueden encontrarse en el glicerol crudo por provenir de la síntesis de biodiesel, sean mono, di o triglicéridos. Debido a su naturaleza, estos glicéridos pueden ensuciar la superficie catalítica o actuar como precursores de coque. La presencia de glicéridos provocó un fenómeno de desactivación, en un catalizador comercial de $\mathrm{Cu}$, debido al bloqueo de los sitios activos del catalizador [86]. 


\section{Bibliografía}

[1] A. Marinas, P. Bruijnincx, J. Ftouni, F. J. Urbano, C. Pinel, Catalysis Today 239 (2015) 3137.

[2] T.A. Nijhuis, M. Makkee, J.A. Moulijn, B.M. Weckhuysen, Ind. Eng. Chem. Res. 45 (2006) 3447.

[3] I. Gandarias, P. L. Arias, J. Requies, M. El Doukkali, M. B. Güemez, Journal of Catalysis 282 (2011) 237-247.

[4] I. Gandarias, P. L. Arias, S. G. Fernandez, J. Requies, M. E. Doukkali, M. B. Guemez, Catalysis Today 195 (2012) 22-31.

[5] J. Yuan, S. Li, L. Yu, Y. Liu, Y. Cao, Chinese Journal of Catalysis 34 (2013) 2066-2074.

[6] C. H. Zhou, K. Deng, M. Di Serio, S. Xiao, D. S. Tong, L. Li, C. X. Lin, J. Beltramini, H. Zhang, W. H. Yu, Molecular Catalysis 432 (2017) 274-284.

[7] M. A. Dasari, P. Kiatsimkul, W. R. Sutterlin, G. J. Suppes, Applied Catalysis A: General 281 (2005) 225-231.

[8] R. V. Sharma, P. Kumar, A. K. Dalai, Applied Catalysis A: General 477 (2014) 147-156.

[9] E. S. Vasiliadou, A.A. Lemonidou, Chemical Engineering Journal 231 (2013) 103-112.

[10] I. Gandarias, S. G. Fernández, M. E. Doukkali, J. Requies, P. L. Arias, Top Catal 56 (2013) 995-1007.

[11] C. V. Rode, A. A. Ghalwadkar, R. B. Mane, A. M. Hengne, S. T. Jadkar, N. S. Biradar, Organic Process Research \& Development 14 (2010) 1385-1392.

[12] D. Jean, B. Nohair, J.-Y. Bergeron, S. Kaliaguine, Ind. Eng. Chem. Res. 53 (2014) 1874018749.

[13] J. Hu, X. Liu, Y. Fan, S. Xie, Y. Pei, M. Qiao, K. Fan, X. Zhang, B. Zong, Chinese Journal of Catalysis 34 (2013) 1020-1026.

[14] T. Rajkhowa, G. B. Marin, J. W. Thybaut, Applied Catalysis B Environmental 205 (2017) 469-480.

[15] F. Cai, X. Song, Y. Wu, J. Zhang, G. Xiao, ACS Sustainable Chem. Eng. 6 (2018) 110-118. 
[16] C. Chiu, A. Tekeei, W. R. Sutterlin, J. M. Ronco, G. J. Suppes, AIChE Journal 54 (9) (2008) 2457-2463.

[17] Y. Nakagawa, K. Tomishige, Catal. Sci. Technol. 1 (2011) 179-190.

[18] J. Feng, B. Xu, Progress in Reaction Kinetics and Mechanism 39 (1) (2014) 1-15.

[19] E. S. Vasiliadou, A. A. Lemonidou, WIREs Energy Environ 2014. doi: 10.1002/wene.159

[20] M. Pagliaro y M. Rossi, The Future of Glycerol, RSC Green Chemistry 8 (2010).

[21] C. Montassier, D. Giraud, J. Barbier, Studies in Surface Science and Catalysts 41 (1988) $165-170$.

[22] C. Montassier, J. C. Menézo, L. C. Hoang, C. Renaud, J. Barbier, Journal of Molecular Catalysis 70 (1991) 99-110.

[23] C. Montassier, J. M. Dumas, P. Granger, J. Barbier, Applied Catalysis A: General 121 (1995) 231-244.

[24] S. Jin, Z. Xiao, C. Li, C. T. Williams, C. Liang, Journal of Energy Chemistry 23 (2014) 185192.

[25] E. P. Maris, R. J. Davis, Journal of Catalysis 249 (2007) 328-337.

[26] J. Feng, J. Wang, Y. Zhou, H. Fu, H. Chen, X. Li, Chemistry Letters 36 (10) (2007) 12741275.

[27] D. C. Cameron, C. L. Cooney, Biotechnology 4 (1986) 651-654.

[28] R. L. Maglinao, B. B. He, Biofuels 3 (6) (2012) 675-682.

[29] J. Guan, X. C. Wang, X. Y. Wang, X. D. Mu, Science China Chemistry 56 (6) (2013) 763 772.

[30] M. R. Nimlos, S. J. Blanksby, X. Qian, M. E. Himmel, D. K. Johnson, Journal of Physical Chemistry A, 110 (2006) 6145-6156.

[31] T. Miyazawa, Y. Kusunoki, K. Kunimori, K. Tomishige, Journal of Catalysis 240 (2006) 213-221.

[32] A. Zeng, H. Biebl, Advances in Biochemical Engineering Biotechnology 74 (2002) 237257. 
[33] A. Perosa, P. Tundo, Ind. Eng. Chem. Res. 44 (2005) 8535-8537.

[34] I. Furikado, T. Miyazawa, S. Koso, A. Shimao, K. Kunimori, K. Tomishige, Green Chemistry 9 (2007) 582-588.

[35] Y. Kusonoki, T. Miyazawa, K. Kunimori, K. Tomishige, Catalysis Communications 6 (2005) 645-649.

[36] Z. Wu, Y. Mao, M. Song, X. Yin, M. Zhang, Catalysis Communications 32 (2013) 52-57.

[37] K. Kongpatpanich, T. Nanok, B. Boekf, M. Probstem, J. Limtrakul, Physical Chemistry Chemical Physics 13 (2011) 6462-6470.

[38] F. Auneau, C. Michel, F. Delbecq, C. Pinel, P. Sautet, Chem. Eur. J. 17 (2011) 14288-14299.

[39] F. Vila, M. López Granados, R. Mariscal, Catal. Sci. Technol. 7 (2017) 3119-3127.

[40] Y. Shinmi, S. Koso, T. Kubota, Y. Nakagawa, K. Tomishige, Applied Catalysis B Environmental 94 (2010) 318-326.

[41] Y. Nakagawa, Y. Shinmi, S. Koso, K. Tomishige, Journal of Catalysis 272 (2010) 191-194.

[42] Y. Amada, Y. Shinmi, S. Koso, T. Kubota, Y. Nakagawa, K. Tomishige, Applied Catalysis B Environmental 105 (2011) 117-127.

[43] J. Guan, X. Chen, G. Peng, X. Wang, Q. Cao, Z. Lan, X. Mu, Chinese Journal of Catalysis 34 (2013) 1656-1666.

[43bis] L.-Z. Qin, M.-J. Song, C.-L. Chen, Green Chemistry 12 (2010) 1466-1472.

[44] L. Liu, Y. Zhang, A. Wang, T. Zhang, Chinese Journal of Catalysis 33 (2012) 1257-1261.

[45] R. Arundhathi, T. Mizugaki, T. Mitsudome, K. Jitsukawa, K. Kaneda, ChemSusChem 6 (2013) 1345-1347.

[46] S. García-Fernandez, I. Gandarias, J. Requies, M. B. Güemez, S. Bennici, A. Auroux, P. L. Arias, Journal of Catalysis 323 (2015) 65-75.

[47] S. García-Fernández, I. Gandarias, J. Requies, F. Soulimani, P. L. Arias, B. M. Weckhuysen, Applied Catalysis B Environmental 204 (2017) 260-272.

[48] Y. Fan, S. Cheng, H. Wang, D. Ye, S. Xie, Y. Pei, H. Hu, W. Hua, Z. H. Li, M. Qiao, B. Zong, Green Chemistry 19 (2017) 2174-2183. 
[49] M. Chia, Y. J. Pagan-Torres, D. Hibbitts, Q. Tan, H. N. Pham, A. K. Datye, M. Neurock, R. J. Davis, J. A. Dumesic, Journal of the American Chemical Society 133 (2011) 12675-12689.

[50] S. Wang, H. Liu, Catalysis Letters 117 (2007) 62-67.

[51] F. B. Gebretsadik, J. Llorca, P. Salagre, Y. Cesteros, ChemCatChem 9 (2017) 3670-3680.

[52] J. Chaminand, L. Djakovitch, P. Gallezot, P. Marion, C. Pinel, C. Rosier, Green Chemistry 6 (2004) 359-361.

[53] C.-J. Yue, Q.-Y. Zhang, L.-P. Gu, Y. Su, S.-P. Zhu, Asia-Pac. J. Chem. Eng. (2014).

[54] C.-J. Yue, L.-P. Gu, Y. Su, S.-P. Zhu, Reac Kinet Mech Cat 111 (2014) 633-645.

[55] A. Wolosiak-Hnat, E. Milchert, G. Lewandowski, B. Grzmil, Polish Journal of Chemical Technology 4 (13) (2011) 71-76.

[56] N. D. Kim, S. Oh, J. B. Joo, K. S. Jung, J. Yi, Topics in Catalysis 53 (2010) 517-522.

[57] Y. S. Yun, T. Y. Kim, D. Yun, K. R. Lee, J. W. Han, J. Yi, ChemSusChem 10 (2016) 442-454.

[58] R.B. Mane, A. A. Ghalwadkar, A. M. Hengne, Y. R. Suryawanshi, C. V. Rode, Catalysis Today 164 (2011) 447-450.

[59] Z. Xiao, X. Wang, J. Xiu, Y. Wang, C. T. Williams, C. Liang, Catalysis Today 234 (2014) 200-207.

[60] Z. Xiao, J. Xiu, X. Wang, B. Zhang, C. T. Williams, D. Sub, C. Liang, Catal. Sci. Technol. 3 (2013) 1108-1115.

[61] S. Wang, Y. Zhang, H. Liu, Chem. Asian J. 5 (2010) 1100-1111.

[62] M. Balaraju, V. Rekha, P. S. Sai Prasad, R. B. N. Prasad, N. Lingaiah, Catalysis Letters 126 (2008) 119-124.

[63] A. Bienholz, F. Schwab, P. Claus, Green Chem. 12 (2010) 290-295.

[64] A. Bienholz, R. Blume, A. Knop-Gericke, F. Girgsdies, M. Behrens, P. Claus, J. Phys. Chem. C 115 (2011) 999-1005.

[65] Q. Gao, B. Xu, Q. Tong, Y. Fan, Bioscience, Biotechnology, and Biochemistry 80 (2) (2016) 215-220. 
[66] Z. Huang, F. Cui, H. Kang, J. Chen, X. Zhang, C. Xia, Chemistry of Materials 20 (2008) 5090-5099.

[67] Z. Huang, F. Cui, H. Kang, J. Chen, C. Xia, Applied Catalysis A: General 366 (2009) 288298.

[68] L. Niu, R. Wei, H. Yang, X. Li, F. Jiang, G. Xiao, Chinese Journal of Catalysis 34 (2013) 2230-2235.

[69] Z. Yuan, J. Wang, L. Wang, W. Xie, P. Chen, Z. Hou, X. Zheng, Bioresource Technology 101 (2010) 7088-7092.

[70] M. Balaraju, K. Jagadeeswaraiah, P. S. Sai Prasad, N. Lingaiah, Catalysis Science and Technology 2 (2012) 1967-1976.

[71] B. K. Kwak, D. S. Park, Y. S. Yun, J. Yi, Catalysis Communications 24 (2012) 90-95.

[72] R. B. Mane, C. V. Rode, Green Chemistry 14 (2012) 2780-2789.

[73] A. Wołosiak-Hnat, E. Milchert, B. Grzmil, Chem. Eng. Technol. 36 (3) (2013) 411-418.

[74] T. Mizugaki, R. Arundhathi, T. Mitsudome, K. Jitsukawa, K. Kaneda, Chem. Lett. 42 (2013) 729-731.

[75] G. Geng, R. Wei, T. Liang, M. Zhou, G. Xiao, Reac Kinet Mech Cat 117 (2016) 239-251.

[76] R. L. Maglinao, B. B. He, Ind. Eng. Chem. Res. 50 (2011) 6028-6033.

[77] R. Valencia, J.A. Tirado, R. Sotelo, F. Trejo, L. Lartundo, Reac Kinet Mech Cat 116 (1) (2015) 205-222.

[78] Z. Xiao, S. Jin, X. Wang, W. Li, J. Wang, C. Liang, J. Mater. Chem. 22 (2012) 16598-16605.

[79] S. A. Nikolaev, G. S. Dmitriev, K. L. Zanaveskin, T. B. Egorova, S. N. Khadzhiev Petroleum Chemistry 57 (2017) 1074-1080.

[80] L. Huang, Y. Zhu, H. Zheng, Y. Li, Z. Zeng, Journal of Chemical Technology and Biotechnology 83 (2008) 1670-1675.

[81] Y. Liu, N. Pasupulety, K. Gunda, G. L. Rempel, F. T. T. Ng, Top Catal 57 (2014) 14541462. 
[82] D. W. Kim, S. H. Ha, M. Jun Moon, K. T. Lim, Y. B. Ryu, S. D. Lee, M. Sig Lee, S.-S. Hong, Journal of Nanoscience and Nanotechnology 15 (2015) 656-659.

[83] J. Kolena, L. Soukupova, J. Kocík, J. Lederer, Reac Kinet Mech Cat 122 (2017) 803-816.

[84] S. Xia, R. Nie, X. Lu, L. Wang, P. Chen, Z. Hou, Journal of Catalysis 296 (2012) 1-11.

[85] L. C. Meher, R. Gopinath, S. N. Naik, A. K. Dalai, Ind. Eng. Chem. Res. 48 (2009) 18401846.

[86] S. Mondal, R. Janardhan, M. L. Meena, P. Biswas, Journal of Environmental Chemical Engineering 5 (2017) 5695-5706.

[87] Z. Zhiming, L. Xun, Z. Tianying, H. Wenbin, C. Zhenmin, Y. Weikang, Chinese Journal of Chemical Engineering, 18 (3) (2010) 384-390.

[88] D. Duran-Martin, M. Ojeda, M. López Granados, J. L. G. Fierro, R. Mariscal, Catalysis Today 210 (2013) 98-105.

[89] V. Rekha, N. Raju, C. Sumana, S. Paul Douglas, N. Lingaiah, Catalysis Letters 146 (8) (2016) 1487-1496.

[90] H. L. Hosgün, M. Yıldız, H. F. Gerçel, Ind. Eng. Chem. Res. 51 (2012) 3863-3869.

[91] B. Chen, B. Zhang, Y. Zhang, X. Yang, ChemCatChem 8 (2016) 1929-1936.

[92] G. Shi, L. Su, K. Jin, Catalysis Communications 59 (2015) 180-183.

[93] X. Li, C. Zhang, H. Cheng, L. He, W. Lin, Y. Yu, F. Zhao, Journal of Molecular Catalysis A Chemical 395 (2014) 1-6.

[94] X. Guo, A. Yin, X. Guo, X. Guo, W. Dai, K. Fan, Chin. J. Chem. 29 (2011) 1563-1566.

[95] Q. Liu, X. Guo, Y. Li, W. Shen, Langmuir 25 (11) (2009) 6425-6430.

[96] Q. Liu, X. Guo, T. Wang, Y. Li, W. Shen, Materials Letters 64 (2010) 1271-1274.

[97] X. Guo, Y. Li, Q. Liu, W. Shen, Chinese Journal of Catalysis 33 (2012) 645-650.

[98] Q. Liu, S.-B. Qiu, T.-J. Wang, L.-L. Ma, Chinese Journal of Chemical Physics 26 (3) (2013) 347-354.

[99] Y.-B. Cao, X. Zhang, J.-M. Fan, P. Hu, L.-Y. Bai, H.-B. Zhang, F.-L. Yuan, Y.-F. Chen, Crystal Growth and Design 11 (2011) 472-479. 
[100] V. Rekha, C. Sumana, S. Paul Douglas, N. Lingaiah, Applied Catalysis A General 491 (2015) 155-162.

[101] T. Miyazawa, S. Koso, K. Kunimori, K. Tomishige, Applied Catalysis A General 318 (2007) 244-251.

[102] E. P. Maris, W. C. Ketchie, M. Murayama, R. J. Davis, Journal of Catalysis 251 (2007) 281-294.

[103] A. Alhanash, E. F. Kozhevnikova, I. V. Kozhevnikov, Catalysis Letters 120 (2008) 307311.

[104] S. Wang, K. Yin, Y. Zhang, H. Liu, ACS Catalysis 3 (2013) 2112-2121.

[105] L. Ma, D. He, Z. Li, Catalysis Communications 9 (2008) 2489-2495.

[106] J. Feng, H. Fu, J. Wang, R. Li, H. Chen, X. Li, Catalysis Communications 9 (2008) 14581464.

[107] E. S. Vasiliadou, E. Heracleous, I. A. Vasalos, A. A. Lemonidou, Applied Catalysis B Environmental 92 (2009) 90-99.

[108] S. Bolado, R. E. Treviño, M. T. García-Cubero, G. González-Benito, Catalysis Communications 12 (2010) 122-126.

[109] L. Ma, D. He, Topics in Catalysis 52 (2009) 834-844.

[110] M. Balaraju, V. Rekha, B. L. A. Prabhavathi Devi, R. B. N. Prasad, P. S. Sai Prasad, N. Lingaiah, Applied Catalysis A General 384 (2010) 107-114.

[111] N. Hamzah, A. Alias, W. Z. Samad, M. Kassim, M. A. Yarmo, Advanced Materials Research 173 (2011) 134-139.

[112] E. Gallegos-Suarez, M. Pérez-Cadenas, A. Guerrero-Ruiz, I. Rodriguez-Ramosa, A. Arcoya, Applied Surface Science 287 (2013) 108-116.

[113] E. Gallegos Suarez, A. Guerrero-Ruiz, I. Rodriguez-Ramos, A. Arcoya, Chemical Engineering Journal 262 (2015) 326-333.

[114] T. S. Ahmed, O. Y. Abdelaziz, G. W. Roberts, Ind. Eng. Chem. Res. 55 (2016) 5536-5544.

[115] B. He, Chuang Li, Zihui Xiao, B. Wang, C. Liang, Reac Kinet Mech Cat 122 (2017) 101115. 
[116] B. Li, L. Li, C. Zhao, Green Chem. 19 (2017) 5412-5421.

[117] R. B. Mane, S. T. Patil, H. Gurav, S. S. Rayalu, C. V. Rode, ChemistrySelect 2 (2017) 1734-1745.

[118] R. Mane, S. Patil, M. Shirai, S. Rayalu, C. Rode, Applied Catalysis B Environmental 204 (2017) 134-146.

[119] W. Zhou, Y. Zhao, S. Wang, X. Ma, Catalysis Today 298 (2017) 2-8.

[120] S. H. Lee, D. J. Moon, Catalysis Today 174 (2011) 10-16.

[121] J. Wang, S. Shen, B. Li, H. Lin, Y. Yuan, Chemistry Letters 38 (6) (2009) 572-573.

[122] M. Balaraju, V. Rekha, P. S. Sai Prasad, B. L. A. Prabhavathi Devi, R. B. N. Prasad, N. Lingaiah, Applied Catalysis A General 354 (2009) 82-87.

[123] N. Hamzah, N. M. Nordin, A. H. A. Nadzri, Y. A. Nik, M. B. Kassim, M. A. Yarmo, Applied Catalysis A: General 419-420 (2012) 133-141.

[124] D. Roy, B. Subramaniam, R. V. Chaudhari, Catalysis Today 156 (2010) 31-37.

[125] T. Jiang, Y. Zhou, S. Liang, H. Liu, B. Han, Green Chemistry 11 (2009) 1000-1006.

[126] A. Von-Held Soares, J. B. Salazar, D. D. Falcone, F. A. Vasconcellos, R. J. Davis, F. B. Passos, Journal of Molecular Catalysis A Chemical 415 (2016) 27-36.

[127] H. Liu, Shuguang Liang, T. Jiang, B. Han, Y. Zhou, Clean - Soil, Air, Water 40 (3) (2012) 318-324.

[128] J. Feng, B. Xu, D. Liu, W. Xiong, J. Wang, Advanced Materials Research 791-793 (2013) 12-15.

[129] J. Feng, B. Xu, W. Jiang, W. Xiong, J. Wang, Advanced Materials Research, 549 (2012) 297-300.

[130] L. Ma, D. He, Catalysis Today 149 (2010) 148-156.

[131] L. Ma, Y. Li, D. He, Chinese Journal of Catalysis 32 (2011) 872-876.

[132] K. -T. Li, R.-H. Yen, Nanomaterials 8 (2018) 153.

[133] J. Feng, Y. Zhang, W. Xiong, H. Ding, B. He, Catalysts 6 (2016) 51. 
[134] B. Li, J. Wang, Y. Yuan, H. Ariga, S. Takakusagi, K. Asakura, ACS Catalysis 1 (2011) 1521-1528.

[135] J. B. Salazar, D. D. Falcone, H. N. Pham, A. K. Datye, F. B. Passos, R. J. Davis, Applied Catalysis A General 482 (2014) 137-144.

[136] A. Von Held Soares, H. Atia, U. Armbruster, F. B. Passos, A. Martin, Applied Catalysis A, General 548 (2017) 179-190.

[137] L. Wei, R. Bibi, W. Tian, L. Chen, Y. Zheng, N. Li, J. Zhou, New J. Chem. 42 (2018) 36333641.

[138] I. Gandarias, P. L. Arias, J. Requies, M. B. Guemez, J. L. G. Fierro, Applied Catalysis B Environmental 97 (2010) 248-256.

[139] J. T. Dam, F. Kapteijn, K. Djanashvili, U. Hanefeld, Catalysis Communications 13 (2011) $1-5$.

[140] T. Kurosaka, H. Maruyama, I. Naribayashi, Y. Sasaki, Catalysis Communications 9 (2008) 1360-1363.

[141] S. N. Delgado, L. Vivier, C. Especel, Catalysis Communications 43 (2014) 107-111.

[142] M. Checa, A. Marinas, J. M. Marinas, F. J. Urbano, Applied Catalysis A General 507 (2015) 34-43.

[143] M. L. Barbelli, M. D. Mizrahi, F. Pompeo, G. F. Santori, N. N. Nichio, J. M. RamalloLopez, J. Phys. Chem. C 118 (2014) 23645-23653.

[144] Y. Yan, Y. Zhang, T. Jiang, T. Xiao, P. P. Edwards, F. Cao, RSC Adv. 7 (2017) 3825138256.

[145] H. Du, S. Chen, H. Wang, J. Lu, Chinese Journal of Catalysis 38 (2017) 1237-1244.

[146] Z. Yuan, P. Wu, J. Gao, X. Lu, Z. Hou, X. Zheng, Catalysis Letters 130 (2009) 261-265.

[147] R. Rodrigues, N. Isoda, M. Gonçalves, F. C. A. Figueiredo, D. Mandelli, W.A. Carvalho, Chemical Engineering Journal 198-199 (2012) 457-467.

[148] W. Oberhauser, C. Evangelisti, R. P. Jumde, R. Psaro, F. Vizza, M. Bevilacqua, J. Filippi, B. F. Machado, P. Serp, Journal of Catalysis 325 (2015) 111-117. 
[149] O. M. Daniel, A. De La Riva, E. L. Kunkes, A. K. Datye, J. A. Dumesic, R. J. Davis, ChemCatChem 2 (2010) 1107-1114.

[150] C. Deng, X. Duan, J. Zhou, D. Chen, X. Zhou, W. Yuan, Catalysis Today 234 (2014) 208214.

[151] S. Liu, M. Tamura, Z. Shen, Y. Zhang, Y. Nakagawa, K. Tomishige, Catalysis Today 303 (2018) 106-116.

[152] A. Villa, M Manzoli, F. Vindigni, L. E. Chinchilla, G. A. Botton, L. Prati, Catalysis Letters 147 (2017) 2523-2533.

[153] M. L. Barbelli, G. F. Santori, N. N. Nichio, Bioresource Technology 111 (2012) 500-503.

[154] A. Von-Held Soares, G. Perez, F. B. Passos, Applied Catalysis B Environmental 185 (2016) 77-87.

[155] N. Hamzah, W. N. Roslam, W. Isahak, N. F. Adnan, N. M. Nordin, M. B. Kassim, M. A. Yarmo, Advanced Materials Research 364 (2012) 211-216.

[156] M. G. Musolino, L. A. Scarpino, F. Mauriello, R. Pietropaolo, Green Chemistry 11 (2009) 1511-1513.

[157] M. G. Musolino, L. A. Scarpino, F. Mauriello, R. Pietropaolo, ChemSusChem 4 (2011) 1143-1150.

[158] F. Mauriello, H. Ariga, M. G. Musolino, R. Pietropaolo, S. Takakusagi, K. Asakura, Applied Catalysis B Environmental166-167 (2015) 121-131.

[159] J. Ge, Z. Zeng, F. Liao, W. Zheng, X. Hong, S. C. E. Tsang, Green Chemistry 15 (2013) 2064-2069.

[160] Y. Li, H. Liu, L. Ma, D. He, RSC Adv. 4 (2014) 5503-5512.

[161] Y. Li, H. Liu, L. Ma, D. He, Applied Catalysis A General 522 (2016) 13-20.

[162] Y. Li, H. Liu, L. Ma, D. He, RSC Adv. 6 (2016) 38680-38689.

[163] S. Xia, Z. Yuan, L. Wang, P. Chen, Z. Hou, Applied Catalysis A General 403 (2011) 173182.

[164] N. D. Kim, J. R. Park, D. S. Park, B. K. Kwak, J. Yi, Green Chemistry 14 (2012) 2638-2646.

[165] Q. Sun, S. Wang, H. Liu, ACS Catal. 7 (2017) 4265-4275. 
[166] X. Li, Q. Wu, B. Zhang, C. Zhang, W. Lin, H. Cheng, F. Zhao, Catalysis Today 302 (2018) 210-216.

[167] T. Jiang, Q. Huai, T. Geng, W. Ying, T. Xiao, F. Cao, Biomass and Bioenergy 78 (2015) 71-79.

[168] S. M. Pudi, P. Biswas, S. Kumar, B. Sarkar, Journal of Brazilian Chemical Society 26 (8) (2015) 1551-1564.

[169] S. Sato, M. Akiyama, R. Takahashi, T. Hara, K. Inui, M. Yokota, Applied Catalysis A General 347 (2008) 186-191.

[170] C. Liang, Z. Ma, L. Ding, J. Qiu, Catalysis Letters 130 (2009) 169-176.

[171] F. Vila, M. L. Granados, M. Ojeda, J. L. G. Fierro, R. Mariscal, Catalysis Today 187 (2012) 122-128.

[172] J. Zhou, L. Guo, X. Guo, J. Mao, S. Zhang, Green Chemistry 12 (2010) 1835-1843.

[173] S. L. Hao, W. Peng, N. Zhao, F. Xiao, W. Wei, Y. Sun, J Chem Technol Biotechnol 85 (2010) 1499-1503.

[174] A. Bienholz, H. Hofmann, P. Claus, Applied Catalysis A General 391 (2011) 153-157.

[175] E. S. Vasiliadou, A. A. Lemonidou, Applied Catalysis A General 396 (2011) 177-185.

[176] E. S. Vasiliadou, T. M. Eggenhuisen, P. Munnik, P. E. de Jongh, K. P. de Jong, A.A. Lemonidou, Applied Catalysis B Environmental 145 (2014) 108-119.

[177] K. Samson, A. Zelazny, R. Grabowski, M. Ruggiero-Mikołajczyk, M. Sliwa, K. Pamin, A. Kornas, M. Lachowska, Res Chem Intermed 41 (12) (2015) 9295-9306.

[178] M. Harisekhar, V. P. Kumar, S. S. Priya, K. VR Chary, J Chem Technol Biotechnol 90 (2015) 1906-1917.

[179] M. L. Dieuzeide, R. de Urtiaga, M. Jobbagy, N. Amadeo, Catalysis Today 296 (2017) 1925.

[180] M. R. Nanda, Z. Yuan, H. Shui, C. Xu, Catalysts 7 (2017) 196.

[181] Z. Yuan, L. Wang, J. Wang, S. Xia, P. Chen, Z. Hou, X. Zheng, Applied Catalysis B Environmental 101 (2011) 431-440. 
[182] L. Niu, R. Wei, F. Jiang, M. Zhou, C. Liu, G. Xiao, Reac Kinet Mech Cat 113 (2) (2014) 543-556.

[183] L. Niu, R. Wei, C. Li, L. Gao, M. Zhou, F. Jiang, G. Xiao, Reac Kinet Mech Cat 115 (1) (2015) 377-388.

[184] Z. Huang, F. Cuia, J. Xue, J. Zuo, J. Chen, C. Xia, Catalysis Today 183 (2012) 42-51.

[185] S. M. Pudi, P. Biswas, S. Kumar, J Chem Technol Biotechnol 91 (2016) 2063-2075.

[186] S. Mondal, A. A. Arifa, P. Biswas, Catalysis Letters 147 (2017) 2783-2798.

[187] J. Zheng, W. Zhu, C. Ma, Y. Hou, W. Zhang, Z. Wang, Reac Kinet Mech Cat 99 (2010) 455-462.

[188] P. Hirunsit, C. Luadthong, K. Faungnawakij, RSC Adv. 5 (2015) 11188-11197.

[189] I. C. Freitas, R. L. Manfro, M. M.V.M. Souza, Applied Catalysis B Environmental 220 (2018) 31-41.

[190] S. Zhu, X. Gao, Y. Zhu, W. Fan, J. Wang, Y. Li, Catal. Sci. Technol. 5 (2015) 1169-1180.

[191] K.-T. Li, C.-H. Wang, H.-C. Wang, Journal of the Taiwan Institute of Chemical Engineers 52 (2015) 79-84.

[192] A. Zelazny, K. Samson, R. Grabowski, M. Sliwa, M. Ruggiero-Mikołajczyk, A. Kornas, Reac Kinet Mech Cat 121 (2017) 329-343.

[193] S. Y. Lee, J.-S. Jung, E.-H. Yang, K.-Y. Lee, D. J. Moon, Journal of Nanoscience and Nanotechnology 15 (2015) 8783-8789.

[194] K. Suthacar, K Shanthi, P Selvam, Molecular Catalysis xxx (2017) xxx-xxx. https://doi.org/10.1016/j.mcat.2017.11.035

[195] Z. Wu, Y. Mao, X. Wang, M. Zhang, Green Chem. 13 (2011) 1311-1316.

[196] W. Zhu, F.-F. Cai, Y. Wang, S.-Y. Sang, G.-M. Xiao, Chemical Papers 71 (2017) 763-773.

[197] S. M. Pudi, T. Mondal, P. Biswas, S. Biswas, S. Sinha, International Journal of Chemical Reactor Engineering 12 (1) (2014) 1-12.

[198] Y. S. Yun, D. S. Park, J. Yi, Catal. Sci. Technol. 4 (2014) 3191-3202. 
[199] A. A. Arifa, S. Mondal, S. M. Pudi, N. N. Pandhare, P. Biswas, Energy Fuels 31 (2017) 8521-8533.

[200] J. Sun, H. Liu, Catalysis Today 234 (2014) 75-82.

[201] W. Yu, J. Xu, H. Maa, C. Chen, J. Zhao, H. Miao, Q. Song, Catalysis Communications 11 (2010) 493-497.

[202] A. Seretis, P. Tsiakaras, Fuel Processing Technology 142 (2016) 135-146.

[203] A. Seretis, P. Tsiakaras, Renewable Energy 97 (2016) 373-379.

[204] J. Zhao, W. Yu, C. Chen, H. Miao, H. Ma, J. Xu, Catalysis Letters 134 (2010) 184-189.

[205] J. Huang, J. Chen, Chinese Journal of Catalysis 33 (2012) 790-796.

[206] R. N. Menchavez, M. J. Morra, B. B. He, Catalysts 7 (2017) 290.

[207] R. N. Menchavez, M. J. Morra, B. B. He, The Canadian Journal of Chemical Engeneering 95 (2017) 1332-1339.

[208] W. Long, F. Hao, W. Xiong, P. Liu, H. Luo, Reac Kinet Mech Cat 122 (2017) 85-100.

[209] V. Rekha, N. Raju, C. Sumana, N. Lingaiah, Catalysis Letters 147 (2017) 1441-1452.

[210] A. Marinoiu, G. Ionita, C. L. Gaspar, C. Cobzaru, S. Oprea, Reactions and Kinetics Catalysis Letters 97 (2009) 315-320.

[211] I. Gandarias, J. Requies, P.L. Arias, U. Armbruster, A. Martin, Journal of Catalysis 290 (2012) 79-89.

[212] A. J. Pamphile-Adrián, P. P. Florez-Rodriguez, M. H. M. Pires, G. Perez, F. B. Passos, Catalysis Today 289 (2017) 302-308.

[213] W. Yu, J. Zhao, H. Ma, H. Miao, Q. Song, J. Xu, Applied Catalysis A General 383 (2010) 73-78.

[214] I. J.- Morales, F. Vila, R. Mariscal, A. J.- López, Applied Catalysis B Environmental 117118 (2012) 253-259.

[215] X. Li, H. Cheng, G. Liang, L. He, W. Lin, Y. Yu, F. Zhao, Catalysts 5 (2015) 759-773. 
[216] X. Guo, Y. Li, R. Shi, Q. Liu, E. Zhan, W. Shen, Applied Catalysis A: General 371 (2009) 108-113.

[217] X. Guo, Y. Li, W. Song, W. Shen, Catalysis Letters 141 (2011) 1458-1463.

[218] Y. Feng, H. Yin, A. Wang, L. Shen, Longbao Yu, T. Jiang, Chemical Engineering Journal 168 (2011) 403-412.

[219] M. L. Dieuzeide, M. Jobbagy, N. Amadeo, Ind. Eng. Chem. Res. 55 (2016) 2527-2533.

[220] N. N. Pandhare, S. M. Pudi, P. Biswas, S. Sinha, Org. Process Res. Dev. 20 (2016) 10591067.

[221] N. N. Pandhare, S. M. Pudi, P. Biswas, S. Sinha, Journal of the Taiwan Institute of Chemical Engineers 61 (2016) 90-96.

[222] M. Akiyama, S. Sato, R. Takahashi, K. Inui, M. Yokota, Applied Catalysis A General 371 (2009) 60-66.

[223] J. Hu, X. Liu, B. Wang, Y. Pei, M. Qiao, K. Fan, Chinese Journal of Catalysis 33 (2012) 1266-1275.

[224] D. Sun, Y. Yamada, S. Sato, Applied Catalysis A General 475 (2014) 63-68.

[225] V. Pavankumar, C. S. Srikanth, A. N. Rao, K. V. R. Chary, Journal of Nanoscience and Nanotechnology 14 (4) (2014) 3137-3146.

[226] V. P. Kumar, S. S. Priya, Y. Harikrishna, A. Kumar, K. V. R. Chary, Journal of Nanoscience and Nanotechnology 2 (16) (2016) 1952-1960.

[227] E. Van Ryneveld, A. S. Mahomed, P. S. van Heerden, H. B. Friedrich, Catalysis Letters 141 (2011) 958-967.

[228] S. S. Priya, V. P. Kumar, M. L. Kantam, S. K. Bhargava, K. V. R. Chary, RSC Adv. 4 (2014) 51893-51903.

[229] S. S. Priya, V. P. Kumar, M. L. Kantam, S. K. Bhargava, A. Srikanth, K. V. R. Chary, Ind. Eng. Chem. Res. 54 (2015) 9104-9115.

[230] S. Xia, Z. Yuan, L. Wang, P. Chen, Z. Hou, Bioresource Technology 104 (2012) 814-817.

[231] M. Hou, H. Jiang, Y. Liu, R. Chen, Reac Kinet Mech Cat 122 (2017) 1129-1143.

[232] L. Huang, Y. Zhu, H. Zheng, G. Ding, Y. Li, Catalysis Letters 131 (2009) 312-320. 
[233] I. Gandarias, P. L. Arias, I. Agirrezabal-Telleria, Environmental Progress \& Sustainable Energy 35 (2) (2015) 447-454.

[234] C. Wang, H. Jiang, C. Chen, R. Chen, W. Xing, Chemical Engineering Journal 264 (2015) 344-350.

[235] D. G. Lahr, B. H. Shanks, Ind. Eng. Chem. Res. 42 (2003) 5467-5472.

[236] A. Marinoiu, C. Cobzaru, E. Carcadea, C. Capris, V. Tanislav, M. Raceanu, Reac Kinet Mech Cat 110 (1) (2013).

[237] T. Miyazawa, S. Koso, K. Kunimori, K. Tomishige, Applied Catalysis: A 329 (2007) 3035.

[238] P. Centomo, V. Nese, S. Sterchele, M. Zecca, Topics in Catalysis 56 (2013) 822-830.

[239] D. G. Lahr, B. H. Shanks, Journal of Catalysis 232 (2005) 386-394.

[240] A. Alias, N. Hamzah, M. A. Yarmo, Advanced Materials Research 173 (2011) 49-54.

[241] J. Hu, Y. Fan, Y. Pei, M. Qiao, K. Fan, X. Zhang, B. Zong, ACS Catalysis 3 (2013) 22802287.

[242] Y. Li, L. Ma, H. Liu, D. He, Applied Catalysis A General 469 (2014) 45-51.

[243] L. Guo, J. Zhou, J. Mao, X. Guo, S. Zhang, Applied Catalysis A: General 367 (2009) 9398.

[244] B. Mallesham, P. Sudarsanam, B. V. S. Reddy, B. M. Reddy, Applied Catalysis B Environmental 181 (2016) 47-57.

[245] Y. Feng, C. Liu, Y. Kang, X. Zhou, L. Liu, J. Deng, H. Xu, Y. Fu, Chemical Engineering Journal 281 (2015) 96-101.

[246] X. Jin, B. Subramaniam, R. V. Chaudhari, AIChE Journal 62 (4) (2016) 1162-1173.

[247] A. Torres, D. Roy, B. Subramaniam, R. V. Chaudhari, Ind. Eng. Chem. Res. 49 (2010) 10826-10835.

[248] I. Gandarias, S. G. Fernández, M. E. Doukkali, J. Requies, P. L. Arias, Topics in Catalysis 56 (2013) 995-1007. 
[249] J. Tao, R. Meixuan, C. Shishi, H. Qiang, Y. Weiyong, C. Fahai, Advanced Materials Research 906 (2014) 103-111.

[250] Z. Zhou, X. Li, T. Zeng, W. Hong, Z. Cheng, W. Yuan, Chinese Journal of Chemical Engineering 18 (3) (2010) 384-390.

[251] Y. Xi, J. E. Holladay, J. G. Frye, A. A. Oberg, J. E. Jackson, D. J. Miller, Organic Process Research \& Development 14 (2010) 1304-1312.

[252] N. Luo, X. Fu, F. Cao, T. Xiao, P. Edwards, Fuel 87 (2008) 3483-3489.

[253] R. Ravenelle, J. Copeland, W. Kim, J. Crittenden, ACS Catal. 1 (2011) 552-561.

[254] W. Ketchie, E. Maris, R. Davis, Chem. Mater. 19 (2007) 3406-3411.

[255] K. Lehnert, P. Claus, Catal. Commun. 9 (2008) 2543-2546.

[256] H. L. Castricum, M. C. Mittelmeijer-Hazeleger, A. Sah, J. E. Ten Elshof, Microporous Mesoporous Mater. 88 (2006) 63-71.

[257] H. Xiong, H. N. Pham, A. K. Datye, J. Catal. 302 (2013) 93-100.

[258] Y. J. Pagan-Torres, J. M. R. Gallo, D. Wang, H. N. Pham, J. A. Libera, C. L. Marshall, J. W. Elam, A. K. Datye, J. A. Dumesic, ACS Catal. 1 (2011) 1234-1245.

[259] H. N. Pham, A. E. Anderson, R. L. Johnson, T. J. Schwartz, B. J. O'Neill, P. Duan, K. Schmidt-Rohr, J. A. Dumesic, A. K. Datye, ACS Catal. 5 (2015) 4546-4555.

[260] H. N. Pham, A. E. Anderson, R. L. Johnson, K. Schmidt-Rohr, A. K. Datye, Angew. Chem. 124 (2012) 13340-13344.

[261] D. Durán-Martin, M. López Granados, J. L. G. Fierro, C. Pinel, R. Mariscal, Topics in Catalysis 60 (2017) 1062-1071.

[262] B. C. Miranda, R. J. Chimentão, J. B. O. Santos, F. Gispert-Guirado, J. Llorca, F. Medina, F. López Bonillo, J. E. Sueiras, Applied Catalysis B Environmental 147 (2014) 464-480.

[263] R. J. Chimentao, B. C. Miranda, J. Szanyi, C. Sepulveda, J.B.O. Santos, J.V.S. Correa, J. Llorca, F. Medina, Molecular Catalysis 435 (2017) 49-57.

[264] J. Sepúlveda, D. Manuale, L. Santiago, N. Carrara, G. Torres, C. Vera, M. Goncalves, W. Carvalho, D. Mandelli, Quim. Nova 40 (4) (2017) 371-377. 
[265] S. Zhu, X. Gao, Y. Zhu, Y. Zhu, H. Zheng, Y. Li, Journal of Catalysis 303 (2013) 70-79.

[266] Y. Du, C. Wang, H. Jiang, C. Chen, R. Chen, Journal of Industrial and Engineering Chemistry 35 (2016) 262-267.

[267] J. Zhou, J. Zhang, X. Guo, J. Mao, S. Zhang, Green Chemistry 14 (2012) 156-163.

[268] X. Li, B. Zhang, Q. Wu, C. Zhang, Y. Yu, Y. Li, W. Lin, H. Cheng, F. Zhao, Journal of Catalysis 337 (2016) 284-292.

[269] Z. Sun, H. Zhang, Y. Zhao, C. Huang, R. Tao, Z. Liu, Z. Wu, Langmuir 27 (2011) 62446251.

[270] Z. Huang, H. Liu, F. Cui, J. Zuo, J. Chen, C. Xia, Catalysis Today 234 (2014) 223-232.

[271] J. A. Posada-Duque, C. A. Cardona-Alzate, Ing. Univ. Bogotá (Colombia), 14 (1) (2010) 9-27.

[272] S. Zhu, Y. Zhu, S. Hao, H. Zheng, T. Mo, Y. Li, Green Chem. 14 (2012) 2607-2616. 


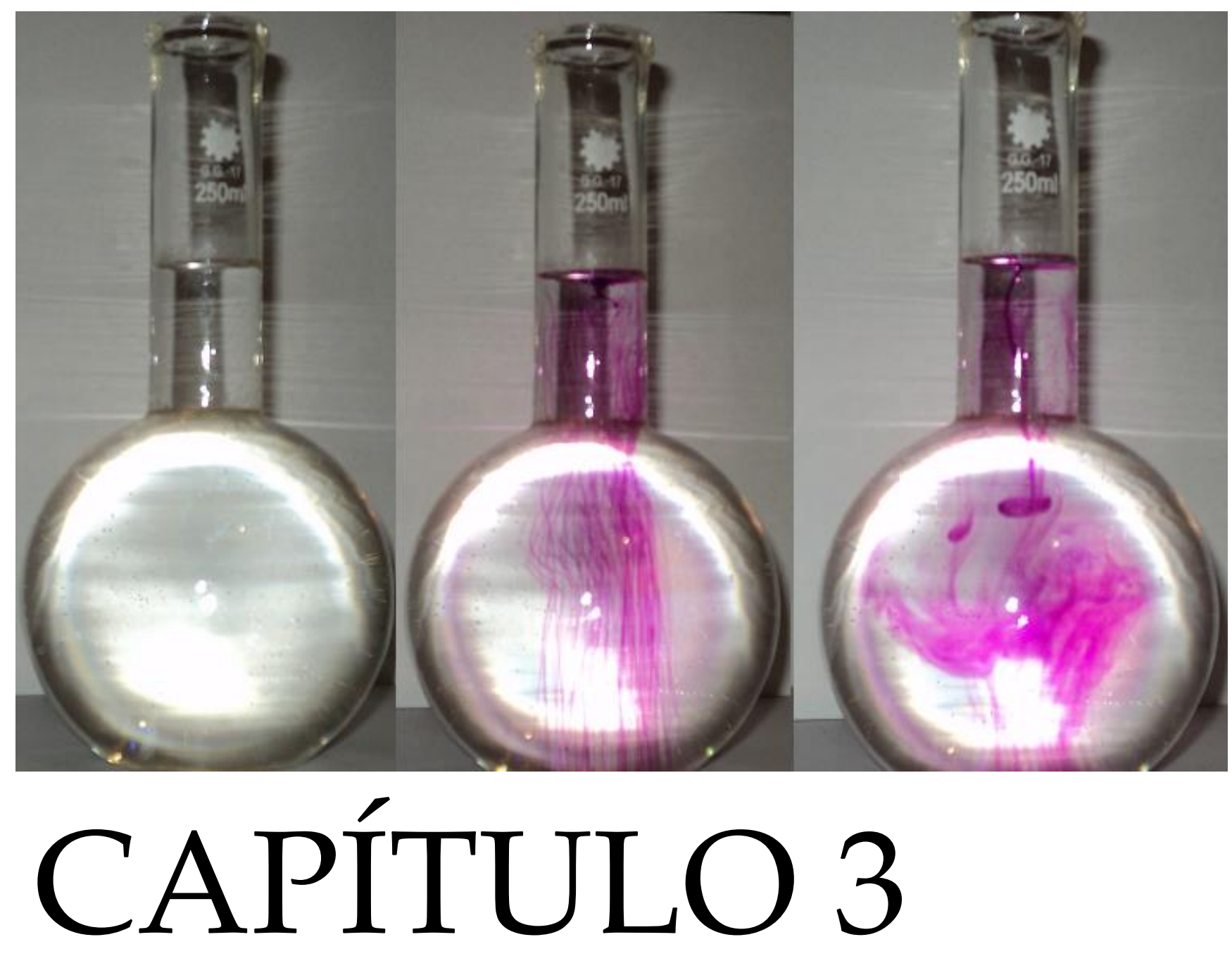

Materiales, equipos y técnicas

\section{experimentales}

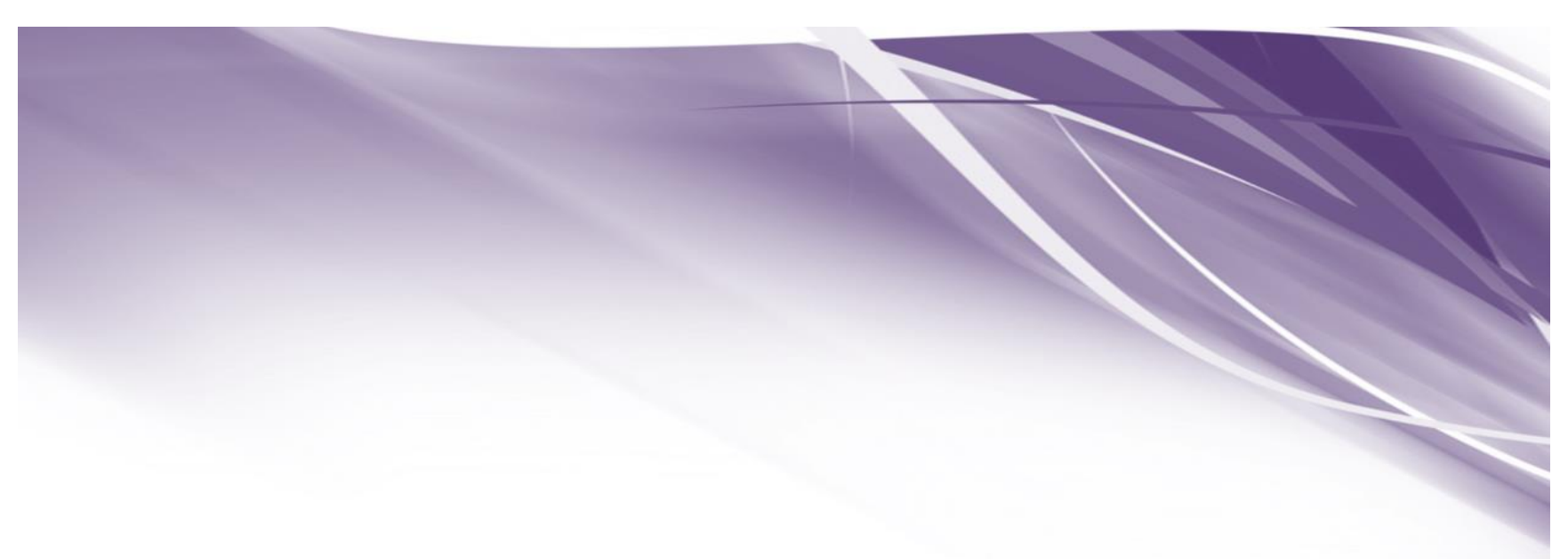




\subsection{Introducción}

En este capítulo se informan los materiales empleados (reactivos, solventes, gases, indicadores, ácidos y bases) para llevar a cabo el estudio experimental de la presente tesis.

Se describen los equipos de reacción empleados, las técnicas experimentales de preparación y caracterización de los catalizadores y la metodología empleada para la cuantificación de los resultados experimentales. Además se presentan las ecuaciones empleadas en los cálculos realizados.

\subsection{Materiales}

Para una mejor descripción de los materiales empleados en los ensayos experimentales, los mismos se dividen en reactivos, solventes, gases, precursores de catalizadores, soportes comerciales, indicadores, ácidos y bases.

\subsubsection{Reactivos}

El glicerol empleado se utilizó bajo la forma de glicerol anhidro del tipo pro-análisis al $99.5 \% \mathrm{p} / \mathrm{p}$ (Cicarelli).

Para los estudios del mecanismo de reacción se emplearon como reactivos del tipo pro-análisis: metanol absoluto (Cicarelli), alcohol etílico absoluto (Cicarelli), acetona (Cicarelli), alcohol propílico normal (Cicarelli), alcohol iso-propílico (Cicarelli), acetol (1hidroxiacetona) (Sigma-Aldrich), etilenglicol (Biopack), 1,2-propilenglicol (1,2-propanodiol) (Biopack) y 1,3-propilenglicol (1,3-propanodiol) (Sigma-Aldrich).

\subsubsection{Solventes}

El solvente empleado en todos los ensayos de reacción fue agua destilada y desionizada. Para la preparación de catalizadores impregnados se utilizó etanol absoluto como solvente.

\subsubsection{Gases}

Se empleó aire medicinal (Linde), nitrógeno 99.99 \% (Linde), argón 99.99 \% (Linde) e hidrógeno 99.99 \% (Linde) para la calcinación y reducción de los catalizadores.

Los gases empleados como atmósfera de reacción fueron nitrógeno 99.99 \% (Linde) y/o hidrógeno $99.99 \%$ (Linde).

\subsubsection{Precursores metálicos}

Para la preparación de catalizadores de $\mathrm{Ru}$ se empleó cloruro de rutenio (III) $\left(\mathrm{RuCl}_{3} . \mathrm{xH}_{2} \mathrm{O}\right)$ pro análisis (Sigma-Aldrich).

Para la preparación de catalizadores de Ni se emplearon tres precursores; cloruro de níquel hexahidratado $\left(\mathrm{NiCl}_{2} .6 \mathrm{H}_{2} \mathrm{O}\right)$ pro-análisis (Sigma-Aldrich), acetato de níquel 
tetrahidratado $\left(\mathrm{Ni}\left(\mathrm{CH}_{3} \mathrm{COO}\right)_{2} .4 \mathrm{H}_{2} \mathrm{O}\right)$ pro-análisis (Sigma-Aldrich) y nitrato de níquel hexahidratado $\left(\mathrm{Ni}\left(\mathrm{NO}_{3}\right)_{2} .6 \mathrm{H}_{2} \mathrm{O}\right)$ pro-análisis (Sigma-Aldrich).

Para la preparación de catalizadores de $\mathrm{Cu}$ se emplearon dos precursores; acetato cúprico monohidratado $\left(\mathrm{Cu}\left(\mathrm{CH}_{3} \mathrm{COO}\right)_{2} \cdot \mathrm{H}_{2} \mathrm{O}\right)$ pro-análisis (Cicarelli) y nitrato cúprico trihidratado $\left(\mathrm{Cu}\left(\mathrm{NO}_{3}\right)_{2} .3 \mathrm{H}_{2} \mathrm{O}\right)$ pro-análisis (Cicarelli).

\subsubsection{Soportes}

La síntesis de los soportes carbonosos se llevó a cabo empleando TEOS (tetraetoxisilano) como precursor de sílice en un medio de etanol al 96 \%p/p (Anedra) y la resina fenólica RL 43003 (Atanor). En la preparación se empleó HF (Sigma-Aldrich).

Como referencia se empleó un soporte de sílice comercial $\mathrm{SiO}_{2}$ (AEROSIL 200, Evonik Industries, Hanau-Wolfgang, Alemania).

\subsubsection{Indicadores, ácidos y bases}

Se empleó fenolftaleína del tipo pro-análisis (Cicarelli) y naranja de metilo del tipo pro-análisis (Anedra) como indicadores ácido-base en las medidas de titulación de Bohem.

El agente empleado para la funcionalización fue ácido nítrico, bajo la forma de ácido nítrico pro-análisis (Cicarelli).

El ácido empleado en las titulaciones de Bohem fue el ácido clorhídrico, bajo la forma de ácido clorhídrico al 37 \%p/p pro-análisis (Anedra). Dado que el ácido clorhídrico no es un patrón primario, sus soluciones fueron estandarizadas con las soluciones de hidróxido de sodio estandarizadas previamente con biftalato de potasio.

Las bases empleadas en las titulaciones de Bohem fueron hidróxido de sodio proanálisis (Anedra), carbonato de sodio pro-análisis (Cicarelli) y bicarbonato de sodio proanálisis (Cicarelli). Dado que el hidróxido de sodio no es un patrón primario, sus soluciones fueron estandarizadas empleando biftalato de potasio. El carbonato de sodio es un patrón primario, aun así, sus soluciones fueron estandarizadas empleando las soluciones de ácido clorhídrico estandarizadas previamente. El bicarbonato de sodio no es un patrón primario y por lo tanto sus soluciones fueron estandarizadas con las soluciones de ácido clorhídrico estandarizadas previamente.

El patrón primario empleado para la estandarización de las soluciones de hidróxido de sodio fue biftalato de potasio, bajo la forma de biftalato de potasio pro-análisis (Cicarelli).

\subsection{Técnicas experimentales de preparación de soportes y catalizadores}

A continuación, se presentan las técnicas empleadas para la síntesis de los soportes, la preparación de los catalizadores y la funcionalización de los soportes. 


\subsubsection{Síntesis de los soportes}

Se prepararon soportes mediante la técnica sol-gel. La propiedad gelificante del TEOS (tetraetoxisilano) fue utilizada en un medio alcohólico (Etanol al $96 \%$ p/p, Anedra) para incluir en su estructura una resina fenólica (RL 43003, Atanor). Con las etapas de secado y de calcinación en atmósfera reductora, esta resina deja una cantidad apreciable de carbono residual.

Para sintetizar un composito de sílice-carbón se mezclaron el TEOS y la resina fenólica en una proporción másica 1:1 bajo agitación magnética hasta obtener una emulsión. Gradualmente se incorporó el etanol hasta obtener un líquido gel de color traslúcido de color ámbar similar al color de la resina. El agua necesaria para la gelificación del TEOS fue provista en parte por el etanol y en parte por la resina. El líquido gel fue dispuesto en moldes cilíndricos cubiertos para gelificar por completo a temperatura ambiente sin la evaporación del etanol ni del agua. Luego de $24 \mathrm{~h}$, los moldes fueron descubiertos para extraer el gel. El gel fue aireado a temperatura ambiente por $24 \mathrm{~h}$ y secado a $50{ }^{\circ} \mathrm{C}$ por otras $24 \mathrm{~h}$. Posteriormente, el material fue calentado $\left(10{ }^{\circ} \mathrm{C} \cdot \mathrm{h}^{-1}\right)$ hasta los $180{ }^{\circ} \mathrm{C}$ durante $3 \mathrm{~h}$ para producir la polimerización de la resina.

El material fue introducido en recipientes refractarios cubiertos por la parte superior con carbón de petróleo pre-calcinado. Luego, se procedió a su calcinación $\left(5{ }^{\circ} \mathrm{C} \cdot \mathrm{min}^{-1}\right)$ en horno eléctrico bajo atmósfera libre de oxígeno durante $3 \mathrm{~h}$ en el rango térmico de $1500{ }^{\circ} \mathrm{C}$ a $1580{ }^{\circ} \mathrm{C}$. El material obtenido por este procedimiento fue denominado SC.

A partir del soporte SC, fue sometido a un tratamiento con ácido fluorhídrico, con una solución al 10 \%p/p de HF (Sigma-Aldrich). Luego este sólido es lavado con agua destilada hasta obtener un valor neutro de $\mathrm{pH}$. Posteriormente es filtrado y secado a $120^{\circ} \mathrm{C}$ durante 24 h. La presencia residual de $\mathrm{H}_{2} \mathrm{~F}_{6} \mathrm{Si}$ fue eliminada por una etapa de calcinación $400{ }^{\circ} \mathrm{C}$ durante $1 \mathrm{~h}$. Este soporte fue denominado $\mathrm{C}$.

\subsubsection{Tratamientos hidrotérmicos}

Para determinar la estabilidad de los soporte SC y C, se realizaron ensayos del material en agua caliente y en las condiciones de la reacción de hidrogenólisis en fase líquida. En cada ensayo se procedió a cargar la muestra de soporte en agua destilada dentro del reactor tipo batch, presurizado a 20 bar de $\mathrm{N}_{2}$. Luego se procedió a calentar hasta la temperatura de tratamiento y se mantuvo a esa temperatura durante $24 \mathrm{~h}$. Se ensayaron tres temperaturas: $150{ }^{\circ} \mathrm{C}$ (SC-150), $200{ }^{\circ} \mathrm{C}$ (SC-200) y $250{ }^{\circ} \mathrm{C}$ (SC-250). La presión autógena fue de aproximadamente 50 bar.

\subsubsection{Preparación del catalizador de $\mathrm{Ru}$}

El catalizador de $\mathrm{Ru}$ fue preparado por el método de impregnación a humedad a incipiente. Se empleó $\mathrm{RuCl}_{3} . \mathrm{xH}_{2} \mathrm{O}$ como precursor, y etanol absoluto como solvente para alcanzar un contenido nominal del $0.2 \% \mathrm{p} / \mathrm{p}$ de Ru en el catalizador final. El sólido obtenido fue secado a $120{ }^{\circ} \mathrm{C}$ por $12 \mathrm{~h}$, calcinado $\left(10^{\circ} \mathrm{C} \cdot \mathrm{min}^{-1}\right)$ en flujo continuo $\left(50 \mathrm{~cm}^{3} \cdot \mathrm{min}^{-1}\right)$ de Ar a 
$300{ }^{\circ} \mathrm{C}$ durante $3 \mathrm{~h}$ y activados $\left(10^{\circ} \mathrm{C} \cdot \mathrm{min}^{-1}\right)$ en flujo continuo $\left(50 \mathrm{~cm}^{3} \cdot \mathrm{min}^{-1}\right)$ de $\mathrm{H}_{2}$ durante 90 $\min$ a $350^{\circ} \mathrm{C}$.

\subsubsection{Preparación de los catalizadores de $\mathrm{Cu}$ y Ni}

El catalizadores de $\mathrm{Cu}$ fue preparado mediante el método de impregnación a humedad incipiente, empleando como precursores $\mathrm{Cu}\left(\mathrm{CH}_{3} \mathrm{COO}\right)_{2} . \mathrm{H}_{2} \mathrm{O}$ y $\mathrm{Cu}\left(\mathrm{NO}_{3}\right)_{2} .3 \mathrm{H}_{2} \mathrm{O}$. En ambos casos se empleó etanol como solvente de impregnación para alcanzar un contenido nominal del $5 \% \mathrm{p} / \mathrm{p}$ de $\mathrm{Cu}$ en el catalizador final. El sólido obtenido es secado a $120^{\circ} \mathrm{C}$ por 12 $\mathrm{h}$, calcinado $\left(10{ }^{\circ} \mathrm{C} \cdot \mathrm{min}^{-1}\right)$ en flujo continuo $\left(50 \mathrm{~cm}^{3} \cdot \mathrm{min}^{-1}\right)$ de $\mathrm{Ar}$ a $300{ }^{\circ} \mathrm{C}$ durante $3 \mathrm{~h}$ y activado $\left(10^{\circ} \mathrm{C} \cdot \mathrm{min}^{-1}\right)$ en flujo continuo $\left(50 \mathrm{~cm}^{3} \cdot \mathrm{min}^{-1}\right)$ de $\mathrm{H}_{2}$ durante $90 \mathrm{~min}$ a $300{ }^{\circ} \mathrm{C}$.

Los catalizadores de $\mathrm{Ni}$ fueron preparados mediante el método de impregnación a humedad incipiente, empleando $\mathrm{NiCl}_{2} .6 \mathrm{H}_{2} \mathrm{O}, \mathrm{Ni}\left(\mathrm{CH}_{3} \mathrm{COO}\right){ }_{2} .4 \mathrm{H}_{2} \mathrm{O}$ y $\mathrm{Ni}\left(\mathrm{NO}_{3}\right)_{2} .6 \mathrm{H}_{2} \mathrm{O}$ como precursores y etanol como solvente de impregnación, para alcanzar un contenido nominal del $5 \%$ p/p de Ni. Los sólidos obtenidos son secados a $120^{\circ} \mathrm{C}$ por $12 \mathrm{~h}$, calcinados $\left(10^{\circ} \mathrm{C} \cdot \mathrm{min}^{-}\right.$ $\left.{ }^{1}\right)$ en flujo continuo $\left(50 \mathrm{~cm}^{3} \cdot \mathrm{min}^{-1}\right)$ de $\mathrm{Ar}, \mathrm{N}_{2}$ o aire (dependiendo del caso) a $300{ }^{\circ} \mathrm{C}$ durante 3 h y activados $\left(10^{\circ} \mathrm{C} \cdot \mathrm{min}^{-1}\right)$ en flujo continuo $\left(50 \mathrm{~cm}^{3} \cdot \mathrm{min}^{-1}\right)$ de $\mathrm{H}_{2}$ durante $90 \mathrm{~min}$ a $400{ }^{\circ} \mathrm{C}$.

\subsubsection{Preparación del catalizador $\mathrm{Ni} / \mathrm{SiO}_{2}$}

El catalizador de $\mathrm{Ni} / \mathrm{SiO}_{2}$ fue preparado mediante el método de impregnación a humedad incipiente, empleando $\mathrm{NiCl}_{2} .6 \mathrm{H}_{2} \mathrm{O}$ como precursor y etanol como solvente de impregnación para alcanzar un contenido nominal del $5 \%$ p/p de Ni. El sólido obtenido es secado a $120{ }^{\circ} \mathrm{C}$ por $12 \mathrm{~h} \mathrm{y}$ activado $\left(10^{\circ} \mathrm{C} \cdot \mathrm{min}^{-1}\right)$ en flujo continuo $\left(50 \mathrm{~cm}^{3} \cdot \mathrm{min}^{-1}\right)$ de $\mathrm{H}_{2}$ durante $1.5 \mathrm{~h}$ a $400^{\circ} \mathrm{C}$.

\subsubsection{Funcionalización del soporte SC}

El soporte SC fue funcionalizado empleando un tratamiento oxidante en fase líquida en un reactor discontinuo tipo batch, utilizando $\mathrm{HNO}_{3}$. Se estudiaron las condiciones operativas de temperatura $\left(80-100^{\circ} \mathrm{C}\right)$, tiempo $(2-6 \mathrm{~h})$ y concentración del ácido $(30-90 \% \mathrm{p} / \mathrm{p})$.

En cada ensayo se emplearon $50 \mathrm{ml}$ de solución de $\mathrm{HNO}_{3}$ por cada $1 \mathrm{~g}$ de soporte $\mathrm{SC}$, manteniendo la solución ácida en reflujo a la temperatura de operación durante el tiempo de funcionalización. Luego, la solución es filtrada y el sólido lavado varias veces con agua destilada hasta $\mathrm{pH}$ 7. Finalmente, el sólido es secado en estufa a $100^{\circ} \mathrm{C}$ durante $24 \mathrm{~h}$.

La Tabla 1-3 indica los distintos tratamientos de funcionalización realizados. 
Tabla 1-3. Condiciones de funcionalización y nomenclatura de materiales.

\begin{tabular}{lccc}
\hline \multirow{2}{*}{ Soporte } & \multicolumn{3}{c}{ Condiciones de funcionalización } \\
\cline { 2 - 4 } & Temperatura $\left({ }^{\circ} \mathrm{C}\right)$ & Concentración de $\mathrm{HNO}_{3}(\% \mathrm{p} / \mathrm{p})$ & Tiempo $(\mathrm{h})$ \\
\hline SC $_{80-30-2}$ & 80 & 30 & 2 \\
SC $_{80-60-2}$ & 80 & 60 & 2 \\
SC $_{80-90-2}$ & 80 & 90 & 2 \\
SC $_{90-60-2}$ & 90 & 60 & 2 \\
SC $_{100-60-2}$ & 100 & 60 & 2 \\
SC $_{100-60-4}$ & 100 & 60 & 4 \\
SC $_{100-60-6}$ & 100 & 60 & 6 \\
\hline
\end{tabular}

\subsubsection{Preparación de los catalizadores bimetálicos NiZn/SC}

Se prepararon catalizadores bimetálicos $\mathrm{NiZn/SC}$, empleando la técnica organometálica de superficies sobre metales (QOMS/M) [1]. Esta técnica permite adicionar de forma controlada y selectiva un metal a otro por medio de una reacción química que ocurre entre los metales. Se empleó dietil cinc, $\mathrm{Zn}\left(\mathrm{C}_{2} \mathrm{H}_{5}\right)_{2}$ en solución de n-heptano. El catalizador $\mathrm{Ni} / \mathrm{SC}$ es previamente activado en atmósfera de $\mathrm{H}_{2}$ a $400{ }^{\circ} \mathrm{C}$ durante $1,5 \mathrm{~h}$. La reacción entre el dietil cinc y el Ni/SC se lleva a cabo en un reactor discontinuo a $80{ }^{\circ} \mathrm{C}$ y 1 bar de $\mathrm{H}_{2}$ durante $2 \mathrm{~h}$. El sólido obtenido es lavado varias veces con $n$-heptano a temperatura ambiente para eliminar posibles restos de grupos etilo, y secados $\left(10^{\circ} \mathrm{C} \cdot \mathrm{min}^{-1}\right)$ en flujo continuo de Ar (50 $\mathrm{cm}^{3} \cdot \mathrm{min}^{-1}$ ) a $100{ }^{\circ} \mathrm{C}$ durante $2 \mathrm{~h}$. Finalmente los catalizadores bimetálicos fueron obtenidos mediante la activación de los sólidos en flujo continuo de $\mathrm{H}_{2}\left(50 \mathrm{~cm}^{3} \cdot \mathrm{min}^{-1}\right)$ a $400{ }^{\circ} \mathrm{C}$ durante $1.5 \mathrm{~h}$.

Se prepararon catalizadores bimetálicos con contenidos de cinc entre 0.08 y 0.5 expresados como una relación atómica $\mathrm{Zn} / \mathrm{Ni}$. Los catalizadores fueron denotados como $\mathrm{NiZnB} / \mathrm{SC}$, donde B indica la relación atómica $\mathrm{Zn} / \mathrm{Ni}$.

\subsection{Técnicas de caracterización}

A continuación, se describen las técnicas empleadas para caracterizar a los soportes y/o catalizadores que se emplearon en esta tesis.

\subsubsection{Análisis químico (AAS/ICP)}

El contenido de $\mathrm{Cu}$, Co y $\mathrm{Ni}$ presente en los catalizadores fue determinado por la técnica de espectrometría de absorción atómica, empleando un espectrofotómetro AA-6650 Shimadzu.

El protocolo para la cuantificación de dichos metales presentes en las muestras sólidas es el siguiente:

1) Pesada de una masa conocida de sólido, entre 10 y $20 \mathrm{mg}$.

2) Disgregación de la muestra empleando $10 \mathrm{ml}$ de una solución 1:1 de $\mathrm{HNO}_{3}$ en agua. 
3) Dilución de la solución anterior con agua destilada en una relación 1:10 empleando un matraz de simple aforo para lograr una concentración de metal entre 5 y 50 ppm (considerando la concentración nominal del metal en el catalizador).

4) Filtración de la solución empleando un filtro de membrana de 0.45 micrones.

5) Preparación de la curva de calibración para cada uno de los metales empleando patrón certificado.

6) Determinación del contenido metálico por duplicado empleando el equipo de absorción atómica.

Para las muestras de $\mathrm{Ru}$, el contenido fue determinado empleando la técnica de espectrometría de masas con plasma acoplado inductivamente (ICP-MS). El equipo empleado para efectuar el análisis fue el NexIon 300X (Perkin Elmer, Shelton, CT, E.E.U.U.).

\subsubsection{Adsorción-desorción de $\mathrm{N}_{2}$ (BET)}

La caracterización textural de los soportes y catalizadores consistió en la determinación de la superficie específica $\left(\mathrm{S}_{\mathrm{BET}}\right)$, el volumen total de poros $\left(\mathrm{V}_{\mathrm{t}}\right)$ y la superficie y volumen total de micro y mesoporos, además de las características porosas de los materiales (si se tratan de materiales micro o mesoporosos y el tipo de poro que presentan).

Para cuantificar los parámetros de porosidad se realizaron medidas de adsorcióndesorción de nitrógeno empleando como equipo el Micromeritics ASAP 2020 (Micromeritics Instrument Corporation, Norcross, GA, USA). Previo a la medida, todas las muestras fueron desgasificadas al vacío en dos etapas de $1 \mathrm{~h}$ cada una a $100{ }^{\circ} \mathrm{C}$ y $300^{\circ} \mathrm{C}$.

Las superficies específicas (S de Brunauer, Emmett y Teller (BET).

La distribución de poros fue calculada a partir de la rama de adsorción de cada una de las isotermas, empleando el modelo de Barrett, Joyner y Halenda (BJH), asumiendo poros del tipo "slit" o rendija.

El volumen total de poro $\left(\mathrm{V}_{\mathrm{t}}\right)$ fue calculado a partir del total de $\mathrm{N}_{2}$ adsorbido a la presión relativa de 0.99 .

Los valores de superficie específica de microporos $\left(\mathrm{S}_{\text {micro }}\right)$ y de volumen de microporos ( $\left.V_{\text {micro }}\right)$ fueron calculados empleando el método de $t$-plot, mientras que la superficie de mesoporos $\left(\mathrm{S}_{\text {meso }}\right)$ fue estimada a partir de la diferencia entre la superficie específica $\left(\mathrm{S}_{\mathrm{BET}}\right)$ y la superficie específica de microporos $\left(\mathrm{S}_{\text {micro }}\right)$.

\subsubsection{Difracción de rayos X (DRX)}

Para identificar las fases cristalinas presentes en los soportes y catalizadores, ya sea una vez pretratados, activados o post-reacción, se empleó la técnica de difracción de rayos $X$ (DRX). El equipo empleado fue un difractómetro de polvos Philips 3020 provisto de radiación de $\mathrm{Cu} \mathrm{K \alpha}(\lambda=1.5418 \AA$ ) y operado con una intensidad de corriente de $40 \mathrm{~mA}$ y un voltaje de $35 \mathrm{kV}$.

Los difractogramas de rayos $\mathrm{X}$ para todas las muestras fueron recolectados en el rango $2 \theta=5-80^{\circ}$, empleando una velocidad de $2^{\circ}$. $\min ^{-1} \mathrm{y} 0.1^{\circ}$ por paso. 
Para los catalizadores con fases cristalinas de Ni se calcularon los tamaños de cristal en aquellas muestras activadas en atmósfera reductora, empleado la ecuación de Scherrer (Ecuación 1-3).

$$
\mathrm{d}_{\mathrm{DRX}}=\frac{\mathrm{K} \cdot \lambda}{\beta \cdot \cos (\theta)}
$$

Ecuación 1-3

En la ecuación anterior, $\mathrm{K}$ es una constante igual a $0.90, \beta$ es el ancho del pico de referencia a la mitad de su máxima intensidad (medido en radianes) y $\theta$ es el ángulo del pico de referencia. Para el Ni el pico de referencia corresponde al plano $\left(\begin{array}{lll}1 & 1 & 1\end{array}\right)$ y se encuentra ubicado a $2 \theta=44.44^{\circ}$, con lo cual $\theta=22.22^{\circ}$. Para aplicar esta ecuación se obtuvo el difractograma del pico de referencia correspondiente a la fase cristalina de $\mathrm{Ni}$ en un rango menor de valores de $2 \theta\left(20-30^{\circ}\right)$ empleando una velocidad de $0.25^{\circ} \cdot \mathrm{min}^{-1}$ y $0.025^{\circ}$ por paso.

También es posible estimar los parámetros de red (a) de la celda unidad del $\mathrm{Ni}$ (Ecuación 2-3) considerando los índices de Miller (h k l) del plano cristalino correspondiente al pico principal de la fase y la distancia al plano cristalino ( $\left.\mathrm{d}_{\mathrm{hkl}}\right)$ (Ecuación 3-3).

$$
\begin{gathered}
a=d_{h k l} \sqrt{h^{2}+k^{2}+1^{2}} \\
d_{h k l}=\frac{\lambda}{2 \cdot \operatorname{sen}(\theta)}
\end{gathered}
$$

Ecuación 2-3

Ecuación 3-3

Para verificar el correcto funcionamiento del equipo de rayos $\mathrm{X}$ y estimar los parámetros de red de forma adecuada, se obtuvo el difractograma de una pastilla de silicio patrón en el rango de $2 \theta$ de 5 a $35^{\circ}$. El resultado del difractograma se visualiza en la Figura 1-3. La aparición de un único pico a $2 \theta=28.4^{\circ}$ confirma la presencia de silicio puro en la pastilla y es un indicio de que la estimación de los parámetros de red es confiable.

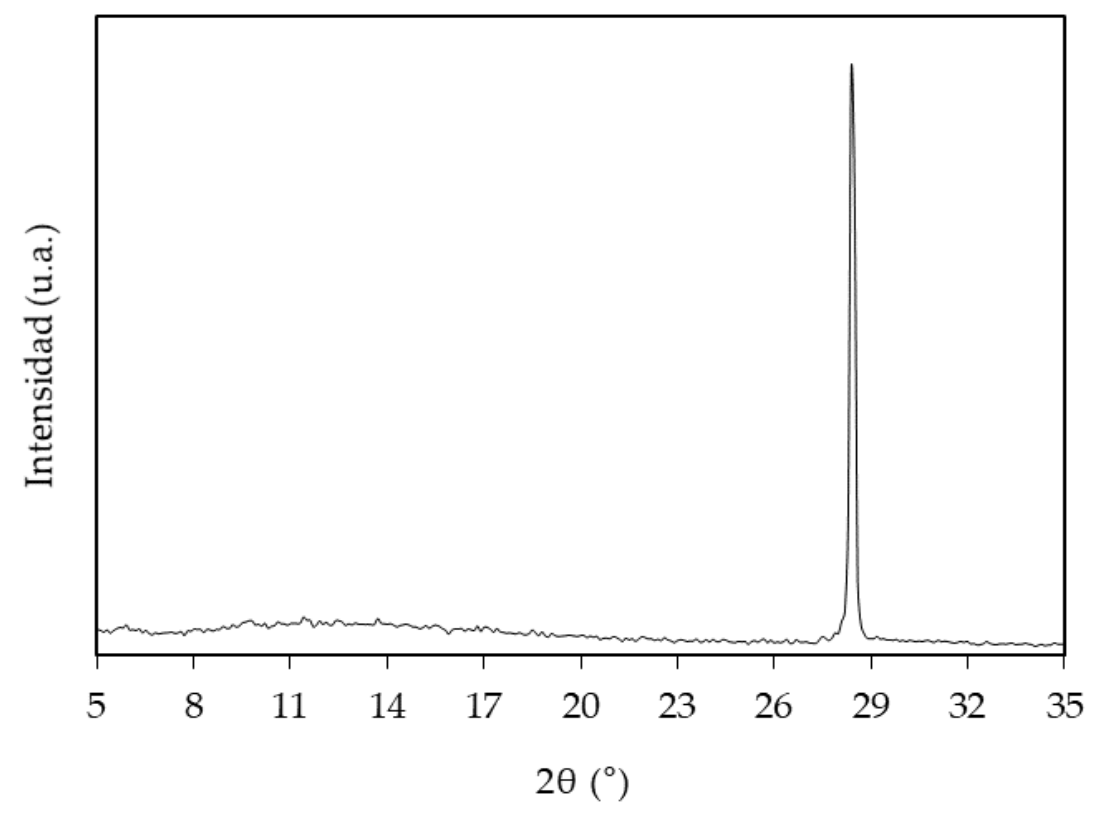

Figura 1-3. Difractograma obtenido para pastilla de silicio patrón. 


\subsubsection{Reducción a temperatura programada (TPR)}

Para llevar a cabo la reducción a temperatura programada se empleó un equipo Micromeritics (Autochem II 2920) consistente de un tubo de cuarzo calefaccionado por un horno eléctrico provisto de una termocupla central de pared y controlador de temperatura para establecer las condiciones de calentamiento. Se utilizaron un detector de conductividad térmica (TCD) y un detector con espectrómetro de masas (MS).

En cada ensayo, se emplearon $50 \mathrm{mg}$ de muestra que fue tratada en flujo de $\mathrm{H}_{2} / \mathrm{N}_{2}(1: 9)$ con un caudal de $20 \mathrm{~cm}^{3} \cdot \mathrm{min}^{-1}$ empleando una rampa de $10{ }^{\circ} \mathrm{C} \cdot \mathrm{min}^{-1}$ desde $20^{\circ} \mathrm{C}$ hasta 1000 ${ }^{\circ} \mathrm{C}$. Para el caso de catalizadores de $\mathrm{Ni}$, se calculó el grado de reducibilidad de las muestras a partir del cociente entre los moles de $\mathrm{H}_{2}$ consumidos en el ensayo de TPR con respecto a los moles de $\mathrm{H}_{2}$ consumidos según el contenido nominal de $\mathrm{Ni}$ en las muestras, considerando que por cada $1 \mathrm{~mol}$ de $\mathrm{Ni}$ en la muestra se consume $1 \mathrm{~mol} \mathrm{de} \mathrm{H}_{2}$. Se realizó una curva de calibración empleando muestras con distintas cantidades de $\mathrm{NiO}^{1}$ (3 a $20 \mathrm{mg}$ ). En primer término, se calculó el consumo teórico de $\mathrm{H}_{2}$ para las muestras con distintas cantidades de $\mathrm{NiO}$, considerando que por cada $1 \mathrm{~mol}$ de $\mathrm{Ni}$ se consume 1 mol de $\mathrm{H}_{2}$. Luego se integraron los picos correspondientes al consumo de $\mathrm{H}_{2}$. Los perfiles de TPR para estas muestras se observan en la Figura 2-4.

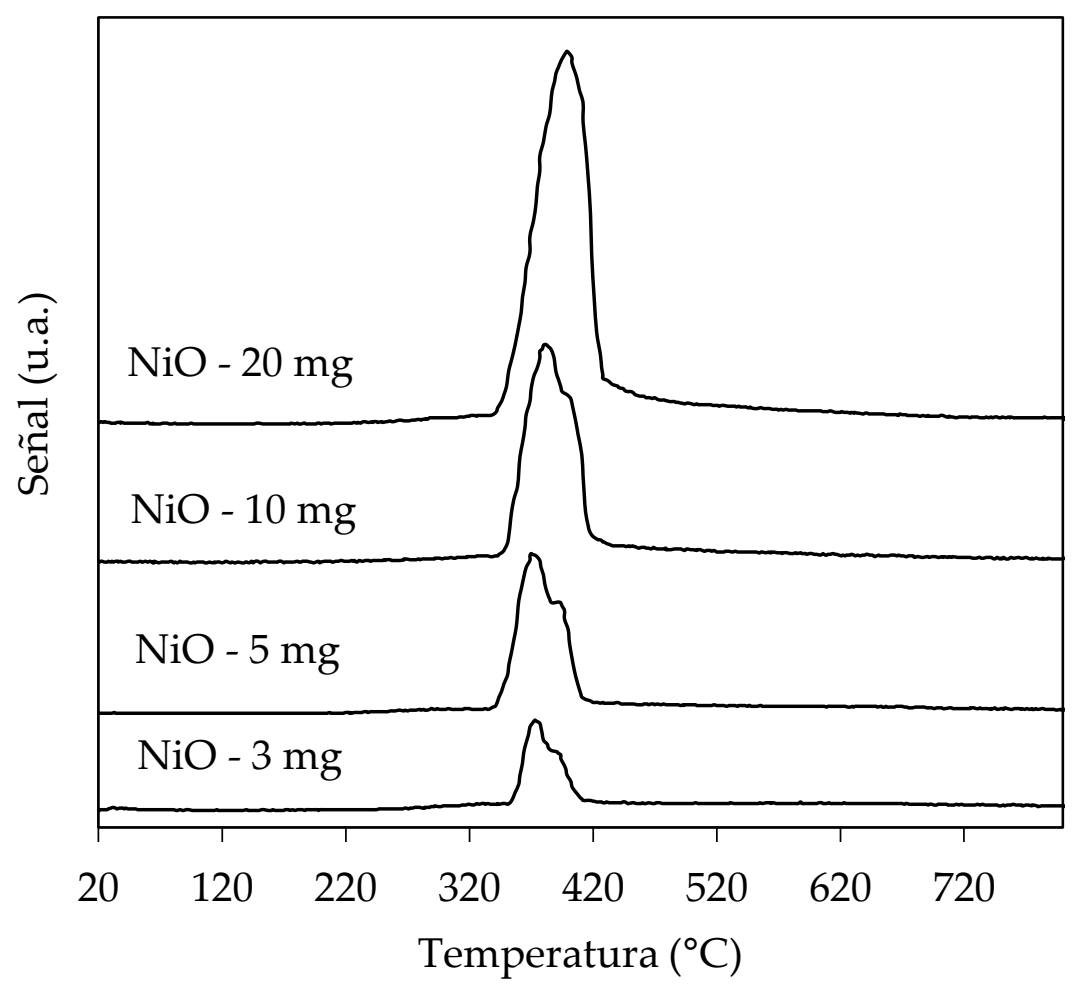

Figura 2-3. Perfiles de TPR para las muestras de NiO.

Con estos datos es posible construir la Tabla 2-3.

${ }^{1} \mathrm{El} \mathrm{NiO}$ fue obtenido a partir de la descomposición térmica del $\mathrm{Ni}\left(\mathrm{NO}_{3}\right) 2 \cdot 6 \mathrm{H}_{2} \mathrm{O}$ a $500{ }^{\circ} \mathrm{C}$ durante $12 \mathrm{~h}$ en mufla. 
Tabla 2-3. Consumo de $\mathrm{H}_{2}$ teórico y valores de las áreas integradas a partir de los perfiles de TPR para las muestras de $\mathrm{NiO}$.

\begin{tabular}{cccc}
\hline Contenido de $\mathrm{NiO}(\mathrm{mg})$ & Contenido de $\mathrm{Ni}(\mathrm{mmol})$ & Consumo de $\mathrm{H}_{2}(\mathrm{mmol})$ & Area (u.a.) \\
\hline 0 & 0 & 0 & 0 \\
2.80 & 0.0374 & 0.0374 & 9.7463 \\
6.90 & 0.0924 & 0.0924 & 22.6450 \\
10.50 & 0.1406 & 0.1406 & 34.8500 \\
19.80 & 0.2651 & 0.2651 & 65.1290 \\
\hline
\end{tabular}

La Figura 3-3 muestra la curva de calibración para efectuar los cálculos de reducibilidad en TPR.

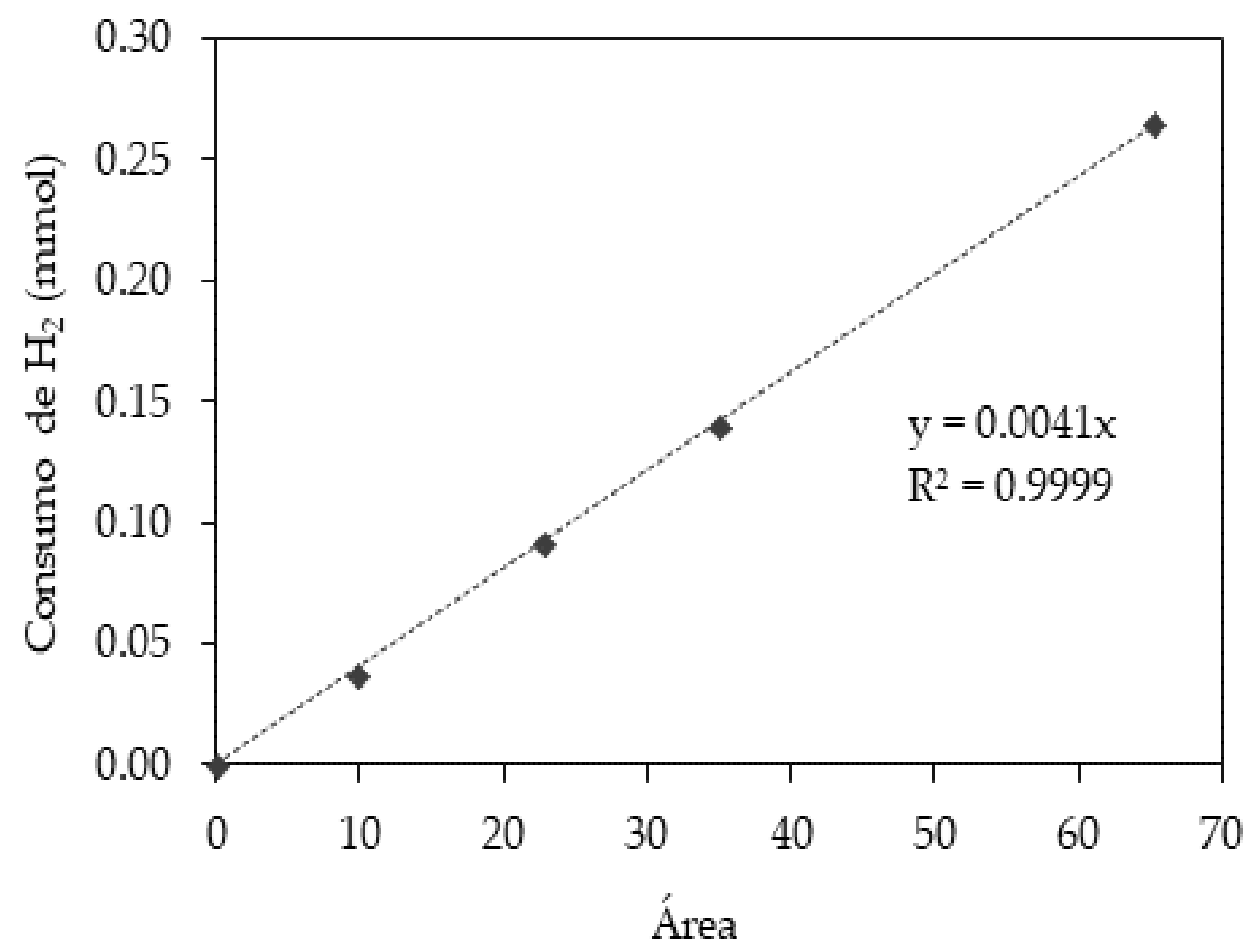

Figura 3-3. Curva de calibración del TPR empleando NiO.

\subsubsection{Titulación potenciométrica}

La titulación potenciométrica es una técnica analítica que permite la determinación del número total de sitios ácidos presentes en un material sólido y su fuerza ácida relativa [2-10]. Como desventaja, podría mencionarse que la acidez se determina en un medio de acetonitrilo que no es el medio de reacción. Además, si bien la técnica permite estimar el número de sitios ácidos presente en el material y su fuerza ácida, no puede precisar si estos sitios son ácidos de Lewis o sitios ácidos de Brønsted, lo cual es una limitación de la técnica. 
Esta técnica emplea n-butilamina como titulante. Dado que se trata de una base orgánica fuerte $(\mathrm{pKa}=10,73)$, su empleo permite titular tanto sitios ácidos fuertes como débiles, independientemente de su naturaleza (sean sitios de Lewis o Brønsted) $[9,10]$.

Se grafica la diferencia de potencial $(\mathrm{mV})$ medida entre el electrodo de trabajo y el electrodo de referencia, ambos sumergidos en el medio que contiene acetonitrilo y la muestra a titular, en función del consumo de n-butilamina por gramo de muestra (mmol nbutilamina. $\left.\mathrm{g}^{-1}\right)$ [2,3]. Se considera que el potencial inicial antes de comenzar la titulación $\left(\mathrm{E}_{\mathrm{i}}\right)$ indica la máxima fuerza ácida de los sitios, mientras que el valor de mmoles de base consumido por gramo de muestra hasta alcanzar un plató en la curva de titulación, indica el número total de sitios ácidos presentes en la muestra titulada $[2,6]$.

La fuerza ácida de los sitios se asigna acorde a un rango establecido para valores de $\mathrm{E}_{\mathrm{i}}$, según se indica en la Tabla 3-3 [4-8].

Tabla 3-3. Criterio de clasificación de la fuerza de los sitios ácidos de acuerdo al Ei.

\begin{tabular}{ll}
\hline Rango de $E_{i}$ & Fuerza ácida \\
\hline$E_{i}>100 \mathrm{mV}$ & Muy fuertes \\
$0 \mathrm{mV}<\mathrm{E}_{\mathrm{i}}<100 \mathrm{mV}$ & Fuertes \\
$-100 \mathrm{mV}<\mathrm{E}_{\mathrm{i}}<0 \mathrm{mV}$ & Débiles \\
$\mathrm{E}_{\mathrm{i}}<-100 \mathrm{mV}$ & Muy débiles \\
\hline
\end{tabular}

El procedimiento para titular consiste en suspender $0.05 \mathrm{~g}$ de sólido (soporte o catalizador) en acetonitrilo (Merck) y mantener en agitación durante un tiempo de $3 \mathrm{~h}$, luego del cual la suspensión es titulada con una solución de n-butilamina (Carlo Erba) en acetonitrilo de concentración $0.05 \mathrm{M}$. Para llevar a cabo el registro de la variación de potencial con el agregado de la base se empleó el equipo Metrohm 794 Basic Titrino.

\subsubsection{Titulación de Bohem}

Para determinar el contenido de grupos superficiales oxigenados ácidos (Figura 4-3) en los soportes carbonosos se empleó la técnica de titulación de Bohem.

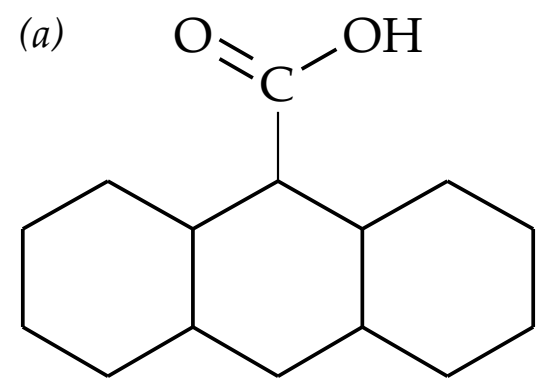

(b)

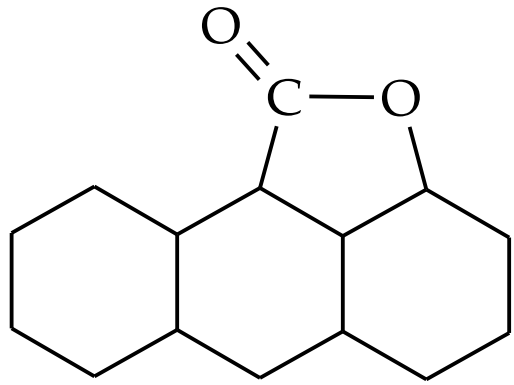

(c)

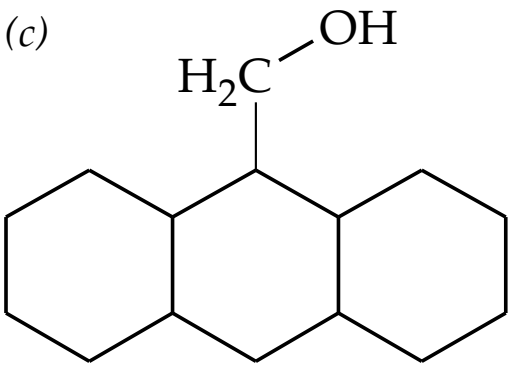

Figura 4-3. Grupos superficiales oxigenados ácidos en la estructura de un carbón (a) carboxílicos (b) lactónicos (c) fenólicos. 
Los resultados de la titulación permitieron obtener la concentración de grupos carboxílicos, lactónicos y fenólicos presentes en los soportes carbonosos, asumiendo que $\mathrm{NaHCO}_{3}$ neutraliza grupos carboxílicos, $\mathrm{Na}_{2} \mathrm{CO}_{3}$ neutraliza grupos carboxílicos y lactónicos y $\mathrm{NaOH}$ neutraliza grupos carboxílicos, lactónicos y fenólicos.

Las titulaciones fueron llevadas a cabo acorde a un procedimiento estandarizado [11,12]. Para ello, $0.5 \mathrm{~g}$ de muestra fueron añadidos a $30 \mathrm{ml}$ de cada una de las siguientes soluciones de base $0.025 \mathrm{M}$ : $\mathrm{NaHCO}_{3}, \mathrm{Na}_{2} \mathrm{CO}_{3}$ y $\mathrm{NaOH}$. Las mezclas preparadas fueron tapadas y agitadas durante $24 \mathrm{~h}$ para dar lugar a la reacción entre los grupos ácidos del material carbonoso y la base en consideración. Luego se procedió al filtrado para remover el sólido. Se tomó una alícuota de $10 \mathrm{ml}$ de cada líquido filtrado y se le añadieron $20 \mathrm{ml}$ de solución $0.025 \mathrm{M}$ de $\mathrm{HCl}$ para neutralizar el exceso de base. Para el caso de la solución de $\mathrm{Na}_{2} \mathrm{CO}_{3}$, fueron necesarios $30 \mathrm{ml}$ para asegurar la neutralización completa. Estas soluciones fueron desgasificadas en flujo continuo $\left(50 \mathrm{~cm}^{3} \cdot \mathrm{min}^{-1}\right)$ de Ar por $2 \mathrm{~h}$ para asegurar la eliminación del posible $\mathrm{CO}_{2}$ disuelto en ellas. Luego, las soluciones fueron tituladas por retroceso empleando una solución de $\mathrm{NaOH} 0.025 \mathrm{M}$ y fenolftaleína como indicador. Debido a la posibilidad de formación de carbonatos, las soluciones de $\mathrm{NaOH} 0.025$ M fueron preparadas con agua hervida y destilada a partir de la pesada del sólido y luego estandarizadas empleando una solución de biftalato de potasio al $1 \% \mathrm{p} / \mathrm{v}$. La concentración efectiva (c.e.) de $\mathrm{NaOH}$ en solución fue $0.0234 \mathrm{M}$. Esta solución fue utilizada luego para estandarizar la solución de $\mathrm{HCl}($ c.e. $=0.0264 \mathrm{M}$ ) y esta a su vez se empleó para estandarizar las soluciones de $\mathrm{NaHCO}_{3}$ (c.e. $=0.0248 \mathrm{M}$ ) y $\mathrm{Na}_{2} \mathrm{CO}_{3}$ (c.e. $=0.0244 \mathrm{M}$ ). Las soluciones fueron preparadas y estandarizadas al momento de efectuar las titulaciones por retroceso.

Para determinar el contenido total de grupos superficiales básicos se empleó una solución de $\mathrm{HCl} 0.025 \mathrm{M}$ (c.e. $=0.0264 \mathrm{M}$ ) asumiendo que el $\mathrm{HCl}$ neutraliza todo el conjunto de grupos básicos presentes en los materiales carbonosos. El procedimiento de titulación fue análogo al caso del $\mathrm{NaOH}$, titulando por retroceso con $\mathrm{HCl}$.

\subsubsection{Reacción test de descomposición de isopropanol (IPA)}

Además de la titulación potenciométrica, se empleó la reacción test de descomposición de isopropanol (IPA) como método indirecto para determinar las propiedades ácido-base de los soportes y catalizadores.

La reacción de descomposición de isopropanol (IPA) ha sido reportada en bibliografía como una medida indirecta para caracterizar la acidez y basicidad de muestras sólidas, así como también la fuerza de esos sitios.

Los resultados obtenidos a partir de la reacción permiten clasificar los sitios presentes en un sólido por su capacidad para deshidratar o deshidrogenar, conduciendo a la formación de propileno (P), di-isopropil éter (DIPE) y $\mathrm{H}_{2} \mathrm{O}$ por deshidratación, o la formación de $\mathrm{H}_{2}$ y acetona $(\mathrm{AcO})$ por deshidrogenación.

$\mathrm{Si}$ los productos de reacción obtenidos son $\mathrm{P}$ y DIPE, entonces los sitios superficiales son del tipo ácidos fuertes (AFL) o bases fuertes de Lewis (BFL).

$\mathrm{Si}$ los productos de reacción obtenidos son $\mathrm{P}$ y $\mathrm{AcO}$, los sitios superficiales son del tipo ácidos débiles de Lewis (ADL) o bases fuertes de Lewis (BFL). 
Si el único producto de reacción obtenido es $\mathrm{P}$, los sitios superficiales pueden ser ácidos fuertes de Lewis (AFL) o BrØnsted (AFB) [13,14].

El Esquema 1-3 muestra las reacciones que intervienen en la descomposición de IPA.<smiles>CC(C)CCCCC(C)O</smiles>

Isopropanol (IPA)<smiles>CC(C)=O</smiles>

Acetona $(\mathrm{AcO})$<smiles>C=CC</smiles>

Propileno (P)<smiles>CCCCC(C)O</smiles>

Isopropanol (IPA)<smiles>CC(C)OC(C)C</smiles>

Di-isopropil éter (DIPE)<smiles>C=CC</smiles>

Propileno $(\mathrm{P})$<smiles>CC(C)CC(C)C(C)O</smiles>

Isopropanol (IPA)<smiles>C=CC</smiles>

Propileno (P)

Esquema 1-3. Reacciones involucradas en la reacción test de descomposición de isopropanol (IPA).

La reacción se llevó a cabo en un reactor continuo alimentado con flujo $\left(40 \mathrm{~cm}^{3} \cdot \mathrm{min}^{-1}\right)$ de helio saturado en IPA al 4.5\%, considerando un rango de temperaturas entre 200 y $300{ }^{\circ} \mathrm{C}$, a presión atmosférica.

El análisis y cuantificación de los productos gaseosos se llevó a cabo empleando el cromatógrafo de gases con detector de ionización a la llama (FID).

\subsubsection{Espectroscopia de infrarrojo (IR)}

Para identificar los grupos químicos funcionales presentes en los soportes carbonosos se empleó la técnica de espectroscopía de infrarrojo, que permite asignar bandas de absorción o transmisión de energía por parte de especies químicas presentes en los sólidos cuando se irradian con luz infrarroja, en la zona del IR medio (400-4000 $\left.\mathrm{cm}^{-1}\right)$. La interacción de las especies químicas con la luz infrarroja se debe a modos de vibración fundamentales y de vibración-rotación por parte de las moléculas correspondientes a dichas especies. 
Para efectuar las medidas de espectroscopia de infrarrojo por transformada de Fourier se utilizó un espectrofotómetro de infrarrojo modelo Bruker IFS 66 FT-IT. En cada ensayo, la muestra se preparó en forma de pastillas de concentración aproximada 1 \%p/p en KBr. El rango de medida fue 400-4000 $\mathrm{cm}^{-1}$ con una resolución de $2 \mathrm{~cm}^{-1}$.

\subsubsection{Espectroscopía Raman}

La espectroscopía Raman permite, entre otras cosas, la identificación de especies químicas mediante la información de espectros absorción de muestras sólidas que tienen la capacidad de absorber energía a bajas frecuencias correspondientes a modos de vibración y rotación de las especies, entre otros.

Los espectros Raman de las muestras sólidas fueron obtenidos a temperatura ambiente en la geometría de retro dispersión empleando un espectrómetro inVia Renishaw (Hoffman Estates, IL, E.E. U.U.) equipado con un dispositivo de carga fría enfriada por aire (CCD), detector y filtros de borde. Se empleó un láser de iones Ar+ con línea de emisión a 488.5 nm y una potencia incidente sobre la muestra de aproximadamente $5 \mathrm{~mW}$. El láser fue centrado sobre la muestra empleando un microscopio Leica DLML (Leica Microsystems, Buffalo Grove, IL, E.E.U.U.) La resolución espectral fue de $2 \mathrm{~cm}^{-1}$. Los espectros fueron calibrados usando la línea a $520.5 \mathrm{~cm}^{-1}$ de una oblea patrón de silicio.

Las posiciones de cada banda, su ancho y la integración de cada una de ellas fueron determinadas mediante un procedimiento de ajuste de curvas empleando funciones del tipo Gauss-Lorentz (PEAKFIT 3.2, Jandel Scientific Inc., San Rafael, CA, E.E.U.U.).

\subsubsection{Análisis termogravimétricos (TGA-ATD)}

Para determinar la temperatura de descomposición de los soportes carbonosos, el contenido de sílice en los mismos y la descomposición térmica de los precursores metálicos de los catalizadores soportados se emplearon las técnicas de análisis termogravimétrico (TGA) y análisis térmico diferencial (ATD).

Ambos análisis fueron realizados en un equipo NETZSCH STA 409 C/CD. En cada ensayo, $0.02 \mathrm{~g}$ de muestra secada y desgasificada fueron sometidos al calentamiento (10 ${ }^{\circ} \mathrm{C} . \mathrm{min}^{-1}$ ) desde la temperatura ambiente hasta $900{ }^{\circ} \mathrm{C}$ en flujo continuo de Ar o una mezcla $\mathrm{N}_{2}(90 \% \mathrm{v} / \mathrm{v})-\mathrm{O}_{2}(10 \% \mathrm{v} / \mathrm{v})$, según el ensayo realizado.

\subsubsection{Microscopía de barrido electrónico (SEM)}

Para estudiar las características morfológicas, de los soportes y catalizadores, se empleó la técnica de microscopía electrónica de barrido (SEM). La alta resolución y profundidad de foco (1-3 micrones) del microscopio otorgan a las muestras sólidas una apariencia tridimensional que permite determinar la forma de las partículas a nivel superficial.

Para llevar a cabo las medidas de microscopía de barrido electrónico se empleó un microscopio Philips SEM 505. En cada ensayo las muestras sólidas en polvo fueron cubiertas con una delgada capa de oro, empleado como material conductor. Este cubrimiento fue 
necesario para evitar la distorsión de las imágenes podría generarse por una acumulación de carga.

Además, se efectuó un análisis de elementos presentes en las muestras empleando el análisis EDAX que es un complemento al microscopio de barrido. Este análisis es semicuantitativo ya que no permite cuantificar de forma certera el contenido de elementos químicos en una muestra sólida.

\subsubsection{Microscopía de transmisión electrónica (TEM)}

La microscopía de transmisión electrónica (TEM) permite la determinación del tamaño y forma de las partículas que forman parte de la fase activa en los catalizadores metálicos soportados.

Las imágenes obtenidas por microscopía de transmisión electrónica de los catalizadores reducidos ex -situ fueron tomadas con un equipo TEM JEOL 100 C (JEOL Ltd., Tokyo, Japón) operado a 200 kV. Para realizar los análisis, se preparó una suspensión de la muestra sólida en 2-propanol y se la mantuvo en agitación con ultrasonido durante $10 \mathrm{~min}$. Luego, unas pocas gotas de dicha suspensión fueron depositadas en una grilla de Cu para el análisis TEM (Lacey Carbon Film 300 mesh, Electron Microscopy Science, Hatfield, PA, USA) y seguidamente secadas y evaporadas antes del análisis. Para estimar el tamaño promedio de partícula metálica, se consideró una geometría de tipo esférica y el diámetro promedio basado en la relación volumen-área de partícula fue calculado con la Ecuación 4-3.

$$
\mathrm{d}_{\mathrm{va}}=\frac{\sum \mathrm{n}_{\mathrm{i}} \cdot \mathrm{d}_{\mathrm{i}}^{3}}{\sum \mathrm{n}_{\mathrm{i}} \cdot \mathrm{d}_{\mathrm{i}}^{2}}
$$

Ecuación 4-3

donde $n_{i}$ es el número de partículas con diámetro $d_{i}$. Utilizando la técnica de campo claro para las distintas micrografías se obtuvieron los histogramas de distribución de tamaño de partícula.

A partir del diámetro promedio obtenido por TEM para los distintos catalizadores se calculó la dispersión metálica (DTEM) de los mismos según la Ecuación 5-3.

$$
\mathrm{D}_{\mathrm{TEM}}=\frac{6 \cdot \mathrm{V}_{\mathrm{m}}}{\mathrm{d}_{\mathrm{TEM}} \cdot \mathrm{A}_{\mathrm{m}}} \cdot 100 \%
$$

Ecuación 5-3

En la ecuación anterior $\mathrm{V}_{\mathrm{m}}$ es el volumen ocupado por un átomo del metal en el seno del catalizador $\left(\mathrm{nm}^{3}\right), \mathrm{Am}_{\mathrm{m}}$ es la superficie ocupada por un átomo del metal expuesto $\left(\mathrm{nm}^{2}\right) \mathrm{y}$ dTEM es el diámetro promedio de partícula metálica (nm).

La Tabla 4-3 muestra los valores de $V_{m}$ y Am para Ru y Ni $[15,16]$.

Tabla 4-3. Valores de $V_{m}$ y Am para Ru y Ni.

\begin{tabular}{ccc}
\hline Metal & $\mathrm{V}_{\mathrm{m}}\left(\mathrm{nm}^{3}\right)$ & $\mathrm{Am}_{\mathrm{m}}\left(\mathrm{nm}^{2}\right)$ \\
\hline $\mathrm{Ru}$ & $1.365 \times 10^{-2}$ & $9.09 \times 10^{-2}$ \\
$\mathrm{Ni}$ & $1.094 \times 10^{-2}$ & $6.76 \times 10^{-2}$ \\
\hline
\end{tabular}




\subsubsection{Espectroscopia de fotoelectrones (XPS)}

Mediante la técnica de espectroscopía de fotoelectrones (XPS) es posible estudiar las especies químicas presentes en las superficies de muestras sólidas, cuantificarlas y en algunos casos obtener información sobre las energías de enlace, los estados de oxidación y entornos de coordinación de los elementos que forman parte de dichas especies químicas. En otros casos es posible obtener la composición de las especies químicas en capas superficiales del orden de 1-3 $\mathrm{nm}$.

El análisis de espectroscopía de fotoelectrones (XPS) se llevó a cabo en un sistema multitécnico (SPECS GmbH, Berlin, Alemania) equipado con una fuente dual de rayos $X$ $\mathrm{Mg} / \mathrm{Al}$ y un analizador hemiesférico PHOIBOS 150 operando en modo fijo de transmisión de análisis (FAT).

Los espectros fueron obtenidos con el pasaje de energía de $30 \mathrm{eV}$ y un ánodo de $\mathrm{AlK} \alpha$ operando a $200 \mathrm{w}$. La presión durante los ensayos fue menor a 2 × $10^{-8} \mathrm{mbar}$.

En todos los casos, las muestras fueron sometidas a un tratamiento en atmósfera de $\mathrm{H}_{2} / \mathrm{Ar}$ a $400{ }^{\circ} \mathrm{C}$ durante 10 min previo al análisis en una cámara de pretratamiento anexo al equipo.

\subsubsection{Absorción de rayos $X$ (XAS) y absorción de rayos $X$ extendido a estructura fina (EXAFS)}

Los espectros de absorción de rayos X (XAS) y la absorción de rayos $\mathrm{X}$ extendida a estructura fina (EXAFS) permiten el análisis de muestras sólidas que contienen más de un elemento químico y son utilizados para la identificación y cuantificación de fases bimetálicas del tipo soluciones sólidas y aleaciones. En este sentido, ambas técnicas fueron implementadas para el estudio de los catalizadores bimetálicos de NiZn/SC.

Los espectros de absorción de rayos X (XAS) fueron adquiridos considerando los bodes K del Ni (8333 eV) y del Zn (9659 ev) [17] en la línea XAFS2 del Laboratorio Nacional de Luz Sincrotrón (LNLS, Campinas, Brasil). Un cristal de Si $\left(\begin{array}{lll}1 & 1 & 1\end{array}\right)$ fue empleado como monocromador en las medidas de absorción en los bordes $\mathrm{K}$ del $\mathrm{Ni}$ y del $\mathrm{Zn}$. Los componentes armónicos del haz de luz fueron menores al $1 \%$ empleando este monocromador. Todos los experimentos fueron llevados a cabo en el modo transmisión, y la intensidad del haz de luz fue medida empleando una serie de tres cámaras de ionización en atmósferas de gases apropiados a temperatura ambiente y presión atmosférica. Las energías de los fotones fueron calibradas a partir de la medida de la transmisión del haz de luz simultáneamente con la muestra sólida, a través de una lámina delgada de $\mathrm{Ni}$ o Zn dependiendo del caso, colocada entre la segunda y la tercera cámara de ionización. Los espectros XAS de los catalizadores bimetálicos fueron obtenidos en los bordes de absorción de ambos metales en el rango $200 \mathrm{eV}$ a $1000 \mathrm{eV}$ antes y después del correspondiente borde. Para la recolección de los espectros las muestras fueron transferidas bajo atmósfera de Ar a temperatura ambiente y presión atmosférica a una celda herméticamente cerrada.

El análisis de absorción de rayos X extendido a estructura fina (EXAFS) fue llevado a cabo empleando la rutina IFFEFIT del software Athenas [18]. La información estructural para los elementos metálicos $\mathrm{Ni} \mathrm{y} \mathrm{Zn,} \mathrm{incluyendo} \mathrm{los} \mathrm{números} \mathrm{de} \mathrm{coordinación} \mathrm{(N),} \mathrm{las} \mathrm{distancias}$ 
interatómicas $(\mathrm{R})$ y los factores de Debye-Waller $\left(\sigma^{2}\right)$ fueron calculados a partir del software Artemis, empleando un ajuste no lineal por mínimos cuadrados a partir de los datos de las transformadas de Fourier en el espacio r, con amplitudes teóricos y el corrimiento de fases calculados con la rutina FEEF [19]. Las amplitudes teóricas y el corrimiento de fase empleados en estos ajustes fueron calculados a partir de las estructuras cristalográficas de los parámetros de red mono-metálicos para Ni-Ni [ICSD 64989] y Zn-Zn [ICSD 64990] o bien de las mezclas Ni-Zn y Zn-Ni [20]. Todas las fases analizadas resultaron cúbicas centradas en las caras (fcc). Los espectros EXAFS de los catalizadores bimetálicos fueron ajustados simultáneamente a ambos bordes de cada metal (Ni y $\mathrm{Zn}$ ), para asegurar la consistencia de las distancias interatómicas y los factores de Debye-Waller.

Para identificar la presencia y contribución de especies oxidadas de $\mathrm{Ni}(\mathrm{NiO})$ y $\mathrm{Zn}$ $(\mathrm{ZnO})$ a las muestras de catalizadores bimetálicos, se llevó a cabo la dispersión individual de fotoelectrones considerando especies de bajo peso molecular $(\mathrm{O})$ con amplitudes teóricas y fases correspondientes a las estructuras cristalográficas de $\mathrm{NiO}$ [ISCD 9866] y ZnO [ISCD 67454].

\subsection{Equipos}

\subsubsection{Reactor de flujo continuo}

Para llevar a cabo los pretratamientos asociados a la preparación de los catalizadores se empleó un reactor de flujo continuo, que consiste de un tubo de cuarzo de $50 \mathrm{~cm}$ de largo y $2 \mathrm{~cm}$ de diámetro, equipado con un horno eléctrico con una termocupla central de pared y un controlador de temperatura.

Anexo al reactor se dispone del sistema de alimentación de gases para pretratamientos ( $\mathrm{Ar}, \mathrm{N}_{2}, \mathrm{H}_{2}$, aire), que emplea una válvula reguladora (para $\mathrm{Ar}, \mathrm{H}_{2}$, aire) o con caudalímetro másico (para $\mathrm{N}_{2}$ ).

\subsubsection{Reactor discontinuo}

Los ensayos de reacción fueron realizados en un reactor discontinuo tipo batch de acero inoxidable provisto de agitación magnética, selector térmico y termocupla, manómetro y conexiones laterales para el ingreso de los gases $\left(\mathrm{N}_{2} \mathrm{y} / \mathrm{o} \mathrm{H}_{2}\right)$ requeridos para presurizar y conexiones para la toma de muestras de productos líquidos y/o gaseosos.

El reactor es de marca BR-100 de la empresa Berghof Instruments y posee un volumen total de $100 \mathrm{ml}$. La Figura 5-3 muestra una fotografía de este equipo.

Para llevar a cabo los ensayos de reacción se empleó el siguiente protocolo:

1) Incorporación de la mezcla reactiva y del catalizador en el interior del reactor. La incorporación del catalizador pretratado ex-situ se realizó bajo atmósfera de Ar.

2) Cierre del reactor.

3) Presurización del reactor con $N_{2}$ de alta presión para verificar pérdidas.

4) Presurización con el gas que formará parte de la atmósfera de reacción $\left(\mathrm{H}_{2}\right)$ hasta la presión deseada. 
5) Selección de la velocidad de agitación (100-250-500-750-1000-1400 rpm).

6) Selección de la temperatura de reacción. El calentamiento del reactor se realiza con la máxima rampa posible $\left(6^{\circ} \mathrm{C}\right.$. $\left.\mathrm{min}^{-1}\right)$, para reducir al mínimo el tiempo de calentamiento. Se considera tiempo "cero" el momento que se alcanza la temperatura deseada.

7) Una vez finalizada la experiencia, se apaga la platina calefactora y el reactor se enfría rápidamente bajo flujo de aire externo a $18{ }^{\circ} \mathrm{C}$. El tiempo estimado de enfriamiento de 250 a $25^{\circ} \mathrm{C}$ es de 10 minutos.

Como se considera tiempo "cero" de reacción al momento en que el reactor alcanza la temperatura de operación, se realizaron pruebas experimentales que permitieron determinar que, durante la etapa de calentamiento de 25 a $250^{\circ} \mathrm{C}$, se emplean aproximadamente 40 min y es despreciable la conversión de glicerol ( $1.5 \%)$.
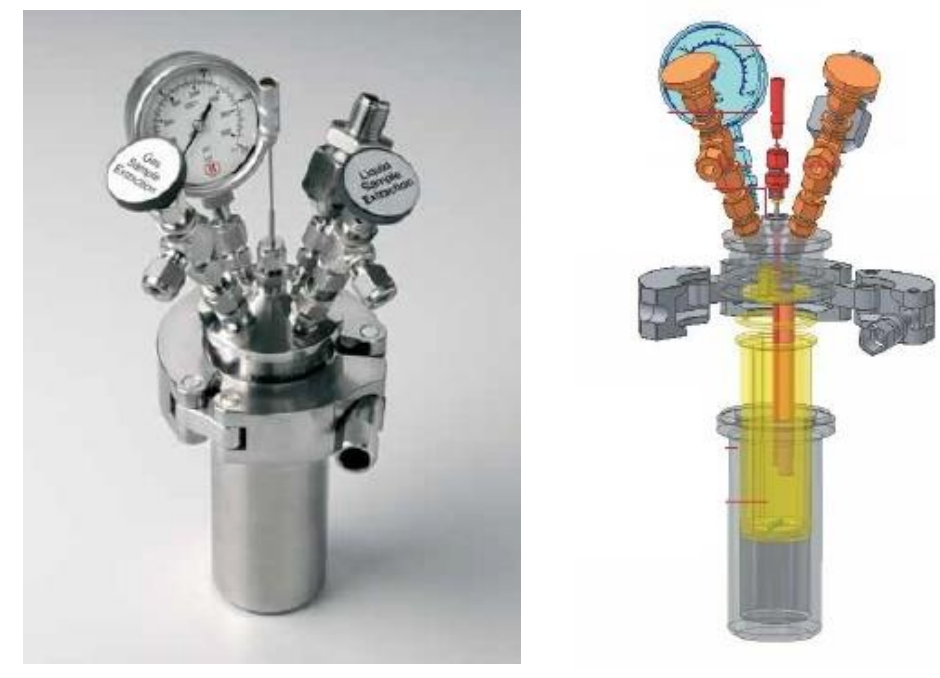

Figura 5-3. Reactor discontinuo Berghof BR-100.

\subsubsection{Cromatógrafo de gases con detector de ionización a la llama (FID)}

Para el análisis y cuantificación de los productos líquidos se empleó un cromatógrafo Shimadzu GCMS-QP505A equipado con una columna capilar 19091S-001 HP PONA de 50 metros con detector de ionización a la llama (FID) y espectrómetro de masa (MS).

Para la identificación de los productos de reacción se llevó a cabo la inyección de los patrones. Los compuestos puros empleados fueron: metanol absoluto del tipo pro-análisis (Cicarelli), alcohol etílico absoluto del tipo pro-análisis (Cicarelli), acetona del tipo proanálisis (Cicarelli), alcohol propílico normal del tipo pro-análisis (Cicarelli), alcohol isopropílico del tipo pro-análisis (Cicarelli), acetol (1-hidroxiacetona) del tipo pro-análisis (Sigma-Aldrich), etilenglicol del tipo pro-análisis (Biopack), 1,2-propilenglicol (1,2propanodiol) del tipo pro-análisis (Biopack), 1,3-propilenglicol (1,3-propanodiol) del tipo pro-análisis (Sigma-Aldrich) y glicerol del tipo pro-análisis (Cicarelli).

El programa de temperatura empleado se muestra en el gráfico de la Figura 6-4. Los tiempos de retención de los patrones se muestran en la Tabla 5-3. 
Tabla 5-3. Tiempos de retención para los compuestos puros empleados como patrones.

\begin{tabular}{lc}
\hline Compuesto & Tiempo de retención \\
\hline Metanol (MeOH) & 5.73 \\
Etanol (EtOH) & 6.12 \\
Acetona (AcO) & 6.46 \\
2-propanol (2-POH) & 6.60 \\
1-propanol (1-POH) & 7.17 \\
Acetol (AcOH) & 8.80 \\
Etilenglicol (EG) & 9.30 \\
1,2-propilenglicol (1,2-PG) & 10.11 \\
1,3-propilenglicol (1,3-PG) & 12.54 \\
Glicerol & 15.70 \\
\hline
\end{tabular}

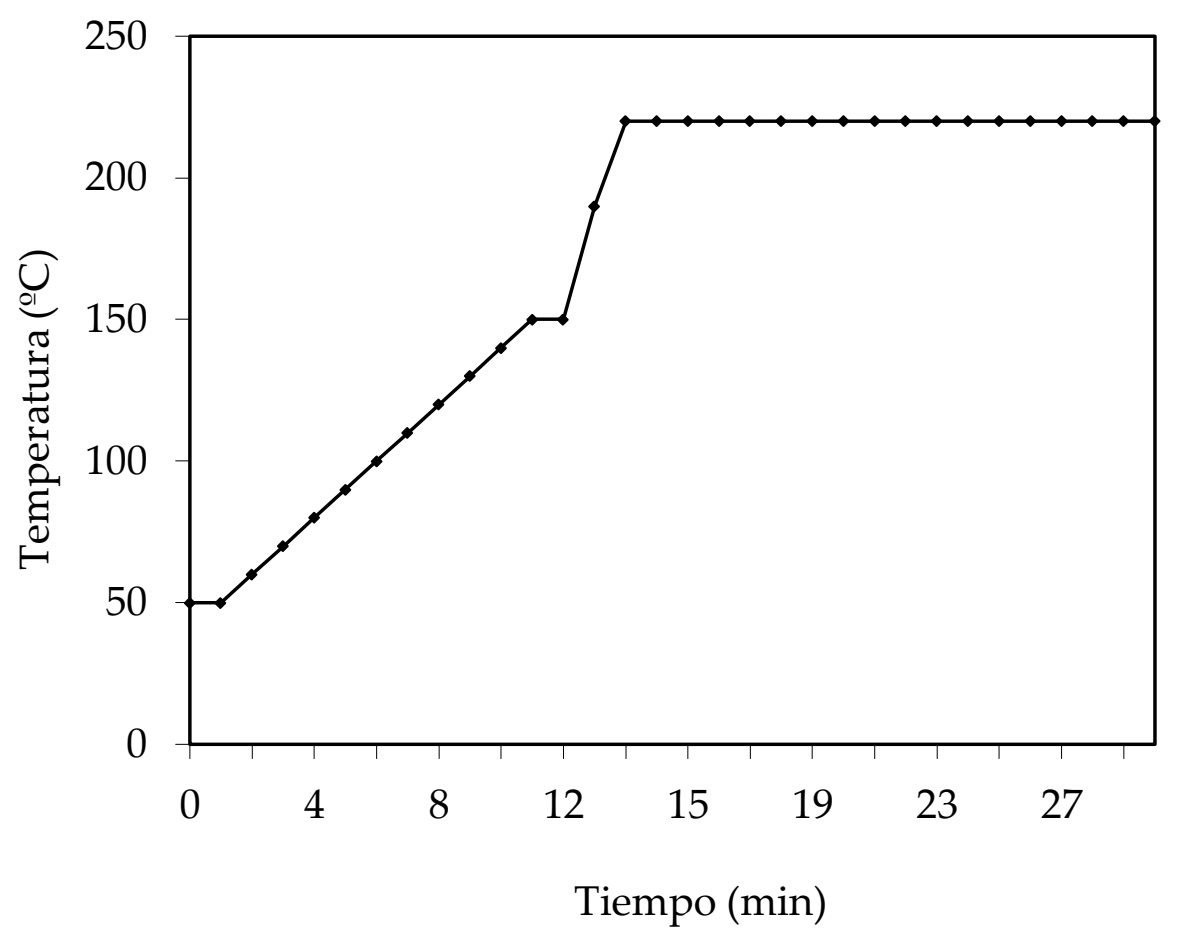

Figura 6-3. Programa de temperaturas y rampas de calentamiento para el CG-FID.

Para la cuantificación de los productos de reacción en fase líquida se calcularon los factores de respuesta de cada uno de los compuestos puros. Para ello se emplearon factores de respuesta basados en la respuesta experimental del detector de ionización a la llama sobre cada compuesto puro. Scanlon y Willis [21] determinaron una ecuación para el cálculo de los factores de respuesta de compuestos puros $\left(\mathrm{f}_{\mathrm{i}}\right)$ cuando el detector empleado es de ionización a la llama (FID). Dicha ecuación tiene en cuenta el peso molecular del compuesto puro en consideración $\left(\mathrm{PM}_{\mathrm{i}}\right)$ y el número efectivo de átomos de carbono del compuesto $\left(\mathrm{ECAN}_{\mathrm{i}}\right)$ (Ecuación 6-3): 


$$
f_{i}=\left(E_{C A N} \cdot P M i\right) /\left(E C A N i . P_{p}\right)
$$

Ecuación 6-3

En la ecuación anterior, $\mathrm{PM}_{\mathrm{p}}$ y ECAN $\mathrm{p}$ son el peso molecular y el número efectivo de átomos de carbono del compuesto patrón. El compuesto patrón es uno de los productos. La elección del compuesto patrón es arbitraria y la composición final de la mezcla no depende del compuesto patrón elegido. Este método permite calcular factores de respuesta sin necesidad de establecer curvas de calibración para cada compuesto en mezclas líquidas complejas.

El número efectivo de átomos de carbono para cada compuesto (ECAN) se calcula teniendo en cuenta el número total de átomos de carbono presentes en cada compuesto y su tipo de enlace $(C-C, C=C, C \equiv C$ ) además de la presencia de otros átomos que pueden estar presentes en los compuestos $(\mathrm{O}, \mathrm{Cl}, \mathrm{N})$. Para cada compuesto, el ECAN se calcula como la suma de los valores que se encuentran en la Tabla 6-3, dependiendo de la cantidad de átomos de carbono y su tipo de enlace o de la presencia de otros átomos.

Tabla 6-3. Tabla de valores para el cálculo del ECAN de cada compuesto.

\begin{tabular}{llc}
\hline Átomo & Tipo de enlace & Valores \\
\hline C & Alifático & 1.00 \\
C & Olefínico & 1.00 \\
C & Acetilénico & 1.30 \\
C & Aromático & 1.00 \\
C & Carbonilo & 0.00 \\
O & Alcohol primario & -0.60 \\
O & Alcohol secundario & -0.75 \\
O & Alcohol terciario & -0.25 \\
\hline
\end{tabular}

Los ECAN para los compuestos puros de la Tabla 5-3 se muestran en la Tabla 7-3.

Tabla 7-3. ECAN para los compuestos puros.

\begin{tabular}{lc}
\hline Compuesto & ECAN \\
\hline Metanol (MeOH) & 0.40 \\
Etanol (EtOH) & 1.40 \\
Acetona (AcO) & 2.00 \\
2-propanol (2-POH) & 2.25 \\
1-propanol (1-POH) & 2.40 \\
Acetol (AcOH) & 1.40 \\
Etilenglicol (EG) & 0.80 \\
1,2-propilenglicol (1,2-PG) & 1.65 \\
1,3-propilenglicol (1,3-PG) & 1.80 \\
Glicerol & 1.05 \\
\hline
\end{tabular}


Tomando como compuesto patrón el glicerol, y considerando los ECAN de cada compuesto y su peso molecular, es posible calcular los factores de respuesta para cada uno de ellos. Esta información se visualiza en la Tabla 8-3.

Tabla 8-3. Factores de respuesta de los compuestos puros según valores de ECAN y PM.

\begin{tabular}{lccc}
\hline Compuesto & PM $\left(\mathrm{g} \cdot \mathrm{mol}^{-1}\right)$ & ECAN & $\mathrm{f}_{\mathrm{i}}$ \\
\hline Metanol (MeOH) & 32.02 & 0.40 & 0.91 \\
Etanol (EtOH) & 46.07 & 1.40 & 0.38 \\
Acetona (AcO) & 58.08 & 3.00 & 0.22 \\
2-propanol (2-POH) & 60.09 & 2.25 & 0.30 \\
1-propanol (1-POH) & 60.09 & 2.40 & 0.29 \\
Acetol (AcOH) & 74.08 & 2.40 & 0.35 \\
Etilenglicol (EG) & 62.07 & 0.80 & 0.88 \\
1,2-propilenglicol (1,2-PG) & 76.09 & 1.65 & 0.53 \\
1,3-propilenglicol (1,3-PG) & 76.09 & 1.80 & 0.48 \\
Glicerol & 92.09 & 1.05 & 1.00 \\
\hline
\end{tabular}

A partir de los factores de respuesta $\left(f_{i}\right)$ es posible calcular los moles $\left(n_{i}\right)$ de cada compuesto presentes en una mezcla integrando las áreas de cada uno de los picos cromatográficos correspondientes a cada compuesto $\left(\mathrm{A}_{\mathrm{i}}\right)$. Para calcular el número de moles se multiplica el factor de respuesta por el área integrada para cada pico (Ecuación 7-3).

$$
n_{i}=f_{i} \cdot A_{i}
$$

Ecuación 7-3

Para verificar que los factores de respuesta calculados permiten predecir la composición en una mezcla se ensayó una mezcla de composición conocida empleando $\mathrm{MeOH}, \mathrm{EtOH}, \mathrm{EG}, 1,2-\mathrm{PG}$ y glicerol. La mezcla se preparó por pesada con los valores que se indican en la Tabla 9-3. Allí también figura su composición molar, en base húmeda y seca (descontando el aporte del agua).

Tabla 9-3. Composición en base húmeda y seca de una mezcla conocida.

\begin{tabular}{lccccc}
\hline Compuestos & Masa (g) & PM (g.mol $\left.{ }^{-1}\right)$ & Masa (mol) & $\begin{array}{c}\text { Composición en base } \\
\text { húmeda (\% molar) }\end{array}$ & $\begin{array}{c}\text { Composición en } \\
\text { base seca (\% molar) }\end{array}$ \\
\hline MeOH & 1.0300 & 32.02 & 0.0322 & 5.93 & 34.66 \\
EtOH & 0.7600 & 46.07 & 0.0165 & 3.04 & 17.78 \\
EG & 0.9122 & 62.07 & 0.0147 & 2.71 & 15.84 \\
1,2-PG & 1.1000 & 76.09 & 0.0145 & 2.67 & 15.58 \\
Glicerol & 1.3800 & 92.09 & 0.0150 & 2.76 & 16.15 \\
$\mathrm{H}_{2} \mathrm{O}$ & 8.0900 & 18.00 & 0.4494 & 82.89 & - \\
\hline
\end{tabular}


Se efectuaron tres inyecciones de la mezcla y se obtuvieron los valores de la Tabla 10-3.

Tabla 10-3. Composición en base húmeda y seca de una mezcla conocida

\begin{tabular}{lccc}
\hline \multirow{2}{*}{ Compuestos } & \multicolumn{3}{c}{ Composición en base seca (\% molar) } \\
\cline { 2 - 4 } & Primera Inyección & Segunda Inyección & Tercera Inyección \\
\hline MeOH & 34.34 & 34.68 & 34.37 \\
EtOH & 16.98 & 17.50 & 16.89 \\
EG & 16.33 & 15.33 & 16.28 \\
$1,2-P G$ & 14.97 & 14.41 & 15.01 \\
Glicerol & 17.37 & 18.08 & 17.45 \\
\hline
\end{tabular}

Como es posible observar, las diferencias entre la composición calculada y la real son muy pequeñas, lo cual indica que el método de cuantificación es apropiado.

\subsubsection{Cromatógrafo de gases con detector de conductividad térmica (TCD)}

Para la identificación de los productos gaseosos se empleó un cromatógrafo Shimadzu GC-8A equipado con una columna Hayesep D 100-120 de 10 m de largo y 1/8" de diámetro con detector de conductividad térmica (TCD). El integrador utilizado fue un Spectra-Physics SP4290.

El programa de temperatura requerido para la separación de los productos se muestra en el gráfico de la Figura 7-3.

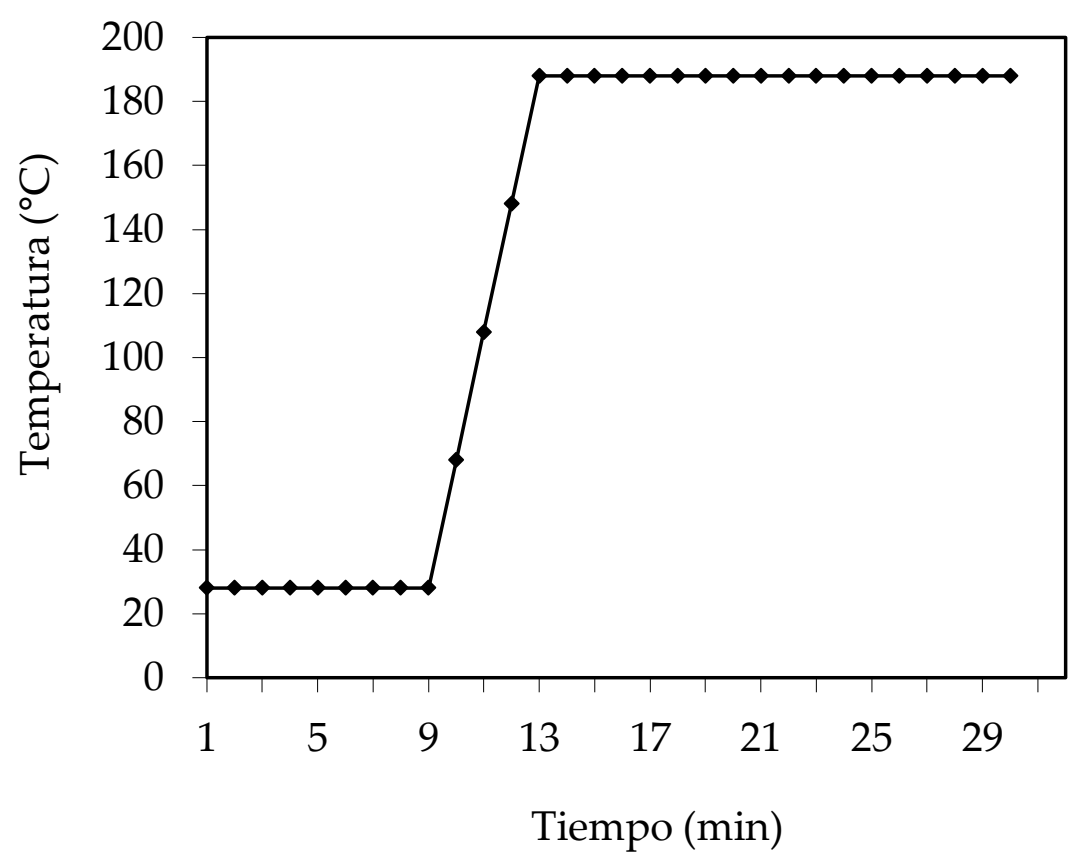

Figura 7-3. Programa de temperaturas y rampa de calentamiento para el CG-TCD.

Los tiempos de retención para los productos puros se muestran en la Tabla 11-3. 
Tabla 11-3. Tiempos de retención para los gases puros.

\begin{tabular}{lc}
\hline Compuesto & Tiempo de retención \\
\hline $\mathrm{H}_{2}$ & 11.30 \\
$\mathrm{~N}_{2}$ & 14.20 \\
$\mathrm{CO}$ & 15.20 \\
$\mathrm{CH}_{4}$ & 24.90 \\
$\mathrm{CO}_{2}$ & 36.40 \\
\hline
\end{tabular}

\subsection{Cálculos de parámetros de actividad}

La conversión total de glicerol $\left(\mathrm{X}_{\mathrm{T}}\right)$ fue calculada como un cociente entre los moles de glicerol consumidos durante la reacción y los moles de glicerol iniciales en la solución acuosa de partida (Ecuación 8-3).

$$
\mathrm{X}_{\mathrm{T}}=\frac{\text { moles de glicerol consumidos }}{\text { moles de glicerol iniciales }} .100 \%
$$

La conversión de glicerol a productos líquidos $\left(\mathrm{X}_{\mathrm{L}}\right)$ fue calculada como el cociente entre la suma total de los moles de carbono presentes en los productos líquidos y los moles de carbono presentes en la solución acuosa de glicerol inicial (Ecuación 9-3).

$$
\mathrm{X}_{\mathrm{L}}=\frac{\sum \text { moles de carbono en productos líquidos }}{\text { moles de carbono iniciales }} .100 \%
$$

Ecuación 9-3

La conversión de glicerol a productos gaseosos $\left(\mathrm{X}_{\mathrm{G}}\right)$ fue calculada como el cociente entre la suma total de los moles de carbono presentes en los productos gaseosos y los moles de carbono presentes en la solución acuosa de glicerol inicial (Ecuación 10-3).

$$
\mathrm{X}_{\mathrm{G}}=\frac{\sum \text { moles de carbono en productos gaseosos }}{\text { moles de carbono iniciales }} .100 \%
$$

Ecuación 10-3

La selectividad a un producto fue calculada como el cociente entre los moles de carbono presentes en el producto y los moles de carbono del glicerol consumido (Ecuación 11-3).

$$
\text { Selectividad }=\frac{\text { moles de carbono en el producto } \mathrm{i}}{\text { moles de glicerol consumidos } .3} \cdot 100 \%
$$


El balance de carbón fue calculado como el cociente entre los moles de carbono presentes en la sumatoria de productos y los moles de carbono iniciales en la solución de glicerol inicial (Ecuación 12-3).

$$
\text { Balance de carbón }=\frac{\sum \text { moles de carbono en productos }}{\text { moles de carbono iniciales }} .100 \% \quad \text { Ecuación } 12-3
$$

\section{Bibliografía}

[1] D.V. Cesar, G.F. Santori, F. Pompeo, M.A. Baldanza, C.A. Henriques, E. Lombardo, M. Schmal, L. Cornaglia, N.N. Nichio, International Journal of Hydrogen Energy 41 (2016) 22000-22008.

[2] R. Cid y G. Pecchi, Applied Catalysis 14 (1985) 15-21.

[3] J. M. Dominguez, J. L. Hernandez, G. Sandoval, Applied Catalysis A General 197 (2000) $119-130$

[4] L. R. Pizzio, P. G. Vázquez, C. V. Cáceres, M. N. Blanco, Applied Catalysis A General 256 (2003) 125-139

[5] L. R. Pizzio, M. N. Blanco, Applied Catalysis A General 255 (2003) 265-277

[6] L. Pizzio y M. Blanco, Microporous and Mesoporous Materials 103 (2007) 40-47

[7] Bennardi, D. O., Romanelli G. P., Autino J. C., Pizzio L. R., Applied Catalysis A General 324 (2007) 62-68

[8] E. Sert, F. S. Atalay, Ind. Eng. Chem. Res. 51 (2012) 6666-6671

[9] M. N. Alaya, M. A. Rabah, Arabian Journal of Chemistry 10 (2017) 439-449.

[10] A. I. Ahmed, S.A. El-Hakam, A.S. Khder, W.S. Abo El-Yazeed, Journal of Molecular Catalysis A Chemical 366 (2013) 99-108.

[11] S. L. Goertzen, K. D. Thériault, A. M. Oickle, A. C. Tarasuk, H. A. Andreas, Carbon 48 (2010) 1252-1261.

[12] A. M. Oickle, S. L. Goertzen, K. R. Hopper, Y. O. Abdalla, H. A. Andreas, Carbon 48 (2010) 3313-3322.

[13] A. Gervasini, G. Bellussi, J. Fenyvesi, A. Auroux, Journal of Physical Chemistry 99 (1995) 5117-5125. 
[14] A. Gervasini, J. Fenyvesi, A. Auroux, Catal. Lett. 43 (1997) 219-228.

[15] C. H. Bartholomew, R. J. Farrauto, Fundamentals of Industrial Catalytic Processes, 2da Edición, John Wiley and Sons: Hoboken (2005) 1-954, E.E.U.U.

[16] B. M. Faroldi, E. A. Lombardo, L. M. Cornaglia, Applied Catalysis A: General 369 (2009)15-26.

[17] J. A. Bearden, Reviews of Modern Physics 39 (1967) 78-124.

[18] B. Ravel, M. Newville, Journal of Synchrotron Radiation 12 (2005) 537-541.

[19] S. I. Zabinsky, J. J. Rehr, A. Ankudinov, R. C. Albers, M. J. Eller, Physical Reviews B 52 (1995) 2995-3009.

[20] R. P. Anantatmula, D. B. Masson, Metallurgical and Materials Transactions 5 (1974) 605613.

[21] J. T. Scanlon y D. E. Willis, Journal of Chromatographic Science 23 (8) (1985) 333-340. 


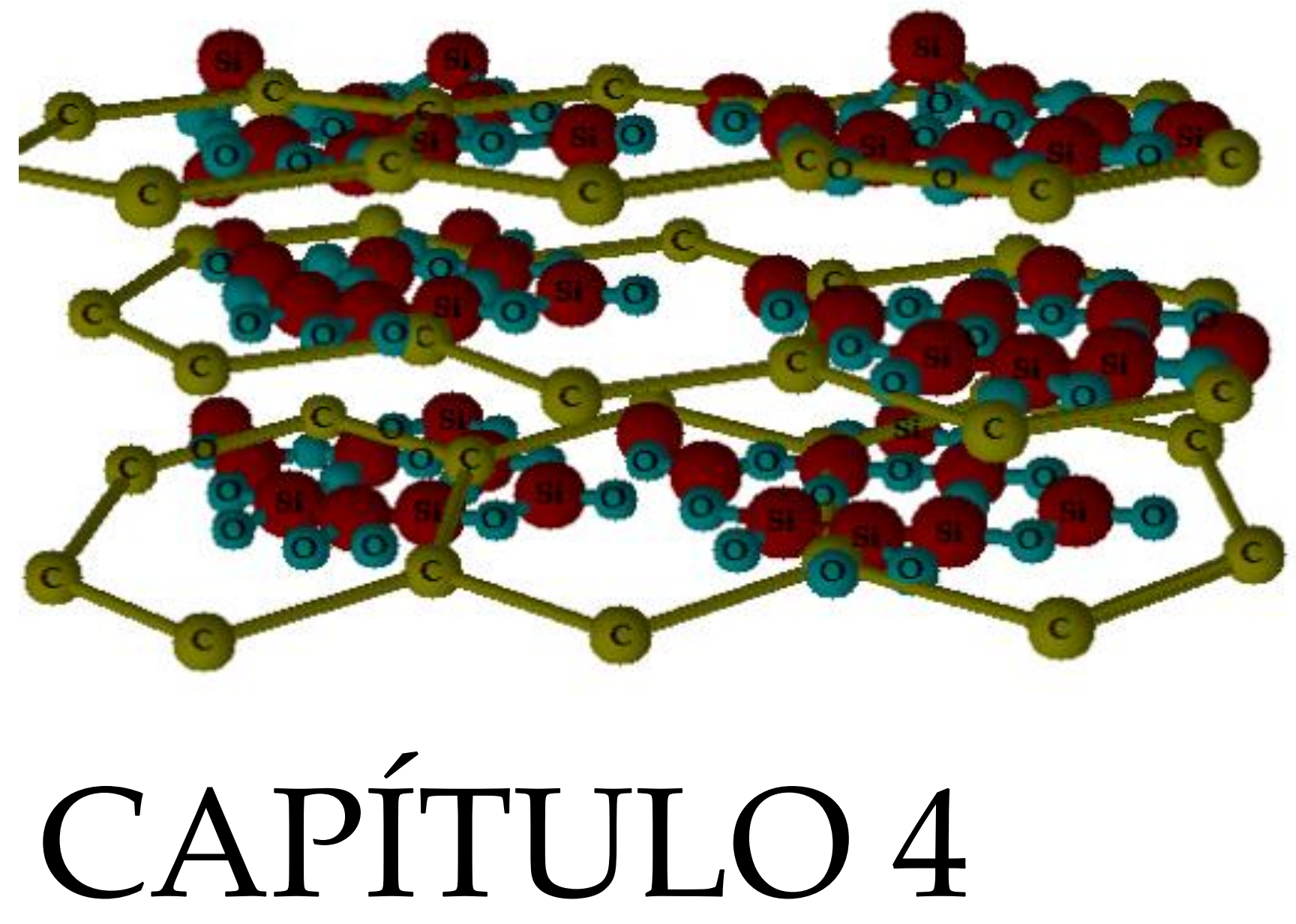

Sintesis y caracterización de los soportes 


\subsection{Introducción}

En la revisión bibliográfica, capítulo 2, queda demostrada la importancia de la estabilidad del soporte en las condiciones de reacción en fase líquida a temperaturas entre 150$260{ }^{\circ} \mathrm{C}$, altas presiones entre $20-80$ bar y la presencia de agua líquida.

En este capítulo se muestran los resultados de la preparación de soportes del tipo silíceos-carbonosos mediante la técnica sol-gel. Esta técnica permite el diseño de estructuras nano y mesoporosas con características texturales controladas, tales como el tamaño y tipo de poros y la superficie específica.

Las propiedades ácido-base del soporte fueron evaluadas empleando varias técnicas que se complementan entre sí: la titulación potenciométrica, la reacción de descomposición de isopropanol y la titulación de Boehm.

Con el objetivo de evaluar la estabilidad de los soportes en las condiciones hidrotérmicas de la reacción de hidrogenólisis en fase líquida, los materiales SC, $\mathrm{C}$ y $\mathrm{SiO}_{2}$ fueron tratados en agua caliente a diferentes temperaturas. Se caracterizaron las muestras de soportes por análisis termogravimétrico (TPO/TGA), análisis térmico diferencial (ATD), adsorción-desorción de $\mathrm{N}_{2}$ (BET), difracción de rayos $\mathrm{X}$ (DRX), espectroscopía de fotoelectrones (XPS) y espectroscopía Raman.

\subsection{Antecedentes sobre estabilidad de soportes}

Los óxidos convencionales $\left(\mathrm{Al}_{2} \mathrm{O}_{3}, \mathrm{SiO}_{2}, \mathrm{ZrO}_{2}, \mathrm{TiO}_{2}\right)$ empleados en las reacciones en fase vapor no son adecuados para reacciones en fase líquida, debido al ataque hidrolítico a estos niveles térmicos. En este sentido, el agua líquida caliente presente en el medio de reacción afecta notablemente la estructura y estabilidad de los catalizadores.

Entre los soportes catalíticos tradicionales, los basados en óxidos de aluminio tales como $\gamma-\mathrm{Al}_{2} \mathrm{O}_{3}$, sufren rehidratación y formación de la fase bohemita entre 200 y $250{ }^{\circ} \mathrm{C}$, lo que genera cambios en las propiedades ácido-base de los catalizadores afectando la selectividad y estabilidad. La transición de fase genera un movimiento a nivel de la partícula metálica que hace perder su interacción con el soporte y lixivia al medio de reacción [1,2]. Similares efectos fueron observados también para $\theta-\mathrm{Al}_{2} \mathrm{O}_{3}$ y $\delta-\mathrm{Al}_{2} \mathrm{O}_{3}$, en donde los catalizadores sufren desactivación en fase líquida debido al sinterizado de las partículas metálicas [3,4].

En el caso de $\mathrm{SiO}_{2}$, el agua puede causar la disociación de los enlaces $\mathrm{Si}-\mathrm{O}-\mathrm{Si}$, lo que eventualmente podría dar lugar a la formación de otra estructura física [5]. Se ha reportado que la superficie específica de la sílice mesoporosa SBA-15 cae de $930 \mathrm{~m}^{2} \cdot \mathrm{g}^{-1}$ a $31 \mathrm{~m}^{2} \cdot \mathrm{g}^{-1}$ luego de un tratamiento en agua líquida a $200{ }^{\circ} \mathrm{C}$ durante $12 \mathrm{~h}$ debido fundamentalmente a un colapso de poros que resulta en la pérdida de su integridad estructural [6,7]. Del mismo modo, otros soportes tipo composito $\mathrm{SiO}_{2}-\mathrm{Al}_{2} \mathrm{O}_{3}$ (SIRALOX 30, SASOL) muestran una pérdida en la superficie específica debido al colapso de poros en agua líquida a $225{ }^{\circ} \mathrm{C}$ y 25 bar [8].

Los soportes carbonosos, por su parte, han mostrado mejores comportamientos debido a las características hidrofóbicas del carbón que protege a los sitios activos del catalizador evitando el efecto del agua [9]. En este sentido, el empleo de carbones activados como soportes catalíticos presentan varias ventajas como su alta superficie específica, necesaria para lograr 
una buena dispersión de la fase activa. Sin embargo, estos materiales presentan también ciertas desventajas debido a la baja interacción metal-soporte, y a la presencia de microporos que causa problemas difusionales tanto para la deposición de la fase activa como para el acceso de los reactivos al interior de los poros [10,11].

\subsection{Síntesis de los soportes}

En este trabajo de tesis se prepararon soportes del tipo silíceos-carbonosos mediante la técnica sol-gel. Esta técnica permite el diseño de estructuras nano y mesoporosas con características texturales controladas, tales como el tamaño y tipo de poros y la superficie específica. En los últimos años la técnica ha ganado un amplio interés debido a las múltiples aplicaciones tecnológicas en las que participan estos materiales. Varios trabajos han publicado información acerca de compuestos silíceos del tipo micro y mesoporosos generados por la gelificación del TEOS (tetraetoxisilano) en presencia de distintos tipos de surfactantes y distintas condiciones experimentales [12]. La propiedad gelificante del TEOS (tetraetoxisilano) fue utilizada en un medio alcohólico (Etanol al 96 \% p/p, Anedra) para incluir en su estructura una resina fenólica (RL 43003, Atanor). Con el curado y pirólisis en ausencia de oxígeno, esta resina deja una cantidad apreciable de carbono residual. A este material se lo denomina sílicecarbón (SC). A partir del soporte de SC se obtuvo otro soporte, denominado C, por tratamiento del SC con ácido fluorhídrico.

Los detalles de las preparaciones se encuentran en el capítulo 3 (materiales, equipos y técnicas experimentales).

También fue incluido un soporte comercial de $\mathrm{SiO}_{2}$ (AEROSIL 200, Evonik Industries, Hanau-Wolfgang, Alemania) con fines comparativos.

\subsection{Caracterización de los soportes}

\subsubsection{Análisis termogravimétrico (TGA)}

El contenido de sílice y carbón en los soportes denominados SC y C fue determinado a partir de la pérdida de peso producido por oxidación de los soportes seguido de un análisis termogravimétrico (TPO/TGA).

La Tabla 1-4 muestra los resultados obtenidos para el análisis termogravimétrico de cada una de las muestras.

Tabla 1-4. Pérdida de peso de los soportes sílice-carbonosos.

\begin{tabular}{lccc}
\hline \multirow{2}{*}{ Soporte } & \multirow{2}{*}{ Pérdida de peso $(\%)$} & \multicolumn{2}{c}{ Relaciones másicas } \\
\cline { 3 - 4 } & & $\mathrm{Si} / \mathrm{C}$ & $\mathrm{C} / \mathrm{Si}$ \\
\hline SC & 33 & 0.95 & 1.06 \\
$\mathrm{C}$ & 68 & 0.15 & 6.79 \\
\hline
\end{tabular}


A partir de la Tabla 1-4 es posible observar que SC posee una relación de Si/C cercana a 1, mientras que el C posee una relación Si/C igual a 0.15. Como se indicó en el capítulo 3, el soporte de C se obtiene a partir del tratamiento de SC con HF. Debido a este tratamiento el contenido de $\mathrm{Si}$ es menor en este material e indicaría que el HF no eliminó completamente el Si.

Para el soporte de SC se realizó el análisis termogravimétrico (TGA) en atmósfera oxidante al $10 \%$ de $\mathrm{O}_{2}$ y en atmósfera inerte de Ar. Los resultados se muestran en la Figura 14. Como es posible observar, en atmósfera oxidante la descomposición del soporte comienza a $550{ }^{\circ} \mathrm{C}$ aproximadamente, mientras que en atmósfera inerte de Ar la descomposición comienza a los $580^{\circ} \mathrm{C}$.

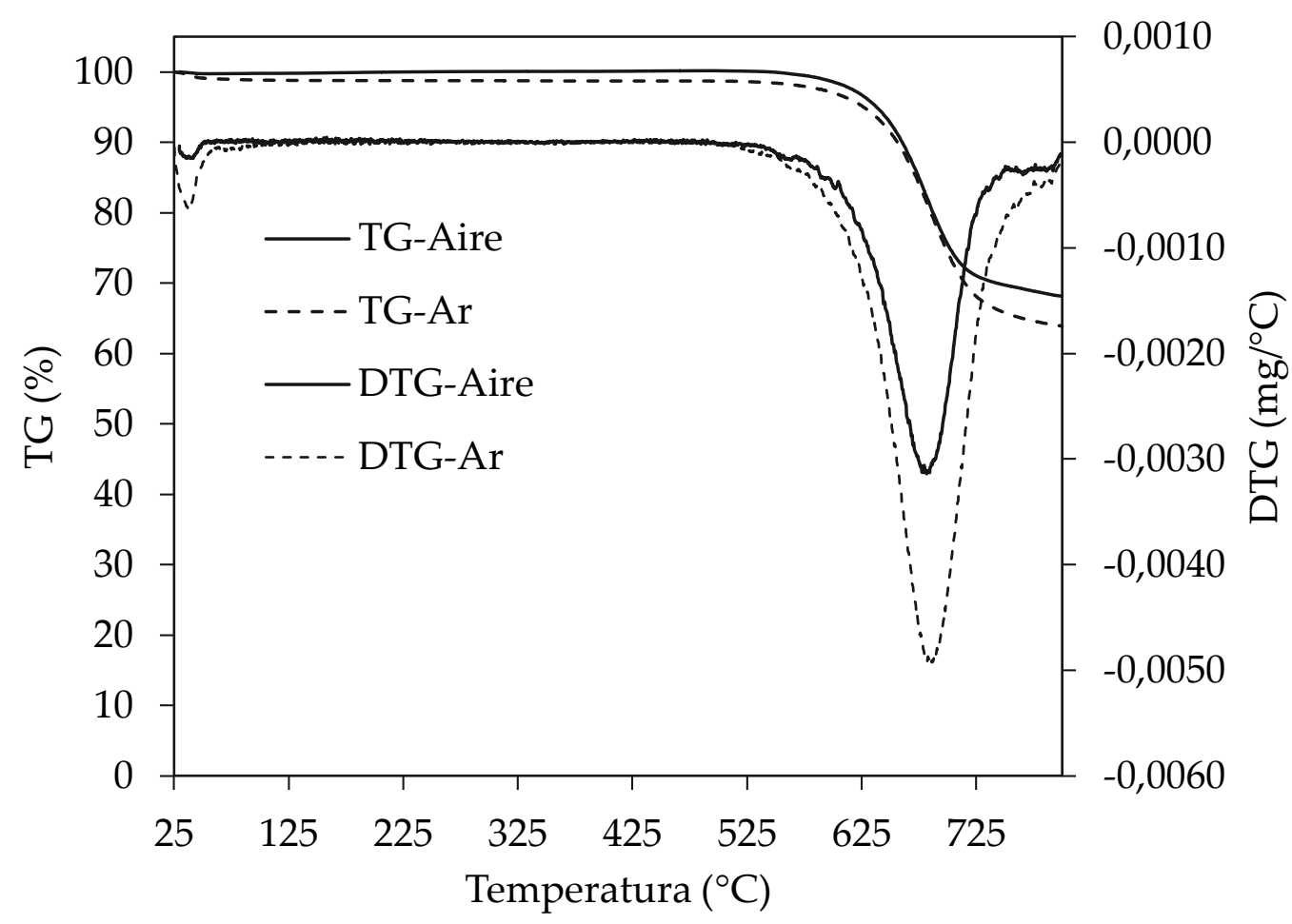

Figura 1-4. Análisis termogravimétricos en atmósfera oxidante e inerte para SC.

\subsubsection{Adsorción-desorción de $\mathrm{N}_{2}$ (BET)}

Las isotermas de adsorción-desorción de nitrógeno obtenidas para los soportes SC, C y $\mathrm{SiO}_{2}$ (Figura 2-4) resultan ser del tipo IV acorde a la clasificación de la IUPAC, indicando que la adsorción del nitrógeno ocurre en multicapas [13]. Además, las isotermas presentan un lazo de histéresis del tipo $\mathrm{H} 3$ a presiones relativas $(\mathrm{P} / \mathrm{Po})$ que van desde 0.45 a 0.98 . Este lazo es característico de materiales micro y mesoporosos y su forma indica que la forma de los poros es del tipo slit (rendija) [14].

La Tabla 2-4 muestra los resultados de superficie específica BET, volumen total de poro y los mismos parámetros para los micro y mesoporos de los soportes.

El soporte de SC presenta una superficie específica del orden de los $200 \mathrm{~m}^{2} \cdot \mathrm{g}^{-1}$ y es principalmente mesoporoso. 
El soporte de C presenta una superficie específica del orden de los $678 \mathrm{~m}^{2} \cdot \mathrm{g}^{-1} \mathrm{y}$ posee una gran contribución de microporos, que podrían haberse generado debido al tratamiento con HF. Un efecto similar ha sido observado en tratamientos ácidos de funcionalización de carbones activados con $\mathrm{HNO}_{3}$ [15].
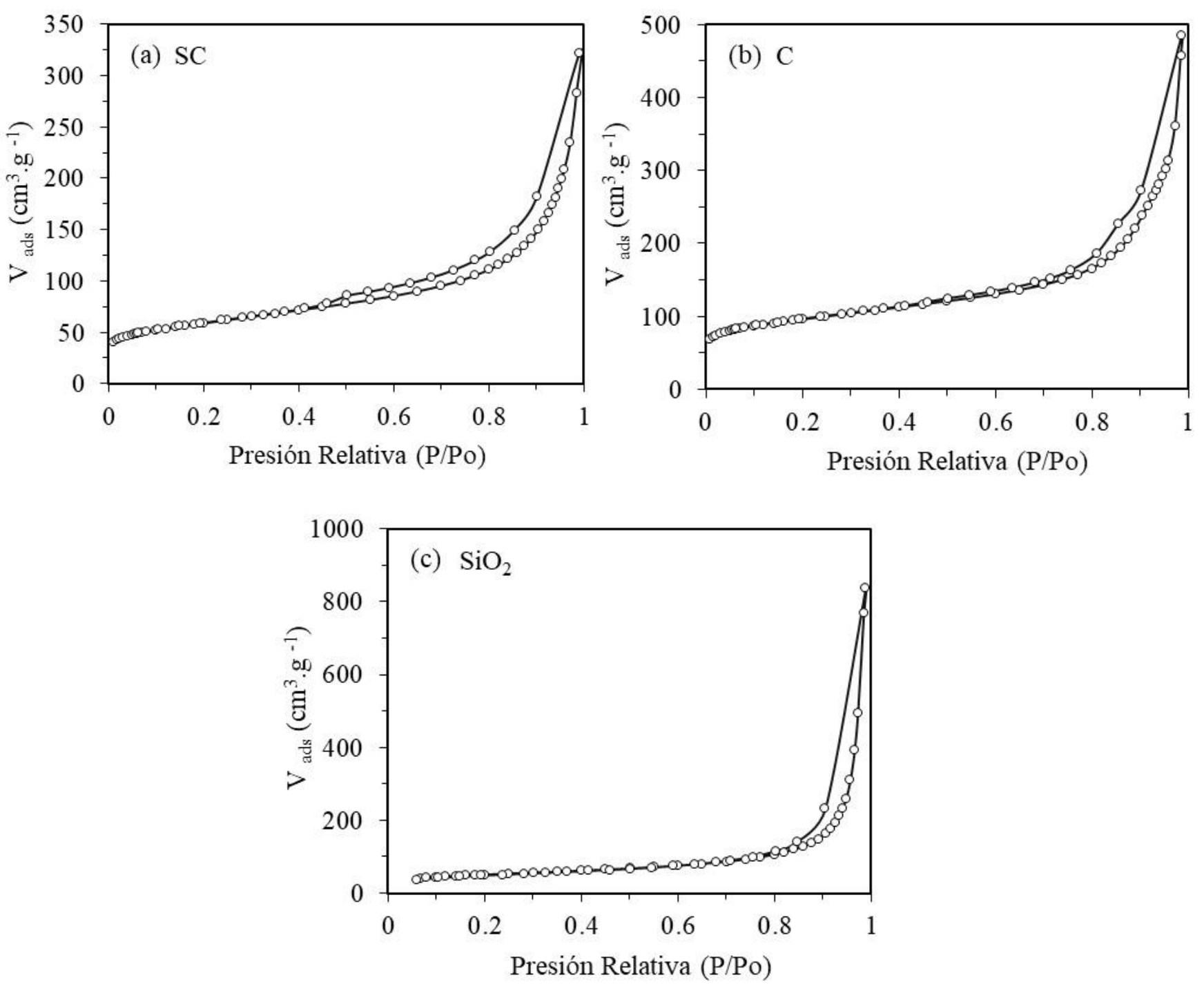

Figura 2-4. Isotermas de adsorción-desorción de $\mathrm{N}_{2}$ para los soportes (a) SC, (b) C y (c) $\mathrm{SiO}_{2}$.

Tabla 2-4. Propiedades texturales de los soportes $\mathrm{SiO}_{2}-\mathrm{C}, \mathrm{C}$ y $\mathrm{SiO}_{2}$.

\begin{tabular}{lcccccc}
\hline \multirow{2}{*}{ Soporte } & \multirow{2}{*}{$\mathrm{S}_{\mathrm{BET}}{ }^{\mathbf{a}}$} & \multirow{2}{*}{$\mathrm{V}_{\mathbf{p}^{\mathbf{b}}}$} & \multicolumn{2}{c}{ Microporos } & \multicolumn{2}{c}{ Mesoporos } \\
& & $\mathrm{S}_{\text {micro }}{ }^{\mathbf{c}}$ & $\mathrm{V}_{\text {micro }}{ }^{\mathbf{c}}$ & Smeso $^{\mathbf{d}}$ & $\mathrm{V}_{\text {meso }}{ }^{\mathbf{d}}$ \\
\hline $\mathrm{SC}$ & 204 & 0.28 & 34 & 0.02 & 170 & 0.26 \\
\hline $\mathrm{C}$ & 678 & 1.42 & 257 & 0.11 & 421 & 1.31 \\
\hline $\mathrm{SiO}_{2}$ & 180 & 0.76 & 35 & 0.01 & 145 & 0.66 \\
\hline
\end{tabular}

a Superficie específica $\left(\mathrm{m}^{2} \cdot \mathrm{g}^{-1}\right)$

b Volumen total de poros $\left(\mathrm{cm}^{3} \cdot \mathrm{g}^{-1}\right)$

c Superficie específica $\left(\mathrm{m}^{2} \cdot \mathrm{g}^{-1}\right)$ y volumen total de microporos $\left(\mathrm{cm}^{3} \cdot \mathrm{g}^{-1}\right)$

d Superficie específica $\left(\mathrm{m}^{2} \cdot \mathrm{g}^{-1}\right)$ y volumen total de mesoporos $\left(\mathrm{cm}^{3} \cdot \mathrm{g}^{-1}\right)$ 


\subsubsection{Difracción de rayos $X(D R X)$}

La Figura 3-4 muestra los difractogramas de rayos $\mathrm{X}$ de los soportes SC, $\mathrm{C}$ y SiO2.

A partir de los mismos es posible visualizar prácticamente los mismos picos para las muestras de SC y C. La presencia de una banda entre $2 \theta=15$ y $30^{\circ}$ indica la presencia de sílice amorfa $[15,16]$, que es también la banda encontrada para el soporte comercial de $\mathrm{SiO}_{2}$. La señal a $2 \theta=43.7^{\circ}$ corresponde al plano $\left(\begin{array}{lll}1 & 0 & 0\end{array}\right)$ de la fase hexagonal de carbono grafito $(\circ)[12,16]$. Los picos característicos que se observan a $2 \theta=21.8^{\circ}, 26.4^{\circ}, 35.7^{\circ}, 41.4^{\circ}, 60.0^{\circ}$ y $71.9^{\circ}$, corresponden

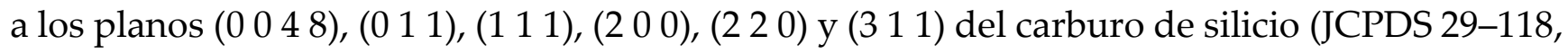
JCPDS 29-129) [17,18].

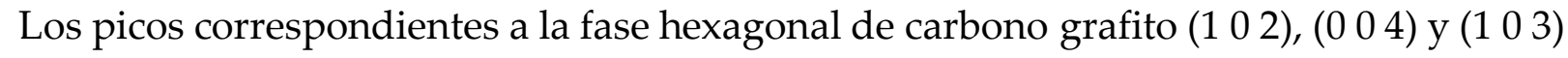
a $2 \theta=51^{\circ}, 54.5^{\circ}$ y $59^{\circ}$ respectivamente, no pueden ser distinguidos en los difractogramas. Esto podría deberse a la formación de carbono turbostrático. En la literatura se ha reportado que el carbono turbostrático es una forma de carbono grafito cuyos planos estructurales están rotados y trasladados respecto de su conformación normal. La presencia de carbono turbostrático provoca un corrimiento de los picos del carbono grafito a menores valores de $2 \theta \mathrm{y}$, en este caso, se solaparían con la banda de la sílice amorfa [19].

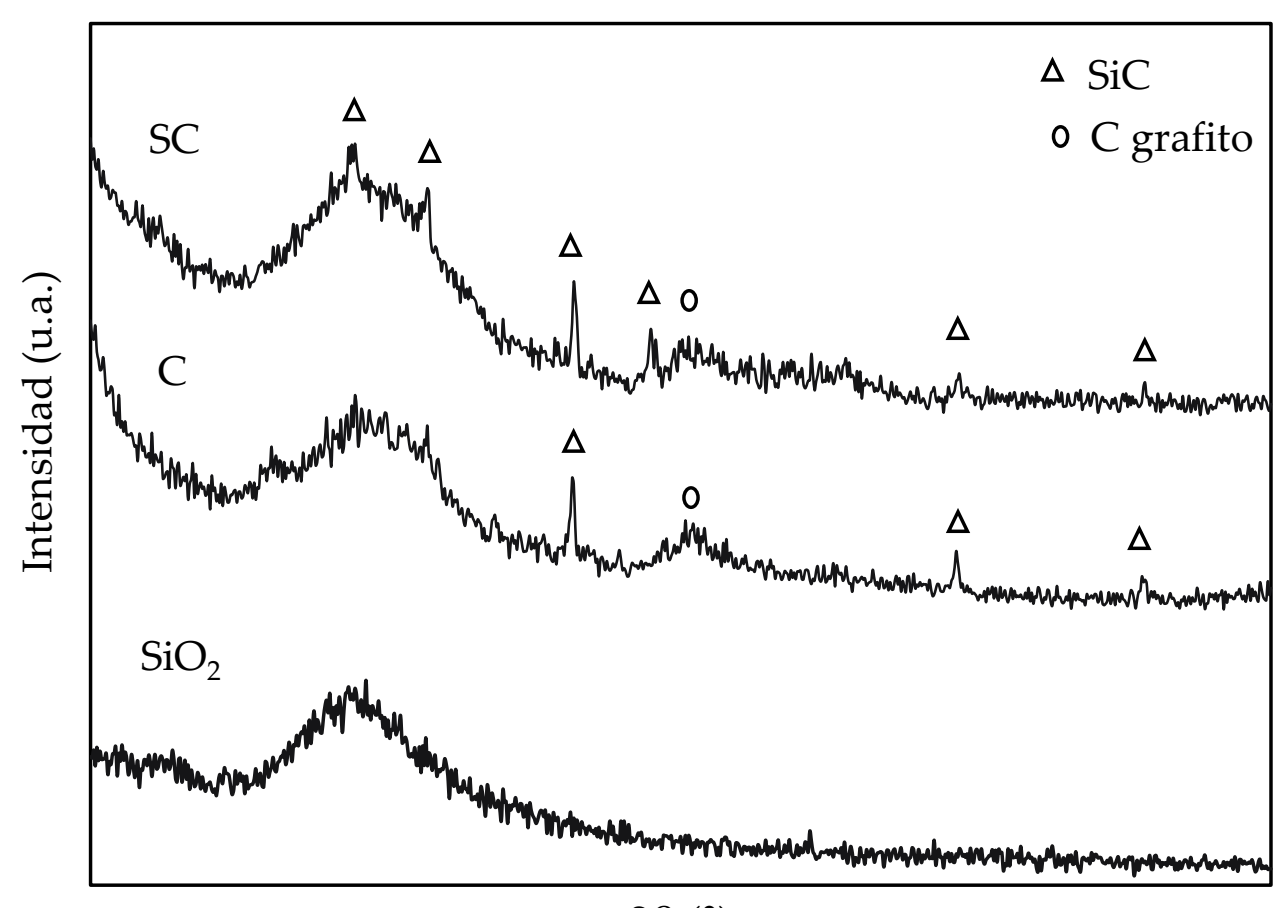

$2 \theta\left(^{\circ}\right)$

Figura 3-4. Difractogramas de rayos X para los soportes SC, C y $\mathrm{SiO}_{2}$.

\subsubsection{Espectroscopía de infrarrojo (IR)}

La presencia de grupos superficiales oxigenados tales como funciones carboxílicas, carbonilos, aldehídos y cetonas, así como la presencia de enlaces $\mathrm{Si}-\mathrm{O}$ fue analizada mediante la técnica de espectroscopía de infrarrojo (IR).

Los espectros IR de los soportes (Figura 4-4) presentan tres picos bien definidos en la zona de la huella digital del espectro. A $470 \mathrm{~cm}^{-1}$ corresponde la vibración de la unión Si-O-Si, 
a $810 \mathrm{~cm}^{-1}$ corresponde la vibración simétrica de la unión Si-O y finalmente la banda centrada en $1100 \mathrm{~cm}^{-1}$, es característica de la vibración asimétrica de la unión Si-O [20-22]. Los soportes de C y SC presentan espectros similares, ambos muestran un pico correspondiente a la vibración característica del grupo alcoxi, C-O, que se ubica entre 1000 y $1150 \mathrm{~cm}^{-1}$, y un pequeño pico a $1560 \mathrm{~cm}^{-1}$, correspondiente a la vibración del grupo alqueno, $C=C$ [23]. A frecuencias más altas, en la banda que corresponde a 3300-3600 cm-1 y centrado en los $3400 \mathrm{~cm}^{-1}$, se encuentra la vibración de los grupos oxhidrilo, $-\mathrm{OH}[23]$.

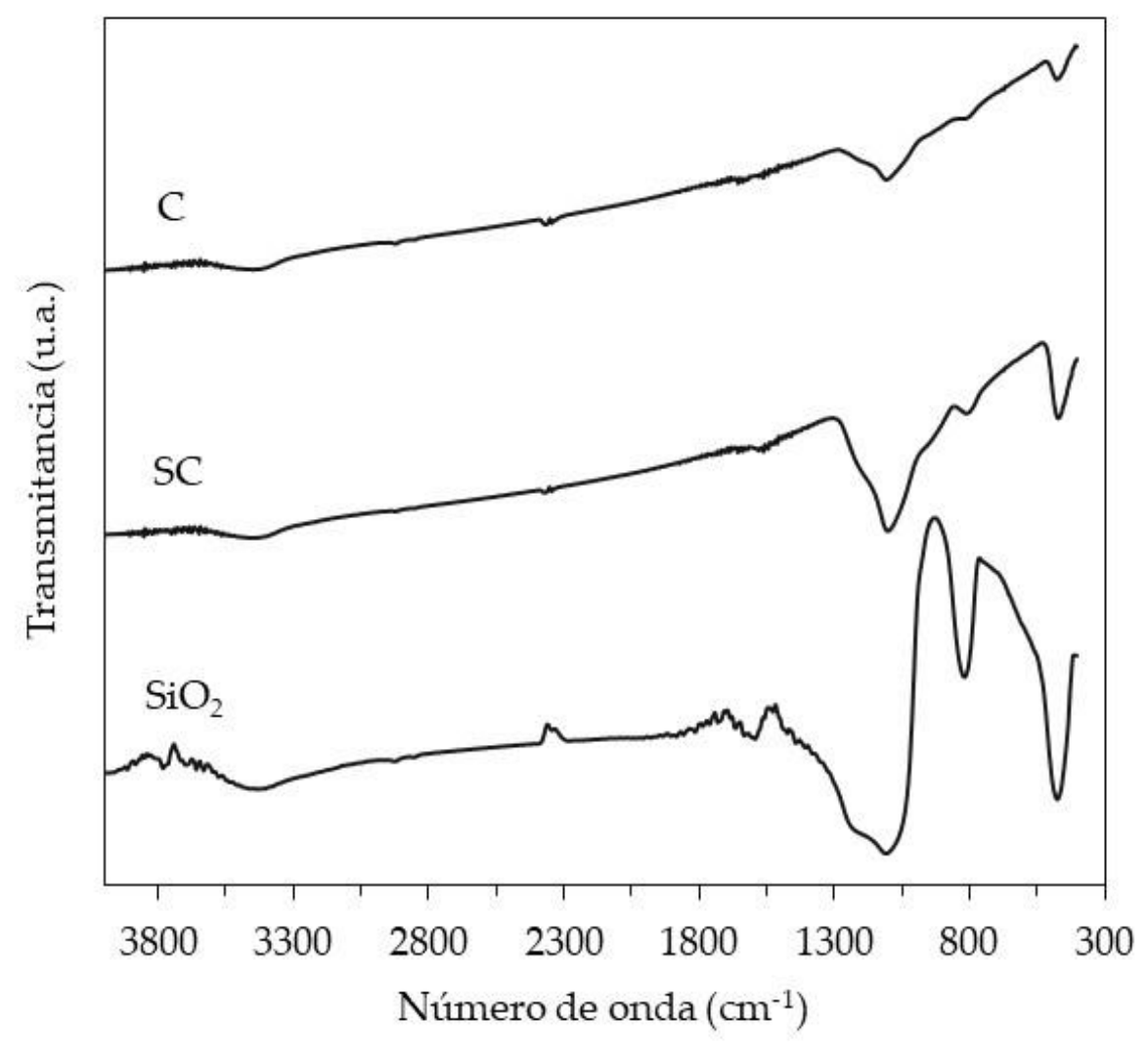

Figura 4-4. Espectros IR para los soportes SC, C y SiO2.

\subsubsection{Titulación potenciométrica}

Las propiedades ácido-base del soporte fueron evaluadas empleando varias técnicas que se complementan entre sí: la titulación potenciométrica, la reacción de descomposición de isopropanol y la titulación de Boehm.

En este apartado se presentan los resultados de titulación potenciométrica con nbutilamina para los soportes de $\mathrm{SC}, \mathrm{C}$ y SiO 2 . El procedimiento para efectuar las titulaciones se indica en el capítulo 3 (materiales, equipos y técnicas experimentales).

La Figura 5-4 muestra las curvas de titulación potenciométrica para los tres soportes. 


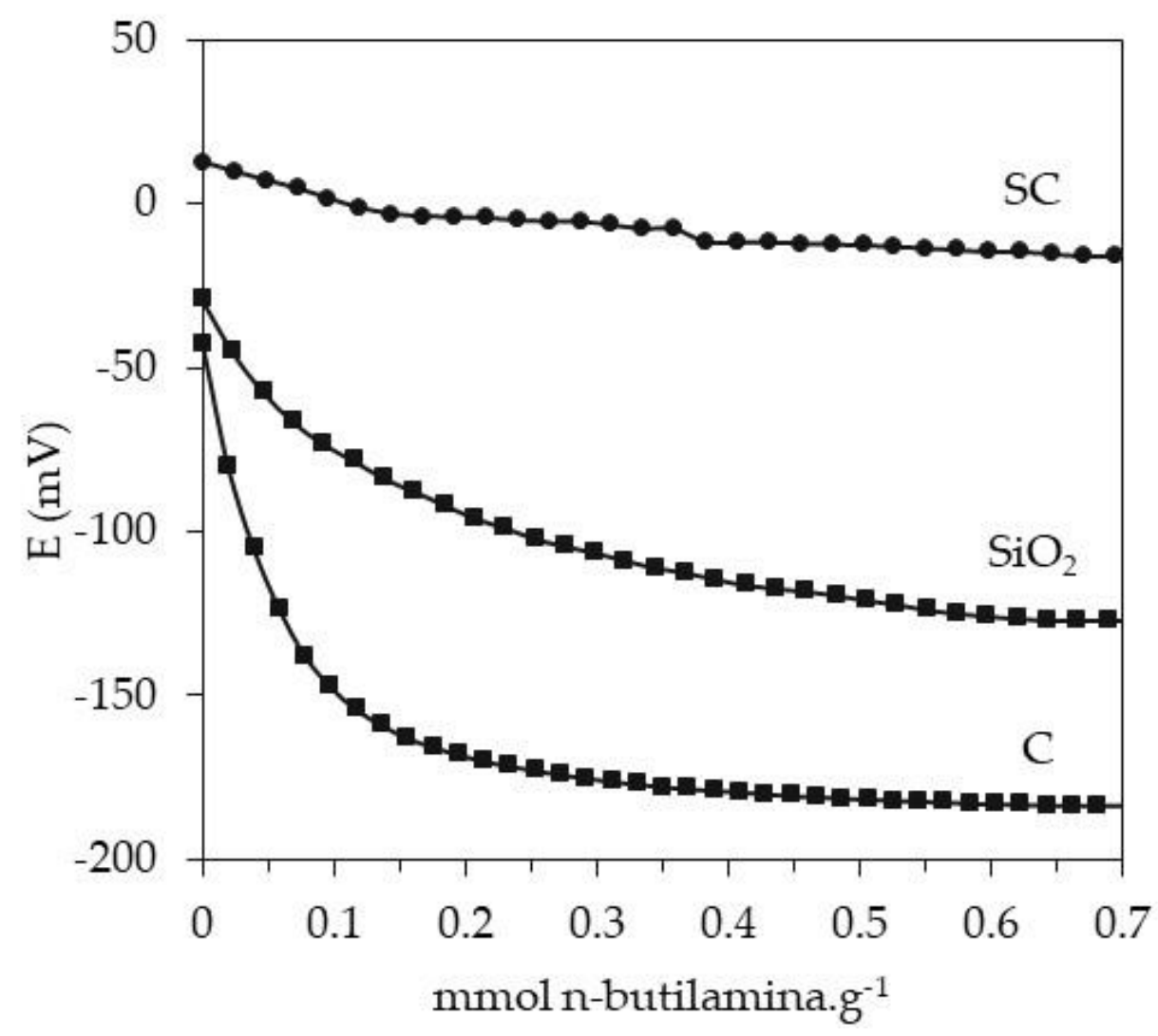

Figura 5-4. Curvas de titulación potenciométrica para los soportes SC, C y SiOz.

La Tabla 3-4 muestra los valores de potencial inicial $\left(E_{i}\right)$ para cada uno de los soportes y la fuerza ácida de los sitios según este valor. Además, se presenta el número total de sitios (NS) para cada una de las muestras.

Tabla 3-4. Número y tipo de sitios ácidos para los soportes SC, C y SiO2.

\begin{tabular}{cccc}
\hline Soporte & $\mathrm{E}_{\mathrm{i}}(\mathrm{mV})$ & Fuerza de los sitios & $\mathrm{NS}\left(\mathrm{mmol} . \mathrm{g}^{-1}\right)$ \\
\hline $\mathrm{SC}$ & 12.6 & Fuertes & 0.18 \\
$\mathrm{SiO}_{2}$ & -28.9 & Débiles & 0.14 \\
$\mathrm{C}$ & -42.7 & Débiles & 0.40 \\
\hline
\end{tabular}

Los resultados de la Tabla 3-4 indican que el soporte de SC posee sitios de naturaleza ácida más fuertes que los de los soportes de $\mathrm{C}$ y SiO 2 . Además, según el número total de sitios NS obtenidos, el soporte de $\mathrm{C}$ posee el mayor número de sitios ácidos débiles.

\subsubsection{Reacción test de descomposición de isopropanol (IPA)}

La reacción test de descomposición de isopropanol (IPA) fue empleada como técnica complementaria para caracterizar la acidez de los soportes. Esta técnica permite de forma indirecta determinar la acidez de sólidos. Los fundamentos de la técnica y condiciones experimentales se describen en el capítulo 3 (materiales, equipos y técnicas experimentales). 
La Tabla 4-4 muestra los resultados de la reacción de descomposición de IPA para una iso-conversión de IPA del $6 \%$ para todos los soportes.

Tabla 4-4. Resultados de la reacción de descomposición de isopropanol (IPA).

\begin{tabular}{cccc}
\hline $\mathrm{X}_{\mathrm{T}}(\%)=6$ & $\mathrm{SiO}_{2}$ & $\mathrm{C}$ & $\mathrm{SC}$ \\
\hline $\mathrm{T}\left({ }^{\circ} \mathrm{C}\right)$ & 260 & 220 & 260 \\
Spropileno $(\%)$ & 7 & 86 & 51 \\
Sacetona $(\%)$ & 93 & 9 & 47 \\
SDIPE $(\%)$ & 0 & 5 & 2 \\
\hline
\end{tabular}

Los resultados indican que, el C es el más activo para la reacción de descomposición de IPA, puesto que alcanza la conversión del $6 \%$ a la menor temperatura: $220{ }^{\circ} \mathrm{C}$. Esto sugiere que el $\mathrm{C}$ posee el mayor número de sitios activos superficiales, resultado que coincide con el obtenido por titulación potenciométrica.

Con respecto al tipo de sitios, el soporte SC posee una selectividad a propileno y acetona muy similar, lo que indica la presencia de sitios ácidos débiles de Lewis.

La alta selectividad a propileno obtenida con el soporte $C$ indica la contribución de sitios ácidos fuertes del tipo Lewis o Brønsted. La presencia de di-isopropil éter (DIPE) en pequeñas cantidades indica una baja concentración de sitios ácidos fuertes de Lewis.

El soporte de $\mathrm{SiO}_{2}$ posee una alta selectividad a acetona, lo que indicaría la presencia de sitios básicos de Lewis.

\subsubsection{Titulación de Bohem}

La técnica de titulación de Bohem, aplicable a materiales del tipo carbonosos, permite la identificación y cuantificación de grupos superficiales oxigenados, principalmente funciones de ácidos carboxílicos, lactonas y fenoles [24,25]. La técnica se basa en tratar muestras sólidas carbonosas con diferentes soluciones alcalinas con el objetivo de neutralizar selectivamente los grupos superficiales oxigenados. Esta técnica asume que los grupos carboxílicos son neutralizados con una base débil como $\mathrm{NaHCO}_{3}$, mientras que bases más fuertes como $\mathrm{Na}_{2} \mathrm{CO}_{3}$ neutralizan tanto grupos carboxílicos como grupos lactónicos. Cuando se emplea $\mathrm{NaOH}$, todos los grupos oxigenados son neutralizados, incluyendo los grupos carboxílicos, lactónicos y fenólicos.

Por titulación es posible obtener las cantidades de cada uno de los grupos superficiales oxigenados que forman parte de un sólido carbonoso.

Cuando se emplea $\mathrm{HCl}$ en lugar de $\mathrm{NaOH}$, mediante un procedimiento de titulación análogo, es posible calcular la concentración de sitios ácidos del material, aunque la diferenciación de los distintos sitios básicos no ha sido reportada aun en la literatura [26,27].

La forma de llevar a cabo la técnica se describe en el capítulo 3 (materiales, equipos y técnicas experimentales).

Los resultados de la titulación para los soportes SC y C se muestran en la Tabla 5-4. 
Tabla 5-4. Resultados de la titulación de Bohem para los soportes SC y C.

\begin{tabular}{|c|c|c|c|c|c|}
\hline \multirow[b]{2}{*}{ Soporte } & \multicolumn{3}{|c|}{ Grupos superficiales ácidos $\left.\left(\mathrm{mmol}^{-1}\right)^{-1}\right)$} & \multirow{2}{*}{$\begin{array}{l}\text { Acidez total } \\
\left(\mathrm{mmol}^{\left.-\mathrm{g}^{-1}\right)}\right.\end{array}$} & \multirow{2}{*}{$\begin{array}{l}\text { Basicidad total } \\
\left(\mathrm{mmol.g}^{-1}\right)\end{array}$} \\
\hline & $\begin{array}{c}\text { Carboxílicos } \\
\mathrm{O}=\mathrm{C}-\mathrm{OH}\end{array}$ & $\begin{array}{c}\text { Lactónicos } \\
\mathrm{O}=\mathrm{C}-\mathrm{O}\end{array}$ & $\begin{array}{c}\text { Fenólicos } \\
\text {-C-OH }\end{array}$ & & \\
\hline SC & 0.2200 & 0.0040 & 0.0340 & 0.2580 & 0.0580 \\
\hline $\mathrm{C}$ & 0.1770 & 0.0190 & 0.1060 & 0.3020 & 0.0180 \\
\hline
\end{tabular}

A partir de la Tabla 5-4 es posible observar que la acidez total del soporte $C$ es mayor que el soporte SC, en concordancia con los resultados de titulación potenciométrica y descomposición de IPA. Con respecto a los grupos superficiales oxigenados, la presencia de grupos carboxílicos es ligeramente mayor para el soporte de SC, mientras que la presencia de grupos lactónicos y fenólicos es mayor para el soporte de $\mathrm{C}$.

Con respecto a la basicidad, el soporte de SC muestra un mayor contenido de sitios básicos, que estarían compuestos por grupos pirona y quinona [26,28]. Este resultado coincide con la mayor selectividad a acetona obtenida en la reacción de descomposición de IPA.

\subsubsection{Microscopia de barrido electrónico (SEM)}

Para los soportes SC y C se presentan las micrografías de barrido electrónico (SEM) en la Figura 6-4.

Para ambos soportes (Figura 6-4 a y b) es posible observar la presencia de estructuras de gran tamaño con defectos como rajaduras e imperfecciones superficiales. Al aumentar la magnificación se observa una estructura con partículas del tipo esféricas.
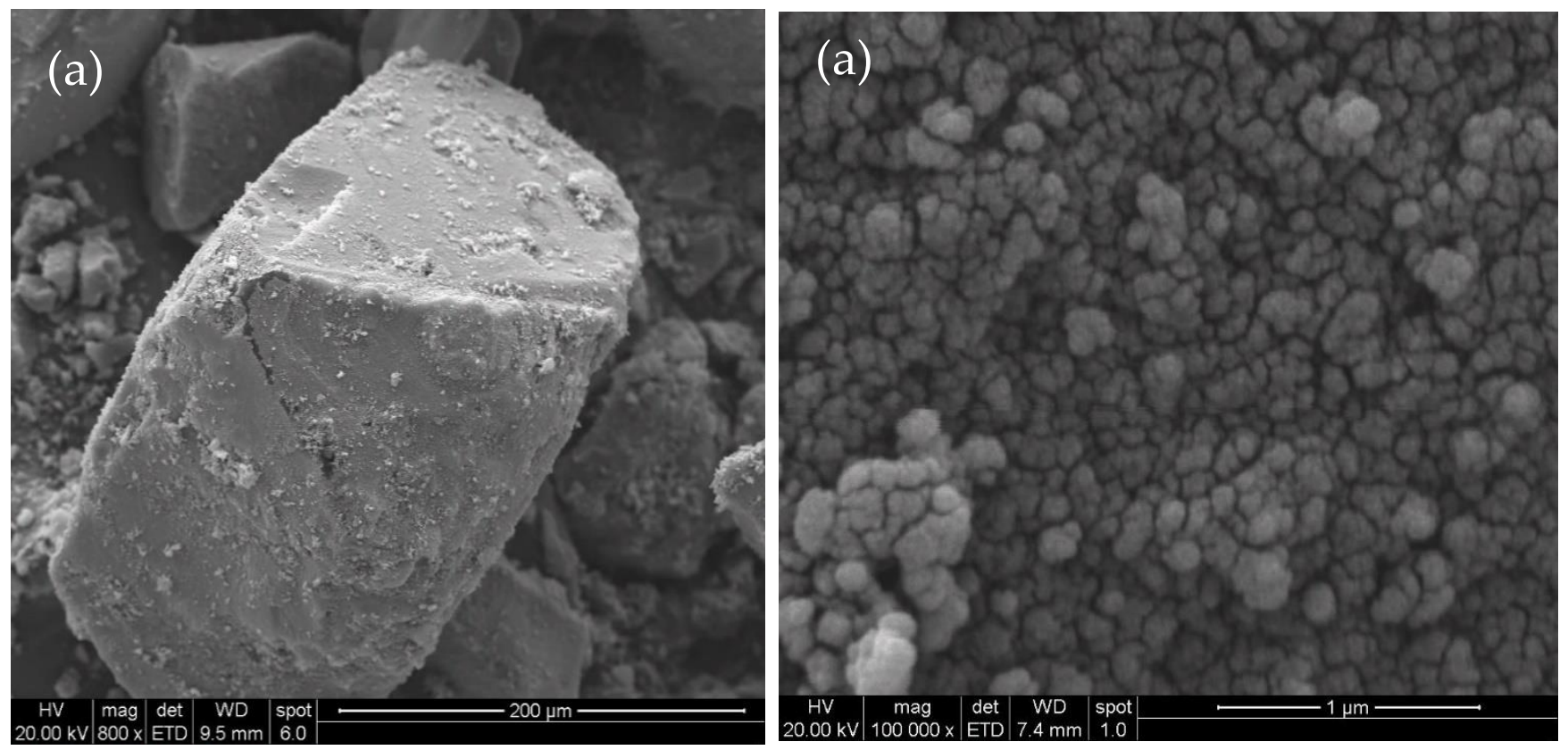

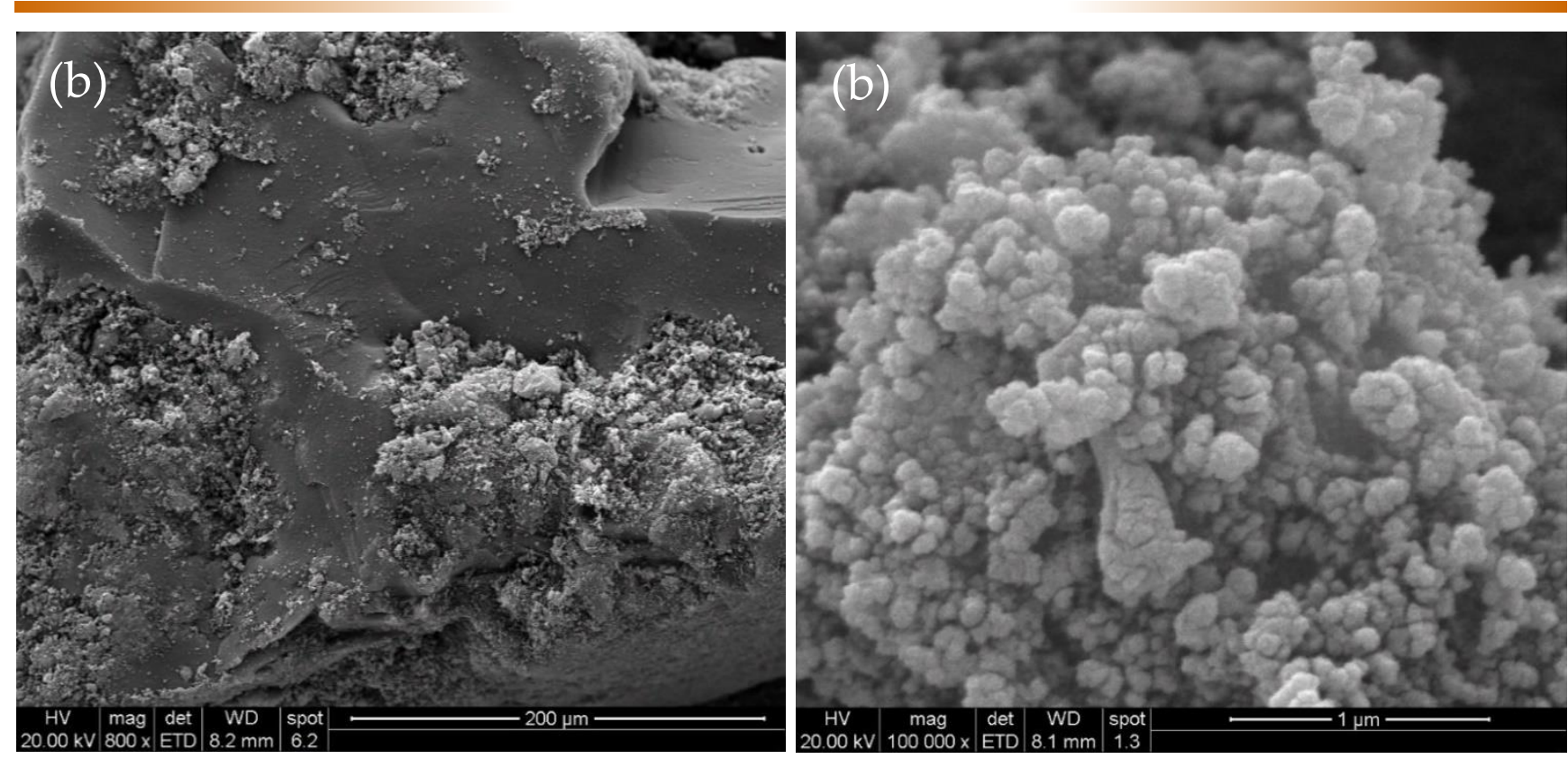

Figura 6-4. Micrografías de barrido electrónico (SEM) para los soportes (a) SC (b) C, contemplando dos magnificaciones (800 x $200 \mu \mathrm{m}$ y $100000 \times 1 \mu \mathrm{m})$.no para la primera

Se efectuó un análisis semicuantitativo de los soportes por EDAX, permitiendo identificar los elementos presentes en ambos soportes (Figura 7-4). En ambos casos los elementos identificados fueron Si y C. La presencia de Au en el análisis EDAX se debe al recubrimiento externo necesario por tratarse de muestras no conductoras. El elemento $\mathrm{O}$ no fue tenido en cuenta para la cuantificación.

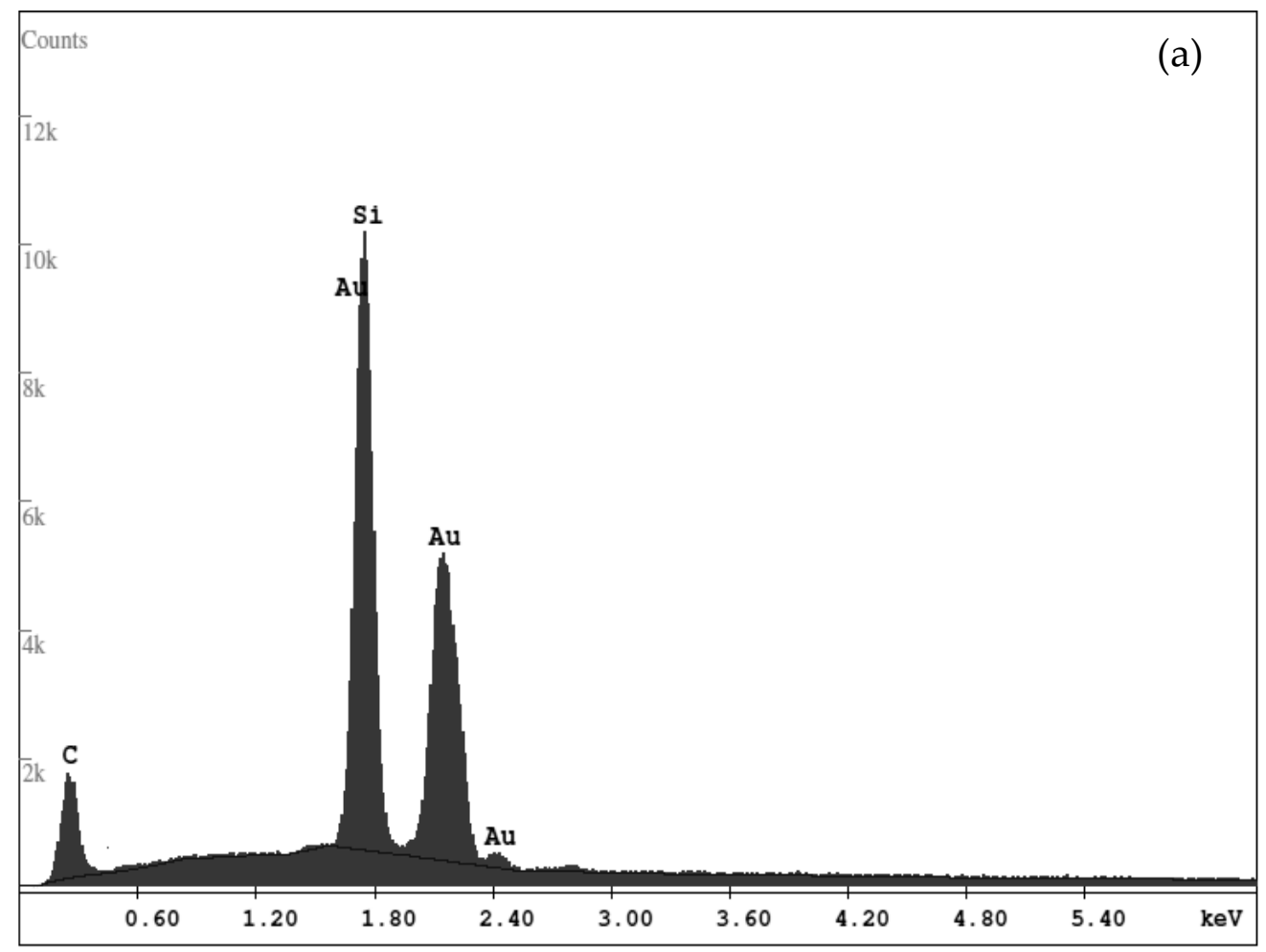




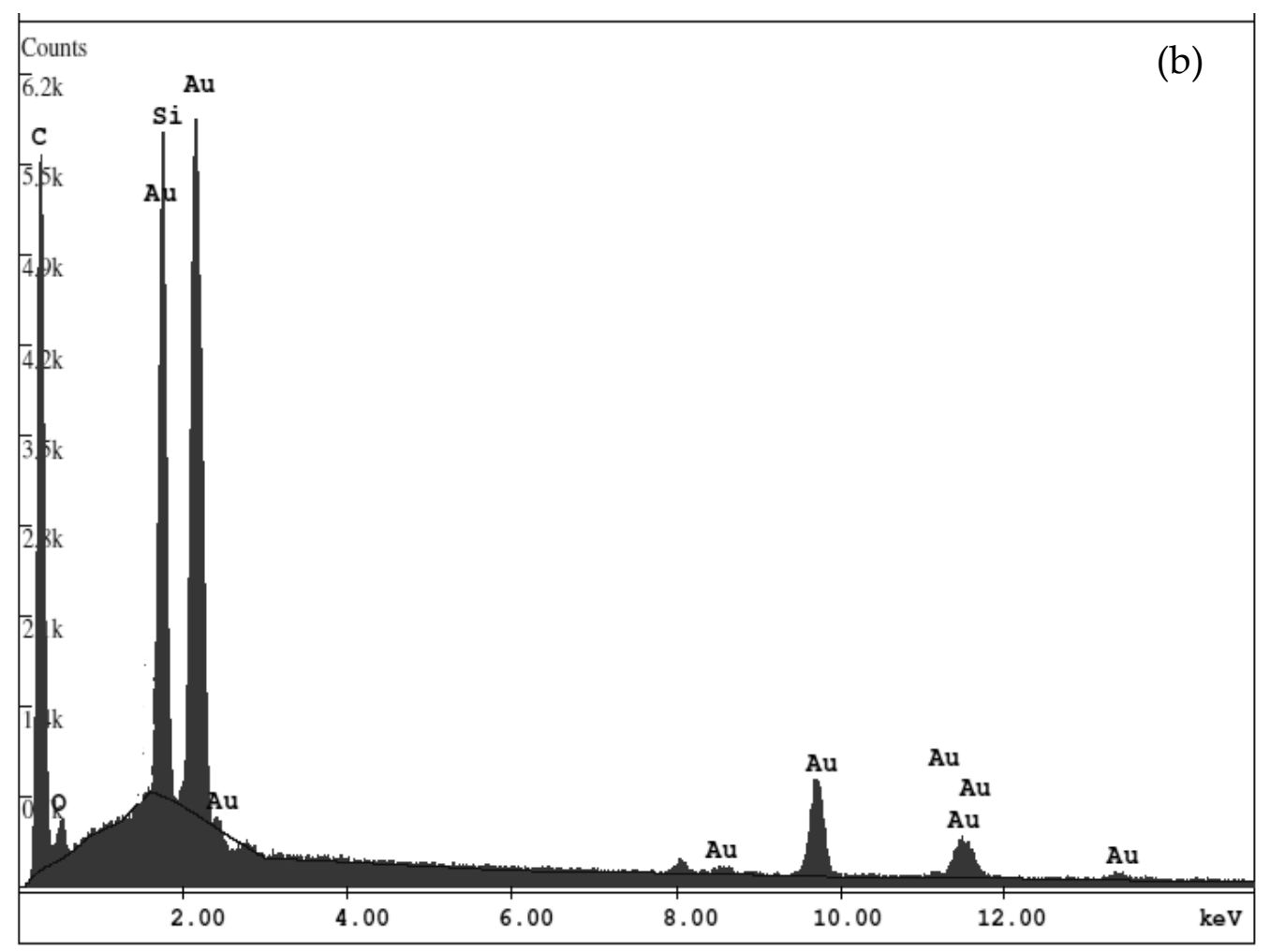

Figura 7-4. Identificación de los elementos presentes en los soportes (a) SC (b) C.

La Tabla 6-4 muestra la relación atómica Si/C y C/Si en estos materiales. Como se puede observar, los valores obtenidos en cada caso son muy similares a los valores obtenidos con el análisis termogravimétrico (TGA).

Tabla 6-4. Composición y relaciones entre elementos obtenidos por EDAX para los soportes SC y C.

\begin{tabular}{cccccc}
\hline \multirow{2}{*}{ Soporte } & \multicolumn{3}{c}{ Composición química } & \multicolumn{2}{c}{ Relaciones másicas } \\
\cline { 2 - 6 } & Elemento & $\% \mathrm{p} / \mathrm{p}$ & \%atómico & $\mathrm{Si} / \mathrm{C}$ & $\mathrm{C} / \mathrm{Si}$ \\
\hline \multirow{2}{*}{$\mathrm{SC}$} & $\mathrm{Si}$ & 49 & 71 & 0.96 & \multirow{2}{*}{1.04} \\
& $\mathrm{C}$ & 51 & 29 & & \\
\hline \multirow{2}{*}{$\mathrm{C}$} & $\mathrm{Si}$ & 17 & 8 & 0.19 & \multirow{2}{*}{5.26} \\
\hline
\end{tabular}

\subsubsection{Microscopía de transmisión electrónica (TEM)}

Las micrografías de transmisión electrónica de los soportes se muestran en la Figura 84, y permite tener una referencia al momento de determinar tamaños de partículas metálicas de los catalizadores que serán preparados. 

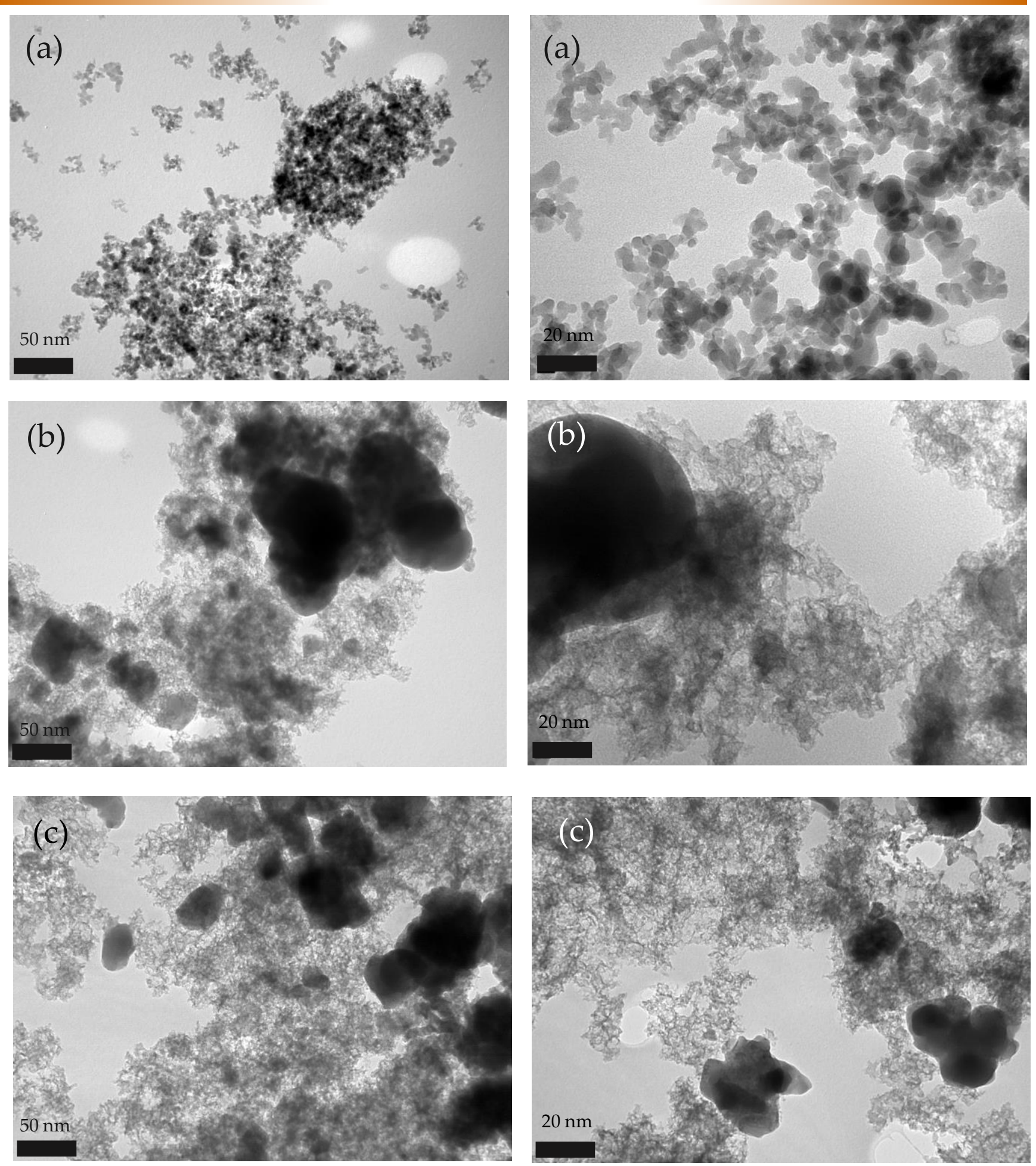

Figura 8-4. Micrografías de transmisión electrónica de los soportes (a) $\mathrm{SiO}_{2}$ (b) SC (c) C.

\subsection{Estabilidad de los soportes}

Con el objetivo de evaluar la estabilidad de los soportes en las condiciones hidrotérmicas de la reacción de hidrogenólisis en fase líquida, los materiales $\mathrm{SC}, \mathrm{C}$ y $\mathrm{SiO}_{2}$ fueron tratados en agua caliente a temperaturas de 150,200 y $250{ }^{\circ} \mathrm{C}$ durante $24 \mathrm{~h}$ en atmósfera de $\mathrm{N}_{2}$ (50 bar). Las muestras fueron denominadas con la temperatura del tratamiento. Para poder evaluar la estabilidad de los soportes se caracterizaron las muestras de soportes por 
análisis termogravimétrico (TPO/TGA), análisis térmico diferencial (ATD), adsorcióndesorción de $\mathrm{N}_{2}(\mathrm{BET})$, difracción de rayos $\mathrm{X}$ (DRX), espectroscopía de fotoelectrones (XPS) y espectroscopía Raman.

Por análisis termogravimétrico (TPO/TGA) no se observaron cambios en el contenido de Si en los soportes C y SC, lo cual permite descartar la pérdida de Si por lixiviación (Tabla 74). La Tabla 7-4 presenta los resultados de análisis BET para los soportes tratados en distintas condiciones hidrotérmicas.

Tabla 7-4. Análisis BET para soportes tratados en distintas condiciones hidrotérmicas.

\begin{tabular}{lccccccc}
\hline \multirow{2}{*}{ Soporte } & $\begin{array}{c}\text { Relación másica } \\
\text { Si/C }\end{array}$ & $\mathrm{S}_{\mathrm{BET}}{ }^{\mathbf{a}}$ & $\mathrm{V}_{\mathrm{p}}^{\mathbf{b}}$ & \multicolumn{2}{c}{ Microporos } & \multicolumn{2}{c}{ Mesoporos } \\
& 0.15 & 678 & 1.42 & 257 & 0.11 & 421 & 1.31 \\
$\mathrm{C}$ & 0.14 & 608 & 1.14 & 255 & 0.09 & 353 & 1.05 \\
$\mathrm{C}-250$ & - & 180 & 0.76 & 35 & 0.01 & 145 & 0.66 \\
$\mathrm{SiO}_{2}$ & - & 119 & 1.16 & 9 & 0.003 & 110 & 1.15 \\
$\mathrm{SiO}_{2}-200$ & 0.95 & 204 & 0.28 & 34 & 0.02 & 170 & 0.26 \\
$\mathrm{SC}$ & 0.95 & 224 & 0.29 & 52 & 0.02 & 172 & 0.26 \\
$\mathrm{SC}-150$ & 0.95 & 272 & 0.35 & 90 & 0.04 & 182 & 0.31 \\
$\mathrm{SC}-200$ & 0.94 & 274 & 0.37 & 90 & 0.04 & 184 & 0.33 \\
$\mathrm{SC}-250$ & & & & & & & $\mathrm{~V}_{\text {micro }}{ }^{\mathbf{c}}$ \\
\hline
\end{tabular}

a Superficie específica $\left(\mathrm{m}^{2} \cdot \mathrm{g}^{-1}\right)$

b Volumen total de poros $\left(\mathrm{cm}^{3} \cdot \mathrm{g}^{-1}\right)$

c Superficie específica $\left(\mathrm{m}^{2} \cdot \mathrm{g}^{-1}\right)$ y volumen total de microporos $\left(\mathrm{cm}^{3} \cdot \mathrm{g}^{-1}\right)$

d Superficie específica $\left(\mathrm{m}^{2} \cdot \mathrm{g}^{-1}\right)$ y volumen total de mesoporos $\left(\mathrm{cm}^{3} \cdot \mathrm{g}^{-1}\right)$

El soporte C sufre una ligera caída del $10 \%$ en la SвEт de 678 a $608 \mathrm{~m}^{2} \cdot \mathrm{g}^{-1}$ debido al tratamiento a $250^{\circ} \mathrm{C}$ por $24 \mathrm{~h}$. Las oxidaciones en fase líquida pueden afectar las propiedades texturales de los materiales carbonosos [29], y depende de la concentración del agente oxidante, la temperatura a la cual se lleva a cabo el proceso y el tiempo durante el cual se produce [30]. Todos estos factores pueden conducir a una caída en los valores de superficie específica y volumen total de poros o producir un incremento en los mismos. Este fenómeno ha sido observado en procesos de funcionalización de carbones activados empleando $\mathrm{HNO}_{3}$ como agente oxidante, en donde la oxidación produce severas transformaciones en las propiedades texturales de los materiales [31,32]. Si se produce una pérdida de superficie específica y volumen total de poros, es indicativo del colapso de poros, comenzando por los microporos y siguiendo con los mesoporos [33].

El soporte comercial de $\mathrm{SiO}_{2}$ fue tratado a $200{ }^{\circ} \mathrm{C}$ durante $24 \mathrm{~h}\left(\mathrm{SiO}_{2}-200\right)$. Los resultados del análisis BET indican que este material presenta una fuerte caída en el valor de $S_{\text {BET de }}$ aproximadamente un $44 \%$. Este cambio va acompañado de una caída en los valores de superficie específica de micro y mesoporos, indicando que ambos tipos de poros sufren un colapso. En particular, el valor de $\mathrm{V}_{\text {micro }}$ para $\mathrm{SiO}_{2}-200$ es $0.003 \mathrm{~cm}^{3} \cdot \mathrm{g}^{-1}$, indicando que los microporos son prácticamente eliminados debido al tratamiento hidrotérmico. 
Para el soporte SC se observa un ligero aumento en el volumen total de poro con respecto al soporte sin tratar, que va acompañado de un aumento en los valores de superficie específica (S $\mathrm{BET}$ ). Cuando aumenta la superficie específica y el volumen total de poros, el fenómeno puede estar asociado con un ensanchamiento del tamaño de poros debido a una gasificación parcial del carbón. En este caso, los microporos son los más afectados debido a su menor tamaño. Cuando el ensanchamiento de microporos tiene lugar, nuevos microporos y mesoporos pueden formarse y por esta razón aumenta el volumen total de poro [34-36].

Dado que el soporte SC resulta el menos afectado por el tratamiento hidrotérmico, se decidió caracterizarlo con mayor profundidad para evaluar su estabilidad estructural y funcional.

El análisis de distribución de tamaño de poro de SC por el método de BJH muestra la presencia de dos poros modales con diámetros de $2 \mathrm{~nm}$ en la zona de microporos y de $5 \mathrm{~nm}$ en la zona de mesoporos. El tratamiento hidrotérmico genera una pequeña desviación en el segundo diámetro de poro modal, de $5 \mathrm{~nm}$ a $6 \mathrm{~nm}$, pero no muestra un colapso de poros o pérdida de superficie de poroso debido a la exposición al agua (Figura 9-4).

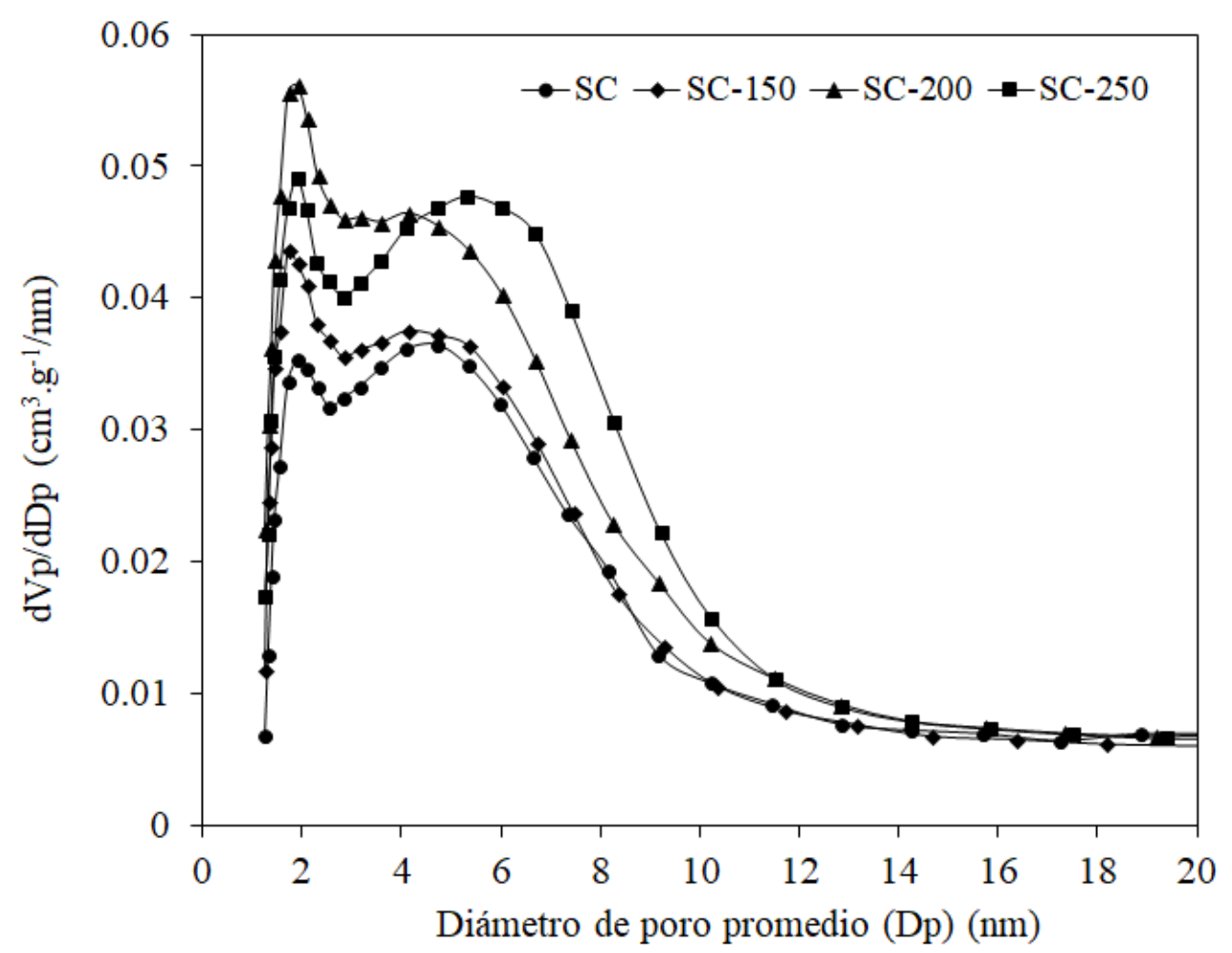

Figura 9-4. Distribución de tamaño de poro del soporte SC según el modelo BJH aplicada a la rama de adsorción de las isotermas considerando poros del tipo slit.

El difractograma de rayos $X(\mathrm{DRX})$ de la muestra SC tratada en la condición hidrotérmica más severa $\left(250^{\circ} \mathrm{C}\right)$ se muestran en la Figura $10-4$. Como se puede observar, no se aprecian cambios estructurales para el soporte de SC tratado a $250{ }^{\circ} \mathrm{C}$. 


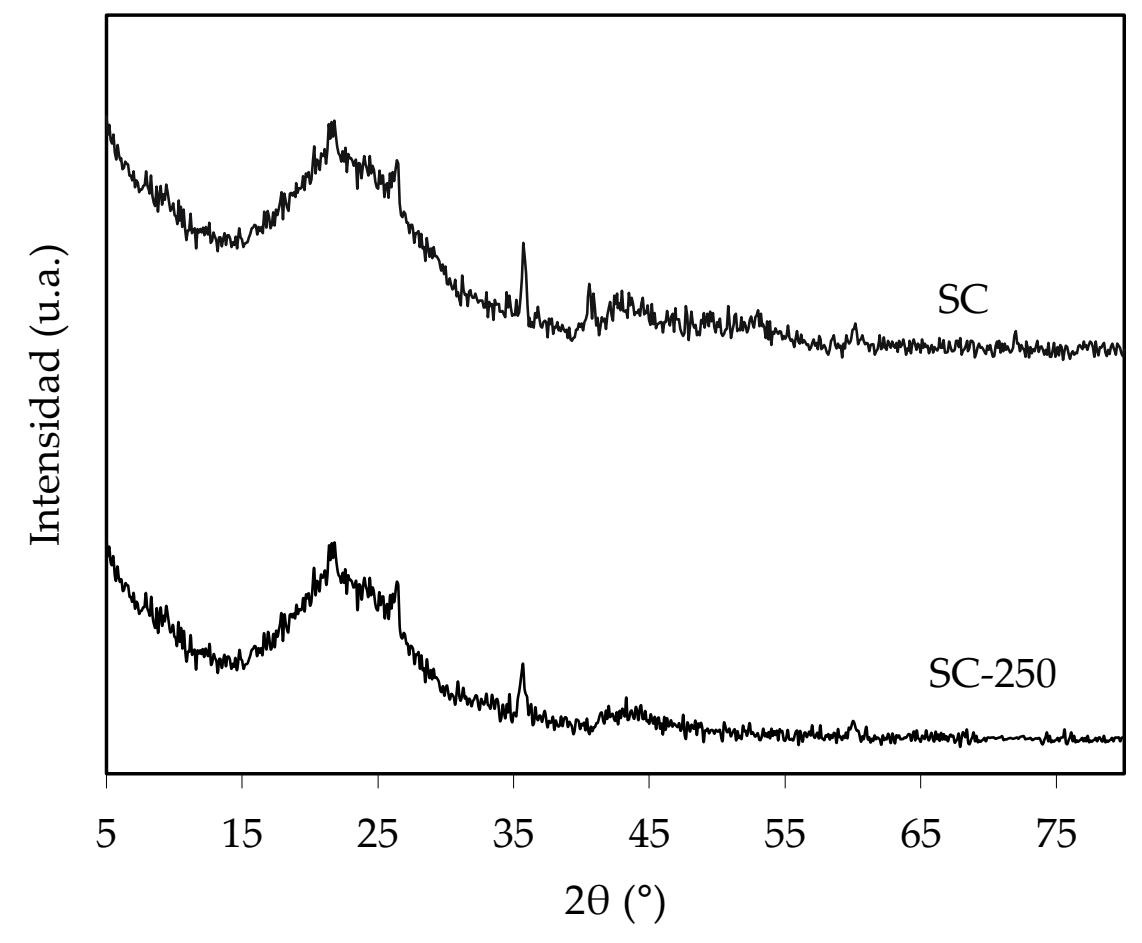

Figura 10-4. Difractogramas de rayos X para las muestras SC y SC-250.

Resultados obtenidos del análisis por espectroscopía Raman muestran que el soporte de SC fresco y luego del tratamiento hidrotérmico a $250{ }^{\circ} \mathrm{C}$ presenta características similares que pueden asociarse a estructuras del tipo silícea y carbonosa. Picos dominantes en la zona de $1340 \mathrm{~cm}^{-1}$ y $1570 \mathrm{~cm}^{-1}$ (bandas D y G respectivamente) y en la zona de $2680 \mathrm{~cm}^{-1}$ y $2910 \mathrm{~cm}^{-1} \mathrm{se}$ asignan a especies carbonosas altamente desordenadas [37,38] (Figura 11-5).

Picos característicos de baja intensidad en la zona de 200 a $1000 \mathrm{~cm}^{-1}$ están relacionados con estructuras compuestas por unidades de Si-O coordinadas tetraédricamente. Se espera que

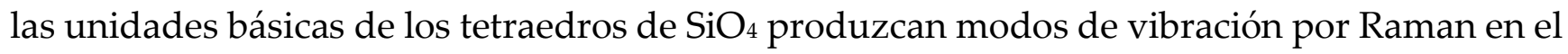
rango de 850-1250 cm-1 (estiramiento Si-O), 350-500 cm-1 (flexión O-Si-O) y menores a $300 \mathrm{~cm}^{-1}$ (flexión $\mathrm{Si}-\mathrm{O}-\mathrm{Si}$, torsión/ torsión y vibraciones reticulares) donde la sílice amorfa da como resultado una banda ancha que abarca el rango de $201-515 \mathrm{~cm}^{-1}[39,40]$.
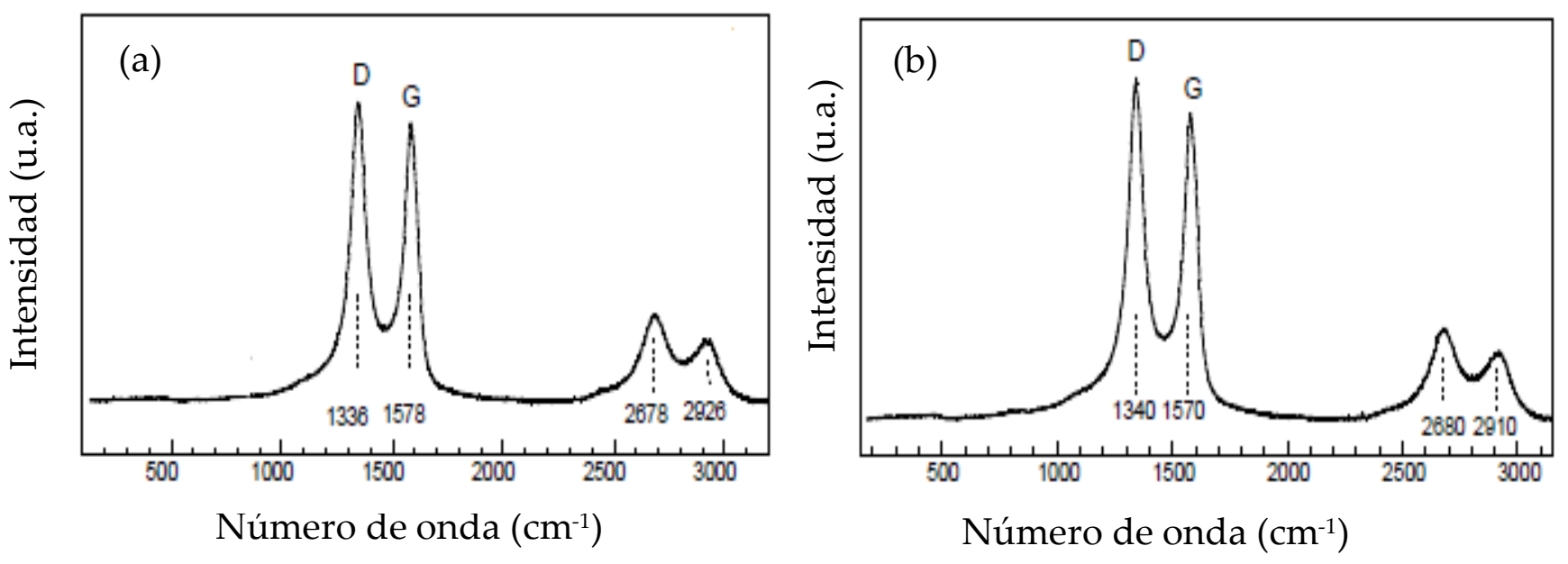

Figura 11-4. Espectros de Raman para las muestras (a) SC (b) SC-250 en el rango 500-3000 cm-1. 
Tanto para el soporte SC como para el soporte tratado SC-250, los picos característicos de baja intensidad en el rango de $200-1000 \mathrm{~cm}^{-1}$ pueden resolverse mediante un ajuste matemático de curvas (Figura 12-4). Las bandas a 467, 690 y $816 \mathrm{~cm}^{-1}$ pueden asociarse a fracciones estructurales de cuarzo, mientras que aquellas a 290 y $400 \mathrm{~cm}^{-1}$ pueden atribuirse a formas polimorfas de tridimita y cristobalita. No se aprecian diferencias estructurales entre ambas muestras, pero sí un grado mayor de cristalinidad para el soporte tratado SC-250.
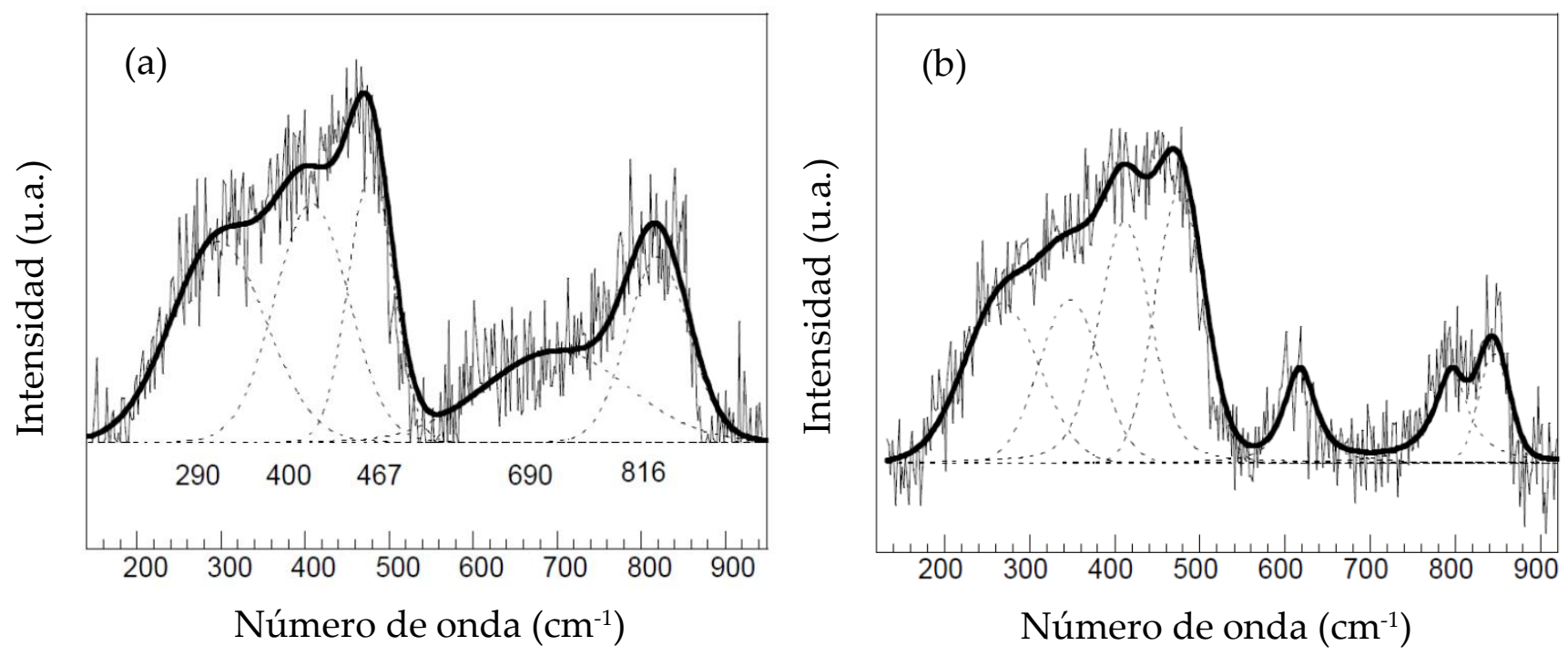

Figura 12-4. Espectros de Raman para las muestras (a) SC (b) SC-250 en el rango 200-1000 cm-1.

También se realizó el análisis térmico diferenciales (DTA) del soporte SC y SC-250, que se muestra en la Figura 13-4.

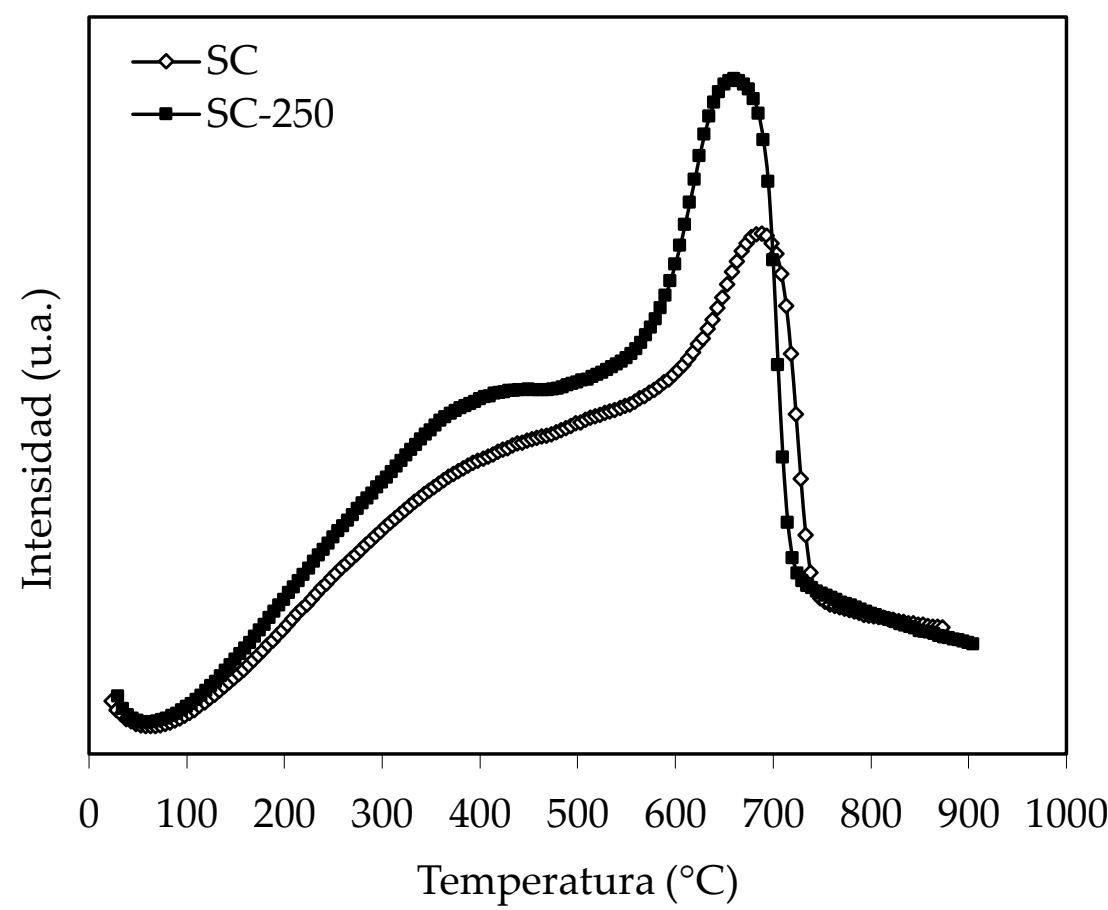

Figura 13-4. Perfiles del análisis térmico diferencial (DTA) para las muestras de SC y SC-250. 
Allí se observan tres zonas en donde aparecen picos característicos. En el rango de 20$100{ }^{\circ} \mathrm{C}$ las curvas presentan un pico endotérmico que podría asignarse a la desorción de gases, probablemente $\mathrm{N}_{2}, \mathrm{O}_{2}$ y moléculas de agua adsorbidas físicamente sobre la superficie de los sólidos [41].

En el rango $300-450{ }^{\circ} \mathrm{C}$ ambas curvas muestran una pequeña meseta que no llega a conformar un pico exotérmico bien definido. Esta forma podría deberse a la combustión de una pequeña cantidad ( $2 \%$ por TGA) de carbono grafito de fase amorfa [42]. En el rango 550$750{ }^{\circ} \mathrm{C}$ se observa un pico exotérmico correspondiente a la combustión de carbono grafito. El máximo del pico exotérmico cambia en la muestra SC-250 respecto de la muestra de SC. El corrimiento hacia menores valores de temperatura indicaría la presencia de carbón más reactivo a la combustión. Esta mayor reactividad podría asociarse a la presencia de grupos oxigenados superficiales originados por el tratamiento en agua caliente debido a la oxidación en presencia de agua [43].

Con el objetivo de analizar la presencia de grupos oxigenados superficiales en el soporte de SC y determinar su concentración con respecto a la muestra SC-250, se empleó la técnica de espectroscopia de fotoelectrones (XPS). La concentración relativa de grupos oxigenados superficiales fue determinada a través del ajuste de los espectros de XPS, por deconvolución de los picos O 1s y C 1s, como fue reportado previamente por Proctor y Sherwood [44].

Los resultados de XPS de las muestras SC y SC-250, indican que la relación superficial atómica Si/C permanece constante $(\sim 0.07)$, lo cual confirmaría que no hay pérdida de Si por lixiviación.

Para el soporte de SC sin tratamientos, los resultados mostraron una concentración superficial de un $44 \%$ de grupos carbonosos con enlaces C-C y un $56 \%$ de grupos superficiales carbonosos oxigenados ( $\sim 8 \%$ con enlaces $\mathrm{C}-\mathrm{O}$ y $7 \%$ con enlaces $\mathrm{O}=\mathrm{C}-\mathrm{O})$ (Tabla $8-4)$. Para la muestra SC-250 se observó un ligero incremento en los grupos superficiales oxigenados que podría deberse a la leve oxidación del carbón por parte del agua, resultado que coincide con el DTA. Debido a las pequeñas diferencias entre SC y SC-250, es posible concluir que el soporte SC presenta también alta estabilidad superficial en cuanto a sus propiedades ácido-base, lo que es esencial para su aplicación como soporte para la reacción de hidrogenólisis en fase líquida.

Tabla 8-4. Resultados obtenidos por XPS para las muestras SC y SC-250.

\begin{tabular}{ccccccccc}
\hline & \multirow{2}{*}{\begin{tabular}{c} 
Relación \\
\cline { 3 - 9 } Muestra
\end{tabular}} & \multicolumn{4}{c}{ Región C 1s } & \multicolumn{3}{c}{ Región O 1s } \\
\cline { 3 - 9 } & atómica & Energía de enlace $(\mathrm{eV})$ & \multicolumn{3}{c}{ Energía de enlace $(\mathrm{eV})$} \\
& $\mathrm{Si} / \mathrm{C}$ & 284.6 & 285.4 & 287.0 & 288.8 & 530.6 & 531.8 & 533.1 \\
\cline { 3 - 9 } & & $\mathrm{C}-\mathrm{C}$ & $\mathrm{C}-\mathrm{O}$ & $\mathrm{C}=\mathrm{O}$ & $\mathrm{O}=\mathrm{C}-\mathrm{O}$ & $\mathrm{O}=\mathrm{C}-\mathrm{O}$ & $\mathrm{C}=\mathrm{O} / \mathrm{C}-\mathrm{OH}$ & $\mathrm{C}-\mathrm{O}$ \\
\hline SC & 0.077 & 44.28 & 48.48 & 0 & 7.23 & 11.00 & 81.00 & 7.35 \\
SC-250 & 0.076 & 38.90 & 49.80 & 0 & 11.28 & 4.64 & 88.25 & 7.11 \\
\hline
\end{tabular}




\section{Conclusiones}

Mediante la técnica sol-gel pudieron prepararse dos tipos de soportes carbonosos, SC y $\mathrm{C}$, que fueron caracterizados empleando varias técnicas para poder determinar su estructura, características texturales y propiedades ácido base.

El soporte de SC tiene una superficie específica del orden de $200 \mathrm{~m}^{2} \cdot \mathrm{g}^{-1}$ resultando ser un material del tipo mesoporoso, con una estructura principalmente amorfa, compuesta por una matriz de sílice y estructuras desordenadas de carbono grafito.

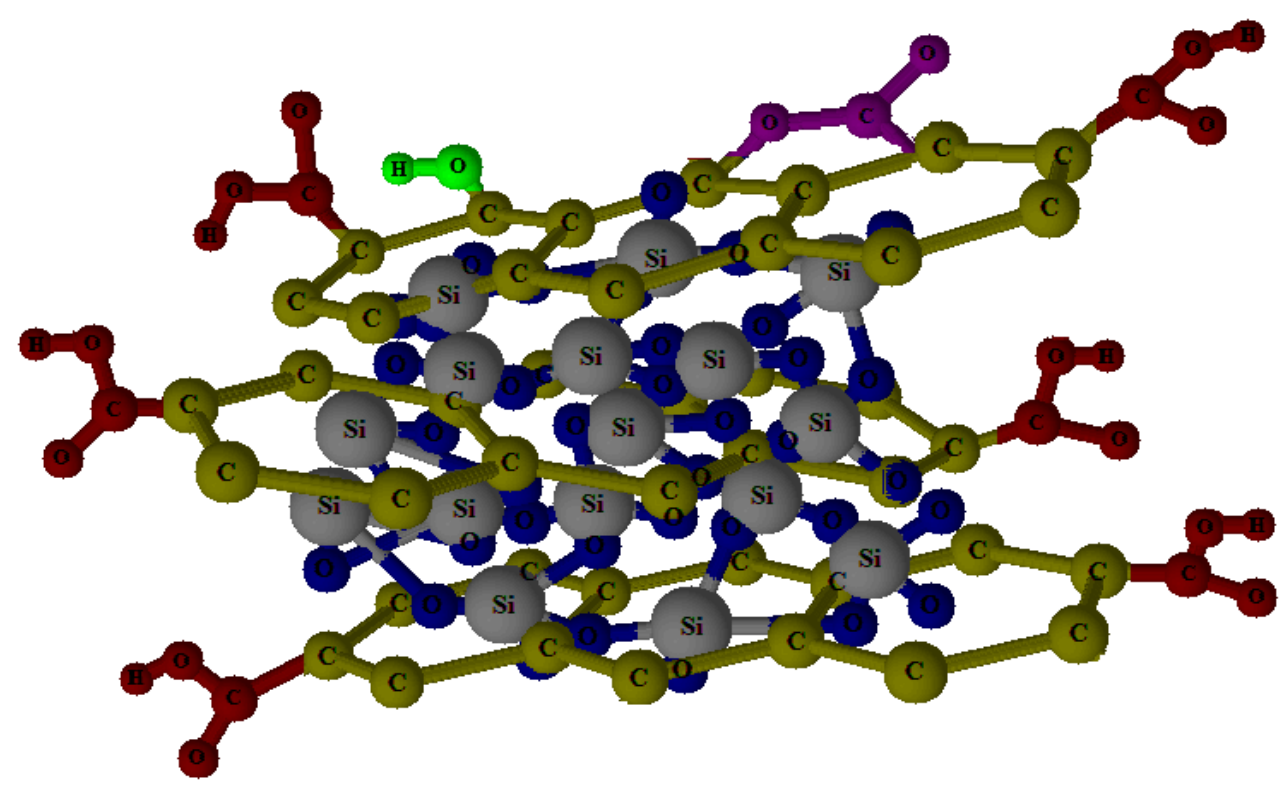

Este material, SC, posee principalmente grupos ácidos débiles de Lewis, basados en grupos carboxílicos resultando levemente más ácido que una sílice comercial. Los resultados de caracterización obtenidos en una condición hidrotérmica severa en fase líquida $\left(250{ }^{\circ} \mathrm{C}, 20\right.$ bar) mostraron que es estable porque no se modifican sus características texturales, su estructura ni sus propiedades ácido-base.

La sílice comercial, $\mathrm{SiO}_{2}$, resultó un material inestable en las condiciones hidrotérmicas de la fase líquida en comparación al material de SC. A $200{ }^{\circ} \mathrm{C}$ mostró un colapso de poros, perdiendo el $44 \%$ de su superficie específica. Estos resultados permitieron demostrar el rol del carbón para estabilizar la estructura de la sílice en el material de SC.

Con respecto al soporte de $\mathrm{C}$, también resultó un material mesoporoso, pero con una mayor contribución de microporos debido al tratamiento con HF. Estos microporos colapsan en la condición hidrotérmica de la fase líquida, mostrando una caída en la superficie específica, que, si bien no es significativa, no guarda la misma estabilidad que el soporte de SC. En comparación a SC, el soporte C es levemente más ácido, con un mayor número de grupos superficiales oxigenados del tipo lactónicos y fenólicos. 


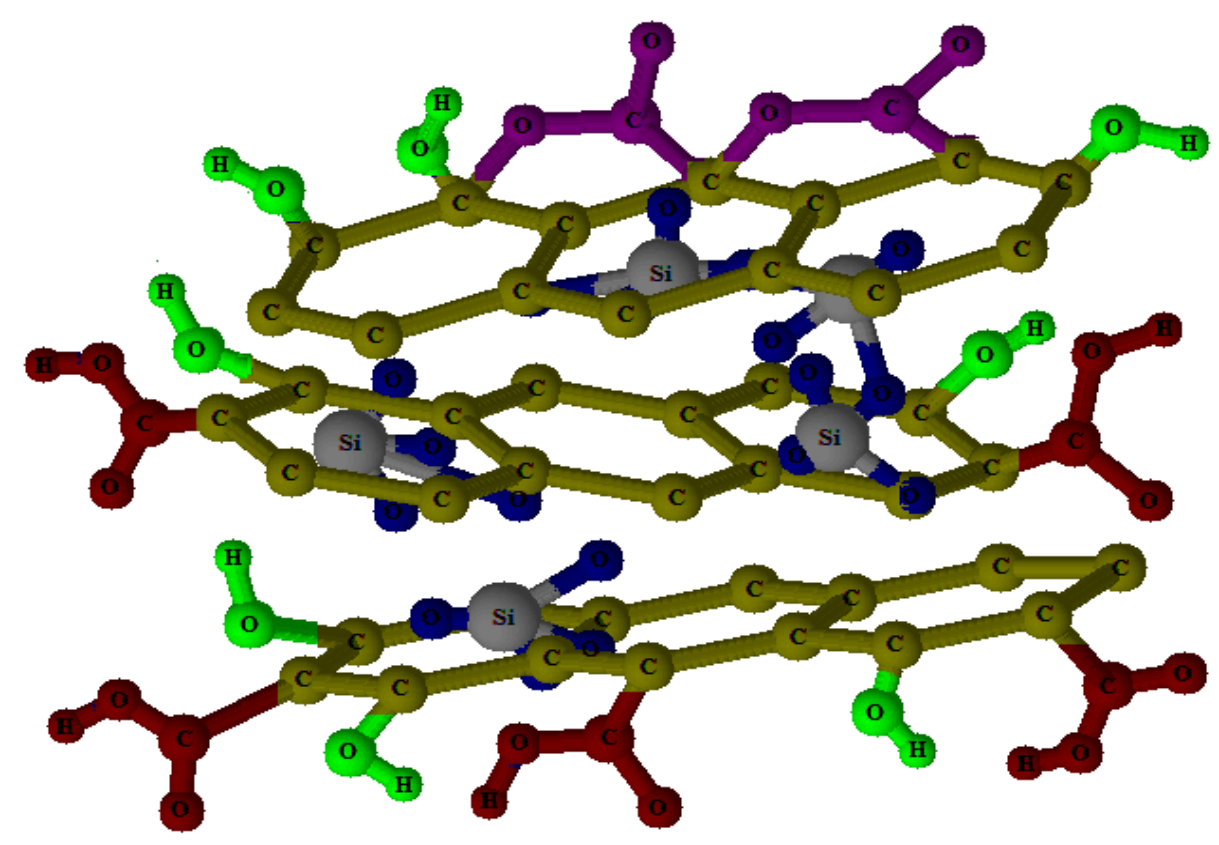

Las conclusiones obtenidas hasta aquí indican que el material SC resulta interesante como soporte catalítico en reacciones en fase acuosa líquida.

\section{Bibliografía}

[1] N. Luo, X. Fu, F. Cao, T. Xiao, P. Edwards, Fuel 87 (2008) 3483-3489.

[2] R. Ravenelle, J. Copeland, W. Kim, J. Crittenden, ACS Catalysis 1 (2011) 552-561.

[3] W. Ketchie, E. Maris, R. Davis, Chemical Materials 19 (2007) 3406-3411.

[4] K. Lehnert, P. Claus, Catalysis Communications 9 (2008) 2543-2546.

[5] H. L. Castricum, M. C. Mittelmeijer-Hazeleger, A. Sah, J. E. ten Elshof, Microporous and Mesoporous Materials 88 (2006) 63-71.

[6] H. Xiong, H. N. Pham, A. K. Datye, Journal of Catalysis 302 (2013) 93-100.

[7] Y. J. Pagan-Torres, J. M. R. Gallo, D. Wang, H. N. Pham, J. A. Libera, C. L. Marshall, J. W. Elam, A. K. Datye, J. A. Dumesic, ACS Catalysis 1 (2011) 1234-1245.

[8] L. Vilcocq, A. Cabiac, C. Especel, S. Lacombe, D. Duprez, D. Catalysis Communications 15 (2011) 18-22.

[9] T. N. Pham, D. Shi, T. Sooknoi, D. E. Resasco, Journal of Catalysis 295 (2012) 169-178.

[10] F. Rodriguez-Reinoso, Carbon 36 (1998) 159-175. 
[11] P. M. Boorman, K. Chong, R. A. Kydd, J. M. Lewis, Journal of Catalysis 128 (1991) 537-550.

[12] B. Lombardi, F. Pompeo, A. N. Scian, N. N. Nichio, Materials Letters 106 (2013) 393-395.

[13] J. Rouquerol, D. Avnir, C. W. Fairbridge, D. H. Everett, J. H. Haynes, N. Pernicone, J. D. F. Ramsay, K. S. W. Sing, K. K. Unger, Pure and Applied Chemistry 66 (1994) 1739-1758.

[14] B. Huang, C. H. Bartholomew, B. F. Woodfield, Microporous and Mesoporous Materials 184 (2014) 112-121.

[15] H. Ding, J. Li, Y. Gao, D. Zhao, D. Shi, G. Mao, S. Liu, X. Tan, Powder Technology 284 (2015) 231-236.

[16] T. Niu, G. L. Liu, Y. Liu, Applied Catalysis B: Environmental 154-155 (2014) 82-92.

[17] R. Dong, W. Yang, P. Wu, M. Hussain, Z. Xiu, G. Wu, P. Wang, Materials Characterization 103 (2015) 37-41.

[18] Z. Omidin, A. Ghasemi, S. Bakhshi, Ceramics International 41 (2015) 5779-5784.

[19] Z. Q. Li, C. J. Lu, Z. P. Xia, Y. Zhou, Z. Luo, Carbon 45 (2007) 1686-1695.

[20] H. Kodama, Infrared Spectra of Minerals. Reference Guide to Identification and Characterization of Minerals for the Study of Soil, 1985, pp. 198.

[21] H. R. Li, J. Lin, H. J. Zhang, H. C. Li, L. S. Fu, Q. G. Meng, Chemical Communications 13 (2001) 1212.

[22] H. Li, J. Yu, F. Liu, H. Zhang, L. Fu, Q. Meng, C. Peng, J. Lin, New Journal of Chemistry 28 (2004) 1137.

[23] M. Rashidi, A. Tavasoli., Journal of Supercritical Fluids 98 (2015) 111-118.

[24] S. L. Goertzen, K. D. Thériault, A. M. Oickle, A. C. Tarasuk, H. A. Andreas, Carbon 48 (2010) 1252-1261.

[25] A. M. Oickle, S. L. Goertzen, K. R. Hopper, Y. O. Abdalla, H. A. Andreas, Carbon 48 (2010) 3313-3322.

[26] G. S. Szymánski, Z. Karpinski, S. Biniak, A. Swiatkowski, Carbon 40 (2002) 2627-2639.

[27] H. P. Bohem, Carbon 40 (2002) 145-149. 
[28] J. Collins, G. Gourdin, M. Foster, D. Qu, Carbon 92 (2015) 193-244.

[29] J. S. Noh, J. A. Schwarz, Carbon 28 (1990) 675-682.

[30] C. Moreno-Castilla, F. Carrasco-Marín, F. J. Maldonado-Hodar, J. Rivera-Utrilla, Carbon 36 (1998) 145.

[31] Z. Guoqiang, Z. Li, H. Zheng, T. Fue, Y. Ju, Y. Wang, Applied Catalysis B: Environmental 179 (2015) 95-105.

[32] M. Steimecke, S. Rümmler, M. Bron, Electrochimica Acta 163 (2015) 1-8.

[33] J. L. Figueiredo, M. F. R. Pereira, M. M. A. Freitas, J. J. M. Órfão y col., Carbon 37 (1999) 1379-1389

[34] C. Alegre, M. E. Gálvez, E. Baquedano, E. Pastor, R. Moliner, M. J. Lázaro, International Journal of Hydrogen Energy 37 (2012) 7180-7191.

[35] N. Mager, N. Meyer, A. F. Léonard, N. Job, M. Devillers, S. Hermans, Applied Catalysis B: Environmental 148-149 (2014) 424-435.

[36] T. G. Ros, A. J. Van Dillen, J. W. Geus, D. C. Koningsberger, Chemistry: A European Journal 8 (2002)1151-1162.

[37] S. Arepalli, P. Nikolaev, O. Gorelik, V. Hadjiev, W. Holmes, B. Files, L. Yowell, Carbon 42 (2004) 1783-1791.

[28] A. Ferrari, J. Robertson, Physical Review B 61 (2000) 14095-14107.

[39] R. N. Tarrant, O. Warschkow, D. R. McKenzie, Vibrational Spectroscopy 41 (2006) 232-239.

[40] J. L. You, G. C. Jiang, H. Y. Hou, H. Chen, Y. Q. Wu, K. D. Xu, Journal of Raman Spectroscopy 36 (2005) 237-249.

[41] N. J. Welham, J. S. Williams, Carbon 36 (9) (1998) 1309-1315.

[42] Z. Shi, Y. Lian, F. Liao, X. Zhou, Z. Gu, Y. Zhang, S. Iijima, Solid State Communications 112 (1999) 35-37.

[43] K. Shibagaki, S. Motojima, Carbon 39 (2001) 411-417.

[44] A. Proctor, P. Sherwood, Journal of Electron Spectroscopy and Related Phenoma 27 (1982) $39-56$ 


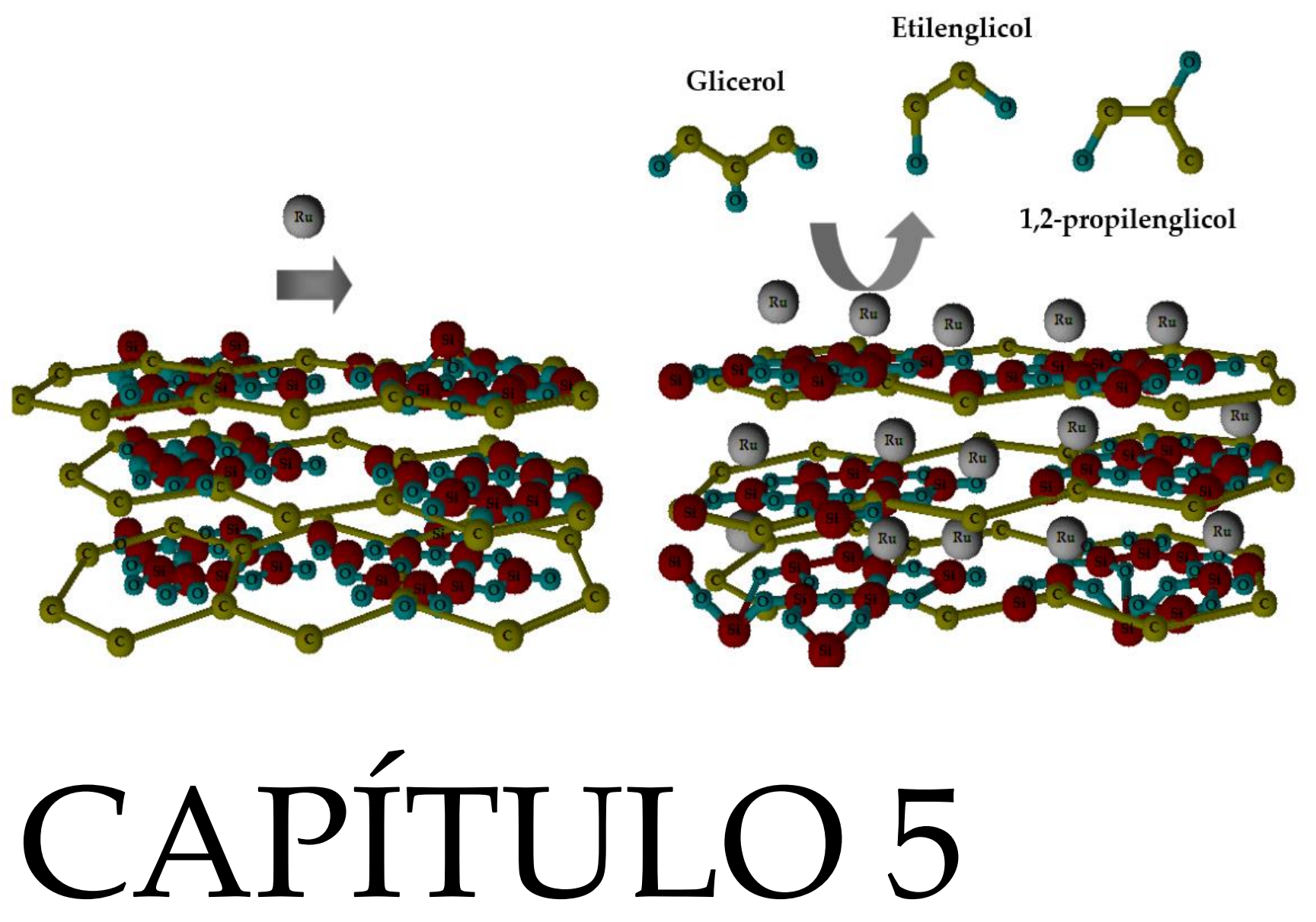

\section{Estudios preliminares de} actividad catalítica 


\subsection{Introducción}

En este capítulo se presenta en primer lugar el análisis realizado para verificar que en las condiciones operativas elegidas, los ensayos se realizan en régimen cinético, con ausencia de resistencias externas e internas a la transferencia de materia y energía.

Dado que el material SC resultó estable frente a las condiciones hidrotérmicas ensayadas, fue elegido como soporte para preparar diferentes catalizadores que permitan seleccionar la fase metálica. En este sentido, se llevaron a cabo ensayos de reacción, con catalizadores de $\mathrm{Ru}, \mathrm{Ni}$ y $\mathrm{Cu}$, en el rango de 200 a $220^{\circ} \mathrm{C}$ a una presión inicial de 20 bar de $\mathrm{H}_{2}$ y una relación $\mathrm{m}_{\mathrm{gli}} / \mathrm{m}_{\mathrm{c}}=4.2$.

Finalmente se seleccionan los catalizadores que serán objeto de posteriores estudios.

\subsection{Puesta en marcha del reactor discontinuo - consideraciones generales}

Para efectuar los ensayos de reacción se empleó un reactor discontinuo tipo batch de acero inoxidable, Bergof BR-100, de $100 \mathrm{ml}$ de capacidad. Detalles del procedimiento empleado en cada experiencia de reacción se han indicado en el capítulo 3.

Para verificar que el soporte SC no tiene actividad catalítica, se efectuaron dos blancos a $200{ }^{\circ} \mathrm{C}$ y $260{ }^{\circ} \mathrm{C}$, y a una presión inicial de 20 bar de $\mathrm{H}_{2}$, empleando soluciones acuosas al 10 $\% \mathrm{p} / \mathrm{p}$ de glicerol con una relación $\mathrm{m}_{\mathrm{gli}} / \mathrm{m}_{\mathrm{c}}=4.2$. Los resultados mostraron que, con ambas temperaturas, el glicerol no reacciona en presencia del soporte SC.

\subsubsection{Verificación de la ausencia de resistencias externas a la transferencia de materia}

Experiencias realizadas previamente al desarrollo de esta tesis permitieron verificar que para valores de agitación mayores o iguales a $700 \mathrm{rpm}$ no se observó un incremento en la velocidad de reacción del glicerol, lo cual permite concluir que por encima de este valor de velocidad existe la ausencia de resistencias difusionales externas a la transferencia de materia entre la superficie catalítica y el seno de la fase líquida. El valor de velocidad elevada es necesaria para asegurar el control cinético es debido a la naturaleza viscosa del glicerol $[1,2]$. Algunos autores en la literatura han empleado velocidades de agitación de hasta $1200 \mathrm{rpm}$ para eliminar la resistencia a la transferencia de materia en la hidrogenólisis de glicerol [3].

En este trabajo de tesis siempre se empleó una velocidad de agitación de $1000 \mathrm{rpm}$ (máxima del equipo). Para verificar efectivamente que no existen resistencias a la transferencia de materia se efectuaron cálculos basados en el criterio de Mears [4]. Para ello es preciso calcular el coeficiente $C_{\mathrm{M}}$ de la Ecuación 1-5.

$$
\mathrm{C}_{\mathrm{M}}=\frac{\left(-\mathrm{r}_{\mathrm{gli}}\right) \mathrm{r}_{\mathrm{p}} \rho_{\mathrm{c}} \mathrm{n}}{\mathrm{k}_{\mathrm{L}} \mathrm{C}_{\mathrm{gli}}{ }^{\mathrm{L}}}
$$

Ecuación 1-5

En la Ecuación 1-6, (- rgli $\left._{1}\right)$ es la velocidad de reacción del glicerol por unidad de masa de catalizador $\left(\operatorname{mol} . \mathrm{kg}^{-1} . \mathrm{s}^{-1}\right), \mathrm{r}_{\mathrm{p}}$ es el radio del polvo de catalizador $(\mathrm{m}), \rho_{\mathrm{c}}$ es la densidad del catalizador $\left(\mathrm{kg} \cdot \mathrm{m}^{-3}\right)$, D gli es el coeficiente de difusión efectivo del glicerol a la temperatura de reacción en el interior del polvo catalítico $\left(\mathrm{m}^{2} . \mathrm{s}^{-1}\right), \mathrm{n}$ es el orden de reacción respecto del 
glicerol, $\mathrm{k}_{\mathrm{L}}$ es el coeficiente de transferencia de materia en la fase líquida y $\mathrm{C}_{\text {gli }}{ }^{\mathrm{L}}$ es la concentración de glicerol en el seno de la fase líquida $\left(\mathrm{mol} . \mathrm{m}^{-3}\right)$.

Una vez hecho el cálculo, se analiza el valor del coeficiente $\mathrm{C}_{\mathrm{M}}$ :

-Si $C_{M}>0.15$, entonces hay resistencias externas a la transferencia de materia.

-Si $C_{M}<0.15$, entonces hay ausencia de resistencias externas a la transferencia de materia.

Para evaluar el coeficiente $\mathrm{C}_{M}$ se empleó un catalizador de $\mathrm{Ni}$ (5\%)/SC cuya preparación se describe en el capítulo 3 y los detalles completos del cálculo se presentan en el Anexo I. El coeficiente $C_{\mathrm{M}}$ tiene un valor de $3.74 \times 10^{-7}$, es decir, un valor mucho menor a 0.15 , lo que verifica efectivamente que hay ausencia de resistencias externas a la transferencia de materia.

\subsubsection{Verificación de la ausencia de resistencias internas a la transferencia de materia}

Para verificar experimentalmente la ausencia de resistencias internas a la transferencia de materia lo conveniente es llevar a cabo ensayos catalíticos con catalizadores de distintos tamaños de pastilla y de esta forma establecer el tamaño adecuado de catalizador para el cual no se observan cambios en la velocidad de reacción del glicerol.

El hecho de que el catalizador sea a base de carbón hace que ya tenga un tamaño muy pequeño que va desde los 0.3 a $0.4 \mathrm{~mm}$ de diámetro.

Aun así, para asegurar la ausencia de resistencias internas a la transferencia de materia, es decir, resistencias difusionales intra-partícula, se efectuaron cálculos basados en el criterio de Wiesz-Prater (Ecuación 2-5) [5].

$$
\mathrm{CWP}_{W \mathrm{P}}=\frac{\left(-\mathrm{rgli}_{\mathrm{i}}\right) \cdot \mathrm{r}_{\mathrm{p}}{ }^{2} \cdot \rho_{\mathrm{c}}}{\mathrm{D}_{\mathrm{gli}}{ }^{\mathrm{ef}} \cdot \mathrm{C}_{\mathrm{gli}}^{\mathrm{S}}}
$$

Ecuación 2-5

En la Ecuación 1-5, (- $\left.\mathrm{rgli}_{\mathrm{gli}}\right)$ es la velocidad de reacción del glicerol por unidad de masa de catalizador $\left(\mathrm{mol} . \mathrm{kg}^{-1} . \mathrm{s}^{-1}\right), \mathrm{r}_{\mathrm{p}}$ es el radio del polvo de catalizador $(\mathrm{m}), \rho_{\mathrm{c}}$ es la densidad del catalizador $\left(\mathrm{kg} . \mathrm{m}^{-3}\right), \mathrm{D}_{\text {gli }}{ }^{\mathrm{ef}}$ es el coeficiente de difusión efectivo del glicerol a la temperatura de reacción en el interior del polvo catalítico $\left(\mathrm{m}^{2} . \mathrm{s}^{-1}\right)$ y $\mathrm{Cgli}_{\mathrm{i}} \mathrm{s}$ es la concentración de glicerol en la superficie catalítica $\left(\mathrm{mol} \cdot \mathrm{m}^{-3}\right)$.

Una vez hecho el cálculo, se analiza el valor del coeficiente CwP:

-Si $C_{W P}>>1$, entonces hay resistencias internas a la transferencia de materia.

-Si $\mathrm{C}_{W P}<<1$, entonces hay ausencia de resistencias internas a la transferencia de materia.

Para evaluar el coeficiente CWP se empleó el catalizador de Ni (5\%)/SC y los detalles completos del cálculo se presentan en el Anexo I.

El cálculo de Cwp arroja un valor de $4.00 \times 10^{-7}$, es decir, mucho menor a la unidad. Esto significa que la reacción está controlada cinéticamente y no existen resistencias difusionales intra-partícula. 


\subsubsection{Verificación de la ausencia de resistencias externas a la transferencia de energía}

La ausencia de resistencias externas a la transferencia de energía fue verificada con el criterio del número de Damkoehler de tercer orden, DaıI, expresado mediante la Ecuación 3-5 [10].

$$
\operatorname{DaIII}=\frac{\left|\Delta \mathrm{H}_{\mathrm{R}}\right|\left(-\mathrm{rrlii}_{\mathrm{il}} \mathrm{r}_{\mathrm{p}} \rho_{\mathrm{c}} \mathrm{E}_{\mathrm{a}}\right.}{\mathrm{h}_{\mathrm{L}} \mathrm{T}^{2} \mathrm{R}}
$$

Ecuación 3-5

En la Ecuación 7-5, (-rgli) es la velocidad de reacción del glicerol por unidad de masa de catalizador (mol.kg-1. $\left.\mathrm{s}^{-1}\right), \mathrm{r}_{\mathrm{p}}$ es el radio del polvo de catalizador $(\mathrm{m}), \rho_{\mathrm{c}}$ es la densidad del catalizador $\left(\mathrm{kg} \cdot \mathrm{m}^{-3}\right), \mathrm{E}_{\mathrm{a}}$ es la energía de activación de la reacción de hidrogenólisis $\left(\mathrm{J} \cdot \mathrm{mol}^{-1}\right), \mathrm{R}$ es la constante universal de los gases $\left(\mathrm{J} \cdot \mathrm{mol}^{-1} \cdot \mathrm{K}^{-1}\right)$, T es la temperatura de reacción (K) y hL es el coeficiente de transferencia de energía de la fase líquida $\left(\mathrm{J} \cdot \mathrm{m}^{-2} \cdot \mathrm{s}^{-1} \cdot \mathrm{K}^{-1}\right)$.

Una vez hecho el cálculo, se analiza el valor del número de Damkoehler, Dam:

-Si DaIII $>0.15$, entonces hay resistencias externas a la transferencia de energía.

-Si Dail $<0.15$, entonces hay ausencia de resistencias externas a la transferencia de energía.

El Dami se evaluó en el rango térmico de $220^{\circ} \mathrm{C}$ a $260^{\circ} \mathrm{C}$, empleando el catalizador de $\mathrm{Ni}(5 \%) / \mathrm{SC}$. Los detalles completos del cálculo se presentan en el Anexo I.

En este rango térmico de $220^{\circ} \mathrm{C}$ a $260^{\circ} \mathrm{C}$, el cálculo de Dam arroja valores del orden de $10^{-6}$, es decir, mucho menor a 0.15 . Esto significa que no existen resistencias externas a la transferencia de materia entre la superficie catalítica y el seno de la fase líquida.

\subsubsection{Verificación de la ausencia de resistencias internas a la transferencia de energía}

La ausencia de resistencias internas a la transferencia de energía fue verificada con el criterio del número de Damkoehler de cuarto orden, Darv, expresado mediante la Ecuación 45 [10].

$$
\text { Darv }=\frac{\left|\Delta \mathrm{H}_{\mathrm{R}}\right|\left(-\mathrm{r}_{\mathrm{gli}}\right) \mathrm{r}_{\mathrm{p}}^{2} \rho_{\mathrm{c}} \mathrm{E}_{\mathrm{a}}}{\kappa_{\mathrm{c}} \mathrm{T}^{2} \mathrm{R}}
$$

Ecuación 4-5

En la Ecuación 13-5, (-r $\left.\mathrm{r}_{\mathrm{gli}}\right)$ es la velocidad de reacción del glicerol por unidad de masa de catalizador $\left(\right.$ mol. $\left.\mathrm{kg}^{-1} . \mathrm{s}^{-1}\right), \mathrm{r}_{\mathrm{p}}$ es el radio del polvo de catalizador $(\mathrm{m}), \rho_{\mathrm{c}}$ es la densidad del catalizador $\left(\mathrm{kg} \cdot \mathrm{m}^{-3}\right), \mathrm{E}_{a}$ es la energía de activación de la reacción de hidrogenólisis $\left(\mathrm{J} \cdot \mathrm{mol}^{-1}\right), \mathrm{R}$ es la constante universal de los gases $\left(\mathrm{J} \cdot \mathrm{mol}^{-1} \cdot \mathrm{K}^{-1}\right)$, T es la temperatura de la superficie del catalizador $(\mathrm{K})$ y $\kappa_{\mathrm{c}}$ es la conductividad térmica del catalizador $\left(\mathrm{J} \cdot \mathrm{m}^{-1} \cdot \mathrm{s}^{-1} \cdot \mathrm{K}^{-1}\right)$.

Una vez hecho el cálculo, se analiza el valor del número de Damkoehler, Darv:

-Si Darv $>0.40$, entonces hay resistencias internas a la transferencia de energía.

-Si Darv $<0.40$, entonces hay ausencia de resistencias internas a la transferencia de energía.

El Darv se evaluó en el rango térmico de $220^{\circ} \mathrm{C}$ a $260{ }^{\circ} \mathrm{C}$, empleando el catalizador de $\mathrm{Ni}(5 \%) / \mathrm{SC}$. Los detalles completos del cálculo se presentan en el Anexo I. 
En el rango térmico de $220{ }^{\circ} \mathrm{C}$ a $260{ }^{\circ} \mathrm{C}$, el cálculo de Darv arroja valores del orden de $10^{-6}$, es decir, mucho menor a 0.40 . Esto significa que no existen resistencias internas a la transferencia de energía entre la superficie catalítica y el interior de la partícula de catalizador.

\subsection{Estudios de actividad catalítica para la selección de la fase metálica}

Del capítulo 2, quedó claro que dentro de los metales nobles que son activos para este tipo de reacción se encuentran $\mathrm{Ru}$ [7-17], Pt [18-26], Rh [27-30] y Pd [31-34], siendo el orden de actividad propuesto el siguiente:

$$
\mathrm{Ru}>\mathrm{Pt}>\mathrm{Rh}>\mathrm{Pd}
$$

De todos ellos, el Ru ha sido reportado como la mejor alternativa para ser empleado como fase activa en la preparación de catalizadores soportados.

Por otro lado, dentro de los metales no nobles, se han reportado catalizadores basados en $\mathrm{Cu}$ [35-40], Ni [41-44] y Co [45-48], siendo el orden de actividad el siguiente:

$$
\mathrm{Cu} \sim \mathrm{Ni}>\mathrm{Co}
$$

Tanto $\mathrm{Cu}$ como $\mathrm{Ni}$ poseen valores de actividad similares en la reacción de hidrogenólisis de glicerol.

Con el objetivo de seleccionar aquellos catalizadores que resulten más atractivos, se llevaron a cabo estudios de actividad catalítica empleando catalizadores metálicos soportados basados en $\mathrm{Ru}, \mathrm{Cu}$ y $\mathrm{Ni}$ como fases metálicas. Todos los catalizadores se prepararon empleando el soporte SC.

\subsubsection{Preparación de catalizadores Ru/SC}

Los catalizadores basados en $\mathrm{Ru}$ como fase metálica, $\mathrm{Ru} / \mathrm{SC}$, se prepararon empleando la técnica de impregnación a humedad incipiente utilizando $\mathrm{RuCl}_{3} \times \mathrm{xH}_{2} \mathrm{O}$ y etanol como solvente. El catalizador se preparó para alcanzar un $0.2 \% \mathrm{p} / \mathrm{p}$ de $\mathrm{Ru}$. En cuanto a los tratamientos necesarios para la descomposición del precursor de $\mathrm{RuCl}_{3} \times \mathrm{xH}_{2} \mathrm{O}$, se ha reportado en bibliografía que el proceso de declorinación reductiva del $\mathrm{RuCl}_{3} \times \mathrm{xH}_{2} \mathrm{O}$ sobre carbones activados comienza a $220{ }^{\circ} \mathrm{C}$ y finaliza a los $350{ }^{\circ} \mathrm{C}$, no obstante, existe un remanente de iones $\mathrm{Cl}^{-}$del $0.08 \% \mathrm{p} / \mathrm{p}$ aun cuando se trata a los catalizadores a $450{ }^{\circ} \mathrm{C}$ durante $24 \mathrm{~h}$ y temperaturas mayores a $450{ }^{\circ} \mathrm{C}$ pueden generar la metanación de los carbones [49]. Para lograr una descomposición completa del precursor y una activación adecuada, los catalizadores de $\mathrm{Ru} / \mathrm{SC}$ fueron primeramente calcinados $\left(10{ }^{\circ} \mathrm{C} \cdot \mathrm{min}^{-1}\right)$ en flujo continuo (50 $\left.\mathrm{cm}^{3} \cdot \mathrm{min}^{-1}\right)$ de Ar a $300{ }^{\circ} \mathrm{C}$ durante $3 \mathrm{~h}$ y posteriormente activados $\left(10{ }^{\circ} \mathrm{C} \cdot \mathrm{min}^{-1}\right)$ en flujo continuo $\left(50 \mathrm{~cm}^{3} \cdot \mathrm{min}^{-1}\right)$ de $\mathrm{H}_{2}$ a $350{ }^{\circ} \mathrm{C}$ durante $90 \mathrm{~min}$. 


\subsubsection{Preparación de catalizadores $\mathrm{Cu} / \mathrm{SC}$}

Los catalizadores basados en $\mathrm{Cu}$ como fase metálica, $\mathrm{Cu} / \mathrm{SC}$, se prepararon empleando la técnica de impregnación a humedad incipiente utilizando dos precursores distintos: $\mathrm{Cu}\left(\mathrm{CH}_{3} \mathrm{COO}\right)_{2} . \mathrm{H}_{2} \mathrm{O}$ y $\mathrm{Cu}\left(\mathrm{NO}_{3}\right)_{2} .3 \mathrm{H}_{2} \mathrm{O}$, y etanol como solvente. La elección de los precursores de $\mathrm{Cu}$ radica en su fácil descomposición, lo cual es fundamental para estos casos en donde el soporte es de tipo carbonoso. Otros precursores, tales como el $\mathrm{CuCl}_{2} 2 \mathrm{H}_{2} \mathrm{O}$, no podrían utilizarse debido a que se descomponen a temperaturas elevadas. En particular, el $\mathrm{CuCl}_{2} 2 \mathrm{H}_{2} \mathrm{O}$ se descompone en atmosfera oxidante en el rango de $400^{\circ} \mathrm{C}$ a $500{ }^{\circ} \mathrm{C}$, y una vez descompuesto el precursor forma $\mathrm{CuCl}$ que vaporiza a $420^{\circ} \mathrm{C}$, impidiendo la fijación del $\mathrm{Cu}$ sobre el soporte $[50,51]$. Los catalizadores de $\mathrm{Cu}$ se prepararon para alcanzar un $5 \% \mathrm{p} / \mathrm{p}$ de $\mathrm{Cu}$, que es uno de los contenidos metálicos más bajos para este tipo de fases metálicas [38, 40], en donde suele haber contenidos en el rango de 10-40 \%p/p [35-37,39].

Se ha reportado en bibliografía que la descomposición del precursor de $\mathrm{Cu}\left(\mathrm{CH}_{3} \mathrm{COO}\right)_{2} \cdot \mathrm{H}_{2} \mathrm{O}$ ocurre aproximadamente a $300{ }^{\circ} \mathrm{C}$ en atmósfera oxidante $\left(90 \% \mathrm{~N}_{2}-10 \%\right.$ $\mathrm{O}_{2}$ ) [52]. Dado que el soporte es de tipo carbonoso no es conveniente descomponer los precursores en atmósfera oxidante. Para el catalizador de $\mathrm{Cu}$ basado en este precursor, $\mathrm{Cu}(\mathrm{Ac}-) / \mathrm{SC}$, se efectuó una calcinación $\left(10{ }^{\circ} \mathrm{C} \cdot \mathrm{min}^{-1}\right)$ en flujo continuo $\left(50 \mathrm{~cm}^{3} \cdot \mathrm{min}^{-1}\right)$ de Ar a $300{ }^{\circ} \mathrm{C}$ durante $3 \mathrm{~h}$.

Para el caso del precursor de $\mathrm{Cu}\left(\mathrm{NO}_{3}\right)_{2} .3 \mathrm{H}_{2} \mathrm{O}$, se han reportado protocolos de calcinación en atmósfera oxidante a $400{ }^{\circ} \mathrm{C}$ [35,37,39], $450{ }^{\circ} \mathrm{C}[38,40]$ y $500{ }^{\circ} \mathrm{C}$ [36]. Para el catalizador de $\mathrm{Cu}$ basado en este precursor, $\mathrm{Cu}\left(\mathrm{NO}_{3-}\right) / \mathrm{SC}$, se efectuó una calcinación (10 $\left.{ }^{\circ} \mathrm{C} \cdot \mathrm{min}^{-1}\right)$ en flujo continuo $\left(50 \mathrm{~cm}^{3} \cdot \mathrm{min}^{-1}\right)$ de Ar a $400{ }^{\circ} \mathrm{C}$ durante $3 \mathrm{~h}$.

En cuanto a la activación, se ha reportado que es suficiente una temperatura de $300{ }^{\circ} \mathrm{C}$ en atmósfera reductora para formar partículas de $\mathrm{Cu}^{0}$ a partir de $\mathrm{Cu}^{+2}[35,37,40]$. Los catalizadores de $\mathrm{Cu} / \mathrm{SC}$ fueron activados en flujo continuo $\left(50 \mathrm{~cm}^{3} \cdot \mathrm{min}^{-1}\right)$ de $\mathrm{H}_{2}$ a $300{ }^{\circ} \mathrm{C}$ durante $90 \mathrm{~min}$.

\subsubsection{Preparación de catalizadores Ni/SC}

Los catalizadores basados en $\mathrm{Ni}$ como fase metálica, Ni/SC, se prepararon empleando la técnica de impregnación a humedad incipiente utilizando tres precursores distintos: $\mathrm{NiCl}_{2} .6 \mathrm{H}_{2} \mathrm{O}, \mathrm{Ni}\left(\mathrm{CH}_{3} \mathrm{COO}\right)_{2} .4 \mathrm{H}_{2} \mathrm{O}, \mathrm{Ni}\left(\mathrm{NO}_{3}\right)_{2} .6 \mathrm{H}_{2} \mathrm{O}$, y etanol como solvente. La elección de los precursores de $\mathrm{Ni}$ radica en su fácil descomposición. Precursores como $\mathrm{NiCO}_{3} \mathrm{Ni}(\mathrm{OH})_{2} \cdot \mathrm{H}_{2} \mathrm{O}$ y $\mathrm{NiSO}_{4} .7 \mathrm{H}_{2} \mathrm{O}$ no pueden emplearse debido a que descomponen a temperaturas elevadas, 500 ${ }^{\circ} \mathrm{C}$ y $800{ }^{\circ} \mathrm{C}$ respectivamente [53]. Dado el menor costo del Ni en comparación al Ru y la similitud en niveles de actividad con los catalizadores de $\mathrm{Cu}$, los catalizadores de Ni/SC se prepararon para alcanzar un $5 \%$ p/p de Ni.

Para el precursor de $\mathrm{NiCl}_{2} .6 \mathrm{H}_{2} \mathrm{O}$ se ha reportado que su descomposición ocurre en el rango de $300{ }^{\circ} \mathrm{C}$ a $400{ }^{\circ} \mathrm{C}$ [53-55]. Para lograr una descomposición completa, los catalizadores de $\mathrm{Ni}$ basados en este precursor, $\mathrm{Ni}(\mathrm{Cl}-) / \mathrm{SC}$, se calcinaron $\left(10{ }^{\circ} \mathrm{C} . \mathrm{min}^{-1}\right)$ en flujo continuo $(50$ $\left.\mathrm{cm}^{3} \cdot \mathrm{min}^{-1}\right)$ de $\mathrm{Ar}$ a $300{ }^{\circ} \mathrm{C}$ durante $3 \mathrm{~h}$ y posteriormente se activaron $\left(10{ }^{\circ} \mathrm{C} \cdot \mathrm{min}^{-1}\right)$ en flujo continuo $\left(50 \mathrm{~cm}^{3} \cdot \mathrm{min}^{-1}\right)$ de $\mathrm{H}_{2}$ a $400{ }^{\circ} \mathrm{C}$ durante $90 \mathrm{~min}$. 
Para el precursor de $\mathrm{Ni}\left(\mathrm{CH}_{3} \mathrm{COO}\right)_{2} .4 \mathrm{H}_{2} \mathrm{O}$ se ha reportado que la descomposición ocurre en atmósfera oxidante de aire entre $300^{\circ} \mathrm{C}$ y $350{ }^{\circ} \mathrm{C}$ [56]. Para lograr una descomposición completa, los catalizadores de $\mathrm{Ni}$ basados en este precursor, $\mathrm{Ni}(\mathrm{Ac}-) / \mathrm{SC}$, se pretrataron de igual modo que el $\mathrm{Ni}(\mathrm{Cl}-) / \mathrm{SC}$.

Para el precursor de $\mathrm{Ni}\left(\mathrm{NO}_{3}\right)_{2} \cdot 6 \mathrm{H}_{2} \mathrm{O}$ se ha reportado que la descomposición finaliza a $400{ }^{\circ} \mathrm{C}$ en atmósfera oxidante [53]. Para lograr una descomposición completa, los catalizadores de $\mathrm{Ni}$ basados en este precursor, $\mathrm{Ni}\left(\mathrm{NO}_{3-}\right) / \mathrm{SC}$, se calcinaron $\left(10{ }^{\circ} \mathrm{C} . \mathrm{min}^{-1}\right)$ en flujo continuo $\left(50 \mathrm{~cm}^{3} \cdot \mathrm{min}^{-1}\right)$ de $\operatorname{Ar}$ a $400{ }^{\circ} \mathrm{C}$ durante $3 \mathrm{~h}$ y posteriormente se activaron $(10$ $\left.{ }^{\circ} \mathrm{C} \cdot \mathrm{min}^{-1}\right)$ en flujo continuo $\left(50 \mathrm{~cm}^{3} \cdot \mathrm{min}^{-1}\right)$ de $\mathrm{H}_{2}$ a $400{ }^{\circ} \mathrm{C}$ durante $90 \mathrm{~min}$.

\subsubsection{Ensayos de actividad empleando los catalizadores $\mathrm{Ru} / \mathrm{SC}, \mathrm{Cu} / \mathrm{SC}$ y Ni/SC}

Los catalizadores de $\mathrm{Ru} / \mathrm{SC}, \mathrm{Cu} / \mathrm{SC}$ y $\mathrm{Ni} / \mathrm{SC}$ fueron evaluados en la reacción de hidrogenólisis de glicerol en fase líquida a $200-220{ }^{\circ} \mathrm{C}$, y una presión inicial de 20 bar de $\mathrm{H}_{2}$.

En cada ensayo se emplearon soluciones de glicerol al $10 \%$ p/p con una relación masa de glicerol a masa de catalizador $\left(\mathrm{m}_{\mathrm{gli}} / \mathrm{m}_{\mathrm{c}}\right)=4.2$. El tiempo de reacción fue de $4 \mathrm{~h}$. La selección de la temperatura y presión operativas se llevó a cabo considerando los valores más usuales encontrados en la bibliografía cuando se emplearon catalizadores basados en $\mathrm{Ru}, \mathrm{Cu}$ y $\mathrm{Ni}$ como fases activas. Los resultados obtenidos se presentan en las Tabla 1-5.

Tabla 1-5. Actividad de Ru/SC, Cu/SC y Ni/SC en la hidrogenólisis de glicerol.

\begin{tabular}{|c|c|c|c|c|c|c|c|c|c|c|}
\hline \multirow{2}{*}{ Catalizador } & \multirow{2}{*}{$\begin{array}{c}\mathrm{T} \\
\left({ }^{\circ} \mathrm{C}\right)\end{array}$} & \multirow{2}{*}{$\begin{array}{c}\mathrm{X}_{\mathrm{T}} \\
(\%)\end{array}$} & \multirow{2}{*}{$\begin{array}{c}X_{\mathrm{L}} \\
(\%)\end{array}$} & \multicolumn{7}{|c|}{ Selectividad (\%) } \\
\hline & & & & $\mathrm{MeOH}$ & $\mathrm{EtOH}$ & $\mathrm{AcO}$ & 1-POH & $\mathrm{AcOH}$ & EG & 1,2-PG \\
\hline $\mathrm{Ru}(\mathrm{Cl}-) / \mathrm{SC}$ & 200 & 3.4 & 2.7 & 1.6 & 2.0 & 0.0 & 0.9 & 0.2 & 40.0 & 55.3 \\
\hline $\mathrm{Ni}(\mathrm{Cl}-) / \mathrm{SC}$ & 200 & 0.7 & 0.6 & 0.6 & 3.6 & 0.1 & 1.2 & 3.2 & 14.3 & 77.0 \\
\hline $\mathrm{Cu}\left(\mathrm{NO}_{3}{ }^{-}\right) / \mathrm{SC}$ & 200 & 0.4 & 0.4 & 0.2 & 0.5 & 0.1 & 0.3 & 7.9 & 12.0 & 79.0 \\
\hline $\mathrm{Ni}(\mathrm{Cl}-) / \mathrm{SC}$ & 220 & 10.5 & 9.8 & 0.3 & 2.0 & 0.0 & 0.2 & 0.3 & 10.7 & 86.5 \\
\hline $\mathrm{Ni}(\mathrm{Ac}-) / \mathrm{SC}$ & 220 & 6.7 & 6.4 & 0.4 & 1.1 & 0.0 & 0.2 & 0.8 & 5.4 & 92.1 \\
\hline $\mathrm{Ni}\left(\mathrm{NO}_{3-}{ }^{-}\right) / \mathrm{SC}$ & 220 & 9.2 & 8.8 & 0.6 & 1.3 & 0.0 & 0.2 & 0.6 & 5.7 & 91.6 \\
\hline $\mathrm{Cu}(\mathrm{Ac}-) / \mathrm{SC}$ & 220 & 3.4 & 3.3 & 0.9 & 0.2 & 0.0 & 0.6 & 2.6 & 0.8 & 94.9 \\
\hline $\mathrm{Cu}\left(\mathrm{NO}_{3}{ }^{-}\right) / \mathrm{SC}$ & 220 & 4.8 & 4.7 & 1.0 & 0.3 & 0.0 & 0.4 & 12.4 & 0.6 & 85.3 \\
\hline
\end{tabular}

${ }^{*} \mathrm{X}_{\mathrm{T}}$ : conversión total de glicerol, $\mathrm{X}_{\mathrm{L}}$ : conversión de glicerol a productos líquidos.

En todos los ensayos realizados se obtuvo una muy baja conversión a productos gaseosos $(<1 \%)$. Los principales productos gaseosos identificados fueron metano, etano y $\mathrm{CO}_{2}$.

Los principales productos líquidos identificados fueron 1,2-propilenglicol (1,2-PG), etilenglicol $(\mathrm{EG})$, acetol $(\mathrm{AcOH})$, 1-propanol $(1-\mathrm{POH})$, etanol $(\mathrm{EtOH})$, metanol $(\mathrm{MeOH}) \mathrm{y}$ acetona $(\mathrm{AcO})$. En ninguno de los ensayos se detectó la presencia de 2-POH, 1,3-PG ni 3HPA. 
La presencia de estos productos hace suponer que la reacción se lleva a cabo mediante el mecanismo de deshidratación-hidrogenación, que fue descripto en el capítulo 2 y se muestra en el Esquema 1-5. Allí, el GLI (glicerol) puede formar AcOH y 3hidroxipropionaldehído (3-HPA) como productos intermediarios, mediante una deshidratación sobre los sitios del soporte o una ruptura C-O sobre la fase activa. Estos intermediarios, adsorbidos sobre la superficie catalítica, mediante un proceso de hidrogenación dan lugar a los glicoles, 1,2-PG y 1,3-propilenglicol (1,3-PG), respectivamente, que a su vez pueden seguir hidrogenándose para formar propanoles, 2-propanol (2- $\mathrm{POH}) \mathrm{y}$ 1-propanol (1-POH). También puede formarse propano por hidrogenación de los propanoles.

Por otro lado, pueden producirse reacciones laterales de ruptura de enlaces $\mathrm{C}-\mathrm{C}$, dando lugar a la formación de etilenglicol (EG) y metanol (MeOH) a partir de glicerol. El EG y el $\mathrm{MeOH}$ pueden seguir hidrogenándose para formar etanol (EtOH) y metano respectivamente. También puede formarse etano por hidrogenación del EtOH.

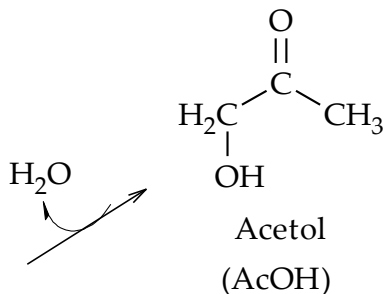

$(\mathrm{AcOH})$<smiles>CCCC</smiles><smiles>O[CH]CO</smiles>

1,2-propilenglicol $(1,2-\mathrm{PG})$<smiles>CC(CC=O)C(O)CO</smiles>
3-hidroxipropionaldehído

Glicerol (GLI)<smiles>CC1CC1</smiles><smiles>CCCCO</smiles>

1,3-propilenglicol (1,3-PG)<smiles>CCCCCC(CC)(CCO)C(C)(CC)CCO</smiles>

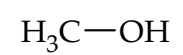

Metanol $(\mathrm{MeOH})$

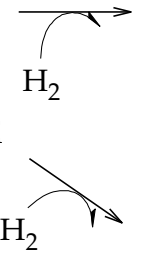

$\mathrm{H}_{2}$

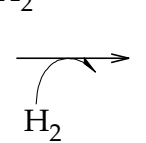<smiles>CCCO</smiles>

2-propanol

(2-POH)<smiles>C1CC2CC12</smiles><smiles>CCC</smiles>

Propano<smiles>CCOCC</smiles>

$(\mathrm{EtOH})$

Esquema 1-5. Mecanismo de deshidratación-hidrogenación de la hidrogenólisis de glicerol.

Con respecto al comportamiento de los catalizadores hay diferencias significativas en los niveles de conversión y selectividad.

$\mathrm{Ru} / \mathrm{SC}$ muestra una actividad a $200{ }^{\circ} \mathrm{C}$ muy superior al Ni/SC y Cu/SC. A pesar de tener una mayor selectividad a 1,2-PG (55\%), presenta una mayor contribución de productos de $\mathrm{C} 2$ y C1, tales como EG (40 \%), EtOH (2 \%) y MeOH (2 \%). Se ha reportado en bibliografía que catalizadores basados en $\mathrm{Ru}$ generan una mayor cantidad de productos de ruptura de enlaces $C-C[8,11,15,16]$. Miyazawa et al. encontraron que para catalizadores de $R u / C$, preparados a partir de $\mathrm{RuCl}_{3} . \mathrm{xH}_{2} \mathrm{O}$, la presencia de partículas de $\mathrm{Ru}$ con tamaño promedio de $1.7 \mathrm{~nm}$ promueven la formación de EG [8]. En catalizadores de $\mathrm{Ru}-\mathrm{Cu} / \mathrm{TiO}_{2}$, la adición de $\mathrm{Ru}$ 
para formar la fase bimetálica produce un cambio en los valores de selectividad a 1,2-PG debido a un aumento en la ruptura de enlaces C-C [11].

Por otro lado, los catalizadores de Ni/SC mostraron conversiones mucho menores que $\mathrm{Ru} / \mathrm{SC}$, pero al incrementar el nivel térmico a $220^{\circ} \mathrm{C}$ es posible alcanzar niveles de conversión igual o superiores al Ru/SC. En la bibliografía se ha reportado que el empleo de metales no nobles como $\mathrm{Ni}$ y $\mathrm{Cu}$ requieren mayores niveles térmicos para mostrar una actividad comparable con la de los metales nobles como Ru y Pt.

Los catalizadores de $\mathrm{Ni} / \mathrm{SC}$ mostraron un orden de actividad según el precursor: $\mathrm{Ni}(\mathrm{Cl}-)>\mathrm{Ni}\left(\mathrm{NO}_{3}-\right)>\mathrm{Ni}(\mathrm{Ac}-)$. Los tres catalizadores de $\mathrm{Ni}$ mostraron alta selectividad a 1,2PG (85-90\%), con baja actividad a reacciones de ruptura de enlaces C-C, lo que se observa por los bajos niveles de selectividad a EG (5-10 \%), EtOH (2 \%) y MeOH (0.5\%).

Los catalizadores de $\mathrm{Cu} / \mathrm{SC}$, mostraron alta selectividad a 1,2-PG (85-95\%), pero niveles de actividad menores a los catalizadores de $\mathrm{Ni} / \mathrm{SC}$. Se ha reportado que el $\mathrm{Cu}$ es un metal que posee una mayor capacidad de ruptura de enlaces $\mathrm{C}-\mathrm{O}[35,39]$ a diferencia de los metales nobles que promueven la ruptura de enlaces $\mathrm{C}-\mathrm{C}$. Catalizadores de $\mathrm{Cu} / \mathrm{Al}_{2} \mathrm{O}_{3}$ han mostrado altos niveles de selectividad ( $97 \%$ ) con una supresión casi por completo de reacciones laterales de ruptura $\mathrm{C}-\mathrm{C}$ a $220^{\circ} \mathrm{C}$ y 15 bar iniciales de $\mathrm{H}_{2}$ [35]. Otros sistemas de $\mathrm{Cu} / \mathrm{SiO}_{2}$ presentaron alta selectividad a 1,2-PG $(90 \%)$ a $200{ }^{\circ} \mathrm{C}$ y 50 bar de $\mathrm{H}_{2}$ [39].

\section{Conclusiones}

Los criterios teóricos de Mears y Weiz-Prater para determinar el efecto de las resistencias externas e internas a la transferencia de materia permitieron verificar que en los ensayos de reacción hay control cinético, permitiendo comparar las diferentes fases metálicas.

Análogamente, el criterio del número de Damkoehler de tercer y cuarto grado permitió verificar la ausencia de gradientes externos e internos de temperatura confirmando que no existen resistencias a la transferencia de energía en el reactor.

El ensayo de los blancos permitió verificar que el soporte de SC no tiene actividad por sí solo y que todos los resultados catalíticos serán asignados al comportamiento de los catalizadores metálicos soportados.

La preparación de catalizadores soportados empleando $\mathrm{Ru}, \mathrm{Cu}$ y $\mathrm{Ni}$ permitió fundamentalmente comparar conversión y selectividad de estos metales. Estos resultados permitieron determinar que los catalizadores de Ni/SC resultan atractivos para continuar los estudios posteriores, debido al nivel de actividad logrado a $220^{\circ} \mathrm{C}$ y la elevada selectividad a 1,2 PG.

\section{Bibliografía}

[1] P. D. Vaidya, V. V. Mahajani, Ind. Eng. Chem. Res. 42 (2003) 3881-3885.

[2] Z. Huang, F. Cui, H. Kang, J. Chen, X. Zhang, C. Xia, Chemical Materials 20 (2008) 50905099 . 
[3] D. G. Lahr, B. H. Shanks, Journal of Catalysis 232 (2005) 386-394.

[4] D. E. Mears, Industrial and Engineering Chemistry Process Design and Development 10 (1971) 541-547.

[5] R. V. Sharma, P. Kumar, A. K. Dalai, Applied Catalysis A: General 477 (2014) 147-156.

[6] D. E. Mears, Journal of Catalysis 20 (1971) 127-131.

[7] T. Miyazawa, Y. Kusunoki, K. Kunimori, K. Tomishige, Journal of Catalysis 240 (2006) 213-221.

[8] T. Miyazawa, S. Koso, K. Kunimori, K. Tomishige, Applied Catalysis A: General 318 (2007) 244-251.

[9] J. Feng, J. Wang, Y. Zhou, H. Fu, H. Chen, X. Li, Chemistry Letters 36 (10) (2007) 12741275.

[10] J. Feng, H. Fu, J. Wang, R. Li, H. Chen, X. Li, Catalysis Communications 9 (2008) 14581464.

[11] J. B. Salazar, D. D. Falcone, H. N. Pham, A. K. Datye, F. B. Passos, R. J. Davis, Applied Catalysis A: General 482 (2014) 137-144.

[12] E. S. Vasiliadou, E. Heracleous, I. A. Vasalos, A. A. Lemonidou, Applied Catalysis B Environmental 92 (2009) 90-99.

[13] R. Mane, S. Patil, M. Shirai, S. Rayalu, C. Rode, Applied Catalysis B Environmental 204 (2017) 134-146.

[14] E. Gallegos-Suarez, M. Pérez-Cadenas, A. Guerrero-Ruiz, I. Rodriguez-Ramos, A. Arcoya, Applied Surface Science 287 (2013) 108-116.

[15] E. Gallegos-Suarez, A. Guerrero-Ruiz, I. Rodriguez-Ramos, A. Arcoya, Chemical Engineering Journal 262 (2015) 326-333.

[16] M. Balaraju, V. Rekha, P. S. Sai Prasad, B. L. A. Prabhavathi Devi, R. B. N. Prasad, N. Lingaiah, Applied Catalysis A General 354 (2009) 82-87.

[17] S. Bolado, R. E. Treviño, M. T. García-Cubero, G. González-Benito, Catalysis Communications 12 (2010) 122-126.

[18] E. P. Maris, R. J. Davis, Journal of Catalysis 249 (2007) 328-337. 
[19] Z. Yuan, P. Wu, J. Gao, X. Lu, Z. Hou, X. Zheng, Catalysis Letters 130 (2009) 261-265.

[20] M. L. Barbelli, G. F. Santori, N. N. Nichio, Bioresource Technology 111 (2012) 500-503.

[21] S. Zhu, Y. Qiu, Y. Zhua, S. Hao, H. Zheng, Y. Li, Catalysis Today 212 (2013) 120-126.

[22] S. N. Delgado, D. Yap, L. Vivier, C. Especel, Journal of Molecular Catalysis A Chemical 367 (2013) 89-98.

[23] C. Deng, X. Duan, J. Zhou, D. Chen, X. Zhou, W. Yuan, Catalysis Today 234 (2014) 208214.

[24] S. N. Delgado, L. Vivier, C. Especel, Catalysis Communications 43 (2014) 107-111.

[25] A. Von-Held Soares, G. Perez, F. B. Passos, Applied Catalysis B Environmental 185 (2016) 77-87.

[26] A. Von Held Soares, H. Atia, U. Armbruster, F. B. Passos, A. Martin, Applied Catalysis A, General 548 (2017) 179-190.

[27] J. Chaminand, L. Djakovitch, P. Gallezot, P. Marion, C. Pinel, C. Rosier, Green Chemistry 6 (2004) 359-361.

[28] I. Furikado, T. Miyazawa, S. Koso, A. Shimao, K. Kunimori, K. Tomishige, Green Chemitry 9 (2007) 582-588.

[29] A. Shimao, S. Koso, N. Ueda, Y. Shinmi, I. Furikado, K. Tomishige, Chemistry Letters 38 (6) (2009) 540-541.

[30] Y. Shinmi, S. Koso, T. Kubota, Y. Nakagawa, K. Tomishige, Applied Catalysis B Environmental 94 (2010) 318-326.

[31] M. G. Musolino, L. A. Scarpino, F. Mauriello, R. Pietropaolo, Green Chemistry 11 (2009) 1511-1513.

[32] Y. Feng, C. Liu, Y. Kang, X. Zhou, L. Liu, J. Deng, H. Xu, Y. Fu, Chemical Engineering Journal 281 (2015) 96-101.

[33] F. Mauriello, H. Ariga, M. G. Musolino, R. Pietropaolo, S. Takakusagi, K. Asakura, Applied Catalysis B Environmental166-167 (2015) 121-131.

[34] Y. Li, H. Liu, L. Ma, D. He, Applied Catalysis A General 522 (2016) 13-20. 
[35] L. Guo, J. Zhou, J. Mao, X. Guo, S. Zhang, Applied Catalysis A General 367 (2009) 93-98.

[36] A. Bienholz, H. Hofmann, P. Claus, Applied Catalysis A General 391 (2011) 153-157.

[37] F. Vila, M. López Granados, M. Ojeda, J. L. G. Fierro, R. Mariscal, Catalysis Today 187 (2012) 122-128.

[38] E. S. Vasiliadou, A. A. Lemonidou, Applied Catalysis A General 396 (2011) 177-185.

[39] S. Zhu, X. Gao, Y. Zhu, Y. Zhu, H. Zheng, Y. Li, Journal of Catalysis 303 (2013) 70-79.

[40] J. Zheng, W. Zhu, C. Ma, Y. Hou, W. Zhang, Z. Wang, Reaction Kinetics Mechanisms and Catalysis 99 (2010) 455-462.

[41] J. Zhao, W. Yu, C. Chen, H. Miao, H. Ma, J. Xu, Catalysis Letters 134 (2010) 184-189.

[42] W. Yu, J. Zhao, H. Ma, H. Miao, Q. Song, J. Xu, Applied Catalysis A General 383 (2010) 73-78.

[43] W. Yu, J. Xu, H. Ma, C. Chen, J. Zhao, H. Miao, H. Miao, Q. Song, Catalysis Communications 11 (2010) 493-497.

[44] I. Jimenez-Morales, F. Vila, R. Mariscal, A. Jiménez-LópezApplied Catalysis B Environmental 117-118 (2012) 253-259.

[45] Q. Liu, X. Guo, Y. Li, W. Shen, Langmuir 25(11) (2009) 6425-6430.

[46] X. Guo, Y. Li, R. Shi, Q. Liu, E. Zhan, W. Shen, Applied Catalysis A General 371 (2009) 108-113.

[47] Q. Liu, X. Guo, T. Wang, Y. Li, W. Shen, Materials Letters 64 (2010) 1271-1274.

[48] X. Guo, Y. Li, W. Song, W. Shen, Catalysis Letters 141 (2011) 1458-1463.

[49] H. S. Zeng, K. Inazu, K. Aika, Applied Catalysis A General 219 (2001) 235-247.

[50] Li Zhong, W. Ruiyu, Z. Huayan, X. Kechang, Fuel 89 (2010) 1339-1343.

[51] Z. Liu, X. Li, J. Y. Lee, T. B. Bolin, Chemical Engineering Journal 275 (2015) 1-7.

[52] K. Zhang, J. Hong, G. Cao, D. Zhan, Y. Tao, C. Cong, Thermochimica Acta 437 (2005) 145-149. 
[53] C. Popescu, I. Ursu, M. Popescu, R. Alexandrescu, I. Morjan, I. N. Mihailescu, V. Jianu, Thermochimica Acta 164 (1990) 79-90.

[54] M. Rashidi, A. Tavasoli, Journal of Supercritical Fluids 98 (2015) 111-118.

[55] Q. Wang, Y. F. Xu, G. L. Xu, H. Su, S. Y. Shen, T. T. Tu, L. Huang, J. T. Li, S. G. Sun, Journal of Alloys and Compounds 648 (2015) 59-66.

[56] J. C. De Jesus, I. Gonzalez, A. Quevedo, T. Puerta, Journal of Molecular Catalysis A: Chemical 228 (2005) 283-291. 



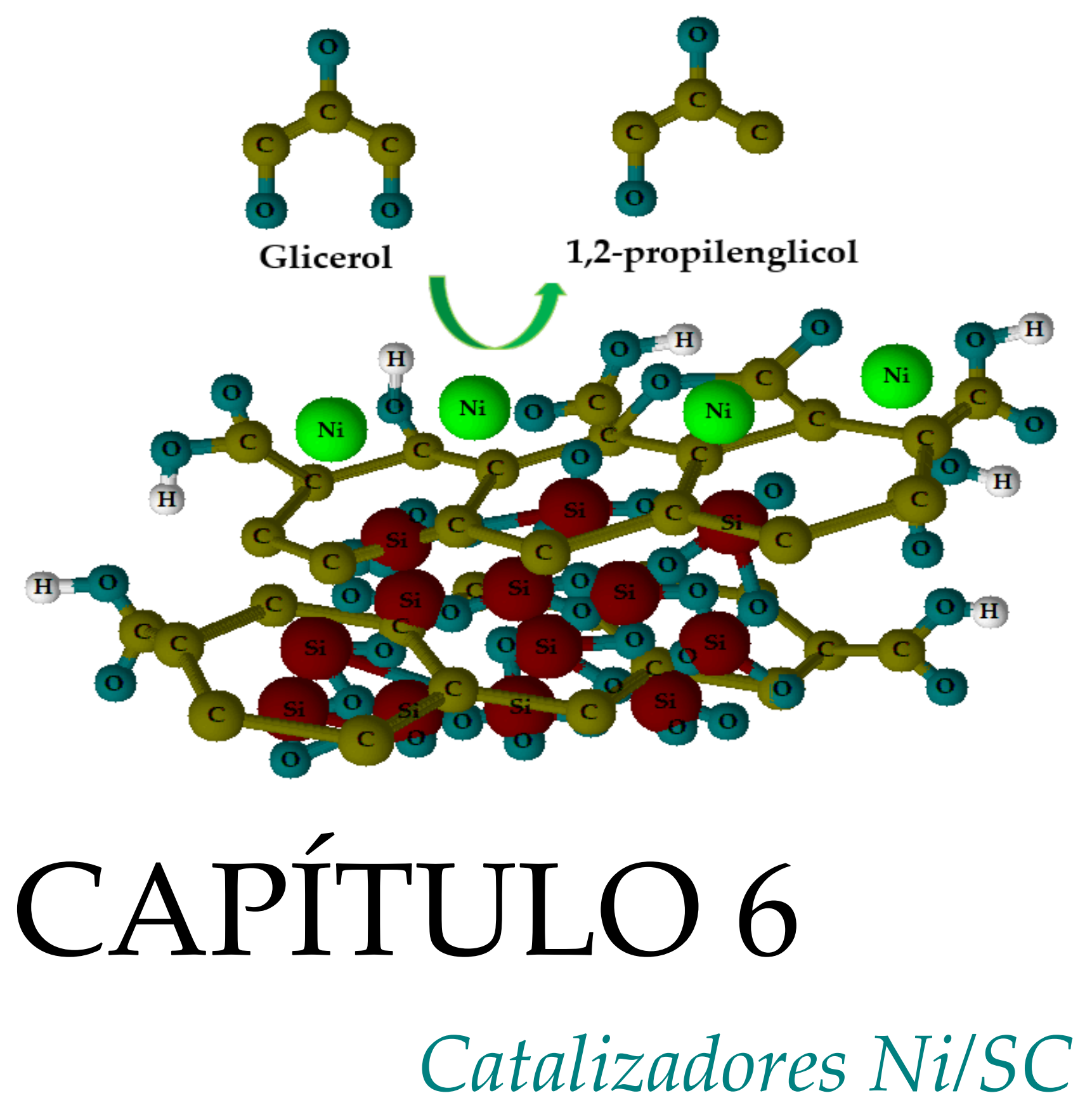




\subsection{Introducción}

En el capítulo 5 se efectuó un estudio experimental de actividad catalítica que indica como promisorios a los catalizadores Ni/SC para continuar con este trabajo de tesis.

En este capítulo se presenta un estudio de los catalizadores de $\mathrm{Ni}$ preparados a partir de tres precursores de $\mathrm{Ni}$; $\mathrm{NiCl}_{2} .6 \mathrm{H}_{2} \mathrm{O}, \mathrm{Ni}\left(\mathrm{CH}_{3} \mathrm{COO}\right)_{2} .4 \mathrm{H}_{2} \mathrm{O}$ y $\mathrm{Ni}\left(\mathrm{NO}_{3}\right)_{2} .6 \mathrm{H}_{2} \mathrm{O}$, cuya denominación es $\mathrm{Ni}(\mathrm{Cl}-) / \mathrm{SC}, \mathrm{Ni}(\mathrm{Ac}-) / \mathrm{SC}$ y $\mathrm{Ni}\left(\mathrm{NO}_{3-}\right) / \mathrm{SC}$ respectivamente.

En primera instancia se estudian los diferentes pretratamientos, considerando que el precursor empleado, las temperaturas, atmósferas y tiempos de los tratamientos afectan al catalizador final.

Posteriormente se estudia el efecto del precursor de níquel, y se selecciona aquel que permita obtener altos niveles de conversión con alta selectividad a 1,2-PG.

Luego, para el precursor seleccionado, se procede a evaluar el efecto del soporte, considerando para este análisis los soportes $\mathrm{C}, \mathrm{SiO}_{2}$, además del SC.

Finalmente, con el catalizador de Ni/SC que resultó óptimo, se estudia el efecto de las principales variables operativas de la reacción de hidrogenólisis y se analizan los cambios estructurales que sufre el catalizador luego de la reacción.

\subsection{Análisis de descomposición de los precursores de Ni por TGA}

Por análisis de TGA se determinaron los perfiles de descomposición de los precursores de los catalizadores Ni/SC, previamente secados en estufa a $120{ }^{\circ} \mathrm{C}$ durante $12 \mathrm{~h}$. Estos análisis de TGA se llevaron a cabo en dos atmósferas distintas, una atmósfera oxidante de aire y otra atmósfera inerte de $\mathrm{Ar}$ en el rango de $25{ }^{\circ} \mathrm{C}$ a $800{ }^{\circ} \mathrm{C}$, con una rampa de calentamiento de $10{ }^{\circ} \mathrm{C} \cdot \mathrm{min}^{-1}$.

Las Figuras 1-6, 2-6 y 3-6 muestran los perfiles de TG/DTG para los precursores de $\mathrm{Ni}(\mathrm{Cl}-) / \mathrm{SC}, \mathrm{Ni}(\mathrm{Ac}-) / \mathrm{SC}$ y $\mathrm{Ni}\left(\mathrm{NO}_{3}-\right) / \mathrm{SC}$ respectivamente. Los perfiles, para las tres muestras, señalan una pérdida de masa entre $25{ }^{\circ} \mathrm{C}$ y $150{ }^{\circ} \mathrm{C}$ correspondiente a la pérdida de agua del precursor de catalizador, tanto en atmósfera oxidante como en atmósfera inerte. La pérdida de agua corresponde a un $9 \%$ para $\mathrm{Ni}(\mathrm{Cl}-) / \mathrm{SC}$, un $3 \%$ para $\mathrm{Ni}(\mathrm{Ac}-) / \mathrm{SC}$ y un $4 \%$ para $\mathrm{Ni}\left(\mathrm{NO}_{3-}\right) / \mathrm{SC}$.

Para Ni(Cl-)/SC en atmósfera inerte, se produce una pérdida de masa del $5 \%$ cerca de los $440{ }^{\circ} \mathrm{C}$, correspondiente a la descomposición del $\mathrm{NiCl}_{2}$ [1]. Posteriormente a $650{ }^{\circ} \mathrm{C}$, con una pérdida de masa del $25 \%$, se produce la gasificación del soporte de SC. En atmósfera oxidante, en cambio, en el rango térmico de $400{ }^{\circ} \mathrm{C}$ a $620^{\circ} \mathrm{C}$ se produce simultáneamente la descomposición del $\mathrm{NiCl}_{2}$ y la gasificación del soporte (Figura 1-6).

Para $\mathrm{Ni}(\mathrm{Ac}-) / \mathrm{SC}$, la descomposición del precursor se produce de forma similar en ambas atmósferas, en el rango entre $200{ }^{\circ} \mathrm{C}$ y $350{ }^{\circ} \mathrm{C}$ con una pérdida de masa del $6 \%$ [2]. La gasificación del soporte en este caso se produce a partir de $350{ }^{\circ} \mathrm{C}$, con una pérdida de masa del $26 \%$. En atmósfera oxidante, por otro lado, la gasificación del soporte es más rápida y alcanza su máximo a $500{ }^{\circ} \mathrm{C}$, mientras que en atmósfera inerte dicho máximo se encuentra a $600{ }^{\circ} \mathrm{C}$, indicando que la gasificación es más lenta (Figura 2-6). 


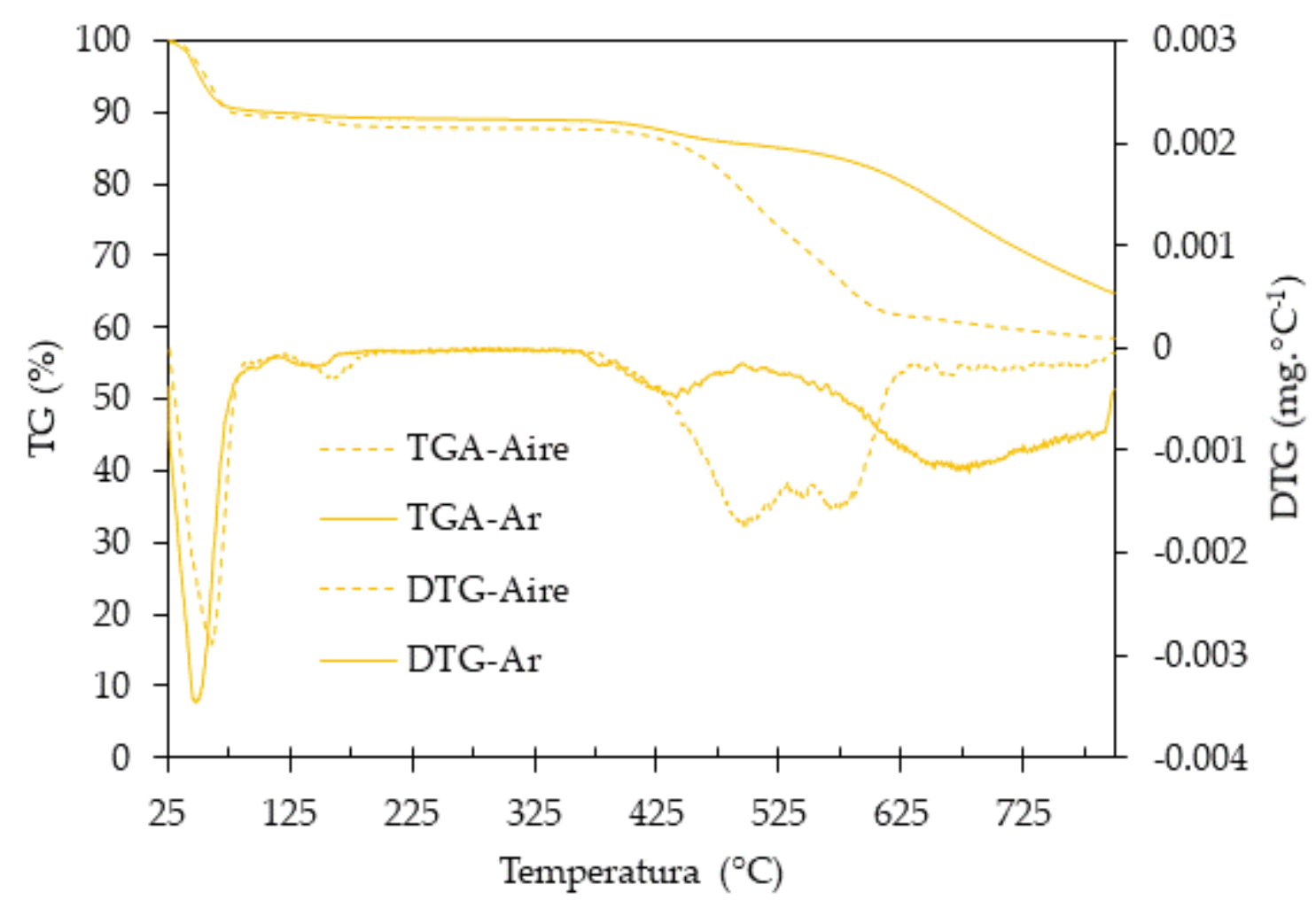

Figura 1-6. Perfiles de TGA para Ni(Cl-)/SC en atmósferas de aire y Ar.

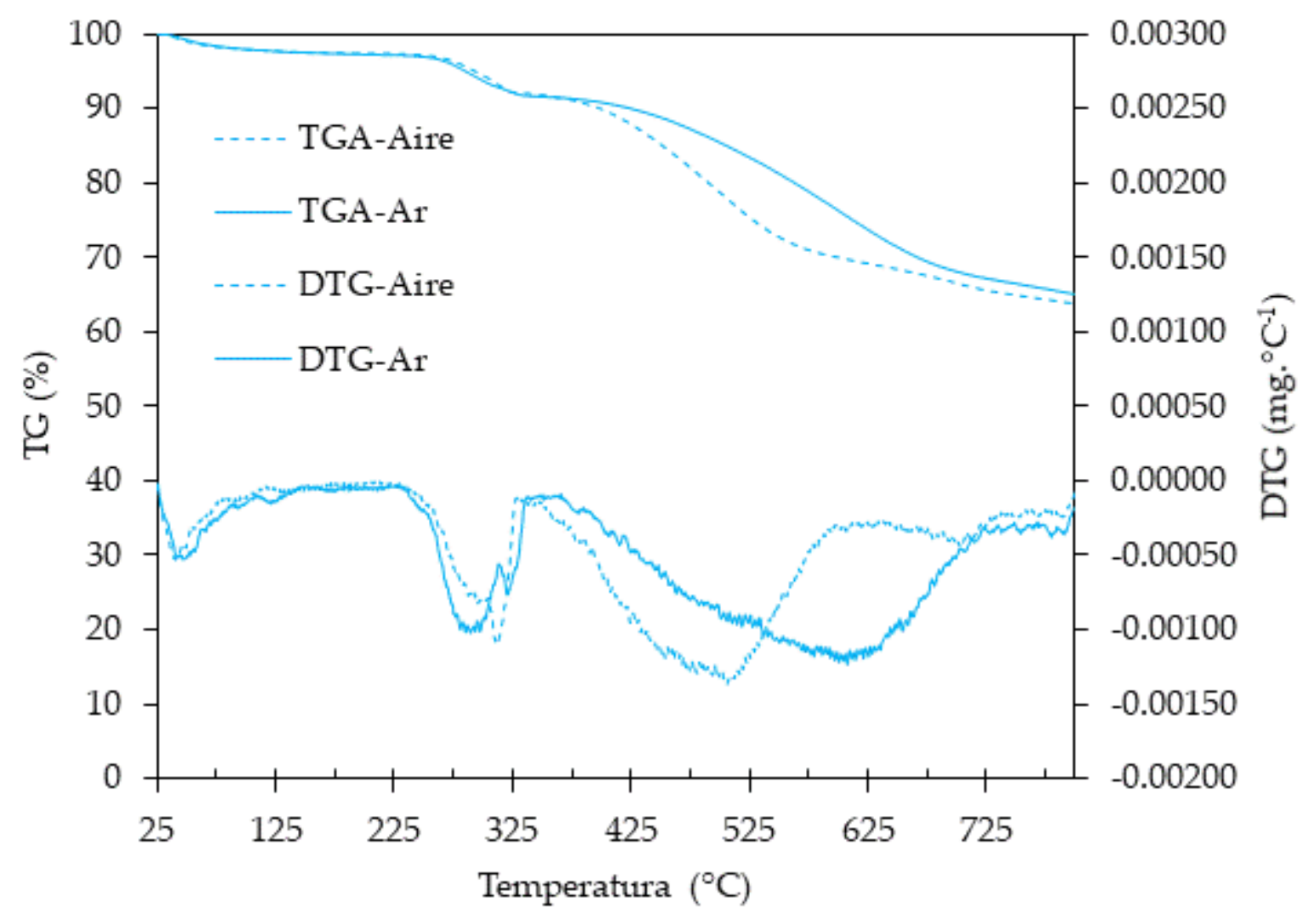

Figura 2-6. Perfiles de TGA para Ni(Ac-)/SC en atmósferas de aire y Ar. 
Para $\mathrm{Ni}\left(\mathrm{NO}_{3-}-\right) / \mathrm{SC}$ la descomposición del precursor es bastante similar al $\mathrm{Ni}(\mathrm{Ac}-) / \mathrm{SC}$, ya que, entre $240{ }^{\circ} \mathrm{C}$ y $370{ }^{\circ} \mathrm{C}$, en ambas atmósferas se produce una pérdida de masa del $6 \%$. La gasificación del soporte inicia a los $350{ }^{\circ} \mathrm{C}$ tanto en atmósfera inerte como oxidante, con una pérdida de masa del $33 \%$. En presencia de aire la descomposición es más rápida y alcanza su máximo a $470{ }^{\circ} \mathrm{C}$ y en atmósfera inerte el máximo se encuentra a $540{ }^{\circ} \mathrm{C}$.

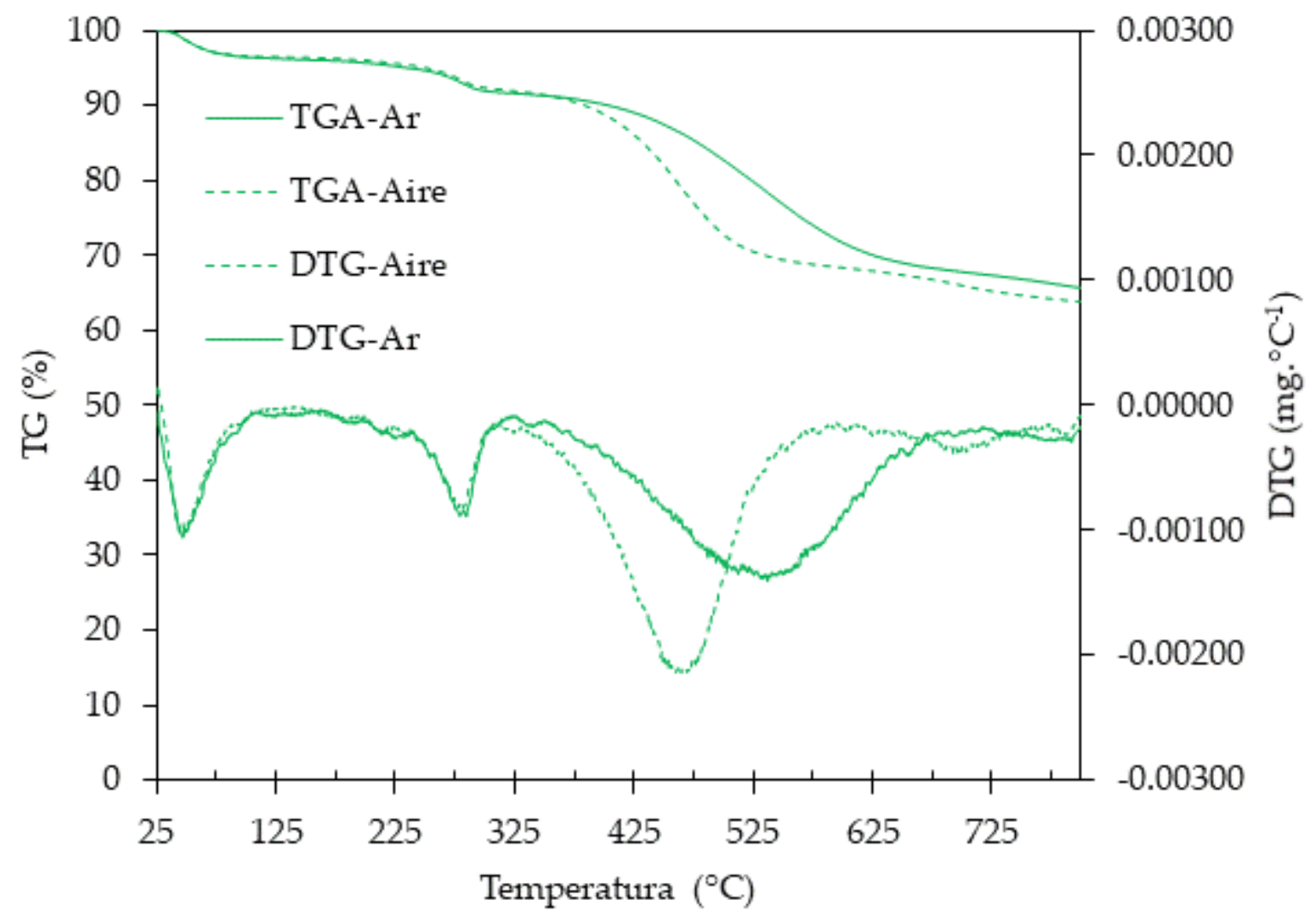

Figura 3-6. Perfiles de TGA para $\mathrm{Ni}\left(\mathrm{NO}_{3}{ }^{-}\right) / \mathrm{SC}$ en atmósferas de aire y Ar.

\subsection{Estudio del pretratamiento de calcinación}

Los pretratamientos de calcinación estudiados en este trabajo de tesis se resumen en la Tabla 1-6.

Tabla 1-6. Pretratamientos de calcinación para precursores de catalizadores Ni/SC.

\begin{tabular}{lccc}
\hline \multirow{2}{*}{ Pretratamiento } & \multicolumn{3}{c}{ Calcinación } \\
\cline { 2 - 4 } & Atmósfera & $\mathrm{T}\left({ }^{\circ} \mathrm{C}\right)$ & $\mathrm{t}(\mathrm{h})$ \\
\hline Ar 200 & Ar & 200 & 3 \\
Ar 300 & Ar & 300 & 3 \\
Ar 350 & Ar & 350 & 3 \\
Ar 400 & Ar & 400 & 3 \\
$\mathrm{~N}_{2} 300$ & $\mathrm{~N}_{2}$ & 300 & 3 \\
Aire 300 & Aire & 300 & 3 \\
\hline
\end{tabular}


Para verificar la completa descomposición de los precursores durante los pretratamientos de calcinación presentados en la Tabla 1-6 se llevaron a cabo análisis de DRX. En las Figuras 5-6, 7-6 y 9-6 los picos a $2 \theta=21.8^{\circ}, 26.4^{\circ}, 35.7^{\circ}, 41.4^{\circ}, 60.0^{\circ}$ y $71.9^{\circ}$

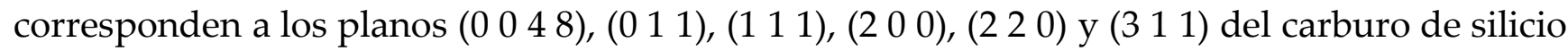
$(\Delta)$, como se describió en el capítulo 4.

En la Figura 4-6 se muestra la JCPDS del $\mathrm{NiCl}_{2}$ (JCPDS 71-2032). A partir de la misma es posible observar que esta sal precursora presenta picos principales $(\bullet)$ a $2 \theta=15.2^{\circ}, 30.8^{\circ} \mathrm{y}$ $36.2^{\circ}$.

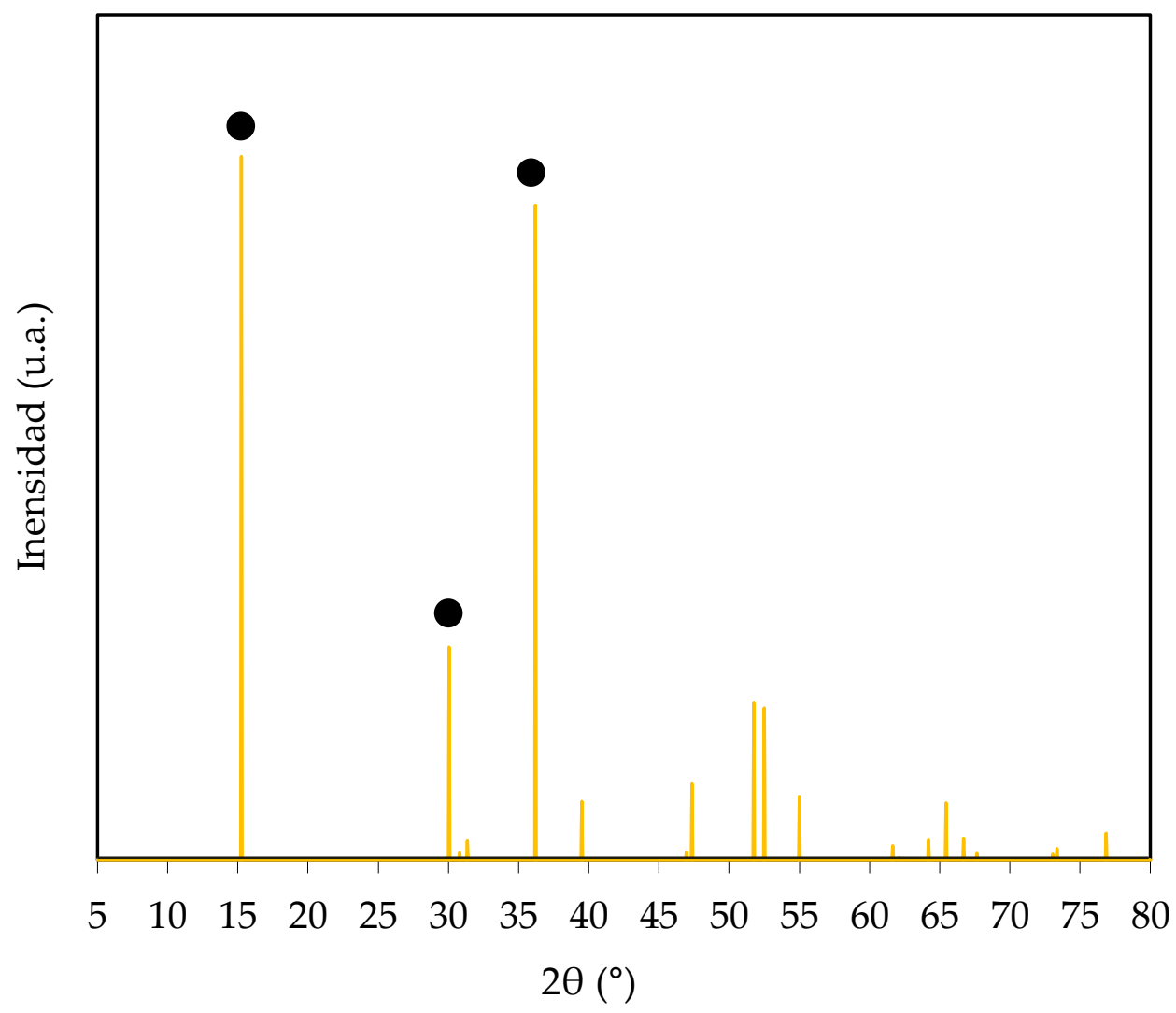

Figura 4-6. Difractogramas de rayos X de $\mathrm{NiCl}_{2}$ (JCPDS 71-2032).

En la Figura 5-6 se visualizan los catalizadores $\mathrm{Ni}(\mathrm{Cl}-) / \mathrm{SC}$ calcinados en diferentes condiciones. Se incluye además el difractograma del catalizador secado a $120^{\circ} \mathrm{C}$ durante 12 h. Los resultados indican que el catalizador secado a $120{ }^{\circ} \mathrm{C}$ mantiene muchos de los picos asociados a la sal de $\mathrm{NiCl}_{2}$, indicando la presencia del precursor. Los pretratamientos en $\mathrm{Ar}$ a $300{ }^{\circ} \mathrm{C}$ y $400{ }^{\circ} \mathrm{C}$, así como en aire y en $\mathrm{N}_{2}$ a $300{ }^{\circ} \mathrm{C}$, no muestran picos correspondientes a la sal, indicando que estos tratamientos descompusieron el precursor. No se observan señales correspondientes a $\mathrm{NiO}$ ni de $\mathrm{Ni}^{0}$, indicando que el $\mathrm{Ni}$ una vez descompuesto se encuentra probablemente como especies de $\mathrm{Ni}^{+2}$. 


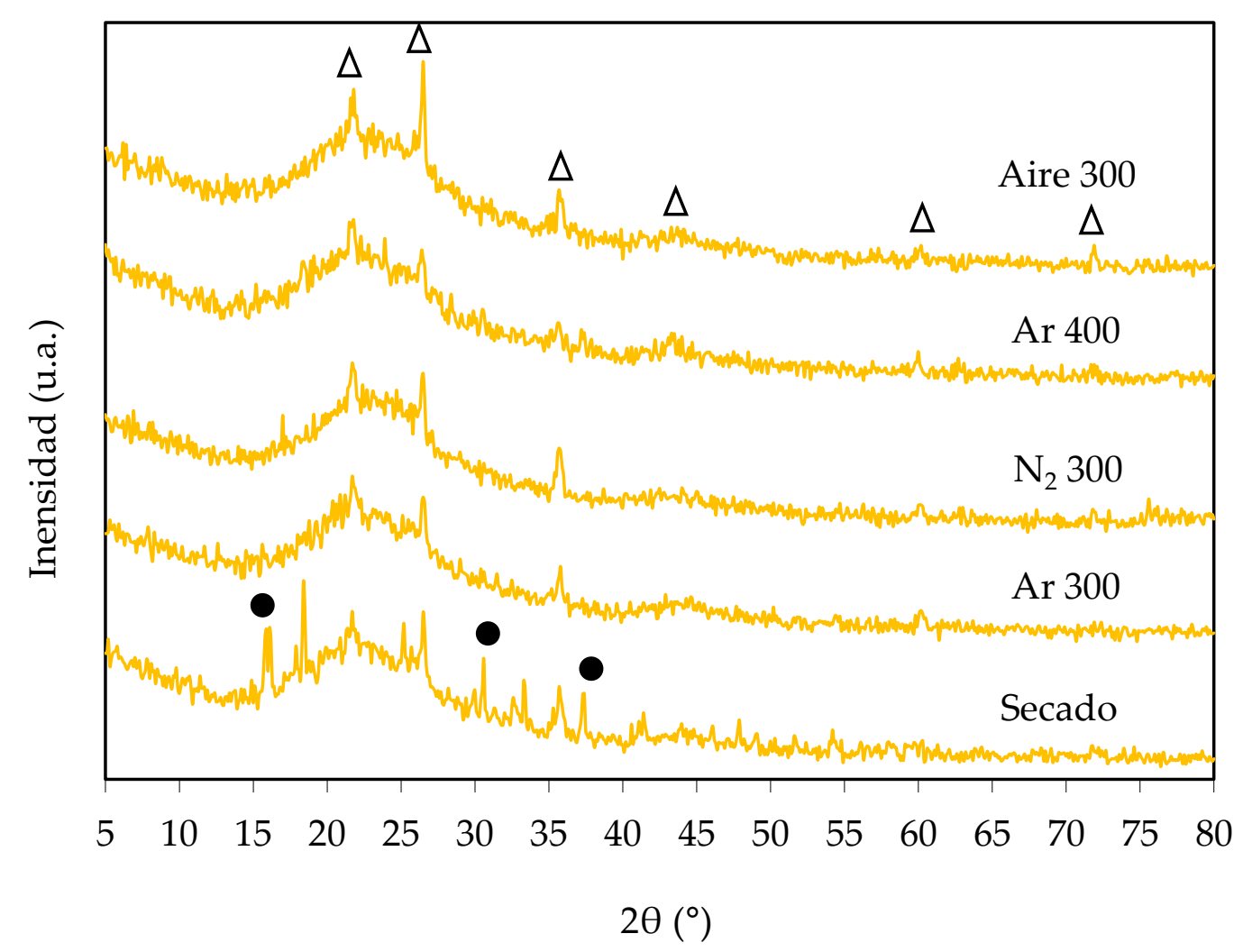

Figura 5-6. Difractogramas de rayos X para catalizadores de $\mathrm{Ni}(\mathrm{Cl}$-)/SC.

En la Figura 6-6 se muestra la JCDPS del Ni(CH3 COO) $)_{2}$ (JCDPS 01-0105). A partir de la misma es posible observar que esta sal precursora presenta picos principales $(\bullet)$ a $2 \theta=5.9^{\circ}$, $8.5^{\circ} 10.4^{\circ}$ y $12.9^{\circ}$.

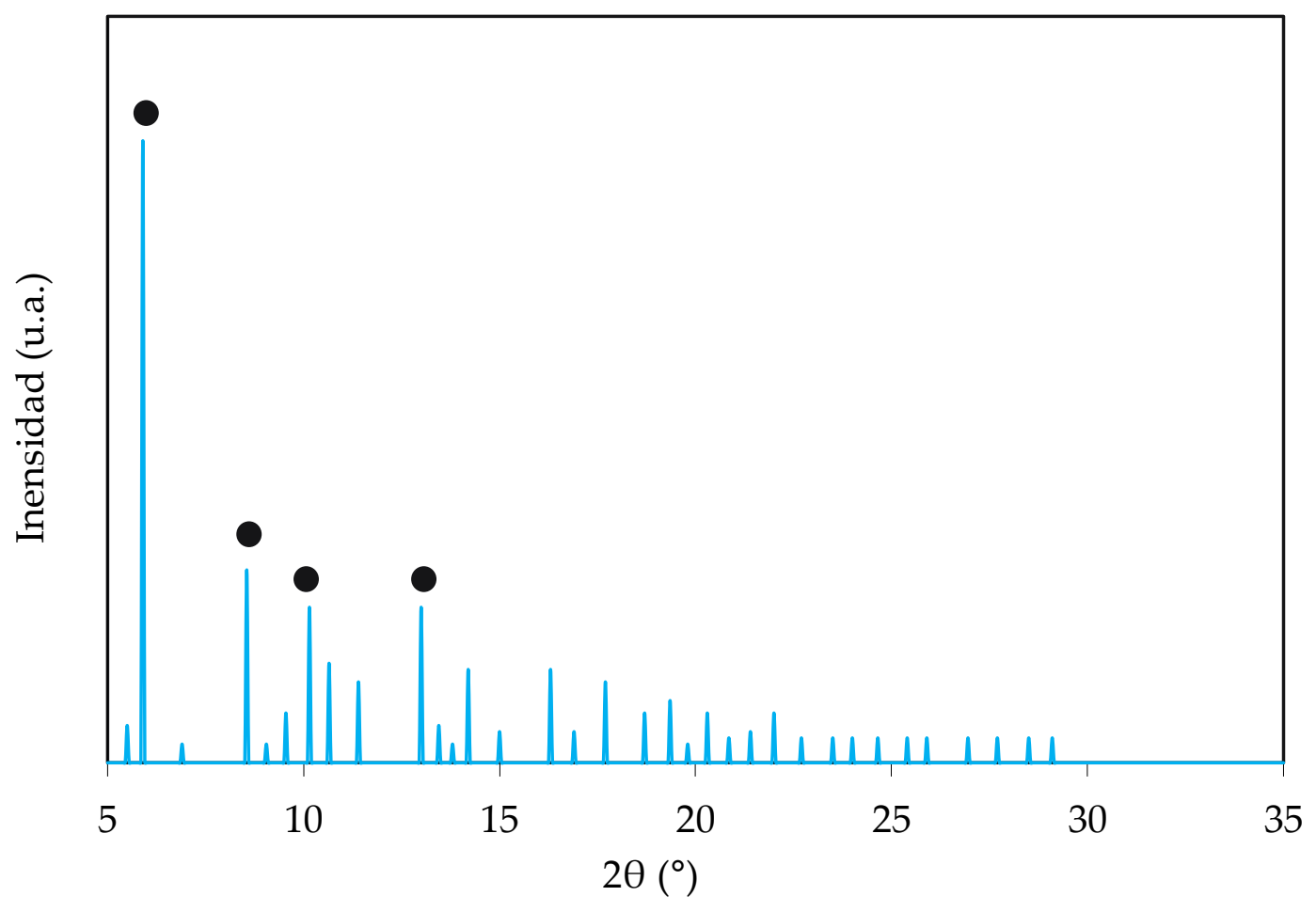

Figura 6-6. Difractogramas de rayos $\mathrm{X}$ de $\mathrm{Ni}\left(\mathrm{CH}_{3} \mathrm{COO}\right)_{2}$ (JCPDS 01-0105). 
En la Figura 7-6 se muestran los catalizadores de Ni(Ac-)/SC calcinados en las distintas condiciones. Los resultados indican que el catalizador secado a $120{ }^{\circ} \mathrm{C}$ mantiene algunos de los picos $(\bullet)$ asociados a la sal de $\mathrm{Ni}\left(\mathrm{CH}_{3} \mathrm{COO}\right)_{2}$, indicando la presencia del precursor sobre el soporte de SC. Lo mismo ocurre para el catalizador calcinado a $200{ }^{\circ} \mathrm{C}$ en atmósfera de Ar, indicando que este tratamiento no es efectivo para descomponer el precursor. Los pretratamientos a $300{ }^{\circ} \mathrm{C}$ en atmósferas de $\mathrm{Ar}$, aire y $\mathrm{N}_{2}$ resultan ser efectivos para descomponer el $\mathrm{Ni}\left(\mathrm{CH}_{3} \mathrm{COO}\right)_{2}$ puesto que no se visualizan picos correspondientes a la fase cristalina del precursor.

Para el caso de la calcinación en aire a $300{ }^{\circ} \mathrm{C}$ se observan tres picos a $2 \theta=37.2^{\circ}, 43.2^{\circ}$ y $62.8^{\circ}$ correspondiente a los planos $\left(\begin{array}{lll}1 & 1 & 1\end{array}\right),\left(\begin{array}{lll}2 & 0 & 0\end{array}\right)$ y $\left(\begin{array}{lll}2 & 2 & 0\end{array}\right)$ del NiO ( $)$ (JCPDS Nº0-0731523) [3]. Para las calcinaciones en $\mathrm{Ar}$ y $\mathrm{N}_{2}$ a $300{ }^{\circ} \mathrm{C}$ no se observa la presencia de NiO. No obstante, se evidencia un pequeño pico a $2 \theta=44.5^{\circ}$ que se asigna al plano $\left(\begin{array}{lll}1 & 1 & 1\end{array}\right)$ del níquel metálico ( $\boldsymbol{\Delta}$ ) (JCPDS 04-0850). De Jesus et al. estudiaron la descomposición del $\mathrm{Ni}\left(\mathrm{CH}_{3} \mathrm{COO}\right)_{2}$ en atmósferas de aire, $\mathrm{H}_{2}$ y $\mathrm{He}$, encontrando que en aire el producto final es $\mathrm{NiO}$, mientras que en $\mathrm{H}_{2}$ y He, el $\mathrm{NiO}$ es el producto intermediario que da lugar a la formación de partículas metálicas de $\mathrm{Ni}^{0}[2]$.

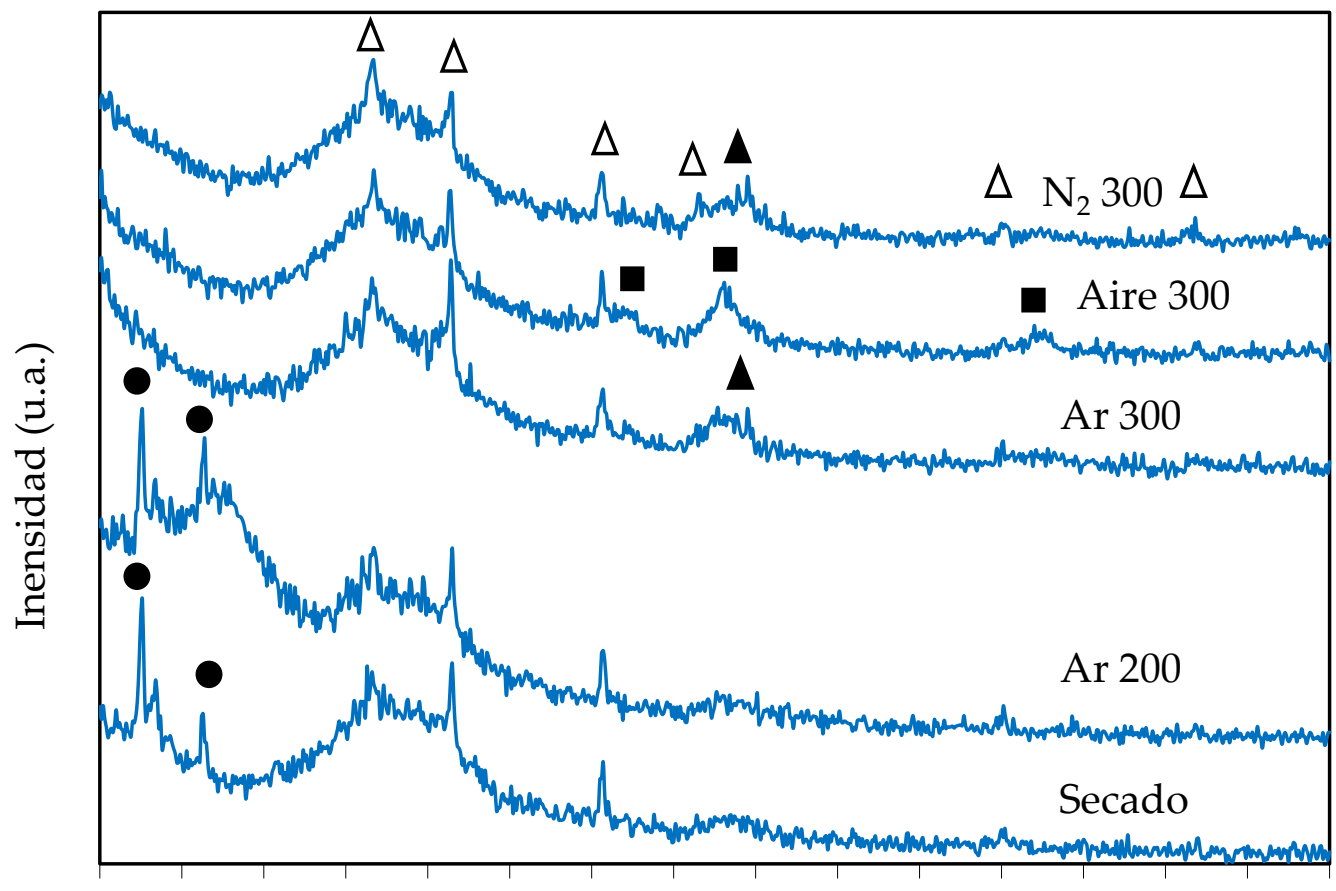

$\begin{array}{llllllllllllllll}5 & 10 & 15 & 20 & 25 & 30 & 35 & 40 & 45 & 50 & 55 & 60 & 65 & 70 & 75 & 80\end{array}$

$2 \theta\left({ }^{\circ}\right)$

Figura 7-6. Difractogramas de rayos X para catalizadores de Ni(Ac-)/SC.

En la Figura 8-6 se muestra la JCPDS del Ni(NO3)2 (JCPDS 22-0751). A partir de la misma es posible observar como la sal precursora presenta picos principales $(\bullet)$ a $2 \theta=13^{\circ}$, $18.2^{\circ}, 18.6^{\circ}, 20.2^{\circ}$ y $30.8^{\circ}$. 


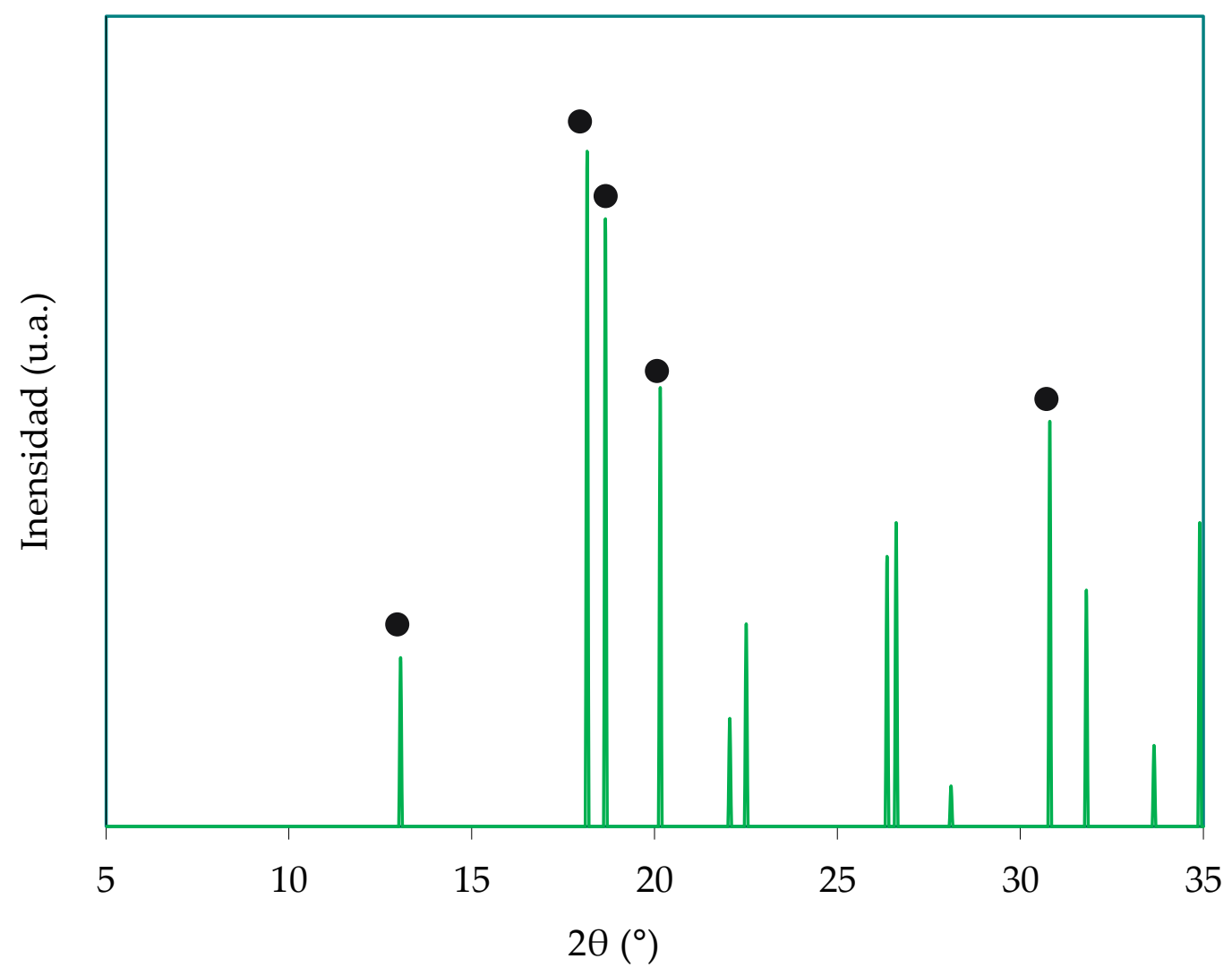

Figura 8-6. Difractogramas de rayos $\mathrm{X}$ de $\mathrm{Ni}\left(\mathrm{NO}_{3-}{ }^{-}\right) / S C$ (JCDPS 22-0751).

En la Figura 9-6 se visualizan los catalizadores de $\mathrm{Ni}\left(\mathrm{NO}_{3}-\right) / \mathrm{SC}$ calcinados en las distintas condiciones.

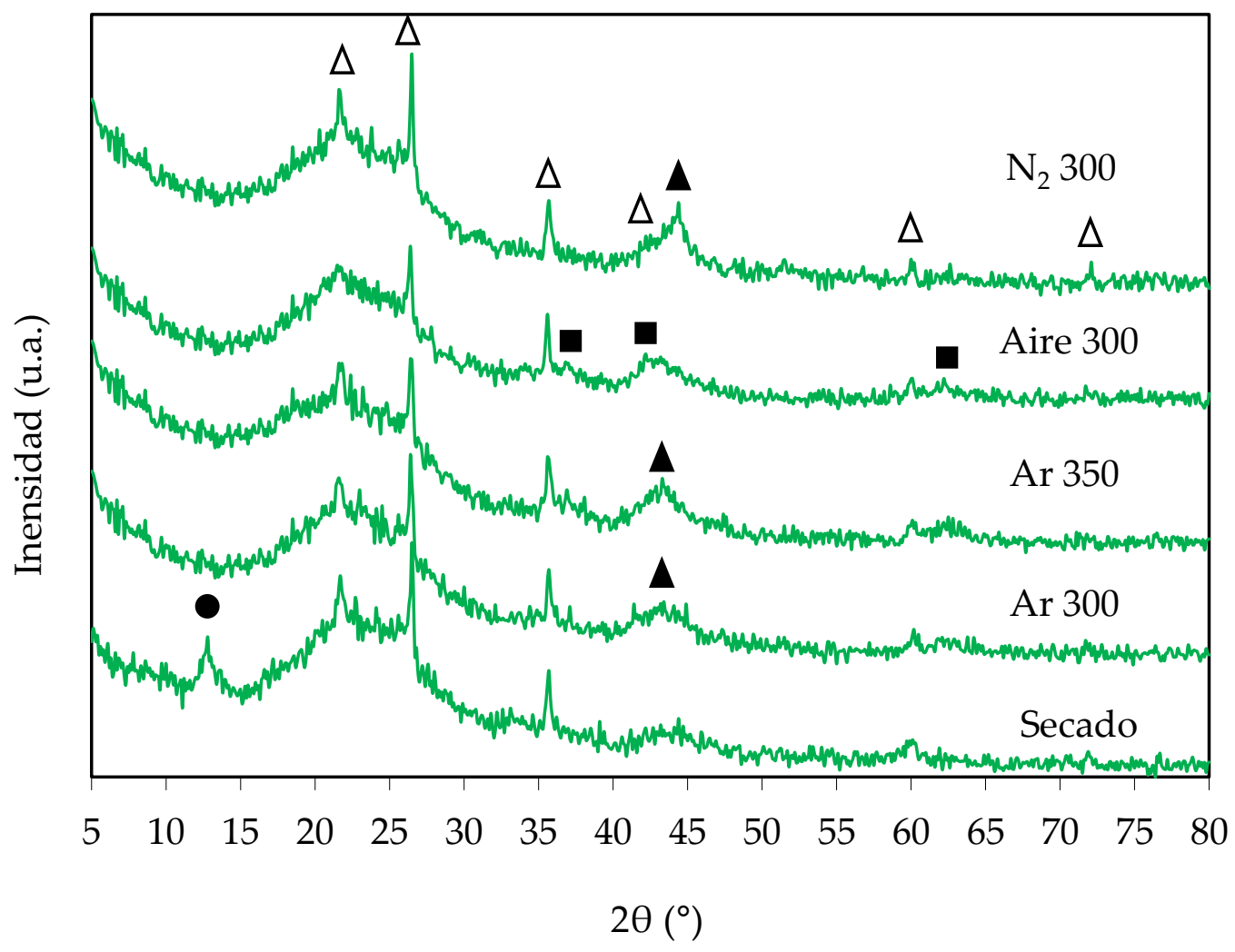

Figura 9-6. Difractogramas de rayos X para catalizadores de $\mathrm{Ni}\left(\mathrm{NO}_{3}-\right) / \mathrm{SC}$. 
Los resultados indican que el catalizador secado a $120^{\circ} \mathrm{C}$ mantiene uno de los picos $(\bullet)$ asociados a la sal de $\mathrm{Ni}\left(\mathrm{NO}_{3}\right)_{2}$, indicando la presencia del precursor sobre el soporte de SC.

Los pretratamientos en aire, $\mathrm{N}_{2}$ y $\mathrm{Ar}$ a $300{ }^{\circ} \mathrm{C}$ y $350{ }^{\circ} \mathrm{C}$ resultan ser efectivos para descomponer el $\mathrm{Ni}\left(\mathrm{NO}_{3}\right)_{2}$.

Para el caso de la calcinación en aire a $300{ }^{\circ} \mathrm{C}$ se observan tres picos a $2 \theta=37.2^{\circ}, 43.2^{\circ}$ y $62.8^{\circ}$ correspondiente a los planos $\left(\begin{array}{lll}1 & 1 & 1\end{array}\right),\left(\begin{array}{lll}2 & 0 & 0\end{array}\right)$ y $\left(\begin{array}{lll}2 & 2 & 0\end{array}\right)$ del NiO (•) (JCPDS N ${ }^{\circ}$ 00-0731523) [3]. Para los casos de las calcinaciones en $\mathrm{Ar}$ y $\mathrm{N}_{2}$ no se observa la presencia de $\mathrm{NiO}$, pero se evidencia un pequeño pico a $2 \theta=44.5^{\circ}$ que se asigna al plano $\left(\begin{array}{lll}1 & 1 & 1\end{array}\right)$ del níquel metálico ( $\mathbf{\Lambda}$ ) (JCPDS 04-0850), tal como sucede con $\mathrm{Ni}\left(\mathrm{CH}_{3} \mathrm{COO}\right)_{2}$.

\subsection{Estudio del pretratamiento de reducción o activación}

Para establecer la condición de reducción o activación se realizaron ensayos de reducción a temperatura programada (TPR) de los catalizadores calcinados. Los perfiles de TPR obtenidos se muestran en las Figura 10-6, 11-6 y 12-6.

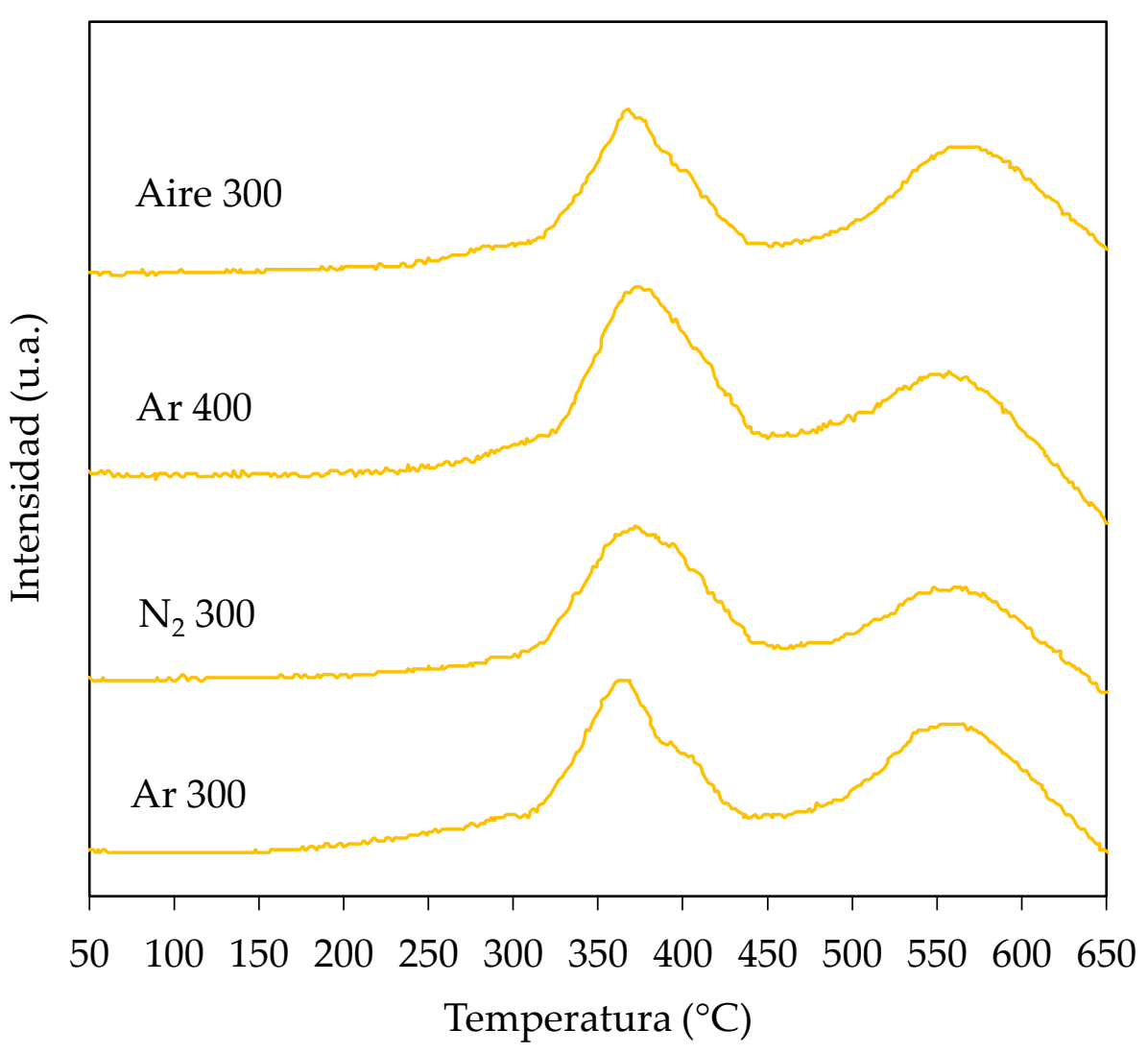

Figura 10-6. Perfiles de TPR para los catalizadores $\mathrm{Ni}(\mathrm{Cl}-) / \mathrm{SC}$. 


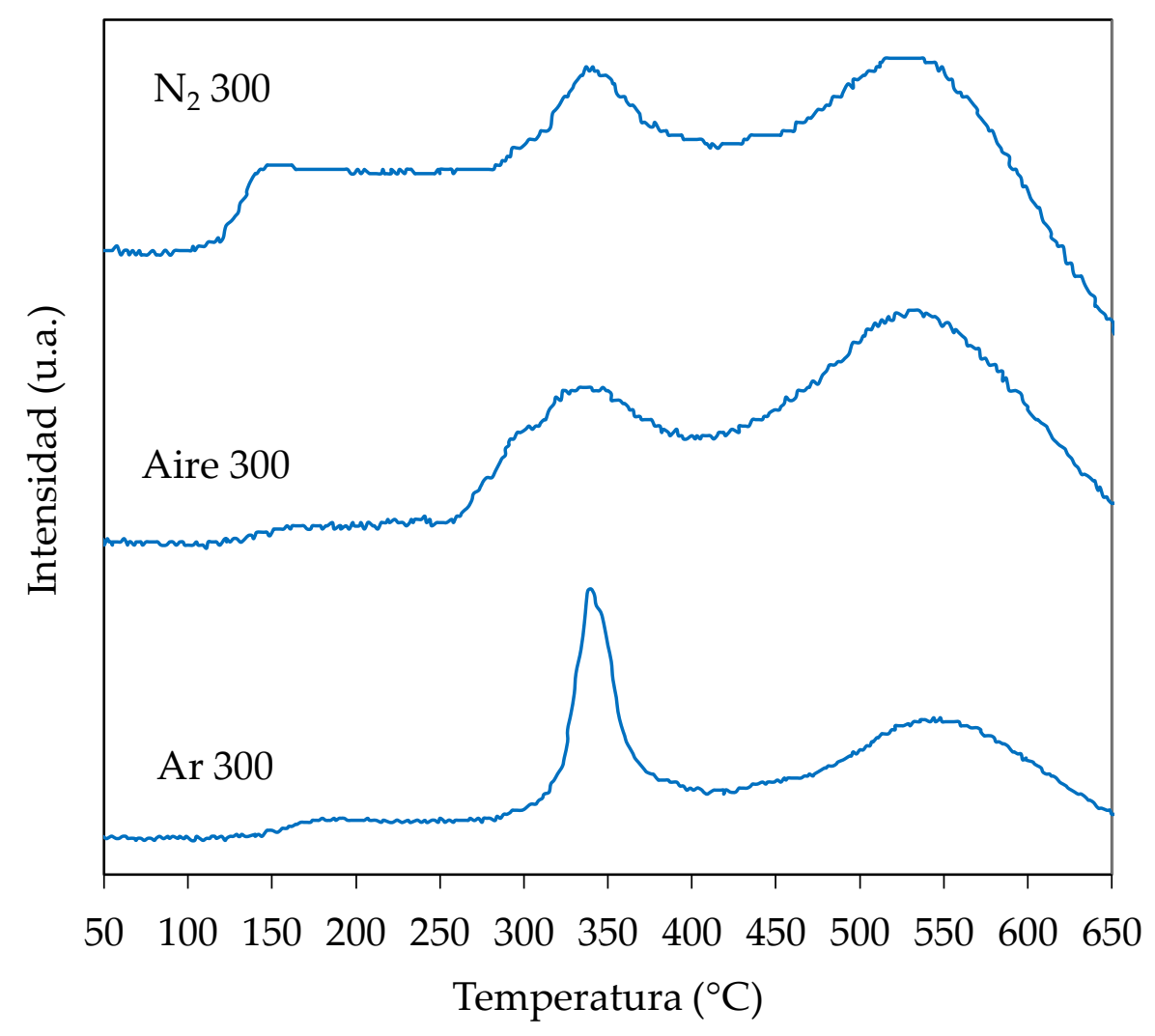

Figura 11-6. Perfiles de TPR para los catalizadores Ni(Ac-)/SC.

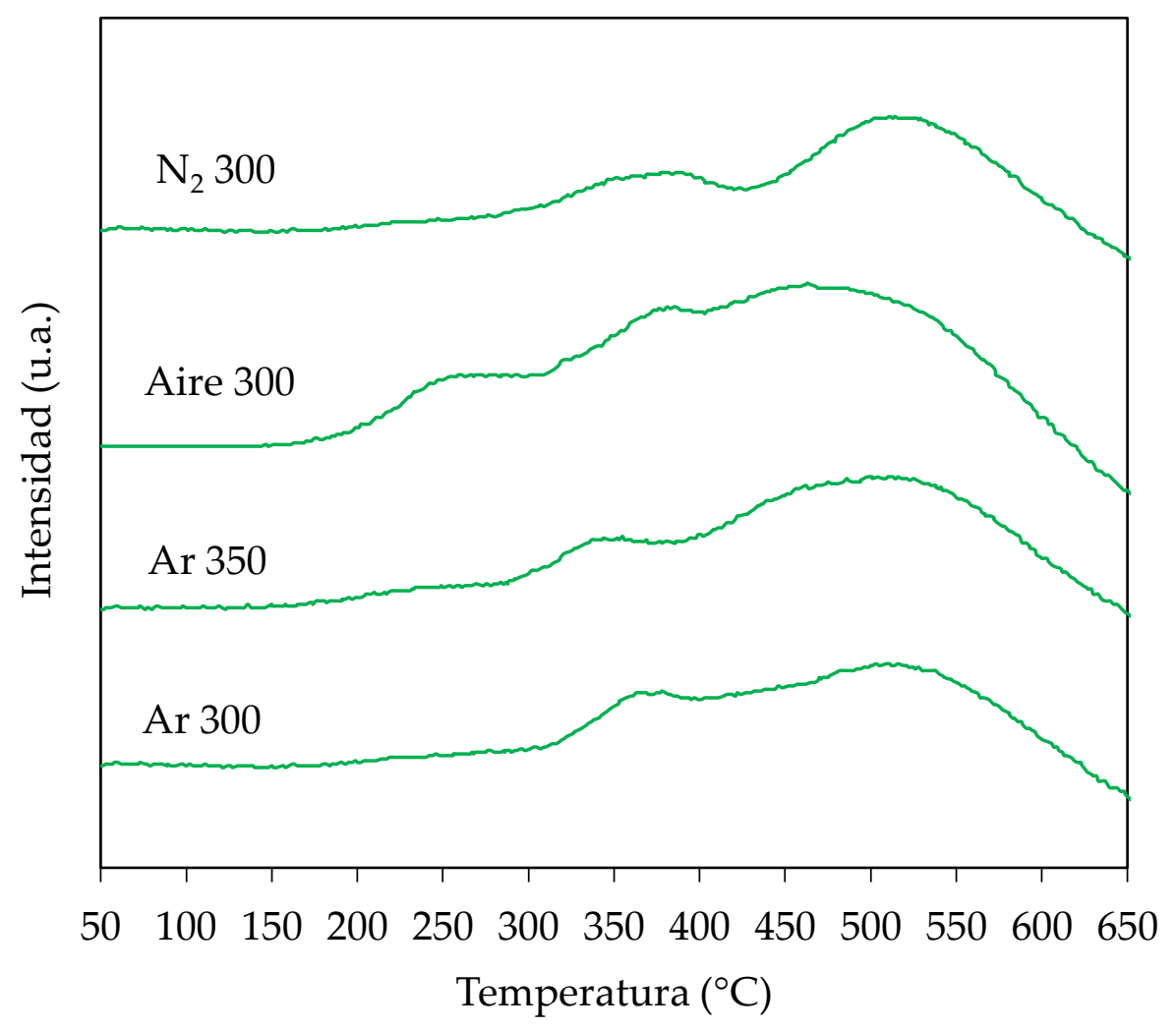

Figura 12-6. Perfiles de TPR para los catalizadores $\mathrm{Ni}\left(\mathrm{NO}_{3-}{ }^{-}\right) / \mathrm{SC}$. 
A partir de la Figura 10-6 se observa que existen dos eventos de consumo de $\mathrm{H}_{2}$. El primero de ellos entre $300-400{ }^{\circ} \mathrm{C}$ y el segundo a $560{ }^{\circ} \mathrm{C}$.

En bibliografía se reporta que existen varias formas de interacción del $\mathrm{Ni}$ con soportes del tipo silíceos. En el rango de $280-300{ }^{\circ} \mathrm{C}$ ocurre la reducción de especies $\mathrm{Ni}^{+2}$ que poseen una muy baja interacción con el soporte; son especies superficiales que se encuentran como fases segregadas. Entre 300-400 ${ }^{\circ} \mathrm{C}$ ocurre la reducción de especies de $\mathrm{Ni}^{+2}$ de moderada interacción con el soporte. $\mathrm{Y}$ finalmente entre $600-700{ }^{\circ} \mathrm{C}$ ocurre la reducción de especies $\mathrm{Ni}^{+2}$ de alta interacción con el soporte; que es el caso de la formación de hidrosilicatos de níquel $[4,5]$.

Las Figuras 10-6, 11-6 y 12-6 indicarían que, para todos los precursores, el evento entre 300-400 ${ }^{\circ} \mathrm{C}$ correspondería a un evento de reducción de especies $\mathrm{Ni}^{+2}$ de mediana interacción con el soporte. Por otro lado, el segundo evento, a $560{ }^{\circ} \mathrm{C}$, no corresponde a un evento de reducción debido a que este consumo de $\mathrm{H}_{2}$ es acompañado con desprendimiento de $\mathrm{CO}$, $\mathrm{CO}_{2} \mathrm{y} \mathrm{CH}_{4}$ y esto es asociado a la gasificación del soporte $\mathrm{SC}$.

Para el caso del Ni(Ac-)/SC se observa además un evento de reducción a $150{ }^{\circ} \mathrm{C}$, solo para el pretratamiento en $\mathrm{N}_{2}$, que correspondería a especies de $\mathrm{Ni}^{+2}$ de muy baja interacción con el soporte.

Teniendo en cuenta estos resultados de TPR se decidió realizar la activación de los catalizadores de $\mathrm{Ni} / \mathrm{SC}$ en flujo continuo $\left(50 \mathrm{~cm}^{3} \cdot \mathrm{min}^{-1}\right)$ de $\mathrm{H}_{2}$ a $400{ }^{\circ} \mathrm{C}$ durante $1.5 \mathrm{~h}$.

Se determinó el contenido de Ni por espectroscopía de absorción atómica (AAS) (Tabla 2-6). Los resultados obtenidos por AAS indican que el contenido de Ni en todos los casos es cercano al calculado en la preparación $(\sim 5 \% \mathrm{p} / \mathrm{p})$.

Tabla 2-6. Contenido metálico de Ni para catalizadores Ni/SC.

\begin{tabular}{|c|c|c|c|}
\hline \multirow{2}{*}{ Catalizador } & \multirow{2}{*}{ Pretratamiento } & \multicolumn{2}{|c|}{ Contenido metálico $(\% \mathrm{p} / \mathrm{p})$} \\
\hline & & Nominal & AAS \\
\hline \multirow{5}{*}{$\mathrm{Ni}(\mathrm{Cl}-) / \mathrm{SC}$} & Ar $300-\mathrm{H}_{2} 400$ & 5.00 & 4.12 \\
\hline & Ar $400-\mathrm{H}_{2} 400$ & 5.00 & 4.42 \\
\hline & $\mathrm{N}_{2} 300-\mathrm{H}_{2} 400$ & 5.00 & 4.20 \\
\hline & Aire $300-\mathrm{H}_{2} 400$ & 5.00 & 3.92 \\
\hline & $\mathrm{H}_{2} 400$ & 5.00 & 4.53 \\
\hline \multirow{4}{*}{$\mathrm{Ni}(\mathrm{Ac}-) / \mathrm{SC}$} & Ar $300-\mathrm{H}_{2} 400$ & 5.00 & 4.25 \\
\hline & $\mathrm{N}_{2} 300-\mathrm{H}_{2} 400$ & 5.00 & 4.50 \\
\hline & Aire $300-\mathrm{H}_{2} 400$ & 5.00 & 4.60 \\
\hline & $\mathrm{H}_{2} 400$ & 5.00 & 4.46 \\
\hline \multirow{5}{*}{$\mathrm{Ni}\left(\mathrm{NO}_{3}{ }^{-}\right) / \mathrm{SC}$} & Ar $300-\mathrm{H}_{2} 400$ & 5.00 & 4.20 \\
\hline & Ar $350-\mathrm{H}_{2} 400$ & 5.00 & 4.00 \\
\hline & $\mathrm{N}_{2} 300-\mathrm{H}_{2} 400$ & 5.00 & 4.15 \\
\hline & Aire $300-\mathrm{H}_{2} 400$ & 5.00 & 4.25 \\
\hline & $\mathrm{H}_{2} 400$ & 5.00 & 4.11 \\
\hline
\end{tabular}




\subsection{Caracterización de los catalizadores Ni/SC}

Los resultados de adsorción-desorción de $\mathrm{N}_{2}$ (BET) se muestran en la Tabla 3-6. En dicha tabla se observan los valores de superficie específica $\left(S_{B E T}\right)$, volumen total de poro $\left(V_{\mathrm{p}}\right)$ y características de superficie específica y volumen específico de micro y mesoporos. Los resultados indican que todos los catalizadores de Ni/SC poseen propiedades texturales similares. La superficie específica es del orden de $200-220 \mathrm{~m}^{2} \cdot \mathrm{g}^{-1} \mathrm{y}$ el volumen total de poro $0.40 \mathrm{~cm}^{3} \cdot \mathrm{g}^{-1}$. La contribución minoritaria de microporos al volumen total de poro los convierte en catalizadores del tipo mesoporosos, con isotermas del tipo IV y lazos de histéresis del tipo H3 según la IUPAC. La adición de Ni al soporte de SC no genera un bloqueo de poros, dado que no se observa una disminución de la superficie específica en ninguno de los catalizadores.

Tabla 3-6. Propiedades texturales de los catalizadores $\mathrm{Ni}(\mathrm{Cl}-) / \mathrm{SC}$.

\begin{tabular}{|c|c|c|c|c|c|c|c|}
\hline \multirow{2}{*}{ Muestra } & \multirow{2}{*}{ Pretratamiento } & \multirow{2}{*}{$\mathrm{S}_{\mathrm{BET}} \mathbf{a}^{\mathbf{a}}$} & \multirow{2}{*}{$V_{p}^{b}$} & \multicolumn{2}{|c|}{ Microporos } & \multicolumn{2}{|c|}{ Mesoporos } \\
\hline & & & & $S_{\text {micro }}{ }^{c}$ & $\mathrm{~V}_{\text {micro }}{ }^{\mathrm{c}}$ & $S_{\text {meso }}{ }^{d}$ & $V_{\text {meso }}{ }^{d}$ \\
\hline $\mathrm{SC}$ & - & 208 & 0.48 & 55 & 0.02 & 153 & 0.46 \\
\hline \multirow{5}{*}{$\mathrm{Ni}(\mathrm{Cl}-) / \mathrm{SC}$} & Ar $300-\mathrm{H}_{2} 400$ & 208 & 0.42 & 57 & 0.03 & 151 & 0.39 \\
\hline & Ar $400-\mathrm{H}_{2} 400$ & 211 & 0.40 & 66 & 0.03 & 145 & 0.37 \\
\hline & $\mathrm{N}_{2} 300-\mathrm{H}_{2} 400$ & 205 & 0.41 & 60 & 0.03 & 145 & 0.38 \\
\hline & Aire $300-\mathrm{H}_{2} 400$ & 207 & 0.41 & 63 & 0.03 & 144 & 0.38 \\
\hline & $\mathrm{H}_{2} 400$ & 211 & 0.41 & 60 & 0.03 & 151 & 0.38 \\
\hline \multirow{4}{*}{$\mathrm{Ni}\left(\mathrm{Ac}^{-}\right) / \mathrm{SC}$} & Ar $300-\mathrm{H}_{2} 400$ & 209 & 0.43 & 57 & 0.02 & 152 & 0.41 \\
\hline & $\mathrm{N}_{2} 300-\mathrm{H}_{2} 400$ & 188 & 0.36 & 54 & 0.02 & 134 & 0.34 \\
\hline & Aire $300-\mathrm{H}_{2} 400$ & 219 & 0.42 & 66 & 0.03 & 153 & 0.39 \\
\hline & $\mathrm{H}_{2} 400$ & 207 & 0.43 & 59 & 0.03 & 148 & 0.40 \\
\hline \multirow{5}{*}{$\mathrm{Ni}\left(\mathrm{NO}_{3}-\right) / \mathrm{SC}$} & Ar $300-\mathrm{H}_{2} 400$ & 233 & 0.41 & 68 & 0.03 & 165 & 0.38 \\
\hline & Ar $350-\mathrm{H}_{2} 400$ & 223 & 0.42 & 57 & 0.03 & 166 & 0.39 \\
\hline & $\mathrm{N}_{2} 300-\mathrm{H}_{2} 400$ & 246 & 0.41 & 76 & 0.03 & 170 & 0.38 \\
\hline & Aire $300-\mathrm{H}_{2} 400$ & 226 & 0.36 & 62 & 0.03 & 164 & 0.33 \\
\hline & $\mathrm{H}_{2} 400$ & 220 & 0.43 & 62 & 0.03 & 158 & 0.40 \\
\hline
\end{tabular}

a Superficie específica $\left(\mathrm{m}^{2} \cdot \mathrm{g}^{-1}\right)$.

${ }^{\mathbf{b}}$ Volumen total de poros $\left(\mathrm{cm}^{3} \cdot \mathrm{g}^{-1}\right)$.

c Superficie específica $\left(\mathrm{m}^{2} \cdot \mathrm{g}^{-1}\right)$ y volumen total de microporos $\left(\mathrm{cm}^{3} \cdot \mathrm{g}^{-1}\right)$.

d Superficie específica $\left(\mathrm{m}^{2} \cdot \mathrm{g}^{-1}\right)$ y volumen total de mesoporos $\left(\mathrm{cm}^{3} \cdot \mathrm{g}^{-1}\right)$.

Para analizar el estado de la fase metálica de Ni y la estructura de los catalizadores luego de ser calcinados y activados se realizaron análisis de DRX. Los difractogramas para todos los catalizadores se presentan en las Figuras 13-6, 14-6 y 15-6.

Los resultados de DRX para los catalizadores Ni/SC muestran la presencia de picos a

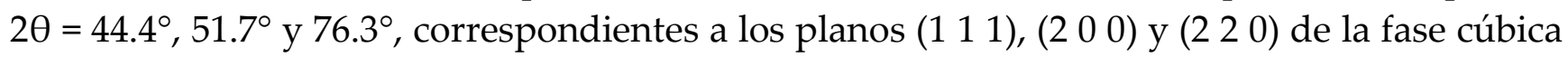
del níquel metálico ( $\mathbf{\Delta}$ ) (JCPDS 04-0850). En todos los casos no se observa la presencia de 
picos correspondientes a $\mathrm{NiO}$, indicando que la activación de los catalizadores produce en todos los casos la reducción de las especies $\mathrm{Ni}^{+2}$ a Ni${ }^{0}$.

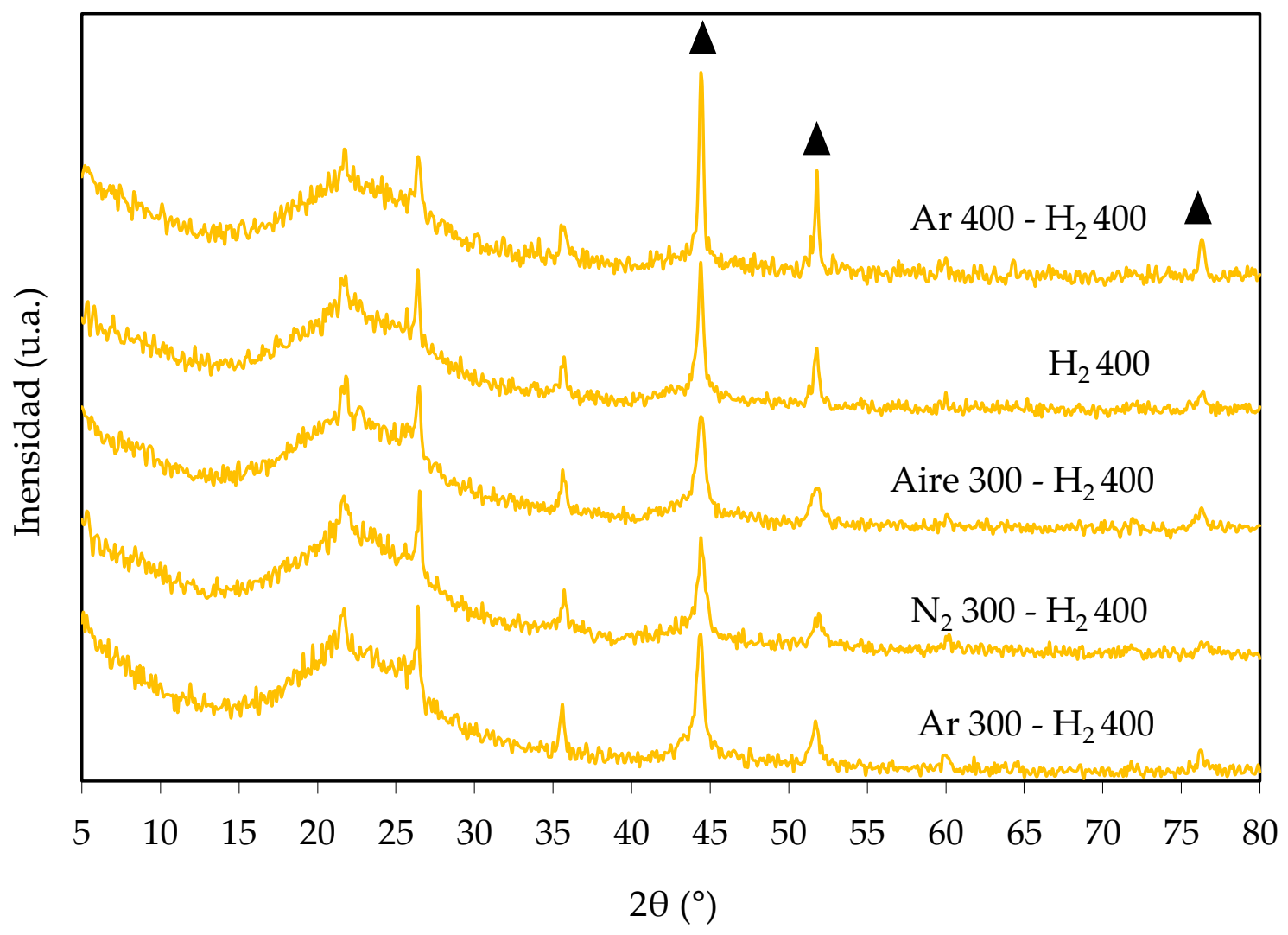

Figura 13-6. Difractogramas de rayos X para los catalizadores $\mathrm{Ni}(\mathrm{Cl}-)$ /SC.

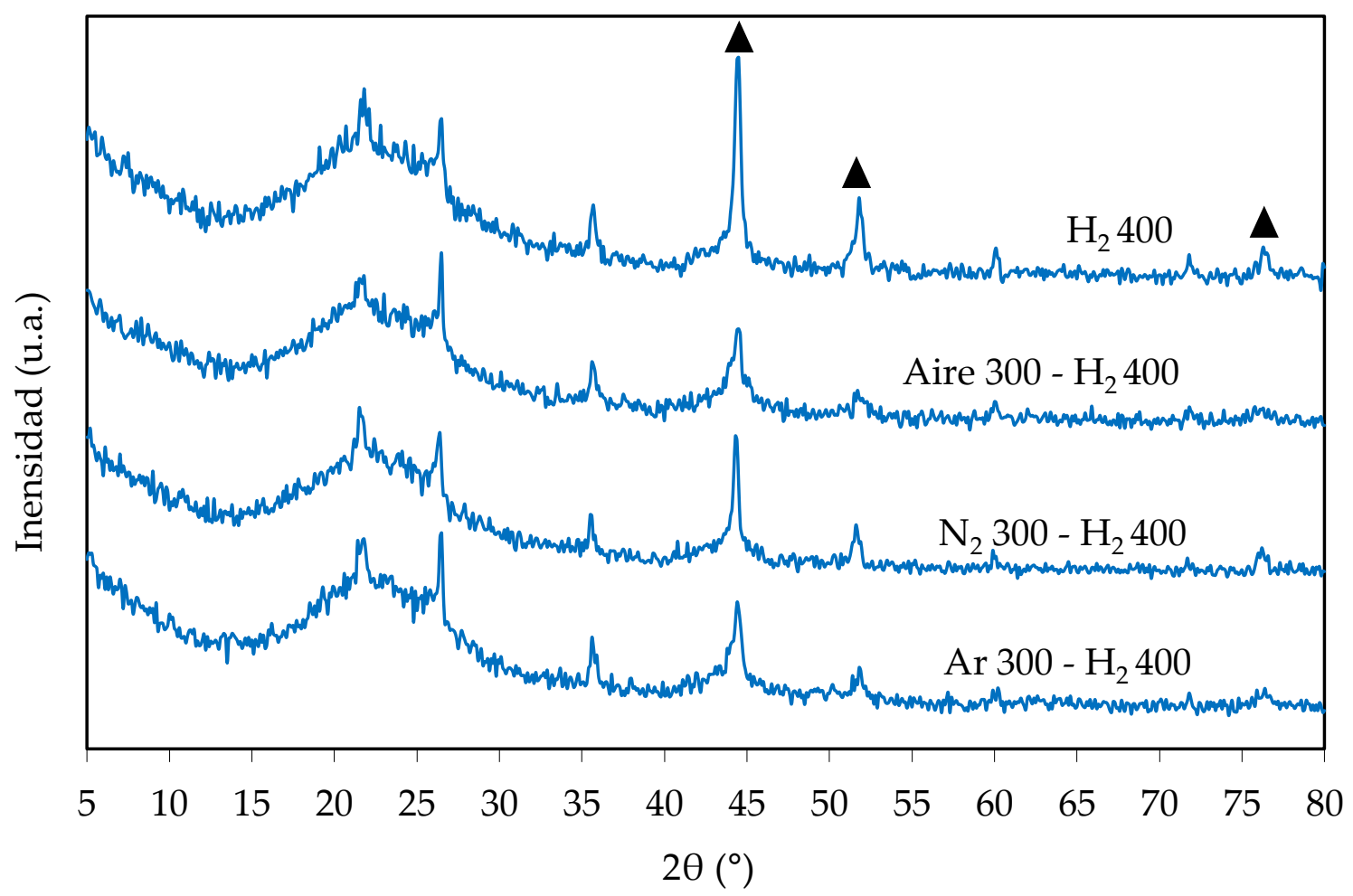

Figura 14-6. Difractogramas de rayos X para los catalizadores Ni(Ac-)/SC. 


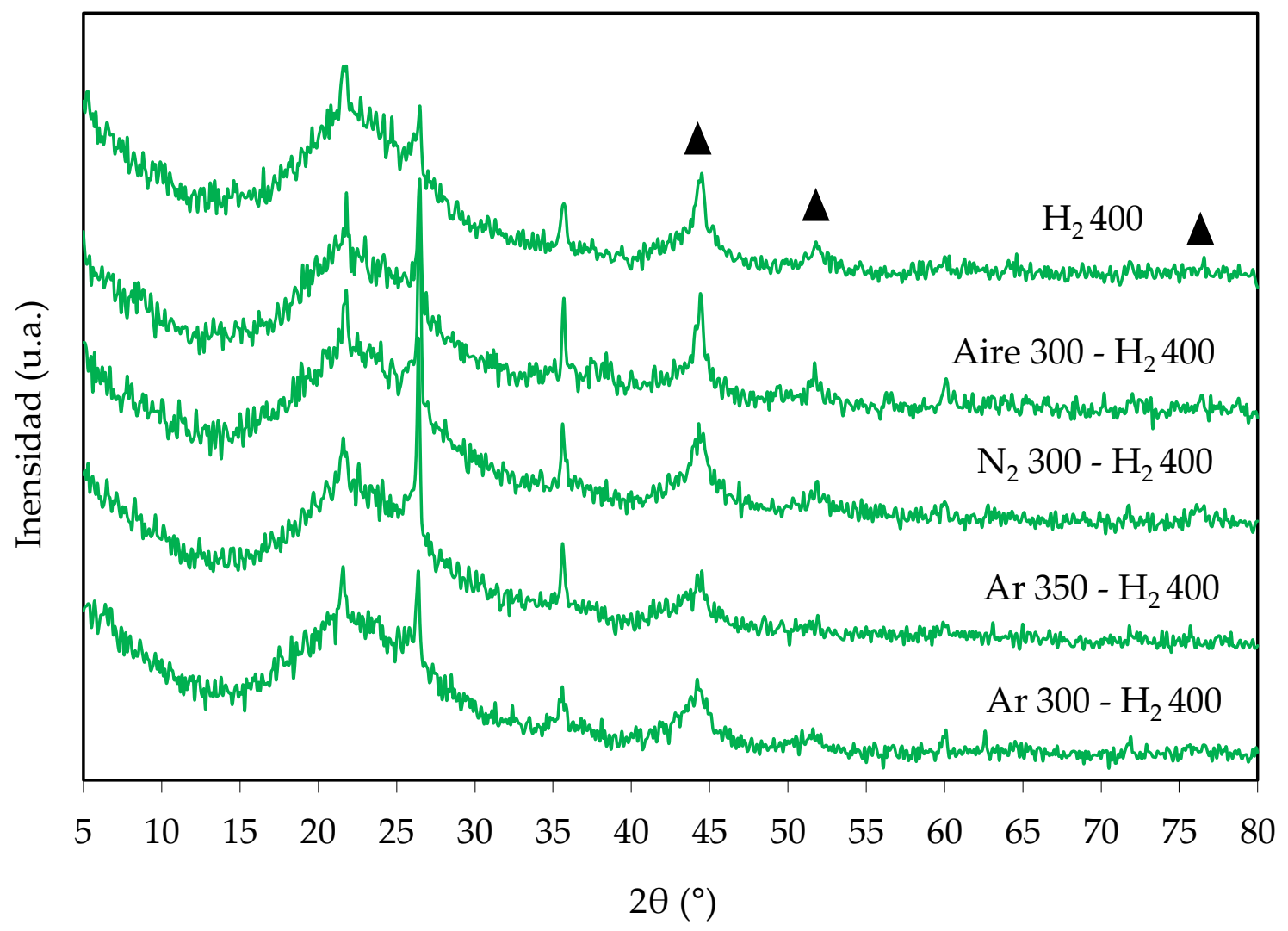

Figura 15-6. Difractogramas de rayos $\mathrm{X}$ para los catalizadores $\mathrm{Ni}\left(\mathrm{NO}_{3}-\right) / \mathrm{SC}$

A partir del pico principal del Ni metálico en todos los difractogramas de rayos X y los índices de Miller del plano (1 111 ) se calcularon los tamaños de cristal mediante la ecuación de Scherrer (Ecuación 1-3, capítulo 3) y el parámetro de red de la celda unidad, a, (Ecuaciones 2-3 y 3-3, capítulo 3). Los resultados se presentan en la Tabla 4-6.

Tabla 4-6. Parámetro de red y tamaños de cristal para los catalizadores de Ni/SC.

\begin{tabular}{llcc}
\hline Catalizador & Pretratamiento & $\mathrm{a}=\mathrm{b}=\mathrm{c}\left(\mathrm{A}^{\circ}\right)$ & $\mathrm{d}$ DRx $(\mathrm{nm})$ \\
\hline & $\mathrm{Ar} 300-\mathrm{H}_{2} 400$ & 3.534 & 9.54 \\
$\mathrm{Ni}(\mathrm{Cl}-) / \mathrm{SC}$ & $\mathrm{N}_{2} 300-\mathrm{H}_{2} 400$ & 3.523 & 6.36 \\
& Aire $300-\mathrm{H}_{2} 400$ & 3.528 & 7.47 \\
& $\mathrm{H}_{2} 400$ & 3.525 & 12.20 \\
\hline & Ar $300-\mathrm{H}_{2} 400$ & 3.529 & 8.59 \\
$\mathrm{Ni}(\mathrm{Ac}-) / \mathrm{SC}$ & $\mathrm{N}_{2} 300-\mathrm{H}_{2} 400$ & 3.537 & 13.21 \\
& Aire $300-\mathrm{H}_{2} 400$ & 3.530 & 4.91 \\
& $\mathrm{H}_{2} 400$ & 3.528 & 14.30 \\
\hline & Ar $300-\mathrm{H}_{2} 400$ & 3.538 & - \\
& $\mathrm{N}_{2} 300-\mathrm{H}_{2} 400$ & 3.530 & - \\
$\mathrm{Ni}\left(\mathrm{NO}_{3}-\right) / \mathrm{SC}$ & Aire $300-\mathrm{H}_{2} 400$ & 3.528 & - \\
& $\mathrm{H}_{2} 400$ & 3.536 & \\
& & & - \\
\hline
\end{tabular}


Como es posible observar a partir de la tabla, el parámetro de red obtenido de la medida de DRX es cercano al valor del parámetro de red para el Ni de fase cúbica centrada en las caras $\left(3.524 \mathrm{~A}^{\circ}\right)$.

En cuanto a los tamaños de cristal obtenidos, hay diferencias por tipo de precursor empleado y según la atmósfera de pretratamiento empleada.

Para los catalizadores de $\mathrm{Ni}(\mathrm{Cl}-) / \mathrm{SC}$, los pretratamientos en $\mathrm{Ar}, \mathrm{N}_{2}$, aire a $300{ }^{\circ} \mathrm{C}$ y posterior reducción a $400^{\circ} \mathrm{C}$ conducen a cristales de tamaño entre 6 y $12 \mathrm{~nm}$, del mismo modo que cuando se realiza la activación directa con $\mathrm{H}_{2}$ a $400^{\circ} \mathrm{C}$.

En cuanto a los catalizadores de $\mathrm{Ni}(\mathrm{Ac}-) / \mathrm{SC}$, se observa que los pretratamientos en $\mathrm{N}_{2}$ y la activación directa en $\mathrm{H}_{2}$ producen los mayores tamaños de cristal, del orden de $14 \mathrm{~nm}$. La calcinación en aire a $300{ }^{\circ} \mathrm{C}$ conduce al menor tamaño de cristal, del orden de los $5 \mathrm{~nm}$, mientras que el pretratamiento en $\mathrm{Ar}$ a $300^{\circ} \mathrm{C}$ a $8.5 \mathrm{~nm}$.

En cuanto a los catalizadores de $\mathrm{Ni}\left(\mathrm{NO}_{3}-\right) / \mathrm{SC}$, no fue posible estimar los tamaños de cristal debido a la poca definición del pico principal correspondiente al Ni metálico.

\subsection{Resultados de actividad catalítica}

Para determinar la influencia de los pretratamientos sobre las propiedades catalíticas, se llevaron a cabo ensayos de reacción durante $2 \mathrm{~h}$ a $220{ }^{\circ} \mathrm{C}$ y 20 bar de $\mathrm{H}_{2}$ iniciales, empleando soluciones de glicerol al $10 \% \mathrm{p} / \mathrm{p}$ y una relación $\mathrm{m}_{\mathrm{gli}} / \mathrm{m}_{\mathrm{c}}=4.2$. Estos resultados de actividad se presentan en la Tabla 5-6. Allí es posible observar que la conversión a productos gaseosos fue baja en todos los ensayos (<1\%). Los productos líquidos obtenidos fueron $\mathrm{MeOH}, \mathrm{EtOH}, \mathrm{AcO}, 1-\mathrm{POH}, \mathrm{AcOH}, \mathrm{EG}$ y 1,2-PG.

Todos los catalizadores mostraron alta selectividad a 1,2-PG ( 86-92 \%), no obstante, mostraron diferencias en cuanto a la conversión. Los mejores resultados catalíticos se obtuvieron con el pretratamiento de activación directo, en atmósfera de $\mathrm{H}_{2}$ a $400{ }^{\circ} \mathrm{C}$.

Tabla 5-6. Actividad de catalizadores Ni/SC.

\begin{tabular}{|c|c|c|c|c|c|c|c|c|c|}
\hline \multirow{2}{*}{ Pretratamiento } & \multirow{2}{*}{$\mathrm{X}_{\mathrm{T}}(\%)$} & \multirow{2}{*}{$\mathrm{X}_{\mathrm{L}}(\%)$} & \multicolumn{7}{|c|}{ Selectividad (\%) } \\
\hline & & & $\mathrm{MeOH}$ & $\mathrm{EtOH}$ & $\mathrm{AcO}$ & 1-POH & $\mathrm{AcOH}$ & EG & 1,2-PG \\
\hline \multicolumn{10}{|l|}{$\mathrm{Ni}(\mathrm{Cl}-) / \mathrm{SC}$} \\
\hline Ar $300-\mathrm{H}_{2} 400$ & 10.5 & 9.8 & 0.3 & 2.0 & 0.0 & 0.2 & 0.3 & 10.7 & 86.5 \\
\hline $\mathrm{H}_{2} 400$ & 10.0 & 9.5 & 0.3 & 1.5 & 0.0 & 0.2 & 0.6 & 8.0 & 89.4 \\
\hline \multicolumn{10}{|l|}{$\mathrm{Ni}(\mathrm{Ac}-) / \mathrm{SC}$} \\
\hline Ar $300-\mathrm{H}_{2} 400$ & 6.7 & 6.4 & 0.4 & 1.1 & 0.0 & 0.2 & 0.8 & 5.4 & 92.1 \\
\hline $\mathrm{H}_{2} 400$ & 9.3 & 9.0 & 0.2 & 1.6 & 0.0 & 0.2 & 0.8 & 4.7 & 92.5 \\
\hline \multicolumn{10}{|l|}{$\mathrm{Ni}\left(\mathrm{NO}_{3-}{ }^{-}\right) / \mathrm{SC}$} \\
\hline Ar $300-\mathrm{H}_{2} 400$ & 6.9 & 6.6 & 0.3 & 0.6 & 0.0 & 0.2 & 1.2 & 5.7 & 92.0 \\
\hline $\mathrm{H}_{2} 400$ & 10.3 & 9.9 & 0.3 & 0.9 & 0.0 & 0.2 & 0.8 & 6.3 & 91.5 \\
\hline
\end{tabular}

${ }^{*}$ Condiciones de reacción: $220^{\circ} \mathrm{C}, 20$ bar de $\mathrm{H}_{2}, 10 \% \mathrm{p} / \mathrm{p}$ de glicerol, $\mathrm{mgli}_{\mathrm{gli}} / \mathrm{m}_{\mathrm{c}}=4.2,2 \mathrm{~h}$.

${ }^{*} \mathrm{X}_{\mathrm{T}}$ : conversión total de glicerol, $\mathrm{X}_{\mathrm{L}}$ : conversión de glicerol a productos líquidos. 


\subsection{Efecto del precursor metálico en la reacción de hidrogenólisis de glicerol}

La Tabla 6-6 muestra los resultados de la caracterización de los catalizadores de Ni/SC, obtenidos por activación directa en flujo de $\mathrm{H}_{2}\left(50 \mathrm{~cm}^{3} \cdot \mathrm{min}^{-1}\right)$ a $400{ }^{\circ} \mathrm{C}$ durante $1.5 \mathrm{~h}$.

Tabla 6-6. Propiedades texturales y fisicoquímicas de los catalizadores de Ni/SC.

\begin{tabular}{|c|c|c|c|c|c|c|c|c|}
\hline \multirow[t]{2}{*}{ Catalizador } & \multirow{2}{*}{$\begin{array}{c}\text { AAS } \\
\mathrm{Ni}(\%)\end{array}$} & \multicolumn{2}{|c|}{ BET } & DRX & \multicolumn{2}{|c|}{ TEM } & \multicolumn{2}{|c|}{$\begin{array}{c}\text { Titulación } \\
\text { potenciométrica }\end{array}$} \\
\hline & & $S_{\text {BET }}\left(m^{2} \cdot g^{-1}\right)$ & $V_{p}\left(\mathrm{~cm}^{3} \cdot \mathrm{g}^{-1}\right)$ & $\operatorname{dDRx}(\mathrm{nm})$ & $\mathrm{d}_{\mathrm{va}}(\mathrm{nm})$ & Dтем $(\%)$ & Ei $(\mathrm{mV})$ & NS (mmol.g-1) \\
\hline $\mathrm{Ni}(\mathrm{Cl}-) / \mathrm{SC}$ & 4.53 & 211 & 0.41 & 12.20 & 8.50 & 11.42 & -2.4 & 0.19 \\
\hline $\mathrm{Ni}($ Ac- $) / \mathrm{SC}$ & 4.46 & 207 & 0.43 & 14.30 & 11.50 & 8.30 & 30.2 & 0.40 \\
\hline $\mathrm{Ni}\left(\mathrm{NO}_{3}{ }^{-}\right) / \mathrm{SC}$ & 4.11 & 220 & 0.43 & 2.86 & 4.70 & 20.65 & 74.9 & 0.40 \\
\hline
\end{tabular}

Los resultados del análisis de microscopía de transmisión electrónica (TEM) indican que el $\mathrm{Ni}(\mathrm{Cl}-) / \mathrm{SC}$ posee un tamaño promedio de $8.5 \mathrm{~nm}$ y dispersión del $11 \%$, mientras que $\mathrm{Ni}(\mathrm{Ac}-) / \mathrm{SC}$ y $\mathrm{Ni}\left(\mathrm{NO}_{3}-\right) / \mathrm{SC}$ presentan tamaños promedios de $11.5 \mathrm{~nm}$ y $4.7 \mathrm{~nm}$, correspondientes a dispersiones del orden del $8 \%$ y $20 \%$ respectivamente.

Además, se realizaron ensayos de titulación potenciométrica para caracterizar la fuerza ácida (Ei) y número de sitios ácidos (NS) de los catalizadores de Ni/SC. Los resultados, en la Tabla 6-6, muestran que los catalizadores con mayor fuerza ácida y número de sitios ácidos son $\mathrm{Ni}\left(\mathrm{NO}_{3}{ }^{-}\right) / \mathrm{SC}$ y $\mathrm{Ni}(\mathrm{Ac}-) / \mathrm{SC}$.

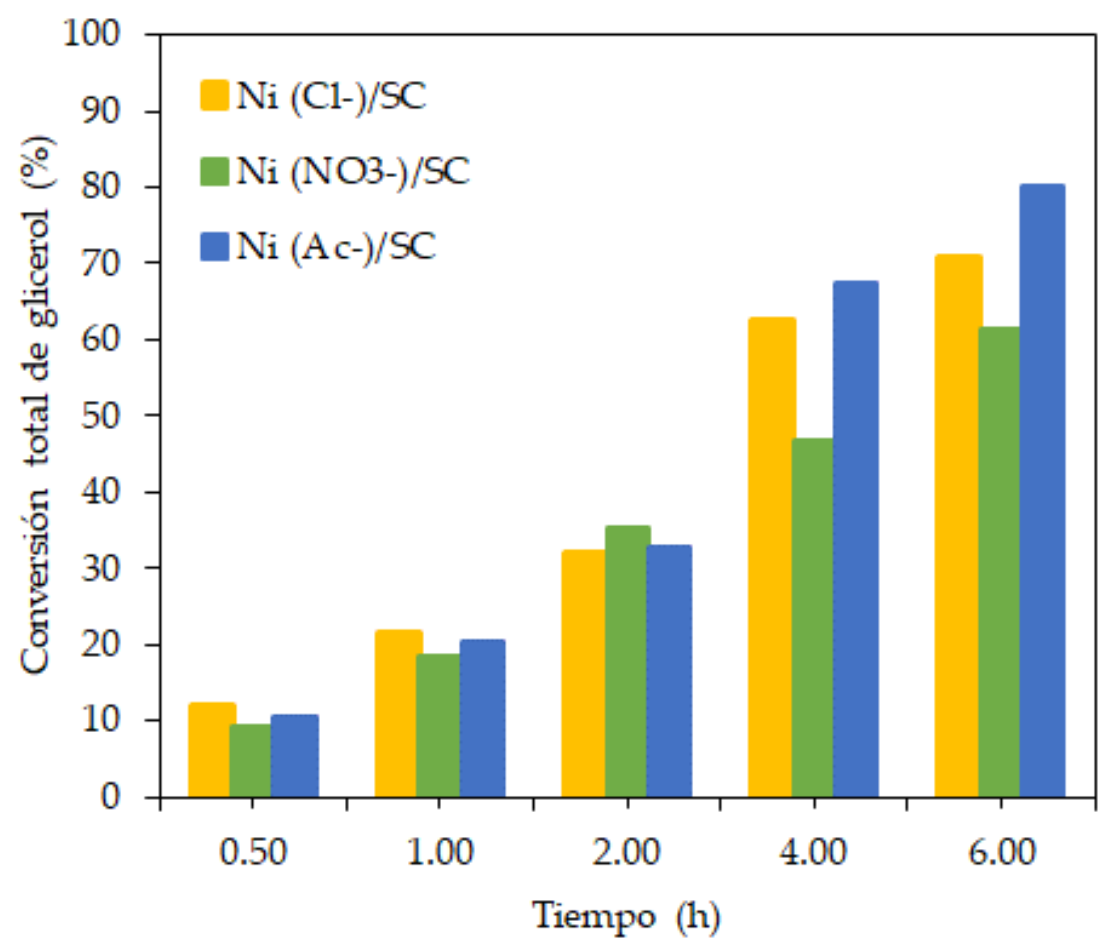

Figura 16-6. Evolución de la conversión total de glicerol con el tiempo para los catalizadores de Ni/SC. 
Se evaluó la actividad de los catalizadores de Ni/SC en la reacción a $260{ }^{\circ} \mathrm{C}$ y 20 bar de $\mathrm{H}_{2}$ iniciales (55 bar de presión autógena) empleando soluciones de glicerol al 30 \% p/p y una relación $\mathrm{m}_{\mathrm{gli}} / \mathrm{m}_{\mathrm{c}}=6.2$. Se estudió la evolución de la conversión de glicerol y la selectividad a los distintos productos líquidos en el rango de 0.5 a 6 h de reacción (Figura 16-6).

Se observa que el catalizador $\mathrm{Ni}\left(\mathrm{NO}_{3}\right)^{-} / \mathrm{SC}$ muestra una menor conversión, que se acentúa con el tiempo, y es el catalizador que presenta un tamaño de partícula de $4.7 \mathrm{~nm}$ que indicaría una mayor interacción metal-soporte.

La Figura 17-6 muestra la evolución en la selectividad a los distintos productos líquidos en función del tiempo. Los tres catalizadores muestran alta selectividad a 1,2-PG ( $\sim 80 \%$ ) y una baja selectividad a productos de $\mathrm{C} 1$ y C2, tales como $\mathrm{MeOH}, \mathrm{EtOH}$ y EG. Se observa que siempre que la selectividad a 1,2-PG aumenta, se acompaña con la disminución de la selectividad a $\mathrm{AcOH}$.

(a)

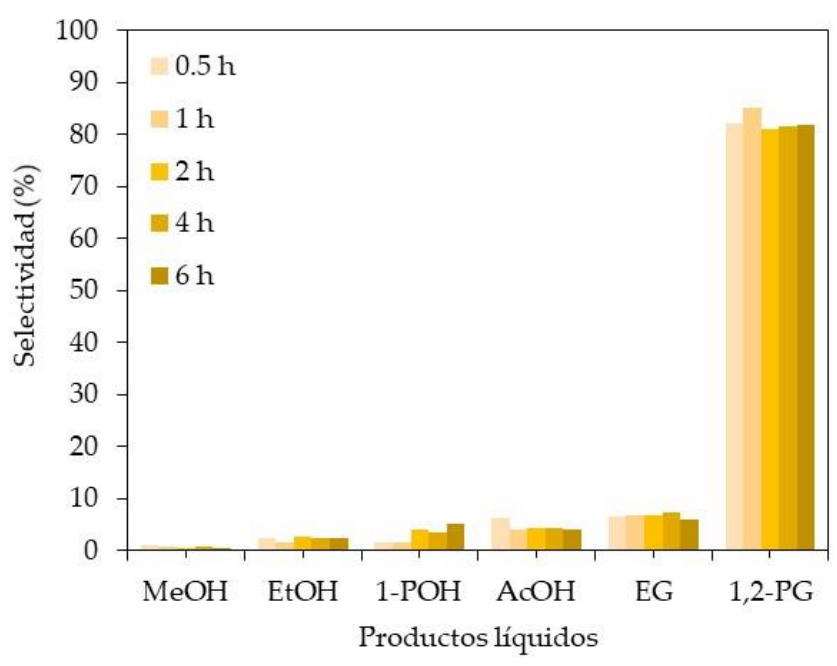

(b)

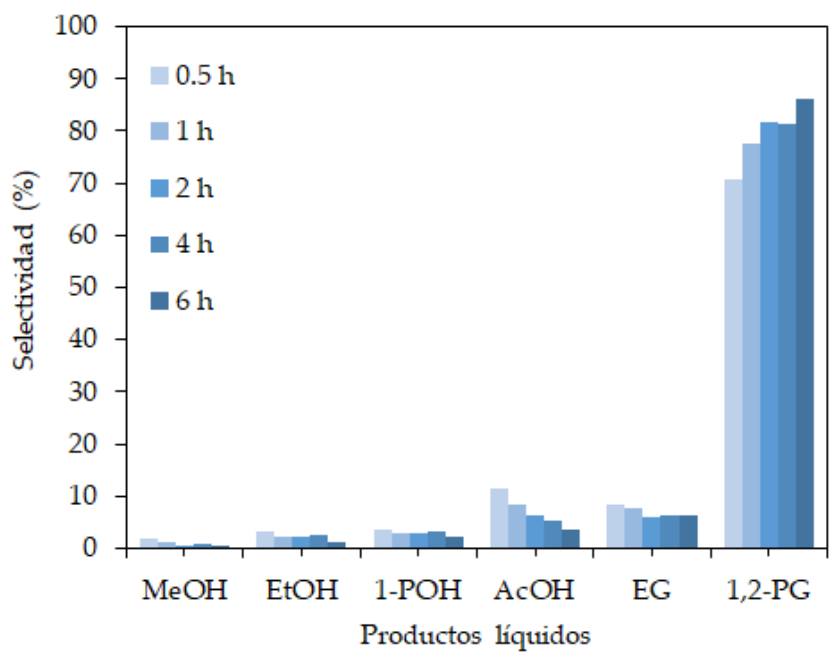

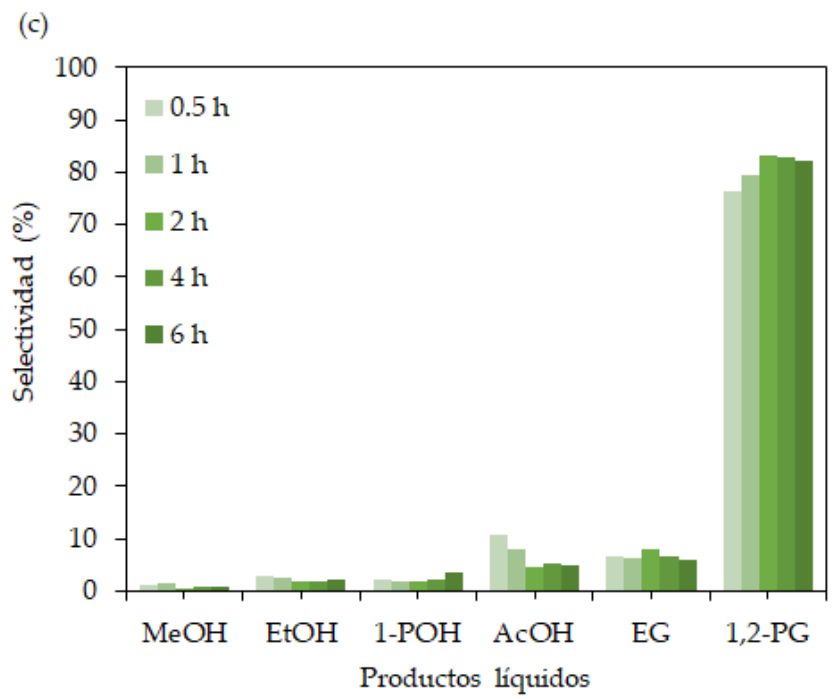

Figura 17-6. Selectividades a productos líquidos en función del tiempo para (a) $\mathrm{Ni}(\mathrm{Cl}-) / \mathrm{SC}$ (b) $\mathrm{Ni}(\mathrm{Ac}-) / \mathrm{SC}(\mathrm{c}) \mathrm{Ni}\left(\mathrm{NO}_{3}{ }^{-}\right) / \mathrm{SC}$. 
Los resultados obtenidos permitirían seleccionar al $\mathrm{Ni}(\mathrm{Ac}-) / \mathrm{SC}$ y $\mathrm{Ni}(\mathrm{Cl}-) / \mathrm{SC}$ como catalizadores interesantes para continuar el estudio, ya que permiten obtener conversiones del orden de 70-80 \% con selectividad a 1,2-PG entre 80-90\%. Considerando también el costo asociado a estos precursores (Tabla 7-6), se decide continuar con el catalizador $\mathrm{Ni}(\mathrm{Cl}-) / \mathrm{SC}$.

Tabla 7-6. Costo de las sales precursoras de níquel.

\begin{tabular}{lcl}
\hline Precursor & Costo $(\mathrm{U} \$ \mathrm{~S} / \mathrm{kg})$ & Proveedor \\
\hline $\mathrm{NiCl}_{2} .6 \mathrm{H}_{2} \mathrm{O}$ & 184 & Tetrahedron \\
$\mathrm{Ni}\left(\mathrm{CH}_{3} \mathrm{COO}\right)_{2} .4 \mathrm{H}_{2} \mathrm{O}$ & 832 & Tetrahedron \\
$\mathrm{Ni}\left(\mathrm{NO}_{3}\right)_{2} .6 \mathrm{H}_{2} \mathrm{O}$ & 228 & Tetrahedron \\
\hline
\end{tabular}

\subsection{Evaluación del rol del soporte}

En esta sección se realiza un estudio comparativo del catalizador de $\mathrm{Ni}(\mathrm{Cl}-) / \mathrm{SC}$ con $\mathrm{Ni}(\mathrm{Cl}-) / \mathrm{C}$ y Ni(Cl-)/SiO 2 . Para simplificar la nomenclatura, de aquí en más se denomina solo $\mathrm{Ni} / \mathrm{SC}, \mathrm{Ni} / \mathrm{C}$ y Ni/SiO 2 .

Los catalizadores fueron caracterizados por espectroscopía de absorción atómica (AAS), adsorción-desorción de $\mathrm{N}_{2}$ (BET), reducción a temperatura programada (TPR), difracción de rayos $X(\mathrm{DRX})$, titulación potenciométrica (TP) y microscopía de transmisión electrónica (TEM).

La Tabla 8-6 informa los valores de contenido metálico por AAS.

Tabla 8-6. Contenido metálico de Ni para los catalizadores $\mathrm{Ni} / \mathrm{SC}, \mathrm{Ni} / \mathrm{C}$ y Ni/SiO2.

\begin{tabular}{lcc}
\hline Catalizador & \multicolumn{2}{c}{$\begin{array}{c}\text { Contenido metálico }(\% \mathrm{p} / \mathrm{p}) \\
\text { Nominal }\end{array}$} \\
\hline $\mathrm{Ni} / \mathrm{SC}$ & 5.00 & 4.50 \\
$\mathrm{Ni} / \mathrm{C}$ & 5.00 & 4.70 \\
$\mathrm{Ni} / \mathrm{SiO}_{2}$ & 5.00 & 4.50 \\
\hline
\end{tabular}

Los resultados de adsorción-desorción de $\mathrm{N}_{2}$ (BET) se muestran en la Tabla 9-6.

Los resultados del análisis BET muestran una caída en los valores de superficie específica para los catalizadores de $\mathrm{Ni} / \mathrm{C}$ y Ni/SiO 2 con respecto a los soportes de $\mathrm{C}$ $\left(678 \mathrm{~m}^{2} \cdot \mathrm{g}^{-1}\right)$ y $\mathrm{SiO}_{2}\left(180 \mathrm{~m}^{2} \cdot \mathrm{g}^{-1}\right)$. Este fenómeno no sucede para el catalizador de Ni/SC que no muestra cambios con respecto al soporte de $\mathrm{SC}\left(208 \mathrm{~m}^{2} \cdot \mathrm{g}^{-1}\right)$. La adición de $\mathrm{Ni}$ a los soportes de $\mathrm{C}$ y $\mathrm{SiO}_{2}$ podría bloquear los poros debido a que estos materiales son principalmente microporosos. 
Tabla 9-6. Propiedades texturales de los catalizadores Ni/SC, Ni/C y Ni/SiOz.

\begin{tabular}{lcccccc}
\hline \multirow{2}{*}{ Catalizador } & \multirow{2}{*}{$\mathrm{S}_{\mathrm{BET}}{ }^{\mathbf{a}}$} & \multirow{2}{*}{$\mathrm{V}_{\mathrm{p}}^{\mathbf{b}}$} & \multicolumn{2}{c}{ Microporos } & \multicolumn{2}{c}{ Mesoporos } \\
& & & $\mathrm{S}_{\text {micro }}{ }^{\mathbf{c}}$ & $\mathrm{V}_{\text {micro }}{ }^{\mathbf{c}}$ & S $_{\text {meso }} \mathbf{d}^{\mathbf{d}}$ & $\mathrm{V}_{\text {meso }}{ }^{\mathbf{d}}$ \\
\hline $\mathrm{Ni} / \mathrm{SC}$ & 211 & 0.41 & 60 & 0.03 & 151 & 0.38 \\
$\mathrm{Ni} / \mathrm{C}$ & 465 & 0.98 & 184 & 0.08 & 281 & 0.90 \\
$\mathrm{Ni} / \mathrm{SiO}_{2}$ & 127 & 1.08 & 13 & 0.01 & 114 & 1.07 \\
\hline
\end{tabular}

a Superficie específica $\left(\mathrm{m}^{2} \cdot \mathrm{g}^{-1}\right)$.

${ }^{\mathbf{b}}$ Volumen total de poros $\left(\mathrm{cm}^{3} \cdot \mathrm{g}^{-1}\right)$.

'Superficie específica $\left(\mathrm{m}^{2} \cdot \mathrm{g}^{-1}\right)$ y volumen total de microporos $\left(\mathrm{cm}^{3} \cdot \mathrm{g}^{-1}\right)$.

${ }^{\mathrm{d}}$ Superficie específica $\left(\mathrm{m}^{2} \cdot \mathrm{g}^{-1}\right)$ y volumen total de mesoporos $\left(\mathrm{cm}^{3} \cdot \mathrm{g}^{-1}\right)$.

Los perfiles de TPR obtenidos para todos los catalizadores se muestran en la Figura $18-6$.

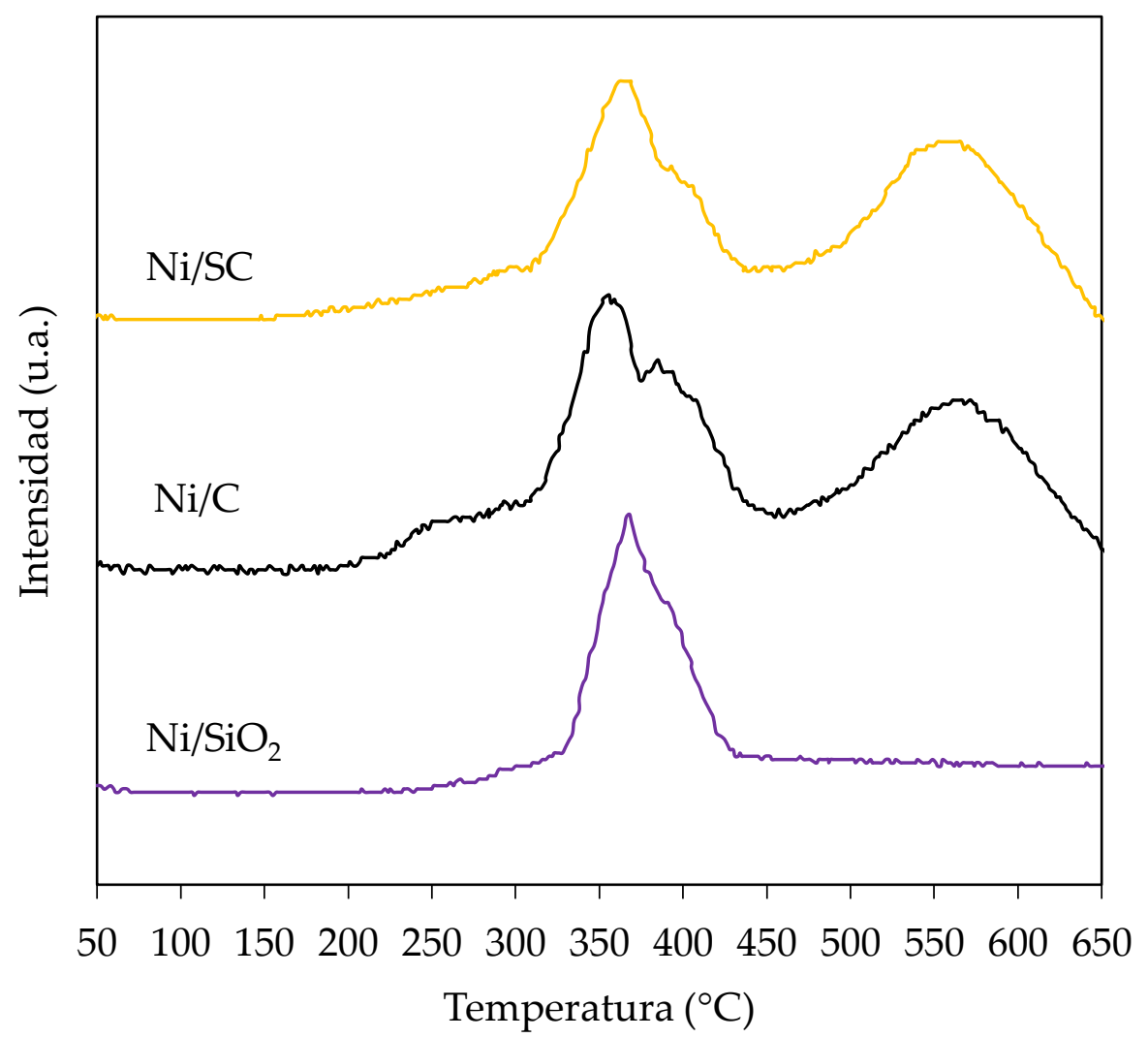

Figura 18-6. Perfiles de TPR para los catalizadores $\mathrm{Ni} / \mathrm{SiO}_{2}, \mathrm{Ni} / \mathrm{C}$ y Ni/SC.

A partir de la Figura 18-6 se observa un evento de reducción ubicado entre 300 y 400 ${ }^{\circ} \mathrm{C}$ que corresponde la reducción de especies de $\mathrm{Ni}^{+2}$ de moderada interacción con el soporte. Para el caso de los catalizadores de Ni/C y Ni/SC se visualiza un segundo evento a alrededor de los $550^{\circ} \mathrm{C}$ que corresponde a la gasificación de los soportes, ya que el consumo de $\mathrm{H}_{2}$ va acompañado con el desprendimiento de $\mathrm{CO}, \mathrm{CO}_{2}$ y $\mathrm{CH}_{4}$.

Los difractogramas para los catalizadores reducidos se presentan en la Figura 19-6. Los resultados de DRX para los tres catalizadores de Ni muestran la presencia de picos a $2 \theta=$ 


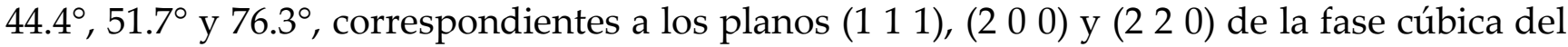
níquel metálico ( $\mathbf{\Lambda}$ ) (JCPDS 04-0850). En todos los casos no se observa la presencia de picos correspondientes a $\mathrm{NiO}$ ni otras especies de $\mathrm{Ni}^{+2}$. A partir del pico principal del $\mathrm{Ni}$ metálico en todos los difractogramas de rayos X y los índices de Miller del plano $\left(\begin{array}{lll}1 & 1 & 1\end{array}\right)$ se calcularon los tamaños de cristal mediante la ecuación de Scherrer y el parámetro de red de la celda unidad, a. Los resultados se presentan en la Tabla 10-6.

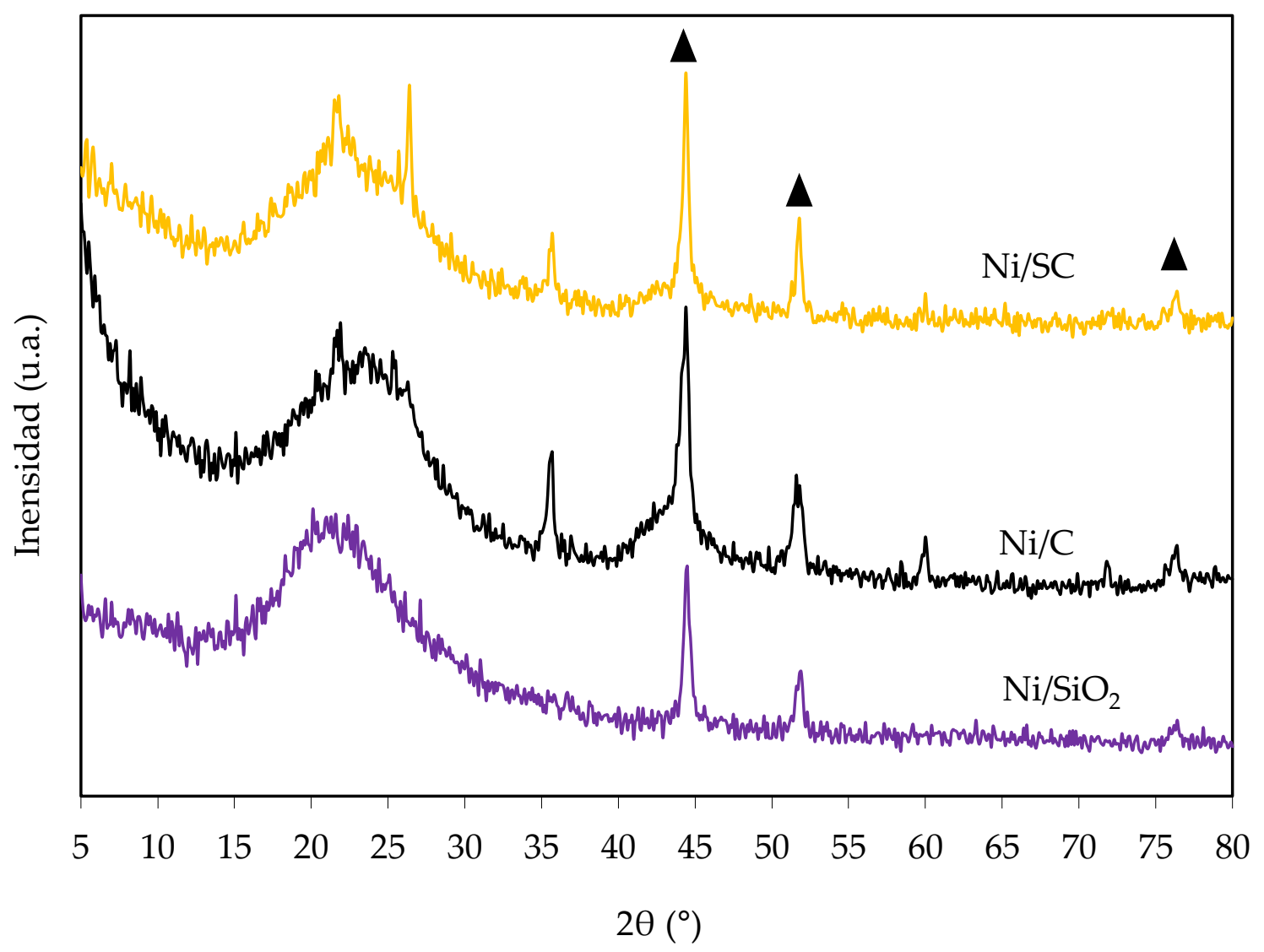

Figura 19-6. Difractogramas de rayos X para los catalizadores $\mathrm{Ni}_{/} \mathrm{SiO}_{2}$, Ni/C y Ni/SC.

Tabla 10-6. Parámetro de red y tamaños de cristal para los catalizadores $\mathrm{Ni}_{\mathrm{SiO}}$, $\mathrm{Ni} / \mathrm{C}$ y Ni/SC .

\begin{tabular}{lcc}
\hline Catalizador & $\mathrm{a}=\mathrm{b}=\mathrm{c}\left(\mathrm{A}^{\circ}\right)$ & $\mathrm{dDRx}(\mathrm{nm})$ \\
\hline $\mathrm{Ni} / \mathrm{SC}$ & 3.534 & 12.20 \\
$\mathrm{Ni} / \mathrm{C}$ & 3.537 & 8.60 \\
$\mathrm{Ni} / \mathrm{SiO}_{2}$ & 3.527 & 13.22 \\
\hline
\end{tabular}

Los parámetros de red calculados para la fase metálica de Ni fueron muy similares al parámetro de red teórico $\left(3.524 \mathrm{~A}^{\circ}\right)$. Los tamaños de cristal calculados en base a la ecuación de Scherrer fueron: Ni/SC (12.20 nm), Ni/C $(8.60 \mathrm{~nm})$ y Ni/SiO $2(13.22 \mathrm{~nm})$.

Por análisis de microscopía de transmisión electrónica (TEM) se obtuvieron las distribuciones de tamaños de partícula para los catalizadores $\mathrm{Ni} / \mathrm{SC}, \mathrm{Ni} / \mathrm{C}$ y Ni/SiO 2 , que se muestran en la Figura 20-6. 

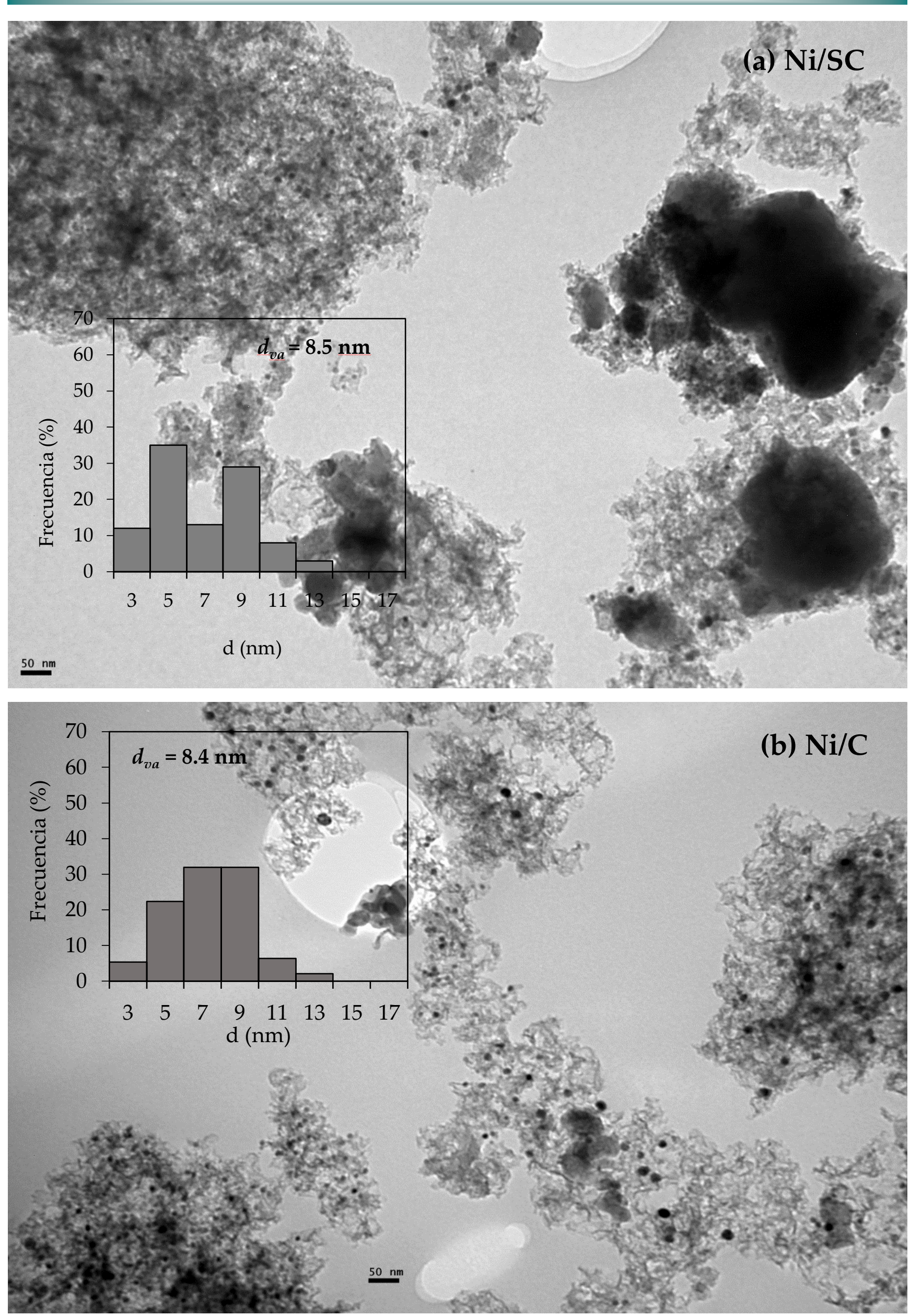


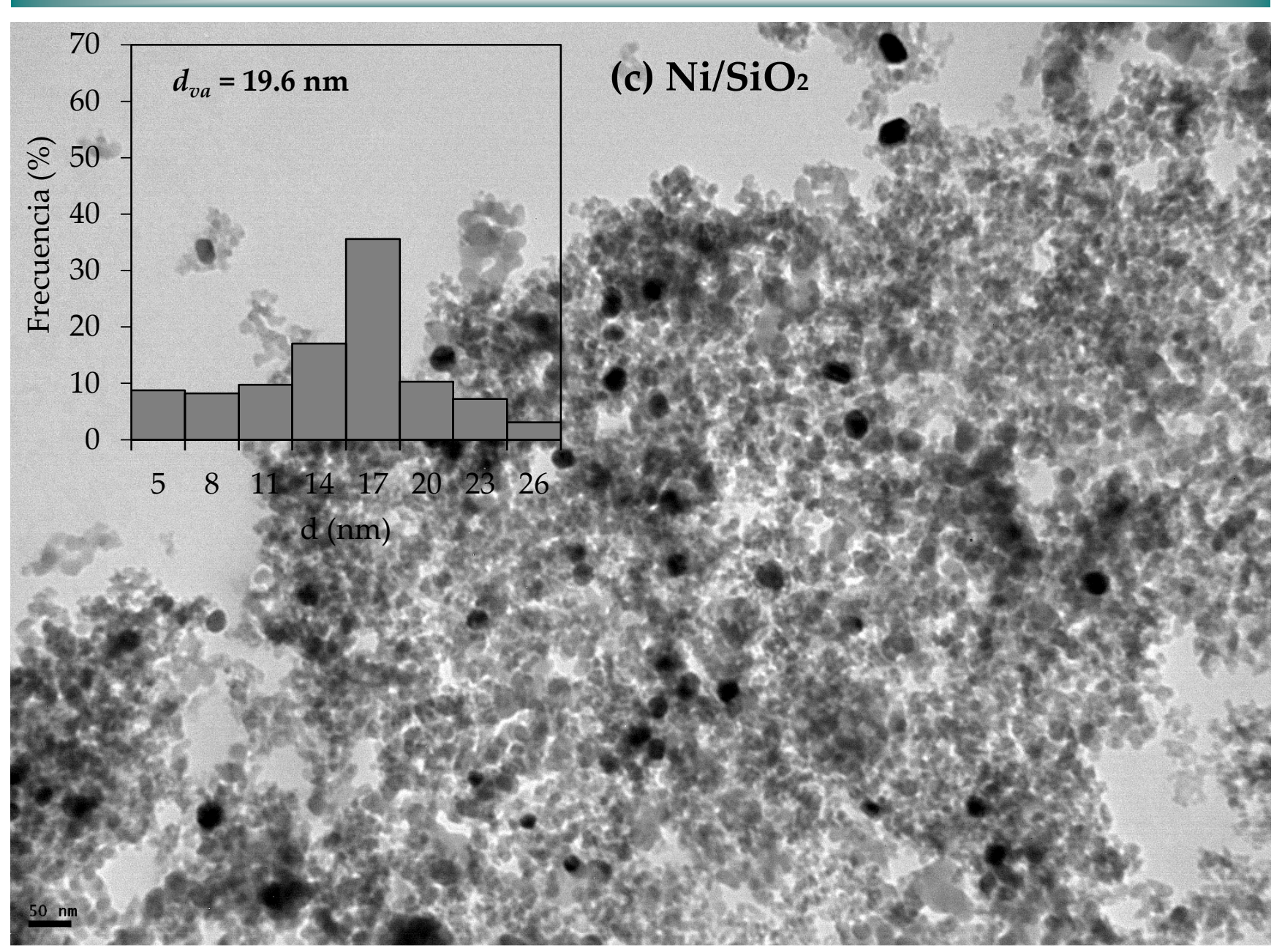

Figura 20-6. Imágenes TEM y distribución de tamaños de partícula para (a) Ni/SC (b) Ni/C (c) $\mathrm{Ni} / \mathrm{SiO}_{2}$

El análisis de microscopía de transmisión electrónica (TEM) permitió determinar el tamaño promedio de partícula y la dispersión metálica. Los resultados se muestran en la Tabla 11-6.

Los resultados muestran que Ni/SC y Ni/C tienen tamaños de partícula muy similares, del orden de $8.5 \mathrm{~nm}$, con una dispersión del orden del $11 \%$. Ni/ $\mathrm{SiO}_{2}$ mostró el mayor tamaño de partícula, del orden de $19.6 \mathrm{~nm}$, con la menor dispersión del orden del $5 \%$.

Tabla 11-6. Tamaños de partícula y dispersiones TEM para los catalizadores $\mathrm{Ni} / \mathrm{SiO}_{2}, \mathrm{Ni} / \mathrm{C}$ y Ni/SC.

\begin{tabular}{lcc}
\hline Catalizador & $\mathrm{d}_{\text {va }}(\mathrm{nm})$ & D \\
& & \\
$\mathrm{Ni} / \mathrm{SC}$ & 8.50 & 11.42 \\
$\mathrm{Ni} / \mathrm{C}$ & 8.40 & 11.56 \\
$\mathrm{Ni} / \mathrm{SiO}_{2}$ & 19.62 & 4.95 \\
\hline
\end{tabular}

Con el objetivo de caracterizar la fuerza ácida (Ei) y el número de sitios ácidos (NS) de los catalizadores soportados de Ni se llevaron a cabo ensayos de titulación potenciométrica. 
La Figura 21-6 muestra las curvas de titulación potenciométrica para los catalizadores de $\mathrm{Ni} / \mathrm{SiO}_{2}, \mathrm{Ni} / \mathrm{C}$ y Ni/SC. Se incluyen además las curvas correspondientes a los soportes.

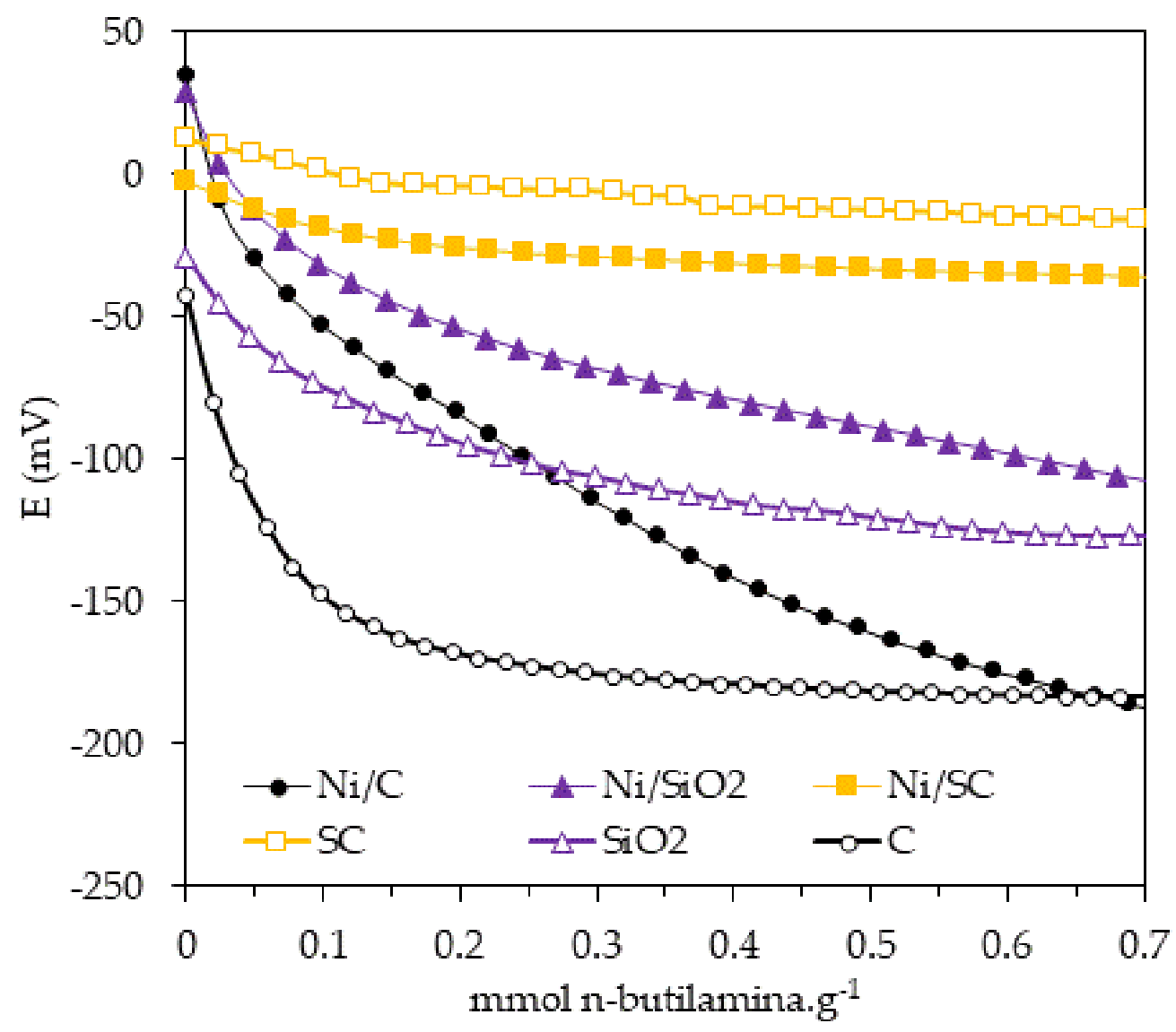

Figura 21-6. Curvas de titulación potenciométrica para los catalizadores de $\mathrm{Ni} / \mathrm{SiO}_{2}, \mathrm{Ni} / \mathrm{C}$ y $\mathrm{Ni} / \mathrm{SC}$ y sus soportes.

Los resultados de la Tabla 12-6 indican que en los catalizadores de $\mathrm{Ni} / \mathrm{C}$ y Ni/SiO 2 la incorporación del Ni genera sitios más fuertes que los del soporte, con una ligera variación en el número de sitios ácidos. En el caso del Ni/SC, se observa una caída en el valor del potencial que indica que la fuerza de los sitios disminuye, probablemente por la interacción entre el Ni y sitios del soporte.

Tabla 12-6. Fuerza ácida y número de sitios ácidos para $\mathrm{Ni} / \mathrm{SiO} 2, \mathrm{Ni} / \mathrm{C}, \mathrm{Ni} / \mathrm{SC}$ y sus soportes.

\begin{tabular}{lccc} 
Muestra & $\mathrm{E}_{\mathrm{i}}(\mathrm{mV})$ & Fuerza de sitios & $\mathrm{NS}\left(\mathrm{mmol}^{-1}\right)$ \\
\hline $\mathrm{SC}$ & 12.6 & Fuertes & 0.18 \\
$\mathrm{C}$ & -42.7 & Débiles & 0.40 \\
$\mathrm{SiO}_{2}$ & -28.9 & Débiles & 0.14 \\
$\mathrm{Ni} / \mathrm{SC}$ & -2.4 & Débiles & 0.19 \\
$\mathrm{Ni} / \mathrm{C}$ & 35.1 & Fuertes & 0.34 \\
$\mathrm{Ni} / \mathrm{SiO}_{2}$ & 28.3 & Fuertes & 0.21 \\
\hline
\end{tabular}


Para evaluar la actividad de los catalizadores de $\mathrm{Ni} / \mathrm{SC}, \mathrm{Ni} / \mathrm{C}$ y Ni/SiO 2 se llevaron a cabo ensayos de reacción a $260{ }^{\circ} \mathrm{C}$ y 20 bar de $\mathrm{H}_{2}$ iniciales (55 bar de presión autógena) empleando soluciones de glicerol al $30 \% \mathrm{p} / \mathrm{p}$, una relación $\mathrm{m}_{\mathrm{gli}} / \mathrm{m}_{\mathrm{c}}=6.2$, y tiempos de reacción entre 0.5 y 6 h. La Figura 22-6 muestra la evolución de la conversión de glicerol en función del tiempo para los catalizadores de $\mathrm{Ni} / \mathrm{SC}, \mathrm{Ni} / \mathrm{C}$ y Ni/SiO 2 .

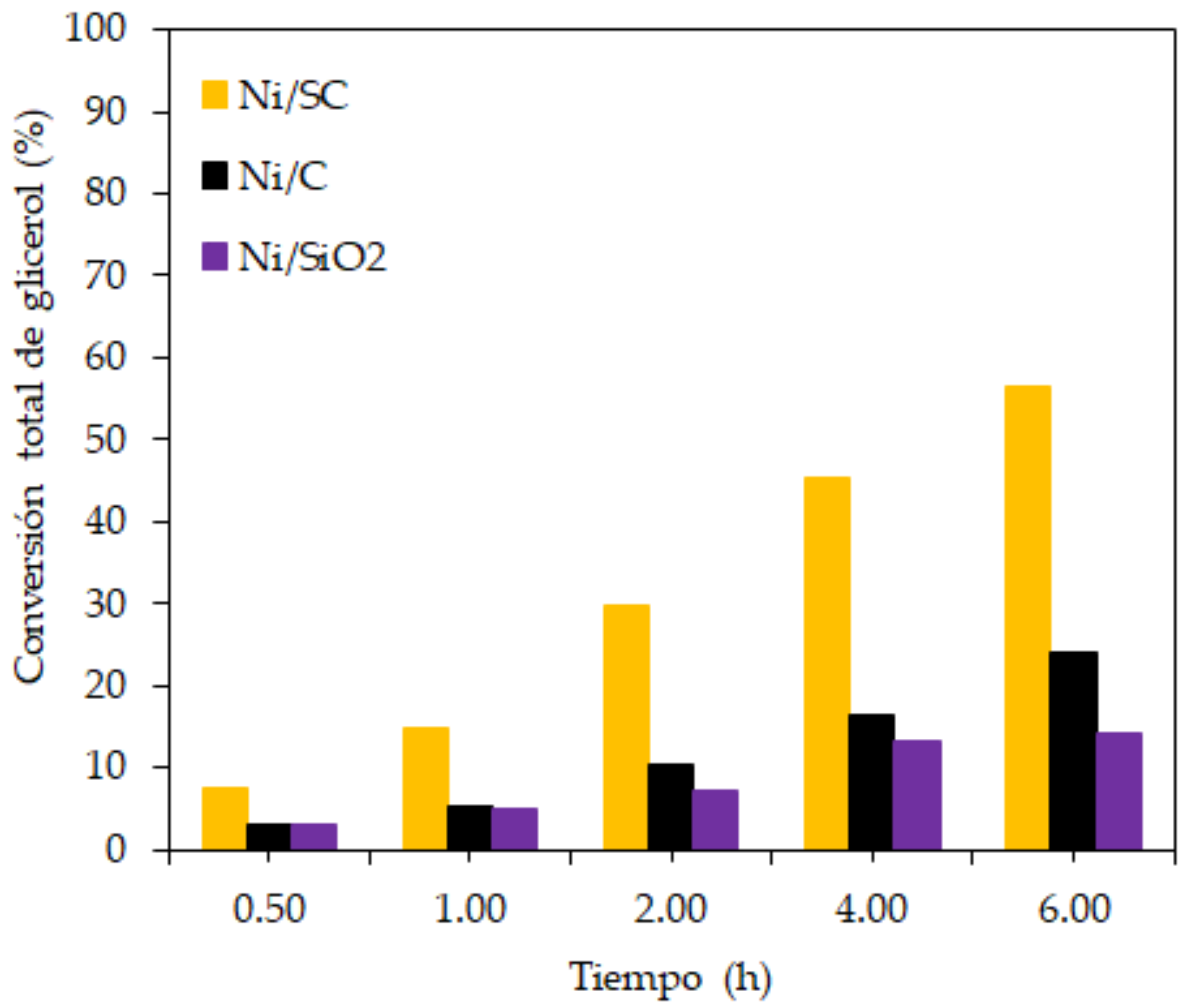

Figura 22-6. Evolución temporal de la conversión total de glicerol para los catalizadores de Ni/SC, $\mathrm{Ni} / \mathrm{C}$ y $\mathrm{Ni}_{\mathrm{SiO}}$.

En todos los ensayos se obtuvieron bajas conversiones a productos gaseosos $(<4 \%)$, siendo $\mathrm{CH}_{4} \mathrm{y} \mathrm{CO}_{2}$ los productos principales. El orden de actividad es el siguiente:

$$
\mathrm{Ni} / \mathrm{SC}>\mathrm{Ni} / \mathrm{C}>\mathrm{NiSiO}_{2}
$$

$\mathrm{Ni} / \mathrm{SC}$ y $\mathrm{Ni} / \mathrm{C}$ muestran un mayor incremento en los valores de conversión con el tiempo de reacción que el catalizador $\mathrm{Ni} / \mathrm{SiO}_{2}$. Los cambios en la estructura de la $\mathrm{SiO}_{2}$ podrían ser la causa de esta aparente desactivación, tal como se destacó en el capítulo 4.

La Figura 23-6 muestra la evolución en los valores de selectividad a los distintos productos líquidos en función del tiempo. En todos los ensayos, los productos líquidos obtenidos fueron $\mathrm{MeOH}, \mathrm{EtOH}, \mathrm{AcO}, 1-\mathrm{POH}, \mathrm{AcOH}, \mathrm{EG}, 1,2-\mathrm{PG}$. Solo para el caso del catalizador de $\mathrm{Ni} / \mathrm{C}$ se detectó la presencia de 1,3-PG. 
(a)

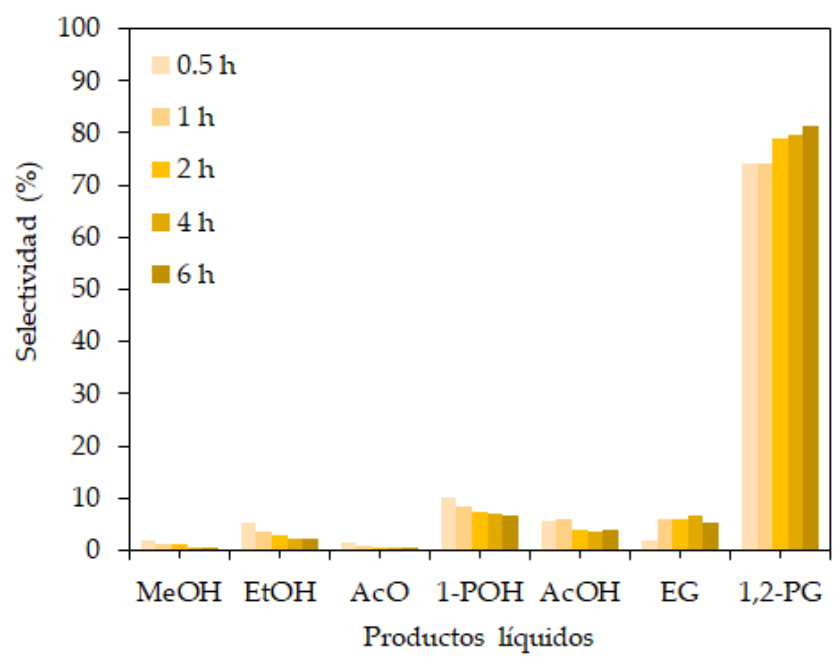

(b)

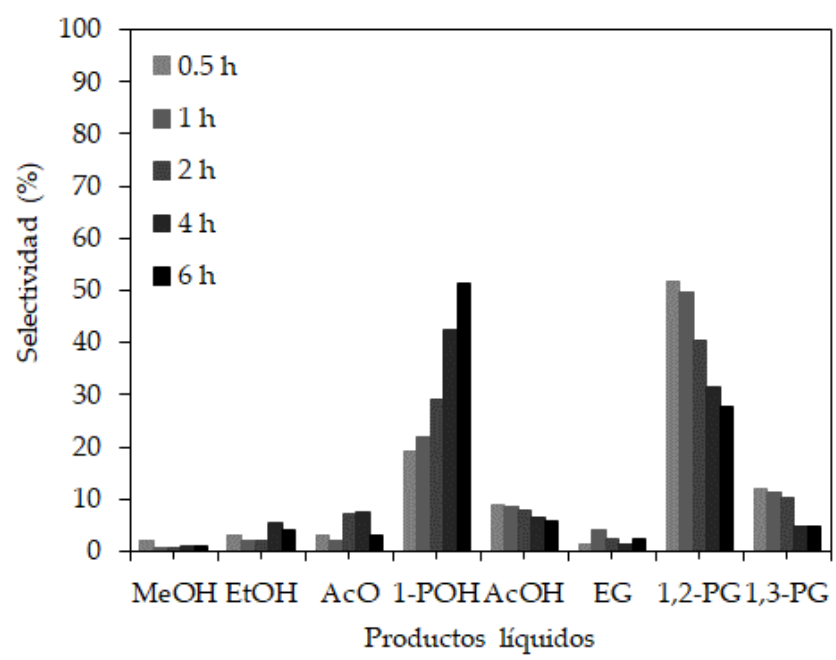

(c)

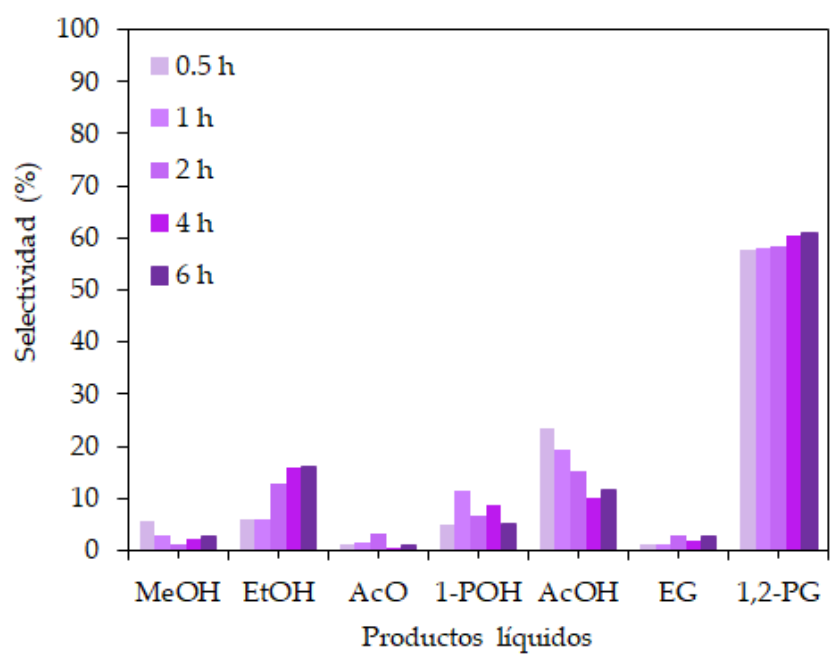

Figura 23-6. Selectividades a productos líquidos en función del tiempo para (a) Ni/SC (b) $\mathrm{Ni} / \mathrm{C}$ (c) $\mathrm{Ni} \mathrm{SiO}_{2}$.

Los resultados de la Figura 21-6 indican que el catalizador Ni/SC es el más selectivo a 1,2-PG ( $80 \%)$, con una baja selectividad a productos de $\mathrm{C} 1$ y C2, tales como $\mathrm{MeOH}$, EtOH y EG. La selectividad a productos de C1 y C2 es baja si se comparan estos resultados con los obtenidos para fases activas basadas en metales nobles, tales como $\mathrm{Ru}$ [6-8] y $\mathrm{Pt}$ [9-11], que tienen alta capacidad para la ruptura de enlaces C-C. Además, puede observarse como la selectividad a $\mathrm{AcOH}$ es baja (<6\%) comparada con catalizadores de $\mathrm{Cu}$, lo cual demuestra la alta actividad de hidrogenación por parte del $\mathrm{Ni}$ [12-14].

El catalizador $\mathrm{Ni} / \mathrm{C}$, a diferencia del Ni/SC, presenta una menor selectividad a 1,2-PG. A medida que aumenta el tiempo de reacción se observa que disminuye la selectividad a 1,2 PG y aumenta la selectividad a 1-POH. La formación de 1-POH a partir de 1,2-PG podría explicarse debido a la excesiva capacidad de $\mathrm{Ni} / \mathrm{C}$ para la ruptura de enlaces $\mathrm{C}-\mathrm{O}$. Además, el catalizador de Ni/C muestra la formación de 1,3-PG, que podría provenir a partir del 3-HPA, un compuesto intermediario formado a partir de la deshidratación del carbón secundario del glicerol, como se ha reportado en la literatura [7,15]. Acorde a los resultados que se presentan 
en la literatura, los sitios ácidos BrØnsted son los que favorecen la remoción del grupo -OH en el carbono secundario del glicerol para generar el 1,3-PG [16].

Dado que los tamaños de partícula son similares para los catalizadores Ni/SC y Ni/C, las diferencias en actividad y selectividad serían atribuidas a las diferencias en sus propiedades ácidas superficiales. La presencia de grupos funcionales lactónicos y fenólicos en el soporte de $\mathrm{C}$, determinada mediante la técnica de titulación de Bohem, serían los responsables de favorecer la ruptura de enlaces $\mathrm{C}-\mathrm{O}$ en el carbono secundario del glicerol para producir 1,3-PG y 1-POH a partir de los glicoles 1,2-PG y 1,3-PG. El soporte de SC no posee tales propiedades ácidas, puesto que se trata de un soporte menos ácido que el $\mathrm{C}$ y los grupos funcionales que posee son del tipo carboxílicos.

El catalizador $\mathrm{Ni} / \mathrm{SiO}_{2}$, por su parte, muestra una buena selectividad a 1,2-PG ( 60\%), pero con el transcurso del tiempo muestra una desactivación debido a cambios estructurales del soporte que afectan la fase metálica.

\subsection{Efecto de las variables operativas}

El objetivo de esta sección es estudiar el efecto de las principales variables operativas sobre la reacción de hidrogenólisis de glicerol empleando el catalizador de Ni/SC.

\subsubsection{Efecto de la relación masa de glicerol a masa de catalizador $\left(\mathrm{m}_{\mathrm{gli}} / \mathrm{m}_{\mathrm{c}}\right)$}

El efecto de la masa de catalizador y/o masa de glicerol sobre la conversión de glicerol y selectividad a 1,2-PG fue estudiado a $260^{\circ} \mathrm{C}, 20$ bar de $\mathrm{H}_{2}$ iniciales y $2 \mathrm{~h}$ de reacción.

La Figura 24-6 muestra la evolución de la conversión y selectividad a 1,2-PG cuando la relación de $\mathrm{m}_{\mathrm{gli}} / \mathrm{m}_{\mathrm{c}}$ fue variada entre 4.2 y 50.4, modificando solo la masa de catalizador. En las experiencias la concentración de glicerol en agua fue del $30 \% \mathrm{p} / \mathrm{p}\left(\mathrm{m}_{22} \mathrm{O} / \mathrm{m}_{\mathrm{gli}}=2.38\right)$.

Como puede observarse a partir del gráfico de la Figura 24-6, con el aumento de la masa de catalizador la conversión total de glicerol aumenta, con una selectividad a 1,2-PG prácticamente constante. Dado que la masa de glicerol es constante, un aumento en la masa de catalizador proporciona un mayor número de sitios activos lo que produce un incremento en la conversión de glicerol. La forma de la curva es similar a la que obtuvieron M. Balaraju et al., empleando un catalizador de $\mathrm{Ru} / \mathrm{C}$ [7].

En la Figura 25-6 se muestra la variación de conversión total de glicerol y la selectividad a 1,2-PG, cuando se varía la concentración de glicerol desde el 30 \%p/p (mH2o/mgli $=2.38)$ hasta el $65 \% \mathrm{p} / \mathrm{p}\left(\mathrm{m}_{2} \mathrm{O} / \mathrm{m}_{\text {gli }}=0.79\right)$, que corresponden a relaciones $\mathrm{mgli}_{\mathrm{g}} / \mathrm{m}_{\mathrm{c}} \mathrm{de} 6.2$ y 18.9 respectivamente. Las experiencias se realizaron a $260{ }^{\circ} \mathrm{C}$ y 20 bar de $\mathrm{H}_{2}$ iniciales, manteniendo constantes el contenido de agua y de catalizador.

A partir del gráfico de la Figura 25-6 es posible observar nuevamente que la conversión de glicerol disminuye a medida que se incrementa la relación $\mathrm{mgli}_{\mathrm{g}} / \mathrm{m}_{\mathrm{c}}$, debido a que el número de sitios activos permanece constante. La conversión de $\sim 30 \%$ obtenida para una concentración del $30 \% \mathrm{p} / \mathrm{p}$ de glicerol $\left(\mathrm{m}_{\mathrm{gli}} / \mathrm{m}_{\mathrm{c}}=6.2\right)$ luego de $2 \mathrm{~h}$ de reacción es destacable si se compara con el resultado de otros autores. Tal como se indicó en el capítulo 2, catalizadores de $\mathrm{Ni} / \gamma-\mathrm{Al}_{2} \mathrm{O}_{3}$ y $\mathrm{Ni} / \mathrm{CeO}_{2}-\mathrm{MgO}$ muestran conversiones del orden del $69 \%$ con selectividad a 1,2-PG de $61 \%$ y $47 \%$ respectivamente luego de 24 h de reacción, empleando 
una relación $\mathrm{m}_{\mathrm{gli}} / \mathrm{m}_{\mathrm{c}}=6[17,18]$. Además, la selectividad a 1,2-PG permanece constante $(\sim 80 \%)$ con el aumento de la concentración de glicerol, sugiriendo la naturaleza selectiva de este catalizador aun en condiciones en donde el contenido de glicerol es alto.

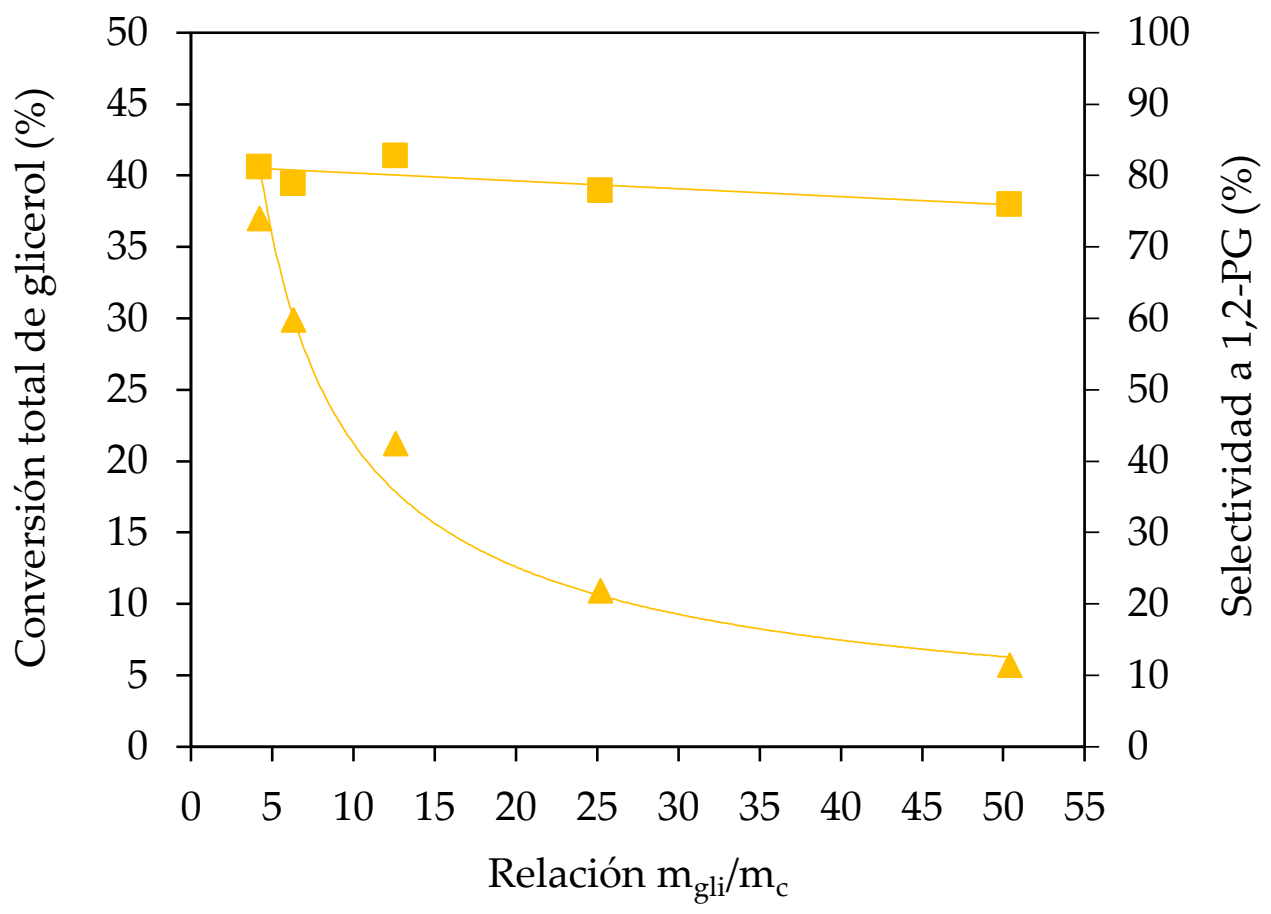

Figura 24-6. Conversión total de glicerol y selectividad a 1,2-PG en función de la relación $m_{g l i} / m_{c}$, variando la masa de catalizador.

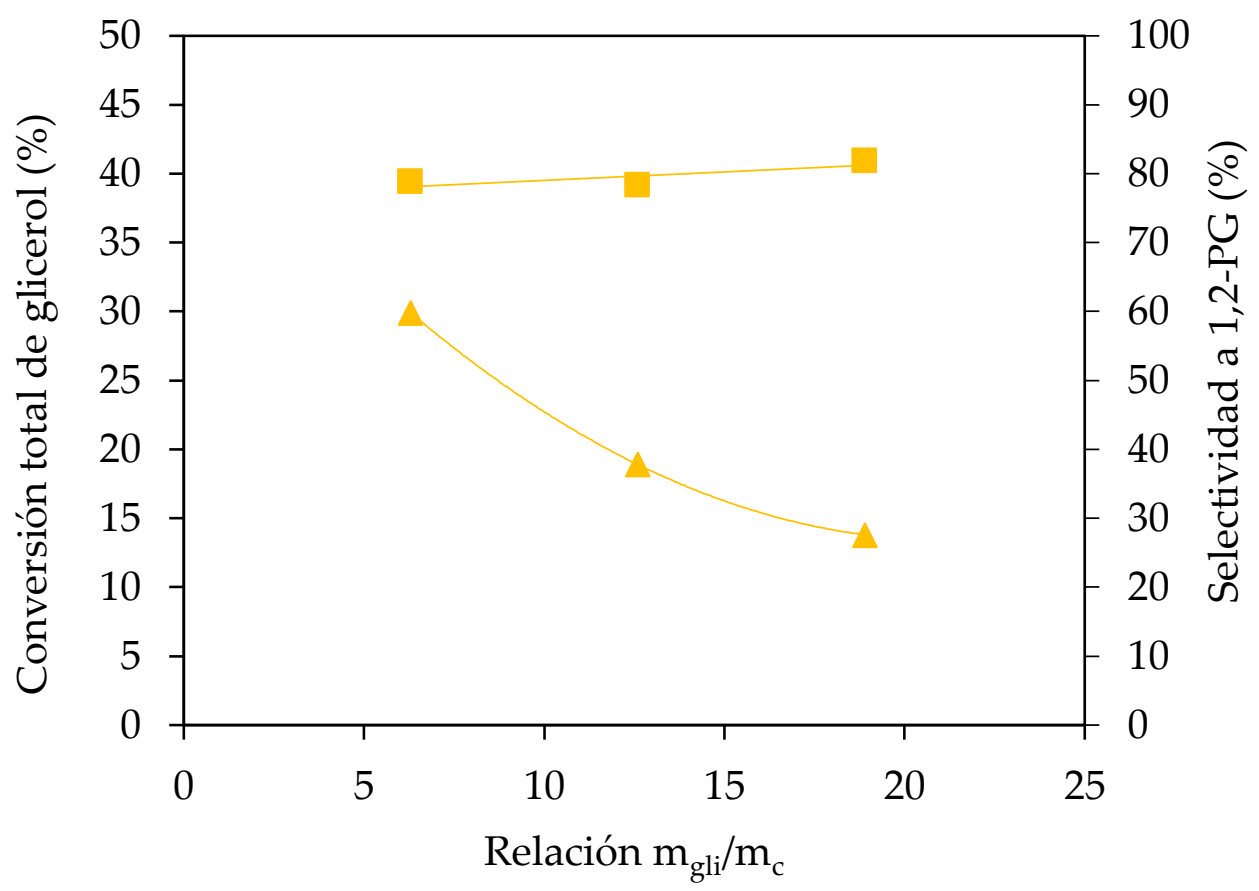

Figura 25-6. Conversión total de glicerol y selectividad a 1,2-PG en función de la relación $m_{g l i} / m_{c}$ variando la concentración de glicerol. 
A partir de los valores de la velocidad de reacción observada para el glicerol, $\left(-\mathrm{r}_{\mathrm{gli}}\right), \mathrm{y}$ los valores de concentración inicial de glicerol, $\mathrm{Cggl}_{\mathrm{gl}} \mathrm{L}$, fue posible estimar un orden de reacción parcial con respecto al glicerol. Los resultados se visualizan en la Figura 26-6.

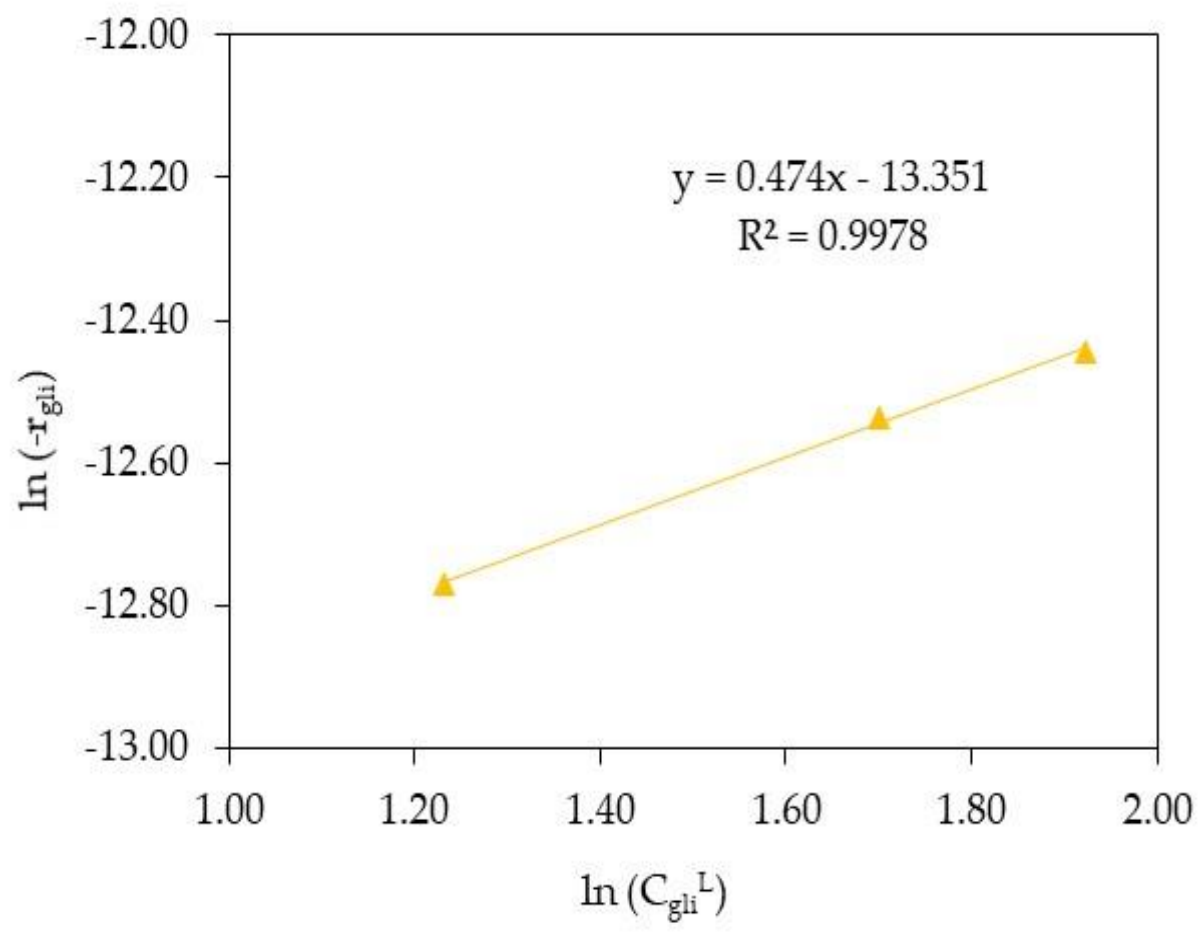

Figura 26-6. Estimación del orden de reacción con respecto al glicerol.

Estos resultados muestran que el orden de reacción con respecto al glicerol es 0.47 . Vasiliadou et al. [19] estudiaron la cinética de hidrogenólisis empleando un catalizador de $\mathrm{Cu} / \mathrm{SiO}_{2}$. Utilizando soluciones de glicerol en el rango del $20 \% \mathrm{p} / \mathrm{p}$ al $40 \% \mathrm{p} / \mathrm{p}$ encontraron que el orden de reacción con respecto al glicerol es 0.27 , valor muy similar a otros catalizadores empleados en reacciones de hidrogenación en fase líquida [20-22]. Estos autores indican que la baja dependencia de la velocidad de reacción con la concentración de glicerol revela que los sitios activos del catalizador están ocupados casi completamente por especies de glicerol adsorbidas.

\subsubsection{Efecto del contenido de agua}

Empleando una relación $\mathrm{m}_{\text {gli }} / \mathrm{m}_{\mathrm{c}}=6.2$, se realizaron ensayos de reacción a $260{ }^{\circ} \mathrm{C}$ y 20 bar de $\mathrm{H}_{2}$ iniciales, durante $2 \mathrm{~h}$, para determinar el efecto del contenido de agua sobre la conversión total de glicerol y la selectividad a los distintos productos líquidos.

La Figura 27-6 muestra los resultados cuando se varía la relación mH2o/mgli en el rango de 2.3 a 79.3, manteniendo constante la masa de glicerol.

Sólo para la relación mHzo/mgli más alta (79.3) se observa que la conversión disminuye a $\sim 24 \%$, indicando que la presencia de agua es perjudicial cuando la solución de glicerol es muy diluida. 


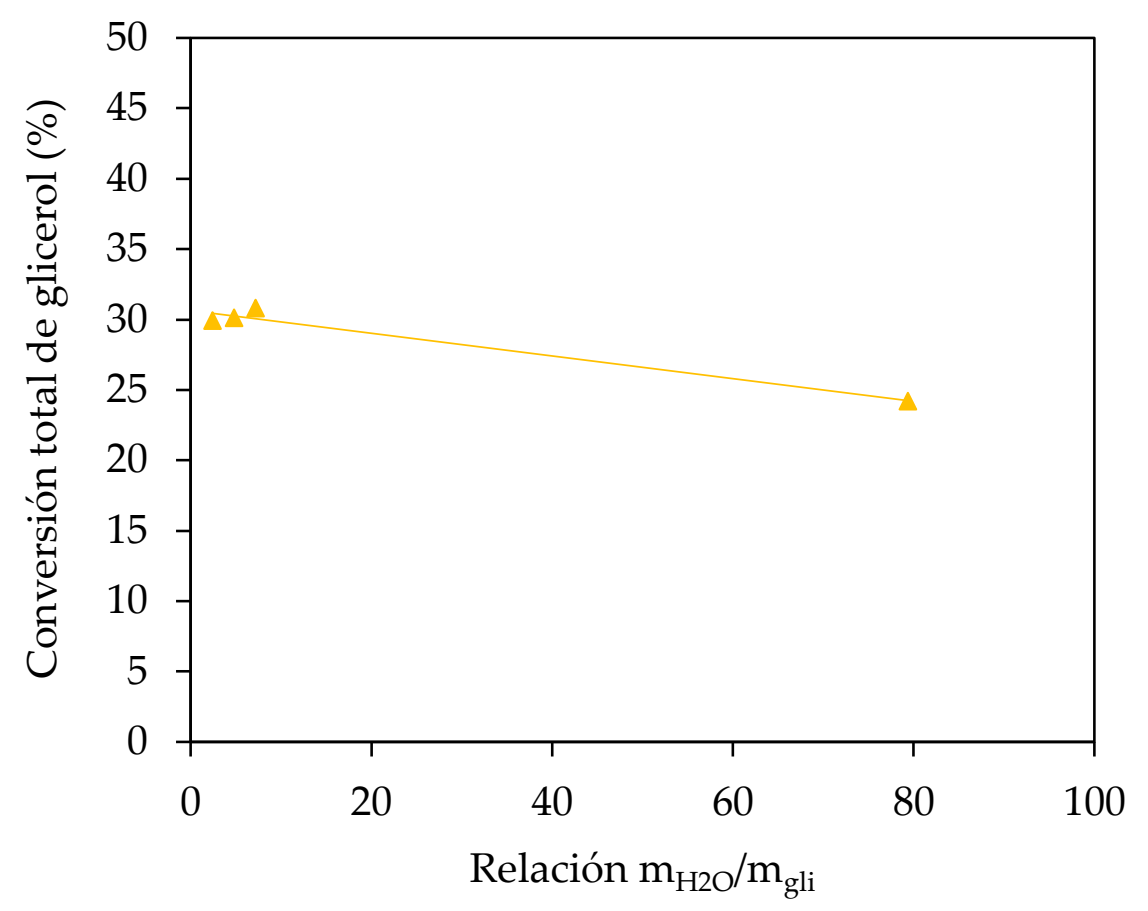

Figura 27-6. Conversión total de glicerol en función de la relación $m_{\mathrm{H} 2 \mathrm{O}} / m_{\mathrm{gl}}$.

La Figura 28-6 muestra los valores de selectividad a 1,2-PG y a $\mathrm{AcOH}$ en función de la relación $\mathrm{m}_{22} \mathrm{O} / \mathrm{m}_{\mathrm{gli}}$. A medida que la relación $\mathrm{m}_{\mathrm{H} 2 \mathrm{O}} / \mathrm{m}_{\mathrm{gli}}$ aumenta se produce una disminución en la selectividad a 1,2-PG y a $\mathrm{AcOH}$, lo que podría explicarse porque la deshidratación se ve desfavorecida por el agua.

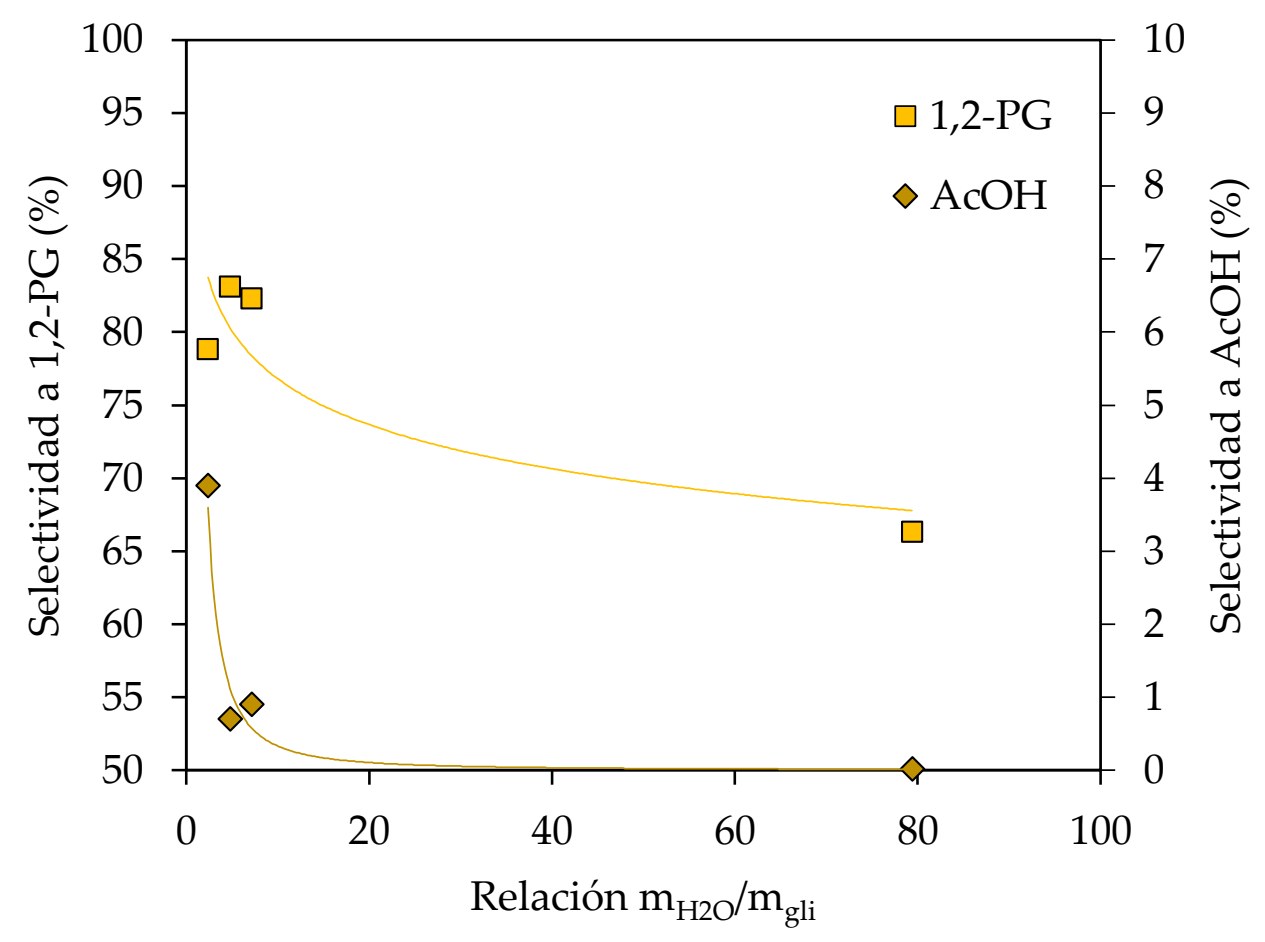

Figura 28-6. Selectividad a 1,2-PG y a AcOH en función de la relación $m_{\mathrm{H} 2 \mathrm{O}} / \mathrm{m}_{\mathrm{gli}}$. 


\subsubsection{Efecto de la presión}

La Figura 29-6 muestra el efecto de la presión de $\mathrm{H}_{2}$ sobre la actividad.

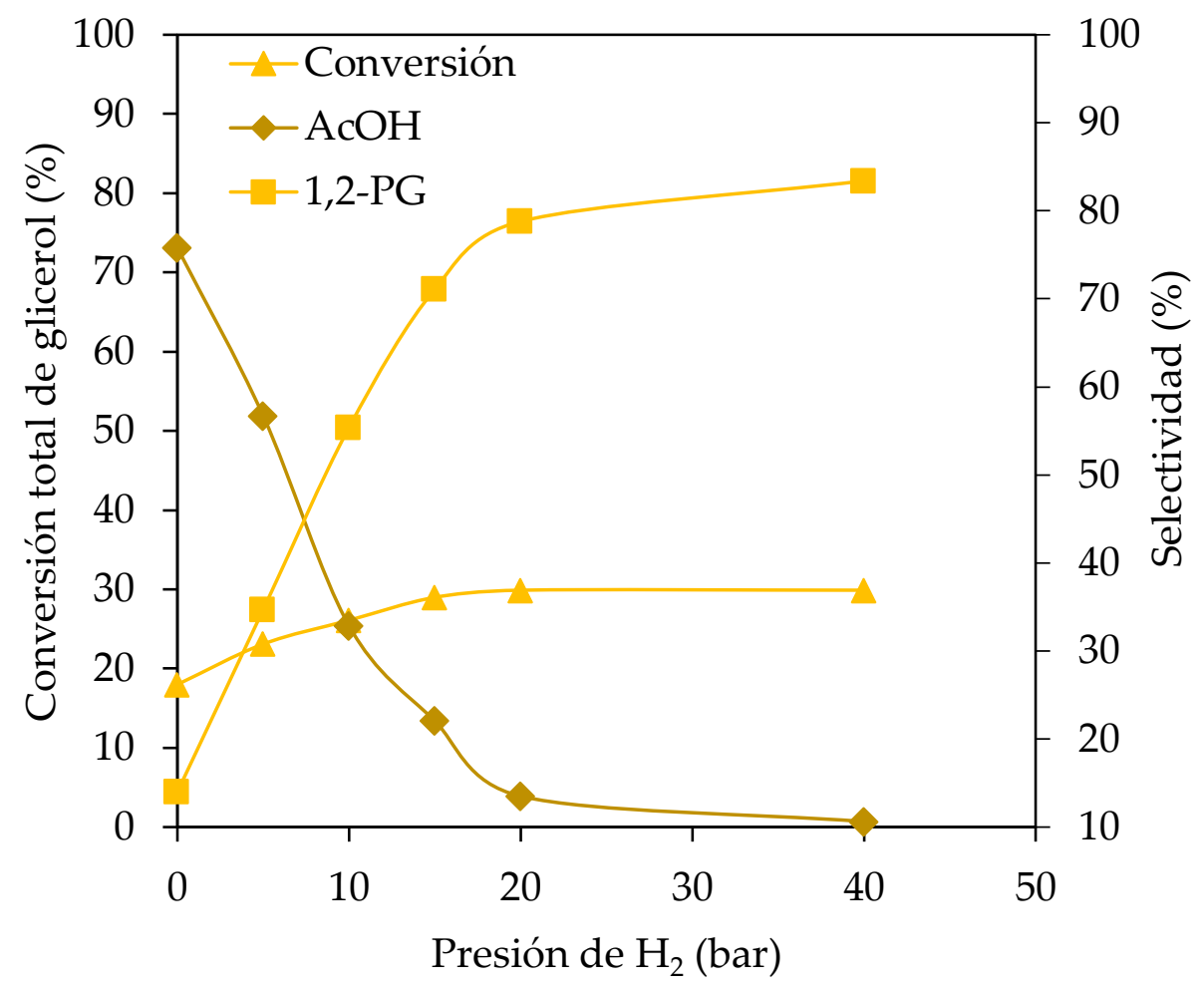

Figura 29-6. Conversión total de glicerol y selectividad a 1,2-PG y AcOH en función de la presión de $H_{2}$.

El efecto de la presión parcial de $\mathrm{H}_{2}$ fue estudiado a $260{ }^{\circ} \mathrm{C}$ empleando soluciones de glicerol al $30 \% \mathrm{p} / \mathrm{p}\left(\mathrm{mH}_{22} / \mathrm{m}_{\mathrm{gli}}=2.38\right)$ y una relación $\mathrm{m}_{\mathrm{gli}} / \mathrm{m}_{\mathrm{c}}=6.2$. Los resultados fueron obtenidos luego de $2 \mathrm{~h}$ de reacción.

Estudios publicados en la literatura han reportado un aumento en la conversión total de glicerol con el aumento de la presión de $\mathrm{H}_{2}$, empleando catalizadores de $\mathrm{Ru}$ [7,23], $\mathrm{Cu}$ [19] y Co [24]. Sharma et al. [25] trabajaron con catalizadores de $\mathrm{Cu}-\mathrm{Cr}-\mathrm{Zn}-\mathrm{Zr}$ a $240{ }^{\circ} \mathrm{C}$ en el rango de 10 a 40 bar de $\mathrm{H}_{2}$ y encontraron que la conversión de glicerol se incrementa con el aumento de la presión de $\mathrm{H}_{2}$ sin afectar la selectividad a 1,2-PG. Vasiliadou et al., por su parte, emplearon un catalizador de $\mathrm{Cu} / \mathrm{SiO}_{2}$ a $240{ }^{\circ} \mathrm{C}$ en el rango de 20 a 80 bar de $\mathrm{H}_{2}$ y reportaron que un aumento en la presión de $\mathrm{H}_{2}$ afecta positivamente tanto la velocidad de reacción como la selectividad a 1,2-PG [19].

Los resultados de la Figura 29-6 muestran que con el incremento en la presión de $\mathrm{H}_{2}$ se produce un aumento en la conversión, pero el mayor cambio se observa en la selectividad a 1,2-PG. Esta figura además muestra que la selectividad a $\mathrm{AcOH}$ disminuye con el aumento de la presión de $\mathrm{H}_{2}$ porque se favorece la formación de 1,2-PG. De este modo, la primera etapa en la reacción de hidrogenólisis de glicerol, la ruptura de enlaces C-O para la producción de $\mathrm{AcOH}$, no se encuentra afectada por la presencia de $\mathrm{H}_{2}$, pero sí la segunda etapa de hidrogenación del AcOH a 1,2-PG. 
A partir de los valores de la velocidad de reacción observada para el glicerol, $\left(-\mathrm{r}_{\mathrm{gli}}\right), \mathrm{y}$ los valores de concentración inicial $\mathrm{de}_{2} \mathrm{H}_{2} \mathrm{C}_{\mathrm{H}} \mathrm{L}$, fue posible estimar un orden de reacción parcial con respecto al $\mathrm{H}_{2}$. Los resultados se visualizan en la Figura 30-6.

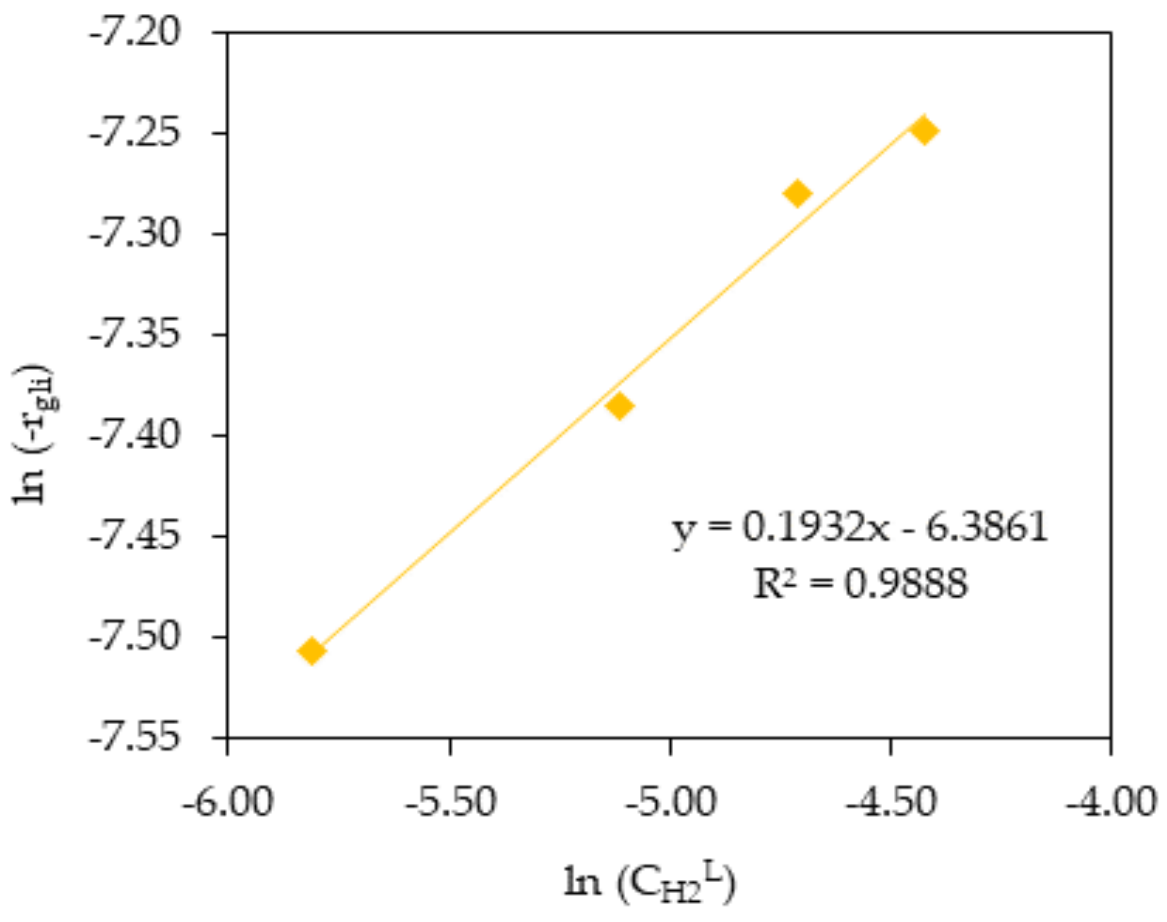

Figura 30-6. Estimación del orden de reacción con respecto al $\mathrm{H}_{2}$.

Los resultados muestran que, en estas condiciones de reacción, el orden de reacción con respecto al $\mathrm{H}_{2}$ es 0.19 . Este número indica que hay una baja dependencia de la velocidad de reacción con la concentración de $\mathrm{H}_{2}$ que se encuentra disuelta en fase líquida.

\subsubsection{Efecto de la temperatura}

El efecto de la temperatura sobre la reacción de hidrogenólisis fue estudiada en el rango de $220{ }^{\circ} \mathrm{C}$ a $260{ }^{\circ} \mathrm{C}$. Estos ensayos de reacción fueron realizados a 20 bar de $\mathrm{H}_{2}$ iniciales empleando soluciones de glicerol al $30 \% \mathrm{p} / \mathrm{p}\left(\mathrm{mH}_{20} / \mathrm{m}_{\text {gli }}=2.38\right)$ y una relación $\mathrm{m}_{\text {gli }} / \mathrm{m}_{c}=6.2$ entre 1 y $6 \mathrm{~h}$. En todos los ensayos se obtuvieron bajas conversiones a productos gaseosos $(<2$ $\%$ ), siendo $\mathrm{CH}_{4}$ y $\mathrm{CO}_{2}$ los productos principales.

La Figura 30-6 muestra la evolución de la conversión total de glicerol en función del tiempo a las temperaturas de $220^{\circ} \mathrm{C}, 240^{\circ} \mathrm{C}$ y $260{ }^{\circ} \mathrm{C}$. Como puede observarse, las tres curvas muestran un aumento de la conversión total de glicerol en función del tiempo. Por otro lado, hasta un nivel de conversión del 30 \% las curvas de conversión total de glicerol versus tiempo muestran una dependencia lineal en el rango térmico estudiado. Para conversiones mayores al $30 \%$ la dependencia ya no es lineal, como se observa para la temperatura de 260 ${ }^{\circ} \mathrm{C}$. 


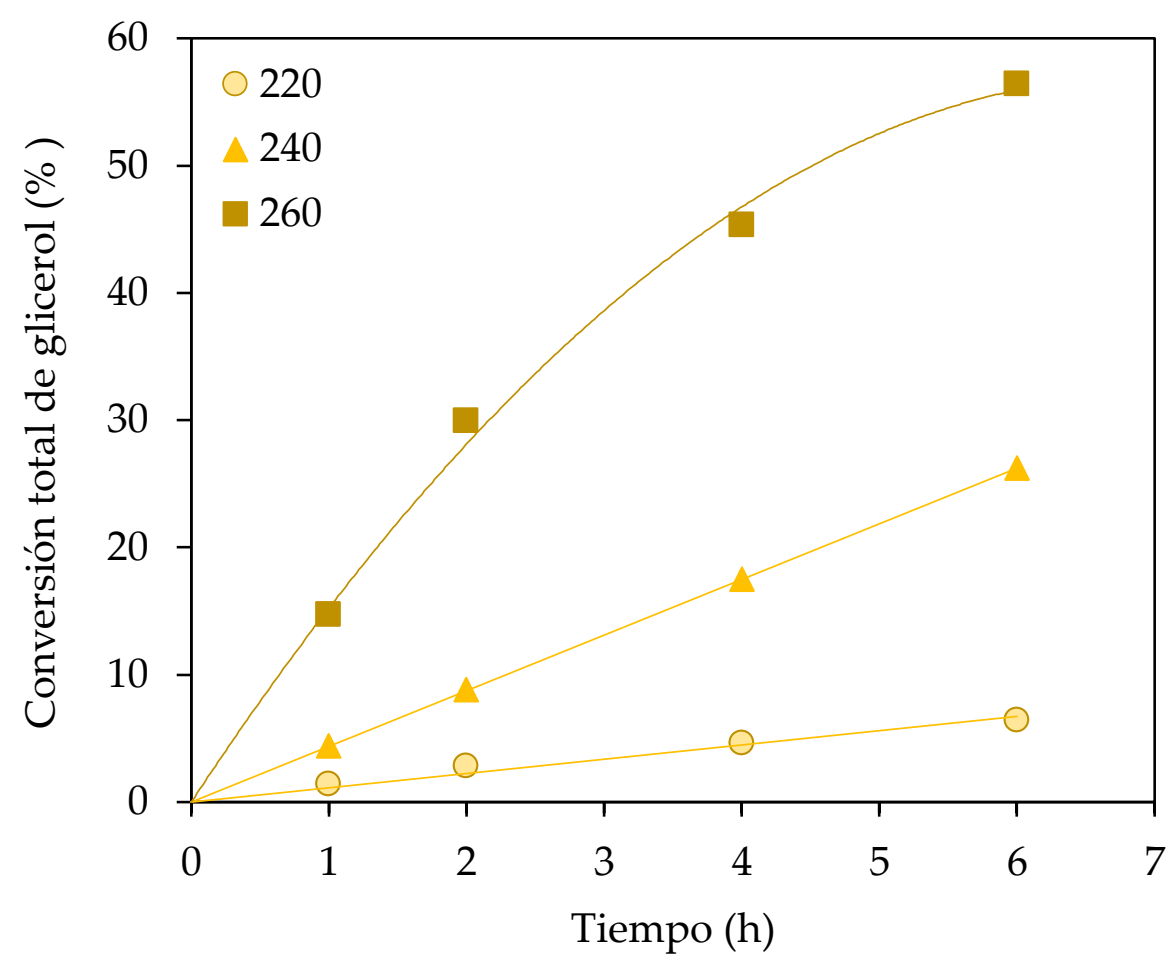

Figura 30-6. Efecto de la temperatura sobre la conversión total de glicerol.

Si se grafica la conversión total de glicerol con respecto a la temperatura en el rango térmico de $220^{\circ} \mathrm{C}$ a $260{ }^{\circ} \mathrm{C}$ se obtiene el gráfico de la Figura 31-6. Estos valores de conversión corresponden a $2 \mathrm{~h}$ de reacción.

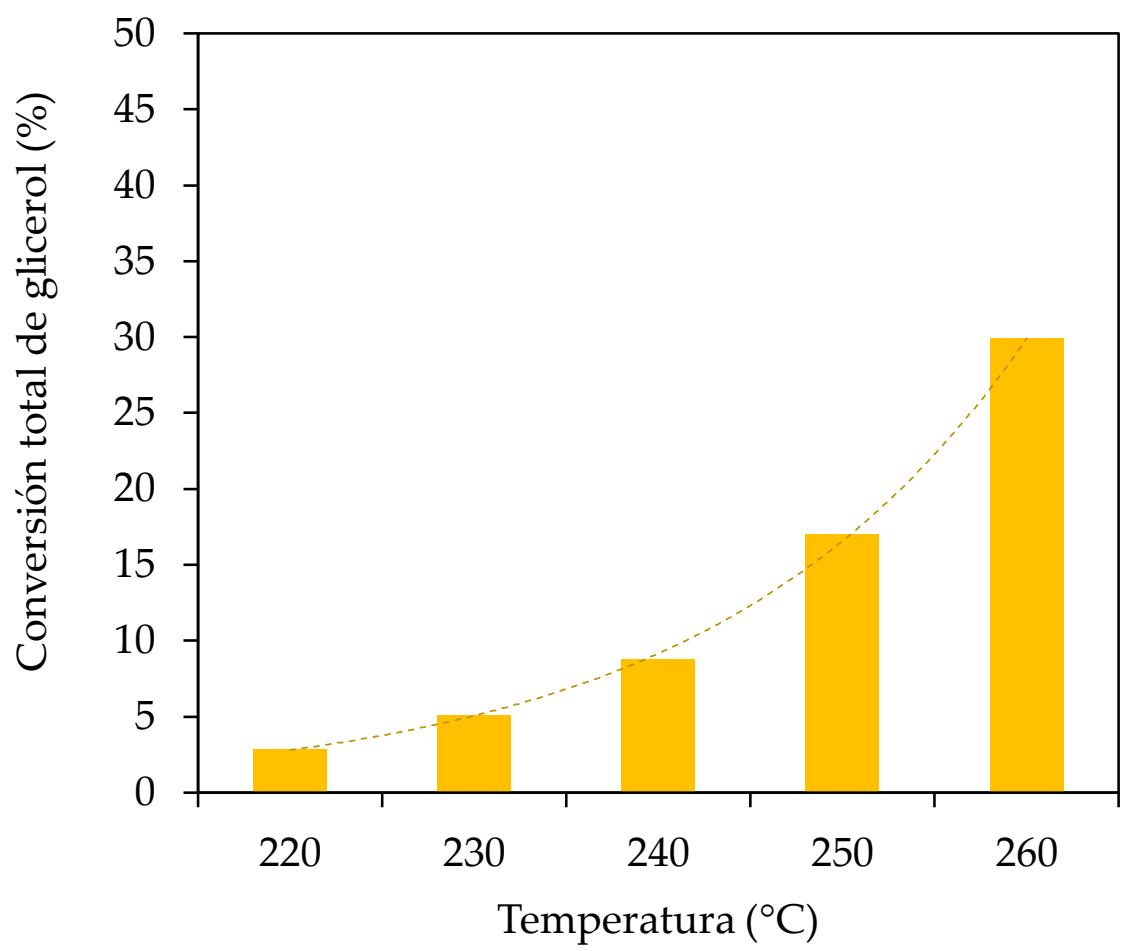

Figura 31-6. Efecto de la temperatura sobre la conversión total de glicerol. 
Como puede apreciarse, la conversión sigue una tendencia exponencial en función de la temperatura, lo que hace suponer una dependencia del tipo ley de Arrhenius entre la velocidad de reacción y la temperatura. Este estudio del efecto de la temperatura permite estimar una energía de activación global para la reacción de hidrogenólisis, empleando una ecuación logarítmica basada en la ley de Arrhenius:

$$
\ln \left(-\mathrm{rgli}_{\mathrm{gl}}\right)=\ln \left(\mathrm{k}_{\mathrm{o}}\right)+\left(-\mathrm{E}_{\mathrm{a}} / \mathrm{R}\right) \cdot(1 / \mathrm{T})
$$

En la ecuación anterior, $\left(-\mathrm{r}_{\text {gli }}\right)$ es la velocidad de reacción observada para el glicerol (moles de glicerol que reaccionaron/moles de metal * tiempo), Ea es la energía de activación aparente y global de la reacción de hidrogenólisis $(\mathrm{kJ} / \mathrm{mol})$ y $\mathrm{k}_{\mathrm{o}}$ es el factor pre-exponencial encontrado en la velocidad de reacción observada para cinética de las reacciones heterogéneas. Se estimó una energía de activación global y aparente de la reacción $\mathrm{E}_{a} \sim 140$ kJ.mol ${ }^{-1}$. Los resultados de la regresión lineal se visualizan en la Figura 32-6.

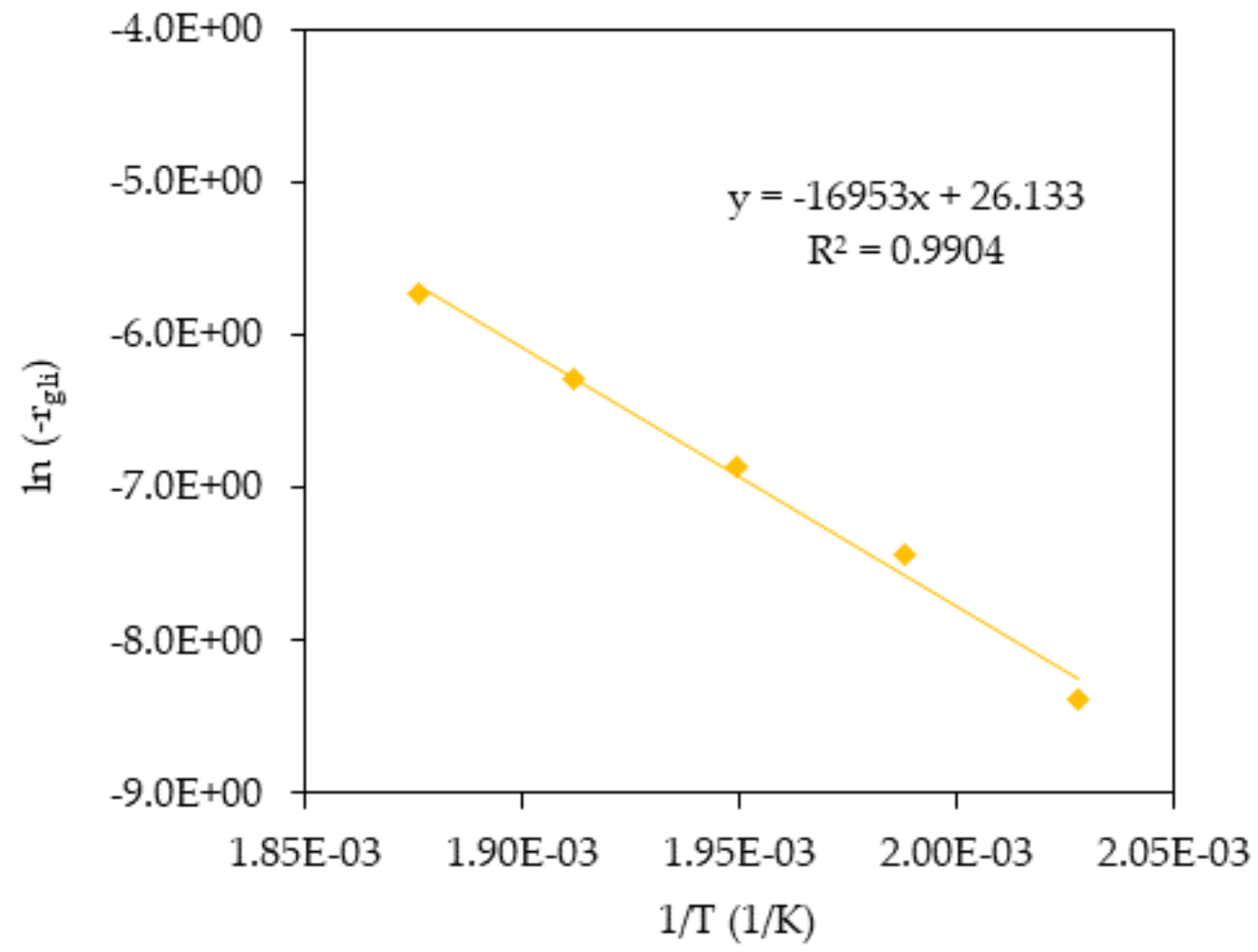

Figura 32-6. Obtención de la energía de activación aparente de la reacción entre 220 y $260{ }^{\circ} \mathrm{C}$.

La Tabla 13-6 muestra resultados de energías de activación reportados en bibliografía. La energía de activación global y aparente obtenida para $\mathrm{Cu} / \mathrm{Zn} / \mathrm{Cr} / \mathrm{Zr}$ [25] fue la más similar al valor obtenido para $\mathrm{Ni} / \mathrm{SC}$.

La Figura 33-6 muestra que el incremento en la temperatura de reacción provoca una caída en la selectividad a 1,2-PG, acompañada por el incremento en la selectividad a productos de C2, debido a una mayor contribución de las reacciones de ruptura de enlaces C- 
C $[7,11,23]$. También se observa un incremento en la selectividad a $\mathrm{AcOH}$, que podría deberse al hecho de que la hidrogenación no se ve favorecida a altas temperaturas.

Tabla 13-6. Catalizadores y condiciones operativas empleadas para obtener energías de activación aparentes de la reacción de hidrogenólisis.

\begin{tabular}{lccr}
\hline Catalizador & Rango $\left({ }^{\circ} \mathrm{C}\right)$ & $\mathrm{Ea}_{(\mathrm{kJ} / \mathrm{mol})}$ & Ref. \\
\hline $\mathrm{Rh} / \mathrm{C}$ & $180-240$ & 98 & {$[20]$} \\
\hline $\mathrm{Cu}-\mathrm{SiO}_{2}$ & $160-220$ & 48 & {$[21]$} \\
\hline $\mathrm{Cu} / \mathrm{SiO}_{2}$ & $180-240$ & 97 & {$[19]$} \\
\hline $\mathrm{Cu} / \mathrm{MgO}$ & $160-220$ & 58 & {$[22]$} \\
\hline $\mathrm{Cu} / \mathrm{CeO} / \mathrm{MgO}$ & $160-220$ & 26 & {$[22]$} \\
\hline $\mathrm{Cu} / \mathrm{Zn} / \mathrm{Cr} / \mathrm{Zr}$ & $220-250$ & 132 & {$[25]$} \\
\hline
\end{tabular}

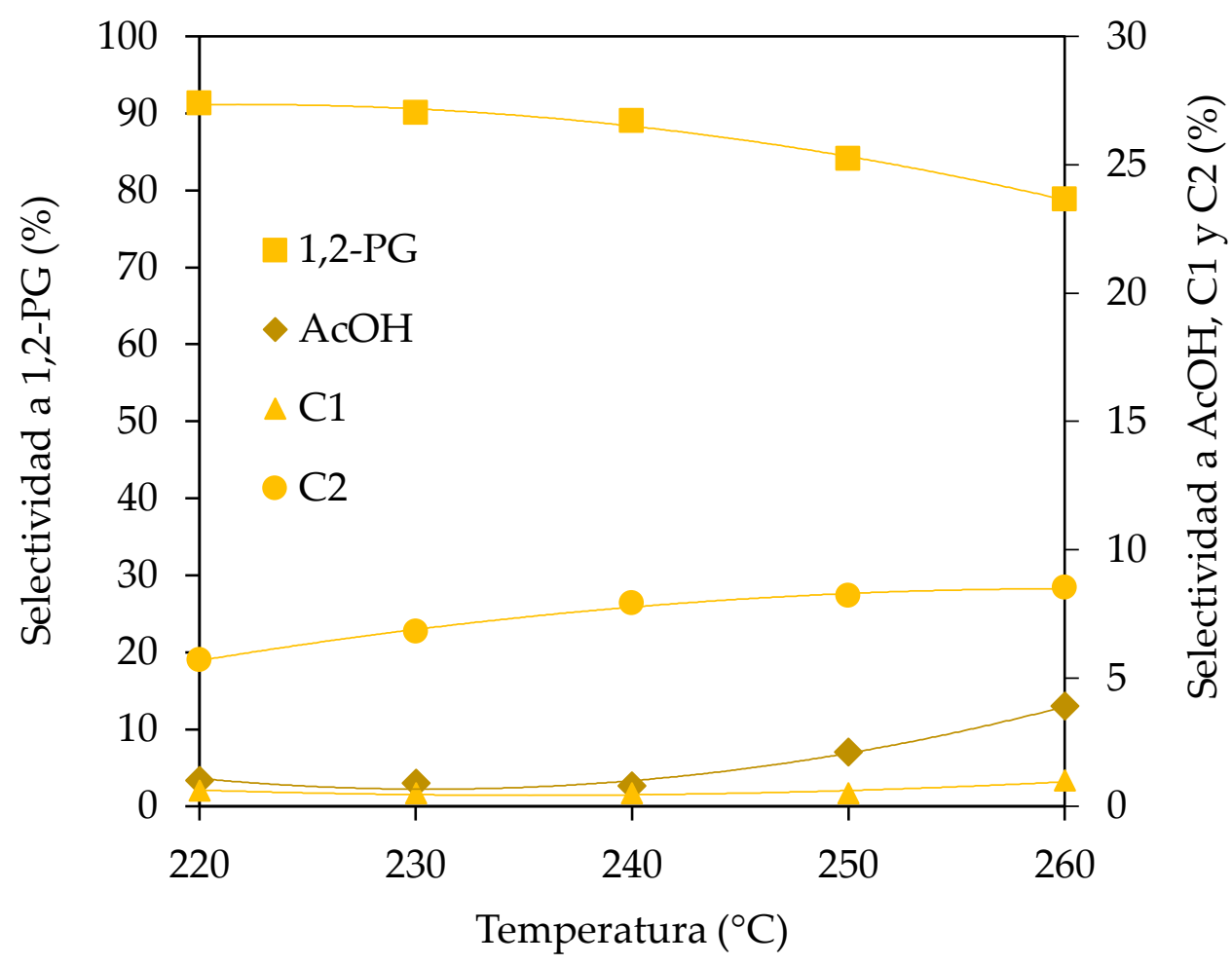

Figura 33-6. Selectividades a 1,2-PG, AcOH, C1 y C2 en función de la temperatura.

\subsection{Estabilidad del catalizador Ni/SC}

Para analizar si la estructura del catalizador Ni/SC se modifica durante los ensayos de reacción, se realizó la caracterización de la muestra $\mathrm{Ni} / \mathrm{SC}$ usada a $260{ }^{\circ} \mathrm{C}$ y 20 bar de $\mathrm{H}_{2}$ luego de $6 \mathrm{~h}$ de reacción. La muestra fue lavada, secada y caracterizada mediante las técnicas de espectroscopía de absorción atómica (AAS), adsorción-desorción de $\mathrm{N}_{2}$ (BET), difracción de rayos X (DRX) y microscopía de transmisión electrónica (TEM). La Tabla 14-6 muestra los resultados, donde se incluyen los resultados del catalizador Ni/SC fresco. 
Tabla 14-6. Propiedades texturales y fisicoquímicas del catalizador de Ni/SC fresco y usado.

\begin{tabular}{lcccccc}
\hline \multirow{2}{*}{ Catalizador } & AAS & \multicolumn{2}{c}{ BET } & \multicolumn{2}{c}{ DRX } & \multicolumn{2}{c}{ TEM } \\
\cline { 2 - 7 } & $\mathrm{Ni}(\%)$ & $\mathrm{S}_{\text {BET }}\left(\mathrm{m}^{2} \cdot \mathrm{g}^{-1}\right)$ & $\mathrm{V}_{\mathrm{p}}\left(\mathrm{cm}^{3} \cdot \mathrm{g}^{-1}\right)$ & $\mathrm{dDRX}_{(\mathrm{nm})}$ & $\mathrm{d}_{\mathrm{va}}(\mathrm{nm})$ & $\mathrm{D}_{\text {TeM }}(\%)$ \\
\hline $\mathrm{Ni} / \mathrm{SC}$ fresco & 4.53 & 211 & 0.41 & 12.20 & 8.50 & 11.42 \\
Ni/SC usado & 4.35 & 195 & 0.37 & 20.00 & 9.70 & 10.01 \\
\hline
\end{tabular}

El contenido de Ni en la solución luego de 6 h de reacción fue del orden de las 100 ppm, determinadas por el análisis de AAS. Esto indica que la pérdida de Ni por leaching es despreciable, del orden del $4 \% \mathrm{p} / \mathrm{p}$. Hay que considerar que este porcentaje se encuentra dentro del error experimental de la técnica.

El análisis BET reveló que la superficie específica para el catalizador de $\mathrm{Ni} / \mathrm{SC}$ es de $195 \mathrm{~m}^{2} \cdot \mathrm{g}^{-1}$ luego de $6 \mathrm{~h}$ de reacción, representando una ligera disminución del $8 \%$ con respecto a la superficie específica del catalizador fresco.

La Figura 34-6 muestra el difractograma de rayos X para los catalizadores de Ni/SC fresco y usado.

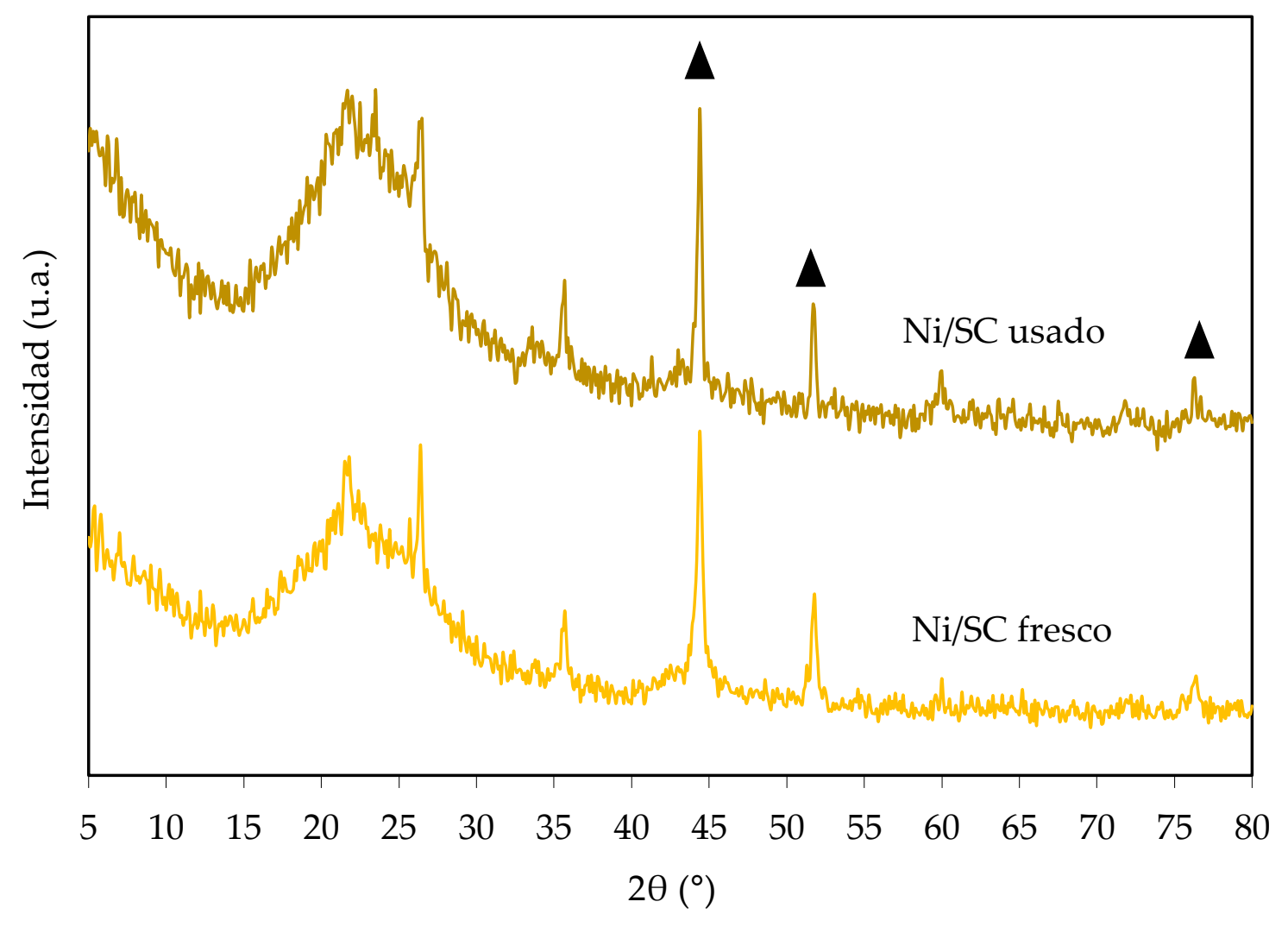

Figura 34-6. Difractograma de rayos X para los catalizadores de Ni/SC fresco y usado.

Como se puede observar no hay presencia de $\mathrm{NiO}$ en la muestra usada. Existe una pequeña diferencia en el ancho del pico correspondiente a la señal de Ni metálico, lo que resultaría en un mayor tamaño de cristal, como se aprecia en los valores de la Tabla 14-6. 
Los resultados obtenidos por DRX son consistentes con los obtenidos por TEM, que muestran un incremento en el tamaño de partícula del catalizador fresco $(8.5 \mathrm{~nm})$ con respecto al usado $(9.7 \mathrm{~nm})$, lo que indica un ligero sinterizado de la partícula metálica.

\section{Conclusiones}

Se prepararon catalizadores de $\mathrm{Ni}$ empleando tres sales de níquel distintas, $\mathrm{NiCl}_{2} .6 \mathrm{H}_{2} \mathrm{O}, \mathrm{Ni}\left(\mathrm{CH}_{3} \mathrm{COO}\right)_{2} .4 \mathrm{H}_{2} \mathrm{O}$ y Ni(NO$)_{2} .6 \mathrm{H}_{2} \mathrm{O}$. Para la preparación de los catalizadores se seleccionó como método de activación el tratamiento directo en flujo de $\mathrm{H}_{2}\left(50 \mathrm{~cm}^{3} \cdot \mathrm{min}^{-1}\right)$ a $400{ }^{\circ} \mathrm{C}$ durante $1.5 \mathrm{~h}$.

Los catalizadores $\mathrm{Ni}(\mathrm{Cl}-) / \mathrm{SC}$ y $\mathrm{Ni}(\mathrm{Ac}-) / \mathrm{SC}$ mostraron el mejor comportamiento catalítico, y sólo por razones de menor costo se decidió por el empleo del $\mathrm{NiCl}_{2} .6 \mathrm{H}_{2} \mathrm{O}$ como precursor metálico para los posteriores estudios.

El estudio del efecto del soporte permitió determinar que el catalizador $\mathrm{Ni}(\mathrm{Cl}-) / \mathrm{SC}$ resultó el más activo y selectivo a 1,2-PG, lo que podría ser explicado por la presencia de una acidez superficial basada en grupos carboxílicos que promueven la ruptura del enlace C-O en el carbono primario del glicerol para producir $\mathrm{AcOH}$, acompañado de la buena actividad hidrogenante sobre el sitio metálico.

Con este catalizador $\mathrm{Ni}(\mathrm{Cl}-) / \mathrm{SC}$ se estudió el efecto de las variables operativas más relevantes en la reacción de hidrogenólisis, tales como la temperatura $\left(220-260{ }^{\circ} \mathrm{C}\right)$, la relación masa de glicerol a masa de catalizador y la presión de hidrógeno (0-40 bar de $\left.\mathrm{H}_{2}\right)$. En las condiciones operativas de $260{ }^{\circ} \mathrm{C}$ y 20 bar de $\mathrm{H}_{2}$ iniciales, para una solución al $30 \% \mathrm{p} / \mathrm{p}$ de glicerol $\left(\mathrm{m}_{2} \mathrm{O} / \mathrm{m}_{\mathrm{gli}}=2.38\right)$ y una relación $\mathrm{m}_{\mathrm{gli}} / \mathrm{m}_{\mathrm{c}}=6.2$, es posible obtener luego de $6 \mathrm{~h}$ de reacción una conversión del 56 \% con una selectividad a 1,2-PG del $80 \%$.

Los resultados de caracterización determinaron que no hay cambios estructurales significativos en el catalizador de $\mathrm{Ni}(\mathrm{Cl}-) / \mathrm{SC}$ usado. Puede apreciarse un ligero cambio en el tamaño de partícula que indicaría una buena resistencia al sinterizado.

Dado que el catalizador resultó selectivo a 1,2-PG pero sería deseable mejorar el nivel de actividad, se plantearon dos estrategias futuras:

-Modificar la superficie del soporte de SC mediante un proceso de funcionalización para aumentar la acidez (capítulo 7).

-Modificar la fase metálica de $\mathrm{Ni}$ mediante la adición de un promotor de $\mathrm{Zn}$ (capítulo 8).

\section{Bibliografía}

[1] C. Popescu, I. Ursu, M. Popescu, R. Alexandrescu, I. Morjan, I. N. Mihailescu, V. Jianu, Thermochimica Acta 164 (1990) 79-90.

[2] J. C. De Jesus, I. Gonzalez, A. Quevedo, T. Puerta, Journal of Molecular Catalysis A: Chemical 228 (2005) 283-291. 
[3] Q. Wang, Y. F. Xu, G. L. Xu, H. Su, S. Y. Shen, T. T. Tu, L. Huang, J. T. Li, S. G. Sun, Journal of Alloys and Compounds 648 (2015) 59-66.

[4] K. Hadjiivanov, M. Mihaylov, D. Klissurski, P. Stefanov, N. Abadjieva, E. Vassileva, L. Mintchevz, Journal of Catalysis 185 (1999) 314-323.

[5] Y. H. Choi, W. Y. Lee, Catalysis Letters 67 (2000) 155-161.

[6] S. Bolado, R. E. Treviño, M. T. García-Cubero, G. Gonzalez-Benito, Catalysis Communications 12 (2010) 122-126.

[7] M. Balaraju, V. Rekha, P. S. Sai Prasad, B. L. A. Prabhavathi Devi, R. B. N. Prasad, N. Lingaiah, Applied Catalysis A: General 354 (2009) 82-87.

[8] E. Vasiliadou, E. Heracleous, I. A. Vasalos, A. A. Lemonidou, Applied Catalysis B: Environmental 92 (2009) 90-99.

[9] D. Roy, B. Subramaniam, R.V. Chaudhari, Catalysis Today 156 (2010) 31-37.

[10] S. N. Delgado, D. Yap, L. Vivier, C. Especel, Journal of Molecular Catalysis A: Chemical 367 (2013) 89-98.

[11] S. Zhu, Y. Qiuc, Y. Zhu, S. Hao, H. Zheng, Y. Li, Catalysis Today 212 (2013) 120-126.

[12] Y. Feng, C. Liu, Y. Kang, X. Zhou, L. Liu, J. Deng, H. Xu, Y. Fu, Chemical Engineering Journal 168 (2011) 403-412.

[13] I. Gandarias, P. L. Arias, J. Requies, M. El Doukkali, M. B. Güemez, Journal of Catalysis 282 (2011) 237-247.

[14] S. Xia, R. Nie, X. Lu, L. Wang, P. Chen, Z. Hou, Journal of Catalysis 296 (2012) 1-11.

[15] E. Gallegos-Suarez, M. Pérez-Cadenas, A. Guerrero-Ruiz, I. Rodriguez-Ramos, A. Arcoya, Applied Surface Science 287 (2013) 108-116.

[16] S. Zhu, Y. Qiu, Y. Zhu, S. Hao, H. Zheng, Y. Li, Catalysis Today 212 (2013) 120-126.

[17] I. Gandarias, P. L. Arias, J. Requies, M. El Doukkali, M. B. Güemez, Journal of Catalysis 282 (2011) 237-247.

[18] R. N. Menchavez, M. J. Morra, B. B. He, Catalysts 7 (2017) 290.

[19] E. S. Vasiliadou, A.A. Lemonidou, Chemical Engineering Journal 231 (2013) 103-112. 
[20] J. Chaminand, L. Djakovitch, P. Gallezot, P. Marion, C. Pinel, C. Rosier, Green Chemistry 6 (2004) 359-361.

[21] Z. Huang, F. Cui, H. Kang, J. Chen, X. Zhang, C. Xia, Chemistry of Materials 20 (2008) 5090-5099.

[22] B. Mallesham, P. Sudarsanam, B. V. S. Reddy, B. M. Reddy, Applied Catalysis B Environmental 181 (2016) 47-57.

[23] M. A. Dasari, P. Kiatsimkul, W. R. Sutterlin, G. J. Suppes, Applied Catalysis A: General 281 (2005) 225-231.

[24] X. Guo, Y. Li, R. Shi, Q. Liu, E. Zhan, W. Shen, Applied Catalysis A: General 371 (2009) $108-113$.

[25] R. V. Sharma, P. Kumar, A. K. Dalai, Applied Catalysis A: General 477 (2014) 147-156. 


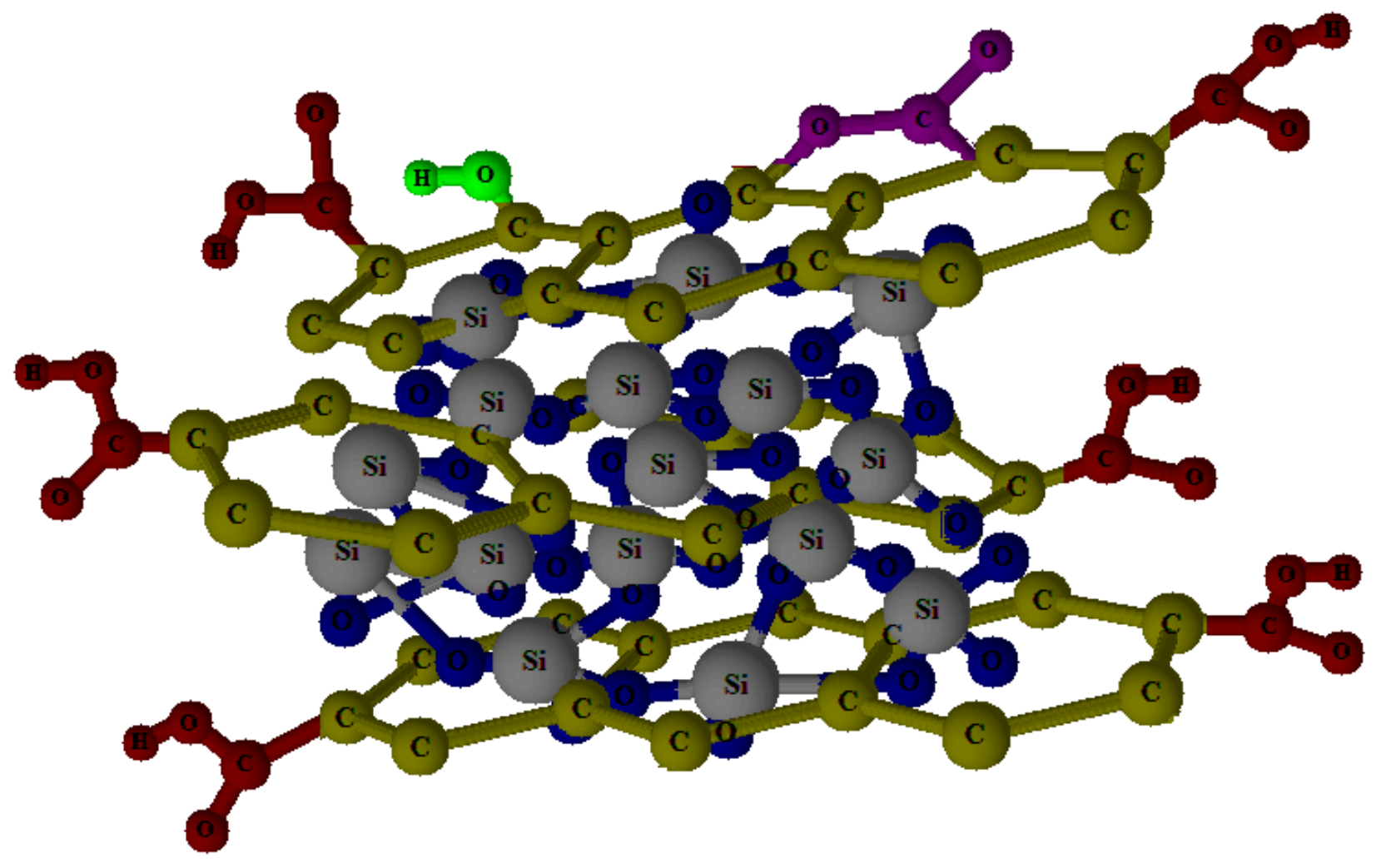

CAPÍTULO 7

Funcionalización del soporte SC 


\subsection{Introducción}

En el capítulo previo se llegó a la conclusión que la preparación de un catalizador empleando $\mathrm{NiCl}_{2} .6 \mathrm{H}_{2} \mathrm{O}$ como precursor metálico y SC como soporte, y activación directa en $\mathrm{H}_{2}$ a $400{ }^{\circ} \mathrm{C}$, permite obtener alta selectividad a 1,2-PG ( $\left.80 \%\right)$. La estabilidad del soporte en las condiciones de reacción y la resistencia al sinterizado por parte de la fase activa son dos propiedades destacables del Ni/SC. No obstante, su acidez superficial podría mejorarse para lograr mayores niveles de actividad. El aumento en el número de sitios ácidos adecuados podría favorecer la primera etapa de deshidratación del glicerol para formar $\mathrm{AcOH}$.

Dado que el soporte de SC es un material de tipo carbonoso, una forma de incrementar el número de sitios ácidos se basa en generar grupos oxigenados superficiales a través de un tratamiento empleando agentes oxidantes, proceso que se denomina funcionalización [1,2]. Sin embargo, tal como se presentó en el capítulo 6, el tipo de sitios ácidos buscados son muy específicos, ya que el soporte $C$ presenta mayor acidez, pero con tipos de sitios que no favorecen la formación de 1,2-PG.

En este capítulo se estudia la funcionalización del soporte SC empleando la técnica de oxidación con $\mathrm{HNO}_{3}$, dado que se logran elevados niveles de acidez con bajas pérdidas de masa de carbón. Se caracterizan las propiedades estructurales y ácidas y se correlacionan con las variables operativas de la funcionalización.

Finalmente se compara la actividad de los catalizadores preparados con los soportes SC funcionalizados con el catalizador Ni/SC.

\subsection{Funcionalización del soporte SC}

Entre las varias técnicas de funcionalización, se encuentra la oxidación con $\mathrm{HNO}_{3}$ $[1,3,4]$. En esta técnica, el material a funcionalizar se mantiene en fase líquida a reflujo total con soluciones de $\mathrm{HNO}_{3}$ de concentración conocida (1-90\%p/p de $\mathrm{HNO}_{3}$ ). El tratamiento se lleva a cabo a presión atmosférica y temperaturas que van desde los $80{ }^{\circ} \mathrm{C}$ hasta los $120{ }^{\circ} \mathrm{C}$, empleando tiempos de tratamiento desde $2 \mathrm{~h}$ a $24 \mathrm{~h}$. Una vez que el tratamiento finaliza, el material funcionalizado se lava con agua destilada hasta la neutralidad $(\mathrm{pH}=7)$ y finalmente se seca en estufa $\left(80-120^{\circ} \mathrm{C}\right)$ durante $24 \mathrm{~h}$. Una ventaja de esta técnica es que se alcanzan valores de puntos de carga cero (PCZ) muy bajos, del orden de 2 o 3. Por otro lado, es posible obtener bajas pérdidas de masa de carbón ( $5 \%)$ si se emplean bajas concentraciones de ácido, mientras que si las concentraciones son elevadas la pérdida de masa es mayor (24\%) $[1,3,4]$.

Pueden emplearse otros ácidos alternativamente al $\mathrm{HNO}_{3}$, con la precaución de que generen no solo un aumento en el número de sitios ácidos sino el tipo de sitios ácidos necesarios para lograr la selectividad al producto de interés. En el caso del empleo de HF como agente oxidante para lograr obtener el soporte $C$ (capítulo 4), condujo a la formación de grupos superficiales del tipo fenólicos $(-\mathrm{COH})$ que promovieron la formación de 1-POH y 1,3-PG (capítulo 6). Con este tratamiento se favoreció la ruptura del enlace C-O del carbono secundario del glicerol, desfavoreciendo la formación de 1,2-PG. 
Comparable a la fuerza ácida del $\mathrm{HNO}_{3}$ puede emplearse $\mathrm{H}_{2} \mathrm{SO}_{4}$ como agente oxidante. En este caso, si bien se alcanzan valores de PCZ bajos y las pérdidas de masa de carbón son bajas $(\sim 7 \%)$ cuando se emplean bajas concentraciones del ácido, tiene la desventaja que pueden aparecer restos de azufre en los materiales funcionalizados ( $\sim .5 \%)$ [5].

Otros agentes oxidantes pueden ser $\mathrm{H}_{2} \mathrm{O}_{2}$ y $\mathrm{KMnO}_{4}$. Debido a la leve oxidación que genera el empleo de $\mathrm{H}_{2} \mathrm{O}_{2}$, la funcionalización empleando este agente conduce a la menor pérdida de masa de carbón ( $2 \%$ ), aunque debido a su baja capacidad oxidativa los niveles de acidez generados en los carbones son menores a los obtenidos con ácidos inorgánicos. Por su parte, el empleo de $\mathrm{KMnO}_{4}$ como agente funcionalizante produce altos niveles de acidez, pero con mayor pérdida de masa de carbón $\sim 10 \%$, que puede llegar a ser aún mayor $\sim 40 \%$, cuando posteriormente se emplea $\mathrm{HCl}$ para remover óxidos de manganeso que pueden permanecer en la superficie de los materiales funcionalizados [6].

En este trabajo de tesis, el soporte SC fue funcionalizado por un tratamiento con ácido nítrico como agente oxidante. Dado que las variables operativas que afectan el grado de funcionalización son la temperatura, la concentración del agente oxidante y el tiempo bajo tratamiento [6], se estudiaron las condiciones operativas de temperatura $\left(80-100{ }^{\circ} \mathrm{C}\right)$, tiempo (2-6 h) y concentración del agente oxidante (30-90\%p/p) en el proceso de funcionalización.

En cada ensayo se emplearon $50 \mathrm{ml}$ de solución de ácido nítrico por cada $1 \mathrm{~g}$ de soporte SC, mantenidos en reflujo a la temperatura de operación durante el tiempo de funcionalización. Luego, la solución fue filtrada y el sólido fue lavado varias veces con agua destilada hasta $\mathrm{pH}$ 7. Finalmente, el sólido fue secado en estufa a $100^{\circ} \mathrm{C}$ durante $24 \mathrm{~h}$. La Tabla 1-7 indica un resumen de los distintos tratamientos de funcionalización ensayados y la nomenclatura utilizada.

Tabla 1-7. Condiciones de funcionalización y denominación de los soportes funcionalizados.

\begin{tabular}{lccc}
\hline \multirow{2}{*}{ Material } & \multicolumn{3}{c}{ Condiciones de funcionalización } \\
\cline { 2 - 4 } & Temperatura $\left({ }^{\circ} \mathrm{C}\right)$ & Concentración de $\mathrm{HNO}_{3}(\% \mathrm{p} / \mathrm{p})$ & Tiempo $(\mathrm{h})$ \\
\hline SC $_{80-30-2}$ & 80 & 30 & 2 \\
SC $_{80-60-2}$ & 80 & 60 & 2 \\
SC $_{80-90-2}$ & 80 & 90 & 2 \\
SC $_{90-60-2}$ & 90 & 60 & 2 \\
SC $_{100-60-2}$ & 100 & 60 & 2 \\
SC $_{100-60-4}$ & 100 & 60 & 4 \\
SC $_{100-60-6}$ & 100 & 60 & 6 \\
\hline
\end{tabular}

\subsection{Caracterización de los soportes SC funcionalizados}

Los soportes de SC funcionalizados fueron caracterizados por adsorción-desorción de nitrógeno (BET), difracción de rayos $\mathrm{X}(\mathrm{DRX})$, espectroscopia de infrarrojo por transformada de Fourier (FTIR), titulación potenciométrica con n-butilamina (TP) y la reacción test de deshidratación de isopropanol (IPA). 
En la Figura 1-7 se presentan las isotermas obtenidas por adsorción-desorción de $\mathrm{N}_{2}$ del composito SC fresco y de los soportes funcionalizados. Los soportes de SC funcionalizados guardan las mismas propiedades texturales que el soporte de SC, siendo materiales del tipo mesoporosos presentando isotermas del tipo IV con lazos de histéresis $\mathrm{H} 3$ según la clasificación de la IUPAC [7].

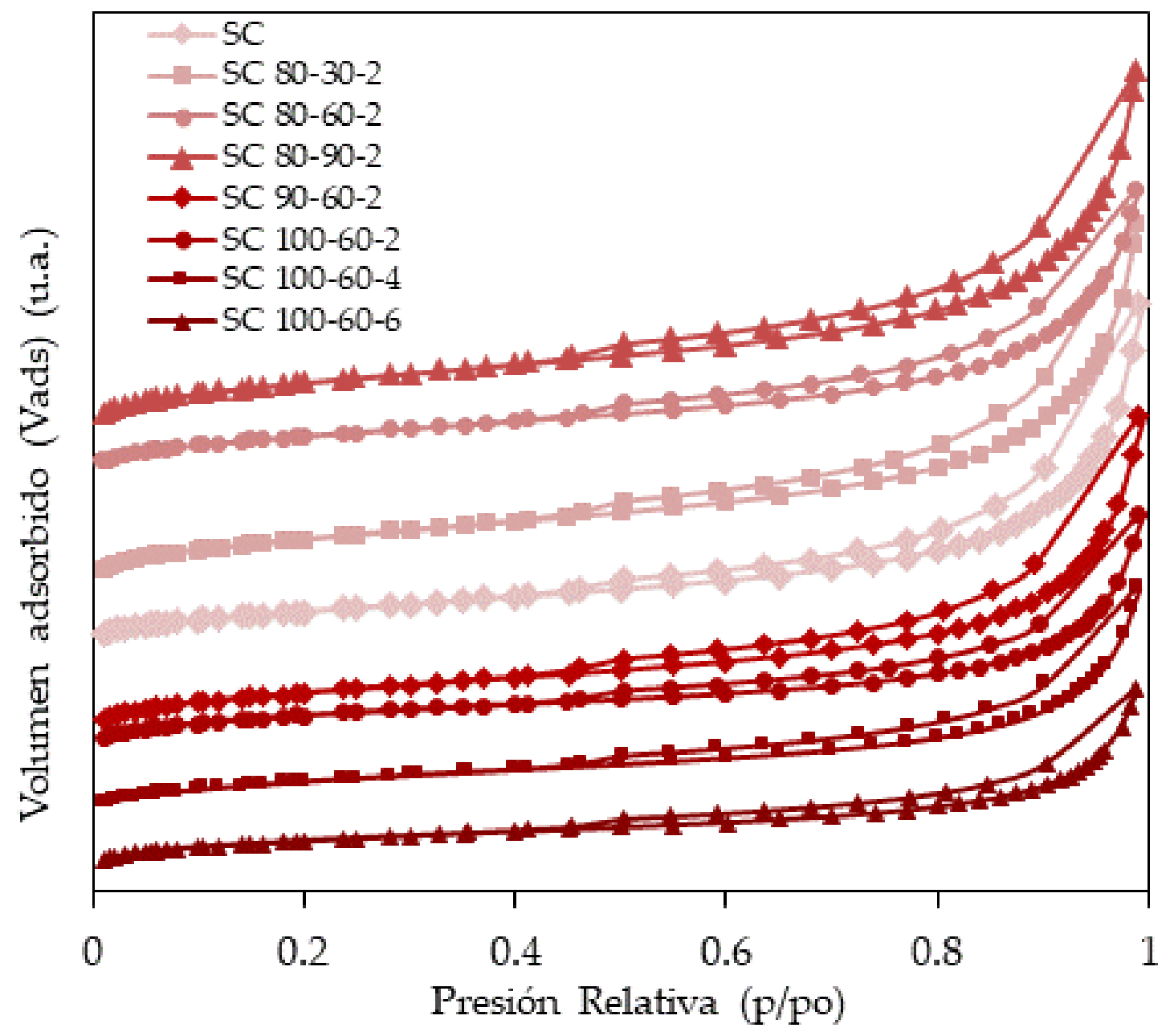

Figura 1-7. Isotermas de adsorción-desorción de $N_{2}$ de los soportes SC y funcionalizados.

Los valores de superficie específica $\left(\mathrm{S}_{\mathrm{BET}}\right)$, volumen total de poros y características de los poros se muestran en la Tabla 2-7. Se observa principalmente la presencia de mesoporos en todos los materiales. Los tratamientos de funcionalización que provocan un aumento en la superficie BET son los realizados en el rango de concentración de ácido nítrico de $30 \%$ al 90 $\%$ a $80{ }^{\circ} \mathrm{C}$ y en el rango de $30 \%$ al $60 \%$ a $90{ }^{\circ} \mathrm{C}$. Este aumento de $\mathrm{S}_{\mathrm{BET}}$, acompañado de un aumento en el volumen total de poro, ha sido explicado en bibliografía por la gasificación parcial del carbón provocada por el proceso de oxidación [4]. Por otro lado, si el tratamiento de funcionalización se realiza a $100{ }^{\circ} \mathrm{C}$, se obtiene una disminución en la SBET. Esta disminución en la superficie específica podría deberse a la destrucción de las paredes y el colapso de los poros por la generación de los grupos oxigenados [1]. 
Tabla 2-7. Propiedades texturales de los soportes de SC y funcionalizados.

\begin{tabular}{|c|c|c|c|c|c|c|}
\hline \multirow{2}{*}{ Material } & \multirow{2}{*}{$\mathrm{S}_{\text {BET }}{ }^{a}$} & \multirow{2}{*}{$\mathrm{V}_{\mathrm{p}}^{\mathrm{b}}$} & \multicolumn{2}{|c|}{ Microporos } & \multicolumn{2}{|c|}{ Mesoporos } \\
\hline & & & $S_{\text {micro }}{ }^{c}$ & $V_{\text {micro }}{ }^{d}$ & $S_{\text {meso }}{ }^{e}$ & $V_{\text {meso }}^{f}$ \\
\hline SC & 208 & 0.28 & 54 & 0.02 & 154 & 0.26 \\
\hline $\mathrm{SC}_{80-30-2}$ & 285 & 0.51 & 90 & 0.03 & 195 & 0.48 \\
\hline $\mathrm{SC}_{80-60-2}$ & 290 & 0.51 & 90 & 0.03 & 200 & 0.48 \\
\hline $\mathrm{SC}_{80-90-2}$ & 301 & 0.52 & 93 & 0.04 & 208 & 0.48 \\
\hline $\mathrm{SC}_{90-60-2}$ & 245 & 0.42 & 70 & 0.03 & 175 & 0.39 \\
\hline $\mathrm{SC}_{100-60-2}$ & 176 & 0.30 & 33 & 0.01 & 143 & 0.29 \\
\hline $\mathrm{SC}_{100-60-4}$ & 160 & 0.27 & 33 & 0.01 & 127 & 0.26 \\
\hline $\mathrm{SC}_{100-60-6}$ & 152 & 0.24 & 32 & 0.01 & 120 & 0.23 \\
\hline
\end{tabular}

a Superficie específica $\left(\mathrm{m}^{2} \cdot \mathrm{g}^{-1}\right)^{\mathrm{b}}$ Volumen total de poros $\left(\mathrm{cm}^{3} \cdot \mathrm{g}^{-1}\right)$

c Superficie específica de microporos $\left(\mathrm{cm}^{2} \cdot \mathrm{g}^{-1}\right)^{\mathrm{d}}$ Volumen total de microporos $\left(\mathrm{cm}^{3} \cdot \mathrm{g}^{-1}\right)$

e Superficie específica de mesoporos $\left(\mathrm{cm}^{2} \cdot \mathrm{g}^{-1}\right)^{\mathrm{f}}$ Volumen total de mesoporos $\left(\mathrm{cm}^{3} \cdot \mathrm{g}^{-1}\right)$

La Figura 2-7 muestra los difractogramas de rayos $X$ para las muestras SC fresca y funcionalizadas.

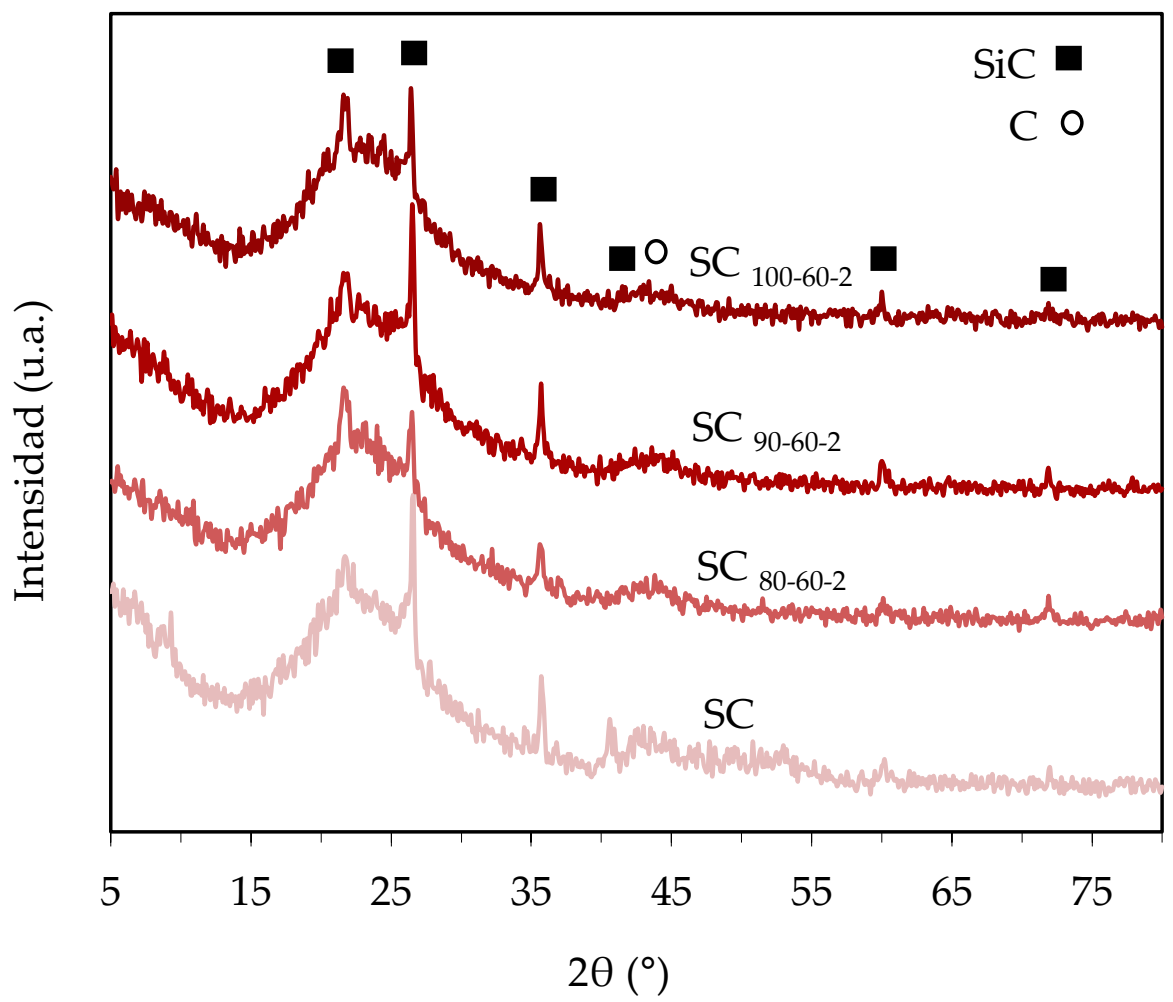

Figura 2-7. Difractograma de rayos X para SC y soportes funcionalizados.

Tanto el soporte de SC como los soportes funcionalizados presentan la banda característica de la sílice amorfa entre $15^{\circ}$ y $30^{\circ}$ [8,9]. Además de esta banda, se observan picos localizados a $21.8^{\circ}, 26.4^{\circ}, 35.7^{\circ}, 41.4^{\circ}, 60.0^{\circ}$ y $71.9^{\circ}$ que corresponden a los planos $(004$

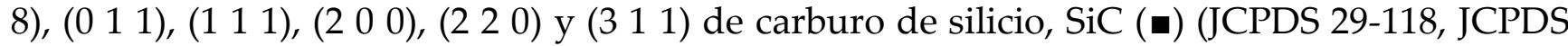


29-129) [10,11]. Existe la presencia de un pico amorfizado a $43.7^{\circ}$ que correspondería al plano $\left(\begin{array}{lll}1 & 0 & 0\end{array}\right)$ de la fase hexagonal del carbono grafito $(0)[9,12]$. Se observa que las muestras funcionalizadas no presentan diferencias en los diagramas de DRX indicando que los tratamientos en ácido nítrico no alteran la estructura del soporte SC.

Por FTIR se determinaron los grupos funcionales presentes en los soportes (Figura 37).

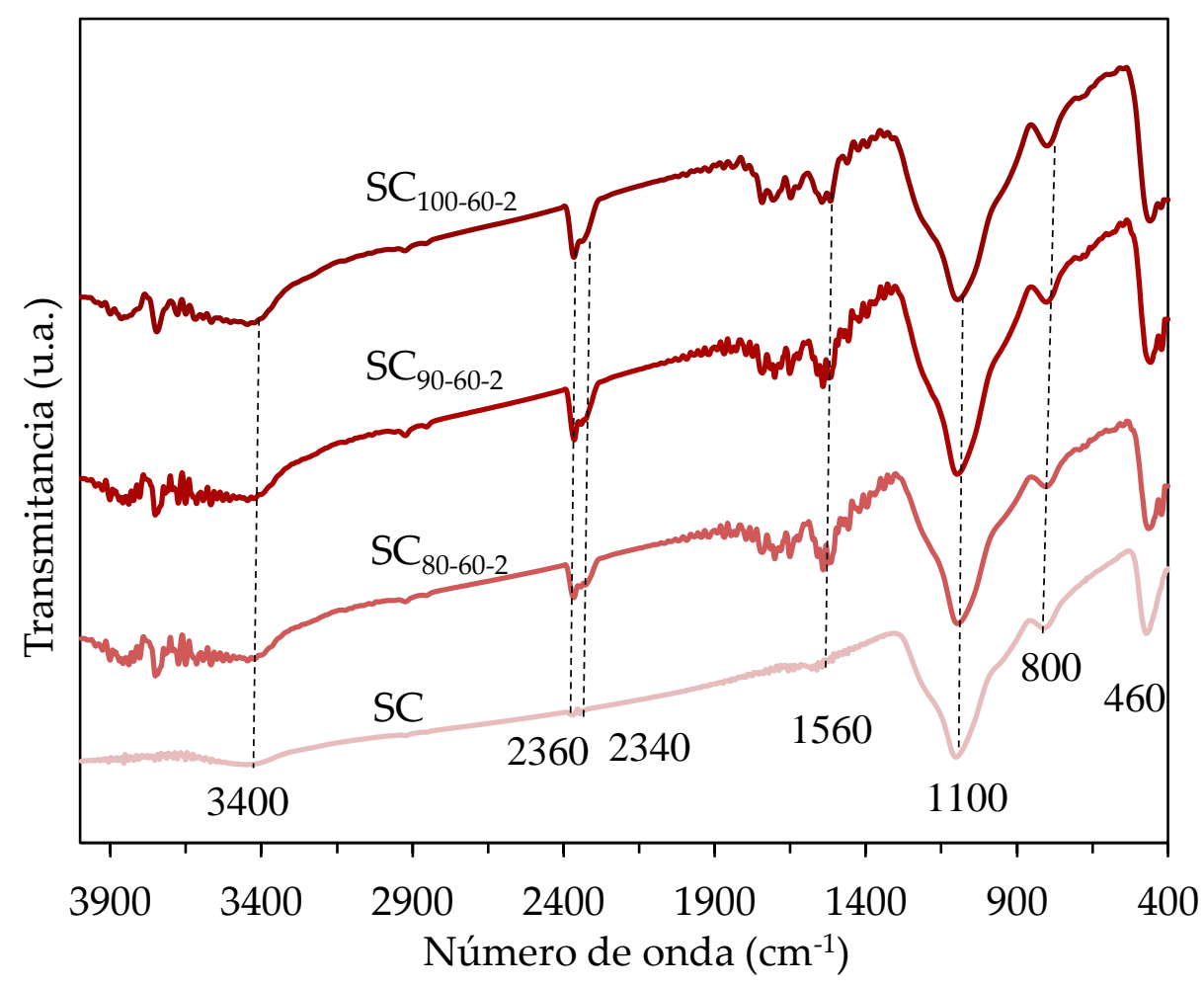

Figura 3-7. Espectros IR para SC y soportes funcionalizados.

En todas las muestras se observa un pico bien definido a $460 \mathrm{~cm}^{-1}$ característico de la vibración de la unión Si-O-Si, un pico más pequeño situado alrededor de los $800 \mathrm{~cm}^{-1}$ correspondiente a la vibración simétrica de la unión $\mathrm{Si}-\mathrm{O}$ y un pico centrado en $1100 \mathrm{~cm}^{-1}$ característico de la vibración asimétrica de la unión Si-O $[13,14]$.

Las señales a 2340 y $2360 \mathrm{~cm}^{-1}$ corresponden al $\mathrm{CO}_{2}$ atmosférico. En los soportes funcionalizados se distingue una señal a $1560 \mathrm{~cm}^{-1}$ que es asignada a la vibración del grupo $\mathrm{C}=\mathrm{C}[15]$.

La banda que va desde 3300 a $3600 \mathrm{~cm}^{-1}$ y centrado en los $3400 \mathrm{~cm}^{-1}$, correspondería a la vibración de los grupos oxhidrilo, $-\mathrm{OH}$, que pueden corresponder a funciones alcohol y funciones carboxilo [16,17].

La Figura 4-7 presenta las curvas de titulación potenciométrica para SC fresco y funcionalizados. Se observa que todos los soportes funcionalizados poseen mayor fuerza ácida que SC fresco. Como se observa en la Figura 4-7 (a), para las muestras tratadas a $80{ }^{\circ} \mathrm{C}$ la forma de las curvas indica que hay un solo tipo de sitios ácidos. Mientras que, en la Figura 4-7 (b), se observa los tratamientos a $100{ }^{\circ} \mathrm{C}$ generan dos tipos de sitios. 
En la Tabla 3-7 se resumen los resultados de la técnica de titulación potenciométrica, que permiten comparar los valores crecientes del potencial inicial Ei a medida que aumenta la temperatura del tratamiento de funcionalización y la concentración de ácido.

Tabla 3-7. Titulación potenciométrica para los soportes SC y funcionalizados.

\begin{tabular}{lccc}
\hline Soporte & $\mathrm{E}_{\mathrm{i}}(\mathrm{mV})$ & Fuerza ácida & $\mathrm{N}_{\mathrm{s}}(\mathrm{m}$ eq.g-1 \\
\hline SC & 12.6 & Fuerte & 0.18 \\
SC $_{80-30-2}$ & 82.5 & Fuerte & 0.63 \\
SC $_{80-60-2}$ & 98.1 & Fuerte & 0.83 \\
SC $_{90-60-2}$ & 157.8 & Muy Fuerte & 0.89 \\
SC $_{100-60-2}$ & 356.1 & Muy Fuerte & 1.00 \\
\hline
\end{tabular}

Cuanto mayor es la concentración de ácido nítrico empleada durante la funcionalización, mayor es la fuerza ácida de los sitios generados porque el potencial inicial Ei aumenta de $82.5 \mathrm{mV}$ a $98.1 \mathrm{mV}$, y el número de sitios aumenta de $0.63 \mathrm{meq} \cdot \mathrm{g}^{-1}$ a $0.83 \mathrm{meq} \cdot \mathrm{g}^{-1}$. Sin embargo, para una misma concentración de ácido (60\%), es mayor el efecto de la temperatura sobre la acidez, ya que cuando se pasa de $80^{\circ} \mathrm{C}$ a $100{ }^{\circ} \mathrm{C}$, el potencial inicial aumenta de $98.1 \mathrm{mV}$ a $356.1 \mathrm{mV}$.

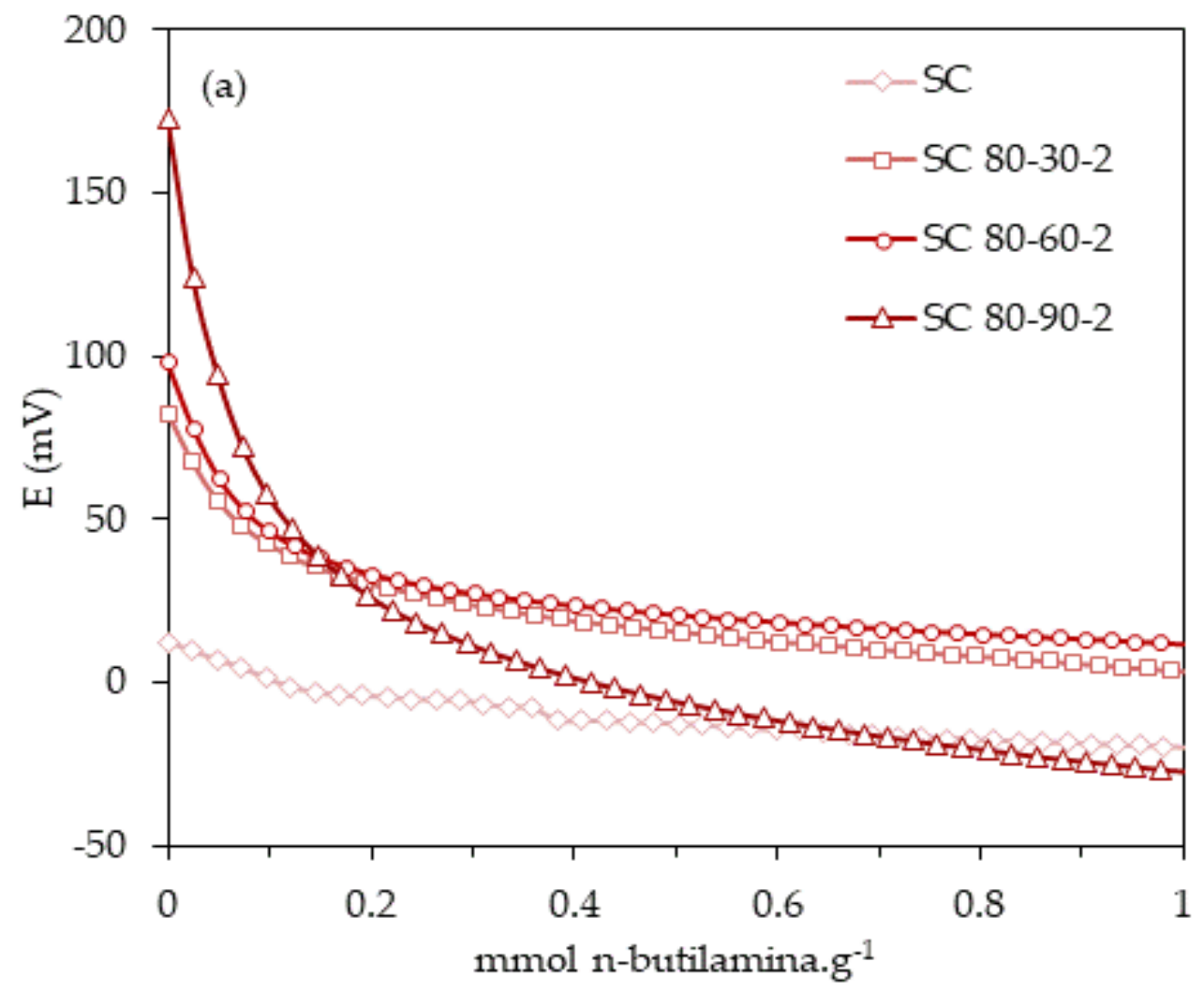




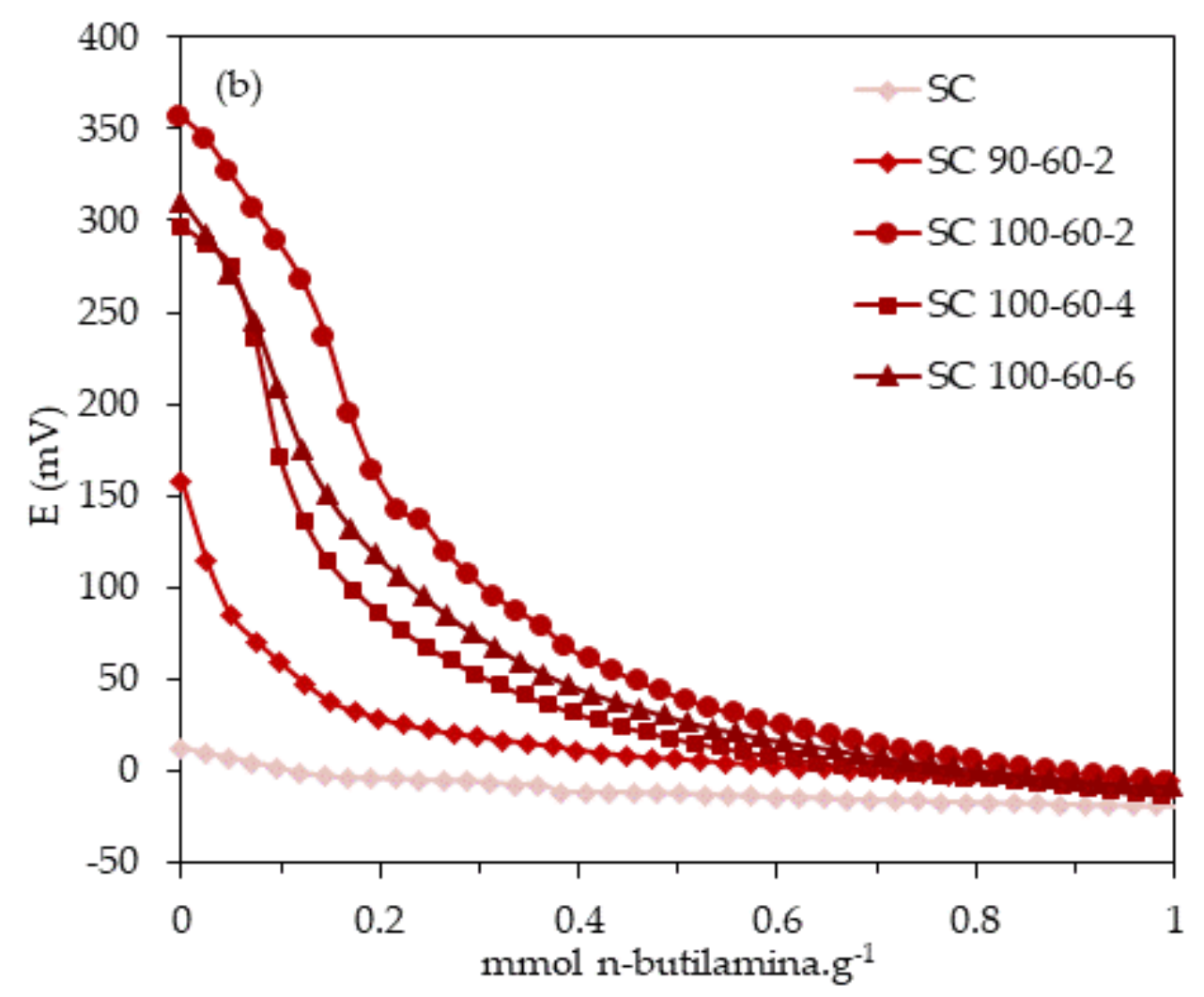

Figura 4-7. Curvas de titulación potenciométrica con n-butilamina para: (a) SC, SC80-30-2, SC $80-60-2$ y SC80-90-2 (b) SC, SC90-60-2, SC $100-60-2, S_{100-60-4}, S_{100-60-6 .}$

Para caracterizar la naturaleza de los sitios ácidos y básicos presentes en los sólidos también se empleó la técnica indirecta de la reacción de descomposición de isopropanol (IPA). En la Tabla 4-7 se muestran los resultados de selectividad a los diferentes productos de reacción obtenidos en la descomposición de IPA en el rango de temperatura de 330 a $380^{\circ} \mathrm{C}$. Para comparar la selectividad a los diferentes productos de reacción se analiza el mismo nivel de conversión para todos los materiales. Así, para una conversión de IPA del 14 \%, se muestran en la Tabla 4-7 la selectividad a los productos de reacción, que fueron principalmente propileno y en menor proporción acetona. Tal como ya ha sido explicado en capítulos anteriores, el aumento de estos productos de reacción indicaría que los materiales poseen un mayor número de sitios ácidos y una baja contribución de sitios básicos.

Tabla 4-7. Resultados de la descomposición de isopropanol para los soportes SC y funcionalizados.

\begin{tabular}{lccc}
\hline \multirow{2}{*}{ Soporte } & \multicolumn{3}{c}{ Descomposición de isopropanol (IPA) } \\
& \multicolumn{3}{c}{$\mathrm{X}_{\mathrm{T}}(\%)=14 \%$} \\
\hline SC & 360 & Spropileno $_{\text {(\%) }}(76$ & Sacetona $(\%)$ \\
SC $_{80-30-2}$ & 350 & 87 & 24 \\
SC $_{80-60-2}$ & 330 & 93 & 13 \\
SC $_{90-60-2}$ & 340 & 93 & 7 \\
SC $_{100-60-2}$ & 360 & 98 & 7 \\
\hline
\end{tabular}


El aumento de la selectividad a propileno en los soportes funcionalizados indicaría un aumento de sitios ácidos del tipo Lewis o Brønsted.

La mayor acidez total del soporte funcionalizado a $80{ }^{\circ} \mathrm{C}$ se pone en evidencia por la menor temperatura requerida para obtener una conversión del IPA de 14 \%. Los soportes funcionalizados a $100{ }^{\circ} \mathrm{C}$ presentan menor actividad pese a la mayor acidez determinada por titulación con n-butilamina. Esto se explicaría por la pérdida de superficie específica ocurrida por la excesiva oxidación del carbón. Dado que el composito SC80-60-2, presentó la mayor actividad en el test del IPA, y además no sufre pérdidas de superficie específica, fue elegido para realizar la titulación de Bohem.

La Tabla 5-7 presenta los resultados donde se observa el aumento en el contenido total de grupos superficiales oxigenados, en concordancia con los resultados obtenidos por titulación potenciométrica y la reacción de descomposición de IPA. El grupo funcional mayoritario, tanto para el soporte fresco SC como para $\mathrm{SC}_{80-60-2}$ es el carboxílico (-COOH). Los grupos del tipo fenólicos $(-\mathrm{COH})$ no sufren un cambio apreciable. Sin embargo, se observa que por el proceso de funcionalización se genera mayor incremento en los grupos lactónicos $(-\mathrm{CO}-\mathrm{C}=\mathrm{O})$, lo que le proporcionaría al composito $\mathrm{SC}_{80-60-2}$ un aumento de los sitios ácidos del tipo Lewis.

Tabla 5-7. Titulación de Bohem para SC y SC80-60-2.

\begin{tabular}{|c|c|c|c|c|}
\hline \multirow[b]{2}{*}{ Soporte } & \multicolumn{3}{|c|}{ Grupos Superficiales Oxigenados (mmol.g $\left.{ }^{-1}\right)$} & \multirow[b]{2}{*}{$\begin{array}{l}\text { Acidez total } \\
\left(\mathrm{mmol}^{-1}\right)\end{array}$} \\
\hline & $\begin{array}{c}\text { Carboxílicos } \\
\text {-COOH }\end{array}$ & $\begin{array}{l}\text { Lactónicos } \\
-\mathrm{CO}-\mathrm{C}=\mathrm{O}\end{array}$ & $\begin{array}{l}\text { Fenólicos } \\
\text {-COH }\end{array}$ & \\
\hline SC & 0.220 & 0.004 & 0.034 & 0.258 \\
\hline $\mathrm{SC}_{80-60-2}$ & 0.253 & 0.020 & 0.043 & 0.316 \\
\hline
\end{tabular}

\subsection{Preparación de catalizadores funcionalizados}

Mediante la técnica de impregnación a humedad incipiente, se prepararon catalizadores de níquel soportados sobre los soportes funcionalizados utilizando $\mathrm{NiCl}_{2} \cdot 6 \mathrm{H}_{2} \mathrm{O}$ como precursor. Las muestras fueron secadas a $120^{\circ} \mathrm{C}$ durante $12 \mathrm{~h}$ y activadas en flujo continuo $\left(50 \mathrm{~cm}^{3} \cdot \mathrm{min}^{-1}\right)$ de $\mathrm{H}_{2}$ a $400{ }^{\circ} \mathrm{C}$ durante $1.5 \mathrm{~h}$.

\subsection{Caracterización de Ni/SC $80-60-2$}

En esta sección se muestran los resultados de caracterización del catalizador Ni/SC80-60-2, debido a que tal como será explicado en la sección 7.6, este catalizador resultó el de mejor comportamiento catalítico. Se emplearon las técnicas de reducción a temperatura programada (TPR), espectroscopía de absorción atómica (AAS), adsorción-desorción de nitrógeno (BET), titulación potenciométrica (TP) y microscopía de transmisión electrónica (TEM).

El contenido metálico de $\mathrm{Ni}$ en el catalizador $\mathrm{Ni} / \mathrm{SC}_{80-60-2}$ se determinó mediante espectroscopía de absorción atómica (AAS), luego de la activación de los mismos en flujo 
continuo $\left(50 \mathrm{~cm}^{3} \cdot \mathrm{min}^{-1}\right)$ de $\mathrm{H}_{2}$ a $400{ }^{\circ} \mathrm{C}$ durante $1.5 \mathrm{~h}$. La Tabla 6-7 informa los valores de contenido metálico obtenido para estos catalizadores.

Tabla 6-7. Contenido metálico de Ni para los catalizadores Ni/SC y Ni/SC80-60-2.

\begin{tabular}{lcc}
\hline \multirow{2}{*}{ Catalizador } & \multicolumn{2}{c}{ Contenido metálico $(\% \mathrm{p} / \mathrm{p})$} \\
& Nominal & AAS \\
\hline $\mathrm{Ni} / \mathrm{SC}$ & 5.00 & 4.53 \\
$\mathrm{Ni} / \mathrm{SC}_{80-60-2}$ & 5.00 & 4.60 \\
\hline
\end{tabular}

En la Figura 5-7 se presentan las isotermas obtenidas por adsorción-desorción de $\mathrm{N}_{2}$ para Ni/SC y Ni/SC80-60-2. Es posible observar como la isoterma de adsorción-desorción de $\mathrm{N}_{2}$ para Ni/SC80-60-2 es similar a la del Ni/SC, siendo isotermas del tipo IV con lazos de histéresis H3 según la clasificación de la IUPAC, correspondientes a materiales del tipo mesoporosos [7].

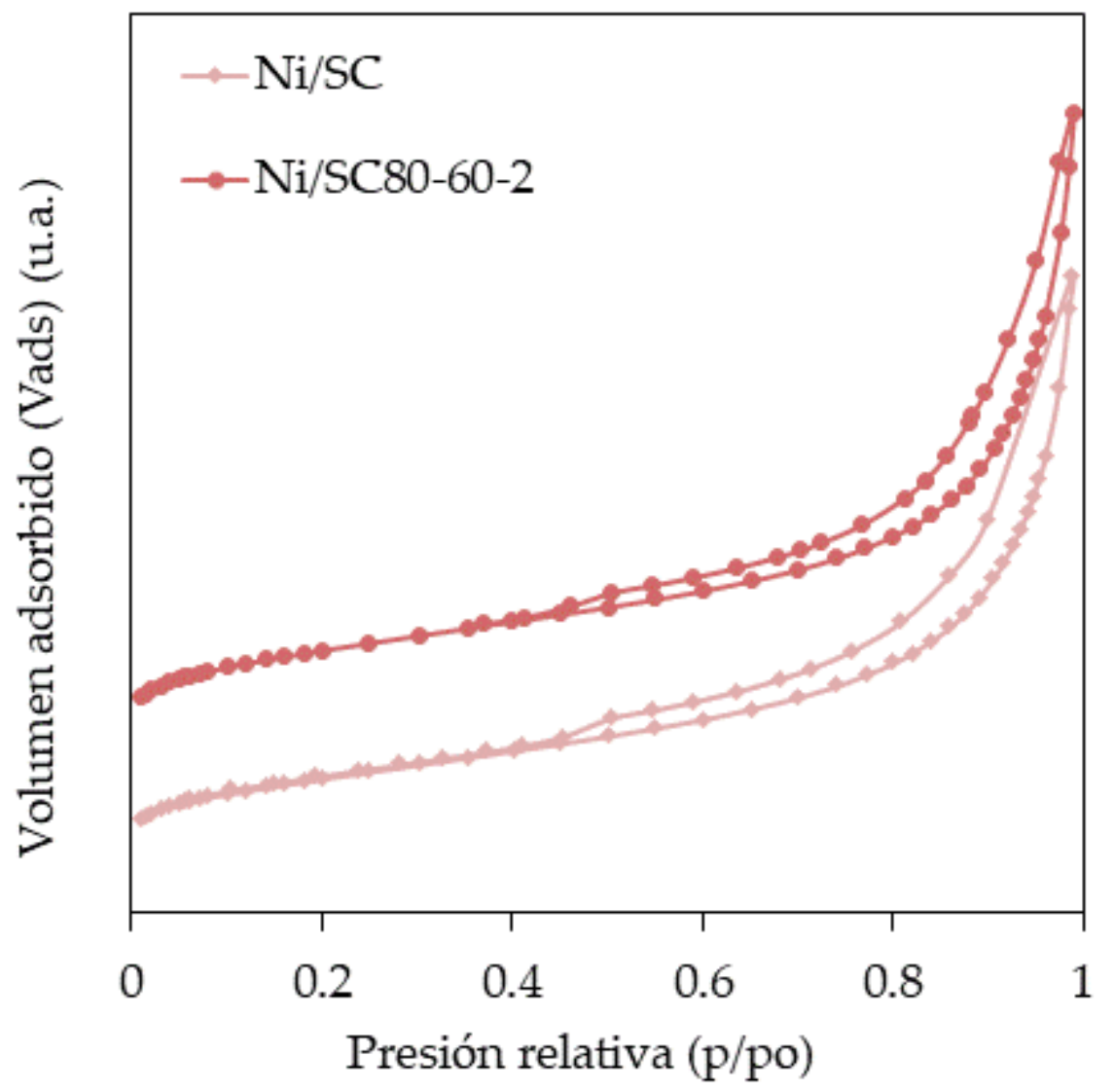

Figura 5-7. Isotermas de adsorción-desorción de N2 para Ni/SC y Ni/SC80-60-2.

La Tabla 7-7 informa sobre los valores de superficie específica BET, volumen total de poro y características de los poros. 
Tabla 7-7. Propiedades texturales para los catalizadores Ni/SC y Ni/SC 80-60-2.

\begin{tabular}{lcccccc}
\hline \multirow{2}{*}{ Catalizador } & \multirow{2}{*}{ S $_{\text {Bet }}{ }^{\mathrm{a}}$} & \multirow{2}{*}{$\mathrm{V}_{\mathrm{p}}{ }^{\mathrm{b}}$} & \multicolumn{2}{c}{ Microporos } & \multicolumn{2}{c}{ Mesoporos } \\
\cline { 4 - 7 } & & & $\mathrm{S}_{\text {micro }}{ }^{\mathrm{c}}$ & $\mathrm{V}_{\text {micro }}{ }^{\mathrm{c}}$ & $\mathrm{S}_{\text {meso }}{ }^{\mathrm{d}}$ & $\mathrm{V}_{\text {meso }}{ }^{\mathrm{d}}$ \\
\hline $\mathrm{Ni} / \mathrm{SC}$ & 211 & 0.41 & 60 & 0.03 & 151 & 0.38 \\
\hline $\mathrm{Ni} / \mathrm{SC}_{80-60-2}$ & 262 & 0.41 & 89 & 0.04 & 173 & 0.37 \\
\hline
\end{tabular}

a Superficie específica $\left(\mathrm{m}^{2} \cdot \mathrm{g}^{-1}\right)$.

b Volumen total de poros $\left(\mathrm{cm}^{3} \cdot \mathrm{g}^{-1}\right)$.

c Superficie específica $\left(\mathrm{m}^{2} \cdot \mathrm{g}^{-1}\right)$ y volumen total de microporos $\left(\mathrm{cm}^{3} \cdot \mathrm{g}^{-1}\right)$.

d Superficie específica $\left(\mathrm{m}^{2} \cdot \mathrm{g}^{-1}\right)$ y volumen total de mesoporos $\left(\mathrm{cm}^{3} \cdot \mathrm{g}^{-1}\right)$.

A partir de la tabla es posible observar que el valor de superficie específica para el $\mathrm{Ni} / \mathrm{SC}_{80-60-2}$ es ligeramente superior al obtenido para el Ni/SC. Esto podría deberse a un ensanchamiento de poros consecuencia de una gasificación parcial del carbón del soporte.

Se llevaron a cabo ensayos de reducción a temperatura programada (TPR) del catalizador de Ni/SC80-60-2 con el objetivo de compararlo con Ni/SC (Figura 6-7). El perfil de TPR para Ni/SC 80-60-2 es similar al del Ni/SC, observándose un primer evento de reducción a $360{ }^{\circ} \mathrm{C}$ con un hombro a $400{ }^{\circ} \mathrm{C}$, que corresponde a la reducción de especies de $\mathrm{Ni}^{+2} \mathrm{de}$ moderada interacción con el soporte. Ni/SC80-60-2 muestra en menor grado un segundo evento a $560{ }^{\circ} \mathrm{C}$, y esto podría deberse al proceso de gasificación del soporte ocurrido durante la funcionalización, tal como fue indicado cuando se explicó el aumento de SBET del catalizador $\mathrm{Ni} / \mathrm{SC}_{80-60-2 .}$

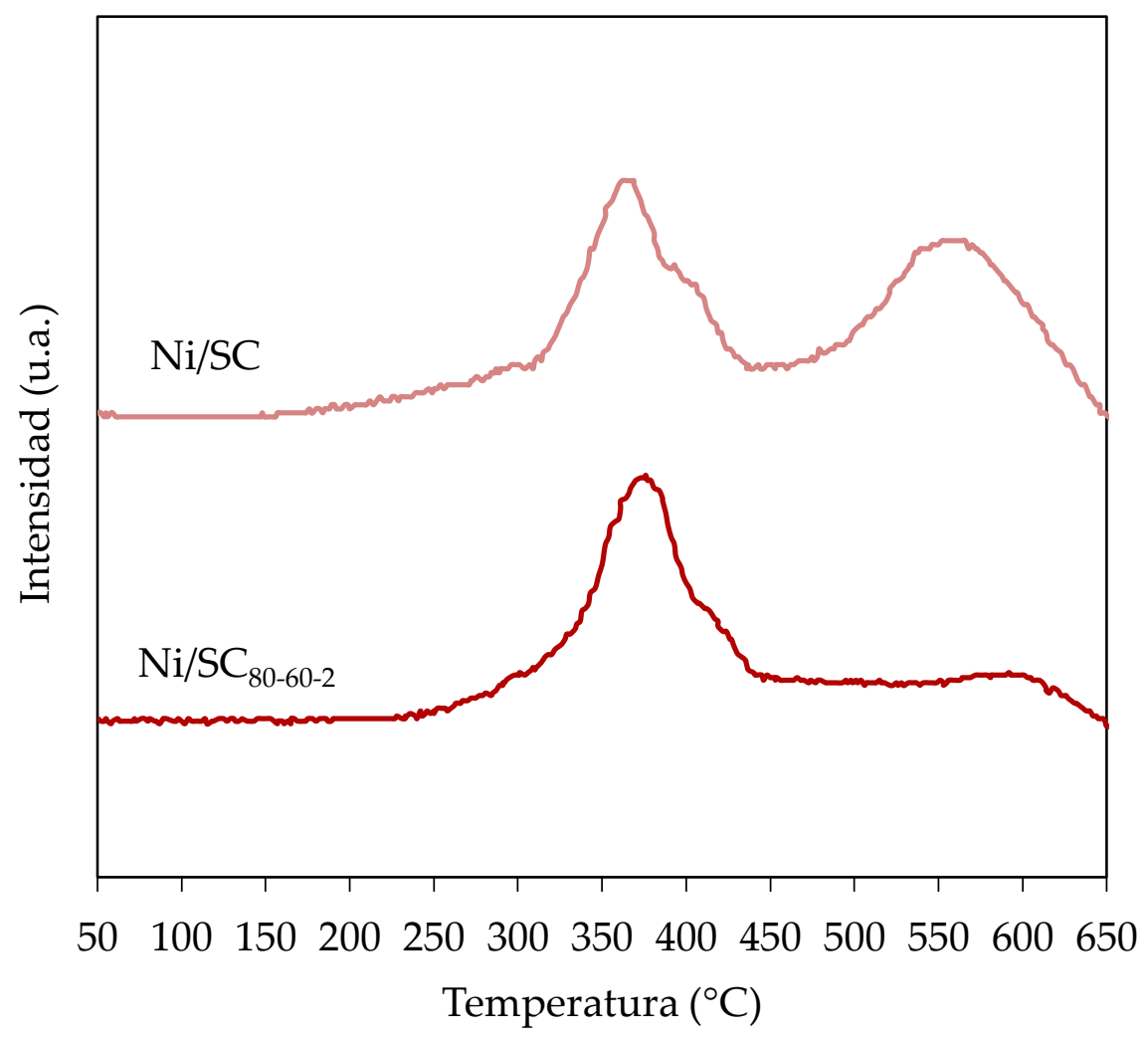

Figura 6-7. Perfiles de TPR para los catalizadores Ni/SC y Ni/SC $80-60-2$. 
La Figura 7-7 presenta las curvas de titulación potenciométrica para los catalizadores $\mathrm{Ni} / \mathrm{SC}$ y Ni/SC80-60-2.

Si se comparan estas curvas con las obtenidas para los soportes SC y SC 80-60-2 es posible observar que la adición de $\mathrm{Ni}$ reduce la acidez superficial de los soportes, probablemente debido a la interacción del precursor metálico con los sitios ácidos superficiales. Aun así, el catalizador $\mathrm{Ni} / \mathrm{SC}$ 80-60-2 presenta mayor acidez superficial que $\mathrm{Ni} / \mathrm{SC}$.

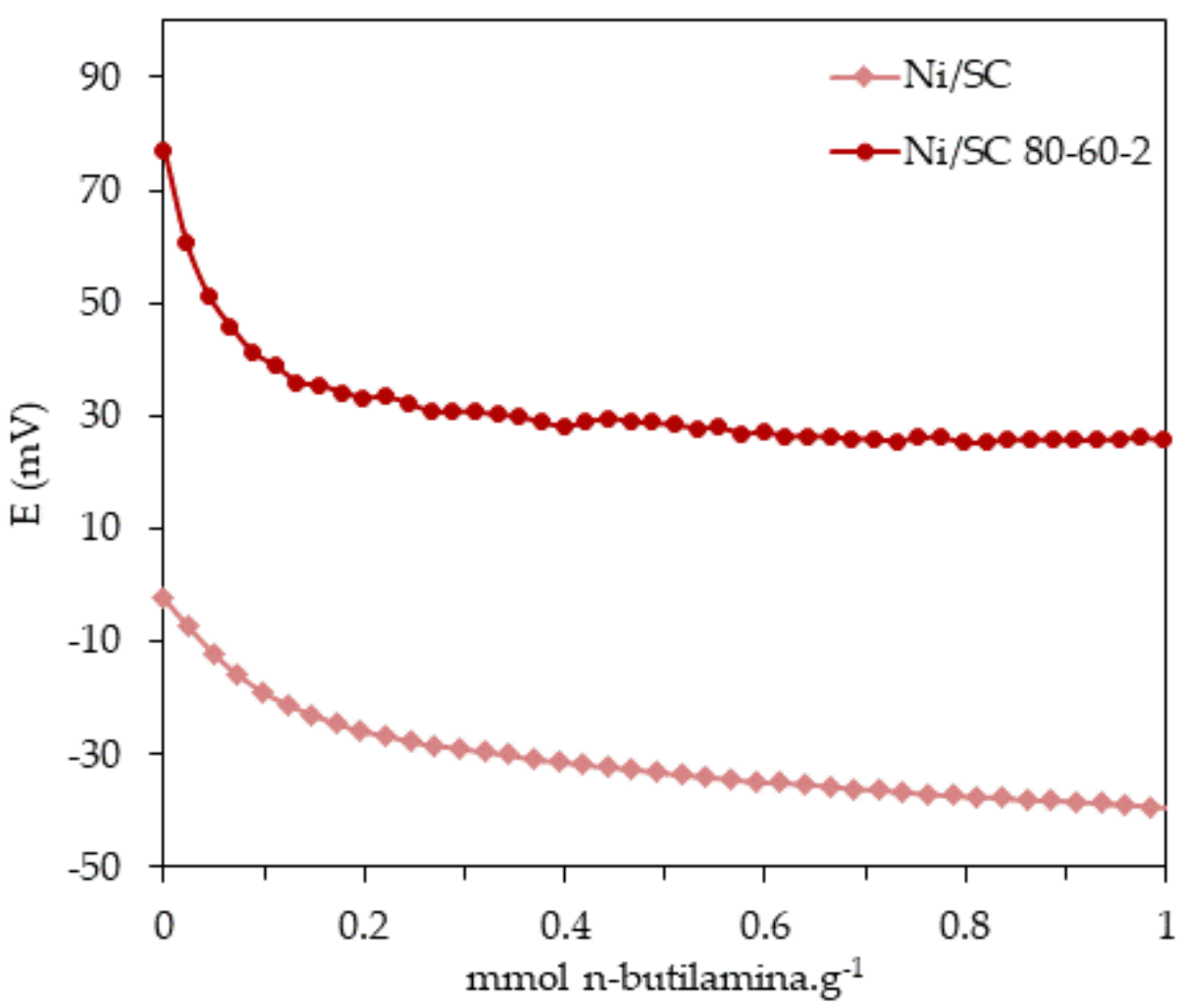

Figura 7-7. Curvas de titulación potenciométrica con n-butilamina para Ni/SC y Ni/SC80-60-2.

Con el objetivo de analizar la presencia de grupos oxigenados superficiales en $\mathrm{Ni} / \mathrm{SC}_{80}$ 60-2, se empleó la técnica de espectroscopia de fotoelectrones (XPS). La concentración relativa de grupos oxigenados superficiales fue determinada a través del ajuste de los espectros de XPS, por deconvolución de los picos $\mathrm{O} 1 \mathrm{~s}$ y C 1s, como fue reportado previamente por Proctor y Sherwood [44].

Los resultados de XPS de las muestras Ni/SC y Ni/SC80-60-2, se indican en la Tabla 8-7.

Tabla 8-7. Resultados de XPS para Ni/SC y Ni/SC80-60-2.

\begin{tabular}{lcccc|ccc}
\hline & \multicolumn{4}{c|}{ Región C 1s } & \multicolumn{3}{c}{ Región O 1s } \\
\cline { 2 - 8 } Muestra & \multicolumn{3}{c}{ Energía de enlace $(\mathrm{eV})$} & \multicolumn{3}{c}{ Energía de enlace $(\mathrm{eV})$} \\
& 284.6 & 285.4 & 287.0 & 288.8 & 530.6 & 531.8 & 533.1 \\
\cline { 2 - 8 } & $\mathrm{C}-\mathrm{C}$ & $\mathrm{C}-\mathrm{O}$ & $\mathrm{C}=\mathrm{O}$ & $\mathrm{O}=\mathrm{C}-\mathrm{O}$ & $\mathrm{O}=\mathrm{C}-\mathrm{O}$ & $\mathrm{C}=\mathrm{O} / \mathrm{C}-\mathrm{OH}$ & $\mathrm{C}-\mathrm{O}$ \\
\hline NiSC80-60-2 & 42.28 & 50.27 & 0 & 7.45 & 0 & 36.29 & 63.7 \\
NiSC & 50.40 & 43.11 & 0 & 6.49 & 0 & 90.46 & 9.54 \\
\hline
\end{tabular}


Para Ni/SC, los resultados mostraron una concentración superficial consistente de $\sim 50 \%$ de grupos carbonosos en enlaces C-C y $\sim 50 \%$ de grupos superficiales carbonosos oxigenados ( $43 \%$ en enlaces $\mathrm{C}-\mathrm{O}$ y $7 \%$ en enlaces $\mathrm{O}=\mathrm{C}-\mathrm{O})$. Para $\mathrm{Ni} / \mathrm{SC}$ 80-60-2se observó un incremento en los grupos superficiales oxigenados a $\sim 60 \%$, y los resultados en la región del $\mathrm{O} 1 \mathrm{~s}$ muestran diferencias, en estos catalizadores, de la distribución de enlaces C-O.

Las imágenes TEM para los catalizadores Ni/SC y Ni/SC $80-60-2$, con sus correspondientes distribuciones de tamaños de partícula, se muestran en la Figura 8-7.
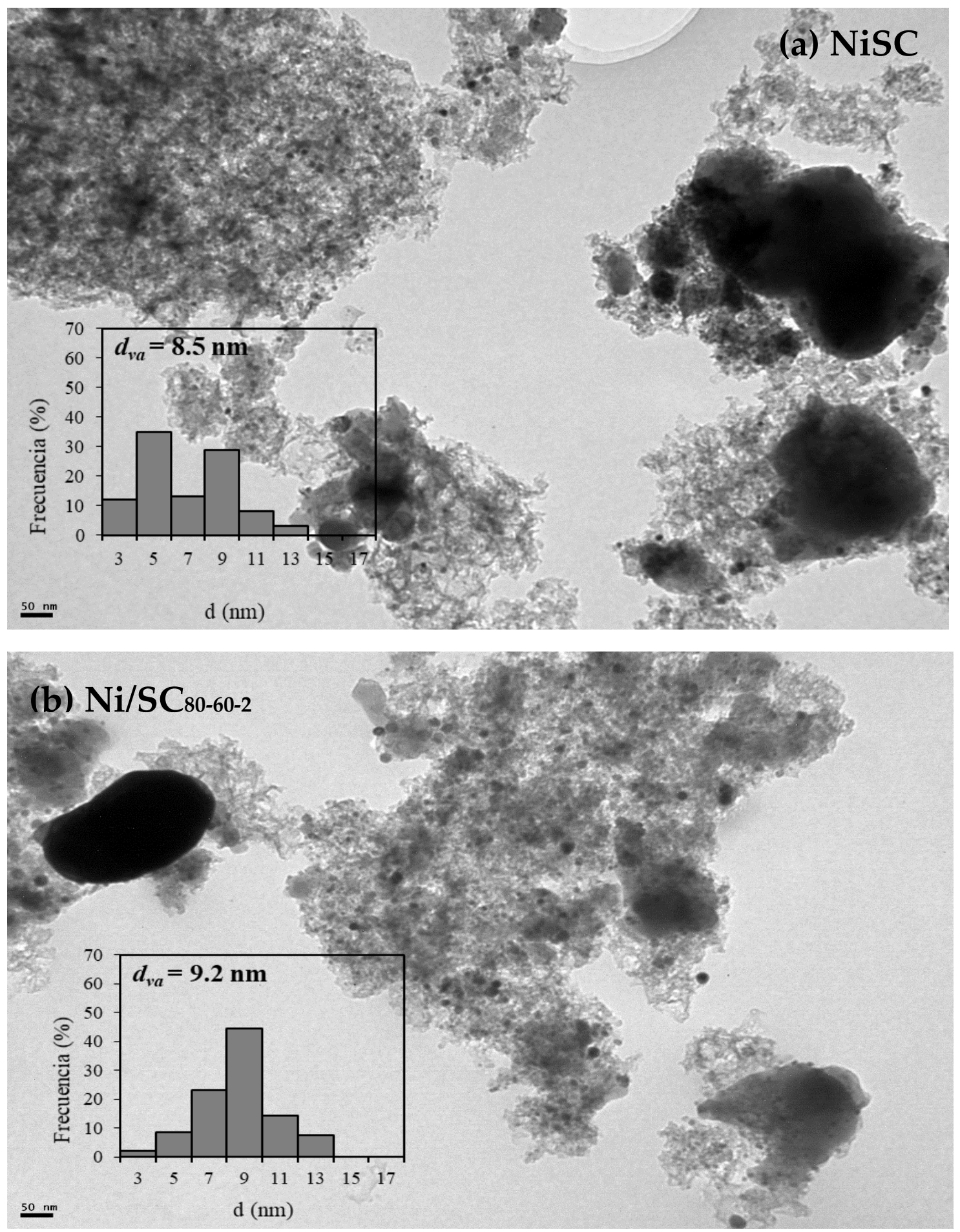

Figura 8-7. Imágenes TEM y distribución de tamaños de partícula para (a) Ni/SC (b) Ni/SC80-60-2. 
El diámetro promedio de partícula, $\mathrm{d}_{\mathrm{va}}$ y la dispersión metálica, DTEM, para los catalizadores Ni/SC y Ni/SC $80-60-2$ se muestran en la Tabla 9-7.

Tabla 9-7. Tamaños promedio de partícula y dispersiones metálicas obtenidas por TEM para Ni/SC y $\mathrm{Ni} / \mathrm{SC}_{80-60-2 .}$

\begin{tabular}{lcc}
\hline Catalizador & $\mathrm{d}_{\mathrm{va}}(\mathrm{nm})$ & $\mathrm{D}_{\text {TEM }}(\%)$ \\
\hline $\mathrm{Ni} / \mathrm{SC}$ & 8.5 & 11.1 \\
\hline $\mathrm{Ni} / \mathrm{SC}_{80-60-2}$ & 9.2 & 10.5 \\
\hline
\end{tabular}

$\mathrm{Ni} / \mathrm{SC}$ y Ni/SC80-60-2 presentan tamaños promedios de partícula de $8.5 \mathrm{~nm}$ y $9.2 \mathrm{~nm}$, correspondientes a dispersiones metálicas muy similares, del $11 \%$ y $10.5 \%$ respectivamente. Estos resultados indican que, a pesar de producirse cambios en la acidez superficial, no se producen cambios en el tamaño de partícula metálica. A diferencia de nuestros resultados, Zhang y col. observaron un incremento en la dispersión metálica debido a la generación de grupos superficiales oxigenados en carbones activados $\left(\mathrm{S}_{\mathrm{BET}}=1640 \mathrm{~m}^{2} \cdot \mathrm{g}^{-1}\right)$ obtenidos a partir de cáscara de coco y tratados con soluciones de ácido nítrico $4 \mathrm{M}$.

\subsection{Actividad catalítica}

La Tabla 10-7 muestra los resultados de la actividad catalítica en la reacción de hidrogenólisis de glicerol en fase líquida para el catalizador Ni/SC y los catalizadores funcionalizados. Los ensayos se llevaron a cabo a $260{ }^{\circ} \mathrm{C}$ y 20 bar de $\mathrm{H}_{2}$ iniciales, empleando soluciones al 30 \%p/p de glicerol y una relación $\mathrm{m}_{\mathrm{gli}} / \mathrm{m}_{\mathrm{c}}=4.16$.

Tabla 10-7. Actividad catalítica de los catalizadores Ni/SC y Ni/SC 80-60-2.

\begin{tabular}{|c|c|c|c|c|c|c|c|c|c|}
\hline \multirow{2}{*}{ Catalizador } & \multirow{2}{*}{$\mathrm{X}_{\mathrm{T}}(\%)$} & \multirow{2}{*}{$X_{L}(\%)$} & \multicolumn{7}{|c|}{ Selectividad (\%) } \\
\hline & & & $\mathrm{MeOH}$ & $\mathrm{EtOH}$ & $\mathrm{AcO}$ & $1-\mathrm{POH}$ & $\mathrm{AcOH}$ & EG & 1,2-PG \\
\hline $\mathrm{Ni} / \mathrm{SC}$ & 38.6 & 36.0 & 0.9 & 3.1 & 0.2 & 2.3 & 3.3 & 8.5 & 81.7 \\
\hline $\mathrm{Ni} / \mathrm{SC}_{80-60-2}$ & 52.2 & 49.0 & 0.3 & 1.6 & 0.1 & 1.1 & 1.8 & 10.2 & 84.9 \\
\hline $\mathrm{Ni} / \mathrm{SC}_{80-90-2}$ & 50.3 & 47.4 & 0.4 & 2.2 & 0.1 & 0.9 & 3.2 & 8.3 & 84.9 \\
\hline $\mathrm{Ni} / \mathrm{SC}_{100-60-2}$ & 44.7 & 41.0 & 1.6 & 4.8 & 0.2 & 0.8 & 7.9 & 6.4 & 78.3 \\
\hline $\mathrm{Ni} / \mathrm{SC}_{100-60-6}$ & 39.1 & 35.9 & 1.7 & 2.9 & 0.7 & 1.0 & 10.5 & 8.2 & 75.0 \\
\hline
\end{tabular}

${ }^{*}$ Condiciones de reacción: $260{ }^{\circ} \mathrm{C}, 20$ bar de $\mathrm{H}_{2}, 30 \% \mathrm{p} / \mathrm{p}$ de glicerol, $\mathrm{m}_{\mathrm{gli}} / \mathrm{m}_{\mathrm{c}}=4.16,2 \mathrm{~h}$.

${ }^{*} \mathrm{X}_{\mathrm{T}}$ : conversión total de glicerol, $\mathrm{X}_{\mathrm{L}}$ : conversión de glicerol a productos líquidos.

A partir de la Tabla 10-7 se observa que tanto Ni/SC como los catalizadores funcionalizados resultaron altamente selectivos a 1,2-PG (> $70 \%)$.

Si se analiza el efecto de la funcionalización del soporte sobre la actividad catalítica, se observa que la conversión aumenta para los soportes modificados. El mejor resultado fue obtenido con Ni/SC $80-60-2$, que alcanzó una conversión del 52 \% con una selectividad hacia 1,2PG $\sim 85 \%$ al cabo de $2 \mathrm{~h}$ de reacción y en las condiciones ya indicadas. Este nivel de 
selectividad hacia 1,2-PG es destacable si se compara con lo que se ha informado en la literatura. Chen et al. [19] evaluaron la actividad de un catalizador comercial de Ni Raney (64 $\%$ p/p de Ni) y obtuvieron una conversión de glicerol del $66 \%$ con una selectividad hacia 1,2PG del 48 \% (20\%p/p de glicerol, 40 bar de $\mathrm{H}_{2}, 210{ }^{\circ} \mathrm{C}$ y 6 h). Dasari et al. [20] evaluaron catalizadores comerciales de $\mathrm{Ni} / \mathrm{C}$ y Ni/SiO $2-\mathrm{Al}_{2} \mathrm{O}_{3}$ y obtuvieron conversiones del 40 al $45 \%$ con selectividades del 68 al $64 \%$, respectivamente $\left(80 \%\right.$ p/p de glicerol, 14 bar de $\mathrm{H}_{2}, 200{ }^{\circ} \mathrm{C}$ y $24 \mathrm{~h}$ ). Xia et al. [21] informaron sobre un catalizador de $\mathrm{Ni} / \mathrm{ZnO}$ con $17 \% \mathrm{p} / \mathrm{p}$ de $\mathrm{Ni}$, con una dispersión metálica del $10 \%$, y obtuvieron una conversión del $57 \%$ con una selectividad hacia 1,2-PG del $44 \%$ (30 bar de $\mathrm{N}_{2}, 235^{\circ} \mathrm{C}$ y $6 \mathrm{~h}$ ).

Para entender el efecto de los cambios producidos por el catalizador Ni/SC $80-60-2$ sobre la actividad y selectividad, se realizaron dos ensayos de reacción complementarios: la deshidratación de glicerol a AcOH en atmósfera de $\mathrm{N}_{2}$ y la hidrogenación de AcOH a 1,2-PG, cuyos resultados se muestran en las Tablas 10-7 y 11-7 respectivamente. La deshidratación de glicerol a $\mathrm{AcOH}$ es la primera etapa, en la reacción que conduce a 1,2-PG, que no requiere $\mathrm{H}_{2}$ y la hidrogenación de $\mathrm{AcOH}$ a 1,2-PG constituye la última etapa y obviamente requiere de una atmósfera de $\mathrm{H}_{2}$.

Los resultados de la deshidratación de glicerol a $\mathrm{AcOH}$ en atmósfera de $\mathrm{N}_{2}$, Tabla 11-7, muestran que el catalizador de Ni/SC80-60-2 es notablemente más activo para la deshidratación del glicerol a $\mathrm{AcOH}$, lo cual puede ser atribuido a la mayor acidez superficial determinada para este catalizador.

Tabla 11-7. Actividad para deshidratar glicerol.

\begin{tabular}{lccccccccc}
\hline \multirow{2}{*}{ Catalizador } & \multirow{2}{*}{$\mathrm{X}_{\mathrm{T}}(\%)$} & $\mathrm{X}_{\mathrm{L}}(\%)$ & \multicolumn{7}{c}{ Selectividad (\%) } \\
\cline { 4 - 10 } & & & $\mathrm{MeOH}$ & $\mathrm{EtOH}$ & $\mathrm{AcO}$ & $1-\mathrm{POH}$ & $\mathrm{AcOH}$ & $\mathrm{EG}$ & $1,2-\mathrm{PG}$ \\
\hline $\mathrm{Ni} / \mathrm{SC}$ & 18.0 & 16.5 & 3.0 & 1.8 & 1.6 & 3.2 & 73.1 & 3.3 & 14.0 \\
$\mathrm{Ni} / \mathrm{SC}_{80-60-2}$ & 30.0 & 27.5 & 3.3 & 0.8 & 1.4 & 0.3 & 84.0 & 3.5 & 6.7 \\
\hline
\end{tabular}

${ }^{*}$ Condiciones de reacción: $260{ }^{\circ} \mathrm{C}, 20$ bar de $\mathrm{N}_{2}, 30 \% \mathrm{p} / \mathrm{p}$ de glicerol, $\mathrm{m}_{\mathrm{c}} / \mathrm{m}_{\mathrm{gli}}=0.16,2 \mathrm{~h}$.

${ }^{*} \mathrm{X}_{\mathrm{T}}$ : conversión total de glicerol, $\mathrm{X}_{\mathrm{L}}$ : conversión de glicerol a productos líquidos.

Con respecto a la actividad para hidrogenar el $\mathrm{AcOH}$ formado a 1,2-PG, se puede observar en la Tabla 12-7 que la misma resulta similar para ambos catalizadores, Ni/SC y $\mathrm{Ni} / \mathrm{SC}_{80-60-2}$, lo que era de esperar considerando las similitudes en tamaños de partícula y dispersiones metálicas del $\mathrm{Ni}$.

Tabla 12-7. Actividad para hidrogenar acetol.

\begin{tabular}{|c|c|c|c|c|c|c|c|c|}
\hline \multirow{2}{*}{ Catalizador } & \multirow{2}{*}{$\mathrm{X}_{\mathrm{T}}(\%)$} & \multirow{2}{*}{$X_{L}(\%)$} & \multicolumn{6}{|c|}{ Selectividad (\%) } \\
\hline & & & $\mathrm{MeOH}$ & $\mathrm{EtOH}$ & $\mathrm{AcO}$ & 1-POH & EG & 1,2-PG \\
\hline $\mathrm{Ni} / \mathrm{SC}$ & 80.0 & 78.5 & 0.7 & 1.2 & 0.4 & 0.7 & 0.0 & 97.0 \\
\hline $\mathrm{Ni} / \mathrm{SC}_{80-60-2}$ & 84.6 & 82.6 & 0.9 & 1.4 & 0.4 & 0.5 & 0.0 & 96.8 \\
\hline
\end{tabular}

${ }^{*}$ Condiciones de reacción: $200{ }^{\circ} \mathrm{C}, 20$ bar de $\mathrm{H}_{2}, 1$ \%p/p de acetol, $\mathrm{mc} / \mathrm{macetol}=0.16,2 \mathrm{~h}$.

${ }^{*} \mathrm{X}_{\mathrm{T}}$ : conversión total de glicerol, $\mathrm{X}_{\mathrm{L}}$ : conversión de glicerol a productos líquidos. 
De este modo se puede concluir que el catalizador $\mathrm{Ni} / \mathrm{SC}$ 80-60-2 resulta más activo y selectivo a 1,2-PG debido a que las modificaciones del soporte le proporcionan una acidez apropiada para favorecer la etapa de deshidratación de glicerol a AcOH. Esta modificación del soporte no afecta la dispersión metálica, por lo que se mantiene su actividad hidrogenante para transformar el AcOH en 1,2-PG.

\subsection{Cambios estructurales}

En el capítulo 4 fue demostrada la estabilidad del soporte SC luego de un tratamiento hidrotérmico a $250^{\circ} \mathrm{C}$ y 20 bar de $\mathrm{H}_{2}$, durante $24 \mathrm{~h}$.

En el capítulo 6 quedó demostrado que, empleando el catalizador Ni/SC luego de $6 \mathrm{~h}$ de reacción a $260^{\circ} \mathrm{C}$ y 20 bar de $\mathrm{H}_{2}$, no se produce leaching de $\mathrm{Ni}$.

En este punto, se estudia la estabilidad de la acidez superficial del catalizador $\mathrm{Ni} / \mathrm{SC}_{80}$ 60-2, dado que es la propiedad determinante de la mejora del comportamiento catalítico.

En la Figura 9-7 presenta las curvas de titulación potenciométrica para los catalizadores $\mathrm{Ni} / \mathrm{SC}_{80-60-2}$ fresco y Ni/SC 80-60-2 usado luego de un tratamiento hidrotérmico a $260^{\circ} \mathrm{C}$, 20 bar de $\mathrm{H}_{2}$, durante $6 \mathrm{~h}$. El potencial inicial Ei es muy similar en ambas muestras, 78 y $89 \mathrm{mV}$ para $\mathrm{Ni} / \mathrm{SC}_{80-60-2}$ fresco y Ni/SC80-60-2 usado respectivamente. El número de sitios ácidos se mantiene, ya que es $0.73 \mathrm{mmol.g}{ }^{-1}$ para Ni/SC $80-60-2$ fresco y $0.70 \mathrm{mmol} . \mathrm{g}^{-1}$ para $\mathrm{Ni} / \mathrm{SC}_{80-60-2}$ usado, indicando que no hay modificaciones apreciables en la muestra usada.

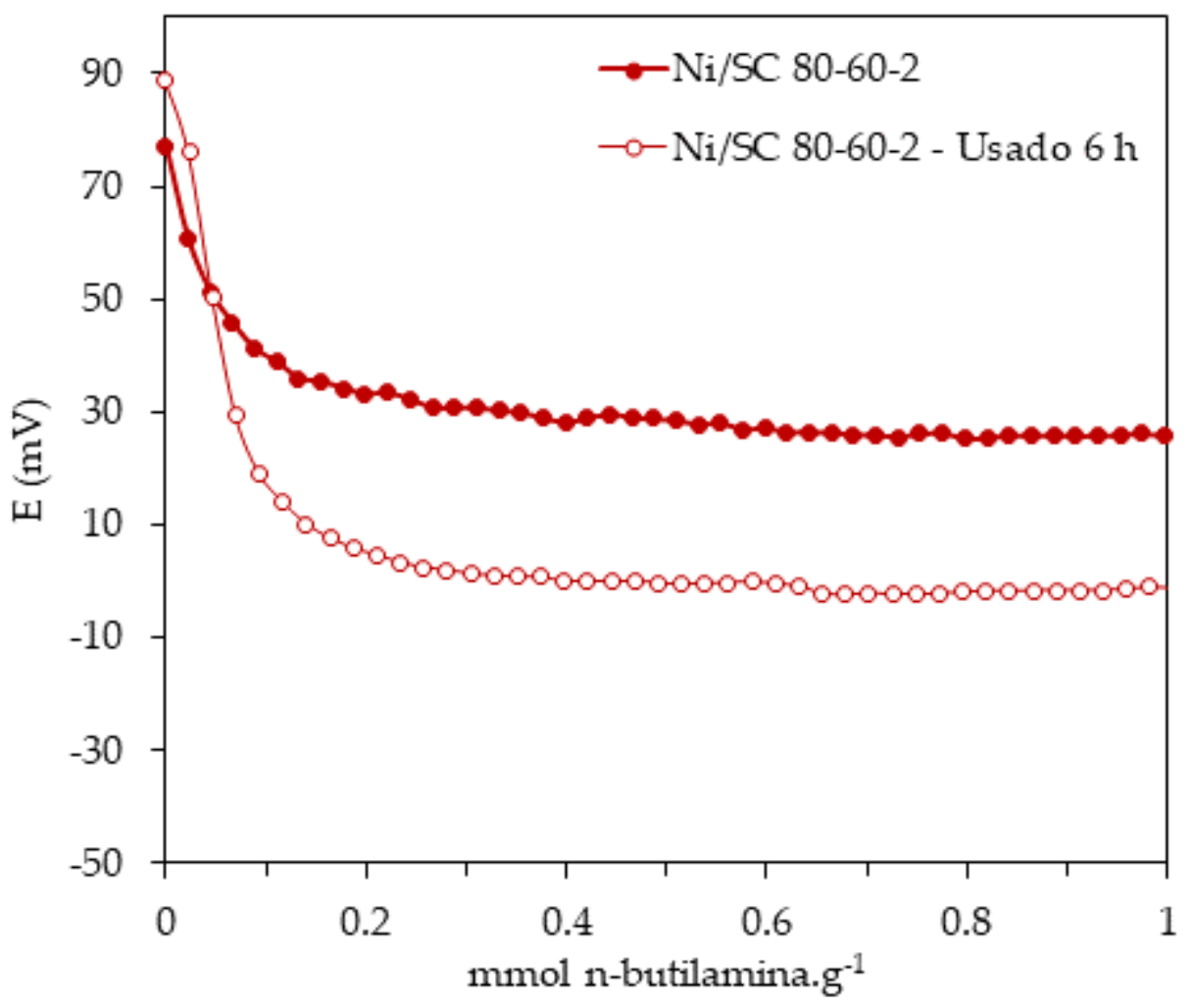

Figura 9-7. Ni/SC80-60-2 fresco y usado. 


\section{Conclusiones}

La funcionalización del soporte SC empleando $\mathrm{HNO}_{3}$ como agente oxidante permitió aumentar el número de sitios ácidos superficiales del material. Los resultados muestran que el tratamiento de funcionalización a $80{ }^{\circ} \mathrm{C}$ durante $2 \mathrm{~h}$ utilizando una solución de $\mathrm{HNO}_{3}$ al 60 $\%$ p/p resulta efectivo para proporcionar mayor acidez superficial, con la presencia de grupos oxigenados superficiales que le otorgan acidez tipo Lewis.

El catalizador de $\mathrm{Ni}$ preparado con este soporte funcionalizado, Ni/SC80-60-2, tiene la mayor actividad en la reacción de hidrogenólisis del glicerol, permitiendo alcanzar $\sim 52 \%$ de conversión en 2 h, con una selectividad a 1,2-PG de $\sim 85 \%$. Esos resultados fueron asignados a la acidez superficial de tipo Lewis que favorece la deshidratación del glicerol a acetol, y mantiene las propiedades de la partícula metálica de Ni para hidrogenar el acetol a 1,2 PG. La acidez de este catalizador Ni/SC $80-60-2$ no se modifica luego de $6 \mathrm{~h}$ de tratamiento hidrotérmico a $260^{\circ} \mathrm{C}$ y 20 bar $\mathrm{H}_{2}$.

\section{Bibliografía}

[1] N. Mager, N. Meyer, A. F. Léonard, N. Job, M. Devillers, S. Hermans, Applied Catalysis B Environmental 148-149 (2014) 424-435.

[2] S. Kundo, Y. Wang, W. Xia, M. Muhler, Journal of Physics Chemistry Carbon 112 (2008) 16869-16878.

[3] G. Viruthagiri, S. Sathiya priya, N. Shanmugam, A. Balaji, K. Balamurugan, E. Gopinathan, Spectrochimica Acta Part A: Molecular and Biomolecular Spectroscopy 149 (2015) 468-475.

[4] C. Alegre, M. E. Gálvez, E. Baquedano, E. Pastor, R. Moliner, M. J. Lázaro, International Journal of Hydrogen Energy 37 (2012) 7180-7191.

[5] A. H. Van Pelt, O. A. Simakova, S. M. Schimming, J. L. Ewbank, G. S. Foo, E. A. Pidko, E. J. M. Hensen, C. Sievers, Carbon 77 (2014) 143-154.

[6] M. Steimecke, S. Rümmler, M. Bron, Electrochimica Acta 163 (2015) 1-8.

[7] B. Huang, C. H. Bartholomew, B. F. Woodfield, Microporous and Mesoporous Materials 184 (2014) 112-121.

[8] H. Ding, J. Li, Y. Gao, D. Zhao, D. Shi, G. Mao, S. Liu, X. Tan, Powder Technology 284 (2015) 231-236.

[9] T. Niu, G. L. Liu, Y. Liu, Applied Catalysis B Environmental 154-155 (2014) 82-92. 
[10] R. Dong, W. Yang, P. Wu, M. Hussain, Z. Xiu, G. Wu, P. Wang. Materials Characterization 103 (2015) 37-41.

[11] Z. Omidin, A. Ghasemi, S. Bakhshi, Ceramics International 41 (2015) 5779-5784.

[12] B. Lombardi, F. Pompeo, A. N. Scian, N. N. Nichio, Materials Letters 106 (2013) 393-395.

[13] H. R. Li, J. Lin, H. J. Zhang, H. C. Li, L. S. Fu, Q. G. Meng, Chemical Communications 13 (2001) 1212.

[14] H. Li, J. Yu, F. Liu, H. Zhang, L. Fu, Q. Meng, C. Peng, J. Lin, New Journal of Chemistry 28 (2004) 1137.

[15] M. Rashidi, A. Tavasoli, Journal of Supercritical Fluids 98 (2015) 111-118.

[16] G. Viruthagiri, S. Sathiya priya, N. Shanmugam, A. Balaji, K. Balamurugan, E. Gopinathan, Spectrochimica Acta Part A: Molecular and Biomolecular Spectroscopy 149 (2015) 468-475.

[17] X. Wu, L. Song, B. Li, Y. Liu, Journal of Luminescence 130 (2010) 374-379.

[18] A. Proctor, P. Sherwood, Journal of Electron Spectroscopy and Related Phenoma 27 (1982) 39-56.

[19] B. Chen, B. Zhang, Y. Zhang, X. Yang, ChemCatChem 8 (2016) 1929-1936.

[20] M. A. Dasari, P. P. Kiatsimkul, W. R. Sutterlin, G. J. Suppes, Applied Catalysis A: General 281 (2005) 225-231.

[21] S. Xia, R. Nie, X. Lu, L. Wang, P. Chen, Z. Hou, Journal of Catalysis 296 (2012) 1-11. 


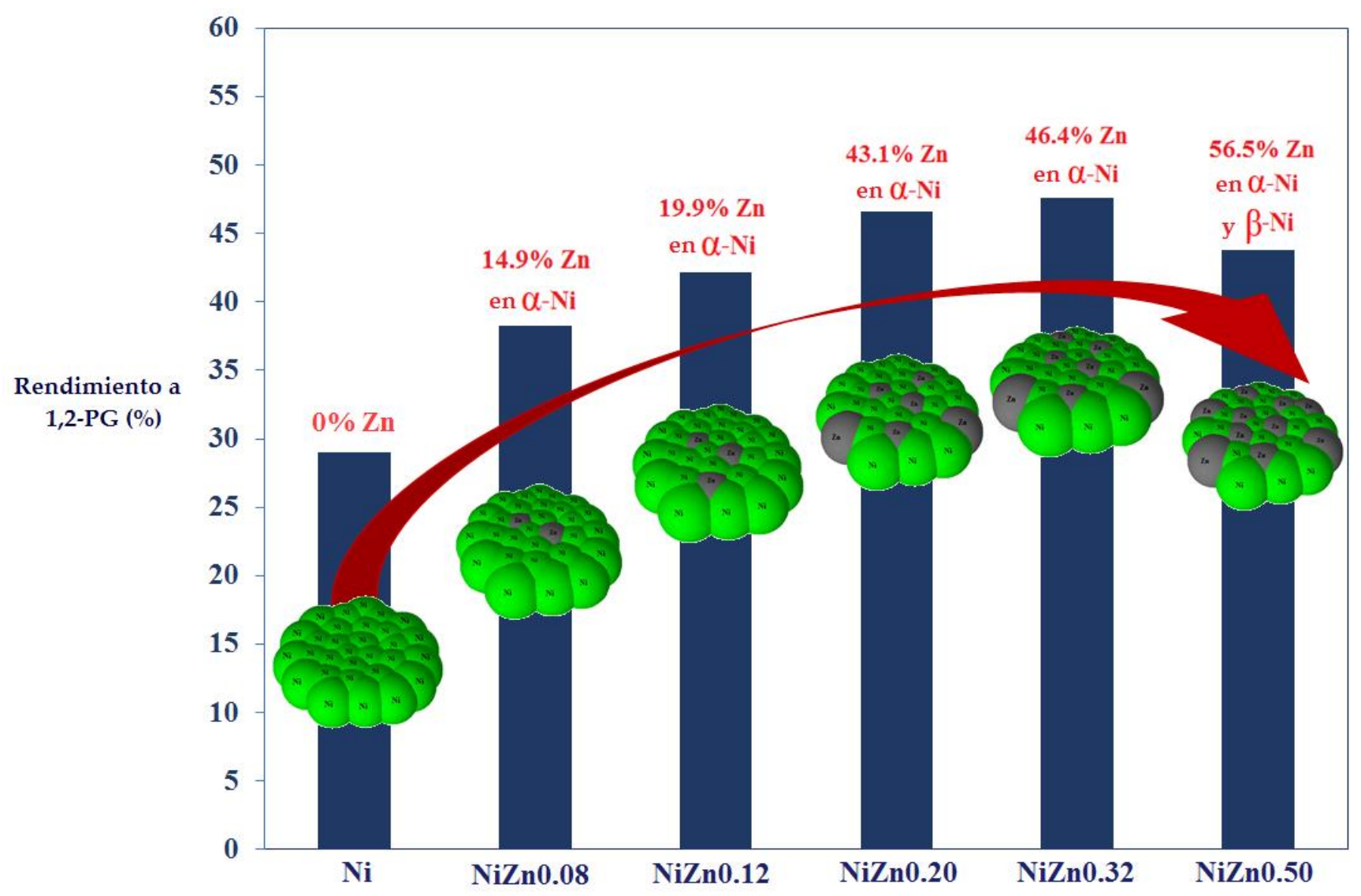

CAPÍTULO 8

Catalizadores NiZn/SC 


\subsection{Introducción}

En el capítulo previo se mostraron los resultados obtenidos por la implementación de una de las estrategias para aumentar el nivel de actividad del catalizador Ni/SC basada en la funcionalización del soporte de SC. En este capítulo se presentan los resultados de la otra estrategia que consiste en la modificación de la fase activa de Ni por adición de un promotor metálico.

En la primer parte de este capítulo se detalla la preparación del catalizador bimetálico mediante la técnica derivada de la química organometálica de superficies (QOMS/M), una técnica de preparación controlada que se caracteriza por la obtención de fases bimetálicas homogéneas y bien dispersas, sobre todo cuando se adicionan muy pequeñas cantidades de un promotor metálico.

Posteriormente se presentan los resultados de caracterización por adsorción-desorción de $\mathrm{N}_{2}$ (BET), microscopía de transmisión electrónica (TEM), titulación potenciométrica, difracción de rayos $X$ (DRX) y absorción de rayos $X$ extendida a estructura fina (EXAFS).

Finalmente se presentan los resultados de actividad catalítica y se correlacionan con los resultados de caracterización de los catalizadores.

\subsection{Antecedentes sobre catalizadores bimetálicos}

En el estudio de la reacción de hidrogenólisis de glicerol, se ha reportado en la bibliografía la preparación de catalizadores basados en fases activas bimetálicas, tales como Pt-Fe [1], Ru-Cu [2], Cu-Ni [3], Ni-Ag [4], entre otras.

Soares et al. [1] sintetizaron catalizadores bimetálicos de $\mathrm{Pt}-\mathrm{Fe} / \mathrm{Al}_{2} \mathrm{O}_{3}$ que resultaron más activos que catalizadores de $\mathrm{Pt} / \mathrm{Al}_{2} \mathrm{O}_{3}$. La adición de $\mathrm{Fe}$ genera la formación de una aleación Pt-Fe que mejora la conversión del 22\% al 33\% manteniendo una selectividad del $60 \%$ a 1,2-PG, a $220{ }^{\circ} \mathrm{C}$ y 20 bar de $\mathrm{H}_{2}$, al cabo de 12 h de reacción.

Salazar et al. [2], estudiaron catalizadores bimetálicos de $\mathrm{Ru}-\mathrm{Cu} / \mathrm{TiO}_{2}$ y encontraron que la adición de $\mathrm{Cu}$ mejora la selectividad a 1,2-PG. Los catalizadores con una relación $\mathrm{Ru} / \mathrm{Cu}=1$ mostraron la mejor performance con un $50 \%$ de conversión y una selectividad del $96 \%$ a 1,2-PG luego de $12 \mathrm{~h}$ de reacción a $200{ }^{\circ} \mathrm{C}$ y 26 bar de $\mathrm{H}_{2}$.

Catalizadores bimetálicos de $\mathrm{Cu}-\mathrm{Ni}$ soportados sobre $\gamma-\mathrm{Al}_{2} \mathrm{O}_{3}$ fueron sintetizados por Pudi et al. [3]. Con una relación $\mathrm{Cu} / \mathrm{Ni}=1$, se alcanzó un $72 \%$ de conversión y una selectividad del $93 \%$ a 1,2-PG, a $210{ }^{\circ} \mathrm{C}$ y 45 bar de $\mathrm{H}_{2}$. Los altos niveles de actividad fueron atribuidos a la formación de una fase bimetálica de $\mathrm{Cu}-\mathrm{Ni}$ con pequeño tamaño de partícula, alta acidez y mejor dispersión que las fases de $\mathrm{Cu}$ y Ni por separado.

Chen et al. [4], prepararon una serie de catalizadores de $\mathrm{Ni}-\mathrm{Ag}$ y encontraron que para una relación $\mathrm{Ni} / \mathrm{Ag}=6$ los catalizadores son más activos (78\% de conversión) y selectivos a 1,2-PG (66\%) a $210{ }^{\circ} \mathrm{C}$ y 40 bar de $\mathrm{H}_{2}$ al cabo de 6 h de reacción empleando una solución al $20 \%$ en peso de glicerol. Los resultados fueron atribuidos a la formación de una aleación NiAg que incrementa la capacidad de adsorción del glicerol y mejora la capacidad de hidrogenación del Ni. 


\subsection{Preparación de los catalizadores NiZn/SC}

Previamente a la adición de Zn, los catalizadores Ni/SC fueron preparados por impregnación a humedad incipiente empleando $\mathrm{NiCl}_{2} .6 \mathrm{H}_{2} \mathrm{O}$ como precursor y etanol como solvente. La concentración del precursor de $\mathrm{Ni}$ en etanol fue calculada para obtener un $5 \%$ p/p de $\mathrm{Ni}$ en el sólido final. Luego, los sólidos fueron secados a $120{ }^{\circ} \mathrm{C}$ durante $12 \mathrm{~h}$ y activados $\left(10^{\circ} \mathrm{C} \cdot \mathrm{min}^{-1}\right)$ en flujo continuo $\left(50 \mathrm{~cm}^{3} \cdot \mathrm{min}^{-1}\right)$ de $\mathrm{H}_{2}$ a $400{ }^{\circ} \mathrm{C}$ durante $1.5 \mathrm{~h}$.

Los catalizadores bimetálicos de NiZn/SC fueron preparados mediante la técnica organometálica de superficies (QOMS/M) [5]. La adición de Zn como promotor fue realizada mediante la reacción entre los catalizadores Ni/SC pre-reducidos y una solución en nheptano de $\mathrm{Zn}\left(\mathrm{C}_{2} \mathrm{H}_{5}\right)_{2}$ a $80{ }^{\circ} \mathrm{C}$ en atmósfera de $\mathrm{H}_{2}$. Dado que los sólidos obtenidos luego de este procedimiento pueden contener restos de grupos etilo adsorbidos en su superficie, los mismos fueron lavados varias veces con n-heptano a temperatura ambiente y luego secados en flujo continuo $\left(50 \mathrm{~cm}^{3} \cdot \mathrm{min}^{-1}\right)$ de $\mathrm{Ar}$ a $100{ }^{\circ} \mathrm{C}$ durante $2 \mathrm{~h}$. Finalmente, los catalizadores bimetálicos fueron activados $\left(10{ }^{\circ} \mathrm{C} \cdot \mathrm{min}^{-1}\right)$ en flujo continuo $\left(50 \mathrm{~cm}^{3} \cdot \mathrm{min}^{-1}\right)$ de $\mathrm{H}_{2}$ a $400{ }^{\circ} \mathrm{C}$ durante $1.5 \mathrm{~h}$.

El contenido de $\mathrm{Zn}$ en los catalizadores se encontró en el rango 0.08-0.5, expresados como una relación atómica $\mathrm{Zn} / \mathrm{Ni}$. Los catalizadores fueron denotados como Ni-ZnB/SC, donde $\mathrm{B}$ indica la relación atómica $\mathrm{Zn} / \mathrm{Ni}$.

\subsection{Caracterización de los catalizadores NiZn/SC}

Los catalizadores Ni/SC y NiZn/SC fueron caracterizados mediante adsorcióndesorción de $\mathrm{N}_{2}$ (BET), microscopía de transmisión electrónica (TEM), titulación potenciométrica, difracción de rayos $\mathrm{X}(\mathrm{DRX})$ y absorción de rayos $\mathrm{X}$ extendida a estructura fina (EXAFS).

La Tabla 1-8 muestra los resultados de la caracterización textural por adsorcióndesorción de $\mathrm{N}_{2}$ (BET) de los catalizadores Ni/SC y NiZn/SC, luego de ser activados en flujo de $\mathrm{H}_{2}$.

Tabla 1-8. Propiedades texturales de los catalizadores Ni/SC y NiZn/SC.

\begin{tabular}{lcccccc}
\hline \multirow{2}{*}{ Catalizador } & \multirow{2}{*}{$\mathrm{S}_{\mathrm{BET}}{ }^{\mathrm{a}}$} & \multirow{2}{*}{$\mathrm{V}_{\mathrm{p}}{ }^{\mathrm{b}}$} & \multicolumn{2}{c}{ Microporos } & \multicolumn{2}{c}{ Mesoporos } \\
\cline { 4 - 7 } & & & $\mathrm{S}_{\text {micro }}{ }^{\mathrm{c}}$ & $\mathrm{V}_{\text {micro }}{ }^{\mathrm{d}}$ & $\mathrm{S}_{\text {meso }}{ }^{\mathrm{e}}$ & $\mathrm{V}_{\text {meso }}{ }^{\mathrm{f}}$ \\
\hline Ni/SC & 211 & 0.41 & 60 & 0.03 & 151 & 0.38 \\
NiZn0.08/SC & 204 & 0.41 & 53 & 0.02 & 151 & 0.39 \\
NiZn0.12/SC & 192 & 0.39 & 56 & 0.02 & 136 & 0.37 \\
NiZn0.2/SC & 190 & 0.37 & 53 & 0.02 & 137 & 0.35 \\
NiZn0.5/SC & 156 & 0.31 & 44 & 0.02 & 112 & 0.29 \\
\hline
\end{tabular}

a Superficie específica $\left(\mathrm{m}^{2} \cdot \mathrm{g}^{-1}\right)^{\mathrm{b}}$ Volumen total de poros $\left(\mathrm{cm}^{3} \cdot \mathrm{g}^{-1}\right)$

c Superficie específica de microporos $\left(\mathrm{cm}^{2} \cdot \mathrm{g}^{-1}\right)^{\text {d }}$ Volumen total de microporos $\left(\mathrm{cm}^{3} \cdot \mathrm{g}^{-1}\right)$

e Superficie específica de mesoporos $\left(\mathrm{cm}^{2} \cdot \mathrm{g}^{-1}\right){ }^{\mathrm{f}}$ Volumen total de mesoporos $\left(\mathrm{cm}^{3} \cdot \mathrm{g}^{-1}\right)$ 
Los resultados de adsorción-desorción de $\mathrm{N}_{2}$ muestran que con el aumento del contenido de Zn resulta menor la superficie específica de los catalizadores NiZn/SC. Si bien entre el catalizador Ni/SC y NiZn0.2/SC, la diferencia de SвEт es muy pequeña (disminuye sólo un 10\%), el cambio es más notorio en el catalizador NiZn0.5/SC con una reducción del $26 \%$ del SBEt.

La Figura 1-8 presenta las curvas de titulación potenciométrica para los catalizadores $\mathrm{Ni} / \mathrm{SC}$ y NiZn/SC.

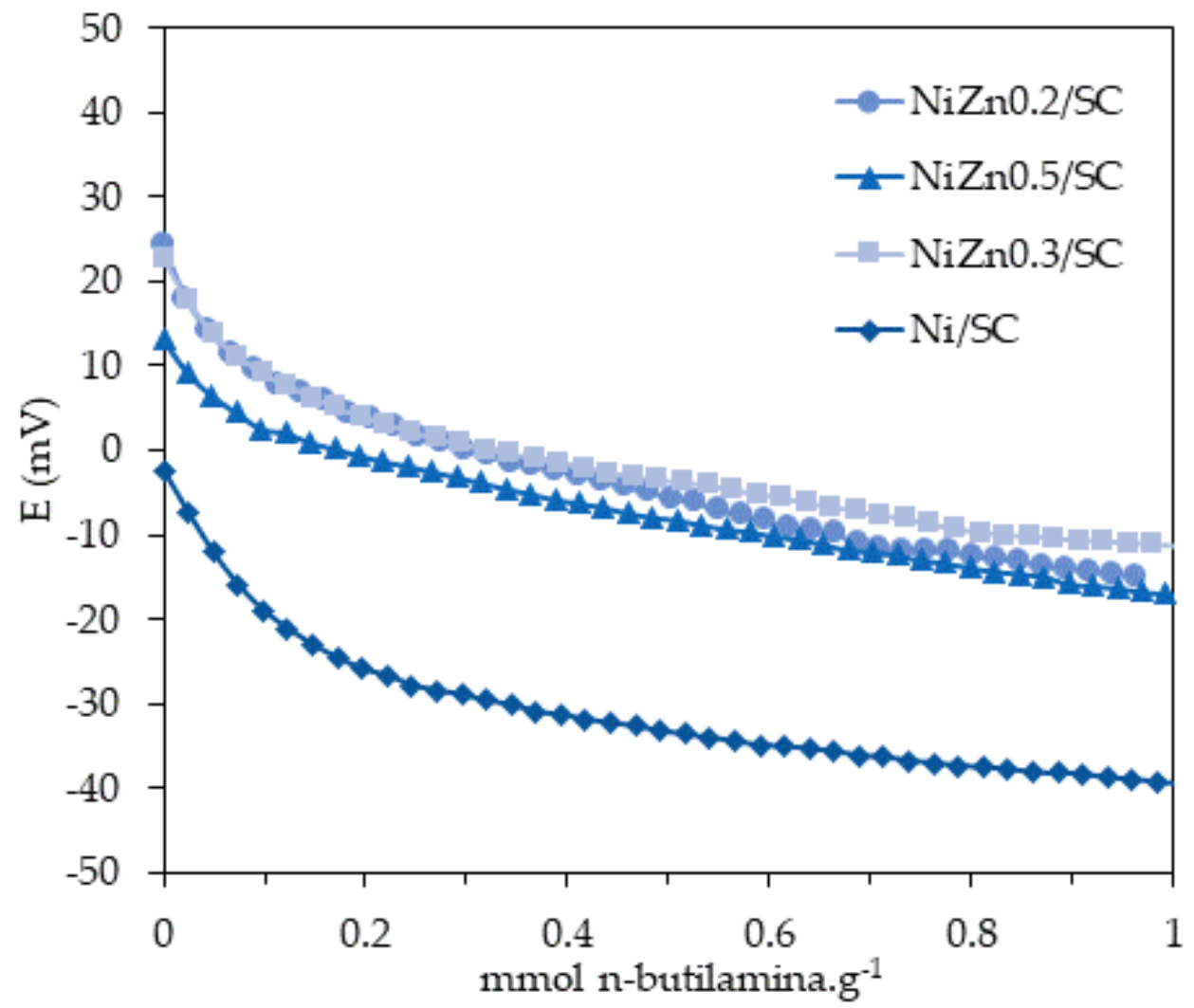

Figura 1-8. Curvas de titulación potenciométrica con n-butilamina para Ni/SC y NiZn/SC.

A partir de la figura, es posible observar un leve incremento en la fuerza ácida debido por la presencia de $\mathrm{Zn}$ en los catalizadores bimetálicos. Además, tampoco se observan diferencias significativas cuando se comparan con el contenido de $\mathrm{Zn}$.

Los resultados de caracterización por TEM se muestran en la Figura 2-8, con las imágenes de los catalizadores Ni/SC, NiZn0.2/SC y NiZn0.5/SC y sus correspondientes distribuciones de tamaños de partícula. El diámetro promedio de partícula, $\mathrm{d}$ va, y la dispersión metálica, DTEM, para los catalizadores Ni/SC, NiZn0.2/SC y NiZn0.5/SC se muestran en la Tabla 2-8. 

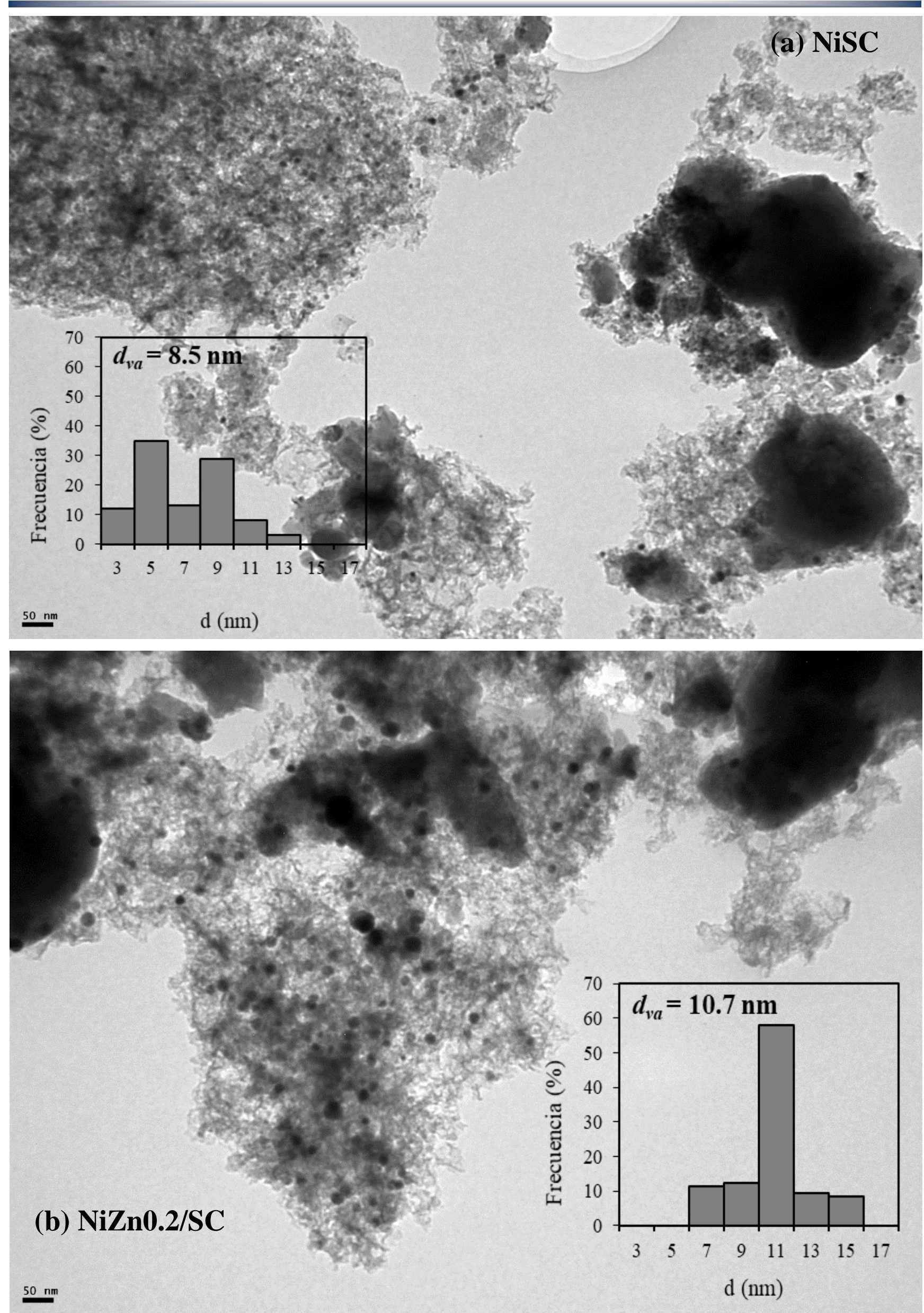


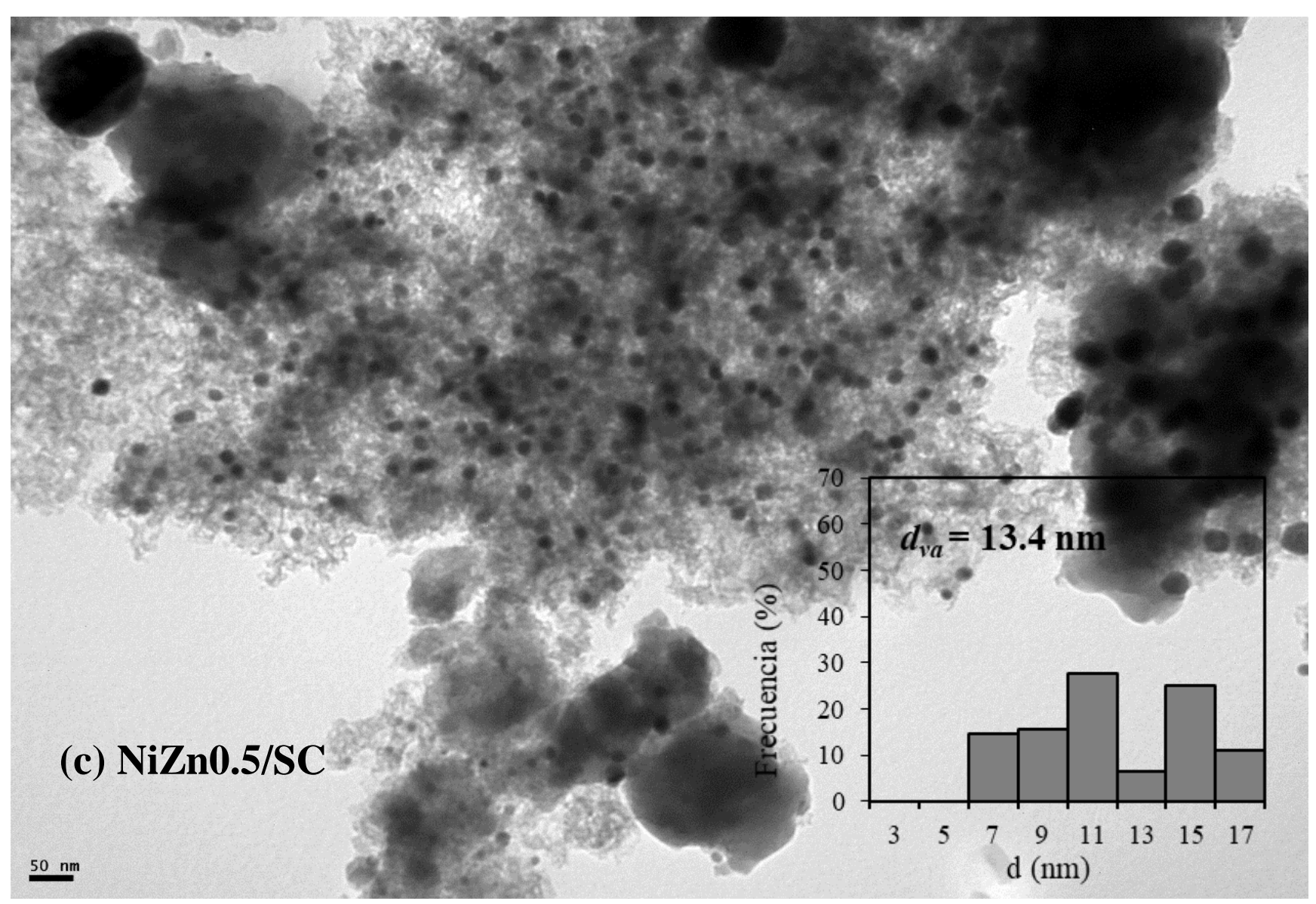

Figura 2-8. Imágenes TEM y distribución de tamaños de partícula para (a) Ni/SC (b) NiZn0.2/SC (c) NiZn0.5/SC.

Tabla 2-8. Resultados obtenidos por TEM para Ni/SC, NiZn0.2/SC y NiZn0.5/SC.

$$
\text { Catalizador } \quad \mathrm{d}_{\mathrm{va}}(\mathrm{nm}) \quad \text { Dтем }(\%)
$$

\begin{tabular}{lcc}
\hline $\mathrm{Ni} / \mathrm{SC}$ & 8.5 & 11.1 \\
\hline $\mathrm{NiZn0.2/SC}$ & 10.7 & 9.1 \\
\hline $\mathrm{NiZn0.5/SC}$ & 13.4 & 7.2 \\
\hline
\end{tabular}

El catalizador bimetálico NiZn0.2/SC tiene un diámetro de partícula ligeramente mayor que el catalizador de Ni/SC. A medida que la relación atómica $\mathrm{Zn} / \mathrm{Ni}$ pasa de 0.2 a 0.5 , el diámetro de partícula se incrementa de $10.7 \mathrm{~nm}$ a $13.4 \mathrm{~nm}$. Este resultado se encuentra en concordancia con lo reportado por Melo et al. [7], quienes observaron un incremento en el diámetro promedio de partícula de $10 \mathrm{~nm}$ a $17 \mathrm{~nm}$ con el incremento en el contenido de $\mathrm{Zn}$ en catalizadores de $\mathrm{NiZn} / \mathrm{SiO}_{2}$.

Los resultados de caracterización por DRX se muestran en la Figura 3-8, para los catalizadores reducidos $\mathrm{Ni} / \mathrm{SC}$ y NiZn/SC. 


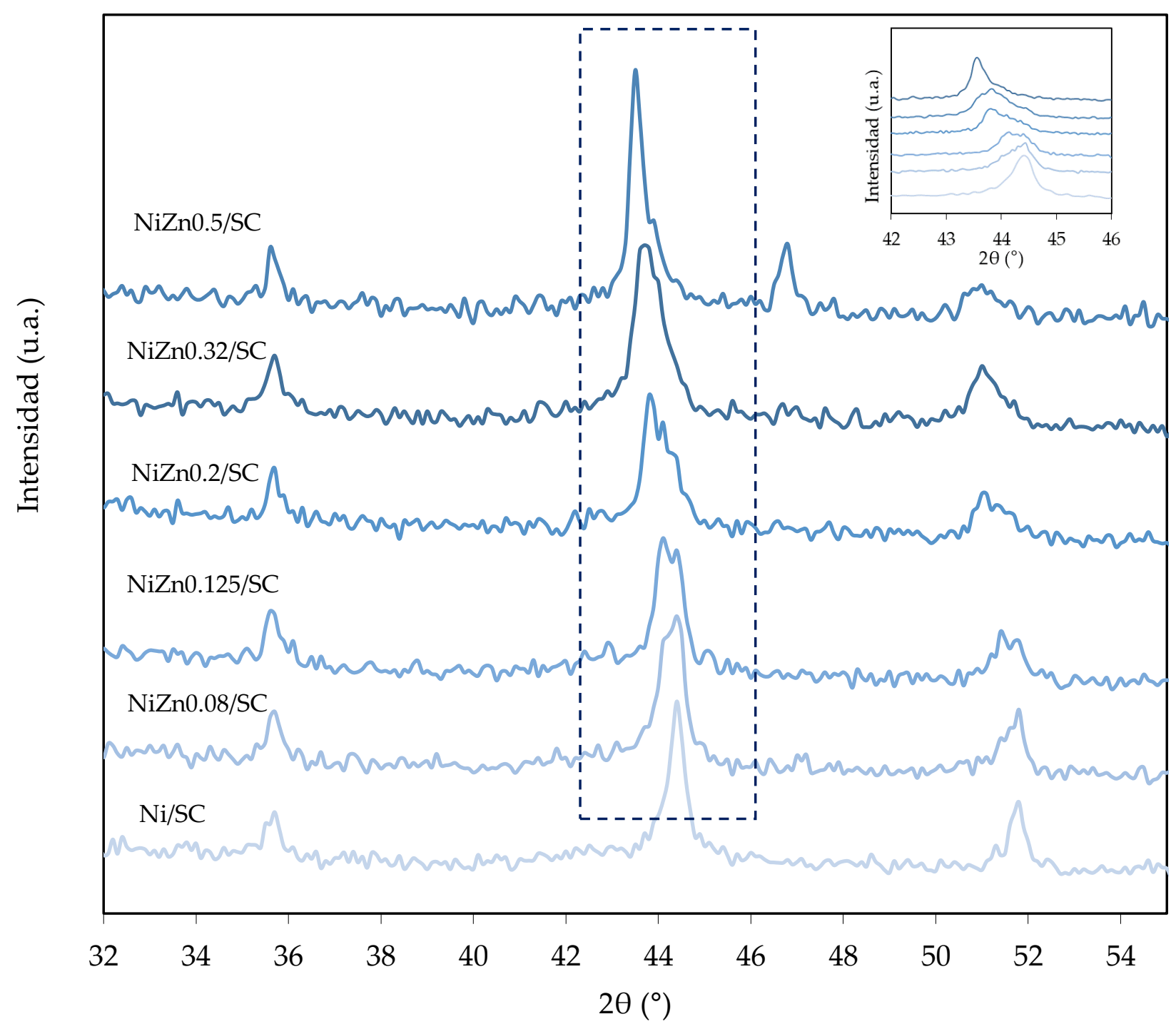

Figura 3-8. Difractograma de rayos X los catalizadores de Ni/SC y NiZn/SC.

El pequeño pico a $2 \theta=35.58^{\circ}$ presente en todas las muestras se debe al soporte de SC. Para el catalizador Ni/SC, se observan los principales picos de la fase metálica de níquel a $2 \theta$ $=44.4^{\circ}$ y $51.7^{\circ}$, con un parámetro de red a $=3.525 \AA$. El tamaño promedio de cristal estimado, empleando la ecuación de Scherrer, es cercano a $12 \mathrm{~nm}$.

Para todos los catalizadores de NiZn/SC, no se observan señales correspondientes a la fase de $\mathrm{Zn}$ ni del $\mathrm{ZnO}$.

Por otro lado, los picos característicos de Ni se vuelven más anchos y se desplazan hacia menores ángulos con el incremento del contenido de Zn. Acorde a la literatura [8], este corrimiento sugeriría la formación de una solución sólida Ni-Zn.

Para los catalizadores bimetálicos, el pico principal del $\mathrm{Ni}$ se ajustó usando dos funciones de Voigt, que se muestran en la Figura 4-8. 

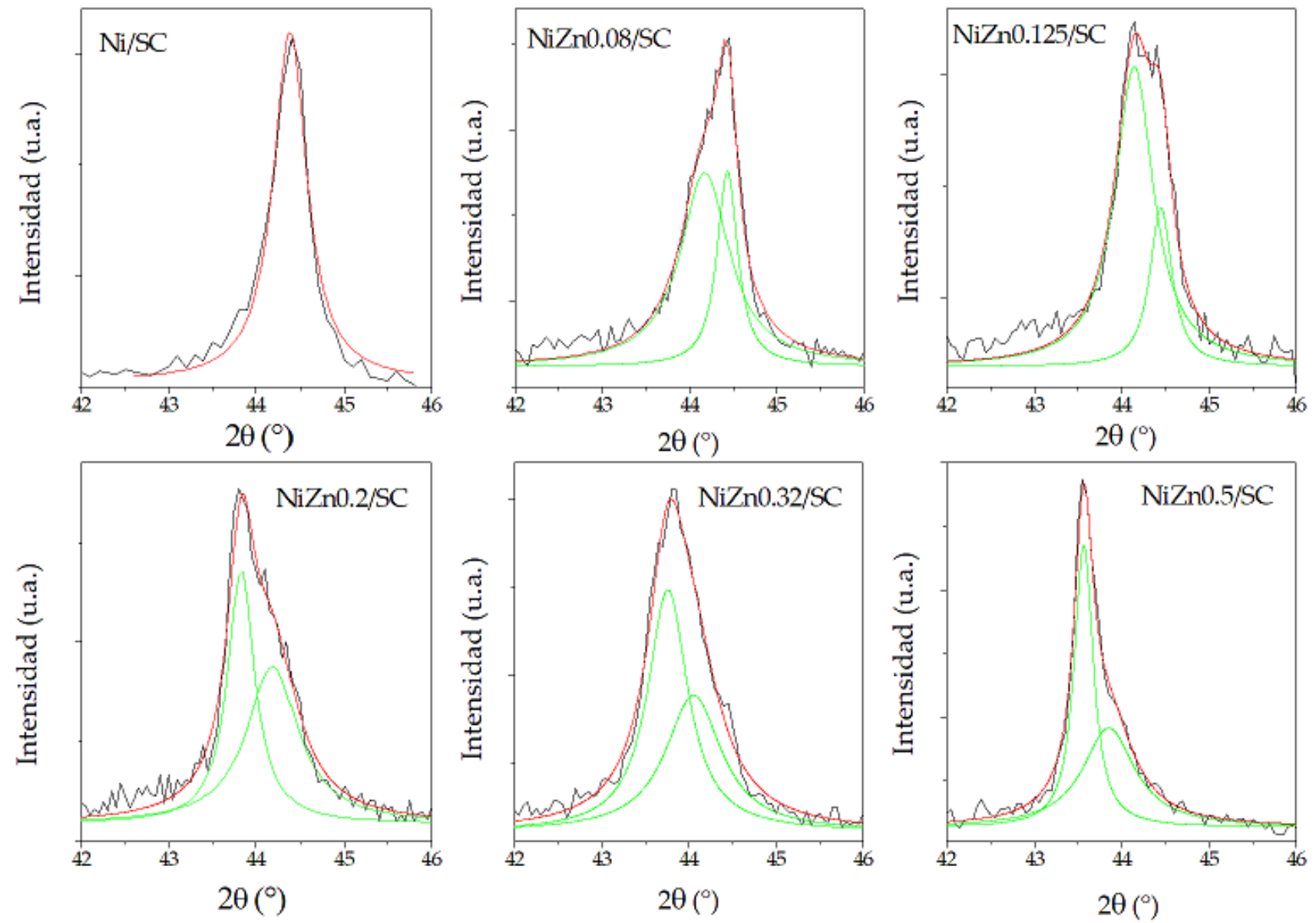

Figura 4-8. Ajuste del pico principal del Ni en catalizadores de Ni/SC y NiZn/SC utilizando funciones de Voigt.

Los resultados del ajuste se muestran en la Tabla 3-8, donde se informan las posiciones de los picos 1 y 2 , los parámetros de red $a_{1}$ y $a_{2}$ respectivamente, y la estimación del \%Zn en la aleación $\alpha-\mathrm{NiZn}$.

A partir de cada componente del ajuste, es posible asociar la posición de los picos con la formación de una aleación $\alpha-N i Z n$ con diferente contenido de $\mathrm{Zn}$.

De la variación de los parámetros de red obtenidos y utilizando la relación lineal informada por Pearson y Thompson [8], es posible estimar el porcentaje de Zn presente en cada aleación. La Figura 5-8 muestra la relación lineal entre los parámetros de red $a_{1}$ y $a_{2}, \mathrm{y}$ la estimación del \%Zn , obtenida de bibliografía [8]. Sobre esta gráfica se dibujaron las líneas azules y verdes que corresponden a los parámetros de red $a_{1}$ y $a_{2}$, obtenidos del ajuste del pico principal de $\mathrm{Ni}$, para las muestras bimetálicas de esta tesis. El \%Zn estimado para cada aleación $\alpha-\mathrm{NiZn}$, a partir de esta correlación, se muestra en la Tabla 3-8. 
Tabla 3-8. Ajuste de Voigt, cálculos de parámetros de red y estimación del \%Zn en la aleación $\alpha$ $\mathrm{NiZn.}$

\begin{tabular}{lccc}
\hline Catalizador & Posición del pico $1\left(^{\circ}\right)$ & Parámetro de red $\left(a_{1}\right)(\AA)$ & $\% \mathrm{Zn}$ \\
\hline NiZn0.08/SC & 44.16 & 3.547 & 12.7 \\
NiZn0.125/SC & 44.13 & 3.553 & 15.6 \\
NiZn0.2/SC & 43.85 & 3.580 & 27.1 \\
NiZn0.32/SC & 43.72 & 3.583 & 28.4 \\
\hline Catalizador & Posición del pico $2\left(^{\circ}\right)$ & Parámetro de red $\left(a_{2}\right)(\AA)$ & $\%$ Zn \\
\hline NiZn0.08/SC & 44.43 & 3.522 & 2.2 \\
NiZn0.125/SC & 44.42 & 3.527 & 4.3 \\
NiZn0.2/SC & 44.08 & 3.554 & 15.7 \\
NiZn0.32/SC & 44.02 & 3.558 & 18.0 \\
NiZn0.5/SC & 43.85 & 3.572 & 23.4 \\
\hline
\end{tabular}

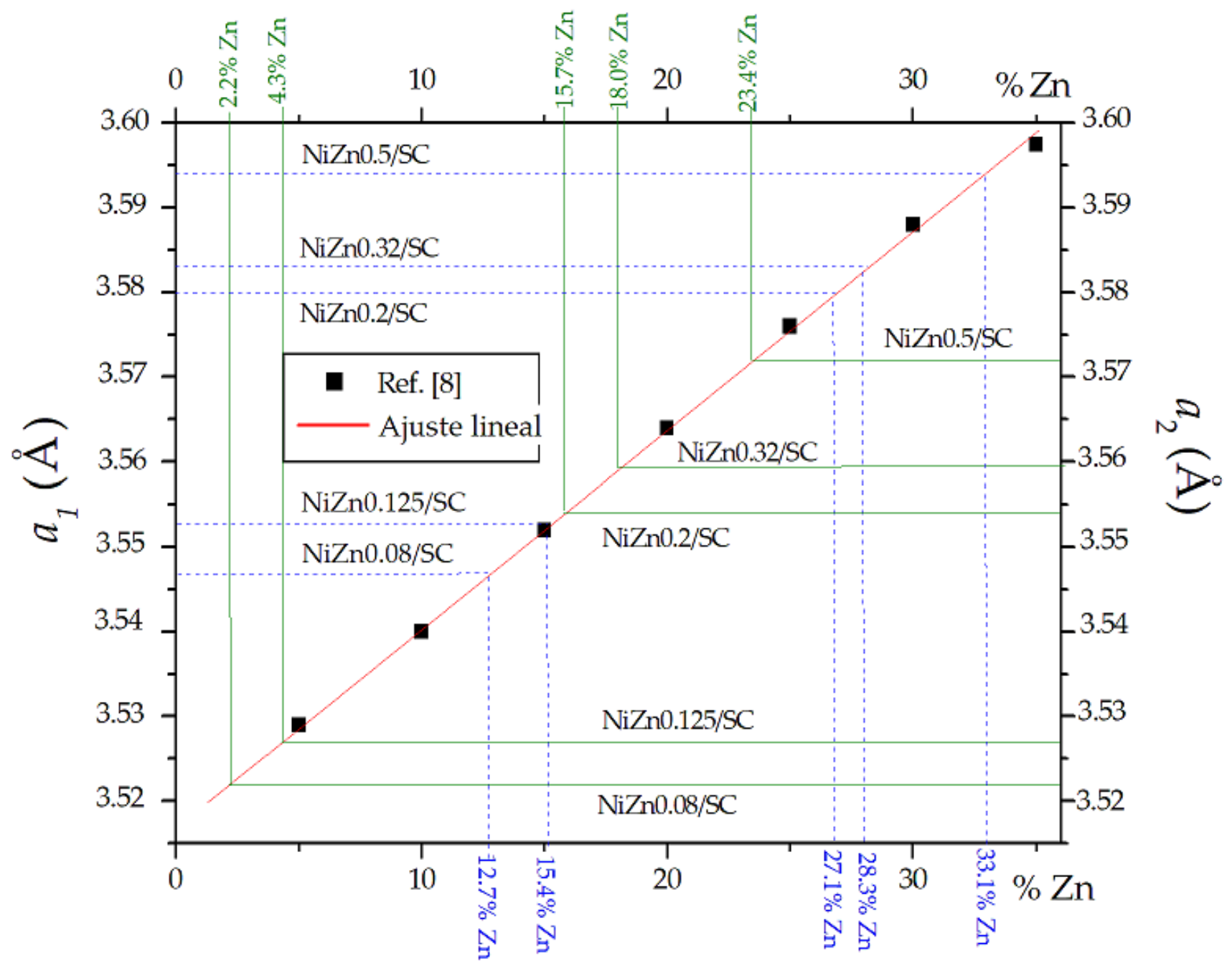

Figura 5-8. Parámetro de red en función de la concentración de Zn para una aleación $\alpha$-NiZn según referencia bibliográfica [8]. 
Para la muestra NiZn0.08/SC, el pico 1 tiene un contenido de $12.7 \%$ de $Z n$, mientras que el pico 2 tiene un 2.2\% de Zn. Para la muestra NiZn0.5/SC, el contenido de Zn aumenta a $33 \%$ en el pico 1 y a $23 \%$ en el pico 2 . Además, en la muestra NiZn0.5/SC aparece un nuevo pico a $2 \theta=46.7^{\circ}$, lo que demostraría la formación de una nueva fase cristalina que coexiste con las previamente mencionadas. De acuerdo con Friedrich et al. [9], la nueva fase formada correspondería a la fase tetragonal de $\beta_{1}-\mathrm{NiZn}$.

Para identificar efectivamente la presencia de la fase $\beta_{1}-\mathrm{NiZn}$ se llevó a cabo un análisis de difracción de rayos $\mathrm{X}$ del catalizador de NiZn0.5/SC en el rango de $2 \theta=40-80^{\circ}$. El resultado se muestra en la Figura 6-8.

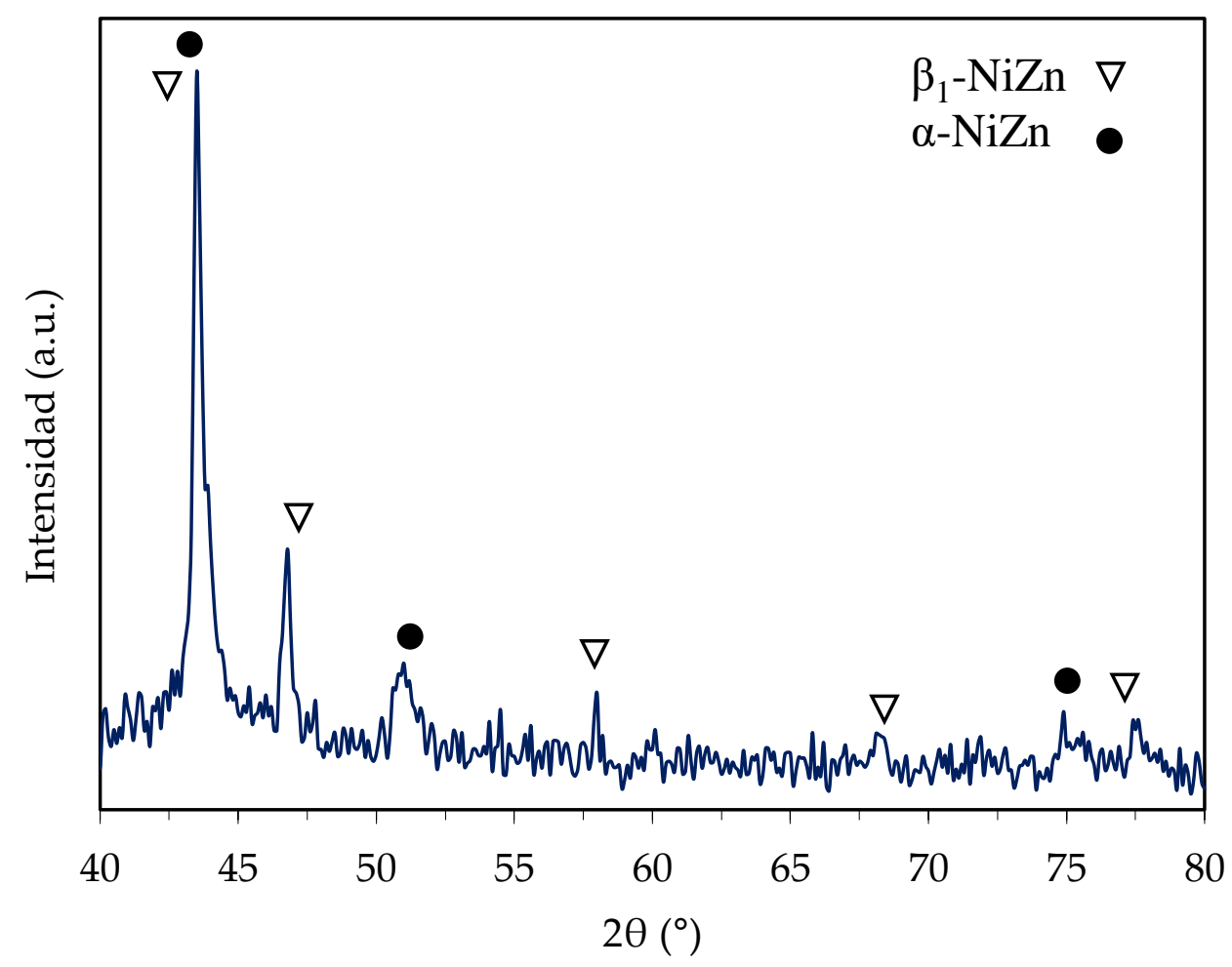

Figura 6-8. Difractograma de rayos X para el catalizador de NiZn0.5/SC en el rango 2 $\theta=40-80^{\circ}$.

En esta figura es posible observar la presencia de otros picos a $42.8^{\circ}, 57.9^{\circ}, 68.4^{\circ} \mathrm{y}$ $77.5^{\circ}$, además del observado a $46.7^{\circ}$, que confirman la presencia de la fase $\beta_{1}-\mathrm{NiZn}$ [9].

Los espectros de absorción de rayos $\mathrm{X}$ extendida a estructura fina (EXAFS) permiten el análisis de muestras sólidas que contienen más de un elemento químico y son utilizados para la identificación y cuantificación de fases bimetálicas del tipo soluciones sólidas y aleaciones. La Figura 7-8 muestra los resultados de las oscilaciones EXAFS extraídas en los bordes k de Zn y Ni respectivamente, para cada muestra.

Las oscilaciones EXAFS en el borde $\mathrm{K}$ del Ni de todas las muestras son casi idénticas al patrón de Ni. Sin embargo, las oscilaciones en el borde K del Zn muestran un comportamiento muy diferente y no corresponden al patrón de Zn. Estas características observadas en los bordes indicarían que los átomos de Zn se encontrarían incorporados a la estructura cristalina de $\mathrm{Ni}$. 

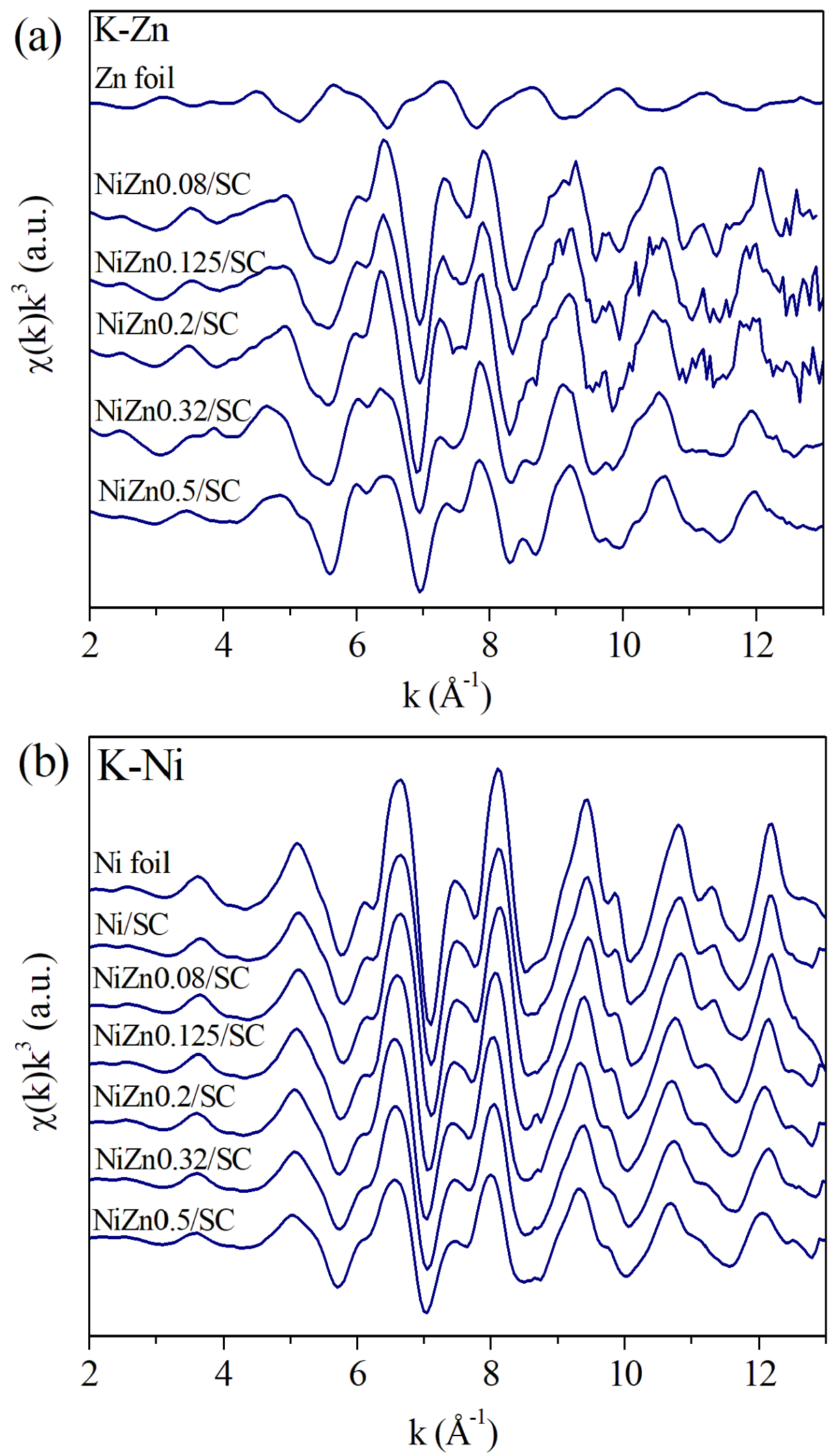

Figura 7-8. Oscilaciones EXAFS extraídas en los bordes $k$ del Zn (a) y del Ni (b) para cada muestra.

Vassilev et al. [10] reportaron que la solubilidad del $\mathrm{Zn}$ en $\mathrm{Ni}$ es cercana al $30 \%$ atómico. Por esta razón, para las muestras con baja relación atómica $\mathrm{Zn} / \mathrm{Ni}$ los cálculos de las 
estructuras bimetálicas (Ni-Zn y Zn-Ni) se efectuaron a partir de una estructura fcc del $\mathrm{Ni}$ que contiene a los átomos de $\mathrm{Zn}$ en posiciones aleatorias y en la misma proporción a la relación $\mathrm{Zn} / \mathrm{Ni}$ de cada muestra. Para el catalizador de NiZn0.5/SC se empleó la fase $\beta_{1}$ de la aleación NiZn [11].

La Figura 8-8 muestra las transformadas de Fourier de las oscilaciones EXAFS y los ajustes correspondientes obtenidos para ambos bordes, donde $\mathrm{R}$ es la distancia interatómica. Los parámetros obtenidos se presentan en la Tabla 4-8 (a y b), donde $\mathrm{N}$ es el número de coordinación promedio, $\sigma^{2}$ es el factor de Debye-Waller.
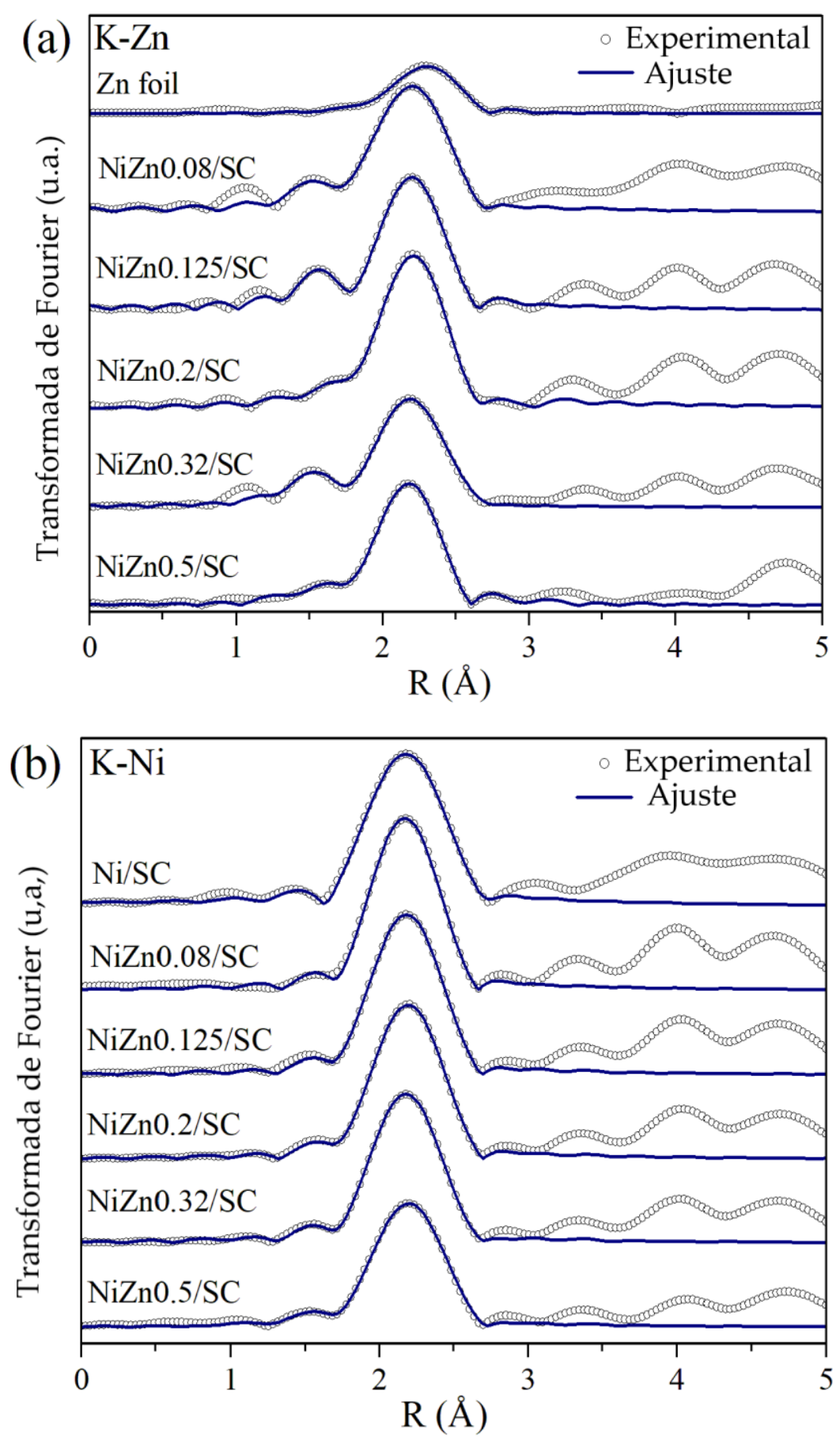

Figura 8-8. Transformadas de Fourier de las oscilaciones EXAFS y los ajustes correspondientes obtenidos para cada muestra en el borde K del Zn (a) y en el borde K del Ni (b). 
Tabla 4-8. Parámetros de ajuste obtenidos por EXAFS (a) borde K-Zn (b) borde K-Ni.

(a)

\begin{tabular}{lccccccccc}
\hline Muestra & NZn-O & RZn-O & $\sigma^{2}$ Zn-O & NZn-Zn & RZn-Zn & $\sigma^{2}$ Zn-Zn & NZn-Ni & RZn-Ni & $\sigma^{2}$ Zn-Ni \\
\hline Zn patrón & - & - & - & $12^{*}$ & $2.743(4)$ & $0.0090(6)$ & - & - & - \\
ZnO & $4^{*}$ & $1.973(4)$ & $0.003(1)$ & - & - & - & - & - & - \\
NiZn0.08/SC & $1.8(4)$ & $1.965(8)$ & $0.007(1)$ & - & - & - & $7.7(8)$ & $2.51(1)$ & $0.0062(5)$ \\
NiZn0.125/SC & $1.5(5)$ & $1.945(7)$ & $0.005(1)$ & - & - & - & $7.4(9)$ & $2.51(1)$ & $0.0066(8)$ \\
NiZn0.2/SC & $0.9(4)$ & $2.03(1)$ & $0.006(1)$ & $1.1^{*}$ & $2.52(1)$ & $0.0076(7)$ & $8.9(9)$ & $2.53(1)$ & $0.0070(8)$ \\
NiZn0.32/SC & $1.5(5)$ & $1.904(9)$ & $0.005(1)$ & $1.3^{*}$ & $2.51(1)$ & $0.0079(7)$ & $6.0(7)$ & $2.54(1)$ & $0.0072(7)$ \\
NiZn0.5/SC & $1.1(5)$ & $1.89(1)$ & $0.009(1)$ & $1.8(6)$ & $2.51(1)$ & $0.0080(7)$ & $5.5(6)$ & $2.55(1)$ & $0.0076(6)$ \\
\hline
\end{tabular}

(b)

\begin{tabular}{lcccccc}
\hline Muestra & $\mathrm{N}_{\mathrm{Ni}-\mathrm{Ni}}$ & $\mathrm{R}_{\mathrm{Ni}-\mathrm{Ni}}$ & $\sigma^{2} \mathrm{Ni-Ni}$ & $\mathrm{N}_{\mathrm{Ni}-Z n}$ & $\mathrm{R}_{\mathrm{Ni}-Z n}$ & $\sigma^{2} \mathrm{Ni-Zn}$ \\
\hline Ni patrón & $12^{*}$ & $2.489(5)$ & $0.0060(6)$ & - & - & - \\
Ni/SC & $10.4(9)$ & $2.47(1)$ & $0.0060(8)$ & - & - & $0.0060(8)$ \\
NiZn0.08/SC & $9.5(7)$ & $2.48(1)$ & $0.0060(5)$ & $0.8^{*}$ & $2.51(1)$ & $0.0062(5)$ \\
NiZn0.125/SC & $9.4(8)$ & $2.48(2)$ & $0.0062(8)$ & $1.0(6)$ & $2.51(1)$ & $0.0066(8)$ \\
NiZn0.2/SC & $8.1(9)$ & $2.49(2)$ & $0.0064(8)$ & $1.9(7)$ & $2.53(1)$ & $0.0070(8)$ \\
NiZn0.32/SC & $7.9(8)$ & $2.49(2)$ & $0.0064(7)$ & $2.1(8)$ & $2.54(1)$ & $0.0072(7)$ \\
NiZn0.5/SC & $5.6(8)$ & $2.49(2)$ & $0.0063(1)$ & $3.0(8)$ & $2.55(1)$ & $0.0076(6)$ \\
\hline
\end{tabular}

Para realizar los ajustes, se podrían utilizar tanto el borde $\mathrm{K}$ del Zn como el borde K del Ni. Como aparecen átomos de $\mathrm{Zn}$ que se encuentran oxidados formando una capa de Zn$\mathrm{O}$, pero no aparecen átomos de $\mathrm{Ni}$ formando una capa de Ni-O, el análisis se realizó a partir de los ajustes en el borde $\mathrm{K}$ del Ni.

Para todas las muestras con $\mathrm{Zn} / \mathrm{Ni} \leq 0.32$, los resultados son consistentes con la formación de una solución sólida de Zn en la estructura de Ni fcc. Además, se observa un aumento en el número de coordinación Ni-Zn a medida que aumenta la relación atómica $\mathrm{Zn} / \mathrm{Ni}$, lo que indicaría que los átomos de $\mathrm{Zn}$ se incorporan en la estructura fcc del Ni. De cualquier manera, el número total de átomos de Ni permanece constante para relaciones $\mathrm{Zn} / \mathrm{Ni} \leq 0.32$, lo que indica que la relación del área superficial a volumen de las partículas de Ni permanece casi constante para estos contenidos de Zn.

La muestra NiZn0.5/SC tiene un número de coordinación total menor que el resto de las muestras, lo que podría indicar la presencia de partículas metálicas más pequeñas. Sin embargo, esto no se evidencia en resultados de DRX y TEM, y esto podría ser explicado por la formación de una aleación $\beta_{1-N i Z n}$. En esta estructura de la $\beta_{1}-\mathrm{NiZn}$, los primeros vecinos del átomo absorbente son reducidos desde 12 (en el crsital fcc) a 8, esto explica el descenso en el número de coordinación total para la muestra NiZn0.5/SC [12]. 
Los resultados en el borde $\mathrm{K}$ del $\mathrm{Zn}$ siguen la misma tendencia, lo que indica que al aumentar el contenido de $\mathrm{Zn}$ aparece una capa de $\mathrm{Zn}$-Zn con distancias similares a las de la capa de $\mathrm{Zn}-\mathrm{Ni}$, indicando que no se forma una estructura metálica de $\mathrm{Zn}$ sino que se produce un aumento de átomos de Zn en la solución sólida de Ni-Zn.

\subsection{Actividad de los catalizadores NiZn/SC}

Los resultados de la actividad catalítica en la reacción de hidrogenólisis de glicerol en fase líquida para los catalizadores NiZn/SC se muestran en la Tabla 5-8. Se incluyen a modo comparativo los catalizadores $\mathrm{Ni} / \mathrm{SC}$ y Ni/SC $80-60-2$ que fueron ya presentado en el Capítulo 7. Los ensayos se realizaron a $260{ }^{\circ} \mathrm{C}$ y 20 bar de $\mathrm{H}_{2}$ iniciales, empleando soluciones al $30 \% \mathrm{p} / \mathrm{p}$ de glicerol y una relación $\mathrm{m}_{\mathrm{gli}} / \mathrm{m}_{\mathrm{c}}=4.2$.

Tabla 5-8. Actividad catalítica de los catalizadores de Ni/SC y NiZn/SC.

\begin{tabular}{lccccccccc}
\hline \multirow{2}{*}{ Catalizador } & \multirow{2}{*}{$\mathrm{X}_{\mathrm{T}}(\%)$} & \multirow{2}{*}{$\mathrm{X}_{\mathrm{L}}(\%)$} & \multicolumn{8}{c}{ Selectividad $(\%)$} \\
\cline { 5 - 10 } & & & $\mathrm{MeOH}$ & EtOH & AcO & 1-POH & AcOH & EG & $1,2-\mathrm{PG}$ \\
\hline Ni/SC & 38.6 & 36.0 & 0.9 & 3.1 & 0.2 & 2.3 & 3.3 & 8.5 & 81.7 \\
Ni/SC $80-60-2$ & 52.0 & 49.0 & 0.3 & 1.6 & 0.1 & 1.1 & 1.8 & 10.2 & 84.9 \\
NiZn0.08/SC & 50.8 & 47.8 & 0.8 & 1.9 & 0.3 & 3.2 & 4.5 & 7.7 & 81.6 \\
NiZn0.12/SC & 55.0 & 51.8 & 0.6 & 1.5 & 0.2 & 2.7 & 3.4 & 6.7 & 84.9 \\
NiZn0.2/SC & 58.6 & 55.7 & 0.9 & 1.2 & 0.2 & 2.7 & 2.7 & 5.6 & 86.7 \\
NiZn0.32/SC & 60.4 & 57.5 & 0.8 & 1.3 & 0.2 & 2.4 & 3.4 & 6.1 & 85.8 \\
NiZn0.5/SC & 53.2 & 50.7 & 0.6 & 1.0 & 0.2 & 2.5 & 2.6 & 6.4 & 86.7 \\
\hline
\end{tabular}

${ }^{*}$ Condiciones de reacción: $260{ }^{\circ} \mathrm{C}, 20$ bar de $\mathrm{H}_{2}, 30 \%$ p/p de glicerol, mgli/mc $=4.2,2 \mathrm{~h}$.

${ }^{*} \mathrm{X}_{\mathrm{T}}$ : conversión total de glicerol, $\mathrm{X}_{\mathrm{L}}$ : conversión de glicerol a productos líquidos.

Se observó que la conversión a productos gaseosos fue muy baja, no superó el $4 \%$, para todos los catalizadores.

Si se analiza el efecto de la adición de $\mathrm{Zn}$ al catalizador $\mathrm{Ni} / \mathrm{SC}$, salvo en la muestra NiZn0.08/SC, la conversión y selectividad a 1,2-PG son mayores a las obtenidas por los catalizadores monometálicos (Ni/SC y Ni/SC80-60-2). La Tabla 5-8 muestra que los catalizadores NiZn0.2/SC y NiZn0.32/SC alcanzan los valores máximos de conversión (56-57\%) y de selectividad hacia 1,2-PG $(86.7 \%$ y $85.8 \%$ respectivamente).

$\mathrm{Li}$ et al. [13] evaluaron catalizadores del tipo hidrotalcita de $\mathrm{ZnNiAl}$ y encontraron que la adición de $\mathrm{Zn}$ afecta fuertemente la actividad y la selectividad debido a la mayor oxofilicidad de Zn que facilita la ruptura de los enlaces C-O de glicerol.

El aumento simultáneo de conversión y selectividad, que se muestra en la Tabla 5-8, indicaría la formación de un sitio activo de naturaleza diferente a la del catalizador Ni/SC. De hecho, los resultados de caracterización muestran que la adición de $\mathrm{Zn}$ hasta $1.8 \%$ en peso de $\mathrm{Zn}$, que corresponde a la muestra NiZn0.32/SC, genera la formación de una aleación $\alpha-\mathrm{NiZn}$ que podría ser la fase responsable del incremento de la actividad. Cuando la adición de Zn es 
de $2.8 \%$ en peso, que corresponde a la muestra NiZn0.5/SC, la generación de una nueva fase tetragonal de $\beta_{1}-\mathrm{NiZn}$ podría causar la disminución de la actividad catalítica.

Con el objetivo de comparar la actividad en la deshidratación de glicerol a $\mathrm{AcOH}$, se realizaron ensayos de reacción complementarios en atmósfera de $\mathrm{N}_{2}$, para favorecer a las reacciones de ruptura C-O y/o deshidratación. Los resultados se muestran en la Tabla 6-8.

Tabla 6-8. Actividad para la formación de AcOH de Ni/SC, Ni/SC80-60-2 y NiZn0.2/SC.

\begin{tabular}{lccccccccc}
\hline \multirow{2}{*}{ Catalizador } & \multirow{2}{*}{$\mathrm{X}_{\mathrm{T}}(\%)$} & \multirow{2}{*}{$\mathrm{X}_{\mathrm{L}}(\%)$} & \multicolumn{7}{c}{ Selectividad $(\%)$} \\
\cline { 4 - 10 } & & & $\mathrm{MeOH}$ & $\mathrm{EtOH}$ & $\mathrm{AcO}$ & $1-\mathrm{POH}$ & $\mathrm{AcOH}$ & $\mathrm{EG}$ & $1,2-\mathrm{PG}$ \\
\hline Ni/SC & 18.0 & 16.5 & 3.0 & 1.8 & 1.6 & 3.2 & 73.1 & 3.3 & 14.0 \\
Ni/SC $80-60-2$ & 30.0 & 27.5 & 3.3 & 0.8 & 1.4 & 0.3 & 84.0 & 3.5 & 6.7 \\
NiZn0.2/SC & 51.0 & 47.0 & 4.1 & 1.7 & 2.4 & 1.1 & 66.2 & 5.8 & 18.7 \\
\hline
\end{tabular}

${ }^{*}$ Condiciones de reacción: $260{ }^{\circ} \mathrm{C}, 20$ bar de $\mathrm{N}_{2}, 30 \% \mathrm{p} / \mathrm{p}$ de glicerol, $\mathrm{m}_{\mathrm{gli}} / \mathrm{m}_{\mathrm{c}}=6.2,2 \mathrm{~h}$.

${ }^{*} \mathrm{X}_{\mathrm{T}}$ : conversión total de glicerol, $\mathrm{X}_{\mathrm{L}}$ : conversión de glicerol a productos líquidos.

La Tabla 6-8 muestra que el catalizador bimetálico NiZn0.2/SC es mucho más activo que Ni/SC80-60-2, $47 \%$ de conversión versus $27.5 \%$, a pesar de la mayor fuerza ácida del catalizador Ni/SC80-60-2. Esto indica que la presencia de la aleación $\alpha-\mathrm{NiZn}$ tiene un efecto más significativo sobre la actividad y la selectividad para la ruptura del enlace C-O que el efecto de la acidez del soporte sobre la reacción de deshidratación.

\subsection{Ciclos de reacción}

Para estimar la estabilidad del catalizador bimetálico, se realizaron 3 ciclos de reacción consecutivos con el catalizador NiZn0.2/SC a $260{ }^{\circ} \mathrm{C}, 20$ bar de $\mathrm{H}_{2}, 30$ \% p/p de glicerol, $\mathrm{m}_{\mathrm{gli}} / \mathrm{m}_{\mathrm{c}}=6.2$, durante $4 \mathrm{~h}$ cada ciclo. El procedimiento consistió el enfriamiento hasta temperatura ambiente luego de $4 \mathrm{~h}$ de reacción, posteriormente se retiran con una pipeta los productos líquidos del reactor y se procedió a cargar una nueva solución del 30\% de glicerol. El catalizador usado permanece siempre dentro del reactor.

Tabla 7-8. Actividad para NiZn0.2/SC durante 3 ciclos de reacción.

\begin{tabular}{lccccccccc}
\hline \multirow{2}{*}{ Ciclos de reacción } & \multirow{2}{*}{$\mathrm{X}_{\mathrm{T}}(\%)$} & \multirow{2}{*}{$\mathrm{X}_{\mathrm{L}}(\%)$} & \multicolumn{1}{c}{ Selectividad (\%) } \\
\cline { 4 - 10 } & & & $\mathrm{MeOH}$ & $\mathrm{EtOH}$ & $\mathrm{AcO}$ & $1-\mathrm{POH}$ & $\mathrm{AcOH}$ & $\mathrm{EG}$ & $1,2-\mathrm{PG}$ \\
\hline 1er ciclo & 54.2 & 51.7 & 0.8 & 1.4 & 0.2 & 4.0 & 2.1 & 5.3 & 86.2 \\
2do ciclo & 41.0 & 39.0 & 0.8 & 1.7 & 0.2 & 4.1 & 2.0 & 4.2 & 87.0 \\
3er ciclo & 35.0 & 33.0 & 0.6 & 1.2 & 0.3 & 4.5 & 2.0 & 2.8 & 88.6
\end{tabular}

${ }^{*}$ Condiciones de reacción: $260{ }^{\circ} \mathrm{C}, 20$ bar de $\mathrm{H}_{2}, 30 \% \mathrm{p} / \mathrm{p}$ de glicerol, mgli/mc $=6.2,4 \mathrm{~h}$.

${ }^{*} \mathrm{X}_{\mathrm{T}}$ : conversión total de glicerol, $\mathrm{X}_{\mathrm{L}}$ : conversión de glicerol a productos líquidos. 
Los resultados de actividad se muestran en la Tabla 7-8, donde se observa que la conversión disminuye un $24 \%$ en el 2 do ciclo, y $15 \%$ en el 3er ciclo, mientras que la selectividad a 1,2 PG se mantiene. Estos primeros resultados podrían indicar la estabilidad del catalizador, dado que la pérdida de conversión podría deberse a la pérdida de material catalítico por la manipulación en la extracción de los productos líquidos (la agitación en el reactor genera finos). También debería considerarse que el catalizador no fue lavado, y la adsorción de productos de reacción podría desactivar el catalizador. Posteriores estudios deberían realizarse para caracterizar las muestras usadas.

\section{Conclusiones}

El objetivo planteado en este capítulo sobre la mejora de la actividad por la adición de Zn fue logrado con éxito. La modificación de la fase metálica por la adición de Zn empleando una técnica de preparación controlada (QOMS/M) permitió la adición selectiva de pequeñas cantidades de $\mathrm{Zn}$ sobre las partículas de $\mathrm{Ni}$. Esto fue confirmado por los resultados de caracterización de EXAFS y DRX, que muestran que todo el Zn está en interacción con el Ni.

La adición del 1.1 al 1.8 \%p/p de Zn (que corresponden a los catalizadores NiZn0.2/SC y NiZn0.32/SC) genera la formación de un sitio activo compuesto por una aleación $\alpha-\mathrm{NiZn}$ responsable del incremento en la actividad. Cuando la adición de Zn es mayor $(2.8$ \%p/p que correspondiente al catalizador NiZn0.5/SC) la generación de una nueva fase tetragonal de $\beta_{1-}$ NiZn podría causar el descenso en la actividad catalítica.

Los resultados de este capítulo indican que la adición del Zn tiene un efecto más significativo sobre la actividad y selectividad sobre las reacciones de ruptura de enlaces C-O, que el efecto de la acidificación del soporte (SC80-60-2) sobre la actividad de deshidratación.

\section{Bibliografía}

[1] A. Von-Held Soares, G. Perez, F. B. Passos, Applied Catalysis B: Environmental 185 (2016) 77-87.

[2] J. B. Salazar, D. D. Falcone, H. N. Pham, A.K. Datye, F. B. Passos, R. J. Davis, Applied Catalysis A: General 482 (2014) 137-144.

[3] S. M. Pudi, P. Biswas, S. Kumar, B. Sarkar, Journal of Brazilian Chemical Society 26 (8) (2015) 1551-1564.

[4] B. Chen, B. Zhang, Y. Zhang, X. Yang, ChemCatChem 8 (2016) 1929-1936.

[5] D. V. Cesar, G. F. Santori, F. Pompeo, M. A. Baldanza, C. A. Henriques, E. Lombardo, M. Schmal, L. Cornaglia, N. N. Nichio, International Journal of Hydrogen Energy 41 (2016) 22000-22008. 
[6] G. Zhang, Z. Li, H. Zheng, T. Fu, Y. Ju, Y. Wang, Applied Catalysis B: Environmental 179 (2015) 95-105.

[7] P. Melo, R. Jiménez, A. Karelovic, XXV Congreso Iberoamericano de Catálisis (2016).

[8] W. B. Pearson, L. T. Thompson, Canadian Journal of Physics 35 (1957) 349-357.

[9] M. Friedrich, D. Teschner, A. Knop-Gericke, M. Armbrüster, Journal of Physical Chemistry C 116 (2012) 14930-14935.

[10] G. P. Vassilev, T. Gomez-Acebo, J. C. Tedenac, Journal of Phase Equilibria 21 (2000) 287301.

[11] R. P. Anantatmula, D. B. Masson, Metallurgical and Materials Transactions 5 (1974) 605613.

[12] L. J. Giovanetti, J. M. Ramallo-López, M. Foxe, L. C. Jones, M. M. Koebel, G. A. Somorjai, A. F. Craievich, M. S. Salmeron, F. G. Requejo, Small 8 (3) (2012) 468-473.

[13] X. Li, C. Zhang, H. Cheng, L. He, W. Lin, Y. Yu, F. Zhao, Journal of Molecular Catalysis A: Chemical 395 (2014) 1-6. 



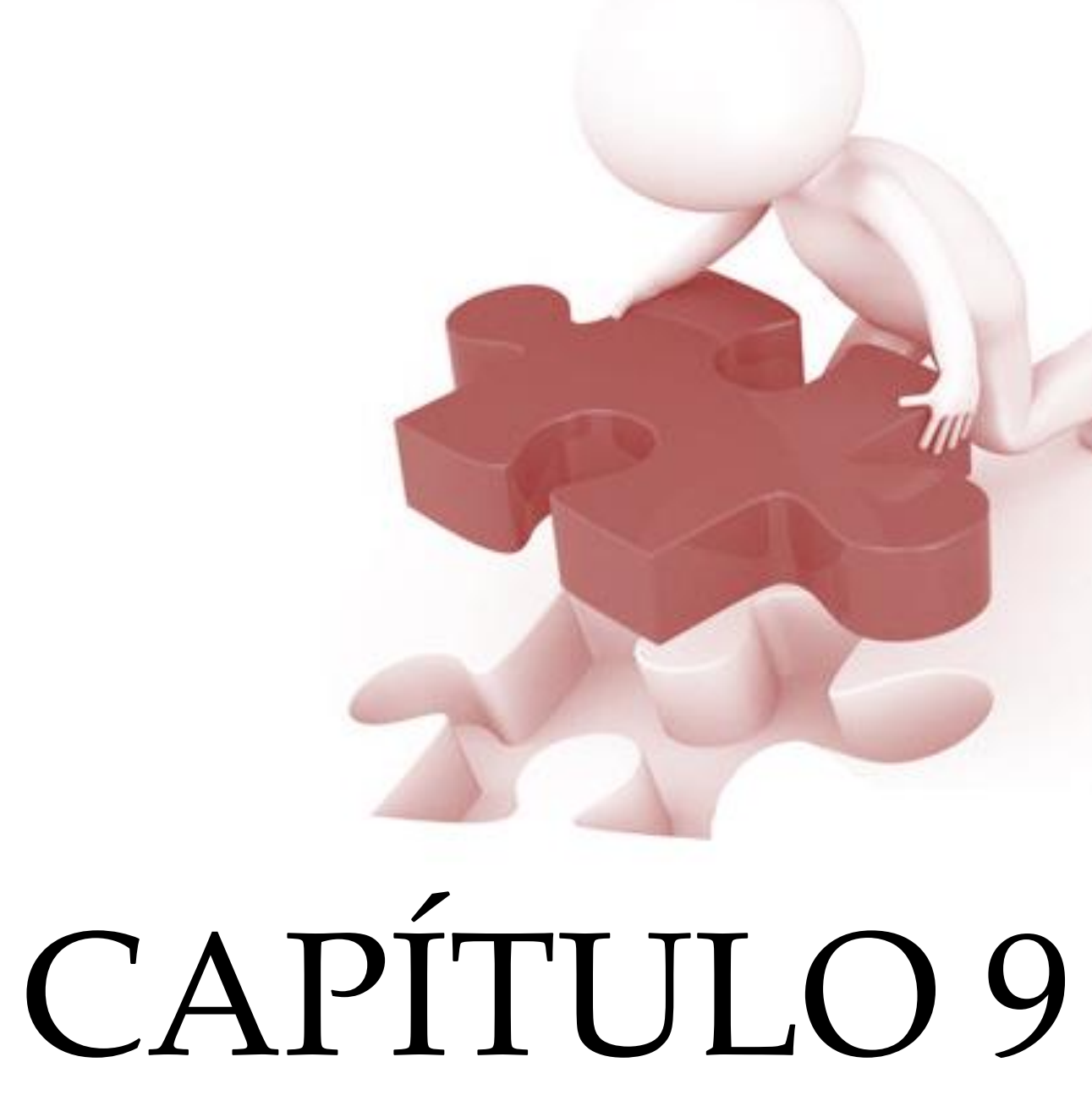

Conclusiones y perspectivas 


\subsection{Conclusiones generales}

El objetivo de este trabajo de tesis fue la preparación y caracterización de catalizadores para ser aplicados en la reacción de hidrogenólisis de glicerol en fase líquida para la producción de 1,2-PG.

El glicerol, como materia prima, es un recurso secundario de la biomasa, obtenido a partir de la producción de biodiesel, de bajo costo y disponibilidad en la Argentina.

El 1,2-propilenglicol (1,2-PG) resulta un producto atractivo desde varios puntos de vista. En primer término porque tiene mayor valor agregado que el glicerol. En segundo lugar, porque en la actualidad se produce a partir de un proceso petroquímico que emplea una materia prima de origen no renovable. Y finalmente porque en Argentina se utiliza 1,2PG en varias aplicaciones industriales pero se importa en su totalidad.

En este trabajo de tesis, mediante la técnica sol-gel se pudieron preparar dos tipos de soportes carbonosos, SC y C, que fueron caracterizados empleando varias técnicas para poder determinar su estructura, características texturales y propiedades ácido base.

Con respecto al soporte $\mathrm{C}$, también resultó un material mesoporoso, pero con una mayor contribución de microporos debido al tratamiento con HF. Estos microporos colapsan en la condición hidrotérmica de la fase líquida $\left(250^{\circ} \mathrm{C}\right.$ y 20 bar), mostrando una caída en la superficie específica, que, si bien no es significativa, no muestra la misma estabilidad que el soporte SC. El soporte C es levemente más ácido, con un mayor número de grupos superficiales oxigenados del tipo lactónicos y fenólicos.

El soporte de SC tiene una superficie específica del orden de $200 \mathrm{~m}^{2} \cdot \mathrm{g}^{-1}$ resultando ser un material del tipo mesoporoso, con una estructura principalmente amorfa, compuesta por una matriz de sílice y estructuras desordenadas de carbono grafito. Este material posee principalmente grupos ácidos débiles de Lewis, basados en grupos carboxílicos resultando levemente más ácido que una sílice comercial. Los resultados de caracterización obtenidos en las muestras tratadas en fase líquida a $250{ }^{\circ} \mathrm{C}$ y 20 bar, mostraron que el soporte SC es estable, no se modifican sus características texturales, su estructura ni sus propiedades ácidobase. En las mismas condiciones, un soporte de sílice comercial, $\mathrm{SiO}_{2}$, resultó inestable, evidenciando un colapso de poros a $200^{\circ} \mathrm{C}$ con una pérdida del $44 \%$ de superficie específica. Estos resultados permitieron demostrar el rol del carbón para estabilizar la estructura de la sílice en el material SC.

La preparación de catalizadores soportados empleando $\mathrm{Ru}, \mathrm{Cu}$ y $\mathrm{Ni}$ permitió fundamentalmente comparar conversión y selectividad de estos metales. Los resultados indicaron que los catalizadores de Ni/SC resultan atractivos debido al nivel de actividad logrado a $220^{\circ} \mathrm{C}$ y la elevada selectividad a 1,2 PG (86-92\%).

Posteriormente, se prepararon catalizadores de $\mathrm{Ni}$ empleando tres sales de níquel, $\mathrm{NiCl}_{2} .6 \mathrm{H}_{2} \mathrm{O}, \mathrm{Ni}\left(\mathrm{CH}_{3} \mathrm{COO}\right)_{2} .4 \mathrm{H}_{2} \mathrm{O}$ y Ni(NO$)_{2} .6 \mathrm{H}_{2} \mathrm{O}$. El estudio de las variables de calcinación y activación permitió seleccionar el tratamiento directo en flujo de $\mathrm{H}_{2}\left(50 \mathrm{~cm}^{3} \cdot \mathrm{min}^{-1}\right)$ a $400{ }^{\circ} \mathrm{C}$ durante $1.5 \mathrm{~h}$ para obtener el catalizador final.

Los catalizadores $\mathrm{Ni}(\mathrm{Cl}-) / \mathrm{SC}$ y $\mathrm{Ni}$ (Ac-)/SC mostraron el mejor comportamiento catalítico, y sólo por razones de menor costo se decidió utilizar $\mathrm{NiCl}_{2} .6 \mathrm{H}_{2} \mathrm{O}$ como precursor metálico para los posteriores estudios. 
El estudio del efecto del soporte, comparando $\mathrm{SC}, \mathrm{C}$ y $\mathrm{SiO}_{2}$, indicó que el catalizador $\mathrm{Ni}(\mathrm{Cl}-) / \mathrm{SC}$ es el más activo y selectivo a 1,2-PG, lo que podría ser explicado por la presencia de una acidez superficial basada en grupos carboxílicos que promueven la ruptura del enlace $\mathrm{C}-\mathrm{O}$ en el carbono primario del glicerol para producir $\mathrm{AcOH}$, acompañado de la buena actividad hidrogenante sobre el sitio metálico. Con este catalizador $\mathrm{Ni}(\mathrm{Cl}-) / \mathrm{SC}$ se estudió el efecto de las variables operativas más relevantes en la reacción de hidrogenólisis, tales como la temperatura $\left(220-260{ }^{\circ} \mathrm{C}\right)$, la relación masa de glicerol a masa de catalizador (4-19) y la presión de hidrógeno (0-40 bar de $\mathrm{H}_{2}$ ). En las condiciones operativas de $260^{\circ} \mathrm{C}$ y 20 bar de $\mathrm{H}_{2}$ iniciales, para una solución al $30 \% \mathrm{p} / \mathrm{p}$ de glicerol $\left(\mathrm{mH}_{\mathrm{H}} / \mathrm{m}_{\mathrm{gli}}=2.38\right)$ y una relación $\mathrm{mgli}_{\mathrm{g}} / \mathrm{m}_{\mathrm{c}}=$ 6.2 , es posible obtener luego de $6 \mathrm{~h}$ de reacción una conversión del $56 \%$ con una selectividad a 1,2-PG del $80 \%$ con $\mathrm{Ni}(\mathrm{Cl}-) / \mathrm{SC}$.

Los resultados de caracterización determinaron que no hay cambios estructurales significativos en el catalizador de $\mathrm{Ni}(\mathrm{Cl}-) / \mathrm{SC}$ usado. Se observó un ligero cambio en el tamaño de partícula que indicaría una buena resistencia al sinterizado.

Dado que el catalizador $\mathrm{Ni}(\mathrm{Cl}-) / \mathrm{SC}$ resultó muy selectivo a 1,2-PG, se plantearon dos estrategias para aumentar el nivel de actividad.

Una estrategia fue la funcionalización del soporte $\mathrm{SC}$ empleando $\mathrm{HNO}_{3}$ como agente oxidante para aumentar el número de sitios ácidos superficiales. Los resultados indicaron que el tratamiento de funcionalización a $80^{\circ} \mathrm{C}$ durante $2 \mathrm{~h}$ utilizando una solución al $60 \% \mathrm{p} / \mathrm{p}$ de $\mathrm{HNO}_{3}$ resulta efectivo para proporcionar mayor acidez superficial, con la presencia de grupos oxigenados superficiales que le otorgan acidez tipo Lewis.

El catalizador de $\mathrm{Ni}$ preparado con este soporte funcionalizado, $\mathrm{Ni} / \mathrm{SC} 80-60-2$, tiene la mayor actividad en la reacción de hidrogenólisis del glicerol, permitiendo alcanzar en sólo 2 $\mathrm{h}$ de reacción $\sim 52 \%$ de conversión y $\sim 85 \%$ de selectividad a 1,2-PG. Estos resultados fueron asignados a la acidez superficial de tipo Lewis que favorece la deshidratación del glicerol a acetol, y mantiene las propiedades de la partícula metálica de Ni para hidrogenar el acetol a 1,2 PG. La acidez de este catalizador Ni/SC80-60-2 no se modifica luego de $6 \mathrm{~h}$ de tratamiento hidrotérmico a $260^{\circ} \mathrm{C}$ y 20 bar $\mathrm{H}_{2}$.

La segunda estrategia fue la mejora de la actividad por la adición de Zn, un metal que no resulta activo en la reacción de hidrogenólisis de glicerol. La modificación de la fase metálica por la adición de Zn empleando una técnica de preparación controlada (QOMS/M) permitió la adición selectiva de pequeñas cantidades de Zn sobre las partículas de Ni. Esto fue confirmado por los resultados de caracterización de EXAFS y DRX, que muestran que todo el Zn está en interacción con el Ni.

La adición del 1.1 al $1.8 \%$ p/p de Zn (que corresponden a los catalizadores NiZn0.2/SC y NiZn0.32/SC) genera la formación de un sitio activo compuesto por una aleación $\alpha-\mathrm{NiZn}$ responsable del incremento en la actividad. Cuando la adición de Zn es mayor (2.8 \%p/p que correspondiente al catalizador NiZn0.5/SC) la generación de una nueva fase tetragonal de $\beta_{1-}$ NiZn podría causar el descenso en la actividad catalítica.

Los resultados indicaron que la adición del $\mathrm{Zn}$ tiene un efecto más significativo sobre la actividad y selectividad sobre las reacciones de ruptura de enlaces $\mathrm{C}-\mathrm{O}$, que el efecto de la acidificación del soporte (SC80-60-2) sobre la actividad de deshidratación. 


\subsection{Perspectivas}

A partir de este trabajo de tesis resulta interesante continuar con la línea de trabajo de conversión del glicerol hacia productos de mayor valor agregado por reacciones en fase líquida.

Con respecto a los materiales desarrollados, se requiere avanzar en el análisis de estabilidad y regenerabilidad.

Además, luego de esta primera etapa de estudio sobre esta temática, surge la necesidad de evaluar los catalizadores utilizando como materia prima el glicerol crudo provisto por industrias de biodiesel de la zona. Para ello se debería estudiar el efecto de metanol, sales orgánicas e inorgánicas, jabones, grasas, aceites, y pH sobre el comportamiento de los catalizadores ya estudiados y en función de estos resultados reformular el catalizador si fuese necesario.

Otro aspecto que surge de la tesis es que, dependiendo de las condiciones operativas y del catalizador, la reacción de hidrogenólisis puede conducir a otros productos diferentes al 1,2-PG, tales como 1-propanol (1-POH) y 2-propanol (2-POH). El 1-propanol resulta interesante por sus variadas aplicaciones en la industria, desde la fabricación de tintas de impresión, anticongelantes, fluidos para frenos como en la fabricación de gomas, lacas y aceites esenciales. En la actualidad el 1-propanol se obtiene sólo por vía petroquímica a partir de la hidroformilación de etileno. En bibliografía la temática es muy reciente, y por ejemplo, se han estudiado catalizadores basados en $\mathrm{Pd}$ y $\mathrm{Ru}$ que alcanzan selectividades a 1-POH entre 50 y $20 \%$ respectivamente. Catalizadores de $\mathrm{Mo} / \mathrm{SiO}_{2}$ presentaron una selectividad del $40 \%$ a $1-\mathrm{POH}$, a $325^{\circ} \mathrm{C}$ y 60 bar $\mathrm{H}_{2}$. También se estudiaron catalizadores de $\mathrm{Ni} / \mathrm{SiO}_{2}$ que alcanzaron $42 \%$ de selectividad a $1-\mathrm{POH}$.

En esta tesis se ha preparado el soporte C (obtenido por tratamiento con HF del SC) para generar una mayor cantidad de grupos superficiales oxigenados de tipo fenólicos. Los primeros resultados exploratorios indican que, los catalizadores $\mathrm{Ni} / \mathrm{C}$ preparados resultan selectivos para la formación de 1-propanol, obteniendo una conversión de glicerol del $24 \%$ con una selectividad a 1-propanol del $46 \%$, a $260{ }^{\circ} \mathrm{C}$ y 20 bar de $\mathrm{H}_{2}$. La modificación de este catalizador $\mathrm{Ni} / \mathrm{C}$ resultaría interesante para formular un catalizador selectivo a 1-propanol. 

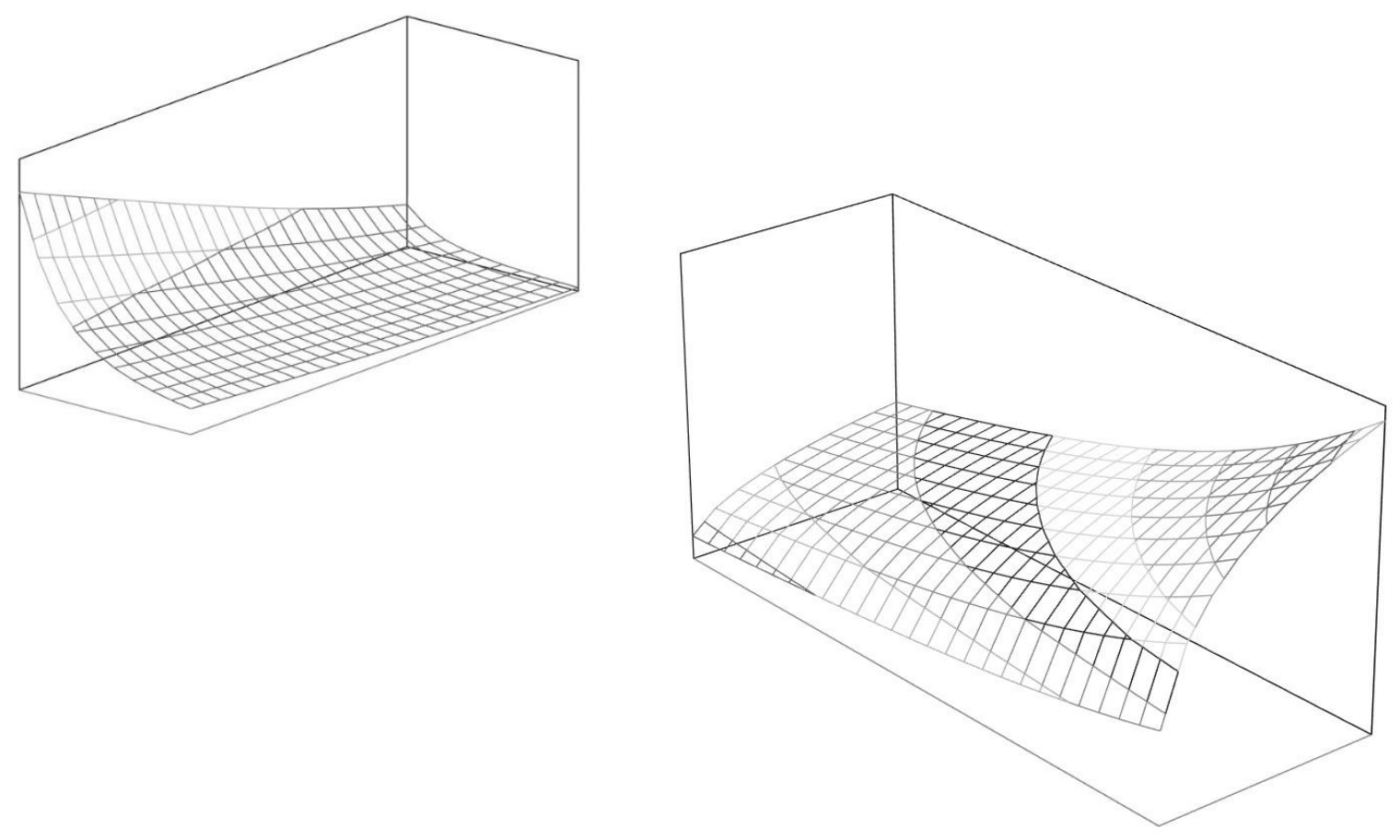

ANEXO I

Verificación de ausencia de resistencias difusionales 


\section{I.1. Verificación de la ausencia de resistencias externas a la transferencia de materia}

Se seleccionó, en este trabajo de tesis, una velocidad de agitación de $1000 \mathrm{rpm}$. Para verificar efectivamente que no existen resistencias a la transferencia de materia empleando 1000 rpm como velocidad de agitación se efectuaron cálculos basados en el criterio de Mears [1]. Para ello es preciso calcular el coeficiente $C_{M}$ de la Ecuación 1-5.

$$
\mathrm{C}_{\mathrm{M}}=\frac{\left(-\mathrm{rg}_{\mathrm{gli}}\right) \mathrm{r}_{\mathrm{p}} \rho_{\mathrm{c}} \mathrm{n}}{\mathrm{k}_{\mathrm{L}} \mathrm{C}_{\mathrm{gli}}^{\mathrm{L}}}
$$

Ecuación 1-5

En la Ecuación 1-6, (- $\left.\mathrm{rgli}_{\mathrm{gi}}\right)$ es la velocidad de reacción del glicerol por unidad de masa de catalizador (mol. $\left.\mathrm{kg}^{-1} . \mathrm{s}^{-1}\right), \mathrm{r}_{\mathrm{p}}$ es el radio del polvo de catalizador $(\mathrm{m}), \rho_{\mathrm{c}}$ es la densidad del catalizador $\left(\mathrm{kg} . \mathrm{m}^{-3}\right)$, $\mathrm{D}_{\text {gli }}$ es el coeficiente de difusión efectivo del glicerol a la temperatura de reacción en el interior del polvo catalítico $\left(\mathrm{m}^{2} . \mathrm{s}^{-1}\right)$, $\mathrm{n}$ es el orden de reacción respecto del glicerol, $\mathrm{k}_{\mathrm{L}}$ es el coeficiente de transferencia de materia en la fase líquida y $\mathrm{C}_{g l i}{ }^{\mathrm{L}}$ es la concentración de glicerol en el seno de la fase líquida $\left(\mathrm{mol}^{-3} \mathrm{~m}^{-3}\right)$.

Una vez hecho el cálculo, se analiza el valor del coeficiente $\mathrm{C}_{\mathrm{M}}$ :

$-S_{i} C_{M}>0.15$, entonces hay resistencias externas a la transferencia de materia.

-Si $C_{M}<0.15$, entonces hay ausencia de resistencias externas a la transferencia de materia.

Para evaluar el coeficiente $\mathrm{C}_{\mathrm{M}}$ se empleó un catalizador de $\mathrm{Ni}(\mathrm{Cl}-) / \mathrm{SC}$ cuya preparación se describe en el capítulo 3 y los valores de las variables que se visualizan en la Tabla 1-5.

Tabla 1-5. Valores de las variables necesarias para el cálculo de $C_{M}$.

\begin{tabular}{lc}
\hline$\left(-\mathrm{rgli}_{\mathrm{gl}}\right)\left(\mathrm{mol} \cdot \mathrm{kg}^{-1} \cdot \mathrm{s}^{-1}\right)$ & $2.90 \times 10^{-3}$ \\
$\mathrm{r}_{\mathrm{p}}(\mathrm{m})$ & $2.00 \times 10^{-4}$ \\
$\rho_{\mathrm{c}}\left(\mathrm{kg} \cdot \mathrm{m}^{-3}\right)$ & 2634 \\
$\mathrm{n}$ & 0.47 \\
$\mathrm{~kL}\left(\mathrm{~m} \cdot \mathrm{s}^{-1}\right)$ & 0.56 \\
$\mathrm{C}_{\mathrm{gli}} \mathrm{L}\left(\mathrm{mol} \cdot \mathrm{m}^{-3}\right)$ & 3423.91 \\
\hline
\end{tabular}

La velocidad de reacción observada, (-robs), fue obtenida a $260{ }^{\circ} \mathrm{C}$ y 50 bar de $\mathrm{H}_{2}$ de presión autógena, empleando una solución acuosa de glicerol al $30 \% \mathrm{p} / \mathrm{p}$, en condiciones donde la conversión de este reactivo fue del $13 \%$. Esta condición resulta ser la más desfavorable para evaluar el coeficiente $\mathrm{C}_{\mathrm{M}}$, puesto que se emplea una concentración diluida de glicerol $(30 \% \mathrm{p} / \mathrm{p})$ y a $260{ }^{\circ} \mathrm{C}$ la velocidad de reacción observada para el glicerol es máxima (se alcanzan los mayores niveles de conversión); esto ocasiona que el valor de $\mathrm{C}_{\mathrm{M}}$ resulte máximo. En cualquier otra condición, por ejemplo, a menores temperaturas partiendo de soluciones más concentradas de glicerol los valores de $C_{M}$ resultan aun menores.

El orden de reacción para el glicerol fue estimado haciendo una regresión lineal entre el logaritmo natural de la velocidad de reacción observada versus el logaritmo natural de la concentración inicial de glicerol. Se consideraron velocidades iniciales de reacción para los 
cuales la conversión de glicerol no superó el 10\%. Se ensayaron tres concentraciones de glicerol en agua: 30\%, 45\% y 55\%. El orden de reacción resultó igual a 0.4, según se observa en la Figura 1-5.

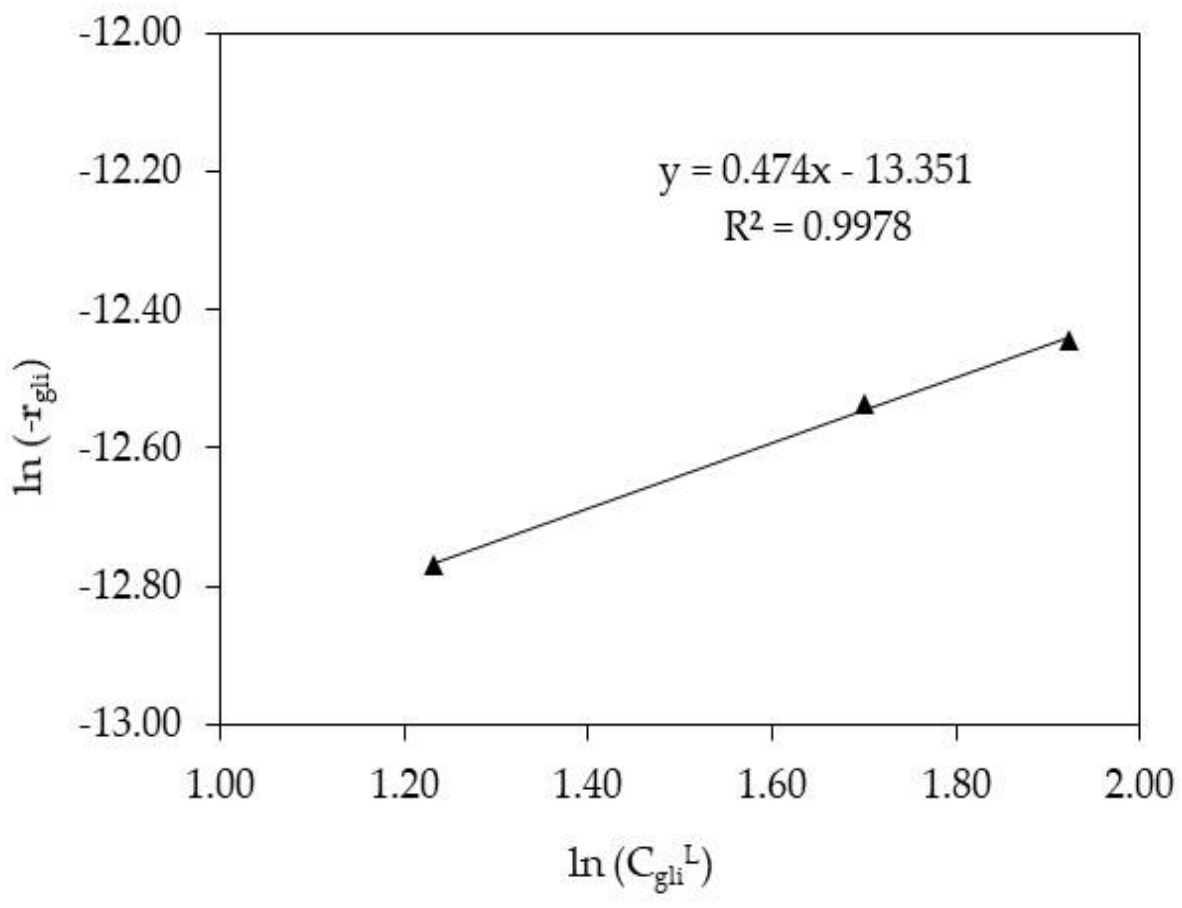

Figura 1-5. Obtención del orden de reacción con respecto al glicerol.

Para todos los ensayos se empleó un polvo de catalizador de $0.2 \mathrm{~mm}$ de radio. La densidad del polvo catalítico, $\rho c$, se aproximó como la densidad de la $\mathrm{SiO}_{2}$ para provocar el mayor efecto sobre el $\mathrm{C}_{\mathrm{M}}$.

El coeficiente de transferencia de materia, $\mathrm{k}_{\mathrm{L}}$, fue estimado empleando la correlación de Thoenes-Kramers [2], que se visualiza en la Ecuación 2-5. Allí, $\mathrm{d}_{\mathrm{p}}$ es el diámetro de partícula del catalizador $(\mathrm{m}), \varepsilon$ es la porosidad del catalizador, $\mathrm{D}_{\mathrm{gli}}{ }^{\mathrm{ef}}$ es el coeficiente de difusión efectivo del glicerol en agua en presencia del catalizador $\left(\mathrm{m}^{2} \cdot \mathrm{s}^{-1}\right), \operatorname{Re}_{\mathrm{p}}$ es el número de Reynolds de partícula y Sc es el número de Schmidt.

$$
\mathrm{k}_{\mathrm{L}}=\frac{\mathrm{D}_{\mathrm{gli}} \mathrm{ef}^{\mathrm{f}}}{\mathrm{d}_{\mathrm{p}}} \frac{(1-\varepsilon)}{\varepsilon} \operatorname{Re}_{\mathrm{p}}{ }^{1 / 2} \mathrm{Sc}^{1 / 3}
$$

Ecuación 2-5

Los valores de las variables para el cálculo de kL se visualizan en la Tabla 2-5.

Tabla 2-5. Variables para el cálculo del coeficiente de transferencia de materia, $k_{L}$.

\begin{tabular}{lc}
\hline $\mathrm{D}_{\mathrm{gli}}{ }^{\text {ef }}\left(\mathrm{m}^{2} . \mathrm{s}^{-1}\right)$ & $2.23 \times 10^{-4}$ \\
$\mathrm{~d}_{\mathrm{p}}$ & $4.00 \times 10^{-4}$ \\
$\varepsilon$ & 0.70 \\
$\operatorname{Re}_{\mathrm{p}}$ & 18319 \\
$\mathrm{Sc}$ & $7.07 \times 10^{-4}$ \\
\hline
\end{tabular}


La porosidad del soporte, $\varepsilon$, fue calculada como el producto entre el volumen total de poro obtenido por adsorción-desorción de $\mathrm{N}_{2}, \mathrm{~V}_{\mathrm{p}}$, y la densidad del polvo catalítico, $\rho$ c. $\mathrm{Su}$ valor resultó de 0.70 (70\%).

Dado que se empleó como tamaño del polvo de catalizador $0.2 \mathrm{~mm}$ de radio, el diámetro de partícula del polvo de catalizador resulta $0.4 \mathrm{~mm}\left(4.00 \times 10^{-4} \mathrm{~m}\right)$.

En cuanto al coeficiente de difusión efectivo, $\mathrm{D}_{\mathrm{gli}} \mathrm{e}^{\mathrm{e}}$, el mismo se calculó en base al coeficiente de difusión del glicerol en agua, $\mathrm{D}_{\text {gli-agua, }}$ afectado por la porosidad del soporte, $\varepsilon, \mathrm{y}$ su tortuosidad, $\tau$, según la Ecuación 3-5.

$$
\mathrm{D}_{\text {gli }}{ }^{\mathrm{ef}}=\frac{\mathrm{D}_{\text {gli-agua. } \varepsilon}}{\tau}
$$

Ecuación 3-5

El coeficiente de difusión de glicerol en agua, $\mathrm{D}_{\text {gli-agua, }}$ se calculó en base a la correlación de Wilke-Chang para soluciones líquidas a $260^{\circ} \mathrm{C}$ considerando una solución de glicerol en agua al $30 \% \mathrm{p} / \mathrm{p}$ [3]. Para la tortuosidad, $\tau$, se tomó un valor de referencia [4]. Los valores de Dgli-agua, $\varepsilon$ y $\tau$ se visualizan en la Tabla 3-5.

Tabla 3-5. Coeficiente de difusión binario glicerol-agua y valores de porosidad y tortuosidad.

\begin{tabular}{lc}
\hline$D_{\text {gli-agua }}\left(\mathrm{m}^{2} . \mathrm{s}^{-1}\right)$ & $4.50 \times 10^{-4}$ \\
$\varepsilon$ & 0.70 \\
$\tau$ & 1.41 \\
\hline
\end{tabular}

El Rep puede calcularse de acuerdo a la Ecuación 4-5 [5]. Allí, u es la velocidad de agitación $\left(\mathrm{m} . \mathrm{s}^{-1}\right)$, $\rho_{c}$ es la densidad de la partícula de catalizador $\left(\mathrm{kg} \cdot \mathrm{m}^{-3}\right), \mathrm{d}_{\mathrm{p}}$ es el diámetro de partícula del catalizador (m) y $\mu_{\text {sol }}$ es la viscosidad de la solución acuosa de glicerol de partida (Pa.s).

$$
\operatorname{Re}_{\mathrm{p}}=\frac{u \rho_{\mathrm{c}} \mathrm{d}_{\mathrm{p}}}{\mu_{\mathrm{sol}}}
$$

Ecuación 4-5

La velocidad de agitación se calculó considerando las 1000 rpm fijadas en los ensayos catalíticos, mientras que la viscosidad de la solución acuosa de glicerol se obtuvo a partir de la base de datos del simulador UniSim Design, considerando una solución acuosa de glicerol al $30 \%$ p/p a $260{ }^{\circ} \mathrm{C}$ y 50 bar. Los valores de $\mathrm{u}, \mathrm{d}_{\mathrm{p}}$ y $\mu_{\text {sol }}$ se visualizan en la Tabla 4-5.

Tabla 4-5. Variables para el cálculo del número de Reynolds de partícula.

\begin{tabular}{lc}
\hline $\mathrm{u}\left(\mathrm{m} \cdot \mathrm{s}^{-1}\right)$ & 1.93 \\
$\rho_{\mathrm{c}}\left(\mathrm{kg} \cdot \mathrm{m}^{-3}\right)$ & 2634 \\
$\mathrm{~d}_{\mathrm{p}}(\mathrm{m})$ & $4.00 \times 10^{-4}$ \\
$\mu_{\text {sol }}$ (Pa.s) & $1.11 \times 10^{-4}$ \\
\hline
\end{tabular}


El Sc puede calcularse de acuerdo a la Ecuación 5-5 [5]. Allí, $\mu_{\text {sol }}$ es la viscosidad de la solución acuosa de glicerol de partida (Pa.s), $\rho_{\text {sol }}$ es la densidad de la solución acuosa de glicerol de partida $\left(\mathrm{kg} \cdot \mathrm{m}^{-3}\right)$ y $\mathrm{D}_{\text {gli }}{ }^{\text {ef }}$ es el coeficiente de difusión efectivo del glicerol en agua en presencia del catalizador $\left(\mathrm{m}^{2} \cdot \mathrm{s}^{-1}\right)$.

$$
\text { Sc }=\frac{\mu_{\text {sol }}}{D_{\text {gli }} \text { ef } \rho_{\text {sol }}}
$$

Ecuación 5-5

Los valores para el cálculo del Sc figuran en la Tabla 5-5.

Tabla 5-5. Coeficiente de difusión efectivo del glicerol en agua, viscosidad y densidad de la solución.

\begin{tabular}{lc}
\hline$D_{\text {gli }}{ }^{\text {ef }}\left(\mathrm{m}^{2} . \mathrm{s}^{-1}\right)$ & $2.23 \times 10^{-4}$ \\
$\rho_{\text {sol }}\left(\mathrm{kg} \cdot \mathrm{m}^{-3}\right)$ & 704 \\
$\mu_{\text {sol }}($ Pa.s $)$ & $1.11 \times 10^{-4}$ \\
\hline
\end{tabular}

El coeficiente $C_{M}$ resulta un valor de $3.74 \times 10^{-7}$, es decir, un valor mucho menor a 0.15 , lo que verifica efectivamente que hay ausencia de resistencias externas a la transferencia de materia.

\section{I.2. Verificación de la ausencia de resistencias internas a la transferencia de materia}

Para asegurar la ausencia de resistencias internas a la transferencia de materia, es decir, resistencias difusionales intra-partícula, se efectuaron cálculos basados en el criterio de Wiesz-Prater (Ecuación 6-5) [6].

$$
\mathrm{CWP}_{W \mathrm{P}}=\frac{\left(-\mathrm{rgli}_{\mathrm{g}}\right) \cdot \mathrm{r}_{\mathrm{p}}{ }^{2} \cdot \mathrm{Q}_{\mathrm{c}}}{\mathrm{D}_{\mathrm{gli}}{ }^{\mathrm{ef}} \cdot \mathrm{C}_{\mathrm{gli}}{ }^{\mathrm{S}}}
$$

Ecuación 6-5

En la Ecuación 1-5, (- $\left.\mathrm{r}_{\text {gli }}\right)$ es la velocidad de reacción del glicerol por unidad de masa de catalizador $\left(\mathrm{mol} . \mathrm{kg}^{-1} . \mathrm{s}^{-1}\right), \mathrm{r}_{\mathrm{p}}$ es el radio del polvo de catalizador $(\mathrm{m}), \rho_{\mathrm{c}}$ es la densidad del catalizador $\left(\mathrm{kg} \cdot \mathrm{m}^{-3}\right), \mathrm{D}_{\text {gli }}{ }^{\mathrm{ef}}$ es el coeficiente de difusión efectivo del glicerol a la temperatura de reacción en el interior del polvo catalítico $\left(\mathrm{m}^{2} . \mathrm{s}^{-1}\right)$ y $\mathrm{Cgli}_{\mathrm{i}} \mathrm{s}$ es la concentración de glicerol en la superficie catalítica $\left(\mathrm{mol} . \mathrm{m}^{-3}\right)$.

Una vez hecho el cálculo, se analiza el valor del coeficiente CwP:

-Si $C_{W P}>>1$, entonces hay resistencias internas a la transferencia de materia.

-Si CWP $<<1$, entonces hay ausencia de resistencias internas a la transferencia de materia.

Para evaluar el coeficiente CwP se empleó el mismo catalizador de Ni (Cl-)/SC utilizado para verificar la ausencia de resistencias externas a la transferencia de materia y valores de las variables que se visualizan en la Tabla 6-5. 
Tabla 6-5. Valores de las variables necesarias para el cálculo de CwP.

\begin{tabular}{lc}
\hline$\left(-\mathrm{r}_{\mathrm{gli}}\right)\left(\mathrm{mol} \cdot \mathrm{kg}^{-1} \cdot \mathrm{s}^{-1}\right)$ & $2.90 \times 10^{-3}$ \\
$\mathrm{r}_{\mathrm{p}}(\mathrm{m})$ & $2.00 \times 10^{-4}$ \\
$\rho_{\mathrm{c}}\left(\mathrm{kg} \cdot \mathrm{m}^{-3}\right)$ & 2634 \\
$\mathrm{D}_{\mathrm{gli}}{ }^{\mathrm{ef}}\left(\mathrm{m}^{2} \cdot \mathrm{s}^{-1}\right)$ & $2.23 \times 10^{-4}$ \\
$\mathrm{C}_{\mathrm{gli}} \mathrm{S}\left(\mathrm{mol} \cdot \mathrm{m}^{-3}\right)$ & 3423.91 \\
\hline
\end{tabular}

En el caso de $\mathrm{C}_{\mathrm{gli}} \mathrm{S}$, dado que no existen resistencias externas a la transferencia de materia puede igualarse a $\mathrm{C}_{\text {gli }}{ }^{\mathrm{L}}$, es decir, la concentración de glicerol en el seno de la fase líquida [6].

Al igual que en el caso anterior, la velocidad de reacción observada, (-robs), fue obtenida a $260{ }^{\circ} \mathrm{C}$ y 50 bar de $\mathrm{H}_{2}$ de presión autógena, empleando una solución acuosa de glicerol al $30 \% \mathrm{p} / \mathrm{p}$, en condiciones donde la conversión de este reactivo fue del $13 \%$. Esta condición resulta ser la más desfavorable para evaluar el coeficiente $C_{w P}$, puesto que se emplea una concentración diluida de glicerol $(30 \% \mathrm{p} / \mathrm{p})$ y a $260{ }^{\circ} \mathrm{C}$ la velocidad de reacción observada para el glicerol es máxima (se alcanzan los mayores niveles de conversión); esto ocasiona que el valor de CwP resulte máximo. En cualquier otra condición, por ejemplo, a menores temperaturas partiendo de soluciones más concentradas de glicerol, los valores de CwP resultan menores.

El cálculo de Cwr arroja un valor de $4.00 \times 10^{-7}$, es decir, mucho menor a la unidad. Esto significa que la reacción está controlada cinéticamente y no existen resistencias difusionales intra-partícula.

\section{I.3. Verificación de la ausencia de resistencias externas a la transferencia de energía}

La ausencia de resistencias externas a la transferencia de energía fue verificada con el criterio del número de Damkoehler de tercer orden, DaıI, expresado mediante la Ecuación 7-5 [7].

$$
\operatorname{DaIII}=\frac{\left|\Delta \mathrm{H}_{\mathrm{R}}\right|\left(-\mathrm{rgli}_{\mathrm{gli}}\right) \mathrm{r}_{\mathrm{p}} \rho_{\mathrm{c}} \mathrm{E}_{\mathrm{a}}}{\mathrm{h}_{\mathrm{L}} \mathrm{T}^{2} \mathrm{R}}
$$

Ecuación 7-5

En la Ecuación 7-5, (- rgli $_{1}$ es la velocidad de reacción del glicerol por unidad de masa de catalizador $\left(\mathrm{mol} . \mathrm{kg}^{-1} . \mathrm{s}^{-1}\right), \mathrm{r}_{\mathrm{p}}$ es el radio del polvo de catalizador $(\mathrm{m}), \rho_{c}$ es la densidad del catalizador $\left(\mathrm{kg} \cdot \mathrm{m}^{-3}\right)$, Ea es la energía de activación de la reacción de hidrogenólisis (J.mol $\left.{ }^{-1}\right), \mathrm{R}$ es la constante universal de los gases $\left(\mathrm{J} \cdot \mathrm{mol}^{-1} \cdot \mathrm{K}^{-1}\right)$, T es la temperatura de reacción $(\mathrm{K})$ y hL es el coeficiente de transferencia de energía de la fase líquida $\left(\mathrm{J} \cdot \mathrm{m}^{-2} \cdot \mathrm{s}^{-1} \cdot \mathrm{K}^{-1}\right)$.

Una vez hecho el cálculo, se analiza el valor del número de Damkoehler, Dam:

-Si DaIII > 0.15, entonces hay resistencias externas a la transferencia de energía.

-Si Daiı < 0.15, entonces hay ausencia de resistencias externas a la transferencia de energía. 
El DaiI se evaluó en el rango térmico de $220{ }^{\circ} \mathrm{C}$ a $260{ }^{\circ} \mathrm{C}$, empleando el mismo catalizador de $\mathrm{Ni}(\mathrm{Cl}-) / \mathrm{SC}$ utilizado para verificar la ausencia de resistencias externas a la transferencia de materia.

Las variables necesarias para su cálculo se presentan en la Tabla 7-5.

Tabla 7-5. Valores de las variables necesarias para el cálculo de DaIII.

\begin{tabular}{lccccc}
\hline \multirow{2}{*}{ Variable } & \multicolumn{5}{c}{ Temperatura $\left({ }^{\circ} \mathrm{C}\right)$} \\
\cline { 2 - 6 } & 220 & 230 & 240 & 250 & 260 \\
\hline$\left|\Delta \mathrm{H}_{\mathrm{R}}\right|\left(\mathrm{J} \cdot \mathrm{mol}^{-1}\right)$ & 35000 & 35000 & 35000 & 35000 & 35000 \\
$\left(-\mathrm{r}_{\mathrm{gli}}\right)\left(\mathrm{mol}_{\mathrm{kg}} \mathrm{kg}^{-1} \cdot \mathrm{s}^{-1}\right)$ & 0.0003 & 0.0005 & 0.0008 & 0.0016 & 0.0029 \\
$\mathrm{r}_{\mathrm{p}}(\mathrm{m})$ & 0.0002 & 0.0002 & 0.0002 & 0.0002 & 0.0002 \\
$\rho_{\mathrm{c}}\left(\mathrm{kg} \cdot \mathrm{m}^{-3}\right)$ & 2634 & 2634 & 2634 & 2634 & 2634 \\
$\mathrm{E}_{\mathrm{a}}\left(\mathrm{J} \cdot \mathrm{mol}^{-1}\right)$ & 140000 & 140000 & 140000 & 140000 & 140000 \\
$\mathrm{~h}\left(\mathrm{~J} \cdot \mathrm{m}^{-2} \cdot \mathrm{s}^{-1} \cdot \mathrm{K}^{-1}\right)$ & 276228 & 284986 & 296312 & 322062 & 319025 \\
$\mathrm{~T}(\mathrm{~K})$ & 493 & 503 & 513 & 523 & 533 \\
$\mathrm{R}\left(\mathrm{J} \cdot \mathrm{mol}^{-1} \cdot \mathrm{K}^{-1}\right)$ & 8.31 & 8.31 & 8.31 & 8.31 & 8.31 \\
\hline
\end{tabular}

El cambio de entalpía de reacción fue obtenido con el simulador UniSim, considerando las reacciones de deshidratación de glicerol a $\mathrm{AcOH}$ (Ecuación 8-5) y la hidrogenación de AcOH a 1,2-PG (Ecuación 9-5). Ambos valores resultaron negativos, y su combinación también (Ecuación 10-5), lo que permite verificar que la reacción de hidrogenólisis es exotérmica. Dado que al aumentar la temperatura los valores de $\Delta \mathrm{H}_{\mathrm{R}}$ disminuyen naturalmente por esta condición, se eligió el valor de $\Delta \mathrm{H}_{\mathrm{R}}$ a $25{ }^{\circ} \mathrm{C}$ para realizar un cálculo conservador y posicionarse en la condición más desfavorable donde esta variable termodinámica es máxima.<smiles>OCC(O)CO</smiles><smiles>CC(=O)CO</smiles>

Acetol $(\mathrm{AcOH})$<smiles>CC(=O)CO</smiles>

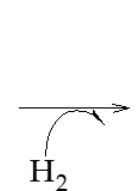<smiles>CC(O)CO</smiles>

Ecuación 8-5

Acetol (AcOH) 1,2-propilenglicol (1,2-PG<smiles>O=C(O)C(O)CO</smiles>

Glicerol<smiles>CC(=O)CO</smiles>

Acetol $(\mathrm{AcOH})$

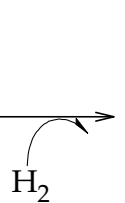<smiles>CC(O)CO</smiles>

$\Delta \mathrm{H}_{\mathrm{R}}=-35000 \mathrm{~J} \cdot \mathrm{mol}^{-1}$

Ecuación 10-5

Ecuación 9-5 
Los valores de velocidad de reacción observada, (-robs), fueron obtenidos a temperaturas de 220, 230, 240, 250 y $260{ }^{\circ} \mathrm{C}$ y 20 bar de $\mathrm{H}_{2}$ iniciales, empleando soluciones acuosas de glicerol al $30 \% \mathrm{p} / \mathrm{p}$, evitando superar el 10\% de conversión de glicerol en todos los casos. Los valores de $r_{p}$ y $\rho_{c}$ son los mismos que fueron empleados para discutir los criterios de transferencia de materia.

En el rango de 220 a $260{ }^{\circ} \mathrm{C}$ se determinó la energía de activación de la reacción de hidrogenólisis, Ea, mediante un ajuste de regresión lineal entre el logaritmo natural de la velocidad observada y $1 / \mathrm{T}$, considerando una ley de activación de tipo Arrhenius (Figura 25). El valor obtenido fue de $140000 \mathrm{~J} . \mathrm{mol}^{-1}$.

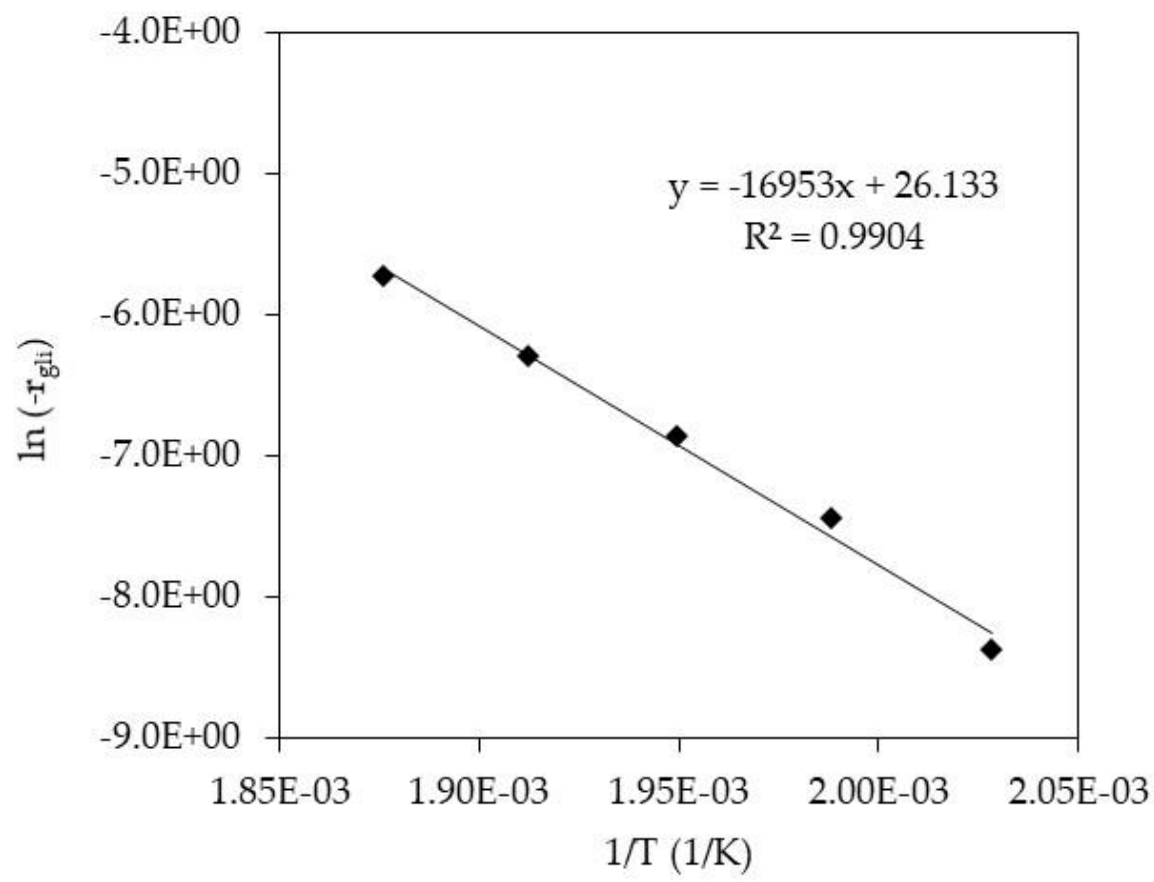

Figura 2-5. Obtención de la energía de activación de la reacción de hidrogenólisis.

Los valores de ht fueron calculados en base a la correlación de la Ecuación 11-5 [8]. Allí, $\kappa_{\mathrm{sol}}$ es la conductividad térmica de la solución acuosa de glicerol $\left(\mathrm{J} \cdot \mathrm{m}^{-1} \cdot \mathrm{s}^{-1} \cdot \mathrm{K}^{-1}\right), \mathrm{d}_{\mathrm{p}}$ es el diámetro de partícula del catalizador $(\mathrm{m}), \varepsilon$ es la porosidad del catalizador, $\operatorname{Re}_{\mathrm{p}}$ es el número de Reynolds de partícula y Pr es el número de Prandtl.

$$
h_{L}=\frac{\kappa_{\text {sol }}}{d_{\mathrm{p}}} \frac{1.192(1-\varepsilon)^{0.41} \operatorname{Re}_{\mathrm{p}} \operatorname{Pr}^{0.33}}{\operatorname{Re}_{\mathrm{p}}{ }^{0.41}-1.52(1-\varepsilon)^{0.41}}
$$

Los valores de las variables para el cálculo de hu en el rango de $220{ }^{\circ} \mathrm{C}$ a $260{ }^{\circ} \mathrm{C}$ se visualizan en la Tabla 8-5. 
Tabla 8-5. Variables para el cálculo del coeficiente de transferencia de energía, $h_{L}$.

\begin{tabular}{lccccc}
\hline \multirow{2}{*}{ Variable } & \multicolumn{5}{c}{ Temperatura $\left({ }^{\circ} \mathrm{C}\right)$} \\
\cline { 2 - 6 } & 220 & 230 & 240 & 250 & 260 \\
\hline$\kappa_{\text {sol }}\left(\mathrm{J} \cdot \mathrm{m}^{-1} \cdot \mathrm{s}^{-1} \cdot \mathrm{K}^{-1}\right)$ & 0.5933 & 0.5829 & 0.5714 & 0.5587 & 0.5450 \\
$\mathrm{~d}_{\mathrm{p}}(\mathrm{m})$ & $4.00 \times 10^{-4}$ & $4.00 \times 10^{-4}$ & $4.00 \times 10^{-4}$ & $4.00 \times 10^{-4}$ & $4.00 \times 10^{-4}$ \\
$\varepsilon$ & 0.70 & 0.70 & 0.70 & 0.70 & 0.70 \\
$\operatorname{Re}_{\mathrm{p}}$ & 9037 & 10536 & 12709 & 18319 & 18319 \\
$\operatorname{Pr}$ & 1.5670 & 1.3870 & 1.1914 & 0.8610 & 0.9020 \\
\hline
\end{tabular}

Los valores de $\kappa_{\text {sol }}$ fueron obtenidos de la base de datos de UniSim, considerando la condición de temperatura y presión y concentración de glicerol en agua establecidas previamente. En todos los cálculos se consideraron los valores de $\mathrm{d}_{\mathrm{p}} \mathrm{y} \varepsilon$ utilizados previamente para el catalizador de $\mathrm{Ni}(5 \%) / \mathrm{SC}$.

Los valores de $\operatorname{Re}_{\mathrm{p}}$ fueron obtenidos mediante el empleo de la Ecuación 4-5. Los valores de las variables para su cálculo se muestran en la Tabla 9-5. La velocidad de agitación se calculó considerando las $1000 \mathrm{rpm}$ fijadas en los ensayos catalíticos, mientras que la viscosidad de la solución acuosa de glicerol se obtuvo a partir de la base de datos del simulador UniSim Design, considerando una solución acuosa de glicerol al 30 \%p/p en el rango de $220^{\circ} \mathrm{C}$ a $260^{\circ} \mathrm{C}$ y 50 bar de presión autógena.

Tabla 9-5. Variables para el cálculo del número de Reynolds de partícula, Rep.

\begin{tabular}{lccccc}
\hline \multirow{2}{*}{ Variable } & \multicolumn{5}{c}{ Temperatura $\left({ }^{\circ} \mathrm{C}\right)$} \\
\cline { 2 - 6 } & 220 & 230 & 240 & 250 & 260 \\
\hline $\mathrm{u}\left(\mathrm{m} \cdot \mathrm{s}^{-1}\right)$ & 1.93 & 1.93 & 1.93 & 1.93 & 1.93 \\
$\rho_{\mathrm{c}}\left(\mathrm{kg} \cdot \mathrm{m}^{-3}\right)$ & 2634 & 2634 & 2634 & 2634 & 2634 \\
$\mathrm{~d}_{\mathrm{p}}(\mathrm{m})$ & $4.00 \times 10^{-4}$ & $4.00 \times 10^{-4}$ & $4.00 \times 10^{-4}$ & $4.00 \times 10^{-4}$ & $4.00 \times 10^{-4}$ \\
$\mu_{\text {sol }}($ Pa.s $)$ & $2.25 \times 10^{-4}$ & $1.93 \times 10^{-4}$ & $1.60 \times 10^{-4}$ & $1.11 \times 10^{-4}$ & $1.11 \times 10^{-4}$ \\
\hline
\end{tabular}

El Pr puede calcularse de acuerdo a la Ecuación 12-5. Allí, Cpsol es el calor específico de

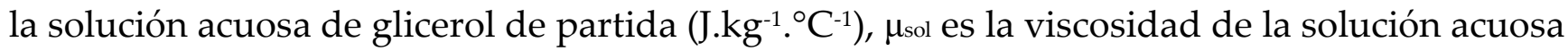
de glicerol de partida (Pa.s) y $\kappa_{\text {sol }}$ es la densidad de la solución acuosa de glicerol de partida $\left(\mathrm{kg} . \mathrm{m}^{-3}\right)$ y $\mathrm{D}_{\text {gli }}{ }^{\text {ef }}$ es el coeficiente de difusión efectivo del glicerol en agua en presencia del catalizador $\left(\mathrm{m}^{2} \cdot \mathrm{s}^{-1}\right)$. Los valores de $\mathrm{Cp}_{\text {sol }}$ fueron obtenidos de la base de datos de UniSim, considerando la condición de temperatura y presión y concentración de glicerol en agua establecidas previamente.

$$
\operatorname{Pr}=\frac{\mathrm{Cp}_{\mathrm{sol}} \mu_{\mathrm{sol}}}{\kappa_{\mathrm{sol}}}
$$

Ecuación 12-5

Los valores para el cálculo del Pr figuran en la Tabla 10-5. 
Tabla 10-5. Variables para el cálculo del número de Prandtl, Pr.

\begin{tabular}{lccccc}
\hline \multirow{2}{*}{ Variable } & \multicolumn{5}{c}{ Temperatura $\left({ }^{\circ} \mathrm{C}\right)$} \\
\cline { 2 - 6 } & 220 & 230 & 240 & 250 & 260 \\
\hline $\mathrm{C} p_{\text {sol }}\left(\mathrm{J} \cdot \mathrm{kg}^{1} \cdot{ }^{\circ} \mathrm{K}^{-1}\right)$ & 4132 & 4189 & 4255 & 4334 & 4429 \\
$\mu_{\text {sol }}(\mathrm{Pa} . \mathrm{s})$ & $2.25 \times 10^{-4}$ & $1.93 \times 10^{-4}$ & $1.60 \times 10^{-4}$ & $1.11 \times 10^{-4}$ & $1.11 \times 10^{-4}$ \\
$\mathrm{\kappa}_{\text {sol }}\left(\mathrm{J} \cdot \mathrm{m}^{1} \cdot \mathrm{s}^{-1} \cdot{ }^{\circ} \mathrm{K}^{-1}\right)$ & 0.5933 & 0.5829 & 0.5714 & 0.5587 & 0.5450 \\
\hline
\end{tabular}

Los valores calculados de Dain en el rango térmico de $220^{\circ} \mathrm{C}$ a $260^{\circ} \mathrm{C}$ se visualizan en la Tabla 11-5.

Tabla 11-5. Valores del número de Damkoehler en el rango térmico de $220^{\circ} \mathrm{C}$ a $260^{\circ} \mathrm{C}$.

\begin{tabular}{cccccc}
\hline & \multicolumn{5}{c}{ Temperatura $\left({ }^{\circ} \mathrm{C}\right)$} \\
\cline { 2 - 6 } & 220 & 230 & 240 & 250 & 260 \\
\hline Da III & $1.38 \times 10^{-6}$ & $2.15 \times 10^{-6}$ & $3.18 \times 10^{-6}$ & $5.64 \times 10^{-6}$ & $9.93 \times 10^{-6}$ \\
\hline
\end{tabular}

En el rango térmico de $220^{\circ} \mathrm{C}$ a $260^{\circ} \mathrm{C}$, el cálculo de Dain arroja valores del orden de $10^{-6}$, es decir, mucho menor a 0.15 . Esto significa que no existen resistencias externas a la transferencia de materia entre la superficie catalítica y el seno de la fase líquida.

\section{I.4. Verificación de la ausencia de resistencias internas a la transferencia de energía}

La ausencia de resistencias internas a la transferencia de energía fue verificada con el criterio del número de Damkoehler de cuarto orden, Darv, expresado mediante la Ecuación 13-5 [7].

$$
\text { Darv }=\frac{\left|\Delta H_{R}\right|\left(-r_{\text {gli }}\right) r_{p}^{2} \varrho_{c} E_{a}}{\kappa_{c} T^{2} R}
$$

Ecuación 13-5

En la Ecuación 13-5, (- $\left.\mathrm{rgli}_{\mathrm{g}}\right)$ es la velocidad de reacción del glicerol por unidad de masa de catalizador $\left(\right.$ mol. $\left.\mathrm{kg}^{-1} . \mathrm{s}^{-1}\right), \mathrm{r}_{\mathrm{p}}$ es el radio del polvo de catalizador $(\mathrm{m}), \rho_{\mathrm{c}}$ es la densidad del catalizador $\left(\mathrm{kg} \cdot \mathrm{m}^{-3}\right), \mathrm{Ea}_{\mathrm{a}}$ es la energía de activación de la reacción de hidrogenólisis $\left(\mathrm{J} \cdot \mathrm{mol}^{-1}\right), \mathrm{R}$ es la constante universal de los gases $\left(\mathrm{J} \cdot \mathrm{mol}^{-1} \cdot \mathrm{K}^{-1}\right)$, T es la temperatura de la superficie del catalizador $(\mathrm{K})$ y $\kappa_{\mathrm{c}}$ es la conductividad térmica del catalizador $\left(\mathrm{J} \cdot \mathrm{m}^{-1} \cdot \mathrm{s}^{-1} \cdot \mathrm{K}^{-1}\right)$.

Una vez hecho el cálculo, se analiza el valor del número de Damkoehler, Davv:

-Si Darv > 0.40, entonces hay resistencias internas a la transferencia de energía.

-Si Darv $<0.40$, entonces hay ausencia de resistencias internas a la transferencia de energía.

El Darv se evaluó en el rango térmico de $220{ }^{\circ} \mathrm{C}$ a $260{ }^{\circ} \mathrm{C}$, empleando el mismo catalizador de $\mathrm{Ni}(\mathrm{Cl}-) / \mathrm{SC}$ utilizado para verificar la ausencia de resistencias externas a la transferencia de materia. Las variables necesarias para su cálculo se presentan en la Tabla 125 . 
Tabla 12-5. Valores de las variables necesarias para el cálculo de DaIV.

\begin{tabular}{lccccc}
\hline \multirow{2}{*}{ Variable } & \multicolumn{5}{c}{ Temperatura $\left({ }^{\circ} \mathrm{C}\right)$} \\
\cline { 2 - 6 } & 220 & 230 & 240 & 250 & 260 \\
\hline$\left|\Delta \mathrm{H}_{\mathrm{R}}\right|\left(\mathrm{J} \cdot \mathrm{mol}^{-1}\right)$ & 35000 & 35000 & 35000 & 35000 & 35000 \\
$\left(-\mathrm{r}_{\mathrm{gli}}\right)\left(\mathrm{mol}^{-1} \mathrm{~kg}^{-1} \cdot \mathrm{s}^{-1}\right)$ & 0.0003 & 0.0005 & 0.0008 & 0.0016 & 0.0029 \\
$\mathrm{r}_{\mathrm{p}}(\mathrm{m})$ & 0.0002 & 0.0002 & 0.0002 & 0.0002 & 0.0002 \\
$\rho_{\mathrm{c}}\left(\mathrm{kg} \cdot \mathrm{m}^{-3}\right)$ & 2634 & 2634 & 2634 & 2634 & 2634 \\
$\mathrm{E}_{\mathrm{a}}\left(\mathrm{J} \cdot \mathrm{mol}^{-1}\right)$ & 140000 & 140000 & 140000 & 140000 & 140000 \\
$\kappa \mathrm{K}\left(\mathrm{J} \cdot \mathrm{m}^{-1} \cdot \mathrm{s}^{-1} \cdot \mathrm{K}^{-1}\right)$ & 142.3 & 142.3 & 142.3 & 142.3 & 142.3 \\
$\mathrm{~T}(\mathrm{~K})$ & 493 & 503 & 513 & 523 & 533 \\
$\mathrm{R}\left(\mathrm{J} \cdot \mathrm{mol}^{-1} \cdot \mathrm{K}^{-1}\right)$ & 8.31 & 8.31 & 8.31 & 8.31 & 8.31 \\
\hline
\end{tabular}

La conductividad térmica del catalizador, $\kappa_{c}$, se ha supuesto igual a la del soporte de SC y esta como un promedio entre la conductividad térmica del carbono grafito y de la sílice, considerando su composición másica en el soporte de SC. Su valor fue calculado a temperatura ambiente $\left(25^{\circ} \mathrm{C}\right)$ y se consideró independiente de la temperatura. Esta suposición tiene sentido en un cálculo conservador para el Dasv, ya que al aumentar la temperatura la conductividad térmica de un sólido tiende a disminuir y el valor máximo de conductividad se obtiene entonces a menores valores de temperatura. Esto haría obtener los máximos valores para el número de Darv.

Los valores calculados de Darv en el rango térmico de $220^{\circ} \mathrm{C}$ a $260^{\circ} \mathrm{C}$ se visualizan en la Tabla 13-5.

Tabla 13-5. Valores del Darv en el rango térmico de $220^{\circ} \mathrm{C}$ a $260{ }^{\circ} \mathrm{C}$.

\begin{tabular}{cccccc}
\hline & \multicolumn{5}{c}{ Temperatura $\left({ }^{\circ} \mathrm{C}\right)$} \\
\cline { 2 - 6 } & 220 & 230 & 240 & 250 & 260 \\
\hline DaIV & $5.38 \times 10^{-7}$ & $8.62 \times 10^{-7}$ & $1.32 \times 10^{-6}$ & $2.55 \times 10^{-6}$ & $4.45 \times 10^{-6}$ \\
\hline
\end{tabular}

En el rango térmico de $220{ }^{\circ} \mathrm{C}$ a $260{ }^{\circ} \mathrm{C}$, el cálculo de Darv arroja valores del orden de $10^{-6}$, es decir, mucho menor a 0.40 . Esto significa que no existen resistencias internas a la transferencia de energía entre la superficie catalítica y el interior de la partícula de catalizador.

\section{Bibliografía}

[1] D. E. Mears, Industrial and Engineering Chemistry Process Design and Development 10 (1971) 541-547.

[2] M. H. Khani, H. Pahlavanzadeh, M. Ghannadi, Annals of Nuclear Energy 35 (2008) 704707. 
[3] R. B. Bird, W. E. Stewart, E. N. Lightfoot, Fenómenos de transporte, Ed. Reverté, 2006, México.

[4] J. J. Carberry, Ingeniería de las Reacciones Químicas y Catalíticas, Ed. Géminis, 1980, Argentina.

[5] A. Pachulski, R. Schödel, P. Claus, Applied Catalysis A: General 445-446 (2012) 107-120.

[6] R. V. Sharma, P. Kumar, A. K. Dalai, Applied Catalysis A: General 477 (2014) 147-156.

[7] D. E. Mears, Journal of Catalysis 20 (1971) 127-131.

[8] R. Adler, Verfahrenstechnische Berechnungsmethoden, Teil 5: Chemische Reaktoren, Deutscher Verlag fur Grundstoffindustrie, Leipzig, 1981. 